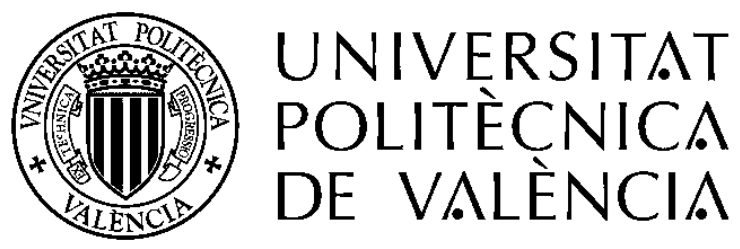

\title{
EFFECTIVENESS OF POLYPROPYLENE FIBRES AS SHEAR REINFORCEMENT IN STRUCTURAL ELEMENTS
}

\author{
Francisco Roberto Ortiz Navas
}

$\mathrm{PhD}$ Thesis

Supervisors:

Dr. Juan Navarro Gregori

Dr. Antonio Conforti

Prof. Dr. Pedro Serna Ros 
Francisco Roberto Ortiz Navas

Instituto de Ciencia y Tecnología del Hormigón

(ICITECH Edificio 4N)

Universitat Politècnica de València,

Camí de Vera s/n, 46022 Valencia, Spain

Tel.: +34 963877563

fraorna@doctor.upv.es

francisco.ortiz.navas@gmail.com 


\title{
EFFECTIVENESS OF POLYPROPYLENE FIBRES AS SHEAR REINFORCEMENT IN STRUCTURAL ELEMENTS
}

\author{
By \\ Francisco Ortiz Navas
}

Thesis

Submitted in fulfilment of the requirements for the degree of Doctor of Philosophy in Building Engineering from the Departamento de Ingeniería de la Construcción y de Proyectos de Ingeniería Civil of the Universitat Politècnica de València

\begin{tabular}{|c|c|c|}
\hline & Supervisor & \\
\hline & Dr. Juan Navarro Gregori & \\
\hline & Dr. Antonio Conforti & \\
\hline & Prof. Dr. Pedro Serna Ros & \\
\hline $\begin{array}{l}\text { UNIVERSITAT } \\
\text { POLITÉCNICA } \\
\text { DE VALÉNCIA }\end{array}$ & & ITEEH \\
\hline $\begin{array}{c}\text { Universitat Politècnica } \\
\text { De València }\end{array}$ & $\begin{array}{c}\text { Departamento de } \\
\text { Ingeniería de la } \\
\text { Construcción y de } \\
\text { Proyectos de Ingeniería } \\
\text { Civil }\end{array}$ & $\begin{array}{l}\text { Instituto de Ciencia y } \\
\text { Tecnología del Hormigón }\end{array}$ \\
\hline
\end{tabular}

Valencia, Spain

July 2020 

To Mery Angélica, my angel in heaven. 



\section{Acknowledgements}

In the next few lines, I wish to thank all the people who directly and indirectly made the present study possible.

I also wish to thank Professor Pedro Serna for allowing me to complete my $\mathrm{PhD}$ thesis in his research group: the No Name Research Group (NNRG). Thank you for giving me the all the advice, experiences and knowledge during my laboratories campaigns.

I also thank Dr. Antonio Conforti for sharing his knowledge and experiences in fibres with me and for giving me all the support during my stay at the University of Brescia.

My special thanks and gratitude go to Dr. Juan Navarro for his trust and guidance in my thesis. I thank him for being my mentor, for introducing me to research, and for his invaluable knowledge, advice and suggestions.

I am grateful to Professor Giovanni Plizzari for allowing me to stay at the DICATAM of the University of Brescia. I thank Erasmus+ Programme for the grants that made this stay possible. I also thank Estefania Cuenca for her hospitality during my stay in Brescia. She and Antonio made me feel at home for that time.

I am also grateful to companies LUFORT S.L. and GRUPPO CENTRO NORD S.p.A, where the big elements of this study were manufactured. I thank BASF Italy and BASF Germany for providing the synthetic fibre used in this thesis.

Ringrazio sinceramente Lucca Scaroni e Alan Piemonti, due grandi amici italiani. Ho condiviso con te molti dei migliori momenti durante il mio dottorato.

To all my friends at ICITECH: Gabriel, Eduard, Majid and Ariel. Thank you for all those long conversations about everything, and for sharing with me your experiences in life research and your laboratory tips. You all made the lab and office work much better in every way.

Quisiera agradecer y dedicar este trabajo a toda mi familia, en especial a mi madre, padre y hermanas: Mery Angélica, Francisco, Daniela y Mery P. Gracias por todo el amor y apoyo durante estos años. Gracias porque a pesar de estar lejos y de las adversidades que nos ha puesto la vida, he sentido su calor siempre junto a mí.

Finalmente quisiera dedicar estas últimas palabras a Andrea, mi compañera de vida y mejor amiga. Gracias por acompañarme en esta etapa lejos de nuestro querido Ecuador. Gracias por tu amor y paciencia. Gracias por cada consejo, cada ánimo que me diste en los momentos difíciles. Muchas gracias mi esposa. 



\section{Abstract}

Several efforts have been made in experimental and theoretical research about shear to understand all the variables that influence the phenomenon. Nowadays, however, due to its complexity, the shear performance of structural concrete elements, especially those without any traditional transversal reinforcement, continue with no clear explanation of the problem. Uncertainty about the problem grows when new variables like fibres are incorporated into the shear study.

Research works have demonstrated the effectiveness of steel fibre in improving the mechanical properties of concrete elements. Experimental results reveal that steel fibres have proven effective in improving shear resistance, and they confer some concrete elements more ductility. In adequate amounts, steel fibres can completely or partially substitute traditional shear reinforcements. This is why international codes have included some requirements to take into account the action of fibres on the shear response of concrete elements. However, most recommendations and requirements for steel fibre-reinforced concrete (SFRC) were originally created.

New fibres with different materials properties and shapes, such as macrosynthetic fibres, are now available on the market. These fibres, some of which are made of polypropylene, are an alternative in the construction industry given their properties and final cost. Initially, polypropylene fibres were used to control shrinkage cracking. Nevertheless, in the last decade the chemical industry has created larger fibres with better surface shapes, which allows polypropylene fibres to meet the requirements of international codes so they can be used in structural elements.

Within this framework, the present $\mathrm{PhD}$ thesis aims to contribute to knowledge about fibre reinforced concrete (FRC), especially to study the effectiveness of polypropylene fibres when used as shear reinforcement. For this purpose, a literature review of the material, polypropylene fibre-reinforced concrete (PFRC) and its structural applications is first carried out. This study also discusses the parameters that affect the shear behaviour of traditional concrete and FRC.

In order to evaluate the effectiveness of polypropylene fibres in shear, three experimental campaigns are presented. Each campaign represents a different level of study. The first corresponds to the material level, where the shear behaviour of PFRC is evaluated by push-off specimens. The second level involves studying shear in real scale elements. For this purpose, shear critical slender beams were manufactured and tested. The last level corresponds to real application of polypropylene fibres to act as shear reinforcement. In this campaign, deep hollow core slabs, with real sections and supports conditions, were tested. At each level, the shear behaviour of PFRC was evaluated against control reinforced concrete specimens, which were also tested during each campaign 



\section{Resumen}

Varias investigaciones experimentales y teóricas han sido realizadas para entender el comportamiento a cortante de elementos de hormigón y sus variables. Sin embargo, hoy en día debido a la complejidad del tema, el comportamiento a cortante de elementos de hormigón armado y en especial aquellos que no tienen refuerzo transversal, continúan sin tener una explicación clara. Por otro lado, esta complejidad del cortante aumenta cuando nuevas variables, como las fibras, se incorporan al estudio.

Investigaciones han demostrado la efectividad de las fibras de acero para mejorar las propiedades mecánicas de hormigón. Según resultados experimentales, la fibra de acero mejora la resistencia cortante y ductilidad de ciertos elementos. $Y$ en cantidades adecuadas, la fibra puede sustituir total o parcialmente los refuerzos tradicionales de cortante. Es así que varios códigos internacionales han incluido requisitos para tener a las fibras en la respuesta estructural de elementos de hormigón. Sin embargo, estos requerimientos se han creado originalmente para el hormigón reforzado con fibra de acero (Steel fibrereinforced concrete-SFRC).

Nuevas fibras con diferentes materiales y formas, como las fibras macro-sintéticas, han sido introducidas en el mercado. Estas fibras, también llamadas fibras de polipropileno o poliolefina, son una alternativa en la construcción debido a su propiedades y costo final. Inicialmente, las fibras de polipropileno eran usadas únicamente en el hormigón para controlar la fisuración por retracción. Sin embargo, en la última década la industria química ha desarrollado fibras más grandes y con mejores prestaciones de adherencia, que permiten a estas fibras cumplir con requisitos para ser utilizadas estructuralmente.

En este contexto, la presente tesis pretende ser una contribución al conocimiento sobre el hormigón reforzado con fibras (Fibre-reinforced concrete - FRC), especialmente en la efectividad de las fibras de polipropileno como refuerzo a cortante. Para esto, primero se realiza un estudio bibliográfico del hormigón reforzado con fibra de polipropileno (PFRC) como material y sus aplicaciones estructurales. Este estudio también tratará sobre los parámetros que afectan el comportamiento a cortante del hormigón tradicional y hormigón reforzado con fibras.

Para evaluar la efectividad de las fibras de polipropileno en el cortante, se realizarán tres campañas experimentales. Cada campaña representa un nivel de estudio diferente. El primero es a nivel material en donde se evalúa el comportamiento a cortante a través de especímenes tipo Push-off. El segundo nivel, corresponde al estudio del cortante en elementos a escala real. Para esto se fabrican y ensayan vigas esbeltas críticas a cortante. El último nivel corresponde a una aplicación real de fibras de polipropileno actuando como refuerzo cortante. En esta campaña, se fabrican y ensayan placas alveolares de gran canto con secciones y condiciones de apoyos reales 



\section{Resum}

Diverses investigacions experimentals i teòriques han estat realitzades per entendre el comportament a tallant d'elements de formigó i les seues variables. No obstant això, hui en dia a causa de la complexitat del tema, el comportament a tallant d'elements de formigó armat i especialment aquells que no tenen reforç transversal, continuen sense tindre una explicació clara. D'altra banda, aquesta complexitat del tallant augmenta quan noves variables, com les fibres, s'incorporen a l'estudi.

Investigacions han demostrat l'efectivitat de les fibres d'acer per a millorar les propietats mecàniques del formigó. Segons resultats experimentals, les fibres d'acer milloren la resistència a tallant i la ductilitat de certs elements. A més, en quantitats adequades, les fibres poden substituir total o parcialment els reforços tradicionals de tallant. Es així que diversos codis internacionals han inclòs requisits per a tindre amb compte la resposta estructural de les fibres en els elements de formigó. No obstant això, aquests requeriments s'han creat originalment per al formigó reforçat amb fibres d'acer (Steel fibre-reinforced concrete -SFRC).

Noves fibres amb diferents materials i formes, com les fibres macro-sintètiques, han estat introduïdes al mercat. Aquestes fibres, també anomenades fibres de polipropilè o poliolefina, són una alternativa a la construcció a causa de les seues propietats i cost final. Inicialment, les fibres de polipropilè eren usades únicament en el formigó per controlar la fissuració per retracció. No obstant això, en l'última dècada, la industria química ha desenvolupat fibres més grans i amb millors prestacions d'adherència, que permeten a aquestes fibres complir amb requisits per a ser utilitzades estructuralment.

En aquest context, la present tesi pretén ser una contribució al coneixement sobre el formigó reforçat amb fibres (Fibre-reinforced concrete - FRC), especialment en l'efectivitat de les fibres de polipropilè com a reforç a tallant. Per això, primer es realitza un estudi bibliogràfic del formigó reforçat amb fibres de polipropilè (PFRC) com a material i les seues plicacions estructurals. Aquest estudi també tractarà sobre els paràmetres que afecten el comportament a tallant del formigó tradicional i del formigó reforçat amb fibres.

Per avaluar l'efectivitat de les fibres de polipropilè en el tallant, es realitzaran tres campanyes experimentals. Cada campanya representa un nivell d'estudi diferent. El primer és a nivell material on s'avalua el comportament a tallant a través d'espècimens tipus Push-off. El segon nivell, correspon a l'estudi del tallant en elements a escala real. Per això es fabriquen $i$ assagen bigues esveltes crítiques a tallant. L'últim nivell correspon a una aplicació real de fibres de polipropilè actuant com a reforç a tallant. En aquesta campanya, es fabriquen $\mathrm{i}$ assagen plaques alveolars de gran cantell amb seccions $\mathrm{i}$ condicions de suports reals. 



\section{Contents}

Acknowledgements

\section{I}

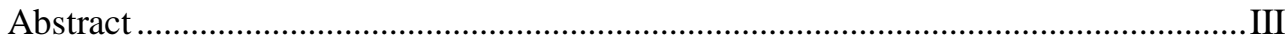

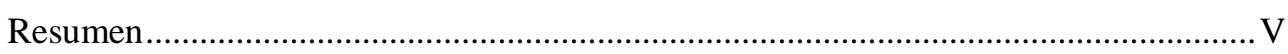

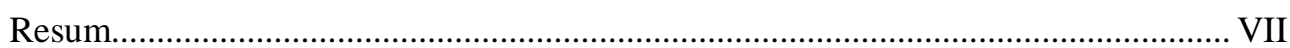

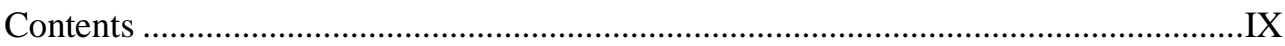

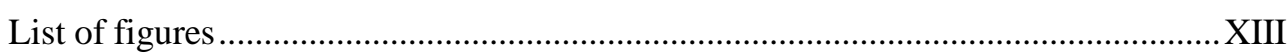

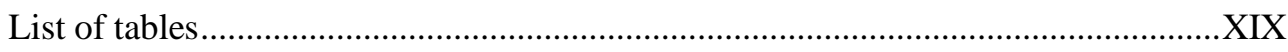

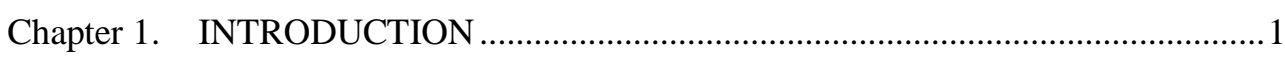

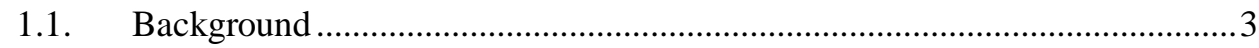

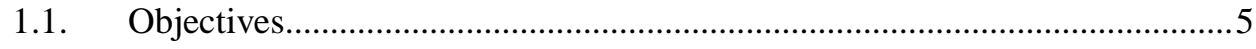

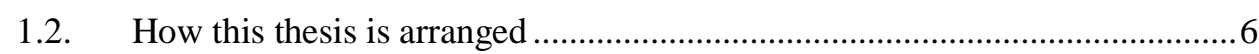

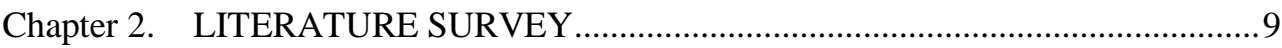

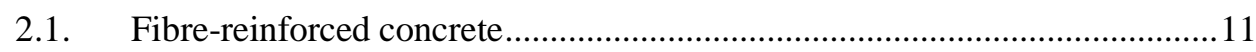

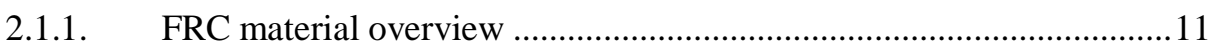

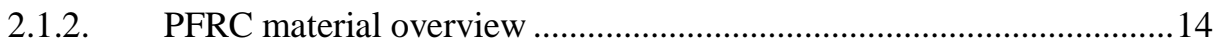

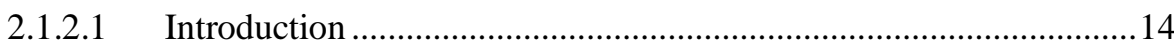

2.1.2.2 Polypropylene fibre types ............................................................. 16

2.1.2.3 Differences between steel and polypropylene fibres .......................22

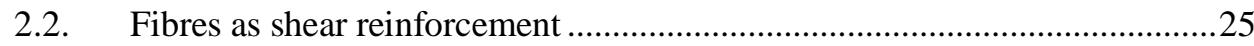

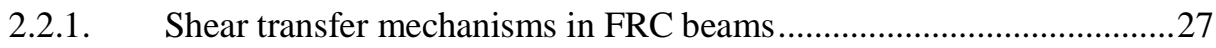

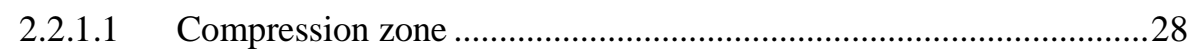

2.2.1.2 Residual tension across cracks .......................................................29

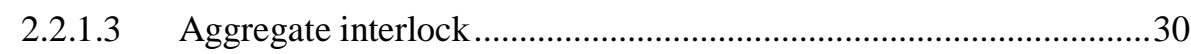

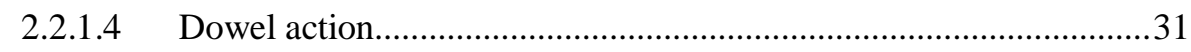

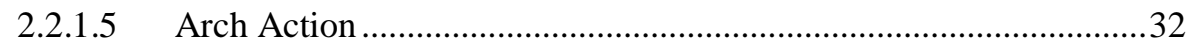

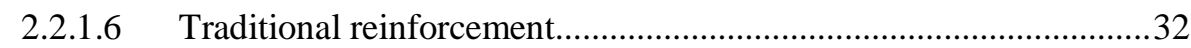

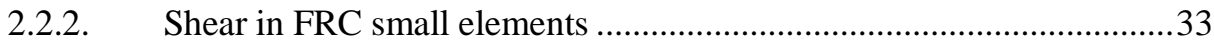

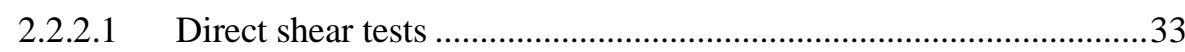




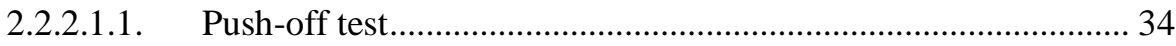

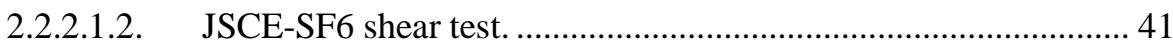

2.2.2.1.3. FIP shear test ......................................................................... 45

2.2.2.1.4. Shear panel test............................................................................ 46

2.2.2.2 Shear models and expressions for FRC........................................... 47

2.2.2.3.1. Shear strength expressions ............................................................... 47

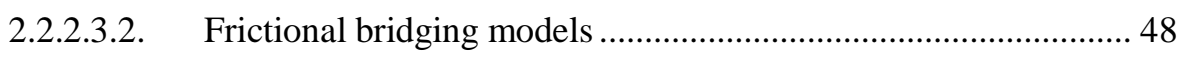

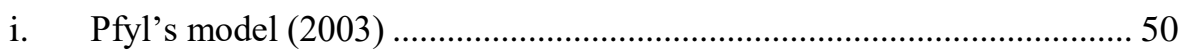

ii. Unified Variable Engagement model (2012)............................................ 51

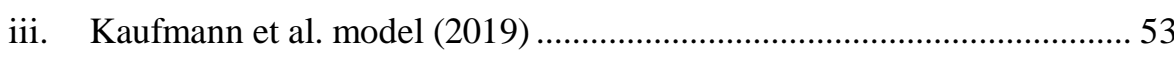

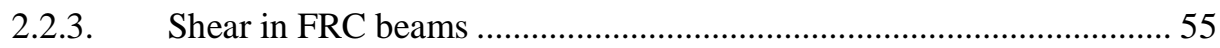

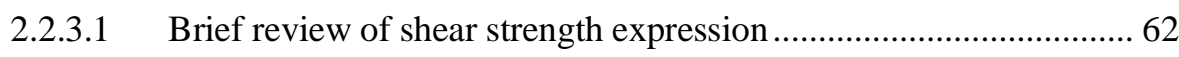

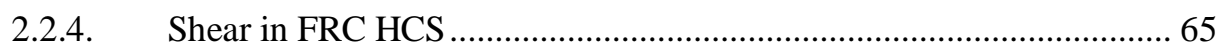

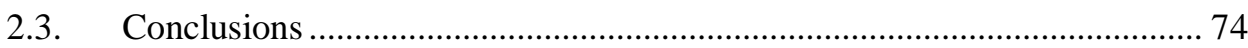

Chapter 3. STUDY OF SHEAR IN SMALL PFRC SPECIMENS ............................. 77

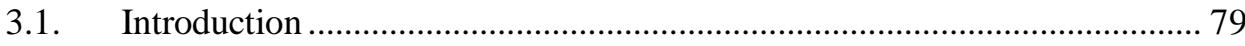

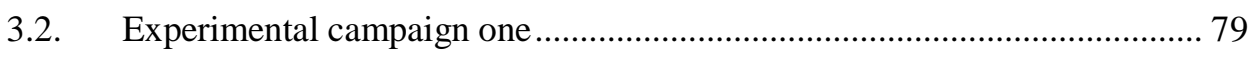

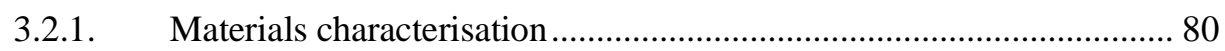

3.2.2. Instrumentation and test setup …………......................................... 85

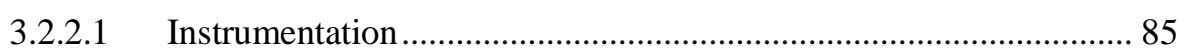

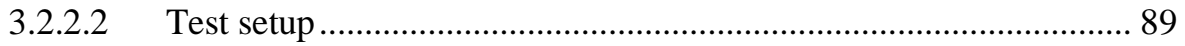

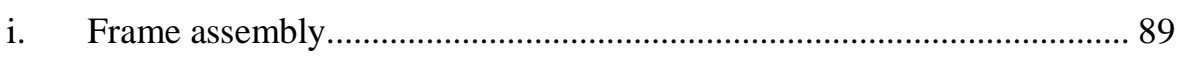

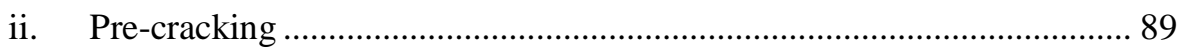

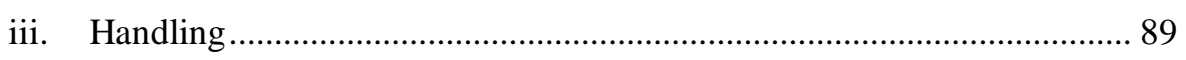

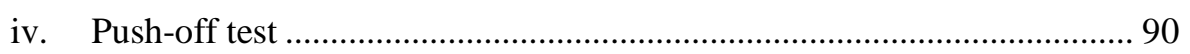

3.2.3. Experimental results and discussion.................................................... 92

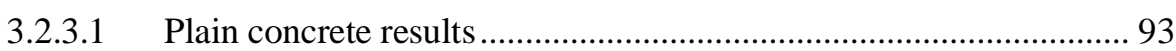

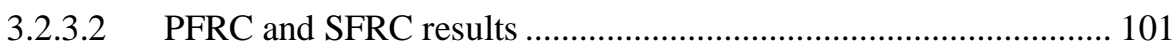

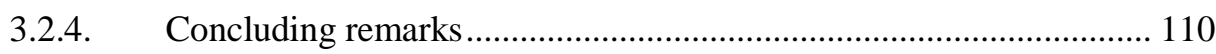

3.3. Experimental campaign two ............................................................... 112

$\mathrm{X}$ 


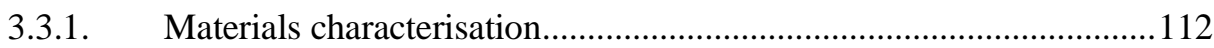

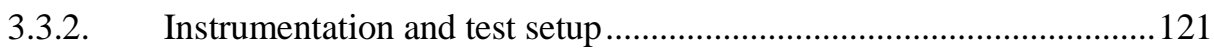

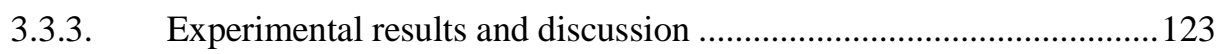

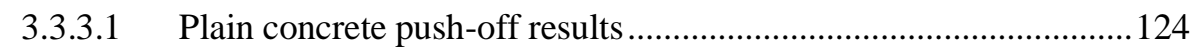

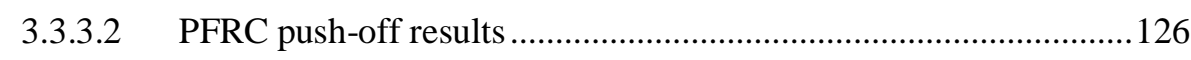

3.3.3.2.1. Effect of fibre content on shear behaviour ..................................129

3.3.3.2.1. Effect of initial confinement on specimens' shear behaviour ....131

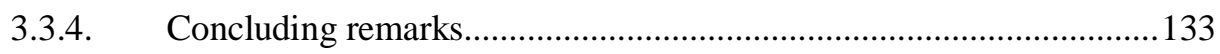

3.4. Analytical modelling of the shear transfer of PFRC cracks .........................134

3.4.1.1 Mechanisms of shear transfer in the pre-cracked push-off test......135

3.4.1.1.1. Initial confinement effect due to pre-compression.......................135

3.4.1.1.2. Confinement effect by an active or passive mechanism .............137

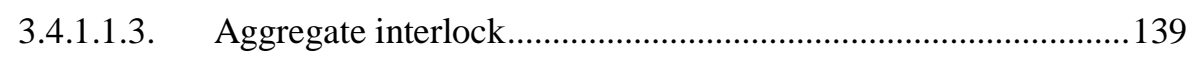

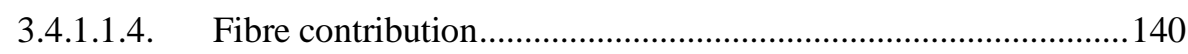

3.4.1.2 Calibration of the aggregate interlock and fibre models ..................142

3.4.1.3 Implementation and verification of the model................................144

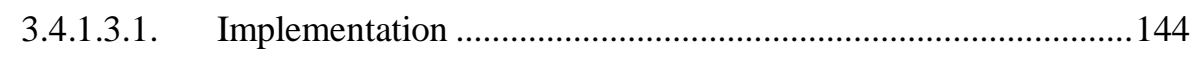

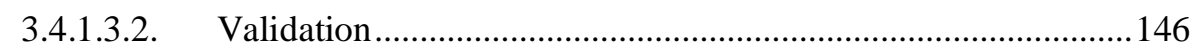

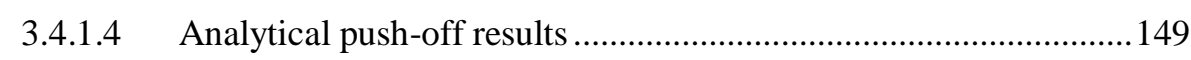

3.4.1.4.1. PC results .......................................................................... 149

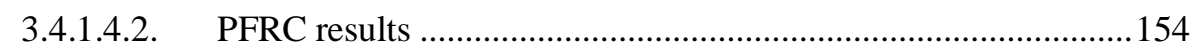

3.4.2. Concluding remarks....................................................................... 168

Chapter 4. STUDY OF SHEAR IN PFRC SLENDER BEAMS …..........................171

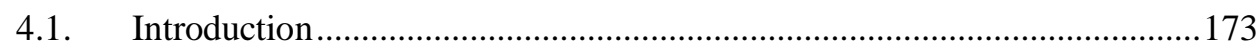

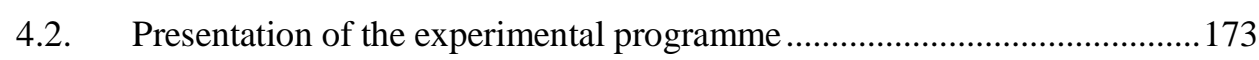

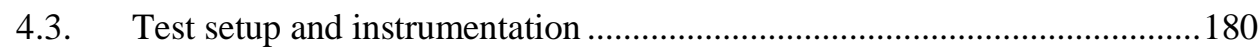

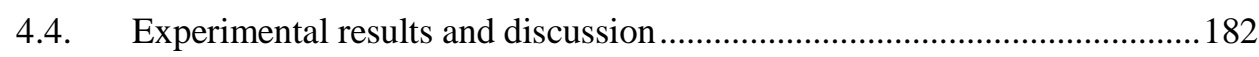

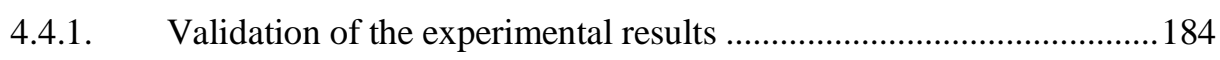

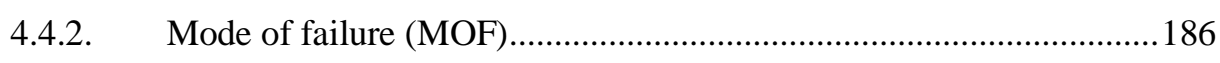

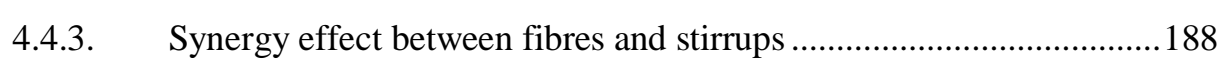


4.4.4. Comparison between beams SFRC and PFRC...................................... 189

4.4.4.1 Crack pattern analysis................................................................... 190

4.4.4.1.1. Number and separation of cracks ............................................... 191

4.4.4.1.2. Influence of fibres on the uncracked zone ................................ 192

4.4.4.1.3. Influence of fibres on the dowel zone ........................................... 193

4.4.4.1.4. Influence of fibres on crack kinematics ..................................... 194

4.4.4.1.5. Effect of fibres on stirrup performance ....................................... 195

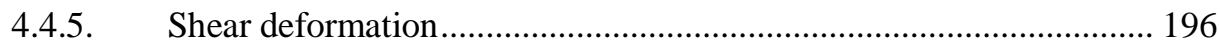

4.5. Comparison to code predictions............................................................... 199

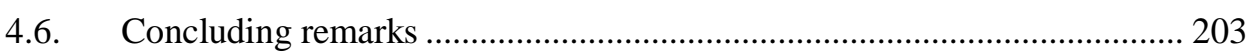

Chapter 5. STUDY OF SHEAR IN HOLLOW-CORE SLABS............................... 205

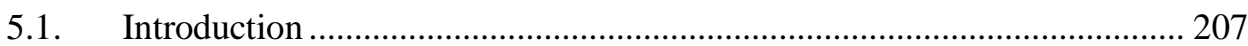

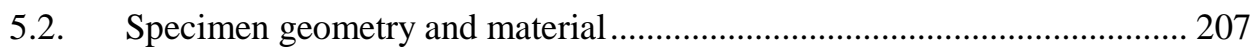

5.3. Test setup and instrumentation ........................................................... 212

5.4. Experimental results and discussion ...................................................... 215

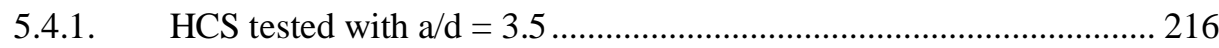

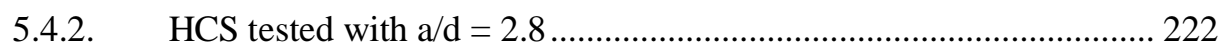

5.4.3. Distribution of polypropylene fibres in HCS webs ............................. 227

5.5. Comparison to code predictions................................................................ 229

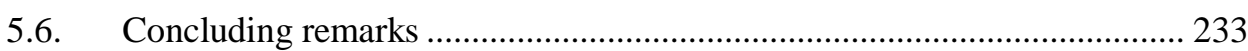

Chapter 6. CONCLUSIONS AND FUTURE RESEARCH LINES .......................... 235

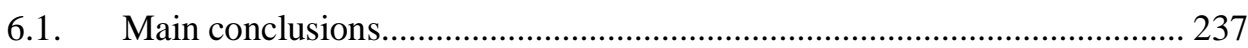

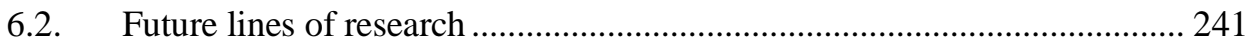

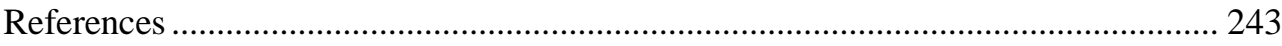

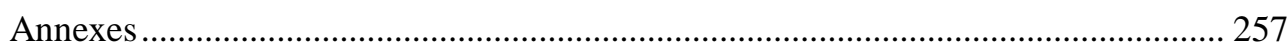

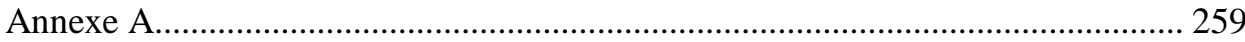

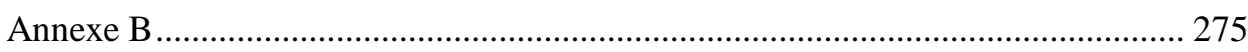

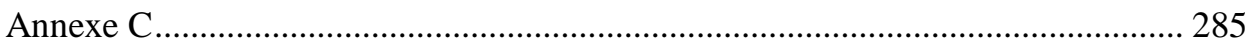




\section{List of figures}

Figure 1-1: SFRC shell roof of the Oceanographic Park in Valencia, Spain [1] (a) and the PFRC vaults of the Cathedral de San Cristobal de la Laguna, Spain (b) [2].

Figure 1-2: Publications per year containing the words "Polypropylene fibre/fibrereinforced concrete", "Macro-synthetic fibre/fibre-reinforced concrete " and "Steel fibre reinforced concrete". Data taken from Google Scholar on 11 November 2019...4

Figure 2-1: Behaviours of FRC in axial tension [7]: softening (a) and hardening (b) ........ 12

Figure 2-2: Test setup required by EN 14651 [7] .................................................... 13

Figure 2-3: Typical load F-CMOD curve for PC and FRC [7] .................................... 13

Figure 2-4: Differences between plain and FRC in normal and high-strength concrete under

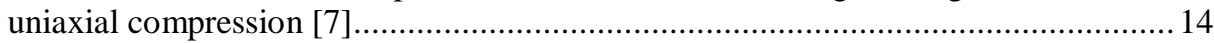

Figure 2-5: Vault prototype using PFRC Palacios et al. [2,34] ..................................... 16

Figure 2-6: Different macrosynthetic fibre types tested by Won et al. [43] ...................... 17

Figure 2-7: Pull-out phases of a straight fibre bonded (a), debonding (b) and sliding (c) [44]

Figure 2-8: Pull-out results of polyolefin fibre for inclination angles of $0^{\circ}(\mathrm{a}), 15^{\circ}(\mathrm{b}), 30^{\circ}(\mathrm{c})$, $45^{\circ}(\mathrm{d})$ and $60^{\circ}(\mathrm{e})[45]$

Figure 2-9: Pull-out peak load comparison between polyolefin and steel fibres [45] ........ 23 Figure 2-10: Comparison of polyolefin and straight steel fibres embedded at $20 \mathrm{~mm}$. Adapted from $[45,56]$

Figure 2-11: Shear transfer mechanisms in FRC beams .......................................... 28

Figure 2-12: Comparison of compression zones between RC and FRC beams [84] .......... 29

Figure 2-13: Representation of effective shear depth [85] ...........................................29

Figure 2-14: The two-phase aggregate interlock model developed by Walraven [92] ........ 30

Figure 2-15: Fibre deviation forces for orthogonal crack opening (a) and inclined crack

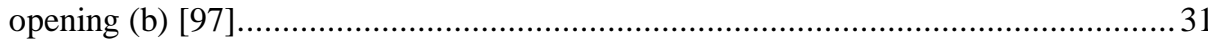

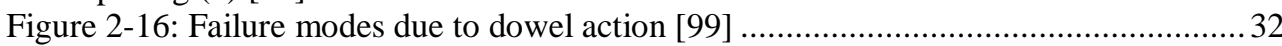

Figure 2-17: Shear test methods in RC and SFRC: Push-off test (a), JSCE shear test (b), FIP shear test (c), Panel Test (d).................................................................... 34

Figure 2-18: Test result of specimen NDSI-30H1:2: Load-slip (a) and Gamma Ray

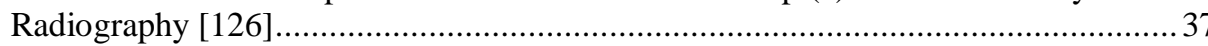

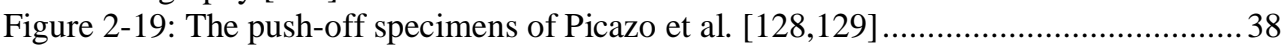

Figure 2-20: Results of Picazo et al. [128,129]: Push-off results (a), Comparison of PFRC and PC (b) and push-off displacement results related to DIC (c) ............................ 39

Figure 2-21: Load deflection plots in: shear load (a); and flexure for concrete with $40 \mathrm{~kg} / \mathrm{m}^{3}$ of flattened-end fibres (b) [132].

Figure 2-22: Picture of the JSCE-SF6 shear test (a), shear strength according to concrete compressive strength (b) and the Orientation factor vs. yield Stress of SFRC(c) [134] 
Figure 2-23: Schematic of the confined JSCE-SF6 test (a) and influence of normal stress on shear stress (b)[135]

Figure 2-24: Shear stress vs. residual flexural tensile strength at $\mathrm{CMOD}=0.5 \mathrm{~mm}$ (a) and $\mathrm{CMOD}=2.5 \mathrm{~mm}(\mathrm{~b})[136]$

Figure 2-25: Result of the JSCE-SF6 tests performed by Majdzadeh et al. [137] using synthetic fibres

Figure 2-26: Scheme of the FIP shear test (a) and picture of a specimen in the FIP shear test [95].

Figure 2-27: Crack pattern of the SFRC (C1F1V3) panel [143] .....................................46

Figure 2-28: Comparison of the maximum strength expressions of hooked-end SFRC ......48

Figure 2-29: Fibre mechanisms: bond (a), bending of fibre (b) and snubbing (c) ..............49

Figure 2-30: Concept of active and inactive fibres ........................................................49

Figure 2-31: Activation and pull-out of steel fibres [97] .............................................50

Figure 2-32: Fibre orientation and definition of the fibre bending angle $(\gamma)[145] \ldots \ldots \ldots \ldots . . .53$

Figure 2-33: Fibres bridging a shear crack according to the Kaufmann et al. model [97] ...54

Figure 2-34: Geometry and reinforcement details of the Furlan and Hanai [163] beams with stirrups (a) and without stirrups (b)

Figure 2-35: Campione's beams geometry and reinforcement details [164] .....................58

Figure 2-36: Beams setup, geometry and reinforcement details of the beams by Majdzadeh et al. [137]

Figure 2-37: The section geometry of deep and wide-shallow beams performed by Conforti et al. $[40,54,166]$

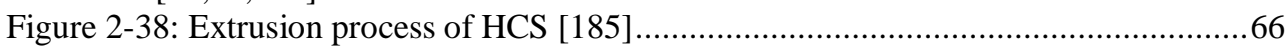

Figure 2-39: Result of Cuenca et al. in Kani's valley[185] ............................................67

Figure 2-40: Prestressing strands at the end of specimens [190] $(a / d=2.73)$ at failure for the

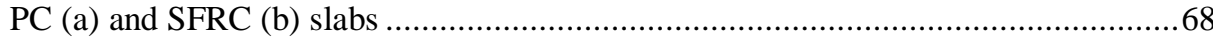

Figure 2-41: Cross-section of Hollow Core Slabs tested by Kankeri et al. [192] ................69

Figure 2-42: MOF of the SFRC hollow core slab [192] ................................................69

Figure 2-43: Web-shear failure [191] (a) and support details according to EN 1168 [193].70

Figure 2-44 Point and lines of failures of different design codes for HCS.......................72

Figure 3-1: Geometry and reinforcement details ........................................................... 80

Figure 3-2: Selected fibre types............................................................................ 82

Figure 3-3: Picture of specimens' formworks (a) and specimens after casting(b)..............83

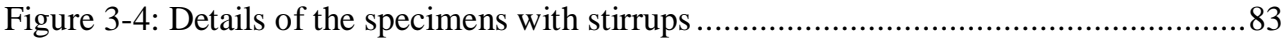

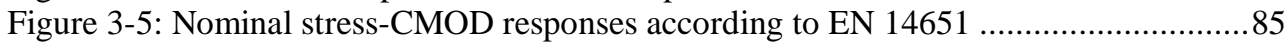

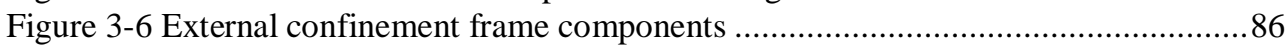

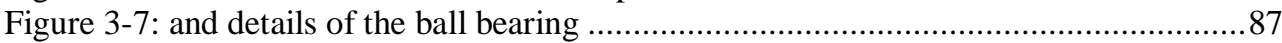

Figure 3-8: Instrumentation arrangement during the pre-cracking (a) and push-off test (b) 88

Figure 3-9: Pre-cracking process and push-off direct shear test ......................................90

Figure 3-10: The nut setting ..................................................................................91

Figure 3-11: PC results: crack opening vs. crack slip curves (a), shear stress vs. crack opening curves (b), shear stress vs. crack slip curves (c) and normal stress vs. crack

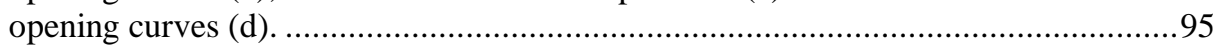

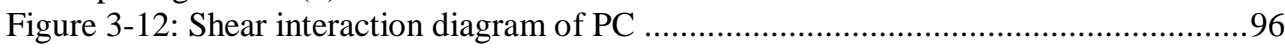

Figure 3-13: Estimation of stirrup contribution to shear (a) and normal stress (b) .............98 
Figure 3-14: Comparison of the plain concrete results to the aggregate interlock models 100 Figure 3-15: PFRC results: crack opening vs. crack slip curves (a), shear stress vs. crack opening curves (b), shear stress vs. crack slip curves (c) and normal stress vs. crack opening curves (d).

Figure 3-16: SFRC results: crack opening vs. crack slip curves (a), shear stress vs. crack opening curves (b), shear stress vs. crack slip curves (c) and normal stress vs. crack opening curves (d)

Figure 3-17: Shear interaction diagram of PFRC (a) and SFRC (b) ..................................... 106

Figure 3-18: Comparison of the results of PC, PFRC and SFRC ……….......................... 107

Figure 3-19: Comparison of specimens with stirrups ................................................... 109

Figure 3-20: Experimental fibre contribution to shear (a), comparison of experimental fibre contribution vs. the contribution obtained by the inverse analysis (b).......................110

Figure 3-21: Theoretical tensile fibre contribution obtained with the inverse analysis. … 110

Figure 3-22: Obtaining specimens for shear characterisation. ........................................ 114

Figure 3-23: Nominal stress-CMOD responses according to EN $14651 \ldots \ldots \ldots \ldots \ldots \ldots \ldots \ldots \ldots . . . . .115$

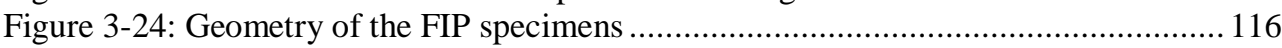

Figure 3-25: Specimens tested for shear characterisation ............................................ 117

Figure 3-26: FIP direct shear test result for $8 \mathrm{~kg} / \mathrm{m}^{3}$ of polypropylene fibre: crack path (a) and shear stress vs. crack opening (b) and crack slip (c)........................................ 118

Figure 3-27: FIP direct shear test result for $12 \mathrm{~kg} / \mathrm{m}^{3}$ of polypropylene fibre: crack path (a) and shear stress vs. crack opening (b) and crack slip (c).

Figure 3-28: Comparison of shear and residual shear strength among concretes (a) and shear vs. total displacement of the crack (b).

Figure 3-29: PC results: crack opening vs. crack slip (a), crack opening vs. shear stress (b), slip displacement vs. shear stress (c), crack opening vs. normal stress (d) and interaction diagram (d).

Figure 3-30: PFRC8 general results: crack opening vs. crack slip (a), crack opening vs. shear stress (b), slip displacement vs. shear stress (c), crack opening vs. normal stress (d) and interaction diagram (d).

Figure 3-31: PFRC12 general results: crack opening vs. crack slip (a), crack opening vs. shear stress (b), slip displacement vs. shear stress (c), crack opening vs. normal stress (d) and interaction diagram (d).

Figure 3-32: Comparison between the PC results and PFRC8 and PFRC12. ................... 130

Figure 3-33: Comparison of the trend lines between PFRC8 and PFRC12 ..................... 131

Figure 3-34: Relation between the initial crack gap with confinement (a) and crack opening (b).

Figure 3-35: Relation between confinement and shear stress at slip $=0.5 \mathrm{~mm}$ (a) and slip $=$

$2.5 \mathrm{~mm}(\mathrm{~b})$

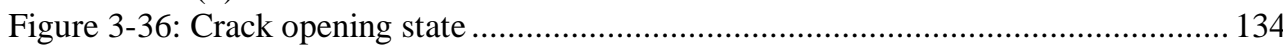

Figure 3-37: Transferring mechanism that acts on the pre-cracked push-off test ............. 135

Figure 3-38: Comparison between friction and cohesion coefficients by applying the Coulomb equation.

Figure 3-39: Function of confinement effect: scheme (a) and PC results adjustments...... 138

Figure 3-40: Tensile behaviour of PFRC obtained by an inverse model .......................... 141

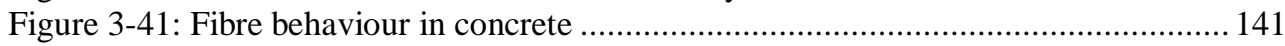


Figure 3-42: PC FIP specimen surface ................................................................... 142

Figure 3-43: Comparison between the FIP experimental results and models: $8 \mathrm{~kg} / \mathrm{m}^{3}$ (a) and $12 \mathrm{~kg} / \mathrm{m}^{3}(\mathrm{~b})$.

Figure 3-44: Numerical procedure, push-off test under crack opening control .................145

Figure 3-45: Analytical validation of specimen 1/0/7.8 (totally confined specimen) tested by Walraven and Reinhardt

Figure 3-46: Analytical validation of specimen 3/0.4/0.6 (totally released specimen) tested

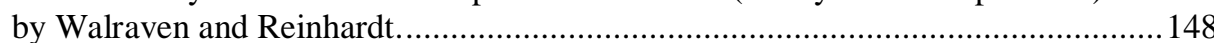

Figure 3-47: Analytical results of specimen Z0A00, $W=0.0 \mathrm{~mm}$ (totally confined)......... 150

Figure 3-48: Analytical results of specimen Z0B00, $W=0.0 \mathrm{~mm}$ (totally confined)......... 150

Figure 3-49: Analytical results of specimen Z0A02, $W=0.2 \mathrm{~mm}$ (partially confined)....... 151

Figure 3-50: Analytical results of specimen Z0A04, $W=0.4 \mathrm{~mm}$ (partially confined)....... 151

Figure 3-51: Analytical results of specimen Z8A00, $W=0.0 \mathrm{~mm}, V_{f}=8 \mathrm{~kg} / \mathrm{m}^{3}$ (totally confined).

Figure 3-52: Analytical results of specimen Z8B00, $W=0.0 \mathrm{~mm}, V_{f}=8 \mathrm{~kg} / \mathrm{m}^{3}$ (totally confined).

Figure 3-53: Analytical results of specimen Z12A00, $W=0.0 \mathrm{~mm}, V_{f}=12 \mathrm{~kg} / \mathrm{m}^{3}$ (totally confined).

Figure 3-54: Analytical results of specimen Z12B00, $W=0.0 \mathrm{~mm}, V_{f}=12 \mathrm{~kg} / \mathrm{m}^{3}$ (totally confined).

Figure 3-55: Analytical results of specimen Z8A02, $W=0.2 \mathrm{~mm}, V_{f}=8 \mathrm{~kg} / \mathrm{m}^{3}$ (partially confined).

Figure 3-56: Analytical results of specimen Z8B02, $W=0.2 \mathrm{~mm}, V_{f}=8 \mathrm{~kg} / \mathrm{m}^{3}$ (partially confined).

Figure 3-57: Analytical results of specimen Z12A02, $W=0.2 \mathrm{~mm}, V_{f}=12 \mathrm{~kg} / \mathrm{m}^{3}$ (partially confined).

Figure 3-58: Analytical results of specimen Z12B02, $W=0.2 \mathrm{~mm}, V_{f}=12 \mathrm{~kg} / \mathrm{m}^{3}$ (partially confined).

Figure 3-59: Analytical results of specimen Z8A04, $W=0.4 \mathrm{~mm}, V_{f}=8 \mathrm{~kg} / \mathrm{m}^{3}$ (partially confined).

Figure 3-60: Analytical results of specimen Z8B04, $W=0.4 \mathrm{~mm}, V_{f}=8 \mathrm{~kg} / \mathrm{m}^{3}$ (partially confined).

Figure 3-61: Analytical results of specimen Z12A04, $W=0.4 \mathrm{~mm}, V_{f}=12 \mathrm{~kg} / \mathrm{m}^{3}$ (partially confined).

Figure 3-62: Analytical results of specimen $Z 12 \mathrm{~B} 04, W=0.4 \mathrm{~mm}, V_{f}=12 \mathrm{~kg} / \mathrm{m}^{3}$ (partially confined).

gure 3-63: Analytical results of specimen Z8A06, $W=0.6 \mathrm{~mm}, V_{f}=8 \mathrm{~kg} / \mathrm{m}^{3}$ (partially confined).

Figure 3-64: Analytical results of specimen $Z 8 B 06, W=0.6 \mathrm{~mm}, V_{f}=8 \mathrm{~kg} / \mathrm{m}^{3}$ (partially confined).

Figure 3-65: Analytical results of specimen Z12A06, $W=0.6 \mathrm{~mm}, V_{f}=12 \mathrm{~kg} / \mathrm{m}^{3}$ (partially confined).

Figure 3-66: Analytical results of specimen Z12A06, $W=0.6 \mathrm{~mm}, V_{f}=12 \mathrm{~kg} / \mathrm{m}^{3}$ (partially confined). 
Figure 4-1: Cross-section details (units in mm)

Figure 4-2: Three-point loading scenario: load scheme for $a / d=3.87$ (a) and $a / d=4.84$. 176

Figure 4-3: Manufacturing beams: formworks (a), full cast beam (b) and slump flow test (c)

178

Figure 4-4: Nominal stress vs. CMOD response in line with EN14651[15] for SFRC (a) and PFRC (b)

Figure 4-5: Beams test setup (a), picture of instrumentation (b), picture of cameras setup (c)

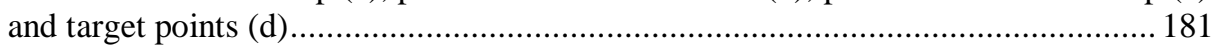

Figure 4-6: Load vs. deflection curves: series A1 (a), A2 (b), B1 (c), and B2 (d) ........... 184

Figure 4-7: Comparison of the Bresler-Scordelis, Vecchio-Shim and ICITECH beams ... 185

Figure 4-8: Crack pattern at failure of series A1 and series A2 ................................... 187

Figure 4-9: Crack pattern at failure of series B1 and series B2 ................................... 187

Figure 4-10: Crack pattern of series A1 w/o stirrups (a), compression zone (b), dowel action crack (c) .....

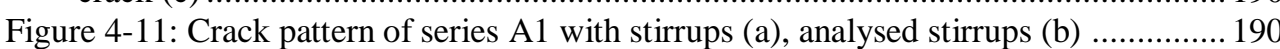

Figure. 4-12: Flexural crack spacing in the beams w/o stirrups ...................................... 192

Figure 4-13: Comparison of compression zone depth.................................................. 193

Figure 4-14: Crack kinematics of the beams w/o stirrups in series A1 ......................... 195

Figure 4-15: Scheme of the area used to measure shear strain .................................... 197

Figure 4-16: Load vs. Shear Deformation, series A1 .................................................. 197

Figure 4-17: Contribution of shear to deflection in series A1 ................................... 199

Figure 4-18: Comparison of the test results to international codes...............................203

Figure 5-1: Manufacturing HCS: picture of tendons prior to casting (a), picture of extruder machine (b) and picture of one manufactured HCS (c)....................................... 208

Figure 5-2: Cross-section details............................................................................ 208

Figure 5-3: Three-point-loading scheme for the end zone: Load scheme for $a / d=2.8$ (a) and

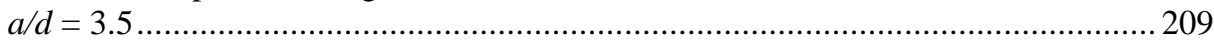

Figure 5-4: The employed crimped polypropylene fibres .......................................... 211

Figure 5-5: Nominal stress vs. CMOD curves according to EN14651[193] for RC and PFRC

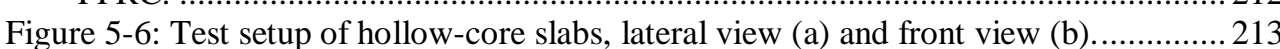

Figure 5-7: Bearing beam details (a), pictures of front and perspective bearing beam ( $b$ and

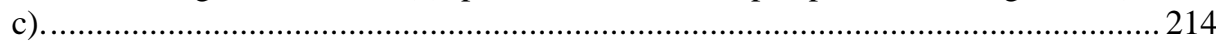

Figure 5-8: Supports detail (a), picture of pinned support (b) and picture of roller support

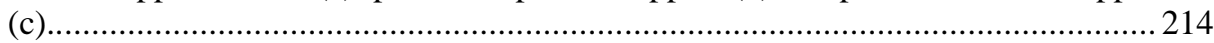

Figure 5-9: Instrumentation details: Picture of PT for the diagonal shear crack opening measurement (a) and picture of PT at the tendon layer (c)..............................215

Figure 5-10: Tested Slab: picture of web-shear failure (a), picture of slip of tendon due to loss of bond (b) and picture of bottom cracks due to loss of bond (c) ....................216

Figure 5-11: Test results using $a / d=3.5$ : load vs. deflection curves (a), tendons slip at 200

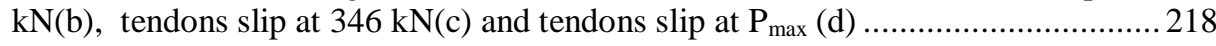

Figure 5-12: Test results using $a / d=3.5$ : load vs. tendon slip of critical web ................... 219

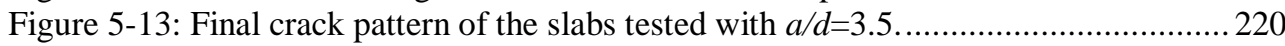

Figure 5-14: Test results using $a / d=3.5$ : load vs. shear crack opening of the most critical external web and load vs. tendon slip of critical web (b) 
Figure 5-15: Pictures of examples of slabs after failure: 42-RC-3.5 (a) and 42-PFRC-3.5-II

(b). 222

Figure 5-16: Test results using $a / d=2.8$ : load vs. deflection curves (a), tendons slip at 170

kN (b) and load vs. tendon slip of critical web (c), and tendons slip at $P_{\text {peak }}(\mathrm{d}) \ldots \ldots .224$

Figure 5-17: Test results using $a / d=2.8$ : load vs. shear crack opening............................225

Figure 5-18: Example pictures of slabs after failure: 42-RC-2.8 (a) and 42-PFRC-2.8-I (b).

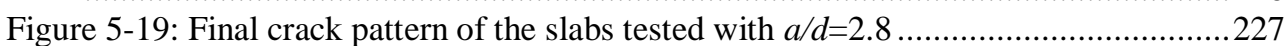

Figure 5-20: Surface treatment: pictures of surface previous treatment (a), after treatment

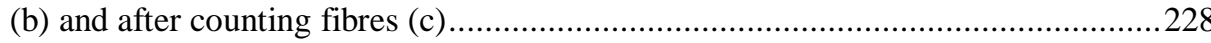

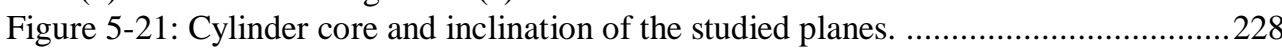

Figure 5-22: Fibre distribution in the external webs ......................................................229

Figure 5-23: Comparison to the shear strength predictions of different standards for:

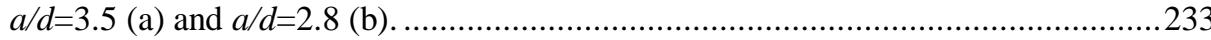

Figure A.1: Distribution of parameters in the shear database for PFRC beams ................261

Figure A.2: Analysis of fibre contribution (a to d) and comparison to MC2010 (e) .........264

Figure B.1: Plain concrete push-off results $\left(W=0.0 \mathrm{~mm}, \mathrm{~V}_{\mathrm{f}}=0.0 \%\right.$ and $\left.f_{c}=43.62 \mathrm{MPa}\right) 275$

Figure B.2: Plain concrete push-off results $\left(W=0.2\right.$ and $0.4 \mathrm{~mm}, \mathrm{~V}_{\mathrm{f}}=0.0 \%$ and $f_{c}=43.62$ $\mathrm{MPa})$

Figure B.3: PFRC push-off results $\left(W=0.0 \mathrm{~mm}, \mathrm{~V}_{\mathrm{f}}=8.0 \%\right.$ and $\left.f_{c}=43.50 \mathrm{MPa}\right) \ldots \ldots \ldots \ldots . . .277$

Figure B.4: PFRC push-off results $\left(W=0.2 \mathrm{~mm}, \mathrm{~V}_{\mathrm{f}}=8.0 \%\right.$ and $\left.f_{c}=43.50 \mathrm{MPa}\right) \ldots \ldots \ldots \ldots . .278$

Figure B.5: PFRC push-off results $\left(W=0.4 \mathrm{~mm}, \mathrm{~V}_{\mathrm{f}}=8.0 \%\right.$ and $\left.f_{c}=43.50 \mathrm{MPa}\right) \ldots \ldots \ldots \ldots . .279$

Figure B.6: PFRC push-off results $\left(W=0.6 \mathrm{~mm}, \mathrm{~V}_{\mathrm{f}}=8.0 \%\right.$ and $\left.f_{c}=43.50 \mathrm{MPa}\right) \ldots \ldots \ldots \ldots . .280$

Figure B.7: PFRC push-off results $\left(W=0.0 \mathrm{~mm}, \mathrm{~V}_{\mathrm{f}}=12.0 \%\right.$ and $\left.f_{c}=45.89 \mathrm{MPa}\right) \ldots \ldots \ldots . .281$

Figure B.8: PFRC push-off results $\left(W=0.2 \mathrm{~mm}, \mathrm{~V}_{\mathrm{f}}=12.0 \%\right.$ and $\left.f_{c}=45.89 \mathrm{MPa}\right) \ldots \ldots \ldots . .282$

Figure B.9: PFRC push-off results $\left(W=0.4 \mathrm{~mm}, \mathrm{~V}_{\mathrm{f}}=12.0 \%\right.$ and $\left.f_{c}=45.89 \mathrm{MPa}\right) \ldots \ldots \ldots . .283$

Figure B.10: PFRC push-off results $\left(W=0.6 \mathrm{~mm}, \mathrm{~V}_{\mathrm{f}}=12.0 \%\right.$ and $\left.f_{c}=45.89 \mathrm{MPa}\right) \ldots \ldots \ldots .284$

Figure C.1: Crack pattern evolution of beams series A2: Beams without stirrups (a) and with stirrups (b).

Figure C.2: Crack pattern evolution of beams series B1: Beams without stirrups (a) and with stirrups (b).

Figure C.3: Crack pattern evolution of beams series B2: Beams without stirrups (a) and with stirrups (b). 


\section{List of tables}

Table 2-1: Pull-out comparison made of different synthetic fibre types ........................... 21

Table 2-2: Typical properties of steel and synthetic fibres (adapted from [55]) ................22

Table 2-3: Codes and guidelines that include fibres for shear capacity .......................... 26

Table 2-4: Push-off specimen's geometry referenced in this thesis ................................ 40

Table 2-5: Selected models of maximum shear strength.......................................... 47

Table 2-6: Selection of formulas to determine the shear strength of SFRC beams ............63

Table 2-7: Shear resistance formulations for RC and FRC elements ............................ 72

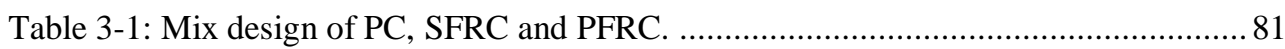

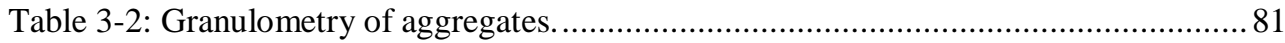

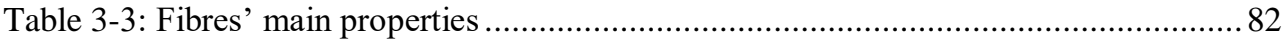

Table 3-4: Mechanical properties of concrete (coefficient of variation in brackets) ...........84

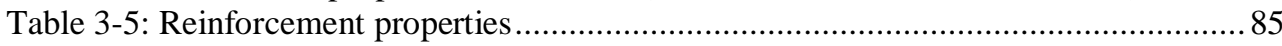

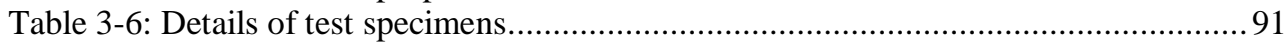

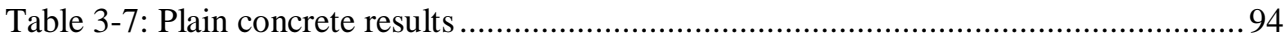

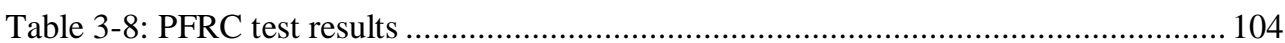

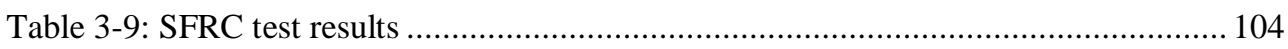

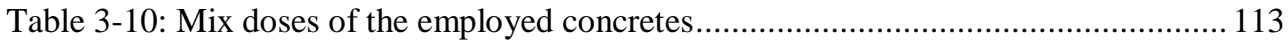

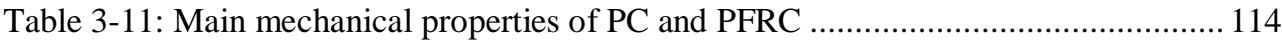

Table 3-12: Summary of the shear strength of PC and PFRC and post-cracking shear strength

Table 3-13: Initial state of the crack for each tested specimen................................... 123

Table 3-14: The Sher tests results comparison (CV in brackets) ................................. 129

Table 3-15: Shear stress results with their corresponding confinement.......................... 131

Table 3-16: Cohesion and friction coefficients of the PC specimens .............................. 136

Table 3-17: Comparison of cohesion and friction coefficients with models ................... 136

Table 3-18: Confinement Adjustment Parameters ................................................... 139

Table 3-19: Fibre pull-out results obtained by Alberti et al. [45] ..................................... 143

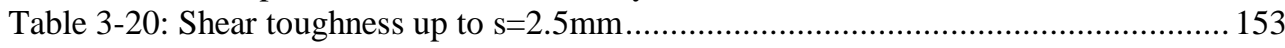

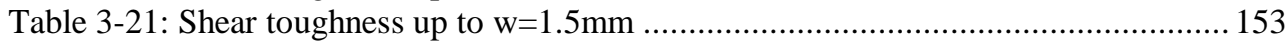

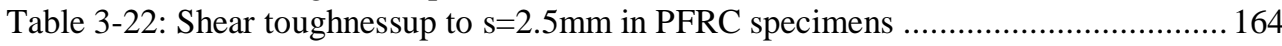

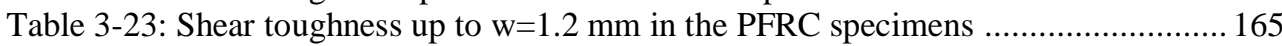

Table 3-24: Shear toughness coefficient up to $\mathrm{s}=2.5 \mathrm{~mm}$ in the PFRC specimens ........... 166

Table 3-25: Shear toughness coefficient up to $\mathrm{w}=1.2 \mathrm{~mm}$ in the PFRC specimens ........... 167

Table 4-1: Geometry and reinforcement of slender beams ...................................... 175

Table 4-2: Mix design of reinforced concrete, SFRC and PFRC ................................. 177

Table 4-3: Concrete mechanical properties. ......................................................... 179

Table 4-4: Summary of the tested beam results ...................................................... 183

Table 4-5: The obtained experimental synergy......................................................... 188

Table 4-6: Measurements of stirrups upon yielding ..................................................... 196

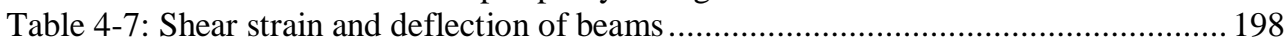

Table 4-8: Shear strength formulations for RC according to MC2010 .......................... 200

Table 4-9: Prediction for the RC beams ................................................................. 201 
Table 4-10: Prediction of the SFRC and PFRC beams.............................................202

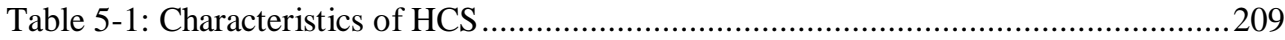

Table 5-2: Mix design of reinforced concrete, SFRC and PFRC .....................................210

Table 5-3: Mechanical properties of concrete................................................................211

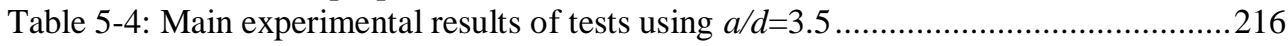

Table 5-5: Average position and average slope of shear cracks. .................................221

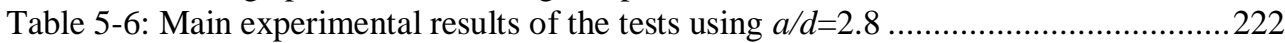

Table 5-7: Average position and average slope of shear cracks. ...................................225

Table 5-8: Shear resistance formulations for elements RC and FRC............................230

Table 5-9: Shear strength prediction of the RC slabs..............................................231

Table 5-10: Comparison between the experiments and predictions of the RC slabs. ........232

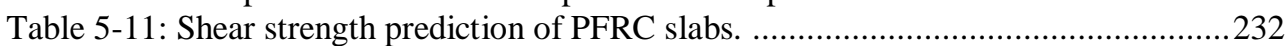


Chapter 1. INTRODUCTION 



\subsection{Background}

The shear behaviour of structural concrete elements remains a topic of interest for the research community. Yet despite the large number of published research works in the literature, no consensus has yet been reached on the topic in the scientific community. In fact, shear failure is considered one of the most critical modes of failure (MOF) in concrete elements as it occurs with no warning, especially in those elements with no shear reinforcement. Hence more research is required to establish more sophisticated and less statistical theoretical models to determine realistic strength and ductility previsions, especially in elements without (w/o) shear reinforcement.

Fibre-reinforced concrete (FRC) has become a novel material recognised by many international codes. This material is characterised by incorporating disperse fibres in the matrix of fresh concrete or mortar. Most widely used fibres are made of steel, polymers, glass and carbon and, depending on their shape and material, they are used to improve concrete properties in fresh and hardened states. Therefore, the study of FRC has been very interesting for the research community in the last 20 years, with benefits reported in the literature like crack control, durability and strength. The most frequently used applications of fibres are pavements and tunnelling. However, classic structural applications in buildings have also been recently explored and have demonstrated their efficiency in redistributing stress or reducing reinforcement congestion. FRC has also been extended to concrete technologies, such as self-compacting concrete, dry-concrete or shotcrete. Figure 1-1 two FRC building applications in Spain. The first shows the application of steel fibre-reinforced concrete (SFRC) combined with shotcrete in the construction of the Oceanographic Park roof in Valencia (see Figure 1-1). The second corresponds to using polypropylene fibre-reinforced concrete (PFRC) combined with a selfcompacting technology to reconstruct the Cathedral de San Cristobal de la Laguna vaults.

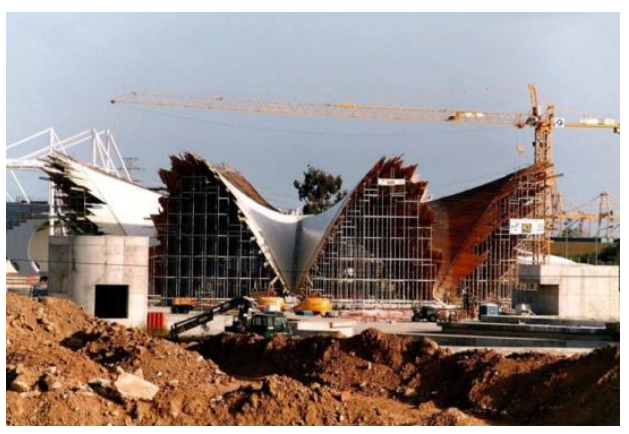

(a)

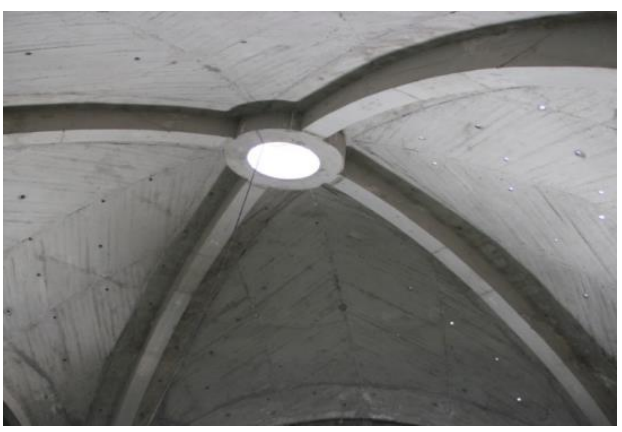

(b)

Figure 1-1: SFRC shell roof of the Oceanographic Park in Valencia, Spain [1] (a) and the PFRC vaults of the Cathedral de San Cristobal de la Laguna, Spain (b) [2]. 
As seen in Figure 1-2, SFRC is one of the main FRCs studied in the literature. However, owing to increasing knowledge of and interest in FRC, new fibre types with novel materials like polypropylene fibres have been studied since 1985 (see PFRC in Figure 1-2). In the last few years, new synthetic fibres designed as larger sized macrosynthetic ones with new surface treatments have been introduced into the construction industry. As Figure 1-2 shows, macrosynthetic fibre-reinforced concrete (MSFRC) from 2008 has been paid considerable attention by the research community.

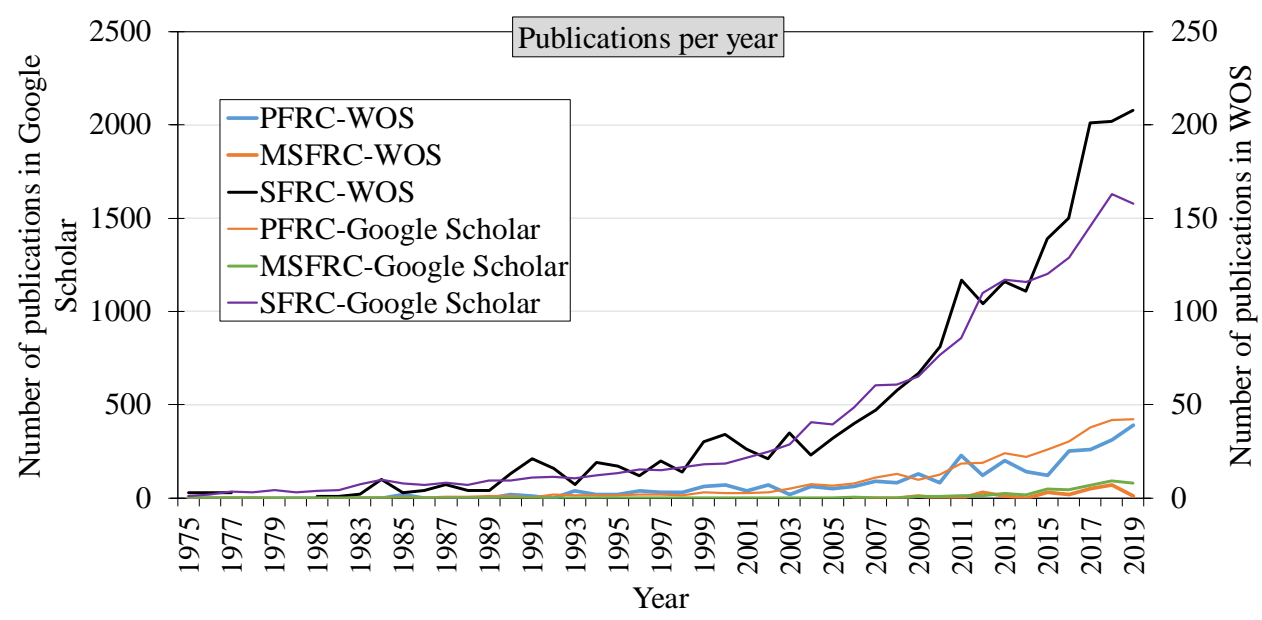

Figure 1-2: Publications per year containing the words "Polypropylene fibre/fibre-reinforced concrete", "Macro-synthetic fibre/fibre-reinforced concrete" and "Steel fibre reinforced concrete". Data taken from Google Scholar on 11 November 2019.

Research on structural FRC applications has focused mainly on using fibres to enhance the shear strength of elements. In this context, considerable research has confirmed their effectiveness, especially with steel fibres, to be used as shear reinforcement. Steel fibres also provide substantial post-peak resistance and ductility after the first shear crack of the element. Therefore, steel fibre is capable of partially or totally replacing stirrups, and of reducing rebar congestions, manufacture costs and construction times. Within this frame, international design codes like ACI 318-2014, Model code 2010 (hereafter MC2010) and Australian Code 2018, among others, have incorporated expressions and models to take into account fibres when used as shear reinforcement. However, most are based on experimental experiments that have mainly used steel fibres.

Some recent publications have also reported the success of macrosynthetic fibres, especially polypropylene ones, to be used as shear reinforcement in structural elements. Even though these studies can certainly be considered to represent the good progress made in 
knowledge about the shear behaviour of elements reinforced by macro-synthetic fibres, some questions still remain.

The present thesis wishes to answer questions like Do macrosynthetic fibres have the same effectiveness as other fibres?; Can we use the expression developed with steel fibres when employing macrosynthetic ones? To attempt to answer these questions, three experimental campaigns were performed to study the shear behaviour of PFRC. These experimental campaigns, carried out at the Universitat Politècnica de València (Spain) and the Università degli Studi di Brescia (Italy), study shear behaviour from a material level, move on to full-scale critical shear beams, and end with a real building application. These campaigns also focus on evaluating the shear transfer mechanism of polypropylene fibres in a shear crack, the effect of polypropylene fibres on shear strength, and compare the performance achieved with steel fibres.

Regarding the first experimental campaign, 41 push-off specimens were tested under direct shear conditions in two subcampaigns. The specimens manufactured with plain concrete $(\mathrm{P})$, PFRC and SFRC were initially pre-cracked to study the shear transfer across cracks under different initial conditions. For full-scale beams, 24 beams were tested by a three-point-loading test. The geometry of beams was inspired in the shear critical beams performed by Bresler-Scordelis in 1963 at the University of Berkeley, and are considered a classic series of beams in shear studies. Beams were manufactured with reinforced concrete (RC), PFRC and SFRC, and covered different shear reinforcement levels. Finally as regards real applications, polypropylene fibres were used as shear-reinforced in hollow core slabs (HCS), which are widely used in residential, parking and industrial buildings for their high quality control, easy installation and short construction times.

The results show that with the correct polypropylene fibre content, the shear strength of elements can be substantially improved, especially in those elements w/o conventional reinforcement. In addition, polypropylene fibres had the same effectiveness as steel fibre in improving the shear strength, toughness and ductility of elements and both fibres provided similar residual flexural tensile strengths. It was evidenced that polypropylene fibres modified the different transfer mechanism just as steel fibres do, which could be a good alternative to improve the shear behaviour in those elements in which conventional transverse reinforcement cannot possibly be used.

\subsection{Objectives}

The main aim of this thesis is to experimentally study the effectiveness of polypropylene fibre in improving the shear strength of concrete elements. For this purpose, the following objectives were included in this thesis:

- Compile the state of the art about the shear behaviour of FRC by emphasising knowledge about PFRC. This part includes the influence of fibre on shear transfer mechanism 
- Prepare a shear database of PFRC beams subjected to shear and make it available in the literature. The results obtained with these beams were analysed to capture the effect of the typical factors that affect their shear behaviour

- Experimentally study the influence of polypropylene fibres on the shear transferring of a crack. An analytical model was developed that included different transfer mechanisms, like aggregate interlock, fibres and confinement

- Compare the shear behaviour of PFRC and SFRC. To do so, besides evaluating shear strength, the influence of fibres on the shear transfer mechanism to act on the elements was also studied, as was their influence on shear deformation, stirrups, mode of failure (MOF) and deflection. Whether FRC shear behaviour, regardless of fibre type, could be related according to FRC post-cracking characterisation, was also evaluated

- Propose a real application of polypropylene fibres in an actual building element critical in shear.

\subsection{How this thesis is arranged}

The present $\mathrm{PhD}$ thesis is divided into seven chapters:

Chapter 1 is the current opening chapter which introduces the objectives and the content of this thesis.

Chapter 2 reports a literature review on the shear behaviour of FRC and PFRC. This chapter also discusses the shear transfer mechanism of FRC and compiles the experimental results of the shear behaviour of PFRC.

Chapter 3 focuses on two experimental campaigns about push-off specimens in PFRC tested under direct shear at the Universitat Politècnica de València. Experimental tests were run to evaluate the behaviour of polypropylene fibres in the transfer across a shear crack. During both campaigns, accompanying specimens also were taken to characterise FRC.

During the first campaign, 21 push-off specimens were manufactured using PC, PFRC and SFRC. Specimens were pre-cracked before the push-off test. The studied variables were type of fibres, crack openings, and the fibres and traditional reinforcement combination.

The second campaign consisted of 20 push-off PC and PFRC specimens. Two different densifications of polypropylene fibres were used. The studied variables were volume fraction and crack opening. The effect of fibres on the macroroughness of a shear crack was also studied.

Finally, a model of shear transfer mechanism in FRC was developed and validated experimentally. The model included the effects of aggregate interlock, any type of fibres 
(fibre included according to residual flexural tensile strengths), confinement and precompression.

Chapter 4 presents an experimental campaign on shear critical slender beams. Twentyfour beams were manufactured and tested at the Universitat Politècnica de València. Beams covered a wide range of reinforcement and span conditions and, hence, a range of influencing factors and MOFs were studied. During this campaign, the shear strength provided by polypropylene fibres and the effects of combining fibres with traditional transversal reinforcement were studied. A comparison of shear performance between steel and PFRC was included.

Chapter 5 describes a real application of polypropylene fibres that acted as shear reinforcement. For this purpose, five hollow core slabs of PFRC and RC were manufactured and tested in both end-zones at the University of Brescia (Italy). Here the possibility of using fibres on those elements w/o traditional reinforcement due to its manufacturing process was evaluated.

Chapter 6 closes this thesis by summarising the main conclusions drawn in the experiment campaigns and provides some future research ideas.

The thesis is complemented with three annexes. Annexe A corresponds to the shear database, while Annexes B and C complement the information in Chapters 3 and 4, respectively. 



\section{Chapter 2. LITERATURE SURVEY}





\subsection{Fibre-reinforced concrete}

\subsubsection{FRC material overview}

Discrete fibres inside concrete have been used since ancient times. The use of horsehair or nature fibres to reinforce plaster is probably the oldest example of reinforcing brittle materials. At the start of the last century, asbestos fibres were introduced to reinforce mortar. Years later, these fibres were discarded in construction applications as they affected people and the environment. Since 1960, new fibre types have been studied indepth in composite materials. Plastic fibres started being investigated to improve the impact resistance of concrete in 1963 by Goldfein [3]. Romualdi and Batson in 1963 [4], and Romualdi and Mandel in 1964 [5], studied the effect of different lengthed steel wires in concrete. In 1968, Majumdar and Rayder [6] explored the benefits of adding glass fibres to composites. Since new fibre type were created with new materials and shapes, novel applications of fibres have been considered in concrete.

Nowadays, fibre-reinforced concrete (FRC) is considered one of the main innovations in the material construction field. The matrix can be concrete or mortar, and can include discontinuous fibres made of steel, polymers, carbon, glass or natural materials $[7,8]$. Applications of fibres have been used mainly to control shrinkage cracks, increase concrete durability, and improve the fire, impact and structural strength of concrete.

In structural uses, fibres are characterised by reducing brittleness of concrete elements. These properties depend on the introduced dose of fibres and on other factors, like material, shapes, bond between fibres and matrix concrete, manufacturing process, among others. Moreover, the orientation and distribution of fibres in the concrete matrix play an important role in achieving acceptable results. However, the maximum volume fraction of fibres has not been directly suggested, and the fibre dose in structural elements is usually around $1-1.5 \%$ in normal strength concrete and $2 \%$ in ultrahigh performance concretes. However as fibre volume increases, fresh concrete properties like its workability reduce. Thus additives to improve concrete workability are normally introduced. FRC' structural behaviour has been widely studied in normal concrete, self-compacting concrete $[9,10]$ and dry concrete $[11,12]$. For structural applications, FRC can be classified according to its post-cracking flexural residual tensile strength in MC2010 regardless of fibre material [7]. Moreover, ACI-318 2014 [13] only allows corrugated steel fibres with an aspect ratio between 50 and 100 to meet ASTM A820M [14] standards, and have to be dosed over $60 \mathrm{~kg} / \mathrm{m}^{3}$ if used as shear reinforcement.

In structural terms, fibres can be used to improve behaviour in Serviceability Limit States (SLS) and Ultimate Limit States (ULS). In the former, fibres can reduce widths and crack spacings, while fibres can partially or totally replace conventional reinforcement in the latter [7]. 
In uniaxial tensile behaviour (see Figure 2-1), FRC can exhibit softening or hardening behaviour. In softening behaviour, one crack occurs, while many cracks take place before the peak load in hardening behaviour. Fibre strength, stiffening and bond of fibres with the concrete matrix are factors that influence fibres' ability to improve concrete postcracking behaviour in tension.

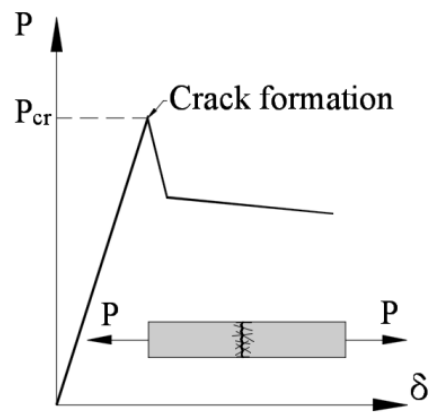

(a)

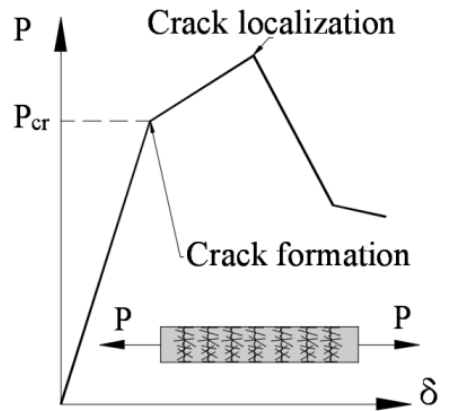

(b)

Figure 2-1: Behaviours of FRC in axial tension [7]: softening (a) and hardening (b)

Given the difficultly to achieve the tensile behaviour of fibres directly in uniaxial tensile tests, the use of flexural or flexural tests to evaluate the postcracking behaviour of FRC is now the most widely used methodology worldwide. In this way, several procedures have been standardised. Common procedures using small beams are EN 14651 [15], ASTM 1609 [16] and JSCE-SF4 [17]. In fact, the post-cracking response of FRC is similarly evaluated and the correlations among the three tests can be obtained [18]. As MC2010 allows EN 14651 to be used, this thesis applies the aforementioned standard to characterise nominal tensile properties of FRC.

By means of three-point bending tests (see Figure 2-2) on notched beam specimens, EN 14654 allows the determination of flexural residual tensile strengths $\left(f_{R, j}\right)$ of FRC. The result after running the test is a diagram of applied load $(F)$ versus deformation expressed in Crack Mouth Opening Displacement (CMOD) terms (see Figure 2-3). In order to obtain residual flexural tensile strengths, the following relation must be evaluated:

$$
f_{R, j}=\frac{3 F_{j} l}{2 b h_{s p}^{2}}
$$

where $f_{R, j}(M P a)$ is the residual flexural tensile strength of $C M O D_{j}, \mathrm{~F}_{\mathrm{j}}(\mathrm{N})$ is the load applied when $C M O D=C M O D_{j}, l(\mathrm{~mm})$ is span length $(500 \mathrm{~mm}), b(\mathrm{~mm})$ is the specimen width $(150 \mathrm{~mm})$ and $h_{s p}(\mathrm{~mm})$ is the distance between the tip of the notch and the top of the specimen $(125 \mathrm{~mm})$. In this way, the limit of proportionality $f_{L}$, residual flexural 
tensile strengths $f_{R, 1}, f_{R, 2}, f_{R, 3}, f_{R, 4}$, corresponding to CMOD equalling 0.5, 1.5, 2.5 and $3.5 \mathrm{~mm}$ are obtained. Characteristic residual tensile strength $f_{R, l k}(\mathrm{CMODs}=0.5 \mathrm{~mm})$ and $f_{R, 3 k}(\mathrm{CMOD}=1.5 \mathrm{~mm})$ are parameters that significantly influence the behaviour of FRC at SLS and ULS, respectively. In fact MC2010 specifies that fibres can partially or totally substitute the conventional reinforcement of ULS if the following relations are fulfilled:

$$
f_{R 1 k} / f_{L k}>0.4
$$

$$
f_{R 3 k} / f_{R 1 k}>0.5
$$
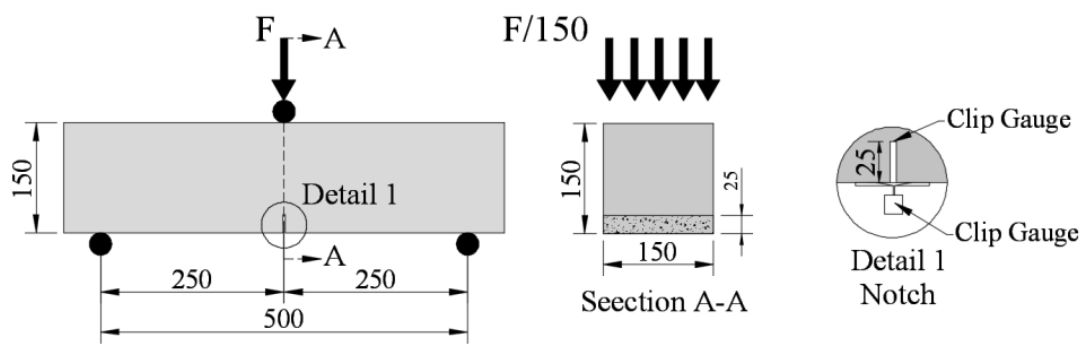

Figure 2-2: Test setup required by EN 14651 [7]

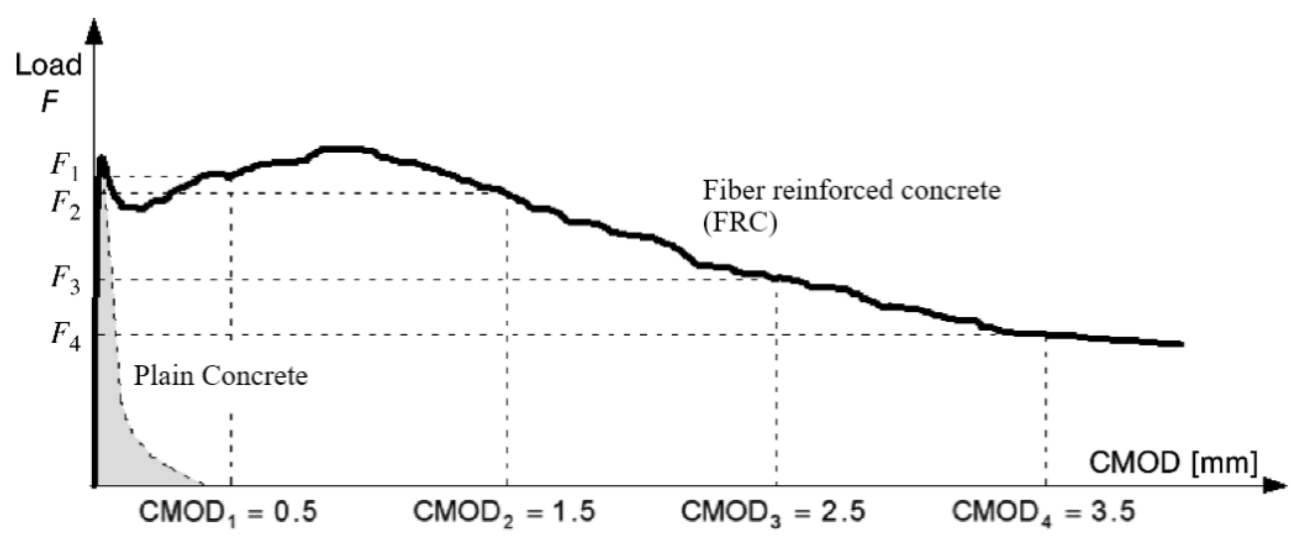

Figure 2-3: Typical load F-CMOD curve for PC and FRC [7]

These parameters are also used to obtain the stress-crack opening constitutive law. MC2010 includes expressions to obtain serviceability residual strength $\left(f_{F t s}\right)$ and ultimate residual strength $\left(f_{F t u}\right)$, and proposes two constitutive laws: a rigid-plastic model and a 
linear model. Moreover, the stress-crack opening law can also be obtained by inverse analyses.

Concerning the compression strength of FRC, adding fibres does not increment, or only modestly increments, compression strength. Yet depending on fibre content, fibres can develop less brittle failures and can increase both strain capacity and toughness. The prepeak behaviour of FRC is similar to PC, while post-peak behaviour may improve, as seen in Figure 2-4.

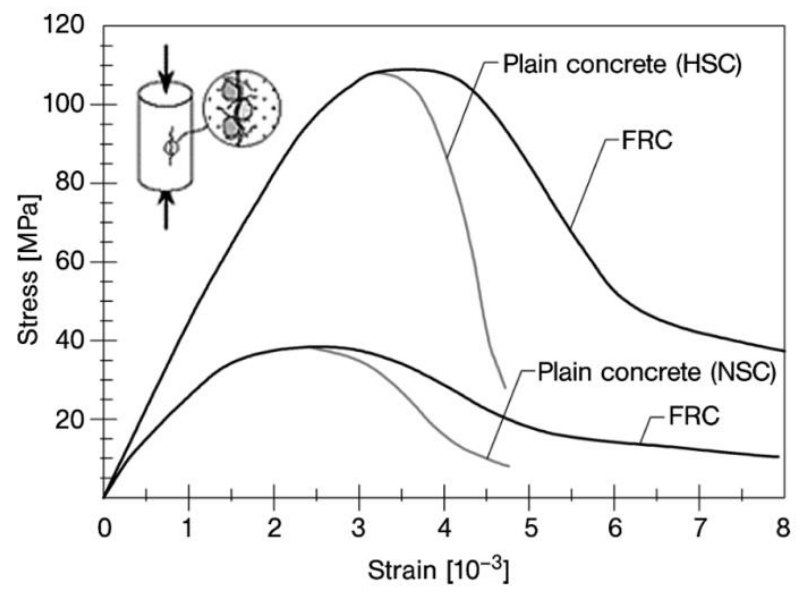

Figure 2-4: Differences between plain and FRC in normal and high-strength concrete under uniaxial compression [7]

\subsubsection{PFRC material overview}

\subsubsection{Introduction}

In past decades, knowledge about FRC has been built according to experimental and numerical studies, most of which employ steel fibres. This is because steel fibres have been the most widely used type to control cracking and improving structural properties of concrete. Moreover in recent decades, synthetic fibres like polypropylene fibres have been introduced for applications in concrete in fresh and hard states. It is necessary to understand the different types of synthetic fibres. For this purpose, EN1889 classifies synthetic fibres as two categories:

- The first, defined as Class I, corresponds to microfibres with equivalent diameters below $0.3 \mathrm{~mm}$. These fibres are generally employed for mitigating plastic shrinkage cracking in concrete. Most of these fibres are manufactured with polyester, nylon, polypropylene or polyethylene. However, fibres manufactured with aramid or acrylic can also be found. This class of fibres is usually incorporated into cementitious matrix in low volumes ranging from $0.03 \%$ to $0.2 \%$, which would be the equivalent of incorporating $0.3-1.80 \mathrm{~kg} / \mathrm{m}^{3}$. 
- The second category, defined as Class II, represents those synthetic fibres whose equivalent diameter is over $0.3 \mathrm{~mm}$ and improves structural behaviour $\left(f_{r l}>1.5\right.$ $M P a$ ). These fibres are made of polypropylene or polyethylene, and are dosed to concrete or mortar in volume fractions of $0.21-1.2 \%\left(2-12 \mathrm{~kg} / \mathrm{m}^{3}\right)$.

Microsynthetic fibres, such as polypropylene ones, were first introduced into the construction industry to control the shrinkage cracking of concrete (fibre is effective as its modulus of elasticity is similar to concrete during the first hours). However, extended applications to improve concrete toughness and impact resistance have been poorly explored. Several experimental campaigns have demonstrated that polypropylene fibres are more efficient (temperature and toughness) than other synthetic fibre types, such as acrylic or polyalcohol fibres, under thermal conditions [19-21].

In the last few decades, the chemical industry has developed new polypropylene fibre types, characterised by being larger in size (both length and diameters) than those that existed until that time. This new generation of synthetic fibres resulted from new treatments of polypropylene material to improve the bond between fibre and the concrete matrix. Some treatments reported in the literature consist in chemical and physical processes in which the surface roughness of polypropylene fibre is chemically or topographically modified to increase the bond and friction of fibres in the matrix. Hence fibres' surface is modified by introducing sodium moieties, colloidal alumina or silica, plasma treatments [22,23] or mechanical topography indentations [24], or simply the damage caused while mixing concrete [25].

Nowadays, applications of polypropylene fibres (macrosynthetic fibres) are capable of providing similar toughness and ductility to the concrete matrix to steel fibres, but with certain limitations. In fact polypropylene fibres display similar post-cracking tensile behaviour to steel fibres, but with lighter fibre content weight. The uses of polypropylene fibres have been extended to applications such as:

- Bridge decks and Jersey barriers [26], where fibres are capable of increasing the toughness, fatigue and impact resistance of concrete;

- Ground-slabs [27], where polypropylene fibres increase the flexural load carrying capacity of slabs compared to RC slabs. In fact deflection in some slabs can be considerably improved using some fibre types, such as monofilament synthetic fibres, compared to other synthetic or steel fibres [28].

- Hyperstatic flat suspended slabs [29], where fibres show high ductility and load level capacity with a considerable capacity to redistribute forces.

- Precast tunnel segments [30-32], where studies have demonstrated that polypropylene fibres can be used as flexural and minimum shear reinforcement as fibres are capable of providing bearing capacity and ductility to the tunnel segment.

- Box culverts, where polypropylene fibres increase shear capacity and ductility [33].

- Building applications like structure retrofitting. Palacios et al. [2,34] used polypropylene fibres to reconstruct the Cathedral of la Laguna in Spain. A prototype of a 
vault (thickness between 7 and $10 \mathrm{~cm}$ ) (see Figure 2-5) using self-compacting concrete and fibres was manufactured and tested.

In durability terms, studies have shown better performance for PFRC in inland and coastal environments than SFRC [35]. In fact the benefits of polypropylene fibres as regards corrosion, magnetic and surface problems have been stated [26].

Polypropylene fibres have been used to date in self-compacting concrete (SCC) [36-39], normal concrete [40-42] and rubberised concrete [36]. Regarding mechanical properties, the characteristic tensile and compression properties of both concrete types was similar between normal concrete and SCC [39]. However, better fibres distribution and wall effect were observed in SCC than in normal concrete [39].

Please note that hereafter when the author of this thesis employs the term polypropylene fibres, it refers exclusively to macrosynthetic fibres.

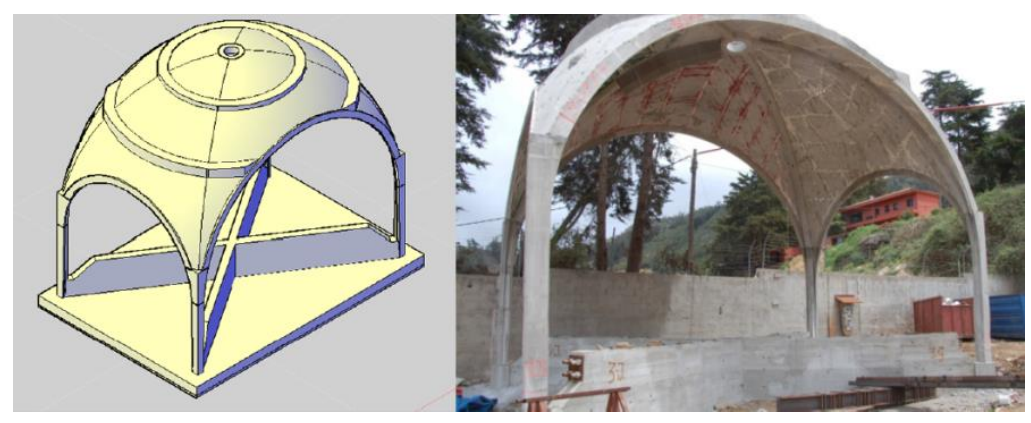

Figure 2-5: Vault prototype using PFRC Palacios et al. [2,34]

\subsubsection{Polypropylene fibre types}

Like steel fibres, polypropylene fibres come in different types and shapes depending on their application. Most present tensile properties over $600 \mathrm{MPa}$ and a modulus of elasticity from 3 to $10 \mathrm{GPa}$. In this context, most polypropylene fibres are monofilament fibres of different shapes (crimped, twisted, enlarged-ends, sinusoidal-ends, hookedends, double duoform or straight fibres), diameter forms (rectangular, circular) or surface treatments (indentated, smooth or with surface treatment). In order to better visualise the different polypropylene fibre types, Figure 2-6 shows the various polypropylene fibres types tested by Won et al. in 2006 [43]. 


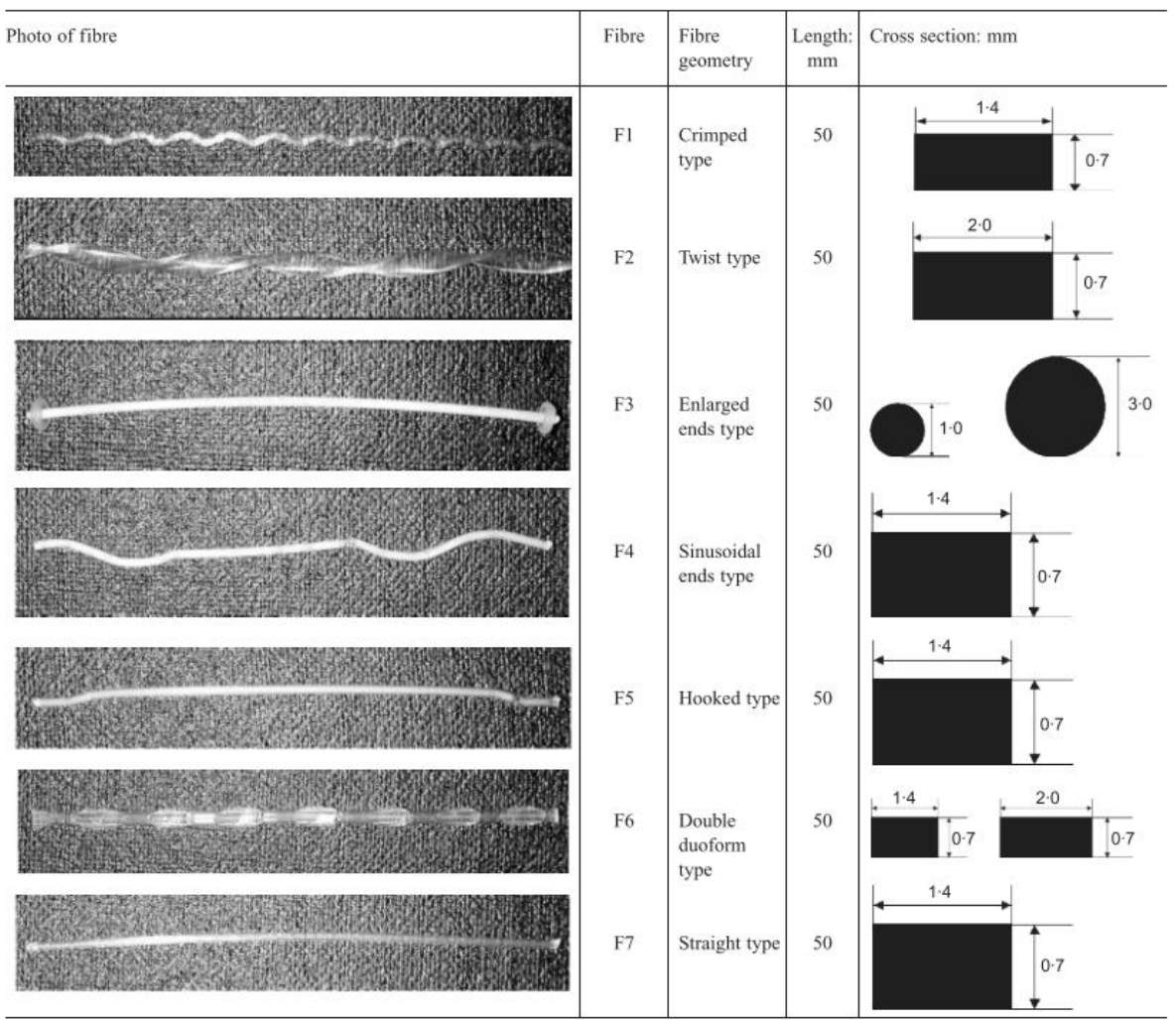

Figure 2-6: Different macrosynthetic fibre types tested by Won et al. [43]

Apart from the geometry of polypropylene fibres, their surface type plays an important role in their performance, especially in the bond strength between fibre and matrix. In order to determine bond strength and the parameters affecting it, several pull-out tests have been conducted using polypropylene fibres.

The pull-out test consists in pulling out a single fibre when portion of its length is embedded in a matrix (concrete or mortar). In a straight fibre with no inclination, Breitenbücher et al. [44] defined the following three phases during the pull-out of the fibre (see also Figure 2-7):

- The bond stage, where the surface of the fibre is connected to the surrounding cementitious matrix;

- The debonding phase, where the interface fibre-matrix is broken;

- The pull-out phase or sliding, where the fibre starts to slide and transmit stresses to the matrix by friction. 


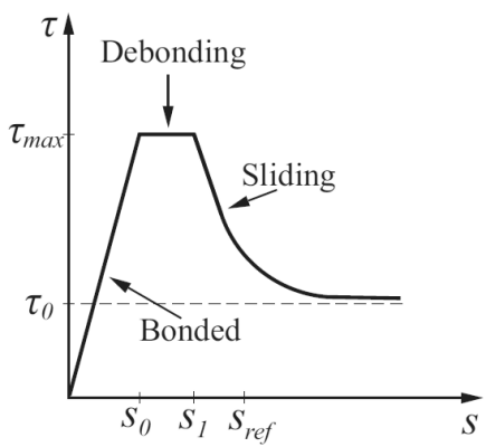

(a)

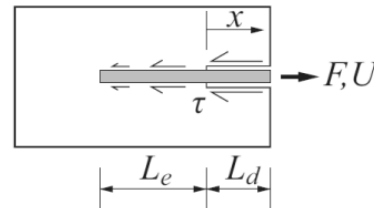

(b)

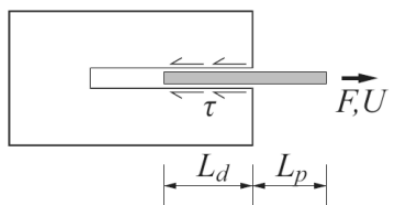

(c)

Figure 2-7: Pull-out phases of a straight fibre bonded (a), debonding (b) and sliding (c) [44]

The reports in the literature about the pull-out behaviour of polypropylene fibres have studied the following variables:

- The effect of embedded length $[24,45]$

- The effect of fibre inclination [45]

- Effect of concrete curing time on bonding (fibre-matrix) strength [24]

- Different surface treatment $[24,46]$

- The effect of the loading pull-out rate [47]

- Pull-out creep [48]

After testing, the following conclusions about the pull-out of polypropylene can be drawn:

- Bonding the fibre to the matrix is maximum within the first 2 concrete curing days, after which time bond strength remains constant [24].

- The MOFs identified during the pull-out of polypropylene fibre are pull-out, matrix spalling and fibre rupture [45].

- The peak load of the pull-out behaviour of a fibre is directly related to its embedded length in the cementitious matrix; i.e. the more embedded fibre is, the bigger the load [24,45], as seen in Figure 2-8a. However depending on fibre type, when fibre is embedded more than $20-25 \mathrm{~mm}$ (approximately half of fibre length), the rupture of fibre occurs [45].

- A fibre's inclination angle directly affects pull-out behaviour, as Figure 2-8a-e shows. This peak is maximum at $45^{\circ}$ and $30^{\circ}$ to produce the maximum work for debonding fibres [45]. 

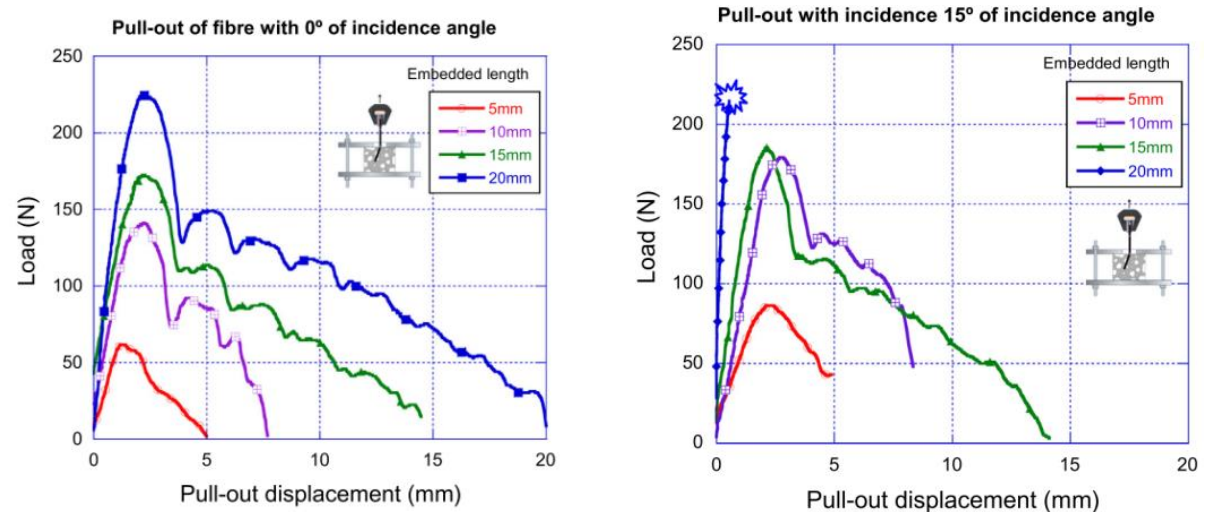

(a)

(b)

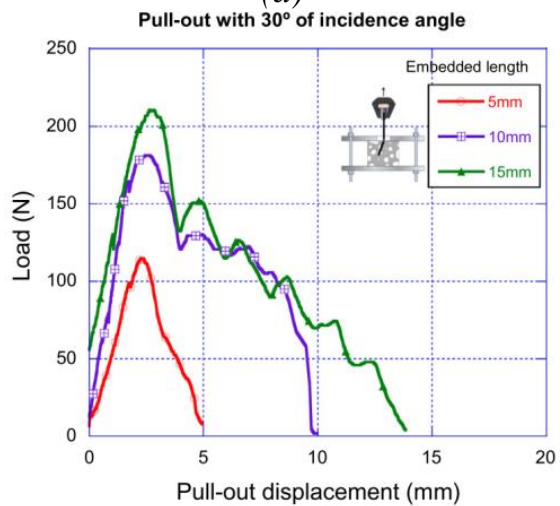

(c)

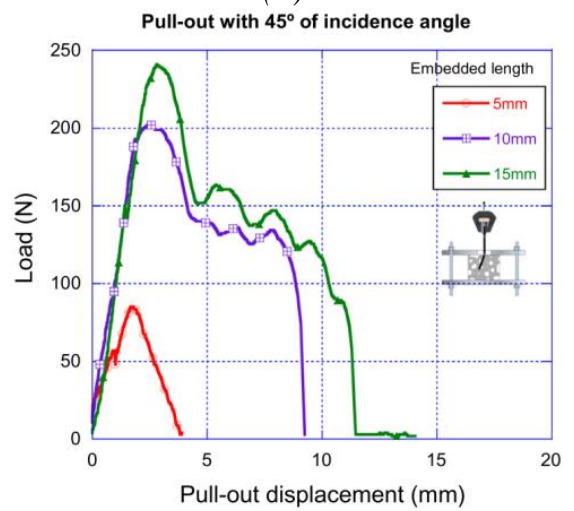

(d)

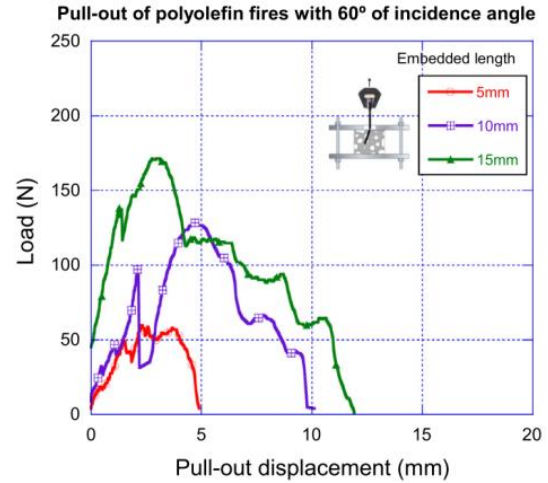

(e)

Figure 2-8: Pull-out results of polyolefin fibre for inclination angles of $0^{\circ}(\mathrm{a}), 1^{\circ}(\mathrm{b}), 30^{\circ}(\mathrm{c})$, $45^{\circ}(\mathrm{d})$ and $60^{\circ}(\mathrm{e})[45]$ 
- Bonding strength is strongly influenced by the fibre and cementitious matrix properties. For fibres with a good characteristic surface (indented or treated chemically), a better debonding strength result is obtained [24,46]. Moreover, better cementitious properties results in better debonding strength.

- The pull-out behaviour of a synthetic fibre is very sensitive to the loading rate. So if the loading rate rises, the maximum pull-out load also increases [47].

The time-dependent pull-out behaviour of polypropylene fibres depends on fibre type. In this context, a better characteristic fibre surface results in less creep pull-out [48]

Table 2-1 summarises the pull-out tests using the polypropylene fibres reported in the literature. As we can see, different fibre types were employed, and fibre lengths $\left(l_{f}\right)$ from $30 \mathrm{~mm}$ to $60 \mathrm{~mm}$ were covered, with the equivalent diameters $\left(d_{f}\right)$ less than $1 \mathrm{~mm}$, aspect ratios from 50 to 89 , tensile strengths $\left(\sigma_{\sigma_{i t}}\right)$ from $500 \mathrm{MPa}$ to $640 \mathrm{MPa}$, and modulus of elasticity $\left(E_{f}\right)$ up to $4 \mathrm{GPa}$. It should be noted that not all the test reports provided complete information about the compression strength of concrete or the mortar matrix $\left(f_{c}\right)$, or the debonding strength of fibre. In this context, debonding strength $\left(\tau_{d}\right)$ was determined using expression (Eq. 2-4), where $L_{b}$ is the load in the debonding stage, $l$ is embedded length and $\Phi$ is the equivalent diameter. Load at debonding was determined by pull-out curves, and corresponded to the point at which the initial stiffness changed (prior to the peak load).

$$
\boldsymbol{\tau}_{\boldsymbol{b}}=\frac{\boldsymbol{L}_{\boldsymbol{b}}}{\boldsymbol{\pi} * \boldsymbol{l} * \emptyset}
$$

As Table 2-1 shows, the debonding load was different for each studied fibre. This is explained because different fibres with distinct properties were compared. Similarly to steel fibres, the matrix characteristic also played an important role in the pull-out behaviour of a single fibre. This behaviour has been studied and is presented in a preliminary report by [49], which found that the water/cement and water/sand ratios play a key role in a synthetic fibre's debonding behaviour. 
Table 2-1: Pull-out comparison made of different synthetic fibre types

\begin{tabular}{|c|c|c|c|}
\hline \multirow{2}{*}{$\begin{array}{l}\text { Singh } \\
{[24]} \\
2004\end{array}$} & & $\begin{array}{l}\text { Polypropylene Smooth } \\
\text { Density }=\text { N.S. } \\
l_{f}=50 \mathrm{~mm} \\
d_{f}=1.25 \times 0.2 \mathrm{~mm} \\
\sigma_{f u}=N . S .\end{array}$ & $\begin{array}{l}\text { Mortar matrix } \\
f_{c}=N . S . \\
\tau_{d}=0.5 \mathrm{MPa}\end{array}$ \\
\hline & 앵 & $\begin{array}{l}\text { Polypropylene Indented } \\
\text { Density }=N . S . \\
l_{f}=50 \mathrm{~mm} \\
d_{f}=1.25 \times 0.2 \mathrm{~mm} \\
\sigma_{f u}=N . S . \\
E_{f}=N . S .\end{array}$ & $\begin{array}{l}\text { Mortar matrix } \\
f_{c}=N . S \\
\tau_{d}=1.5 \mathrm{MPa}\end{array}$ \\
\hline $\begin{array}{l}\text { Maida et al. } \\
{[46]} \\
2015\end{array}$ & & $\begin{array}{l}\text { Polypropylene Monofilament } \\
\text { Density }=N . S . \\
l_{f}=30-60 \mathrm{~mm} \\
d_{f}=0.78 \mathrm{~mm} \\
\sigma_{f u}=500 \mathrm{MPa} \\
E_{f}=4 \mathrm{GPa}\end{array}$ & $\begin{array}{l}\text { Mortar matrix } \\
f_{c}=N . S . \\
\tau_{d}=1.07 \mathrm{MPa}\end{array}$ \\
\hline $\begin{array}{l}\text { Alberti et } \\
\text { al. } \\
{[45]} \\
2015\end{array}$ & | & $\begin{array}{l}\text { Polyolefin } \\
\text { Monofilament } \\
\text { Density }=0.91 \mathrm{~g} / \mathrm{cm}^{3} \\
l_{f}=60 \mathrm{~mm} \\
d_{f}=0.92 \mathrm{~mm} \\
\sigma_{f u}=560 \mathrm{MPa} \\
E_{f}=>9 \mathrm{GPa}\end{array}$ & $\begin{array}{l}\text { Mortar matrix } \\
f_{c}=N . S . \\
\tau_{d}=2.33 \mathrm{MPa} \\
\text { SCC matrix } \\
f_{c}=39 \mathrm{MPa} \\
\tau_{d}=4.96 \mathrm{MPa}\end{array}$ \\
\hline $\begin{array}{l}\text { Babafemi } \\
\text { and Boshof } \\
{[47]} \\
2016\end{array}$ & & $\begin{array}{l}\text { Polyolefin crimped Monofilament } \\
\text { Density }=0.88-0.92 \mathrm{~g} / \mathrm{cm}^{3} \\
l_{f}=40 \mathrm{~mm} \\
d_{f}=0.80 \mathrm{~mm} \\
\sigma_{f u}=400 \mathrm{MPa} \\
E_{f}=4.3 \mathrm{GPa}\end{array}$ & $\begin{array}{l}\text { Concrete ma- } \\
\text { trix } \\
f_{c}=N . S \\
\tau_{d}=2 \mathrm{MPa}(\mathrm{ap}- \\
\text { prox. for Lr } \\
=0.1 \mathrm{~mm} / \mathrm{s})\end{array}$ \\
\hline \multirow{3}{*}{$\begin{array}{l}\text { Babafemi et } \\
\text { al. [48] } \\
2018\end{array}$} & & $\begin{array}{l}\text { Polyolefin Monofilament } \\
\text { Density }=0.91 \mathrm{~g} / \mathrm{cm}^{3} \\
l_{f}=54 \mathrm{~mm} \\
d_{f}=0.85 \mathrm{~mm} \\
\sigma_{f u}=640 \mathrm{MPa} \\
E_{f}=40 \mathrm{GPa}\end{array}$ & $\begin{array}{l}\text { Concrete } \\
\text { matrix } \\
f_{c}=35.9 \mathrm{MPa} \\
\tau_{d}=2.5 \mathrm{MPa} \\
\text { (approx.) }\end{array}$ \\
\hline & & $\begin{array}{l}\text { Polyolefin Monofilament crimped } \\
\text { Density }=0.91 \mathrm{~g} / \mathrm{cm}^{3} \\
l_{f}=50 \mathrm{~mm} \\
d_{f}=0.71 \mathrm{~mm} \\
\sigma_{f u}=405 \mathrm{MPa} \\
E_{f}=4.3 \mathrm{GPa}\end{array}$ & $\begin{array}{l}\text { Concrete } \\
\text { trix } \\
f_{c}=35.9 \mathrm{MPa} \\
\tau_{d}=2.05 \mathrm{MPa} \\
\text { (aprox) }\end{array}$ \\
\hline & & $\begin{array}{l}\text { Polyolefin Monofilament } \\
\text { Density }=0.91 \mathrm{~g} / \mathrm{cm}^{3} \\
l_{f}=48 \mathrm{~mm} \\
d_{f}=0.70 \mathrm{~mm} \\
\sigma_{f u}=640 \mathrm{Mpa} E_{f}=10 \mathrm{GPa}\end{array}$ & $\begin{array}{l}\text { Concrete } \\
\text { matrix } \\
f_{c}=35.9 \mathrm{MPa} \\
\tau_{d}=3.28 \mathrm{MPa} \\
\text { (approx.) }\end{array}$ \\
\hline
\end{tabular}




\subsubsection{Differences between steel and polypropylene fibres}

The first difference between both fibre types is related to their physical properties. Table 2-2 summarises the typical properties of both fibre types. As we can see, major differences in their specific gravity exist, which is 8 -fold heavier for steel fibres than for synthetic ones. This difference in fibre density directly influences the amount of fibres introduced into the cementitious matrix; i.e. when the same weight of fibres is introduced into the concrete matrix, there will be more synthetic fibres than steel ones. The increased number of fibres in the matrix could directly affect the workability of concrete and its orientation and distribution inside the matrix. Thus probably more attention and quality controls will be necessary in PFRC than in SFRC. Moreover, the use of additives, such as plasticisers or super-plasticisers, could help concrete workability. On the contrary, when polypropylene and steel fibres are dosed as a volume fraction, no change in workability is observed in concrete [50]. Some improvements in the fibre distribution of macrosynthetic fibres inside the matrix in relation to steel fibres have also been found, which are related to the ability of macrosynthetic fibres to bend versus rigid ones [51,52]. Nevertheless, the literature reports how fibre contents of synthetic fibres act as shear reinforcement, ranging from $4.6 \mathrm{~kg} / \mathrm{m}^{3}$ [53] to $13 \mathrm{~kg} / \mathrm{m}^{3}$ [54].

Table 2-2: Typical properties of steel and synthetic fibres (adapted from [55])

\begin{tabular}{|c|c|c|c|c|c|}
\hline Fibre type & $\begin{array}{c}\text { Diameter } \\
{[\mathbf{m m}]}\end{array}$ & $\begin{array}{c}\text { Specific } \\
\text { gravity } \\
{\left[\mathbf{g} / \mathbf{c m}^{\mathbf{3}}\right]}\end{array}$ & $\begin{array}{c}\text { Tensile } \\
\text { strength } \\
{[\mathbf{G P a}]}\end{array}$ & $\begin{array}{c}\text { Modulus of } \\
\text { elasticity } \\
{[\mathbf{G P a}]}\end{array}$ & $\begin{array}{c}\text { Ultimate } \\
\text { elongation } \\
{[\mathbf{\%}]}\end{array}$ \\
\hline Steel & $0.1-1.0$ & 7.84 & $0.3-2.4$ & 200 & $0.5-3.5$ \\
\hline Polypropylene & $0.02-0.4$ & $0.90-0.95$ & $0.45-0.76$ & $3.5-10$ & $15-25$ \\
\hline Others Polyolefin & $0.15-0.64$ & 0.91 & $0.2-1.1$ & $2.7-20$ & 15 \\
\hline
\end{tabular}

The second difference lies in fibres' mechanical properties. As seen in Table 2-2, the modulus of elasticity of macrosynthetic fibres differs by at least 20 -fold compared to steel fibres. This difference will influence the mechanical performance of PFRC. Although PFRC meets the residual flexural tensile strength demands set out in existing standards $\left(f_{R I k} / f_{L k}>0.4\right.$ and $\left.f_{R 3 k} / f_{R l k}>0.5\right)$, particularly MC2010 [7], its performance has distinctive characteristics to that of SFRC.

Although the pull-out behaviour of steel fibres has been extensively studied, limited information about the pull-out behaviour of macrosynthetic fibres is available in the literature, as presented in 2.1.2.1. Alberti et al. [45] complemented his research about the pull-out of polyolefin fibres by comparing their result with the pull-out results of the steel fibres available in the literature [56,57]. They found that polyolefin fibres offered similar pull-out peak loads to steel fibres (see Figure 2-9). In fact when comparing only straight fibres (the straight fibres used by Cunha et al. [56]), polyolefin fibres exceeded 
the peak load in all the combinations of embedded lengths and inclination angles. However, no clear tendencies appeared for hooked-end steel fibres.

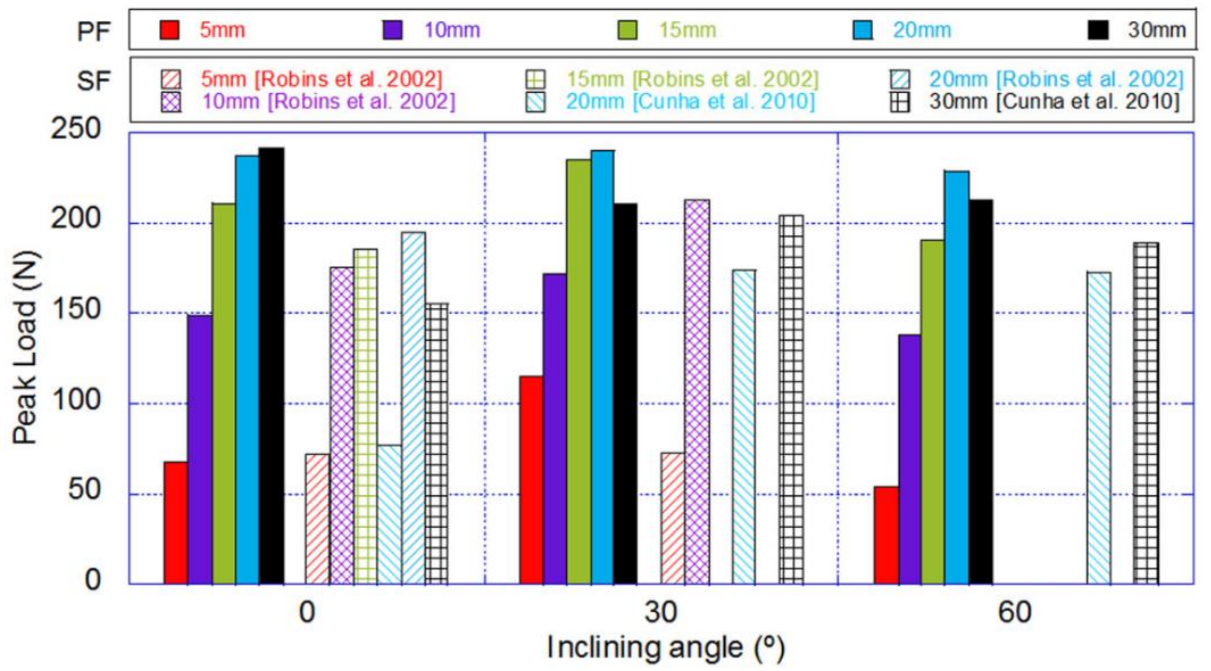

Figure 2-9: Pull-out peak load comparison between polyolefin and steel fibres [45]

Although polyolefin fibres exceeded the maximum pull-out load of a straight steel fibre, it is worth mentioning that the debonding phase in polyolefin fibres occurred 10 -fold later than in steel fibres (in slip terms). Figure 2-10 shows a comparison of the pull-out response of polyolefin and straight steel fibres when embedded at $20 \mathrm{~mm}$. This behaviour, which is related to their modulus of elasticity, allows polyolefin fibres to absorb more energy than steel fibres. Alberti et al. observed this behaviour in all their combined cases (fibres embedded and inclination angle), except in those fibres embedded at $5 \mathrm{~mm}$. As a result of this debondig slip difference, SFRC and PFRC could present different post cracking residual tensile strength behaviours at small crack openings; i.e. PFRC could present less residual tensile strength at small crack openings $(0.5-1 \mathrm{~mm})$ than SFRC.

In addition, their differences in modulus of elasticity could also affect their long-term behaviour. After their experimental campaign, in which steel (dosed at $40 \mathrm{~kg} / \mathrm{m}^{3}$ ) and polypropylene (dosed at $5 \mathrm{~kg} / \mathrm{m}$ ) fibres were used to evaluate the post-cracking creep response of PFRC and SFRC, Pujadas et al. [58] observed that creep caused crack width to increase by between 6- and 10-fold in PFRC than its counterpart in SFRC. Pujadas et al. underlined the importance of considering creep deformation in PFRC elements when designing, and ensured that secondary creep did not occur under the serviceability condition in PFRC elements. 


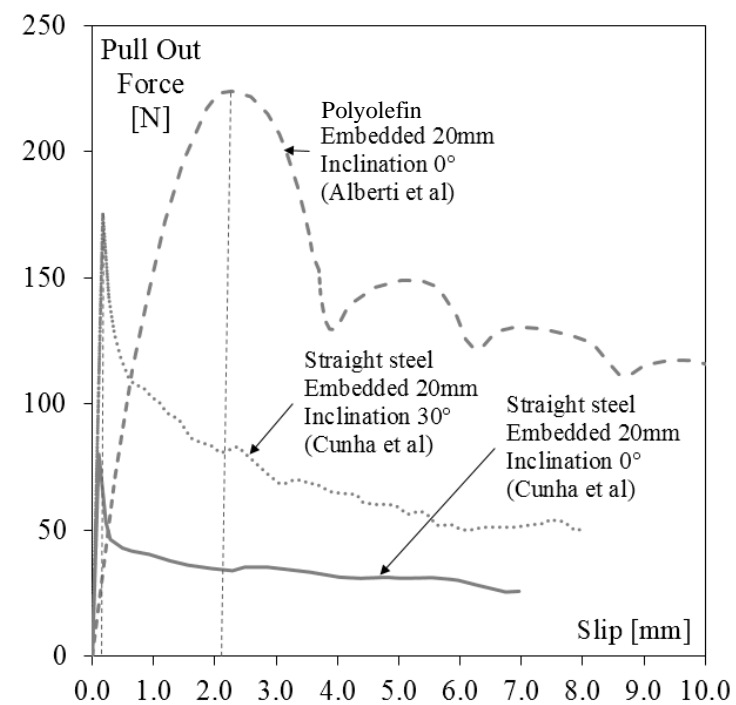

Figure 2-10: Comparison of polyolefin and straight steel fibres embedded at 20mm. Adapted from $[45,56]$

The discussion of using, or not, polypropylene fibres in structural applications involves continuous debate. Alani et al. [59] conducted experimental investigation to debate about some recommendations given by the Concrete industrial ground floors TR34 standard (2003) on employing polypropylene fibres: "Macrosynthetic fibres provide some postcracking or residual moment capacity but with significantly lower performance than steel fibres. They are not known to be used in industrial floor construction". Alani et al. tested a full-scale ground slab and reported that using synthetic fibre dosed at $7 \mathrm{~kg} / \mathrm{m}^{3}$ is the equivalent of $40 \mathrm{~kg} / \mathrm{m}^{3}$ of hooked-end steel fibres. In the same context, Behfarnia and Behravan [50] compared PFRC and SFRC (dosed at 0.5, 0.6 and 0.4 volume fractions, and the same aspect ratio) in the lining of water tunnels. They concluded that PFRC presented better flexural toughness, resistance to chloride penetration and permeability characteristics than SFRC.

Some design codes, such as ACI 318-14 (American standard) or ROM 4.1-94 (Spanish recommendation for harbour pavements), only allow steel fibres to be used in structural concrete elements, while codes like MC2010 permit the use of any macrofibres, as long as their residual flexural tensile strength fulfils its requirements (Eq. 2-2)(Eq. 2-3). In this context, after testing slabs by totally substituting reinforcement for polyolefin fibres, Pujadas et al. [29,60] concluded that, in spite of most design codes being based on SFRC experiments, the fibre models in these codes could be fitted to include PFRC behaviour. 


\subsection{Fibres as shear reinforcement}

Shear failure is considered the most critical MOF in concrete structures, especially for members without (w/o) shear reinforcement. Consequently, researchers have shown much interest in studying shear in concrete elements since 1955. Today however, and despite acquiring knowledge, the shearing problem continues w/o a clear answer and a consensus reached by the research community for both FRC and RC.

One of the main applications studied in FRC is to use fibres (macrofibres) as shear reinforcement. Most research on this topic has been done with steel fibres. According to the experimental results, it is well-known that steel fibres are used to enhance concrete shear capacity and post-cracking tensile strength as FRC is characterised by enhanced toughness given the bridging effects provided by steel fibres $[61,62]$. Steel fibres also provide substantial post-peak resistance and ductility $[61,63,64]$, and can transform brittle MOFs into ductile ones [64-68].

Steel fibres in sufficient amounts have proven efficient in substituting the amount of transverse reinforcement and to, hence, reduce congestion at critical sections in elements [69-72] . In fact ACI 318-14 [13] allows the replacement of minimum stirrup reinforcement in beams with steel fibres if:

- Fibre content is at least $60 \mathrm{~kg} / \mathrm{m}^{3}(0.75 \%$ of the volume fraction);

- The element's total depth is less than $600 \mathrm{~mm}$;

- Shear strength $\left(V_{u}\right)$ is less than $\emptyset 0.17 \sqrt{f^{\prime}}{ }_{c} b d$ (in MPa);

- Concrete compression strength is less than $41 \mathrm{MPa}$;

- $V_{u}$ is higher than $0.5 \emptyset V_{c}$, where $V_{c}$ is the shear strength provided by concrete.

Despite the fact that fibres have proven effective in shear, not all codes provide expressions to include fibres in evaluations of the strength of concrete elements. Table 2-3 offers a selection of the expressions included in codes. The included expressions are Australian codes AS 3600-2018 [73], MC2010 [7] and RILEM TC 162-TDF standard [74]. As seen in Table 2-3, both Australian and RILEM standards include fibres separately from concrete shear behaviour ((Eq. 2-5) and (Eq. 2-25) respectively), while MC2010 mixes both (concrete and fibres) as a unique material (Eq. 2-15). MC2010 proposes two expressions to determine the shear behaviour of FRC. The first expression was proposed by Minelli and Plizzari [75] (Eq. 2-16), where fibres are included as a factor to modify longitudinal reinforcement $(\rho)$ using the expression proposed in Eurocode 2 [76] for RC, limited to $\rho=0.02$. The second expression (Eq. 2-17) in MC2010 was proposed by Foster [77], where the effect of fibres is included in the expression developed in MC2010 for the concrete contribution in RC members with shear reinforcement at approximation III level. This expression is based on the Modified Compression Field Theory (MCFT) [78]. 
Effectiveness of polypropylene fibres as shear reinforcement in structural elements

Table 2-3: Codes and guidelines that include fibres for shear capacity

\begin{tabular}{|c|c|c|}
\hline Reference & Expression & ID \\
\hline Australian & $V_{u}=V_{u, c}+V_{u, f}+V_{u, s}$ & (Eq. 2-5) \\
\hline AS 3600- & $V_{u, c}=\left(k_{v} \cdot \sqrt{f_{c}}\right) z \cdot b_{w}$ & (Eq. 2-6) \\
\hline [79] & $V_{u, f}=k_{s} f_{w}^{\prime} \cot \theta \cdot b_{w} \cdot z$ & (Eq. 2-7) \\
\hline & $k_{s}=0.64$ & (Eq. 2-8) \\
\hline & $\theta=29^{\circ}+7000 \cdot \varepsilon_{x}$ & (Eq. 2-9) \\
\hline & $\varepsilon_{x}=\frac{1}{2 E_{S} A_{s}}\left(\frac{M_{E d}}{z}+V_{E d}+N_{E d}\left(0.5 \pm \frac{\Delta_{e}}{z}\right)\right) \leq 0.003$ & (Eq. 2-10) \\
\hline & $w_{u}=\left(0.2+1000 \varepsilon_{x}\right)\left(\frac{1000+k_{d g} z}{1300}\right) \frac{1}{\cos \theta} \geq 0.125 \mathrm{~mm}$ & (Eq. 2-11) \\
\hline & $f_{w}^{\prime}\left\{\begin{array}{l}f_{0.5}^{\prime}=k_{3 D b}\left(-0.04 f_{R, 4 k}+0.37 f_{R, 2 k}\right) \leq k_{3 D b} 0.36 \sqrt{f_{c}^{\prime}} \\
f_{1.5}^{\prime}=k_{3 D b}\left(0.4 f_{R, 4 k}-0.07 f_{R, 2 k}\right) \leq k_{3 D b} 0.36 \sqrt{f_{c}^{\prime}}\end{array}\right.$ & (Eq. 2-12) \\
\hline & $k_{3 D b}=\frac{1}{1+0.19 \frac{l_{f}}{b_{p}}} \leq 1 ; b_{p}$ is the prism sectional width & (Eq. 2-13) \\
\hline & $V_{u, s}=\frac{A_{s w}}{s} z d f_{y w} \cos \theta$ & (Eq. 2-14) \\
\hline \multirow{6}{*}{ MC2010 } & $V_{u}=V_{u, c F}+V_{u, s}$ & (Eq. 2-15) \\
\hline & $V_{u, c F 1}=\left(0.18 \cdot k\left(100 \cdot \rho \cdot\left(1+7.5 \cdot \frac{f_{F t u k}}{f_{c t}}\right) \cdot f_{c}\right)^{\frac{1}{3}}+0.15 \sigma_{c p}\right) b_{w} \cdot d$ & (Eq. 2-16) \\
\hline & $V_{u, c F 2}=\left(k_{v} \cdot \sqrt{f_{c}}+k_{f} \cdot f_{F t u k} \cot \theta\right) z \cdot b_{w}$ & (Eq. 2-17) \\
\hline & $\theta=29^{\circ}+7000 \cdot \varepsilon_{x}$ & (Eq. 2-18) \\
\hline & $k_{v}=\frac{0.4}{\left(1+1500 \varepsilon_{x}\right)} \cdot \frac{1300}{\left(1000+k_{d g} z\right)}$ for $\rho_{w}<0.08 \sqrt{\frac{f_{c k}}{f_{y w}}}$ & (Eq. 2-19) \\
\hline & $k_{v}=\frac{0.4}{\left(1+1500 \varepsilon_{x}\right)}$ for $\rho_{w} \geq 0.08 \sqrt{\frac{f_{c k}}{f_{y w}}}$ & (Eq. 2-20) \\
\hline
\end{tabular}




\begin{tabular}{|l|l|l|}
\hline Reference & \multicolumn{1}{c|}{ Expression } & \multicolumn{1}{c|}{ ID } \\
$\varepsilon_{x}=\frac{1}{2 E_{S} A_{s}}\left(\frac{M_{E d}}{z}+V_{E d}+N_{E d}\left(0.5 \pm \frac{\Delta_{e}}{z}\right)\right) \leq 0.003$ \\
$k_{f}=0.8$
\end{tabular}

\subsubsection{Shear transfer mechanisms in FRC beams}

Shear transfer in RC beams constitutes a complex interaction of mechanisms interacting with one another. As some act in different stages in an indeterminate system and depend on several factors (the element's geometry, longitudinal reinforcement ratio, aggregate size, the element's slenderness and external load type), it is difficult to theoretically quantify the contribution of each mechanism to the element's shear strength. Moreover, these shear transfer mechanisms are also affected if shear is combined with axial and bending loads. For those beams w/o transverse reinforcement, the shear transfer mechanisms reported in the literature $[80,81]$ correspond to the compression zone, dowel action, aggregate interlock, the residual tension in the crack and arch action. In the beams with conventional reinforcement, the aforementioned mechanisms work in smaller pro- 
portions as the stirrup acts as the main mechanism to transmit shear force along the element. Figure 2-11 displays the shear transfer mechanisms that act on an FRC beam with and w/o stirrups. Although all the mechanisms have been studied, no consensus exists about how much shear strength each mechanism provides. This problem is further complicated when fibres are incorporated into the concrete matrix as the fibre mechanism interacts with all the other shear transfer mechanisms.
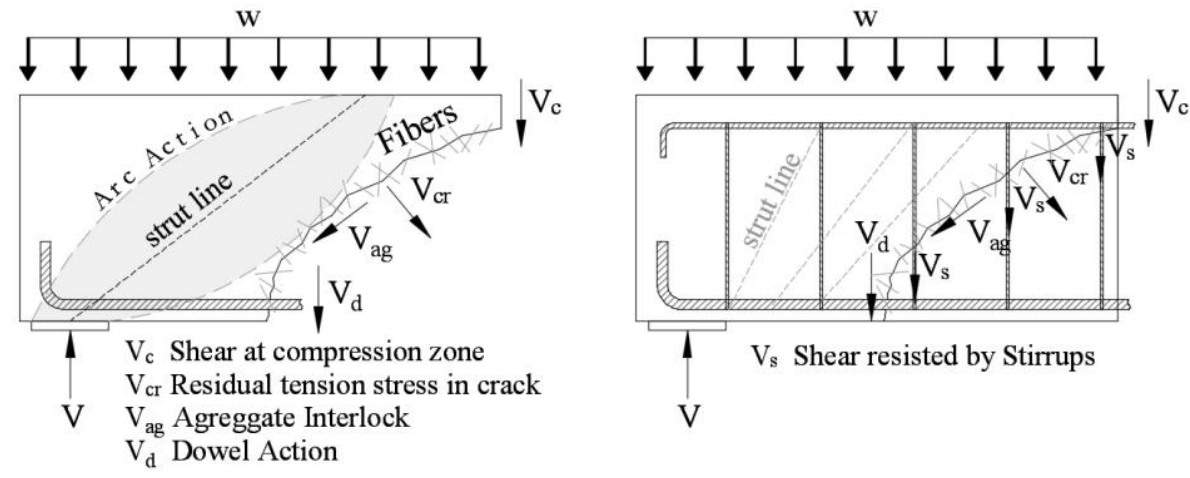

Figure 2-11: Shear transfer mechanisms in FRC beams

\subsubsection{Compression zone}

When an RC beam is uncracked, shear force is transferred by inclined principal tensile and compressive stresses. When cracks occur, a portion of shear is transferred in the compressed zones not yet reached by cracks (see Figure 2-11). In this way, the contribution of this mechanism to shear strength (i.e., concrete's contribution) results from integrating shear stresses over the compression zone depth. The uncracked zone is a effective shear transfer mechanisms in RC beams. However in slender beams, this mechanism does not significantly contribute, especially when members are not subjected to axial compression. Although no consensus has been reached about what this mechanism contributes exactly, some authors have estimated that it ranges between $20 \%$ and $40 \%$ of a beam's total shear strength $[82,83]$.

As fibres do not affect concrete's compression strength, the effect of fibres on the compression zone is limited. However, as fibres improve the tension zone of a beam under bending, the neutral axis of the section descends and the depth of the compression zone will be larger in FRC than in RC. This mechanism vanishes in RC when the critical inclined crack propagates through the uncracked zone towards the loading point as it can be seen in Figure 2-12 where measurements taken by non-contact techniques (Digital image Correlation) [84] have shown that the compression zone of SFRC beams can remain stable even when the critical inclined crack propagates into it. 


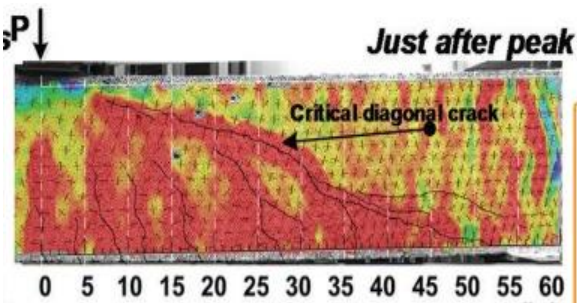

(a)

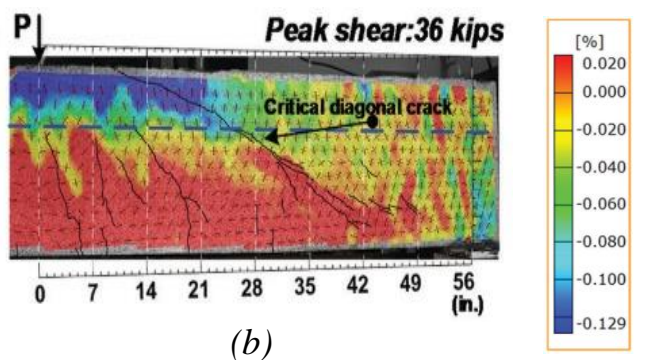

(b)

Figure 2-12: Comparison of compression zones between RC and FRC beams [84]

\subsubsection{Residual tension across cracks}

Residual tension across plain concrete cracks occurs in some load stages when the crack is not completely opened, and some concrete portions continue transmitting tensile forces up to crack openings from 0.05 to $0.15 \mathrm{~mm}$ [81] and are, hence, able to transfer shear stress. This mechanism is significant for small members (depth below $100 \mathrm{~mm}$ ) where small cracks take place $[81,85]$.

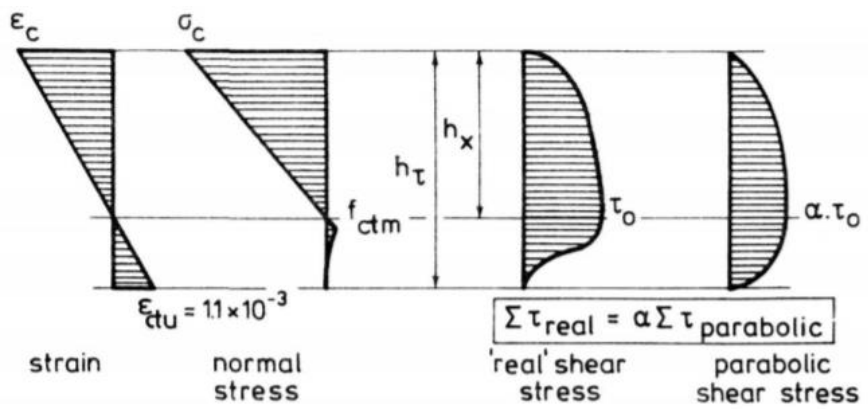

Figure 2-13: Representation of effective shear depth [85]

In FRC elements, the tension force across a crack is mainly produced by the bridging effect of fibres. In this way, fibres sew crack faces and restrain them from opening. However, this behaviour is influenced mainly by the amount and type of fibres, and by fibre matrix bond strength. Several models [86-88] have estimated the contribution of fibres to shear according to the volume of fibres and their bond strength, mostly using hookedend or double-hooked-end steel fibres. Nevertheless, these models are not applicable when new fibre types, like polypropylene fibres, are available on the market. Thus developing more general models like RILEM [74] (independently of the type of material, fibre volume and geometry) according to material parameters, like residual flexural tensile strengths, is highly recommended for practical design purposes. 


\subsubsection{Aggregate interlock}

The aggregate interlock, also called interface shear transfer, is a property of a concrete crack to continue transmitting stresses by the friction between the aggregates protruding from both surface cracks. In normal strength concrete, a crack usually surrounds aggregates while a crack normally passes across aggregates in lightweight and high-performance concretes. Hence, the aggregate interlock depends mainly on aggregate types, and on the bond between aggregates and the matrix. Several models [89-92] have been developed to explain this mechanism and it was introduced for the first time in 1968 [82]. The two-phase model developed by Walraven in 1979 [92] is probably the most accepted and widely used aggregate interlock model $[78,93]$. This model involves a relation that links crack opening, crack slip, shear stress and normal stress, and is formulated analytically according concrete's aggregate size and compressive strength.

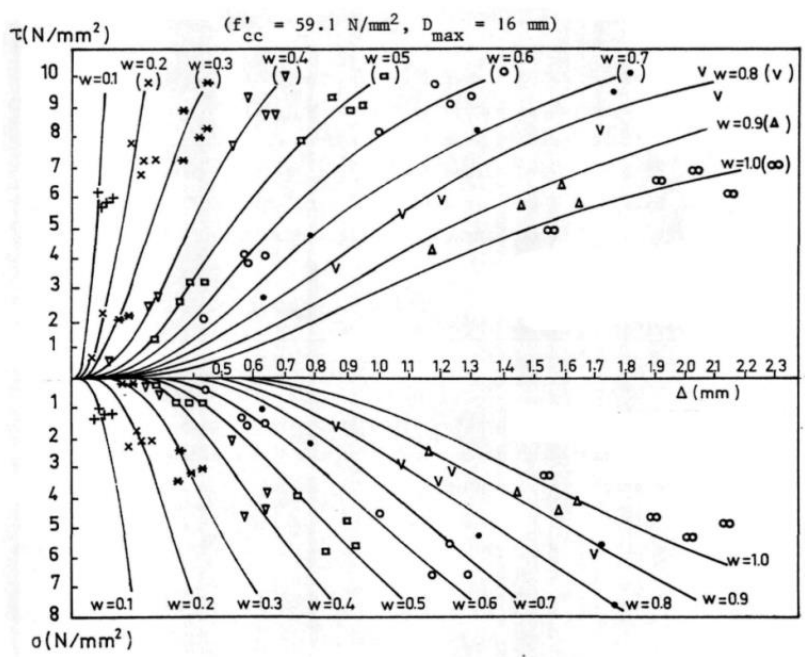

Figure 2-14: The two-phase aggregate interlock model developed by Walraven [92]

Due to the bridging effect of fibres, the aggregate interlock can be improved in FRC. In this way, when comparing RC and FRC elements, and in the same load stages, fibres reduce both crack slip and crack opening by theoretically enhancing the aggregate interlock effect for longer periods. Several research works $[10,67,94-96]$ have been conducted to determine the effect of fibres on shear transfer. Most of them have been conducted with small elements under direct shear, like push-off specimens, FIP shear tests or Japanese shear tests. However, the fibres-aggregate interlock interaction has not been completely studied experimentally. Kaufmann et al. [97] theoretically studied this interaction and the effect of the stresses transferred from the fibre to the matrix by fibre deviations (see $p_{d i}$ in Figure 2-15), which can affect aggregate interlock behaviour. In this way, a reduction factor that affects the aggregate interlock is proposed (see (e.q. 2-31)). 


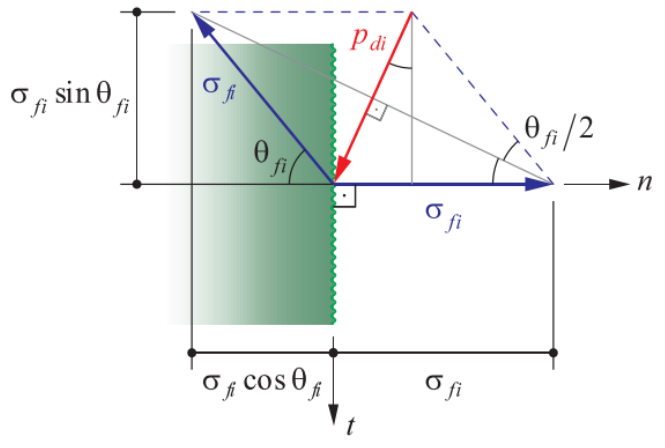

(a)

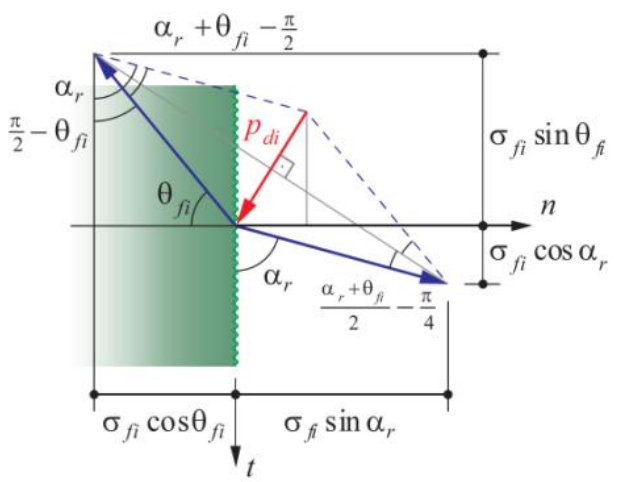

(b)

Figure 2-15: Fibre deviation forces for orthogonal crack opening (a) and inclined crack opening (b) [97]

$$
k=1+\frac{\sigma_{c f d n}-\sqrt{\frac{\sigma_{c f d t n}^{2}}{4}+\tau_{c f d n}^{2}}}{\sigma_{p u}} \leq 1
$$

where $\sigma_{c f d n}$ and $\tau_{c f d t n}$ are the portions of fibre stress component (normal and parallel to the crack face) transmitted by fibre deviation, respectively; $\sigma_{p u}$ is the matrix yielding stress.

\subsubsection{Dowel action}

Dowel action is the effect of longitudinal reinforcement to restrain the opening and sliding of shear cracks. In elements w/o stirrups, the shear transmitted by dowel action is limited to the tension strength of concrete covering reinforcement. However, this mechanism is also influenced by the amount of longitudinal reinforcement, the number of layers of longitudinal reinforcement, concrete compression strength, the bond of bars with the matrix, the element's width and the position of bars when the element is cast [80]. Thus dowel action can be considered a minor transferring mechanism compared to others, especially when small amounts of longitudinal reinforcement are used. Moreover, two failure types can occur in relation to this mechanism, as indicated in Figure 2-16. The first is related to a crack occurring at the same layer level or under longitudinal reinforcement. The second failure is related to concrete splitting below the longitudinal bar [98]. Hence the presence of fibres can control the dowel crack and delay its propagation (because the bond between the bar matrix is lost), especially in cracks related to failure mode I. Consequently, fibres increase the effectiveness of dowel action and the shear stiffness of the dowel zone by improving concrete's tensile strength [86]. 


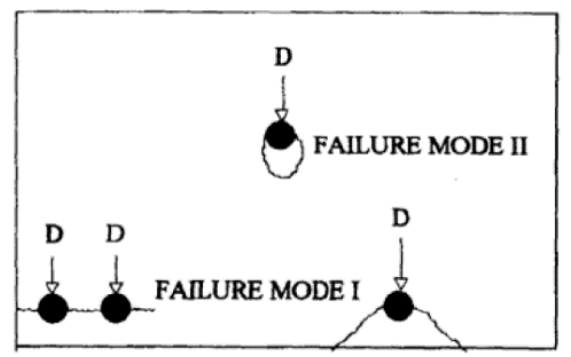

Figure 2-16: Failure modes due to dowel action [99]

Although no experimental tests or models explain the effectiveness of fibres in the dowel zone, the influence of steel fibres on dowel action has been reported in several research works $[84,86,100,101]$. However, further research on this topic is required to make the best of all the benefits provided by fibres.

\subsubsection{Arch Action}

Archi action is a resisting mechanism that results in the direct transmission of the loads applied to the support by an inclined compression strut. Arch action is very important in those elements in which the shear span-to-effective depth ratio $(a / d)$ is less than 2.5 , and over 2.5 in some cases, if active reinforcement like tendons is present in beams.

With FRC elements, several test campaigns [68,102-107] have been conducted on SFRC, including beams tested with configurations $a / d<2.5$. Most include an empirical formulation (based on a statistical analysis) to predict the shear strength of FRC beams by taking the arch effect into account $[66,86,108,109]$.

FRC short beams $(\mathrm{a} / \mathrm{d}<2.5)$ exhibit more diagonal cracks near the support [68], and incremented shear strength can be more effective on FRC in beams with low a/d values than those higher larger $a / d$ values [86,110]. According to Gali and Subramaniam [111], fibres are effective in continuing to transfer shear after a main diagonal crack forms, and change the MOF from a brittle to a ductile one.

\subsubsection{Traditional reinforcement}

In RC beams, traditional transverse reinforcement is activated only after diagonal cracks form. In this way, the function of stirrups is to redistribute shear stresses and to transfer stresses back to concrete to form a new diagonal crack. This mechanism works as a truss, and is constituted by the bottom and top longitudinal reinforcements (one acting in the tensile chord and the other in the compression chord, along with concrete), stirrups (inclined or orthogonal to longitudinal reinforcement) and inclined compression struts of concrete. This mechanism was first introduced by Ritter (1899) and Mörsch (1920), and is the basis of most international design codes to predict the shear strength of RC elements with stirrups. 
The effect of fibres when combined with stirrups is described in the literature by experimental tests. The first observed effect corresponds to the improved shear strength resisted by beams [112-115]. This is because fibres enhance mechanisms like the aggregate interlock and dowel action. As fibres can delay the appearance of inclined cracks, stirrups start working later. The strain of stirrups is also modified when fibres are present [116]. Insofar as fibres reduce crack spacing and control cracks by the bridging effect, a synergy effect along with stirrups has been described [117]. This phenomenon is probably due to the fact that a stirrup can sew more cracks in FRC than RC beams. Fibres are also effective in changing MOF from shear compression to a flexural one [113].

\subsubsection{Shear in FRC small elements}

\subsubsection{Direct shear tests}

Usually shear force acts combined with other forces, such as bending moment or axial force. In this way, in order to decouple and isolate the effect of shear from other mechanisms, small specimens and tests procedures have been carried out and reported in the literature. Most are not standardised, which makes it difficult to reproduce tests. The commonest objectives of these test procedures are related to determine the Mode II fracture, shear strength, crack kinematics, aggregate interlock behaviour, or the shear strains of different types of concretes containing fibres or not. The most frequent specimens and test procedures are the push-off test (see Figure 2-17a), the JSCE shear test (Figure 2-17b), the FIP shear test (Figure 2-17c), and the panel test (Figure 2-17d). In all these test setups except for the panel test, specimens are pre-cracked or notched to define a clear crack plane. It is worth mentioning that the JSCE shear tests considered in this thesis are JSCE-SF6 [118] and JSCE-G 553 [119], designed to determine the shear strength of steel FRC. 


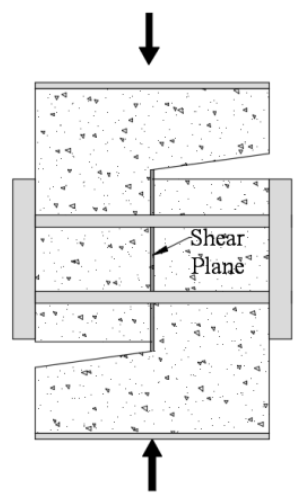

(a)

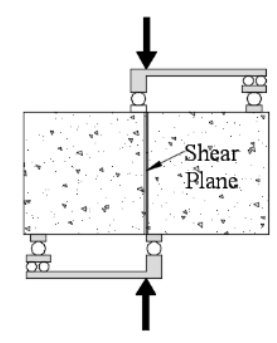

(c)

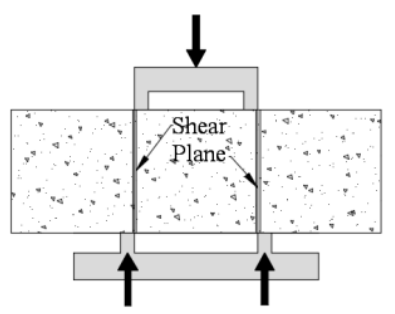

(b)

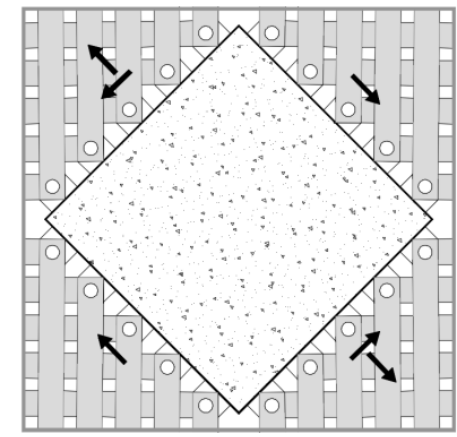

(d)

Figure 2-17: Shear test methods in RC and SFRC: Push-off test (a), JSCE shear test (b), FIP shear test (c), Panel Test (d)

\subsection{Push-off test}

Probably the most famous specimens for push-off tests in RC are those by Walraven and Reinhardt [96]. The aggregate interlock was studied in pre-cracked specimens and several models of this mechanism were developed and calibrated [78,90,92]. in some pushoff tests, like those performed by Walraven, crack opening is constrained by either internal reinforcement bars crossing the crack plane or an external rigid frame providing the specimen confinement. This test assumes that shear stress is uniform along the crack plane; however, small bending in the L shape and rotations may be present in the test.

Similarly to RC, the shear behaviour of FRC has been studied using push-off tests (see the geometry in Table 2-4). In 1985, Liu et al. [120] measured fracture toughness in shear (Mode II) using SFRC and PFRC push-off specimens. The fracture toughness in mode II was compared to its counterpart in Mode I. Push-off specimens were cut from a standardised prismatic small beam $(100 \times 100 \times 500 \mathrm{~mm})$ that resulted in push-off specimens 
measuring 100x100x200 mm. The crack plane was one of the studied variables to range from 100x20 mm to 100x50 mm. As the toughness in Mode II was evaluated until concrete failed and the post-cracking residual strength was not taken into account, Liu et al. stated that toughness does not vary when the content of steel or polypropylene fibres increases. This conclusion is probably evident today, but was major step forward in fibre knowledge at that time. Following the same procedures as Liu et al. [120], Barrt et al. [121] evaluated the shear strength of FRC with three types of push-off specimens: rectangular, cylindrical and cubic. Specimens were manufactured with PFRC and SFRC. These authors found that the shear strength of SFRC increased the higher the fibre content. However despite increasing fibre content in PFRC, shear strength did not improve, and shear strength even decreased in some cases. Nevertheless, these authors also found that shear strength depended on the direction of specimens' casting.

In 1987, Van de Loock [122] tested SFRC pre-cracked push-off specimens (see the geometry in Table 2-4) to study the bridging effect provided by steel fibres. An external frame confined specimens to better control cracks. The studied fibre type was hookedend steel fibres ( $0.8 \mathrm{~mm}$ in diameter, $60 \mathrm{~mm}$ long). Normal concrete (35MPa) was used. Crack opening was achieved immediately before the push-off test, and ranged between $0.015 \mathrm{~mm}$ and $0.02 \mathrm{~mm}$. The studied parameters were fibre content and the effect of confinement. Van de Loock observed that increased fibre content was associated with improved shear strength, and that as external confinement increased, the effect of fibres diminished.

In 1993, Balaguru and Dipsia [123] reported an experimental campaign that evaluated the effect of steel fibres on semi-lightweight concrete mechanical properties. To investigate shear, push-off specimens were manufactured and tested. Three hooked-end steel fibre types were used with length and aspect ratios of 30,50 and $60 \mathrm{~mm}$ and 1.2, 2.0 and 2.4 , respectively. A higher fibre length to aspect ratio resulted in increased shear strength. Moreover, the contribution of fibres increased shear ductility.

Valle and Büyüköztürk in 1993 [124] studied the effect of steel and polypropylene fibres on shear in normal and high-strength concrete. The effect of combining stirrups and fibres also was studied. All together, 48 specimens were tested under direct shear. The employed steel fibres were crimped-ended ( $31 \mathrm{~mm}$ long and an aspect ratio of 62, while polypropylene fibres were fibrillated. Valle and Büyüköztürk concluded that the inclusion of steel fibres $\left(V_{f}=1 \%\right)$ increased the shear strength of normal $(18 \%)$ and high$(60 \%)$ strength concrete. The use of polypropylene fibres did not increase shear strength with normal concrete, while the increment was $17 \%$ in high-strength concrete. Nevertheless in all the cases to which fibres were added, both deformation and ductility increased. Finally in those specimens in which fibres and stirrups were combined, no significant increment in shear strength took place for normal concrete compared to the specimens only with stirrups. Similar results were obtained by Khaloo and Kim in 1997, who investigated the shear strength of steel fibre by varying the fibre content, aspect ratio and compression strength of concrete by push-off tests. Hooked-end twisted steel 
fibres were studied at doses of $0 \%$ to $1.5 \%$. Fibre lengths were $16 \mathrm{~mm}$ and $32 \mathrm{~mm}$ with an aspect ratio of 29 and 58 , respectively.

In 2006, Barragan et al. [125] studied the shear failure in push-off specimens obtained from prismatic beams tested previously by bending tests. Two concrete types were used (normal and high-strength) and two types of steel hook-end fibres $(60 \mathrm{~mm}$ and $30 \mathrm{~mm}$ long, with a diameter of 0.75 and 0.38 ). Barragan observed that fibres were capable of limiting the opening of tensile cracks in SFRC specimens compared to PC specimen, in which the crack was dominated by tensile splitting. Nevertheless, Barragan observed that shear failure was dominant in SFRC specimens.

In 2007, Gregory Lee [126] studied the direct shear behaviour of steel fibres in a cement matrix. Discrete fibres were introduced at pre-defined angles and embedment lengths in push-off specimens (see the geometry in Table 2-4). The used fibres were hooked-end steel fibres and straight steel fibres obtained from cutting the hooks off fibres. The fibre lengths employed in the test were 13,35, 48 and $60 \mathrm{~mm}$ with an aspect ratio of 65, 64, 53 and 67, respectively. At the same time by using the same push-off specimens' geometry, Lee studied the shear behaviour of randomly distributed steel fibres at doses from 0 to $2 \%$. The discrete fibres' behaviour was monitored during tests in different load stages by Gamma Ray Radiographies. The pull-out and fracture of fibres in mode II were thus analysed. The research stated that fibres' inclination angle in relation to the analysed plane is an important parameter in shear behaviour. During the bridging effect of fibres and depending on fibres' orientation, several mechanisms take place. The effect of hooked-end of steel fibres becomes less significant for more acute angles (see Figure 2-18), and fibre bending and snubbing effect on the matrix becomes more influential. Conversely to what other research works previously stated, the traditional bond stress along fibres was not found significant, and other mechanisms, such as snubbing, were more significant in the fibre-matrix anchorage. 


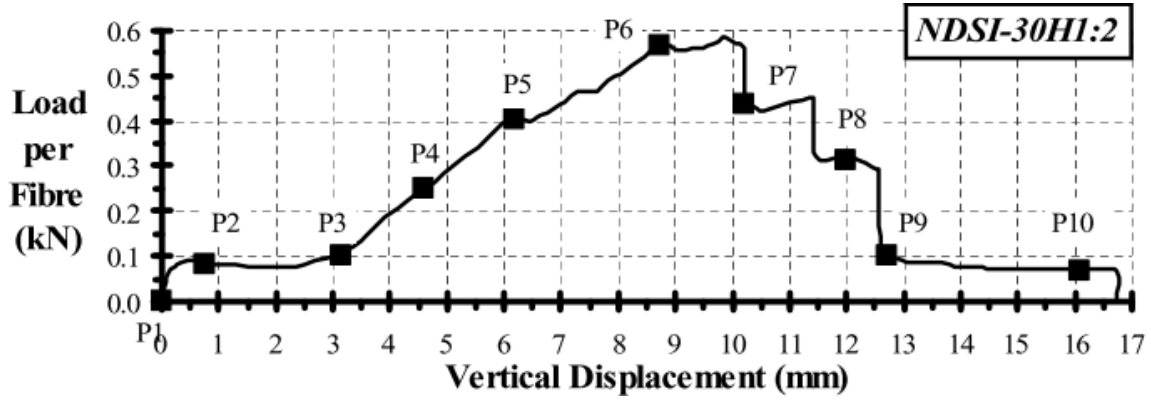

(a)
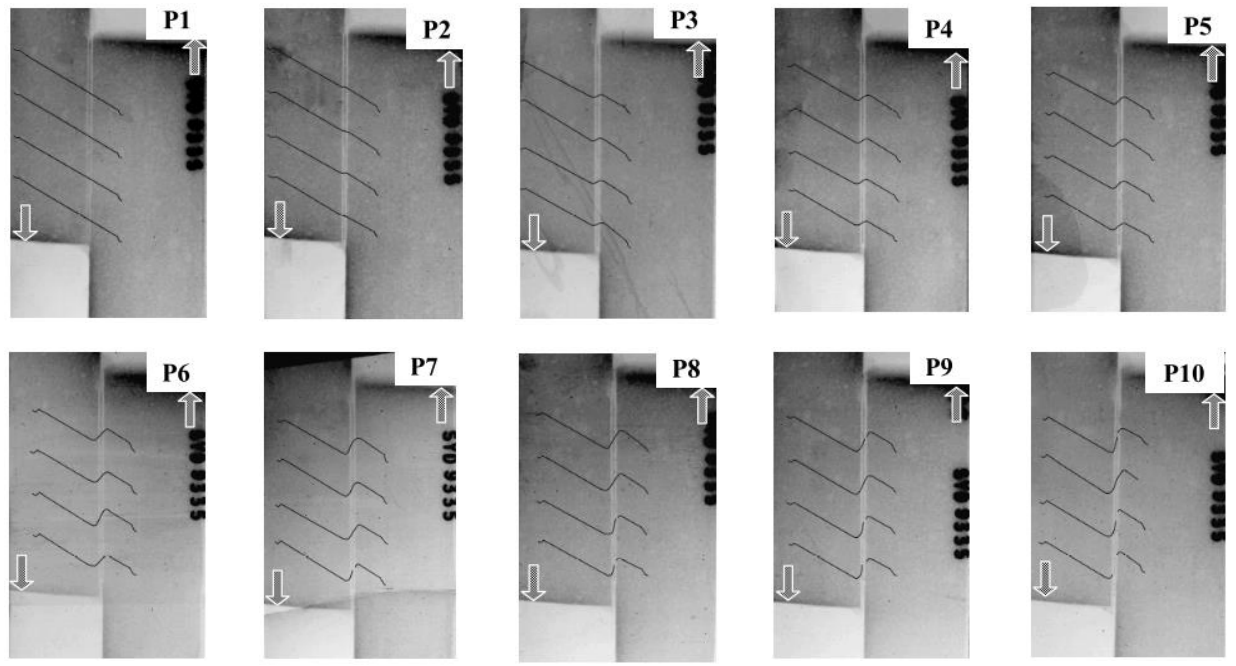

(b)

Figure 2-18: Test result of specimen NDSI-30H1:2: Load-slip (a) and Gamma Ray Radiography [126]

In 2014 at the Universitat Politécnica de Valencia, Javier Echegaray [127] modified the push-off test to analyse concrete cracks' shear behaviour. In this way, a methodology test was confined in two stages: pre-crack test and direct shear. To control crack opening, specimens were confined with an external rigid frame made of steel. Prior to the direct shear test, the initial crack opening was set up by placing nuts on the bars forming the external frame. A ball-bearing system was used to eliminate any friction between the external cage and specimens because it could affect shear behaviour. Echegaray evaluated the influence of crack width, amount of fibres and fibre types on the shear behaviour of SFRC. The study concluded that regardless of fibre type, shear strength improved when fibre volume increased. The initial confinement did not seem to affect shear improvement due to fibres. 
Concerning PFRC, in 2019 Picazo et al. [128,129] evaluated the shear behaviour of PFRC with push-off specimens. Similarly to Barragan et al. [125], the push-off specimens were obtained from the small beams $(150 \times 150 \times 600 \mathrm{~mm})$ previously tested (EN 14651), as shown in Figure 2-19. The studied variables were four concrete types (two normal concrete (MSC), self-compacting concrete (SCC) and conventional vibrated concrete (VCC) with $f_{c}$ ranging from 20.1 to $51.5 \mathrm{MPa}$ ), fibre length (48 and $60 \mathrm{~mm}$ with a $0.9 \mathrm{~mm}$ diameter) and fibre content ranged from 6 to $106 \mathrm{~kg} / \mathrm{m}^{3}$.

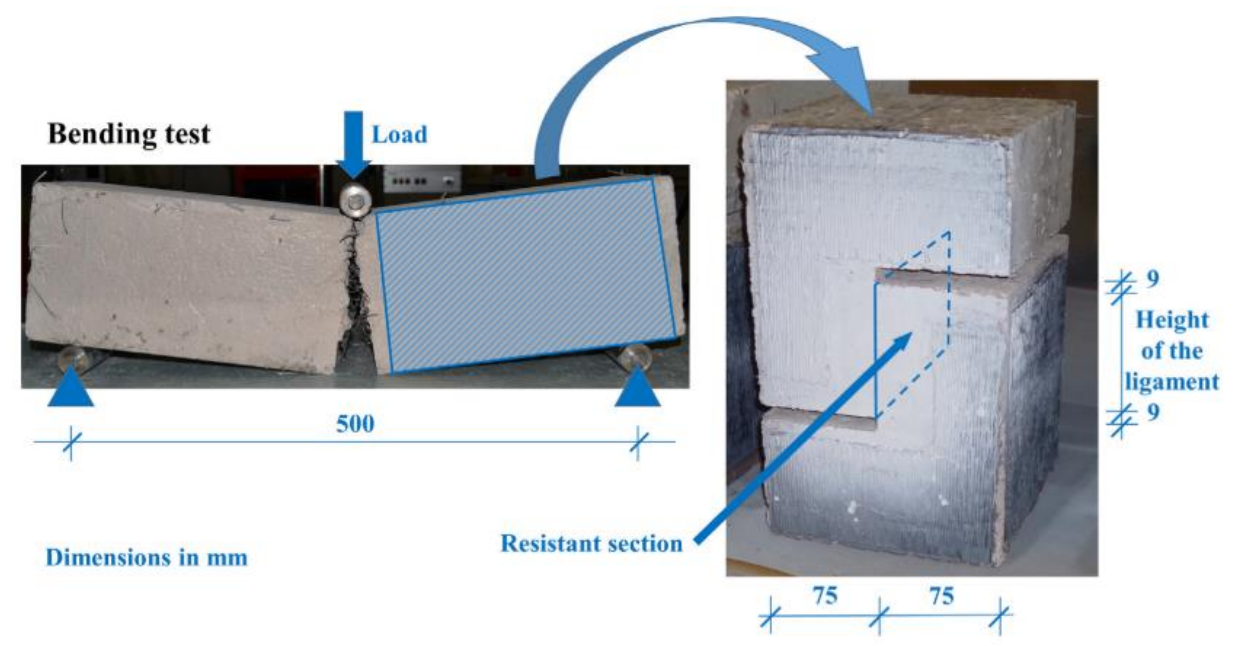

Figure 2-19: The push-off specimens of Picazo et al. [128,129]

The results showed that shear strength increased, as did the compression strength of each concrete. However, shear post-cracking behaviour was similar for all concrete types (see Figure 2-20a). This could be due to the significant importance of the aggregate interlock and the fact that the same maximum aggregate size of $12.7 \mathrm{~mm}$ was used in all the concretes. As Figure 2-20b shows, considerable toughness was obtained in the PFRC specimens compared to the control ones. This toughness is seen in Figure 2-20c using digital image correlations when studying the shear crack. Nevertheless, Figure 2-20c also shows that some flexural cracks occurred during the shear test. 


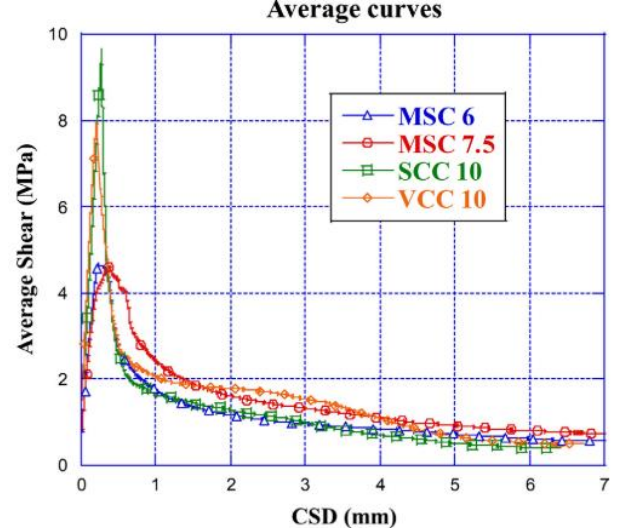

(a)

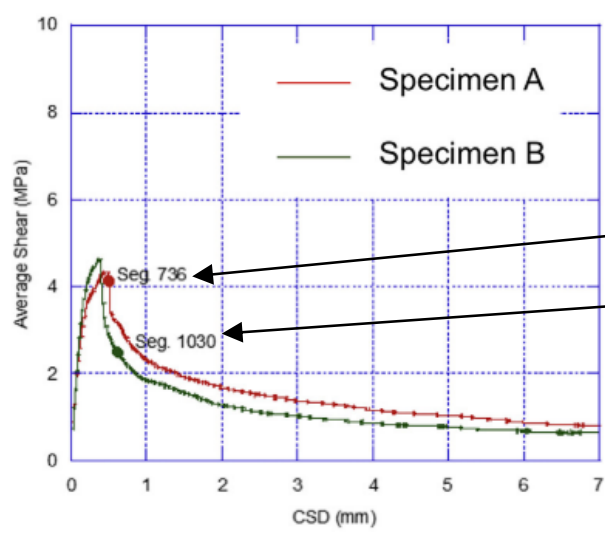

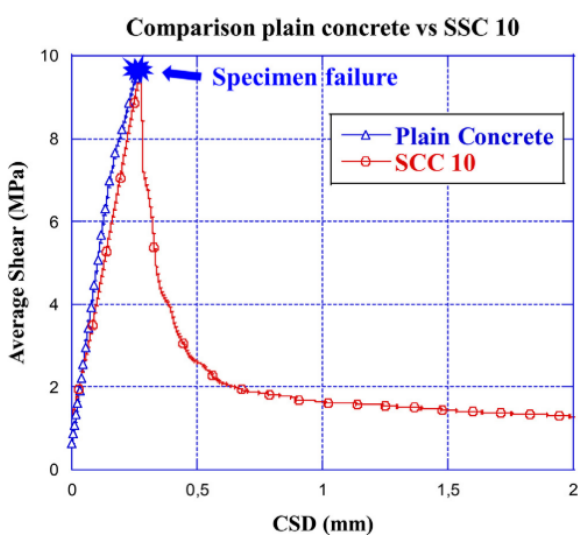

(b)
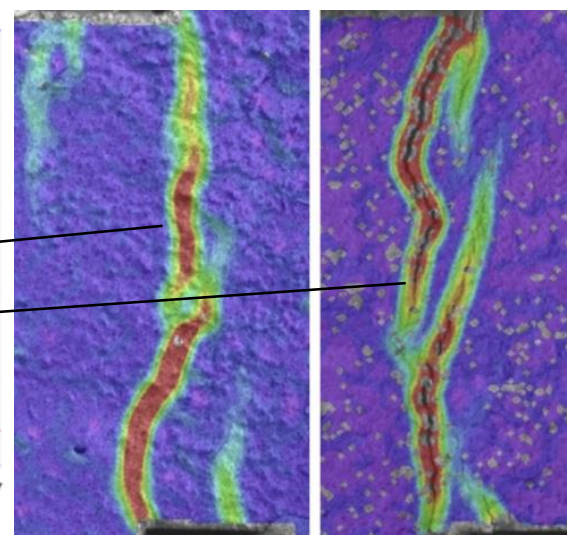

(c)

Figure 2-20: Results of Picazo et al. [128,129]: Push-off results (a), Comparison of PFRC and PC (b) and push-off displacement results related to DIC (c) 
Chapter 2. Literature Survey

Table 2-4: Push-off specimen's geometry referenced in this thesis

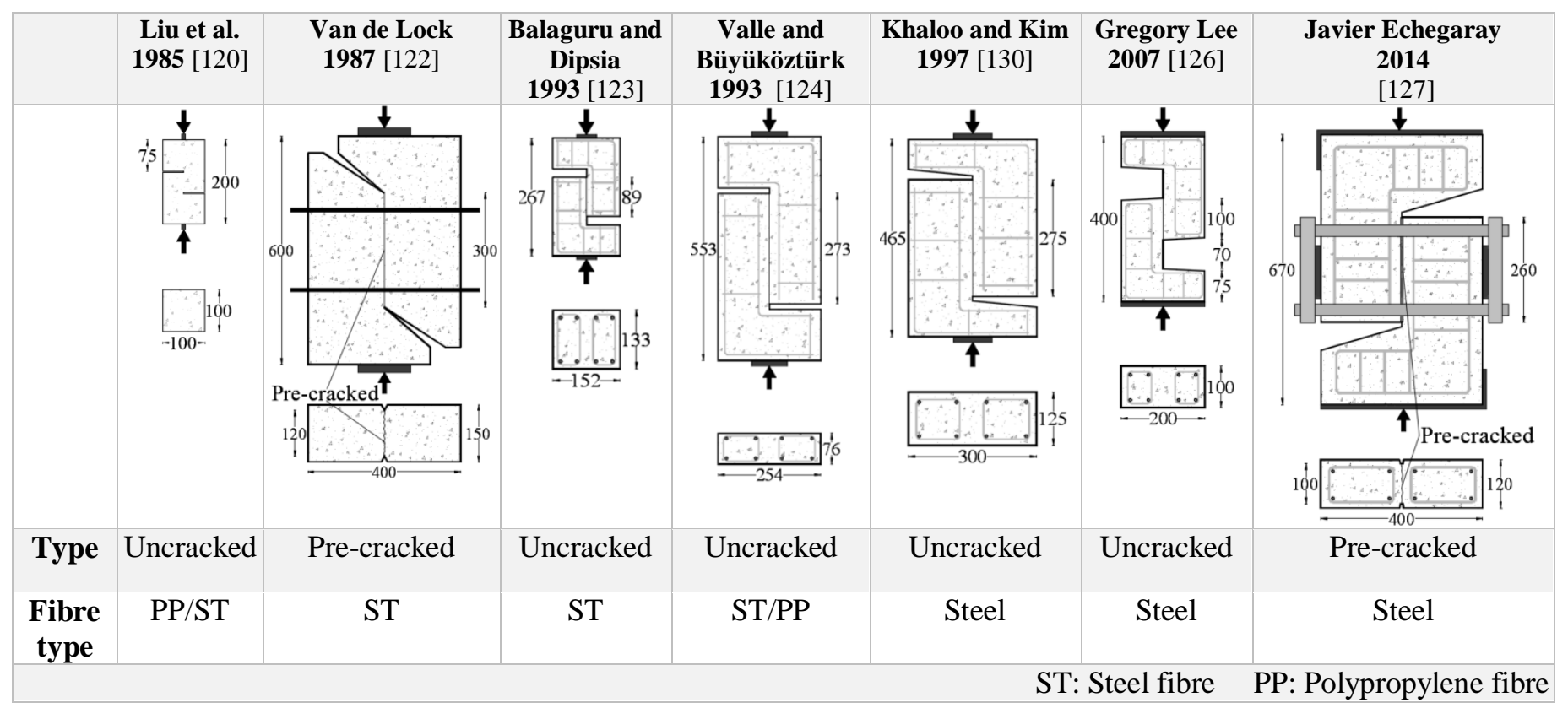




\subsection{JSCE-SF6 shear test.}

As the presence of tensile splitting cracks has been observed during push-off tests [125], other tests have been proposed in the literature. The Japanese Society of Civil Engineers developed the JSCE test for steel FRC [118], which is simpler than push-off tests and more controllable because it has two shear planes. However, as it is a four-point bending test, bending actions are present and, by means of the arch effect (and a type of supports), shear can be transferred directly to supports, and the load values are high in the test.

In 2002, Mirsayah and Banthia [131] studied the effect of different types of steel fibres (flattened-end and crimped fibres) dosed at concentrations ranging from $0.25 \%$ to $1 \%$ in normal strength concrete (47 MPa). Shear tests were performed based on the JSCESF6 [118] standard in specimens sized 150x150x500 mm. Despite both fibre types increasing shear strength, these authors concluded that flattened-end fibres provided better shear strength than crimped ones. The flexural toughness obtained following ASTM C 1018 [132] was compared to shear toughness, and both toughness types did not differ, and were correlated (see Figure 2-21). In this context, Appa Rao and Sreenivasa Rao [133] studied the toughness rates of SFRC under mode II loading by a JSCE-SF6 test (specimens sized 150x150x600 mm). In this research, straight steel fibres $(25 \mathrm{~mm}$ long) with an aspect ratio of 44.6 were dosed in a volumes fraction of $0 \%$ to $1.5 \%$. The study concluded that shear toughness was about 15 -fold flexural toughness.

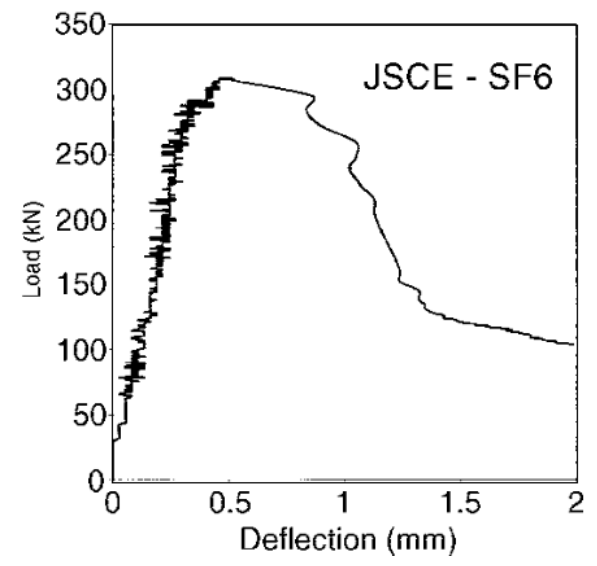

(a)

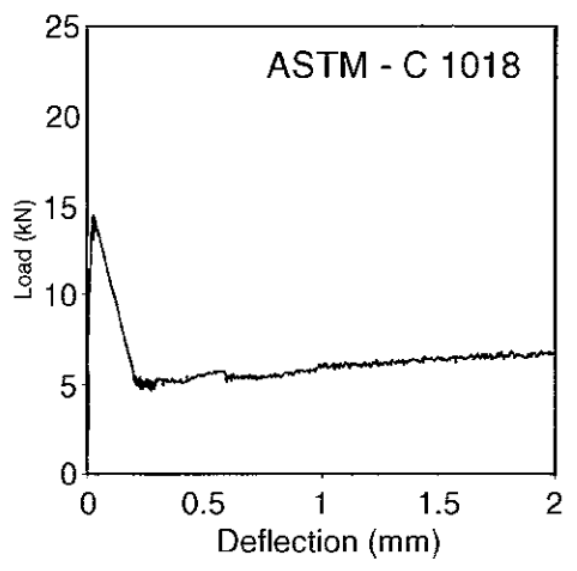

(b)

Figure 2-21: Load deflection plots in: shear load (a); and flexure for concrete with $40 \mathrm{~kg} / \mathrm{m}^{3}$ of flattened-end fibres $(b)$ [132].

In 2011, Boulekbache et al. [134] studied the influence of yield stress (minimum stress needed before concrete started to flow in the fresh state) and concrete compressive strength on the shear behaviour of SFRC. For this purpose, two types of hooked-end steel fibres (lengths of $35 \mathrm{~mm}$ and $60 \mathrm{~mm}$ and aspect ratios of 65 and 80, respectively) were 
added in fractions of $0 \%$ to $1 \%$ in the matrix. Normal, self-compacting and high-strength concrete with $f_{c}$ ranging between 30 and $80 \mathrm{MPa}$ were used. Specimens were tested by JSCE-SF6 with some modifications (specimens sized 100x100x350) (see Figure 2-22a). The conclusions revealed that yield stress played an important role in fibre orientation and, hence, in shear strength) (see Figure 2-22b). As both compressive strength and fibre content increased (see Figure 2-22c), shear also improved, but the ductility due to fibres improved more in the normal and self-compacted concretes than in the high-strength concrete

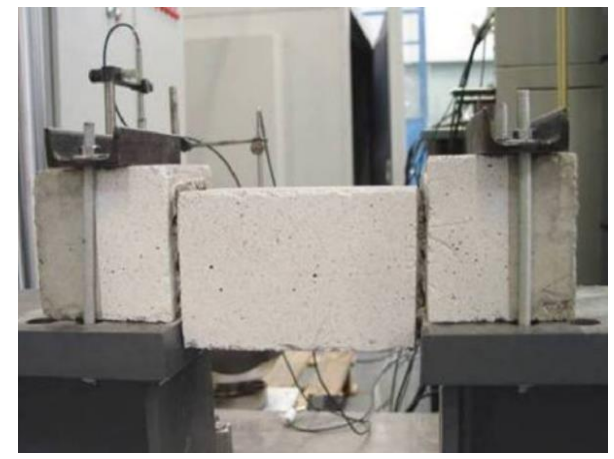

(a)

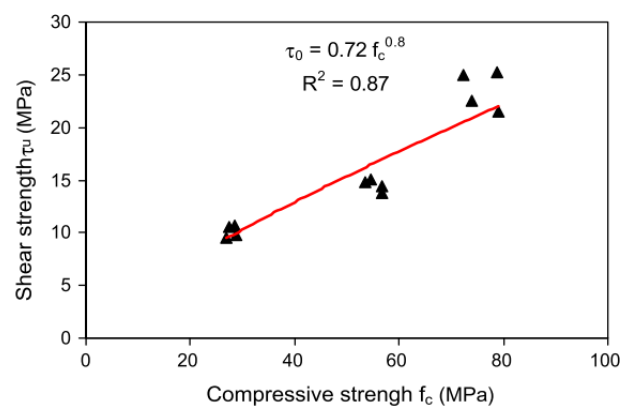

(b)

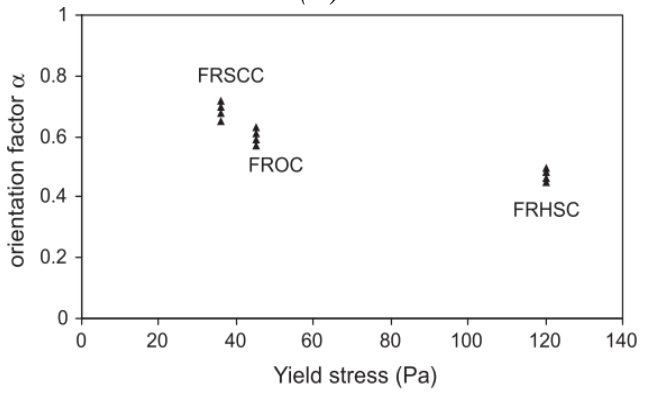

(c)

Figure 2-22: Picture of the JSCE-SF6 shear test (a), shear strength according to concrete compressive strength (b) and the Orientation factor vs. yield Stress of SFRC(c) [134]

In 2017, Soetens and Matthys [135] modified JSCE-SF6 to control the normal stresses in the crack, as seen in Figure 2-23a. Thus different horizontal load levels were applied and remained constant during the test. The authors evaluated the direct shear behaviour of two SFRC types using 69 specimens $(150 \times 150 \times 600 \mathrm{~mm})$. Two different lengthed hooked-end steel fibres $(30 \mathrm{~mm}$ and $60 \mathrm{~mm}$ ) were used in both self-compacting and normal concretes. The authors concluded that shear stress increased while normal stress incremented (see Figure 2-23b). However, the ratio between the normal and shear stresses lowered for larger slips due to damage and the crushing of aggregates. Finally, similarly to previous research works, the authors concluded that shear strength increased linearly with incremented fibre content. 


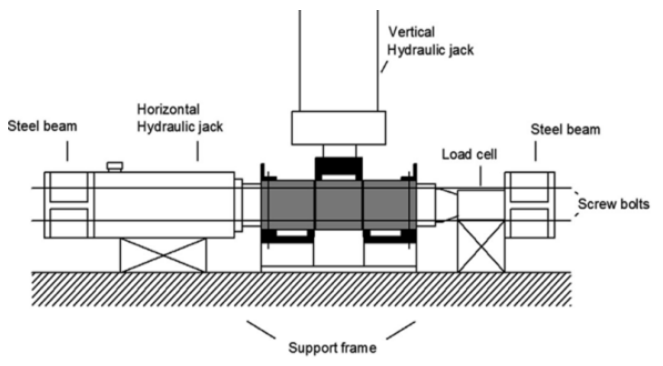

(a)

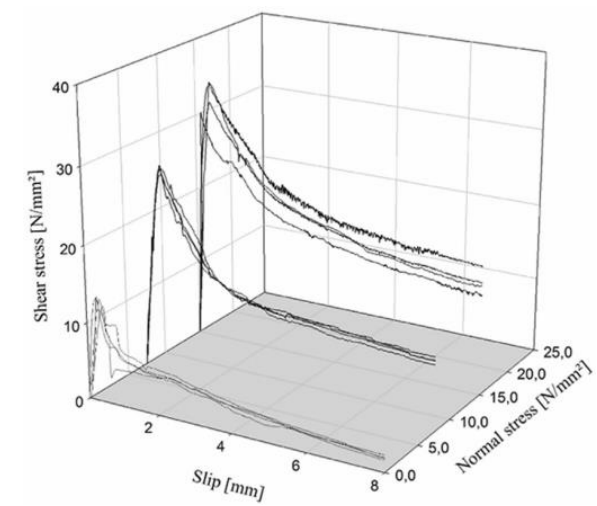

(b)

Figure 2-23: Schematic of the confined JSCE-SF6 test (a) and influence of normal stress on shear stress (b) [135]

In 2019, Cuenca et al. [136] studied shear transfer in alkali-activated and normal FRC. To do so, 20 samples (150x150x450 mm) were tested under direct shear following standard JSCE-SF6. The studied variables were concrete type (two types) and three different fibre types (two steel fibres, one polypropylene fibre). Polypropylene fibres were $54 \mathrm{~mm}$ long with a 66 aspect ratio. Fibre content $\left(V_{f}=0.51 \%\right)$ was the same in all the fibre types, but each provided distinct post-cracking residual strengths. Unlike previous experimental campaigns, Cuenca et al. determined the rotations on the shear crack plane to evaluate their influence on the shear test. The results showed that for a given crack opening, a close relation exists between post-cracking residual strength and shear stresses (see Figure 2-24). 
Effectiveness of polypropylene fibres as shear reinforcement in structural elements

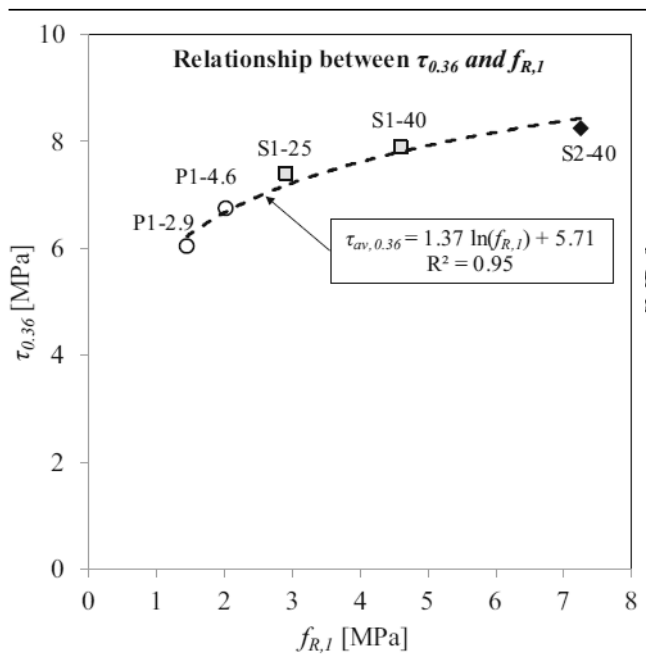

(a)

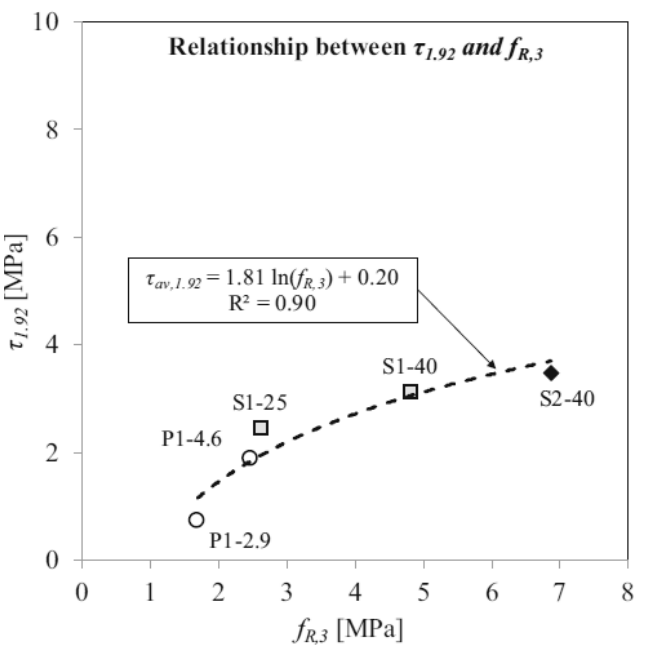

(b)

Figure 2-24: Shear stress vs. residual flexural tensile strength at $\mathrm{CMOD}=0.5 \mathrm{~mm}$ (a) and CMOD $=2.5 \mathrm{~mm}($ b) $[136]$

Regarding PFRC, in 2016 Majdzadeh et al. [137] conducted an experimental campaign to evaluate where two synthetic fibre types and one steel fibre type under direct shear by JSCE-SF6 with some modifications. Two synthetic fibre types were employed: self-fibrillating, $54 \mathrm{~mm}$ length and $0.15 \mathrm{~mm}$ equivalent diameter, and a polypropylene straight fibre, $50 \mathrm{~mm}$ length and $0.58 \mathrm{~mm}$ of equivalent diameter. The studied fibre contents were $0.5 \%, 1.0 \%$ and $1.5 \%$. As in previous studies, shear strength increased, whereas the volume fraction of fibres rose. Considerable toughness was found in the PFRC specimens, but not in the PC ones. Nevertheless, a minor difference in the post-cracking shear strength was found between fibre volumes of $0.5 \%$ and $1 \%$. When comparing PFRC and SFRC, the results of Majdzadeh et al. showed that the steel fibres dosed at the same amount as the synthetic ones were more effective in shear than synthetic fibres. Similar results were obtained by Mostafazadeh et al. in 2016 [33,138] after testing PFRC specimens following JSCE-SF6, which included polypropylene fibres $(54 \mathrm{~mm}$ length with a 67 aspect ratio) dosed at $0.26 \%, 0.52 \%, 0.78 \%$ and $1.0 \%$ of volume fraction. 
Chapter 2. Literature Survey

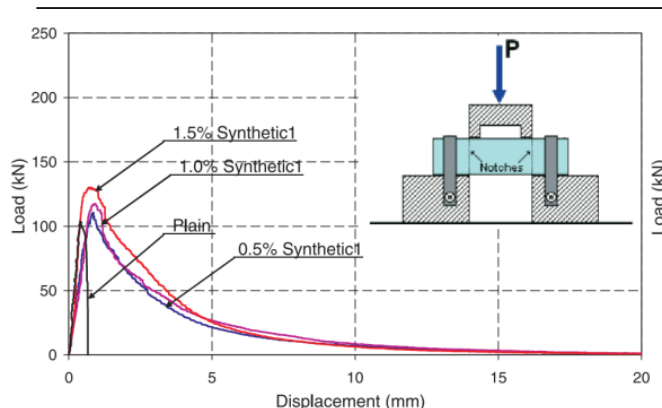

(a)

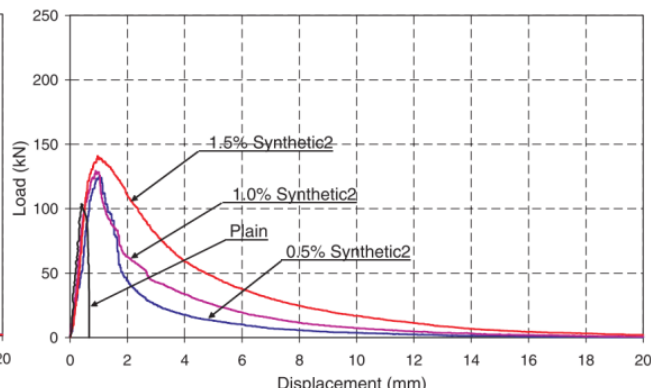

(b)

Figure 2-25: Result of the JSCE-SF6 tests performed by Majdzadeh et al. [137] using synthetic fibres

\subsection{FIP shear test}

Another alternative is the FIP shear test [139], which consists of an asymmetric fourpoint test as Figure 2-26a shows. In this test, the loading point is positioned to avoid the bending effect as moments are zero on the crack plane. Notwithstanding, the use of this test method to study shear behaviour is limited in the literature.

Khanlou et al. in 2012 [95] conducted an experimental programme of 20 specimens (250x250x540 mm) (see Figure 2-26b) on normal and high strength SFRC. Concrete compression strength ranged between 35 and $60 \mathrm{MPa}$, and fibres were dosed at rates of $20-80 \mathrm{~kg} / \mathrm{m}^{3}$. Hooked-end steel fibres $(60 \mathrm{~mm}$ length, an 80 aspect ratio) were used. Similar conclusions to those in previous studies about improved shear strength and ductility were drawn, but no information about the existence of undesired movements that could influence tests was reported.

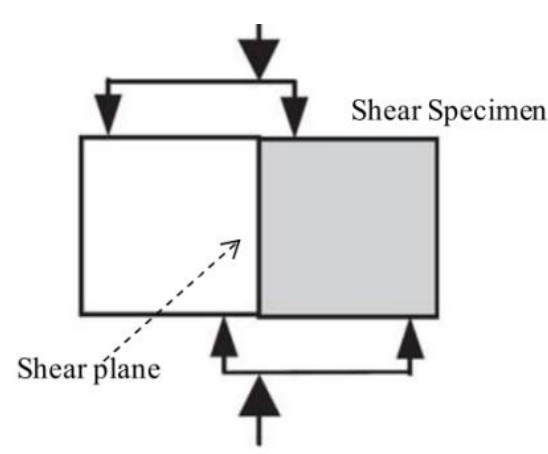

(a)

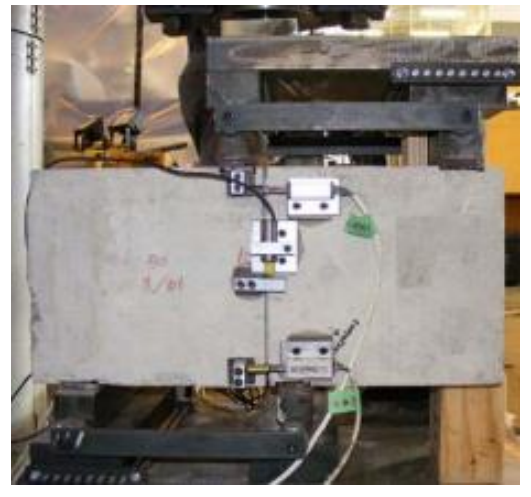

(b)

Figure 2-26: Scheme of the FIP shear test (a) and picture of a specimen in the FIP shear test [95] 
Effectiveness of polypropylene fibres as shear reinforcement in structural elements

\subsection{Shear panel test}

The shear panel test was developed in 1982 at the University of Toronto in Canada by Collins and Mitchell [140]. In this panel, shear is introduced in a pure state to measure the relation between the principal stresses and the corresponding principal strains. By this test, the MCFT, the simplified and the disturbed field theory were developed, and most formed part of concrete design codes around the world. However, given the complexity of the facilities to perform the test, the panel test proved very complex to be reproduced. However, the shear panel test could well be one of the most realistic procedures for studying shear behavidur in concrete. In fact this test provides more information, such as crack width and crack spacing, than other shear tests. Nevertheless, the shear panel test provides such information in average terms instead of local ones like other shear test types do.

Susetyo et al. [62] studied the effectiveness of steel fibres as minimum reinforcement on 10 SFRC panels $(890 \times 890 \times 70 \mathrm{~mm})$ under monolithically loading. Three types of hooked-end steel fibres were studied $(30,35$ and $50 \mathrm{~mm}$ length with aspect ratios of 79, 64 and 81 respectively), dosed in volume contents from $0.5 \%$ to $1.5 \%$. In all SFRC cases, good shear behaviour was obtained, even in those elements with no traditional reinforcement. All the SFRC panels failed in MOF controlled by crack interface shear as Figure 2-27 shows. The SFRC panels resisted at least $87 \%$ of the maximum shear stresses of the control panels (CP). In some panels with $1.5 \%$ fibres, shear stress was exceeded by $16 \%$ than in the counterparts, while shear stress was $60 \%$ of the control specimens in the panels with the smallest amount of fibres $(0.5 \%)$. To conclude, the fibres on panels presented at least a $62 \%$ increase in ductility than the control panels and, to ensure good shear behaviour, the authors suggested that the volume fibres should be greater than $0.5 \%$. Finally, a reduction in crack opening and crack spacing was observed in the FRC panels. Further research about FRC panels has been done by Susetyo et al. [141] and Carnovale and Vecchio [142] to model and study FRC shear behavior under reversed cyclic in-plane shear loading.
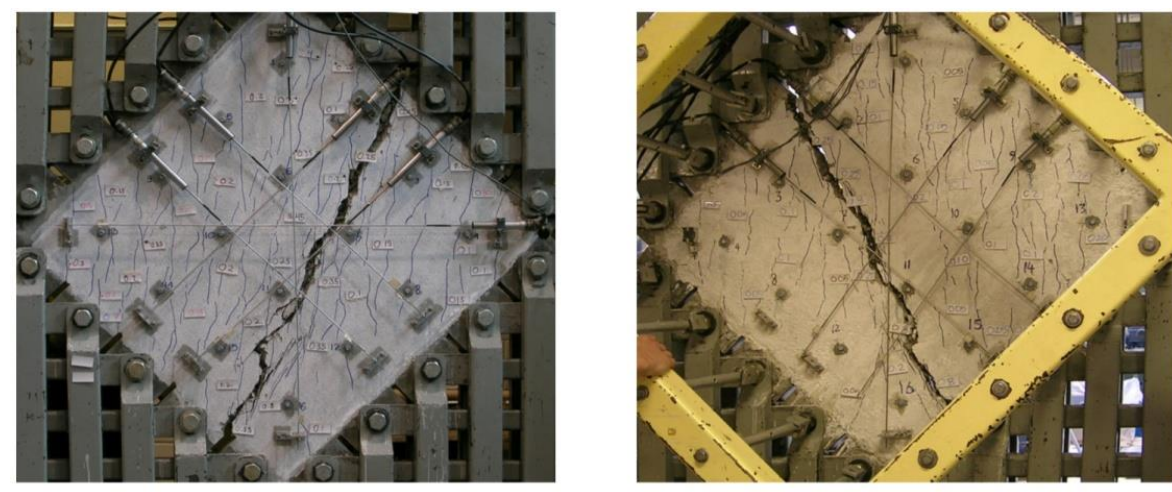

At Failure: $V_{x y}=5.37 \mathrm{MPa}, \gamma_{x y}=5.10 \times 10^{-3}$.

Figure 2-27: Crack pattern of the SFRC (C1F1V3) panel [143]. 


\subsubsection{Shear models and expressions for FRC}

\subsection{Shear strength expressions}

Based on the results of the direct shear tests conducted with small specimens using pushoff, JSCE-SF6 and FIP shear tests, different empirical expressions have been proposed to predict the shear strength of RC and FRC. Most have been obtained by regression analyses. Table 2-5 lists the expression proposed by Khaloo and Kim obtained from push-off tests [130], Boulekbache et al. from JSCE-SF6 [134] tests and Khanlou et al. [95] from FIP tests. These empirical expressions are formulated according to concrete compression strength and volume of fibres $\left(V_{f}\right)$. However, some incorporated variables, such as fibre aspect ratio $\left(l_{f} / d_{f}\right)$ or coefficients, depending on fibre type $\left(B_{c}, C_{c}\right.$ and $\left.D_{c}\right)$. Expressions were developed specifically for hooked-end steel fibres, except for Khaloo and Kim expressions, which used hooked-end steel fibres with triangular cross-sections and twisted longitudinal axes. The employed tensile strength of fibres were $1050 \mathrm{MPa}$, $1100 \mathrm{MPa}$ and $520 \mathrm{MPa}$ for the Khanlou et al., Boulekbache et al. and Khaloo and Kim expressions, respectively.

As seen in Table 2-5, the authors provided expressions, which the effect of concrete and fibres are combined. Figure 2-28 shows a comparison of the Khanlou et al. and Boulekbache et al. models decoupled in concrete (dotted lines) and fibre contribution (dashed lines). The expression proposed by Khaloo and Kim was not considered as it was developed exclusively for a different steel fibre type. A comparison was made by considering a $1.5 \%$ fibre content of hooked-end steel fibres with an aspect ratio that equalled 80, and different concrete compression strengths. As we can see in Figure 2-28, major differences were found in the shear strength predictions between both expressions. In fact the shear strength provided only by concrete in some concrete compression doubled or tripled the others. Different predictions were obtained for fibre contributions, in spite of the same amount of fibres being compared.

Table 2-5: Selected models of maximum shear strength

\begin{tabular}{|l|l|l|}
\hline Khaloo and Kim [130] & $\tau_{\max }=0.65 f_{c}^{0.50}+B_{c} V_{f+} C_{c} V_{f}^{2}+D_{c} V_{f}^{3}$ & (E.q. 2-32) \\
\hline Boulekbache et al. [134] & $\tau_{\max }=0.72 f_{c}^{0.80}+0.08 V_{f}\left(\frac{l_{f}}{d_{f}}\right)$ \\
\hline Khanlou et al. [95] & $\tau_{\max }=0.75 f_{c}^{0.50}+4 V_{f}^{0.9}$ & (E.q. 2-33) \\
\hline
\end{tabular}


Effectiveness of polypropylene fibres as shear reinforcement in structural elements

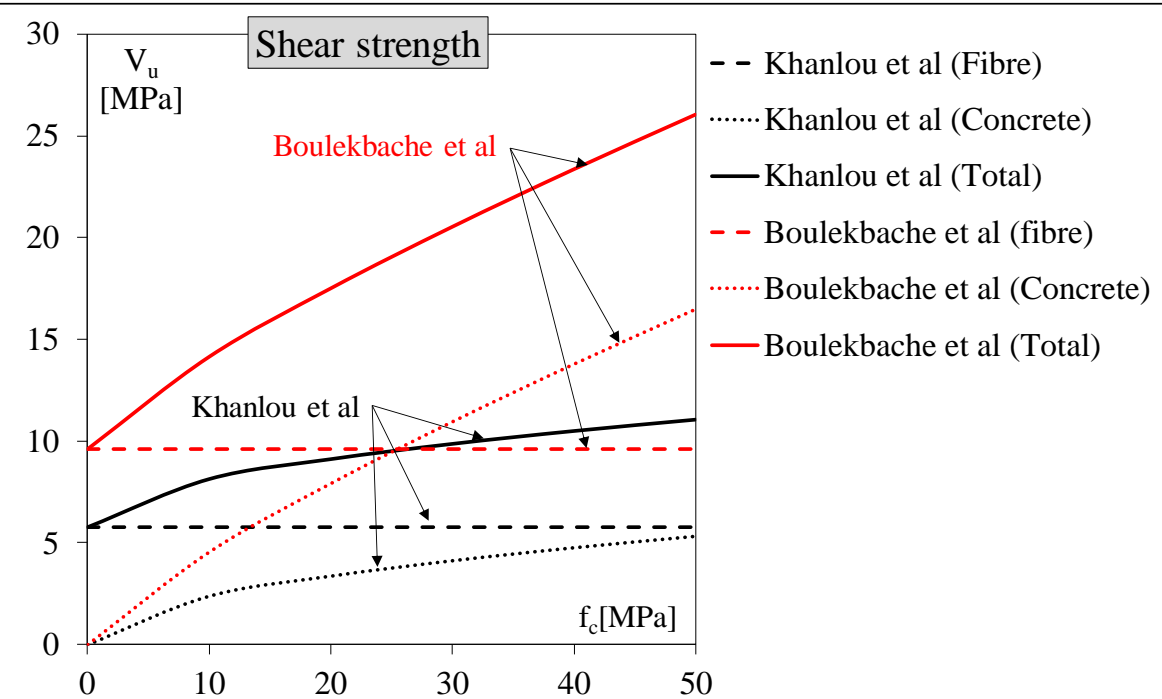

Figure 2-28: Comparison of the maximum strength expressions of hooked-end SFRC

At this point, we may wonder why so many differences appeared between experimental results and, consequently, between empirical expressions. We can probably attribute the answer to differences in test procedures. Khanlou et al. used the FIP shear test, while Boulekbache et al. resorted to JSCE-SF6 with some modifications. Evidently, both test methodologies presented different failure aspects because one shear plane existed in one case, the second one included two shear planes. In the FIP tests conducted by Khanlou et al., (see Figure 2-26b), the friction between the specimen and supports was isolated by using rollers, while the specimen was fixed to a support table to avoid undesired rotations in the test of Boulekbache et al. In this way, undesired horizontal strengths can be introduced into the test by means of friction and not measured as Soetens and Matthys [135] did. To clarify this point, more information about test measurements, and a comparison among the tests proposed in the literature, are required.

\subsection{Frictional bridging models}

When movements (slip and opening) take place in a FRC shear crack, several shear transfer mechanisms act along the crack. On the one hand, some of these mechanisms, such as the aggregate interlock and macroroughness, depend on matrix properties (concrete compression strength, aggregate size). On the other hand, bridging fibres enable new shear-transfer mechanisms to occur when fibre is pulled out from the matrix. Some of these are the bond of the fibres to the matrix, the bending of fibres and the snubbing effect (see Figure 2-29). The shear transfer mechanisms provided by fibres depend on the volume, shape and material of fibres, and also on concrete matrix properties. All these mechanisms act together and can improve shear strength, toughness and ductility 
of FRC as seen in previous sections. Nevertheless, all these mechanisms significantly influence shear crack kinematics.

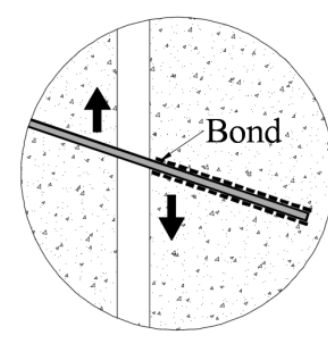

(a)

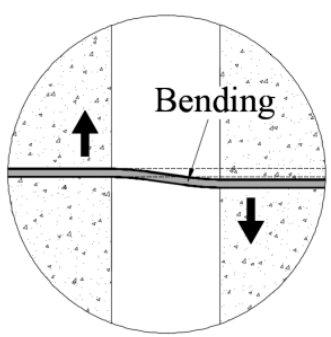

(b)

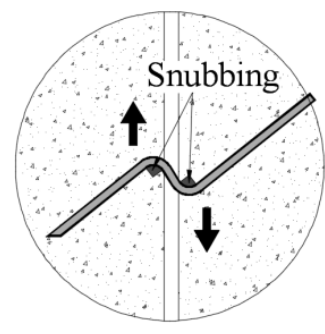

(c)

Figure 2-29: Fibre mechanisms: bond (a), bending of fibre (b) and snubbing (c)

Other parameters that influence the bridging effect of fibres include the inclination or orientation of fibres in relation to the shear plane. As Lee [126] demonstrated, when fibres are inclined with acute angles in relation to the loading direction (as Figure 2-29c shows), fibres transfer fewer shear stresses in small slips than those aligned with obtuse angles (see Figure 2-30). In other words, the bridging effect is not immediately activated and fibres start acting with marked slips. In this case, fibre's MOF is the fracture of fibres in one snubbing zone [126].

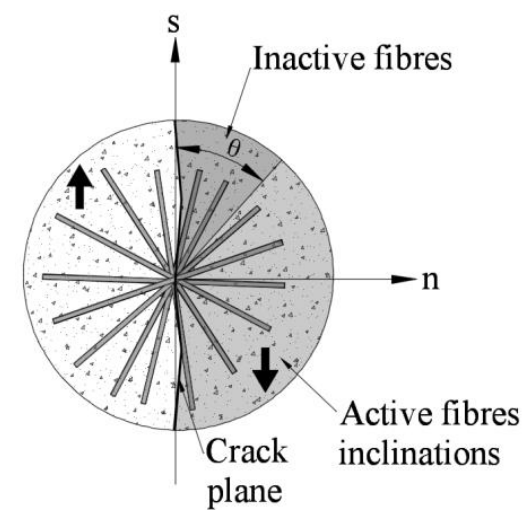

Figure 2-30: Concept of active and inactive fibres

By taking into account all these considerations, several authors have proposed analytical models to simulate fibre behaviour in shear. To this end, the following models were selected and are summarized below: (a) Pfyl's model; (b) Unified Variable Engagement model; (c) Kaufmann's model. 
Effectiveness of polypropylene fibres as shear reinforcement in structural elements

i. Pfyl's model (2003)

Thomas Plyl developed [144] an engagement model in 2003 to predict the tensile behaviour of steel fibres in concrete. This model makes the following assumptions for both the concrete matrix and fibres:

- The energy dissipation and softening response of concrete in tension are neglected

- Matrix deformation is ignored

- Fibres are randomly orientated and homogeneously distributed in the concrete matrix (straight fibres with length $l_{f}$, circular diameter $d_{f}$ and content $\rho_{f}$ are considered)

- The elastic elongation of fibres between a crack face is neglected and is considered a pure pull-out of the fibre from its shorter embedded length

- The flexural stiffness of fibre is ignored

- A constant bond between the fibre matrix along the embedded length of fibres is assumed

- The snubbing effect is neglected

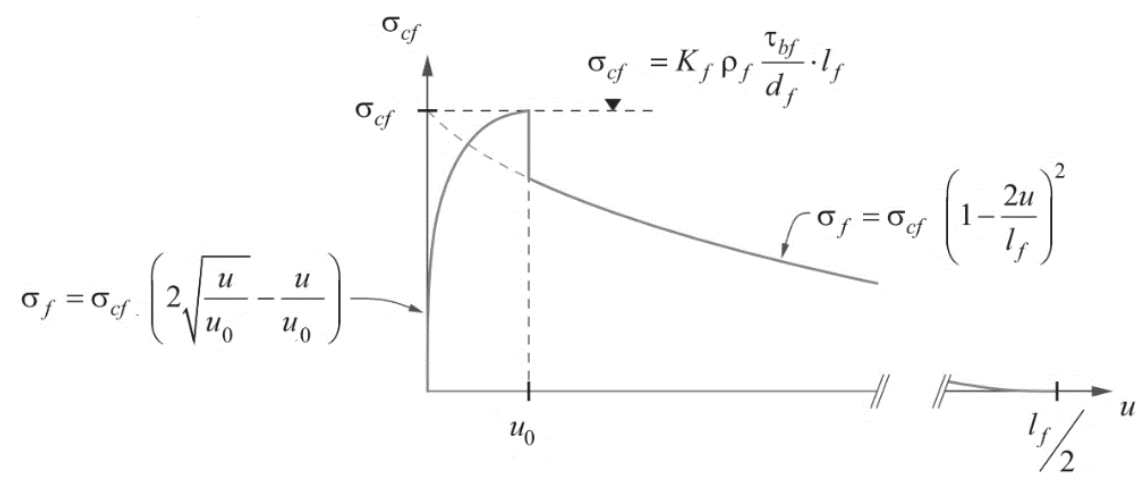

Figure 2-31: Activation and pull-out of steel fibres [97]

After integrating all the fibres that contribute to bridge the crack, the tensile stress transferred to the matrix by fibres $\sigma_{c f}$ can be evaluated according to the expression (Eq. 2-35) for fibre activations, and (Eq. 2-36) for fibre pull-out.

$$
\begin{gathered}
\sigma_{c f}=\sigma_{c f o} 2 \sqrt{\frac{u}{u_{0}}}-\frac{u}{u_{0}}, 0 \leq u \leq u_{0} \\
\sigma_{c f}=\sigma_{c f o}\left(1-\frac{2 u}{l_{f}}\right)^{2}, u_{0}<u \leq \frac{l_{f}}{2}
\end{gathered}
$$


where $u_{0}$ is the maximum crack opening (Eq. 2-37) at the beginning of the pull-out of the fibre with the embedded length $l_{f} / 2$ (longest embedded length). $\tau_{b f}$ is the fibre average bond stress. $\sigma_{c f o}$ is fibre effectiveness (Eq. 2-39) which is in accordance with fibre orientation factor $g, u$ is crack opening while $E_{f}$ represents the modulus of elasticity of fibres.

$$
\begin{aligned}
& u_{0}=\frac{\tau_{b f} l_{f}^{2}}{d_{f} E_{f}} \\
& \tau_{b f}=0.6 \sqrt[3]{f_{c}^{2}} \\
& \sigma_{c f o}=k_{f} \frac{\rho_{f} \tau_{b f} l_{f}}{d_{f}}
\end{aligned}
$$

Fibre orientation factor $k_{f}$ in a bi-dimensional stress-strain plane (2D) is determined with (Eq. 2-40) where the array of possible angles of fibre orientation $\theta_{f}$ is limited as some fibres are not activated at small crack widths because their orientation is unfavourable (see Figure 2-30) to shear. Hence all the possible inclination fibres were integrated after discounting those fibres whose inclinations exceeded $\theta_{w}-\pi / 2$, where $\theta_{w}$ represents the inclinations of ineffective fibres and is determined by (Eq. 2-41).

$$
\begin{aligned}
& k_{f}=\frac{1}{\pi} \int_{\theta_{w}-\frac{\pi}{2}}^{\frac{\pi}{2}} \cos \theta_{f} \delta \theta_{f}=\frac{1+\cos \theta_{w}}{\pi} \\
& \theta_{w}=\tan ^{-1} \frac{\delta_{s}}{\delta_{w}}
\end{aligned}
$$

\section{ii. $\quad$ Unified Variable Engagement model (2012)}

The Unified Variable Engagement model (UVEM) [145] results from joining Variable Engagement Model I (VEMI) [146] and Variable Engagement Model II (VEMII) [147], which were developed to explain the fracture of SFRC in modes I and II. In this context, UVEM model makes the following assumptions for both the concrete matrix and fibres:

- The component contributing to the shear in SFRC is the strength of the unreinforced matrix $\left(\sigma_{c}\right)$ and the contribution of each individual fibre crossing the shear plane (failure plane) $\left(\sigma_{f}\right)$. 
Effectiveness of polypropylene fibres as shear reinforcement in structural elements

$$
\sigma=\sigma_{c}+\sigma_{f}
$$

(Eq. 2-42)

- The geometric centres of fibres are homogeneously dispersed in the matrix and all fibres have the same probability of being orientated in any direction

- The wall effect influences those fibres centred at less than one half of the fibre length from the boundary

- Pull-out occurs from the shorter embedded length of fibres, while the length side remains embedded in the matrix

- The energy associated with the bending of fibres is neglected

- A uniform bond stress model is adopted

In UVEM, the tensile contribution of fibres $\sigma_{f}$ is determined with (Eq. 2-43), where, $k_{f}$ is the fibre orientation factor, $\alpha_{f}$ is the aspect ratio of fibre $\left(l_{f} / d_{f}\right), \rho_{f}$ is the fibre volumetric content and $t_{b, a v g}$ is the average fibre bond stress.

$$
\sigma_{f}=k_{f} \alpha_{f} \rho_{f} \tau_{b, a v g}
$$

UVEM adopts a uniform bond modelling approach, but adjusts the bond stress according to the angle of fibre. Hence the fibre average bond stress $\left(\tau_{b, a v g}\right)$ is determined by (Eq. $2-44)$, where $\tau_{b, 0}$ is the initial fibre bond stress $\left(\tau_{b, 0}=0.8 \sqrt{f_{c m}}\right.$ and $0.4 \sqrt{f_{c m}}$ for hooked-end and straight steel fibres, respectively). $\gamma_{c r i t}$ represents the critical angle at which fibres become active (the point where the fibres oriented at $\gamma \leq \gamma_{\text {crit }}$ carry loads, while they are yet to be engaged for the fibres at $\gamma>\gamma_{\text {crit }}$ (see Figure 2-32)) as determined by (Eq. 2-45).

$$
\begin{aligned}
& \tau_{b, a v g=} \tau_{b, 0}+0.0625 \gamma_{c r i t}^{3} \\
& \gamma_{\text {crit }}=\frac{2 \gamma_{\text {max }}}{\pi} \tan ^{-13} \sqrt{\frac{\frac{w}{3.5 \alpha_{f}} l_{f}}{3}}
\end{aligned}
$$

$\gamma_{\max }$ represents the maximum fibre bending angle determined by (Eq. 2-46), and $w$ is crack opening displacement $w=\sqrt{u^{2}+v^{2}}$. 


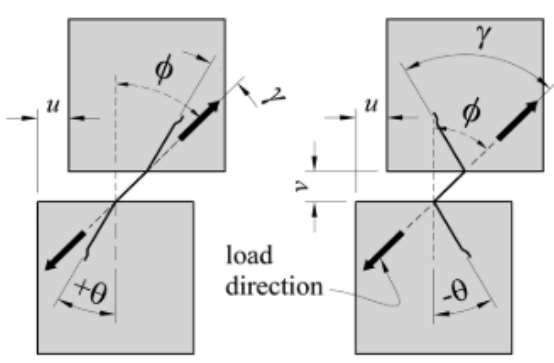

Figure 2-32: Fibre orientation and definition of the fibre bending angle $(\gamma)$ [145]

$$
\gamma_{\max }=|\phi|+\frac{\pi}{2} \quad, \quad \frac{\pi}{2} \leq \gamma_{\max } \leq \pi
$$

The maximum fibre bending angle $\gamma_{\max }=\pi / 2$ for Mode I and $\gamma_{\max }=\pi$ for the Mode II fracture. $\Phi$ is the angle between the applied load and a line normal to the crack plane (see Figure 2-32).

Fibre orientation factor $k_{f}$ is determined by (Eq. 2-47), where $\left(\frac{a+b}{\pi}\right)$ represents the probability density function of a fibre crossing the crack, and $\left(1-\frac{2 w}{l_{f}}\right)$ is the reduction of the bond strength of fibres due to incremented crack opening $w$, i.e. the fibre embedment length shortens, whereas the proportion of bonded fibres also linearly lowers.

$$
\begin{aligned}
& k_{f}=\frac{1}{2}\left(\frac{a+b}{\pi}\right)\left(1-\frac{2 w}{l_{f}}\right)^{2} \\
& a=\min \left(\gamma_{\text {crit }},|\phi|+\frac{\pi}{2}\right) \\
& b=\gamma_{\text {crit }}
\end{aligned}
$$

\section{iii. Kaufmann et al. model (2019)}

Kaufmann et al. developed a model [97] that not only captures the shear transfer mechanism of fibres, but also captures the fibre-matrix interaction. To this end, and based on Pfyl's model, the Kaufmann model takes into account bond stresses action on the embedded length transferred by fibres and the deviation force produced by fibres that acts on crack faces. Moreover, the same assumptions as in Pfyl's model are considered. In this context, Kauffman considers the bridging effect of fibres as indicated in (Eq. 2-50). 
Effectiveness of polypropylene fibres as shear reinforcement in structural elements

$$
\sigma_{c f \alpha}=\frac{\sigma_{c f}}{\sin \alpha_{r}}
$$

where $\sigma_{\mathrm{cf}}$ is the tensile stress transferred to the matrix by fibres $\left(\sigma_{\mathrm{cf}}\right)$ expressed in (Eq. 2-35) for fibre activation and (Eq. 2-36) for fibre pull-out; $\alpha_{r}$ is the crack opening inclination in relation to the crack face (see Figure 2-33). Thus replacing (Eq. 2-35) and (Eq. 2-36) in (Eq. 2-50) yields (Eq. 2-51) for fibre activation and (Eq. 2-52) for fibre pull-out.

$$
\begin{aligned}
& \sigma_{c f \alpha}=\frac{1}{\sin \alpha_{r}} \sigma_{c f o}\left(2 \sqrt{\frac{\delta}{u_{0}}}-\frac{\delta}{u_{0}}\right), 0 \leq \delta \leq u_{0} \\
& \sigma_{c f \alpha}=\frac{1}{\sin \alpha_{r}} \sigma_{c f o}\left(1-\frac{2 u}{l_{f}}\right)^{2}, u_{0}<\delta \leq \frac{l_{f}}{2}
\end{aligned}
$$

(a)

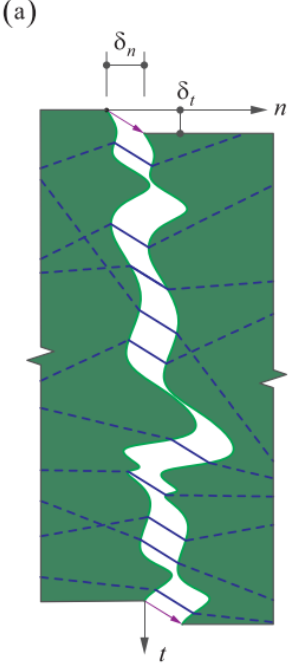

(b)

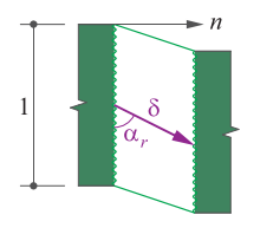

(c)

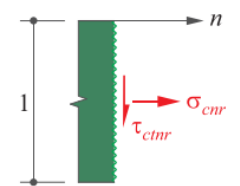

(d)

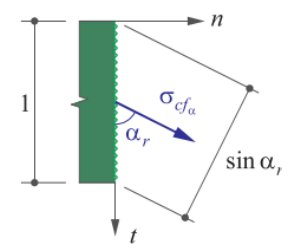

fibres in tension (active)

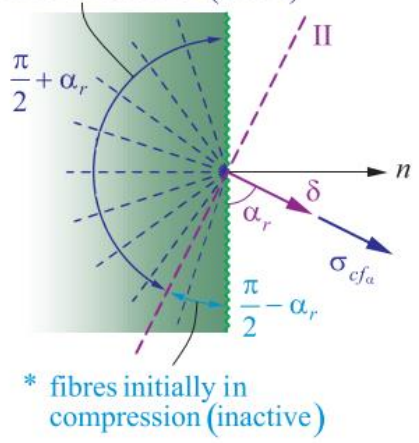

Figure 2-33: Fibres bridging a shear crack according to the Kaufmann et al. model [97]

Fibre effectiveness $\left(\sigma_{c f o}\right)$, is determined similarly to Pfyl's model, where $k_{f a}$ is the orientation factor, $\rho_{f}$ is the amount of fibres and $\tau_{b f}$ is the bond stress of the hooked-end steel fibres determined by (Eq. 2-38). 
Chapter 2. Literature Survey

$$
\sigma_{c f o}=k_{f a} \frac{\rho_{f} \tau_{b f} l_{f}}{d_{f}}
$$

For fibre orientation factor $\left(k_{f a}\right)$, the Kaufmann et al. model does not consider all those fibres initially subjected to compression (see Figure 2-33) (the fibres that incline more than $\pi / 2$ form crack displacement). As the model is developed for small crack displacements (where the aggregate interlock is the main shear transfer mechanism), it considers that all those fibres inclined close to the crack plane are effective in shear. In this context $k_{f a}$ is determined as follows (Eq. 2-54).

$$
k_{f a}=\frac{1+\sin \alpha_{r}}{\pi}
$$

Finally, in relation to the interaction between the aggregate interlock and fibre bridging, Kaufmann's model determines a deviation force (Figure 2-15) for skew cracks opening. The model suggests reducing aggregate interlock stresses by a factor determined by (e.q. 2-31).

\subsubsection{Shear in FRC beams}

In RC and FRC beams, a/d strongly influences the shear behaviour and MOF of the element. Kani in 1966 [148] characterised shear according to $a / d$ and determined that the most critical position for shear is considered when $a / d=2.5$ (Kani's valley). However, Kani also stated that this value depends on the longitudinal reinforcement ratio. Accordingly, beams can be characterised as short beams $(a / d<2.5)$ and slender beams $(a / d>2.5)$. However in prestressed elements, as prestressing can reduce the inclination of the diagonal strut (load-support), some elements with $a / d>2.5$ can also be considered short beams.

In 1986, Mansur et al. [87] ran a shear experimental campaign on 24 rectangular simply supported beams by four-point tests. The studied beams covered $a / d$ ranging from 2 to 4.4 to study of effect the fibres. Hooked-end steel fibres were employed and dosed in volumes from $0 \%$ to $1 \%$. Mansur et al. found that fibres increased the element's shear strength and, in some cases, MOF shifted from shear to flexure-compressional failure. Furthermore, the critical $a / d$ ratio required to induce shear failure was lowered by incrementing fibre content. Similar conclusions have been reported by other authors $[68,102-$ 107] after conducting experimental tests on slender and short beams.

In 2019, Gali and Subramaniam studied [149] SFRC slender and non-slender beams w/o stirrups. By digital image correlation, they determined that shear diagonal crack opening increased, while slenderness increased. This behaviour was attributed to the contribution of bending force to crack opening.

The use of steel fibres on beams has been extensively studied, and the research community now fully acknowledges the effectiveness of fibres. A wide range of studies in the literature are available on the effectiveness of fibres on shear behaviour in SFRC slender beams. The main conclusions drawn from these studies are: 
- Fibres significantly enhance the shear strength and ductility of beams $[61,150]$. This conclusion has been observed in normal-strength concrete beams $[151,152]$, self-compacting concrete beams $[10,153]$ and high concrete compression strength beams $[102,124]$.

- Increased fibre content results in higher FRC element 's shear strength both with $[154]$ and w/o $[151,155]$ stirrups. In fact fibres with dose contents ranging from $0.5 \%$ to $1 \%$ effectively control crack openings similarly to traditional reinforcement [142], while fibre contents below $0.5 \%$ are insufficient to provide adequate shear strength and shear deformation [62]. Incremented shear strength due to fibres reduces for fibre contents above $1 \%$ [156] .

- The effectiveness of macrofibres (SFRC) in bridging cracks and, hence, in enhancing shear strength is related to its shape (geometry and type) and fibre content. At a higher aspect ratio $\left(l_{f} / d_{f}\right)$, increased shear strength [151], load at the first shear crack [157], and post-cracking behaviour capacity [158] occur.

- Contradictory conclusions are reported about the size effect on FRC beams. With a shear database of 139 beams, Kwak et al. [110] determined that size effect would be less significant in SFRC beams than in RC ones. These authors attributed this phenomenon to either the incremented ductility in SFRC beams compared to RC ones or to few analysed beams. After an experimental campaign of 28 slender beams $(a / d=3.43)$, Dinh et al. [151] found that some were deep beams, and concluded that the inclusion of fibres could potentially mitigate or eliminate the size effect due to the reduced crack spacing in SFRC compared to RC. Yoo and Yang [159] studied the size effect on SFRC beams and concluded that size effect would more stronger in SFRC beams w/o stirrups than with stirrups. Casanova et al. [71] determined with double $\mathrm{T}$ beams that steel fibres in appropriate proportions were much more effective in controlling crack development in small beams than in deep ones. Finally, with increase element size, the minimum fibre content required to avoid the size effect, just as transverse reinforcement does, also needs to be increased [160].

- Fibres in adequate contents can partially or totally substitute stirrups [161,162], as well as the minimum transverse reinforcement required to warn the element's structural collapse [161]. In fact one research work has reported that SFRC beams with the fibre content required by codes to provide minimum shear reinforcement actually confer more reinforcement than that expected by the same codes [72]. Moreover, beams with fibre contents above $1.25 \%$ have improved ductility and mitigate crack growth compared to beams containing minimum conventional shear reinforcement [71].

- Since fibres improve post-cracking behaviour and, hence, increase beams' ductility, fibres dosed with adequate contents are able to transform shear brittle failure into a ductile one $[64,65,68]$.

Although the shear behaviour of SFRC beams has been widely studied, research that has focused on the shear behaviour of PFRC beams is limited. In this context, experimental 
Chapter 2. Literature Survey

campaigns using macrosynthetic fibres, such as polypropylene fibres used as shear reinforcement, are described below. It is worth mentioning that more information on the following experimental campaigns, such as reinforcement or materials' properties, is found in Table A.1 in Annexe A, where a shear database of beams using exclusively synthetic fibres appears.

One of the first approaches to study the shear behaviour of PFRC beams was followed by Furlan and Hanai [163] in 1997, where square section beams (100x100 mm) with and w/o stirrups were tested according to a four-point loading scheme with a/d equalling 3.5. The employed fibres were multifilament polypropylene fibres ( $42 \mathrm{~mm}$ long, $0.05 \mathrm{~mm}$ in diameter) and steel fibres (lengths $25.4 \mathrm{~mm}$ and $38.1 \mathrm{~mm}$ ). Only two beams were manufactured using PFRC with $0.5 \%$ fibre content (one w/o stirrups and one with stirrups). Surprisingly, the authors did not draw any conclusions about PFRC beams, despite the fact that their results showed that polypropylene fibres incremented the shear strength of PFRC beams with stirrups by $12 \%$, and by $9 \%$ of the beams w/o stirrups. In addition, polypropylene fibres changed the MOF of beams with stirrups from diagonal tension to flexural failure. Furlan and Hanai studied this type of polypropylene fibres in the 1990s on other beam types, such as prestressed I section beams [116], and reported similar results to those previously obtained.

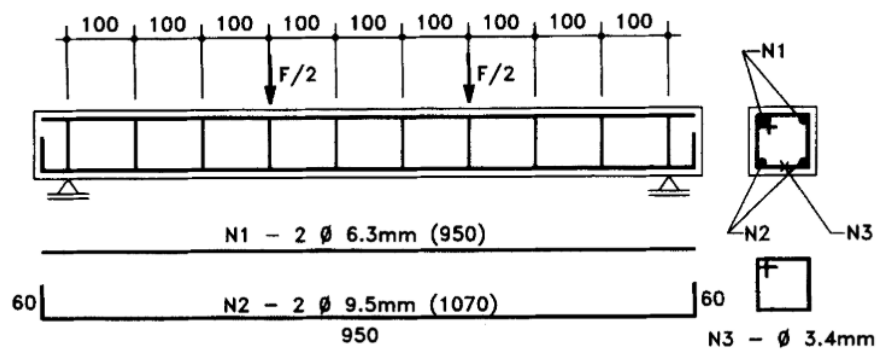

(a)

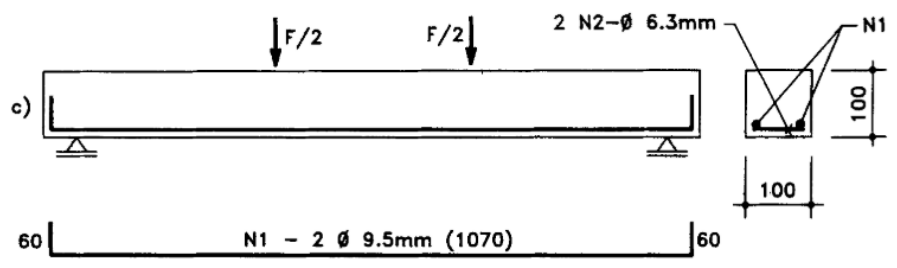

(b)

Figure 2-34: Geometry and reinforcement details of the Furlan and Hanai [163] beams with stirrups (a) and without stirrups (b)

In 1999, Campione et al. [164] used four fibre types (polyolefin, carbon, crimped steel, hooked-end steel) to enhance the shear behaviour of FRC beams combined with traditional transverse reinforcement. Twenty rectangular-sectioned beams (100x125 mm) 
were tested under four-point monotonic and cyclic loading. The polyolefin fibres (dosed at a $2 \%$ volume fraction) were a straight fibre ( $25 \mathrm{~mm}$ long, $0.8 \mathrm{~mm}$ equivalent diameter). Two transverse reinforcement ratios were used for each fibre type, as well as plain concrete (see Table A.1 in Annexe A). Campione et al. found that polypropylene fibres increased shear strength by $14 \%$ compared to the beams with no type of fibres, while the increment exceeded $25 \%$ with steel fibres.
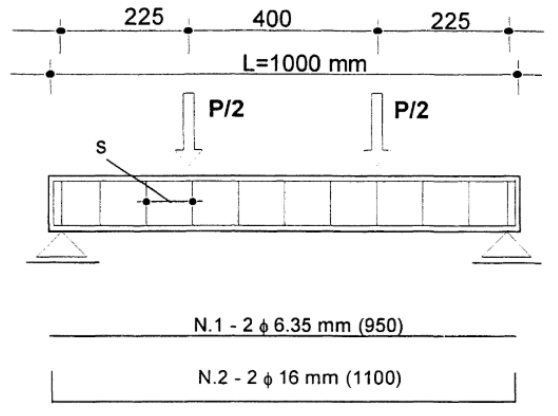

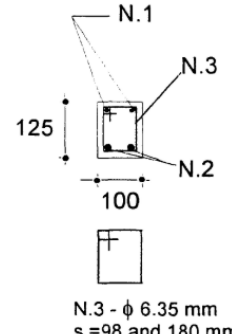

N. $3-\phi 6.35 \mathrm{~mm}$

Figure 2-35: Campione's beams geometry and reinforcement details [164]

In 2006, Majdzadeh et al. [137] investigated the influence of three fibre types (steel and two types of polypropylene fibres) on shear strength using 14 square-sectioned (150x 150 $\mathrm{mm}$ ) concrete slender beams with and w/o stirrups. Beams were tested by a four-pointloading scheme with a/d equalling 3.02. Only eight of the 14 beams were PFRC beams (two with stirrups, six w/o stirrups) (see Table A.1 in Annexe A). Synthetic fibres were self-fibrillating that were $54 \mathrm{~mm}$ long with a 360 aspect ratio, and polypropylene straight fibres that were $50 \mathrm{~mm}$ long with an 86 aspect ratio. The fibre content in SFRC and PFRC was $0.5 \%, 1.0 \%$ and $1.5 \%$. Once beams had been tested, both synthetic fibre types enhanced shear capacity, ductility and shear toughness compared to the RC beams. When comparing the results between SFRC and PFRC with similar fibre contents, steel fibres were more efficient than both synthetic ones. Majdzadeh et al. concluded that the optimum fibre content was $1 \%$, and beyond this percentage no major benefits are found in shear. Finally, a synergy effect between fibres and stirrups in the FRC beams was also observed. 


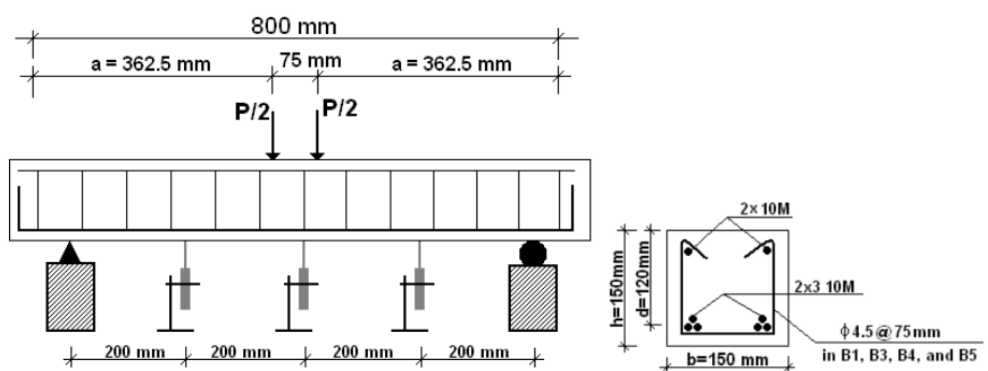

Figure 2-36: Beams setup, geometry and reinforcement details of the beams by Majdzadeh et al. [137]

In 2009, Altoubat et al. [53] conducted an experimental campaign of 27 full-scale beams to specifically study the shear behaviour of macrosynthetic fibres. Beams were tested by a three-point-loading scheme by covering shear spans of $3.5 \mathrm{~d}$ (slender) and $2.3 \mathrm{~d}$ (short). Fibres were made of polypropylene and polyethylene (40 mm long, 90 aspect ratio). Fibre content ranged from $0.50 \%$ to $1.0 \%$. At least two beams were tested per fibre content in the short and slender beams. More details about the geometry and reinforcement details can be found in Annexe A.

Altoubat et al. reported that synthetic fibres increased the load at which the first crack appeared by $10 \%, 18 \%$ and $12 \%$ for $0.50 \%, 0.75 \%$ and $1.0 \%$ of volume fractions in slender beams $(a / d=3.5)$, and by $7 \%$ and $14 \%$ for $0.50 \%$ and $0.75 \%$ in short beams $(a / d=2.3)$. Maximum load was incremented by $14 \%, 23 \%$ and $30 \%$ for $0.5 \%, 0.75 \%$ and $1.0 \%$ in slender beams, and over $20 \%$ and $28 \%$ in short beams with $0.50 \%$ and $0.75 \%$. The MOF of beams was observed, and turned from a brittle MOF into a ductile one. In fact with the short beams, fibres could change MOF from diagonal tension in RC beams into a flexural one in PFRC. Due to fibres, the observed deflection increased by over $40 \%$ compared to the control beams.

In 2012, Altoubat et al. [165] extended the first experimental campaign to beams containing the minimum amount of transverse reinforcement set out by ACI-318 [13] and combining them with fibres. Hence several shear reinforcement levels were evaluated:

- Without shear reinforcement

- Reinforced by $0.5 \%$ (volume fraction) polypropylene fibres

- Minimum amount of stirrups required by ACI-318

- Combining the minimum amount of stirrups and $0.5 \%$ polypropylene fibres

Slender beams $(a / d=3.5)$ and short beams $(a / d=2.3)$ were evaluated by a three-pointloading scheme. As in previous studies, the authors concluded that $0.5 \%$ fibres combined with stirrups could increase shear strength by over $40 \%$ compared to the control beam with only stirrups. This behaviour was observed in both slender and short beams. Fibres modified the crack pattern of beams (many cracks were detected), which improved post- 
Effectiveness of polypropylene fibres as shear reinforcement in structural elements

cracking behaviour and ductility, and changing beams' MOF in some cases. Finally, as in previous studies, a synergy effect between fibres and stirrups was reported.

From 2010 to 2014, Conforti et al. [40,54,166] studied the applicability of polypropylene fibres on deep and wide-shallow beams subjected to shear. For this purpose, 14 wideshallow and 19 deep beams were manufactured to cover three shear reinforcement levels. The first level corresponded to any reinforcement type (PC beams). The second was reinforced by crimped polypropylene fibres dosed at $13 \mathrm{~kg} / \mathrm{m}^{3}$. The third level corresponded to the minimum shear reinforcement (MSR) required by MC2010. The employed polypropylene fibres were $40 \mathrm{~mm}$ long, diameter of $0.75 \mathrm{~mm}$. The section of the wide-shallow beams were $430-890 \mathrm{~mm}$ wide and $250-330 \mathrm{~mm}$ deep, while the section of the deep beams were 150-300 mm wide and 600-800 mm deep. More details can be found in Table A.1 in Annexe A. For each type of the section and reinforcement level, two specimens were tested by a four-point loading scheme with $a / d$ of 2.5 .

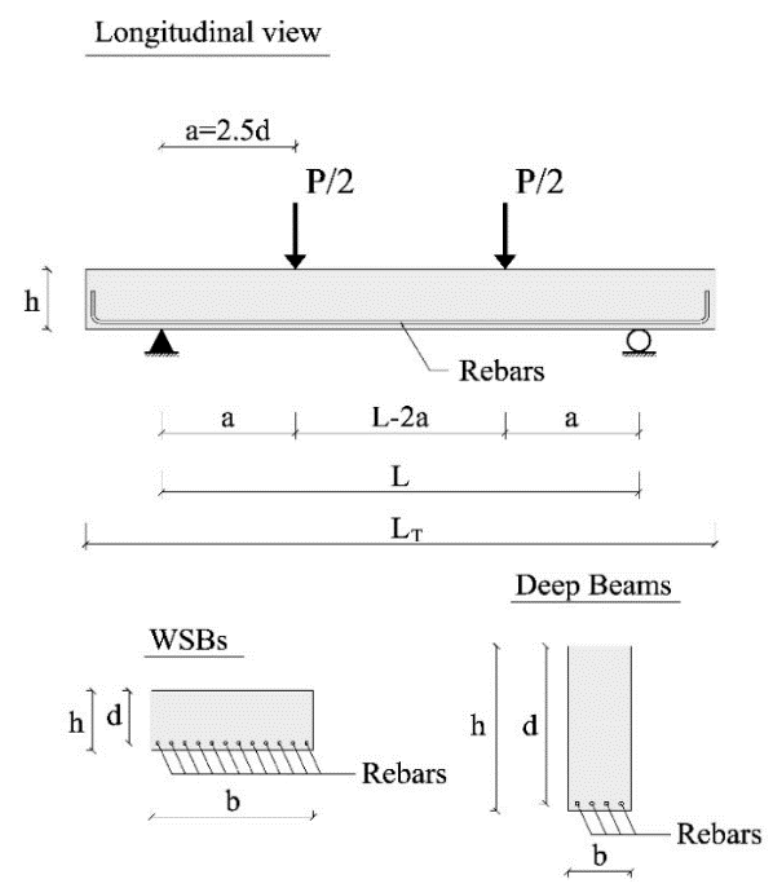

Figure 2-37: The section geometry of deep and wide-shallow beams performed by Conforti et al. $[40,54,166]$

Conforti et al. observed that polypropylene fibres can provide the shear reinforcement required for the equilibrium in wide-shadow beams. When comparing beams with the minimum amount of reinforcement and PFRC beams, both displayed similar shear behaviour and MOF (flexural failure). Nevertheless, fibres could cause several progressive cracks during loading, which implies more ductile behaviour than in PC beams. In the 
Chapter 2. Literature Survey

deep beams, fibres could enhance shear strength and provide twice the ductility than their counterparts in PC. When comparing the PFRC and MSR deep beams, their shear strength was similar, but the MSR beams obtained a more ductile MOF (flexure) than the PFRC beams (shear).

In 2012, Parmentier et al. [167] tested 28 short and slender beams by a four-point loading scheme. The explored $a / d$ ranged from 0.5 to 2.5 . Beams contained two shear reinforcement levels: the first with no reinforcement type (PC) and the second using three fibre types (two steel and one macrosynthetic) dosed at different volume fractions. Nevertheless, only four beams were manufactured using macrosynthetic fibres at the $4.5 \mathrm{~kg} / \mathrm{m}^{3}$ dose ( $0.49 \%$ of the volume fraction), tested with $a / d$ of 1.5 and 2.5 . The macrosynthetic fibres were fibrillated fibres manufactured using polypropylene and polyethylene (50 mm long). Parmentier et al. observed that PFRC beams performed in shear terms similarly to SFRC, and also with similar volume fractions. When comparing the PFRC beams tested with $a / d=2.5$ to their PC counterparts, shear strength improved by $4 \%$.

In 2015, Sahoo et al. [168] studied the effect of polypropylene, steel, and a combination of both fibres, on the shear behaviour of rectangular $(200 \times 150 \mathrm{~mm})$ beams. Seven beams (RC, SFRC, PFRC and hybrid FRC) were tested by three-point-loading tests with $a / d$ of 5. However, only one beam was manufactured using PFRC with fibres dosed at a $1 \%$ volume fraction. Polypropylene fibres were $12.5 \mathrm{~mm}$ long with a $0.5 \mathrm{~mm}$ equivalent diameter. After testing, the PFRC beams had the lowest shear strength throughout the experimental campaign. These authors observed that shear strength and ductility had reduced by $70 \%$ and $50 \%$, respectively, in the PFRC beams compared to the control beams. However, this comparison was made by taking the RC beams with stirrups (8mm@300mm) as the control beams.

In 2016, Ensan Navadeh [169] studied the shear behaviour of slender PFRC beams. Beams were subjected to three-point tests with $a / d$ of 2.4. Four shear reinforcement types were investigated and compared to one another: the beams w/o stirrups, the beams with the minimum amount of stirrups required by ACI-318, and the beams with polypropylene fibres dosed at volume fractions of 0.5 and $0.75 \%$. All the beams presented the same rectangular section $(254 \times 381 \mathrm{~mm})$ and longitudinal reinforcement, which was calculated to avoid flexural MOF. The fibres used in PFRC were polypropylene fibre $(54 \mathrm{~mm}$ long with $0.80 \mathrm{~mm}$ ). Ensan Navadeh observed that by incorporating $0.5 \%$ and $0.75 \%$ of fibres into concrete, the shear strength of beams increased by $17 \%$ and $29 \%$, respectively, compared to PC. The increased shear strength, especially in the beams with a $0.75 \%$ volume fraction, was relatively similar to the increased shear conferred by the minimum amount of stirrups (31\%).

Based on Navadeh's beams, Daniel Michael in 2017 conducted an extensive campaign of PFRC beams in which long-term shear behaviour was investigated. In addition to the eight beams investigated by Navadeh, 16 beams were manufactured, and cured in a chemical solution (controlled calcium hydroxide dose) at different temperatures for the 
Effectiveness of polypropylene fibres as shear reinforcement in structural elements

purpose of finding the long-term strength of material in short times. New beams of different ages were tested (1, 3, 6 months) and compared to the control ones (beams tested by Ensan Navadeh). It is worth mentioning that Michael's experimental campaign was related to the durability instead of creep behaviour of beams.

The results demonstrated that the shear and tensile strength degradation of concrete after 100 years results in $24.2 \%, 26.5 \%$ and $26.8 \%$ for beams with fibres dosed at $0,0.5 \%$ and $0.75 \%$ of fibres, respectively. These beams are not considered in Annexe A because their original properties were modified.

In 2016 and 2019, Arslan et al. [170,171] evaluated the shear behaviour of PFRC rectangular $(150 \times 240 \mathrm{~mm})$ beams with and w/o stirrups. Twenty-three beams were tested by a three-point-loading scheme to cover different $a / d(2.5,3.5$ and 3.5). Several transverse reinforcement levels were studied: PC beams w/o stirrups, beams with stirrups, PFRC with fibres dosed at 1\%,2\% and 3\% volume fractions, and a combination of fibres and stirrups. The used polypropylene fibres were the crimped type with a rectangular cross section of $0.93 \times 0.50 \mathrm{~mm}^{2}$, and $39 \mathrm{~mm}$ long. The concrete compression strength of the entire campaign ranged from 13 to $27 \mathrm{MPa}$, but it is highlighted that compression strength considerably reduced with the incremented fibre volume. As in previous studies, Arslan et al., observed that polypropylene fibres incremented the shear strength and ductility of beams compared to those in PC. Moreover, fibres could change MOF from a shear failure to a flexure one.

\subsubsection{Brief review of shear strength expression}

In order to better understand the shear behaviour of FRC, several authors have created FRC shear databases [172-177], which have been used to evaluate, improve or create new expressions to predict the shear strength of FRC beams. Expressions are usually mechanical or empirical, and developed statistically by regression analyses, artificial neural networks or multi-expression programming. Several others have been incorporated into international code designs.

Cuenca et al.[173] found that only $28 \%$ of the experimental results of FRC beams in the last 30 years report post-cracking mechanical properties of fibres. The remaining $72 \%$ provided only fibre information, such as content, material and geometry. Such lack of information leads to the development of non-robust expressions that truly capture the variables acting on shear behaviour in FRC beams. In fact most are based on unquantifiable or irreproducible factors, such as steel fibre type or fibre orientation, which do not make models or expressions helpful when different types, shapes or materials are employed.

Table 2-6 summarises some selected expressions (empirical, semi-empirical and mechanical) to predict the shear strength of SFRC beams. In 1986, Sharma developed [178] a similar expression (Eq. 2-55) to the ACI-318 equation and used a relation $(k=2 / 3)$ to link concrete compressive strength $\left(f_{c}\right)$ with tensile strength of concrete $\left(0.8 \sqrt{f_{c}}\right)$ ob- 
tained from indirect tensile tests. Nevertheless, Sharma's expression was developed using low-carbon steel fibres (50 mm long, 83 aspect ratio) that was also validated for round and crimped fibres.

In 2002, Kwak et al. [110] developed an expression (Eq. 2-56) that includes the fibre contribution in Zsutty's equation [179]. This equation includes effects such as dowel action and slenderness of beam, and is calibrated for different types of steel fibres by means of fibre-matrix bond factors.

Minelli and Plizzari [75] proposed in 2006 a semi-empirical equation (Eq. 2-57) that incorporates into Eurocode 2's equation [76] a toughness parameter, which is the equivalent to post-cracking flexural tensile strengths. The toughness parameter $\left(f_{\text {eq( }(0-3)}\right)$ is related to the crack tip opening displacement, which ranges from 0.6 to $3 \mathrm{~mm}$ in the ultimate limit state. The contribution of fibres is integrated into concrete behaviour, and is modified directly by the longitudinal reinforcement ratio $\left(\rho_{l}\right)$, analogously to distributing more longitudinal reinforcement layers throughout the specimen's depth. This equation was included in MC2010 [7] with some modifications, as seen in (Eq. 2-16) in Table 2-3. Finally, it is worth mentioning that this expression can be used for any fibre types as it employs parameters of fibres like residual flexural tensile strengths, which can be obtained from test EN14651 [15]. A similar approach was developed by Dinh et al. [180], in which shear is calculated (Eq. 2-58) as the additive contribution of fibres in tension (in an inclined plane of 45 degrees) and the shear stress distribution in the compression zone. In this case, the average tensile stress $\left(\sigma_{t}\right)_{\text {avg }}$ of fibres can be determined by ASTM 1609 [16]. Finally, Dinh's expression also offers the possibility of evaluating the shear strength of FRC beams with any fibre type.

Table 2-6: Selection of formulas to determine the shear strength of SFRC beams Reference Expressions

ID

\begin{tabular}{|c|c|c|}
\hline $\begin{array}{l}\text { Sharma } \\
1986 \\
{[178]}\end{array}$ & $V_{c f}=\left(k 0.8 \sqrt{f_{c}}\left(\frac{d}{a}\right)^{1 / 4}\right) b d$ & (Eq. 2-55) \\
\hline $\begin{array}{l}\text { Kwak et al. } \\
2002 \\
{[110]}\end{array}$ & $\begin{array}{l}V_{u}=\left[3.7 e f_{s p f c}^{2 / 3}\left(\rho \frac{d}{a}\right)^{1 / 3}+0.8(0.41 \tau F)\right] \\
e=1 \text { for } \frac{a}{d}>3.4 \text { and } 3.4 \frac{a}{d} \text { for } \frac{a}{d} \leq 3.4 \\
f_{\text {spcf }}=\frac{f_{\text {cuf }}}{(20-\sqrt{F})}+0.7+\sqrt{F} \\
F=\left(L_{f} / D_{f}\right) V_{f} d_{f}\end{array}$ & (Eq. 2-56) \\
\hline
\end{tabular}


Effectiveness of polypropylene fibres as shear reinforcement in structural elements

\begin{tabular}{|c|c|c|}
\hline Reference & Expressions & ID \\
\hline & $\begin{array}{l}d_{f}=\left\{\begin{array}{c}0.5 \text { for round fibres } \\
0.75 \text { for crimped fibres } \\
1 \text { for intended fibres }\end{array}\right. \\
\tau=4.15 \mathrm{MPa} \text { (fibre bond })\end{array}$ & \\
\hline $\begin{array}{l}\text { Minelli and } \\
\text { Plizzari [75] } \\
2006\end{array}$ & $\begin{aligned} & V_{c}=\left[\frac{0.18}{\gamma_{c}} \xi\left(100 \rho_{l}\left(1+\frac{a}{d} \frac{f_{e q(0.6-3)}}{f_{c t}}\right) f_{c k}\right)^{1 / 3}+0.15 \sigma_{c}\right] b d \\
& V_{c}= {\left[\frac{0.18}{\gamma_{c}} \xi\left(100 \rho_{l}\left(1+2.5 \frac{f_{e q(0.6-3)}}{f_{c t}}\right) f_{c k}\right)^{1 / 3}+0.15 \sigma_{c}\right] b d \text { for } \frac{a}{d} } \\
&>2.5\end{aligned}$ & (Eq. 2-57) \\
\hline $\begin{array}{l}\text { Dinh et al. } \\
{[180]} \\
2011\end{array}$ & $\begin{array}{l}V_{n}=V_{c c}+V_{F R C} \\
V_{c c}=0.11 f^{\prime}{ }_{c} \beta_{1} c b=0.11 \frac{T_{s}}{0.85}=0.13 A_{s} f_{y} \\
V_{F R C}=\left(\sigma_{t}\right)_{\text {avg }} b(d-c) \text { cotana }\end{array}$ & (Eq. 2-58) \\
\hline $\begin{array}{l}\text { Sarveghadi et } \\
\text { al. [177]. } \\
2015\end{array}$ & 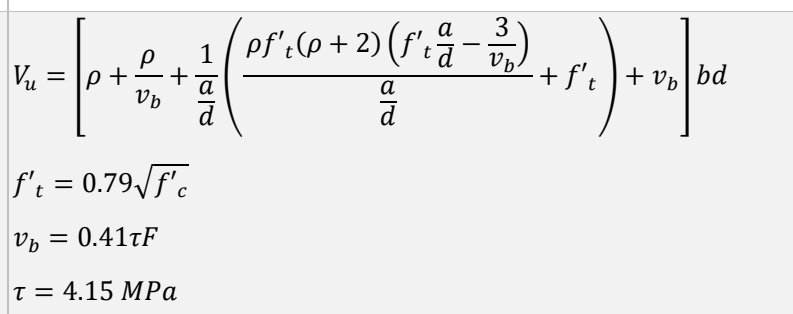 & (Eq. 2-59) \\
\hline $\begin{array}{l}\text { Matthys and } \\
\text { Soetens [181] } \\
2018\end{array}$ & $\begin{array}{l}V_{u}=\left[k_{v} \sqrt{1+k_{p}}\left(1+\sqrt{\frac{200}{d}}\right)\left(3 \frac{d}{a} \rho_{l}\right)^{1 / 3} \sqrt{f_{c m}}+f *_{F t u}\left(1+4 k_{p)}\right] b d\right. \\
k_{v}=0.388 \text { (determined by MCFT) } \\
k_{p}=\frac{\sigma_{c p}}{f_{c k}} \\
f *_{F t u}=\min \left\{f_{\text {Ftum }}, f_{c t m}\left(1-2 k_{p}\right)\right\}\end{array}$ & (Eq. 2-60) \\
\hline $\begin{array}{l}\text { Barros and } \\
\text { Foster [175] } \\
2018\end{array}$ & $\begin{array}{l}V_{R d, F}=k_{f}\left(V_{R d, c}+V_{R d, f}\right) \\
V_{R d, c}=\frac{k_{p} k_{v}}{\gamma_{F}} \sqrt{f_{c k}} z b \text { for } f_{c k} \leq 8 M P a \\
V_{R d, f}=\frac{F_{f u k}\left[w_{u v}\left(w_{u}\right)\right]}{\gamma_{F}} \\
F_{f u k}\left[w_{u v}\left(w_{u}\right)\right]=\sum_{i=1}^{n \Delta \varphi} P_{f u k, \varphi_{i}}\left[w_{u v}\left(w_{u}\right)\right]\end{array}$ & (Eq. 2-61) \\
\hline
\end{tabular}


Chapter 2. Literature Survey

With increasing knowledge about artificial intelligence, such as artificial neural networks, genetic programming or multi-expression programming, new shear empirical expressions have recently been developed. In these methodologies, several parameters that affect shear behaviour are computationally evaluated by algorithms and genetic operations. In such methodologies, an extensive database is necessary for the algorithm to learn, evaluate and select the most significant variables. Sarveghadi et al. al [177] used multi-expression programming and found that the variables that most influenced the shear performance of SFRC beams were $a / d$, amount of longitudinal reinforcement $(\rho)$, fibre pull-out strength $\left(v_{b}\right)$ and splitting tensile strength $\left(f_{t}^{\prime}\right)$. With these variables, Sarveghadi et al. wrote an empirical expression (Eq. 2-59) to determine the shear strength of FRC elements. In this expression, variables are combined with one another to fulfil precision. However, the equation does not offer a clear explanation of how, or how much of, each variable has a mechanical effect.

Unlike empirical expressions, mechanical-theoretical expressions have been created in SFRC. Most of these expressions are based on the Modified Compression Field Theory (MCFT), including fibres. Zhang [182] developed an expression based on tensile stressstrain constitutive equations that consider the distribution of fibres. A similar proposal was developed by Lee et al. [183], into which modifications to the Disturbed Stress Field Model (DSFM) based on MCFT were incorporated. These modifications include constitutive equations from the Diverse Embedment Model (DEM) [184] developed by these authors. In 2018, Matthys and Soetens [181] considered that despite their good predictions, expressions in codes are not easy to implement in the engineering community given the iterative process that their application entails. In this context, and in order to develop an easy-to-use practical model, Matthys and Soetens introduced an expression (Eq. 2-60) based on MCFT and the most important parameters involved in shear, such as concrete strength, dowel action, shear slenderness, size effect, level of prestress or FRC post-cracking tensile strength.

Additionally, models based on MCFT and mechanical performance of fibres, such as those described in the frictional bridging models section of this thesis, are present in the literature. Foster's model [77], based on the VEM, developed an expression where the shear provided by the concrete matrix and fibres is coupled. This expression was included in MC2010 [7] as an option to determine the shear strength of FRC elements. Barros and Foster [175] presented an integrated model in 2018 to predict the shear strength of SFRC beams (Eq. 2-61). The model integrates fibre orientation, the fibre pullout constitutive law and the predicted number of fibres crossing the critical diagonal crack $F_{f u k}\left[w_{u v}\left(w_{u}\right)\right]$ (some obtained from UVEM) with the MCFT by an iterative process.

\subsubsection{Shear in FRC HCS}

Hollow core slabs (HCS) are precast concrete elements employed in industrial, parking, recreational or residential buildings for their easy installation, high quality control and 
short construction times. HCS are usually manufactured by an extrusion or slip-formwork process (see Figure 2-38) using low workable concrete (zero slump). The HCS section consists of including hollows in a concrete section to form several internal concrete webs. In order to make the HCS section more efficient, their hollows, initially provided with circular voids, are improved to non-circular ones. In addition, prestressed tendons are incorporated to improve their span range and deflection control. Nowadays, HCS are capable of span long distances with low self-weight and material costs.

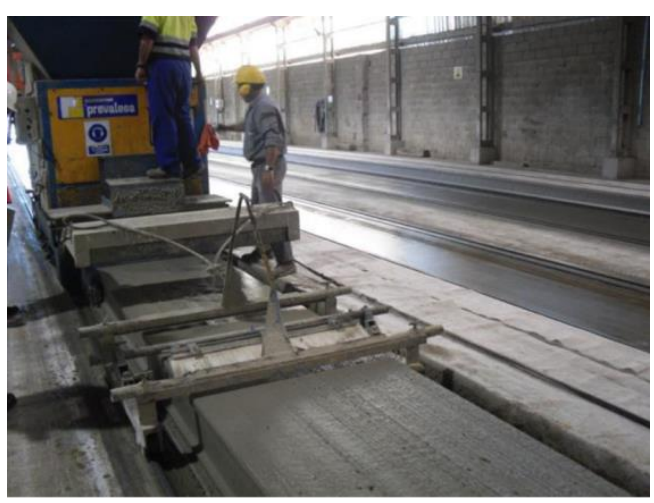

Figure 2-38: Extrusion process of HCS [185]

As some restrictions on placing conventional reinforcement exist in HCS due to using low workable concrete and a manufacturing process, HCSs are generally made w/o any web reinforcement and mechanism to improve tendon end anchorage. Hence HCS are exempt from the minimum amount of shear reinforcement requested by codes. Moreover, as HCS are simply supported at their ends (support width of usually $10-15 \mathrm{~cm}$ ), it is known that their end zones (where the transferring length of tendon occurs, i.e. transfer length equal to 60-70-fold the tendon diameter [186]) are very critical regions. In fact end zones are disturbed regions stressed mainly in tension by shear forces (in a zone where the beneficial effects of prestressing are not completely active) and splitting actions (caused by transferring prestressing force from steel to concrete). All this makes end zones critical in shear and highlights the importance of studying them and evaluating new shear reinforcement solutions to prevent HCS from critical shear failure. In fact two MOF in shear can occur in HCSs flexural-shear and web-shear failure.

In order to improve the shear strength of HCS ends, alternatives like reducing the number of voids (increasing the width of webs) or filling locally voids with concrete in the fresh state are common practices in the construction industry. However, these practices are employ considerable time and resources, and result in element weight gain. This is why the use of steel or polypropylene fibres is appealing to improve shear strength. 
Chapter 2. Literature Survey

The first attempts to introduce fibres were reported by Bernander [187] in 1986, when slit sheet steel fibres with enlarged ends (18 $\mathrm{mm}$ long) were incorporated into concrete at a $1 \%$ volume fraction. The slabs ( $380 \mathrm{~mm}$ deep) with four cores were sawn into beams and tested with $\mathrm{a} / \mathrm{d}=4$. Fibres increased element shear strength by $25 \%$ compared to their plain concrete counterparts. In 1998, Paine et al. $[188,189]$ examined nine HCS $(200 \mathrm{~mm}$ deep, 1,200 $\mathrm{mm}$ wide) to study the influence of steel fibres on shear strength. The analysed parameters were prestressing configuration, steel fibre type (hooked-end and amorphous steel fibre), fibre content $(0.5 \%$ and $1 \%)$ and the shear span-to-effective depth ratio $(a / d=2.0$ and 2.8$)$. Paine et al. $[13,14]$ found that steel fibres dosed at $0.5 \%$ increased first crack shear strength by $4 \%$ and $31 \%$ in the tested slabs with $a / d=2.8$ and $a / d=2.0$, respectively. Moreover in HCS with $1.0 \%$ fibres, the average increase was only $5 \%$. Finally, improved post peak ductility in FRC slabs compared to the sample in conventional reinforcement was observed.

Cuenca et al. [185] tested 26 hollow core slabs of PC and SFRC in 2012. Slabs were 260 $\mathrm{mm}$ deep and $960 \mathrm{~mm}$ wide. SFRC slabs included steel fibres of $40 \mathrm{~mm}$ long and a 65 aspect ratio. The studied parameters were: the shear span-to-effective depth ratio ( $a / d=2.3,3,3.4,4.4$ and 8.6), fibre content $\left(0,50\right.$ and $\left.70 \mathrm{~kg} / \mathrm{m}^{3}\right)$ and the pre-cracking effect. The involved parameters were combined to one another to study the MOFs of HCS. To study the pre-cracking effect, three of the 26 slabs were pre-cracked (up to 0.2 $\mathrm{mm}$ ) before shear tests by loading slabs in a configuration $a / d=4.9$. Similarly to Paine et al. [188,189], Cuenca et al. observed that the shear strength and ductility of the element incremented by adding fibres. Several MOFs were observed during the test according to $a / d$ test schemes, where the most brittle was web-shear failure and anchorage failure. Figure 2-39 represents the capacity achieved to calculate the ratio in flexure (SM) versus the a/d of Cuenca's elements placed on the Kani's valley [185]. As we can see, most of the results were higher than expected by Kani's valley, which could mean that diagonal failure disappeared in Kani's valley when an adequate amount of fibres was incorporated into concrete.

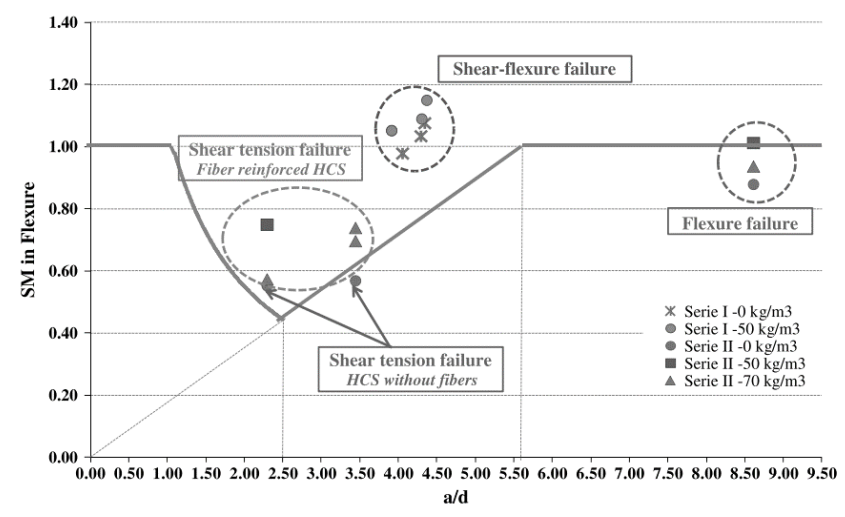

Figure 2-39: Result of Cuenca et al. in Kani's valley[185]. 
Effectiveness of polypropylene fibres as shear reinforcement in structural elements

In 2015, Simasathien and Chao [190] studied eight RC and SFRC HCS (460 mm depth, $1,220 \mathrm{~mm}$ ) manufactured by the traditional wet-cast method. Slabs were tested in shear with different shear span-to-effective depth ratios $(a / d=2,2.73,3.45,4.36,5.09)$ to obtain several MOFs. The used fibres were steel hooked-end steel ones $(50 \mathrm{~mm}$ long, 67 aspect ratio). Volume fractions of $0.50 \%$ and $0.75 \%$ were used to analyse the effect of steel fibres on deeper slabs. The authors showed that the presence of steel fibres significantly increased shear strength by $79 \%$ in those slabs failing in web-shear failure $(a / d=2$ and 2.73 ), and by $90 \%$ in those slabs failed by flexural-shear failure compared to the predicted shear strengths. Simasathien and Chao [190] also observed that fibres were capable of preventing the slip of tendons and splitting of concrete at the end of strands (see Figure 2-40), which was probably one reason for increasing the shear strength in those slabs that failed by web-shear failure. This observation is similar to that of Palmer and Schultz [191] who, after testing reinforced concrete HCS, concluded that the greater the end slip of tendons, the lower shear strength became.

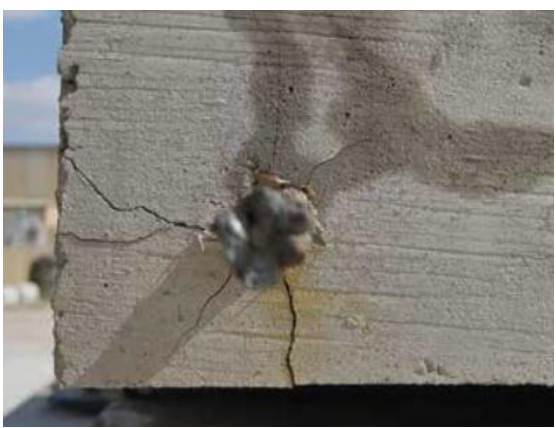

(a)

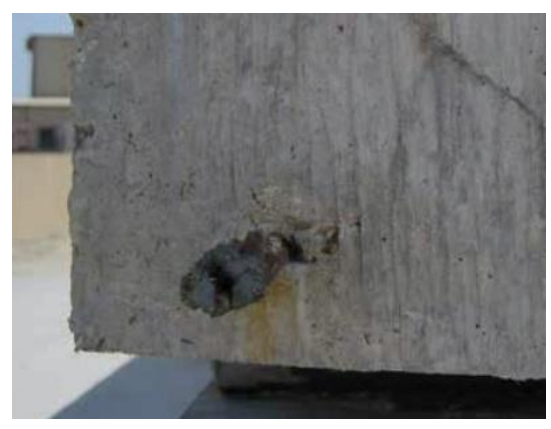

(b)

Figure 2-40: Prestressing strands at the end of specimens [190] $(a / d=2.73)$ at failure for the PC (a) and SFRC (b) slabs

Dudnik et al. [17] studied in 2017 the shear behaviour of 10 HCS (300 and $410 \mathrm{~mm}$ depths) reinforced by different steel fibre contents $(0.38 \%, 0.50 \% 0.76 \%)$. Slabs were manufactured using low workable concrete. Dudnik et al. [17] highlighted that fibre contents above $0.5 \%$ may lead to concrete compaction problems, with potential disadvantageous effects on the shear strength of slabs. Slabs were tested by a three-point-loading scheme with a/d equalling 3 and 3.5. As in previous studies, Dudnik et al. observed that fibres increased shear strength in both HCS depth types. However, no appreciable enhanced shear was observed when fibres were increased from $0.5 \%$ to $0.76 \%$. Unlike previous studies, Dudnik et al. measured tendon behaviour while testing and observed that the slip of tendons in some strands decreased as the amount of fibres increased [17].

The applicability of polypropylene fibres as shear reinforced in HCS has not been explored in-depth, and limited information is available in the literature. Kankeri et al. [192] 
Chapter 2. Literature Survey

studied in 2019 the structural effect of macrosynthetic fibres on HCS at three different a/d $(2.5,3.75,7.50)$. Two slabs were tested for each $a / d$, one containing fibres at a $0.33 \%$ volume fraction $\left(3 \mathrm{~kg} / \mathrm{m}^{3}\right)$, and the second w/o any type of transverse reinforcement; i.e. six slabs were fully tested. The used fibre was a monofilament polypropylene fibre: 50 $\mathrm{mm}$ long, $0.5 \mathrm{~mm}$ diameter, $618 \mathrm{MPa}$ tensile strength, 10GPa modulus of elasticity. The section details of HCS were obtained by cutting an entire HCS section $(1,200 \mathrm{~mm} \times 150$ $\mathrm{mm}$ ) into two pieces of $600 \mathrm{~mm}$ width (see Figure 2-41). The prestressing force of each strand $(9.53 \mathrm{~mm}$ ) was $70 \mathrm{kN}$, which introduced a compressive strength of $7.3 \mathrm{MPa}$. Slabs were tested by a four-point loading scheme, hbut the cantilever spans after supports were considered to avoid bond loss of strands and concrete in end zones. This end zones configuration cannot represent the real scheme of HCS supports in which widths of 100-150 $\mathrm{mm}$ are usual.

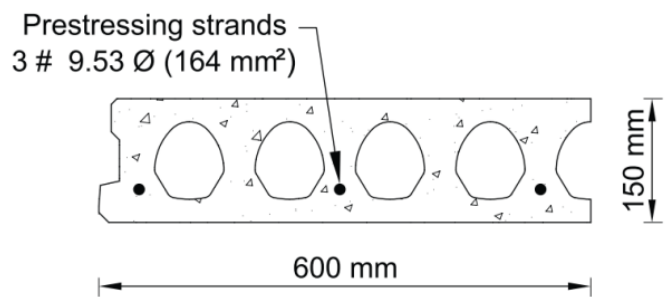

Figure 2-41: Cross-section of Hollow Core Slabs tested by Kankeri et al. [192]

The results demonstrated the efficiency of macrosynthetic fibres in increasing both shear and flexural strength in all the studied $a / d$. As expected, and based on Kani's valley [148], at small a/d ratios, shear was predominant in the MOF of slabs. Shear diagonal tension MOF occurred in $a / d=2.5$ slabs (see Figure 2-42), while flexural failure occurred in the remaining slabs $(a / d=3.75$ and 7.50). In slabs tested with $a / d=2.5$, an increment of $30 \%$ and $8 \%$ appeared in the first crack load and peak load, respectively, compared to the control slab, respectively. In the slabs failing in flexure, a maximum increment of $19 \%$ in flexural strength was observed. Nevertheless, the number of cracks (flexural and shear) increased, and they were better distributed along the PFRC slabs.

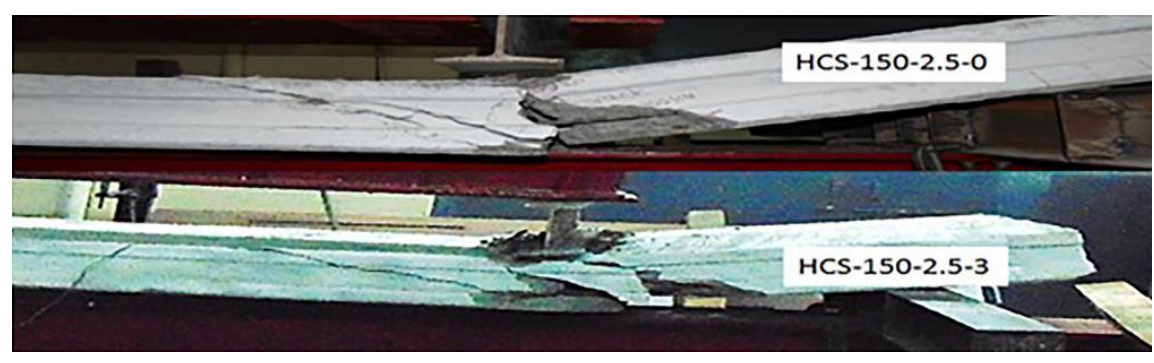

Figure 2-42: MOF of the SFRC hollow core slab [192] 
Effectiveness of polypropylene fibres as shear reinforcement in structural elements

Two key aspects in web-shear failure (see Figure 2-43a) in critical shear zones (ends of slabs) are the support width and cantilever span after the adopted support. As a wider support width and greater cantilever length allow the transmission length of strands to the concrete section to increase which can, in turn, increase shear strength, in real construction applications slabs are usually placed over the support's widths of $100-150 \mathrm{~mm}$, which makes web-shear failure more critical. In this context, the differences in fibre contribution to shear strength in HCS according to several authors may be related to this parameter. Cuenca et al. [185] did not specify the support width, but studied a cantilever span from $120 \mathrm{~mm}$ to $2,500 \mathrm{~mm}$ (measured from the centre of the support). They observed that small cantilevers produced slip of tendons, followed by web-shear failure. Paine et al. used supports of $100 \mathrm{~mm}$ width with no cantilever span. Simasathien and Chao [190] employed supports of $150 \mathrm{~mm}$ with $300 \mathrm{~mm}$ of cantilever (measured from the centre axis of the support), while Dudnik et al. [17] used supports of $40 \mathrm{~mm}$ and cantilever span of $24.5 \mathrm{~mm}$ (measured from the external edge of the support). In this context, European standard EN 1168 [193] proposes a shear test setup for HCS, where support details (support width of $100 \mathrm{~mm}$, see Figure 2-43b) and loading schemes $(a / d=2.8)$ are required.

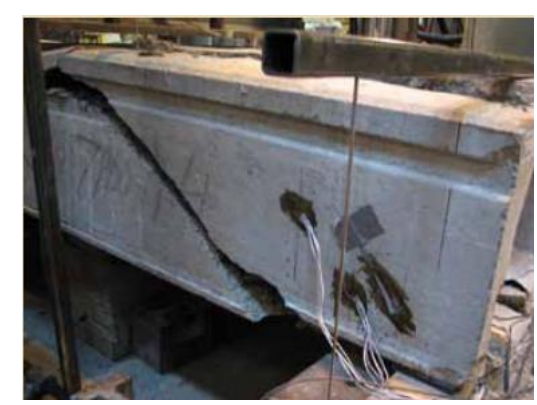

(a)

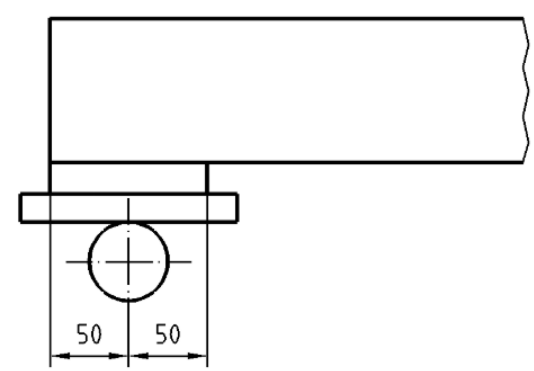

(b)

Figure 2-43: Web-shear failure [191] (a) and support details according to EN 1168 [193]

The failure criterion of HCS is set when the maximum principal stress $\left(\sigma_{1}\right)$ in the web corresponds to the tensile strength of concrete $\left(f_{c t}\right)$ (Eq. 2-62). Moreover, maximum principal stresses must be determined by Mohr's circle from the normal $(\sigma)$ and shear $(\tau)$ stresses (Eq. 2-63). In addition, based on Collignon-Jourawsky formula, it is known that maximum shear stress in a symmetrical section can be expressed according to the first moment of the area above and around the centroid axis $(S)$, the section's second moment of area $(I)$, the section's width $(b)$ and shear force $(V)$, as (Eq. 2-64) shows. Replacing (Eq. 2-62) and (Eq. 2-64) in (Eq. 2-63) allows shear force $(V)$ to be evaluated, as shown in (Eq. 2-65).

$$
\sigma_{1}=f_{c t}
$$




$$
\begin{aligned}
& \sigma_{1}=\frac{\sigma}{2}+\sqrt{\left(\frac{\sigma}{2}\right)^{2}+\tau^{2}} \\
& \tau=\frac{S}{b I} V \\
& V=\frac{b I}{S} \sqrt{f_{c t}{ }^{2}-\sigma f_{c t}}
\end{aligned}
$$

As web-shear failure usually occurs in zones w/o flexural cracks, some expressions based on (Eq. 2-65) have been proposed in design codes to determine the shear strength of HCS. In this context, Eurocodes 2 [76], MC2010 [7], EN1168 [193] and ACI 318-14 [13] include expressions (summarised in Table 2-7) to determine shear strength in uncracked regions. Expressions limit web-shear stress to the design value of axial tensile strength of concrete, denoted as $f_{c t d}$ in all the codes, except ACI 318-14, where it is represented by $\sqrt{f^{\prime} c}$. Moreover, MC2010 [7] and EN1 168 [193] propose two calculation levels that differ in terms of their level of accuracy. Eurocode 2 (Eq. 2-66) MC2010 level I (Eq. 2-67) and EN1168 Level II (Eq. 2-70) propose expressions that are similar to (Eq. 2-65). However, MC2010 level I and EN1 168 level II include a reduction factor of 0.8. Expressions (Eq. 2-66), (Eq. 2-67) and (Eq. 2-71) disregard shear stresses due to the transfer of prestressing strands. MC2010 level II (Eq. 2-68) and EN1168 level I (Eq. 2-69) are more refined expressions based on Yang's method [194], which includes shear stressed $\tau_{c p}$ due to the transfer of prestressing force. For ACI 318-14, the shear calculation should be taken as the lowest value given by expressions (Eq. 2-71).

The control section of the slab in shear should be evaluated at distance $h / 2$ from the support's internal face in ACI 318-14, and distance $l_{x}$ from the slab edge to the intersection of the axis that passes the centre of gravity of the gross section and an inclined line of slope $45^{\circ}$ for Eurocode 2, and slope $35^{\circ}$ for MC2010 and EN1168. In more refined expressions, MC2010 level II (Eq. 2-68) and EN1 168 level I (Eq. 2-69), the critical point is the point on the aforementioned inclined line where shear is the lowest. Critical point and lines sections are summarised graphically in Figure 2-44. 
Effectiveness of polypropylene fibres as shear reinforcement in structural elements

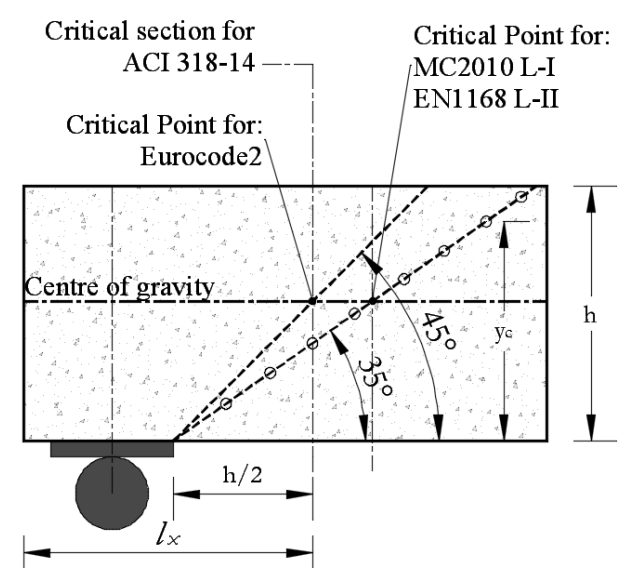

Figure 2-44 Point and lines of failures of different design codes for HCS

As regards the expression that predicts shear strength in the web-shear failure of FRC without flexural cracks, Narayanan and Darwish [195] suggested in 1987 an expression to predict web failure according to the spitting tensile strength of concrete $f_{c t, s p}$ instead of $f_{c t}$ in Equation (Eq. 2-65) in prestressed beams. Nowadays it might not bet appropriate, but at that time Narayanan and Darwish obtained good results with their experimental test.

Currently, no international code includes an expression of shear strength on uncracked regions in FRC elements. However, an approximation using expression (Eq. 2-17) of MC2010, by considering $\varepsilon_{x}=0$ that results in expression (Eq. 2-73), could be attempted. It is stressed that expression (Eq. 2-73) does not consider the influence of normal stresses induced by prestressing tendons.

If the MOF of HCS results in flexural shear, the two expressions (see (Eq. 2-16) and (Eq. 2-17)) included in MC2010 to predict the shear strength of FRC elements can be used because these expressions were developed for regions with flexural cracks.

Table 2-7: Shear resistance formulations for RC and FRC elements

\begin{tabular}{|c|c|c|}
\hline Reference & Expressions & ID \\
\hline EC-2 & $V_{R d, c}=\frac{I b_{w}}{S} \sqrt{\left(f_{c t d}\right)^{2}+\alpha_{1} \sigma_{c p} f_{c t d}}$ & (Eq. 2-66) \\
\hline $\begin{array}{c}\text { MC2010 } \\
\text { Level I }\end{array}$ & $V_{R d, c t}=0.8 \frac{I b_{w}}{S_{c}} \sqrt{\left(f_{c t d}\right)^{2}+\alpha_{1} \sigma_{c p} f_{c t d}}$ \\
\hline
\end{tabular}


Chapter 2. Literature Survey

\begin{tabular}{|c|c|c|}
\hline Reference & Expressions & ID \\
\hline $\begin{array}{c}\text { MC2010 } \\
\text { Level II }\end{array}$ & $\begin{array}{l}V_{R d, c t}=\frac{I b_{w}(y)}{S_{c}(y)} \sqrt{\left(f_{c t d}\right)^{2}+\alpha_{1} \sigma_{c p}(y) f_{t d}}-\tau_{c p}(y) \\
\sigma_{c p}(y)=\left[\frac{1}{A_{c}}+\frac{y_{c}-y}{I}\right] F_{p}\left(l_{x}\right) \\
\tau_{c p}(y)=\frac{1}{b_{w}(y)}\left[\frac{A_{c}(y)}{A_{c}}-\frac{S_{c}(y)\left(y_{c}-y_{p t}\right)}{I}\right] \frac{d F_{p}\left(l_{x}\right)}{d_{x}}\end{array}$ & (Eq. 2-68) \\
\hline $\begin{array}{c}\text { EN1168 } \\
\text { Level I }\end{array}$ & $\begin{array}{l}V_{R d c}=\frac{I b_{w}(y)}{S_{c}(y)} \sqrt{\left(f_{c t d}\right)^{2}+\sigma_{c p}(y) f_{t d}}-\tau_{c p}(y) \\
\sigma_{c p}(y)=\sum_{i=1}^{n}\left\{\left[\frac{1}{A}+\frac{\left(Y_{c}-y\right)\left(Y_{p}-Y_{p t}\right)}{I}\right] P_{t}\left(l_{x}\right)\right\} \\
\quad-\frac{M_{E d}}{I}\left(Y_{c}-y\right) \\
\tau_{c p}(y)=\frac{1}{b_{w}(y)} \sum_{i=1}^{n}\left\{\left[\frac{A_{c}(y)}{A}-\frac{S_{c}(y)\left(Y_{c}-Y_{p t}\right)}{I}+C p_{t}(y)\right] \frac{d P_{t}\left(l_{x}\right)}{d_{x}}\right\}\end{array}$ & (Eq. 2-69) \\
\hline $\begin{array}{l}\text { EN1168 } \\
\text { Level II }\end{array}$ & $\begin{array}{l}V_{R d, c t}=\varphi \frac{I b_{w}}{S} \sqrt{\left(f_{c t d}\right)^{2}+\beta \alpha_{1} \sigma_{c p} f_{t d}} \\
\varphi=0.8 \text { and } \beta=0.9\end{array}$ & (Eq. 2-70) \\
\hline ACI-318 & $\begin{array}{l}V_{c w}=\left(0.29 \lambda \sqrt{f^{\prime} c}+0.3 f_{p c}\right) b_{w} d_{p}+V_{p} \\
V_{c i}=0.05 \lambda \sqrt{f^{\prime} c} b_{w} d_{p}+V_{d}+\frac{V_{i} M_{c r e}}{M_{\max }}\end{array}$ & (Eq. 2-71) \\
\hline $\begin{array}{l}\text { Narayanan } \\
\text { and } \\
\text { Darwish } \\
\text { [195] }\end{array}$ & $\begin{array}{l}V_{u}=0.67 b h \sqrt{\left(f_{c t, s p}\right)^{2}+\sigma_{c p} f_{c t, s p}} \\
f_{c t, s p}=\frac{f_{c}}{20-\sqrt{F}}+0.8+\sqrt{F}\end{array}$ & (Eq. 2-72) \\
\hline $\begin{array}{c}\text { MC2010 } \\
\text { FRC }\end{array}$ & $\begin{array}{l}V_{R d, F}=\frac{1}{\gamma_{F}}\left(\frac{520}{\left(1000+k_{d g} z\right)} \sqrt{f_{c k}}+k_{f} f_{F t u k} \cot \theta\right) z b_{w} \\
\theta=29^{\circ}\end{array}$ & (Eq. 2-73) \\
\hline
\end{tabular}


Effectiveness of polypropylene fibres as shear reinforcement in structural elements

\subsection{Conclusions}

Experimental tests carried out on FRC elements in recent decades have demonstrated the effectiveness of fibres in enhancing shear behaviour. However, this chapter reveals that most experimentation has been done using SFRC and campaigns limited by employing PFRC. In addition, most knowledge about the contributions of fibres to shear has been obtained by testing specimens with direct shear or big elements such as beams or slabs. Within this framework, the main conclusions are summarised below:

a) Steel hooked-end fibres have been the most widely used fibres to enhance shear behaviour, while straight polypropylene fibres have been more commonplace in the case of macrosynthetic fibres. The explored fibre contents ranged from $0.05 \%$ to $2 \%$ (4 to $160 \mathrm{~kg} / \mathrm{m}^{3}$ in steel fibres, 0.5 to $18 \mathrm{~kg} / \mathrm{m}^{3}$ in synthetic fibres), and $1 \%\left(10 \mathrm{~kg} / \mathrm{m}^{3}\right)$ was the most widely used fibre content in PFRC

b) Regardless of the employed direct shear (push-off, JSCE-SF6, FIP shear test, panel test), shear strength, ductility and toughness improved with incremented fibre content, especially in SFRC. However with PFRC, no major differences in fibre contents of $0.2,0.5$ and 0.75 were observed

c) Despite microfibres like fibrillated polypropylene fibres improving a specimen's shear ductility, these fibres do not improve the element's shear strength. Therefore, the aspect radio (fibre length/fibre diameter) plays a key role in shear behaviour; i.e. greater shear strength is obtained with higher aspect ratios

d) Fibres are able to control crack kinematics. Crack behaviour depends mainly on the volume and orientation of fibres, and several mechanisms of bridging, such as bond along the fibre, snubbing or bending, have been identified

e) The fracture or pull-out of fibres is influenced mainly by the inclination of fibres in relation to the analysed crack plane

f) Experimental results have established that shear toughness and the material's flexural toughness are directly correlated. Studies have established that shear toughness is 15-fold the flexural one and depends on the properties of fibres (fibre type, aspect ratio, volume) and concrete matrix (compression strength, aggregate size). There is also evidence for a close relation between the shear stress transfer in a crack and the post-cracking flexural tensile strength of the material

g) Despite similar conclusions being drawn among the different direct shear tests herein presented, major differences appeared in the results even when similar fibres type and contents, and similar concretes, were used. This was due to each methodology being influenced by several factors that could affect the results; i.e. undesired rotations, tensile splitting. These differences increased when tests were modified. These results evidence the need for a standardised methodology, and one recognised worldwide, to better understand the real contribution of fibres to shear

h) Steel and synthetic fibres significantly enhance the shear strength and ductility of beams or HCS. Indeed increased fibre content enhances shear strength 
Chapter 2. Literature Survey

i) Adequate contents of steel fibres can partially or totally substitute stirrups. Steel fibres effectively substitute the minimum transverse reinforcement required to avoid an element's structural collapse

Despite most knowledge about the benefits of fibres on shear behaviour having been generated and based on steel fibres, some questions still need to be answered by the present thesis:

- Are polypropylene fibres as effective as steel fibres?

- Can the expression developed to predict the shear strength of SFRC be used directly in PFRC elements?

- What is the shear transfer mechanism of PFRC like exactly? 



\section{Chapter 3. STUDY OF SHEAR IN SMALL PFRC SPECI- MENS}





\subsection{Introduction}

In this chapter, two experimental campaigns conducted on pre-cracked push-off specimens of plain concrete (PC), SFRC and PFRC are presented. The main objective in both campaigns was to study the shear transfer mechanisms in a shear crack of PFRC. To do so, and based on the test methodology proposed by Echegaray in 2014 [127], the following variables were studied during the first experimental campaign:

- Three concrete types: PC, SFRC and PFRC

- Different fibre types with similar residual flexural tensile strengths

- Several initial crack openings

In order to validate the experimental campaign and the employed test methodology, the PC results were compared to the analytical aggregate interlock models proposed in the literature. Some conclusions were drawn to test the methodology.

For the second experimental campaign, new pre-cracked push-off specimens were manufactured and tested to explore the following variables:

- Comparison of PC and PFRC

- Two volume fractions of polypropylene fibres

- Different initial confinement and initial crack gaps

The FIP shear test specimens were used to calibrate the aggregate interlock and fibres model proposed in the literature to validate the second experimental campaign.

After experimentally studying the shear transfer mechanism in the shear plane, an analytical model that involves all the mechanisms acting on the pre-cracking push-off specimens (aggregate interlock, polypropylene fibres, confinement) was developed. The analytical results obtained using different aggregate and fibres models were compared to the experimental ones to validate the experimental campaign and to test the methodologies.

\subsection{Experimental campaign one}

Twenty-one push-off specimens were tested under direct shear. Specimens were manufactured with PC (seven), SFRC (six) and PFRC (eight). Each push-off specimen constituted two L-shaped blocks, which are the active and passive blocks in Figure 3-1. The active block was that which was displaced as a consequence of the applied load, while the passive block remained static. Specimen geometry was $670 \mathrm{~mm}$ length, $400 \mathrm{~mm}$ width and $120 \mathrm{~mm}$ thickness. Two trapezoidal notches were formed on the specimen's faces during casting by two metal plates $(260 \times 10 \times 6 \mathrm{~mm})$ arranged in the formwork. 
Effectiveness of polypropylene fibres as shear reinforcement in structural elements

Therefore, the thickness in the notched zones was reduced to $100 \mathrm{~mm}$, which resulted in a shear plane area of $260 \mathrm{~mm} \times 100 \mathrm{~mm}$.

To avoid the flexural cracks that distort the results, longitudinal reinforcement comprised deformed bars $(12 \mathrm{~mm})$ laid in two layers, and stirrups $(8 \mathrm{~mm})$ placed inside each block (see Figure 3-1). Finally, four 10-mm diameter connector links of threaded rods were embedded inside each bock to fix the specimen to the external frame while testing.
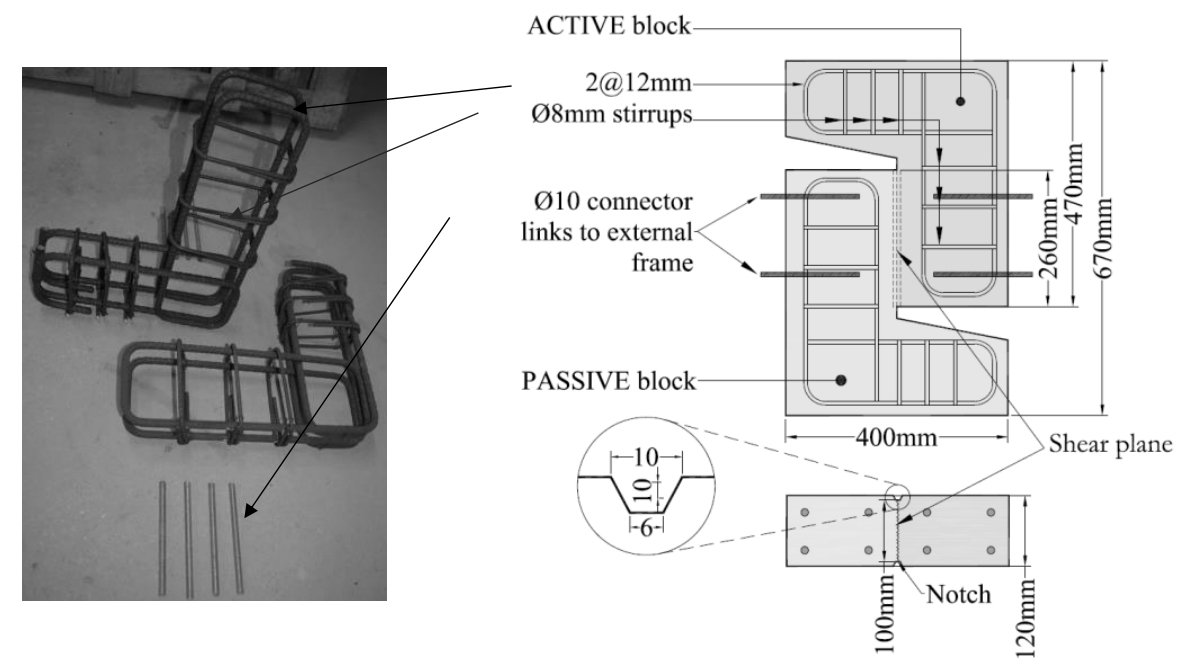

Figure 3-1: Geometry and reinforcement details

\subsubsection{Materials characterisation}

Table 3-1 shows the mix proportions of the concrete used for each batch. Specimens were manufactured in a precast concrete plant. For this purpose, portland cement type CEM I $42.5 \mathrm{~N}$ was used, along with two gravel and three sand types as shown in Table $3-2$, with a maximum aggregate size of $20 \mathrm{~mm}$. The amounts of the concrete main components were constant in all concrete types (PC, SFRC, PFRC). However, superplasticiser (SIKA 5920) was used at different doses to ensure correct workability, especially in the produced fibre-reinforced concrete (FRC). Before casting specimens, concrete workability was measured for each batch by a concrete slump-flow test according to EN 12350-8 (see Table 3-1). The mix design was carried out to assure a characteristic concrete compression strength of $35 \mathrm{MPa}$. 
Table 3-1: Mix design of PC, SFRC and PFRC.

\begin{tabular}{|c|c|}
\hline Cement CEM I 42.5N $\left[\mathrm{kg} / \mathrm{m}^{3}\right]$ & 350 \\
\hline Crushed sand type $1\left[\mathrm{~kg} / \mathrm{m}^{3}\right]$ & 482 \\
\hline Crushed sand type $2\left[\mathrm{~kg} / \mathrm{m}^{3}\right]$ & 168 \\
\hline Crushed sand type $3\left[\mathrm{~kg} / \mathrm{m}^{3}\right]$ & 482 \\
\hline Gravel 6/12 mm [kg/m³] & 591 \\
\hline Gravel 12/20 mm [ $\left.\mathrm{kg} / \mathrm{m}^{3}\right]$ & 118 \\
\hline & 0 (PC) $V_{f}=0.0 \%$ \\
\hline Fibres $\left[\mathrm{kg} / \mathrm{m}^{3}\right]$ & $10\left(\right.$ PFRC) $V_{f}=1.1 \%$ \\
\hline & 30 (SFRC) $V_{f}=0.38 \%$ \\
\hline \multirow{3}{*}{ Superplasticiser $\left[\mathrm{It} / \mathbf{m}^{3}\right]$} & $3.5(\mathrm{PC})$ \\
\hline & 3.8 (SFRC) \\
\hline & 4.7 (PFRC) \\
\hline \multirow{3}{*}{ Slump [mm] } & $650(\mathrm{PC})$ \\
\hline & 583 (SFRC) \\
\hline & 588 (PFRC) \\
\hline
\end{tabular}

Table 3-2: Granulometry of aggregates.

\begin{tabular}{|c|c|c|c|c|c|}
\hline $\begin{array}{c}\text { Sieve } \\
\text { [mm] }\end{array}$ & $\begin{array}{c}\text { Sand } \\
\text { Type 1 }\end{array}$ & $\begin{array}{c}\text { Sand } \\
\text { Type 2 }\end{array}$ & $\begin{array}{c}\text { Sand } \\
\text { Type 3 }\end{array}$ & $\begin{array}{c}\text { Gravel } \\
\mathbf{6 / 1 2}\end{array}$ & $\begin{array}{c}\text { Gravel } \\
\mathbf{1 2 / 2 0}\end{array}$ \\
\hline 20 & 100,0 & 100,0 & 100,0 & 100,0 & 100,0 \\
\hline 16 & 100,0 & 100,0 & 100,0 & 100,0 & 56,0 \\
\hline 12 & 100,0 & 100,0 & 100,0 & 100,0 & 3,9 \\
\hline 10 & 98,3 & 100,0 & 100,0 & 93,3 & 1,2 \\
\hline 8 & 97,3 & 100,0 & 100,0 & 76,7 & 0,8 \\
\hline 4 & 92,0 & 99,0 & 90,0 & 4,7 & 0,7 \\
\hline 2 & 81,4 & 94,8 & 71,4 & 3,0 & 0,7 \\
\hline 1 & 68,9 & 80,6 & 53,0 & 1,0 & 0,7 \\
\hline 0,5 & 50,8 & 64,3 & 28,3 & 1,0 & 0,7 \\
\hline 0,25 & 27,2 & 47,5 & 13,1 & 1,0 & 0,7 \\
\hline 0,125 & 11,9 & 30,1 & 5,6 & 1,0 & 0,7 \\
\hline 0,063 & 3,4 & 22,4 & 1,5 & 1,0 & 0,4 \\
\hline
\end{tabular}

Table 3-3 shows the main geometry and mechanical properties of the two macrofibres employed. Both were selected for providing good post-cracking mechanical performance 
to concrete given their high aspect ratio (47 in polypropylene fibres, 66 in steel fibres; Figure 3-2). The polypropylene and steel fibres were manufactured with $100 \%$ polyolefin and treated steel (bright steel), respectively. Nevertheless, both fibres were commercial and are frequently used in the construction industry.

In order to compare the shear performance between both fibre types, the selected amounts $\left(10 \mathrm{~kg} / \mathrm{m}^{3}\right.$ in PFRC and $30 \mathrm{~kg} / \mathrm{m}^{3}$ in SFRC) were chosen to provide similar flexural strength and residual flexural tensile strength to concrete. Therefore, it was possible to evaluate if the results of the post-cracking behaviour in shear correlated with the post-cracking behaviour in flexure.

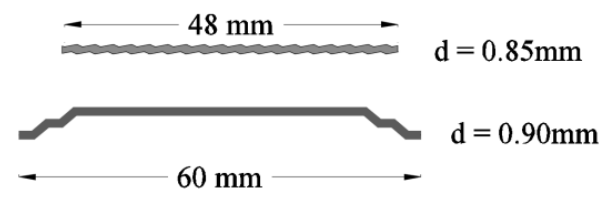

Figure 3-2: Selected fibre types

Table 3-3: Fibres' main properties

\begin{tabular}{|c|c|c|}
\hline Properties & PFRC & SFRC \\
\hline Material & Polyolefin & Bright Steel \\
\hline Design & Monofilament & Double hooked-end \\
\hline Shape & Elliptical & Circular \\
\hline Equivalent diameter [mm] & 0.85 & 0.9 \\
\hline Length [mm] & 48 & 60 \\
\hline Tensile strength [MPa] & 400 & 2300 \\
\hline Modulus of elasticity [GPa] & 4.7 & 210 \\
\hline Density [g/cm & & 7.85 \\
\hline
\end{tabular}

Figure 3-3a displays the employed metal formworks, the steel reinforcement and connector links placed before casting. Figure 3-3b shows the specimens after casting. Four specimens were cast per day using each produced concrete type (PC, PFRC and SFRC). No mechanical vibration was applied because the three-manufactured concrete presented the same high workability. It should be noted in Figure 3-3a and Figure 3-3b the use of two metal rules $(260 \times 10 \times 6 \mathrm{~mm})$ to generate a trapezoidal notch $(10 \mathrm{~mm}$ deep $)$ on the face of both specimens: one incorporated into the formwork and another placed after casting.

In order to better control the initial crack opening, in some specimens two 8-mm rebars were placed at the mid-depth before casting, as Figure 3-4 shows. Therefore, two 8-mm bars constitute the stirrup cross the shear plane. The entire experimental campaign one is summarised in Table 3-6. 


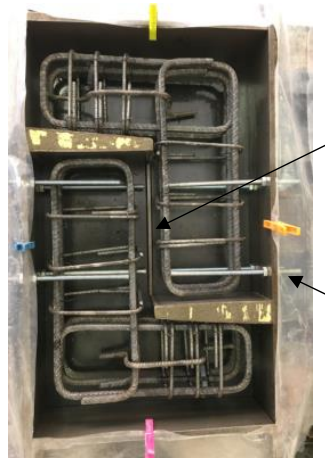

(a)

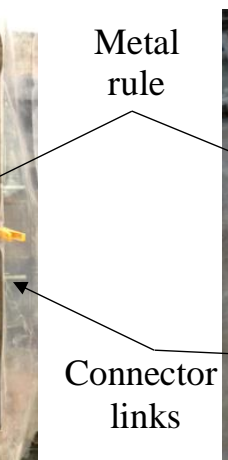

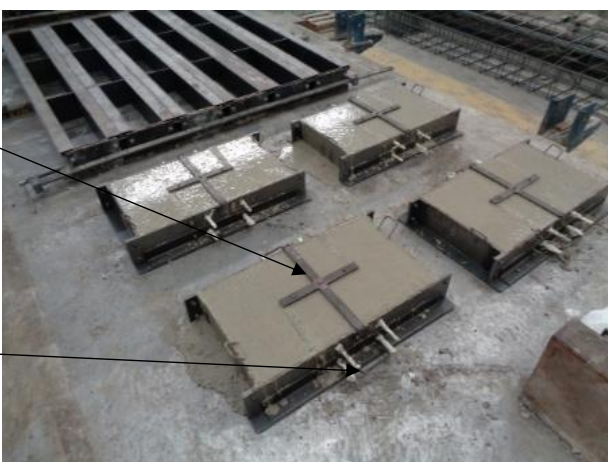

(b)

Figure 3-3: Picture of specimens' formworks (a) and specimens after casting(b)

In order to characterise the mechanical properties of the three employed concretes, cylindrical $(150 \times 300 \mathrm{~mm})$ and prismatic $(150 \times 150 \times 600 \mathrm{~mm})$ samples were manufactured along with the push-off specimens. Table 3-4 lists the main values of: concrete compression strength $\left(f_{c}\right)$; modulus of elasticity $\left(E_{c}\right)$; flexural strength $\left(f_{L}\right)$; residual flexural tensile strength $\left(f_{R_{j}}\right)$ with CMOD (crack mouth opening displacement) values of $0.5,1.5$, 2.5 and $3.5 \mathrm{~mm}$, respectively. $f_{c}$ and $E_{c}$ were determined according to EN 12390-3 [196] and EN 12390-13 [197], respectively, using 24 cylindrical specimens (4 specimens per batch), while $f_{L}$ and $f_{R j}$ were in accordance with EN 14651 [15] on 22 notched prismatic specimens.

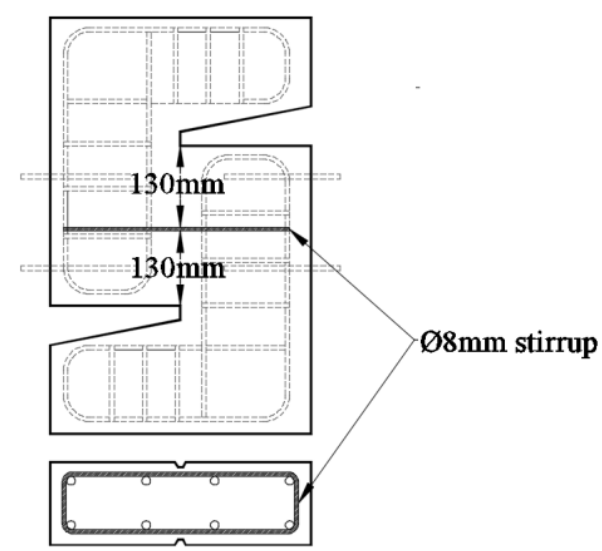

Figure 3-4: Details of the specimens with stirrups 
Effectiveness of polypropylene fibres as shear reinforcement in structural elements

Table 3-4: Mechanical properties of concrete (coefficient of variation in brackets)

\begin{tabular}{|c|c|c|c|}
\hline Property & RC & SFRC & PFRC \\
\hline$f_{c}[\mathrm{MPa}]$ & $41.6(0.04)$ & $39.9(0.04)$ & $42.4(0.03)$ \\
\hline$E_{c}[\mathrm{MPa}]$ & $29420(0.04)$ & $28901(0.02)$ & $29621(0.05)$ \\
\hline$f_{L}[\mathrm{MPa}]$ & $4.51(0.06)$ & $4.86(0.08)$ & $4.42(0.08)$ \\
\hline$f_{R, 1}[\mathrm{MPa}]$ & - & $3.00(0.30)$ & $2.97(0.17)$ \\
\hline$f_{R, 2}[\mathrm{MPa}]$ & - & $3.73(0.23)$ & $4.29(0.19)$ \\
\hline$f_{R, 3}[\mathrm{MPa}]$ & - & $3.83(0.21)$ & $4.74(0.17)$ \\
\hline$f_{R, 4}[\mathrm{MPa}]$ & - & $3.60(0.28)$ & $4.83(0.18)$ \\
\hline Fibres $\left[\right.$ fibres $\left./ \mathrm{cm}^{2}\right]$ & - & $0.242(0.21)$ & $0.602(0.16)$ \\
\hline
\end{tabular}

To supplement Table 3-4, Figure 3-5 plots the nominal shear stress vs. the CMOD responses of the fibre-reinforced beam samples tested according to EN 14651. We can see that the steel fibres conferred SFRC slightly more residual flexural tensile strength at a CMOD that equalled $0.5 \mathrm{~mm}$ than in PFRC, while PFRC presented more $f_{R, j}$, than SFRC up to $2.5 \mathrm{~mm}$. Thus steel fibres better controlled the initial crack opening, which is related to SLS (serviceability limit states) than PFRC. On the contrary, PFRC provided more residual flexural tensile strength than SFRC with large openings $\left(f_{R, 3}\right.$ and $\left.f_{R, 4}\right)$, which are related to ultimate limit states (ULS). In addition, more variation in the results was observed in SFRC than in PFRC (see the coefficient of variation in Table 3-4). This could be due to the high probability of polypropylene fibres to better distribute inside the matrix than steel ones as the number of polypropylene fibres was 2.9 -fold the number of steel ones. This trend was also observed in the number of fibres crossing the failure plane of the prismatic beams, which were visually counted after performing the EN 14651 bending test (see Table 3-4). 
Chapter 3. PFRC in small specimens

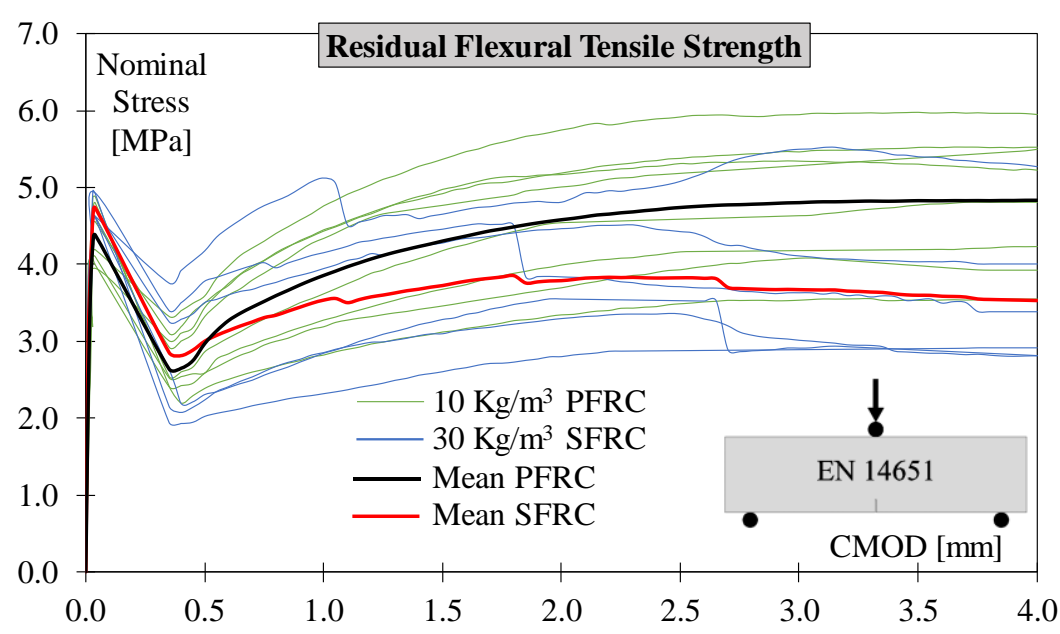

Figure 3-5: Nominal stress-CMOD responses according to EN 14651

Finally, the steel reinforcement samples were taken to determine their yield and ultimate tensile strength $\left(f_{y}\right.$ and $\left.f_{u}\right)$ according to EN-ISO 6892-1. The results are shown in Table 3-5. A $200 \mathrm{GPa}$ modulus of elasticity was assumed for steel reinforcement.

Table 3-5: Reinforcement properties

\begin{tabular}{|c|c|c|c|}
\hline $\begin{array}{c}\text { Diameter } \\
{[\mathbf{m m}]}\end{array}$ & $\begin{array}{c}\text { Area } \\
{\left[\mathbf{m m}^{\mathbf{2}}\right]}\end{array}$ & $\begin{array}{c}\boldsymbol{f}_{\boldsymbol{y}} \\
{[\mathbf{M P a}]}\end{array}$ & $\begin{array}{c}\boldsymbol{f}_{\boldsymbol{u}} \\
{[\mathbf{M P a}]}\end{array}$ \\
\hline 8 & 50.27 & 518 & 660 \\
\hline 12 & 113.10 & 529 & 640 \\
\hline
\end{tabular}

\subsubsection{Instrumentation and test setup}

\subsubsection{Instrumentation}

The total procedure to test the specimens consisted in four stages:

- Frame assembly

- Pre-cracking

- Handling

- Push-off test.

As the push-off test was performed on the pre-cracked specimens, an external frame that confined the specimen during the pre-cracking process and push-off test was required. The main objective of this device was to control crack opening throughout the whole procedure. Therefore, different initial normal stresses $\left(\sigma_{i n i}\right)$ could be set up on the frame assembly. Figure 3-6 details the external frame components, which are: 


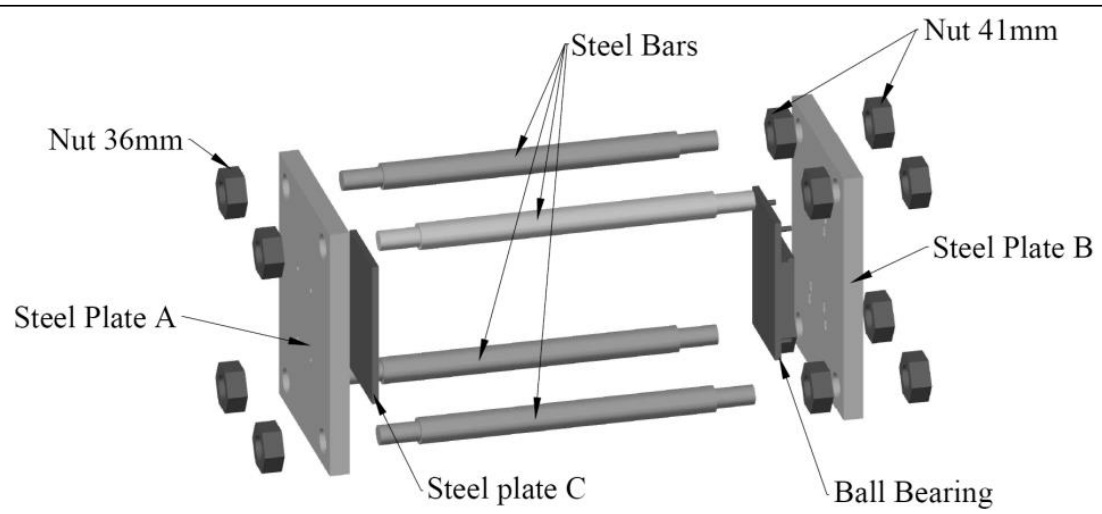

Figure 3-6 External confinement frame components

- Steel plate A: steel plate $(390 \times 300 \times 30 \mathrm{~mm})$ placed on the passive block connected to the specimen by four connector links, and interconnected to the rest of the external frame by steel bars

- Steel plate B: steel plate $(390 \times 300 \times 30 \mathrm{~mm})$ placed on the active block, but not directly fixed to the specimen. Steel plate B was connected by friction to the ball bearing, and linked to the specimen by steel bars

- Steel bars: these bars are the link between steel plates A and B. The four bars were $576 \mathrm{~mm}$ long and $41 \mathrm{~mm}$ in diameter. In one of the end zones, the diameter lowered to $35 \mathrm{~mm}$ to stop steel plate A and to fix the plate by one nut ( $36 \mathrm{~mm}$ ). In the opposite end zone, a millimetre screw thread allowed bars to fixed to steel plate B by two nuts $(41 \mathrm{~mm})$ per bar. This pair of nuts created a much stiffer link. We should bear in mind that steel plate B was not linked to the specimen

- Steel plate C: steel plate $(120 \times 250 \times 10 \mathrm{~mm})$ used to adjust the link between plate $\mathrm{A}$ and the specimen

- Ball bearing: mechanism used to reduce the frictional forces between the specimen and the external confinement steel frame as much as possible. It was directly linked with the specimen by four connector link bars (see Figure 3-3), but not to steel plate B; i.e. ball bearing lay between the specimen and steel plate B. The ball bearing was made of steel formed by two pieces: body and cover (see Figure 3-7a). The body's dimensions were 270x120x15 mm, while that of the cover was $130 \times 120 \times 15 \mathrm{~mm}$. Between the body and cover, approximately 200 steel and greased steel balls $(5 \mathrm{~mm}$ diameter) were placed inside (see Figure 3-7b). Finally, the ball bearing device only allowed vertical displacements up to $15 \mathrm{~mm}$. 

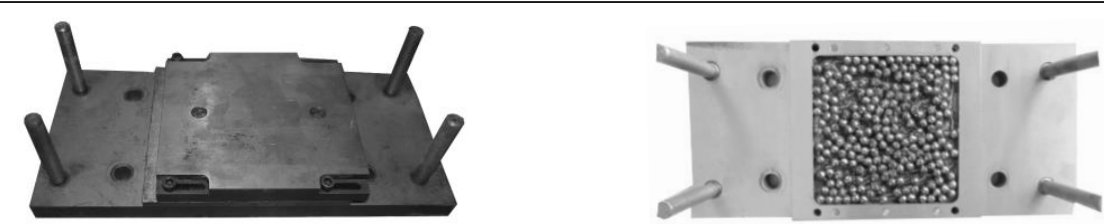

Figure 3-7: and details of the ball bearing

- Nuts: steel nuts, with $36 \mathrm{~mm}$ and $41 \mathrm{~mm}$ internal diameter, used to fix steel plates A and B to the steel bars. The nuts used to fix steel plate B had a millimetre screw thread in order to adjust the desired crack opening.

Two types of instrumentation were used to capture the displacement of the active block vs. the passive block; i.e. crack opening and slip. During the pre-cracking process, two potentiometric displacement transducers $(P T s)$ of $25 \mathrm{~mm}$ were placed on the specimen's top face, as indicated in Figure 3-8a, whereas 10 DEMEC target points were pasted to specimen surfaces (five DEMEC target for each specimen's face) separated from each other by $100 \mathrm{~mm}$, as indicated in Figure 3-8a. As the base plate provided enough space to place PT, only the DEMEC measurements were taken on the bottom face. Nevertheless on the top surface, where both types of instrumentation were used, the DEMEC measurements were compared and validated with the PT ones.

During the push-off test, 10 PTs and 10 DEMEC targets were used to track the crack kinematics. Two PTs $(100 \mathrm{~mm})$ and four PTs $(25 \mathrm{~mm})$ were placed on both faces of the specimen to measure vertical and horizontal movements (crack opening and slip) (see Figure 3-8b). At the same time, in order to determine the shear stress transmitted to the external confinement bars, four PTs $(50 \mathrm{~mm})$ were used to measure the relative displacement $(\Delta)$ of the external confinement frame and to correct the shear stresses transmitted to specimens. The relative displacement $(\Delta)$, at instant ' $i$ ' of the push-of test, was determined using PTs C1, C2, C3 and C4 (Figure 3-8b) and applying the equation (Eq. 3-1).

$$
\Delta_{i}=\left|\frac{C 1+C 3}{2}-\frac{C 2+C 4}{2}\right|
$$


(a)
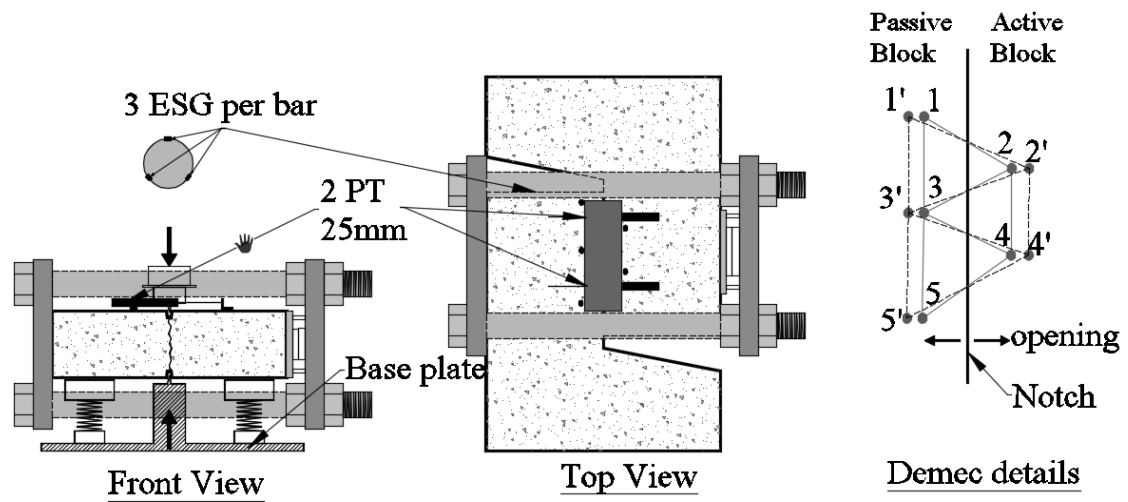

Front View

\section{Demec details}

(b)

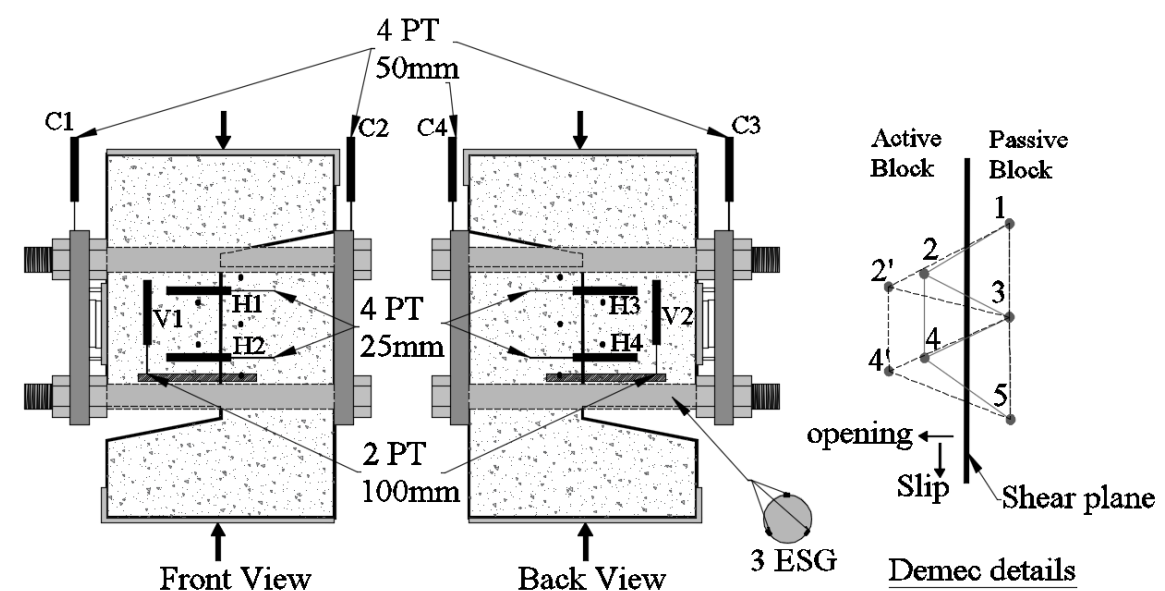

Figure 3-8: Instrumentation arrangement during the pre-cracking (a) and push-off test (b)

As the confinement applied to the specimen was passively controlled by the external confinement frame, 12 electrical strain gauges (ESG) were placed on the external steel bars. Three ESG, separated $120^{\circ}$ from one another (see Figure 3-8a and b), were placed on each bar in its middle position to measure strains during the frame assembly, precracking process, handling and push-off test. The average value of the three strain gauges was used as the bar's experimental average normal strain value, evaluated according to (Eq. 3-2). With the average strain $\left(\varepsilon_{j}\right)$, the tensile force $\left(F_{b}\right)$ that acted on each ' $j$ '-bar was determined with (Eq. 3-3).

$$
\varepsilon_{j}=\frac{\varepsilon_{j, 1}+\varepsilon_{j, 2}+\varepsilon_{j, 3}}{3}
$$




$$
F_{b, j}=E_{s} \varepsilon_{j} A_{b}
$$

where $E_{s}$ is the modulus of elasticity of eternal confinement i-bar $(1,2,3$ or 4$)$ and $A_{b}$ is the cross-section of the external confinement i-bar.

Further details about the components of both the external frame and instrumentation can be found in $[94,127]$.

\subsubsection{Test setup}

\section{i. Frame assembly}

In the frame assembly, all the external confinement steel frame components were as indicated in Figure 3-6. The assembly started by fixing steel plate $\mathrm{C}$ and steel plate A to the passive block by the four-connector links. Then the ball bearing was threaded through the connector links to the specimen's active block. Steel bars $C$ were threaded through steel plate A by $35-\mathrm{mm}$ nuts. It was necessary to apply the correct torque to nuts to guarantee a perfect fix of both bars and plate. Steel plate B was placed and threaded through steel bars by the four 41-mm nuts. It was necessary for the internal and external nuts result to be well-adjusted to guarantee a perfectly fixed end of the bars' plates.

In this stage, the desired initial confinement $\left(\sigma_{i n i}\right)$ was set up. It is worth mentioning that Echegaray's methodology suggested setting up an average strain of 0.015 microstrains on each bar. Therefore, the $\sigma_{\text {ini }}$ of the specimen was $0.01 \mathrm{MPa}$. Table 3-6 summarises the $\sigma_{i n i}$ of the tested specimens. The frame assembly stage finished by measuring the separation among the DEMEC targets.

\section{ii.Pre-cracking}

Specimen pre-cracking was done with a hydraulic jack $(100 \mathrm{kN})$ fastened to a reaction steel frame as Figure 3-9 shows. Each specimen was laid down over the pre-cracking sliding base plate. The crack was formed by splitting the shear plane using two knives (one placed on the base plate and the other on the hydraulic jack) (see Figure 3-8a and Figure 3-9). To avoid rotating the specimen's blocks around the notch, four springs were used during the pre-cracking process. The pre-cracking process finished when the crack formed. In this stage, the final confinement $\left(\sigma_{p}\right)$ and the crack opening $\left(w_{p}\right)$ due to the pre-cracking process were measured by ESG (placed around the steel bars of the external confinement frame) and PTs, respectively. Finally, the measurements obtained with DEMEC and PTs were compared to one another.

\section{iii. Handling}

In this stage, the cracked specimen was lifted up to the vertical position and placed under the second hydraulic jack (see Figure 3-9), where the push-off test was performed. Two 
steel plates were fixed at the top and bottom of the specimen to improve load transmission. When this stage ended, the distances between the DEMEC targets were measured to capture any variation in crack opening and slip. Table 3-6. lists the final $w_{p}$ values of the whole experimental campaign.

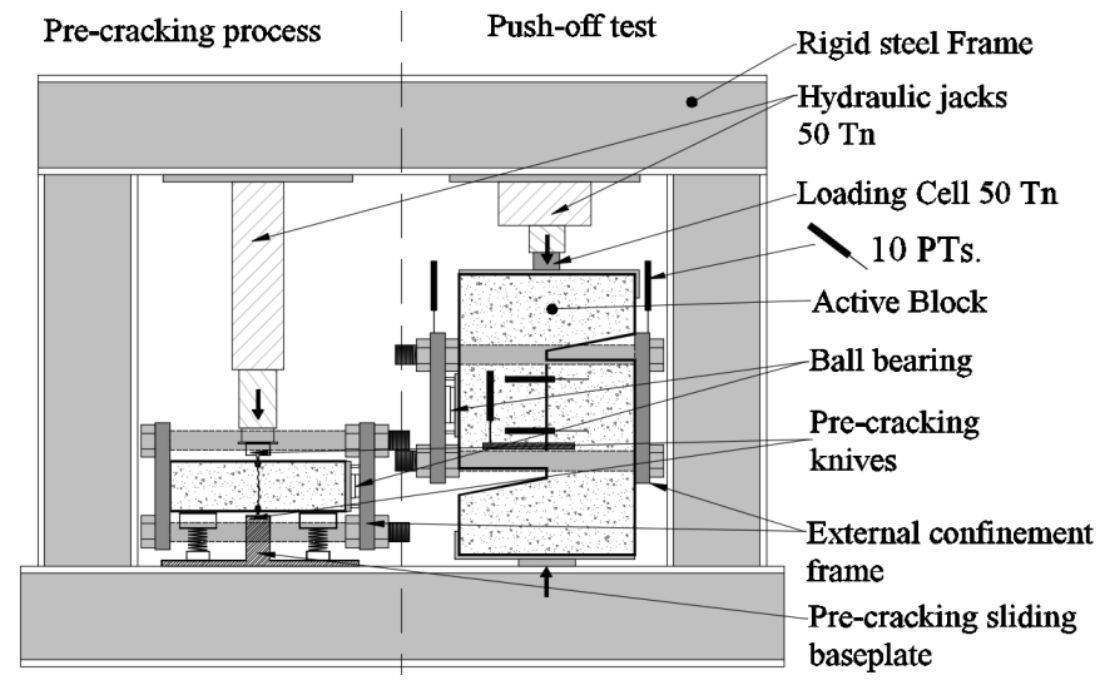

Figure 3-9: Pre-cracking process and push-off direct shear test

\section{iv. Push-off test}

Before the push-off test, an allowed initial gap $(W)$ was established by unscrewing the external $41 \mathrm{~mm}$ nuts as Figure 3-10 shows (it was necessary to turn nuts $360^{\circ}$ to introduce $1 \mathrm{~mm}$ of $W$ ). As $W$ introduced a desired separation between the ball bearing device and steel plate B, the specimen's confinement release $\left(\sigma_{d}\right)$ came into play; therefore, three possible confinement scenarios before the push-off test could occur: totally confined (Eq. 3-4), partially confined (Eq. 3-5) and totally released (Eq. 3-6). It is worth mentioning that Echegaray's methodology only took into account the third confinement scenario as $\sigma_{\text {ini }}$ was very low. By introducing $W$, the initial crack opening ( $\left.w_{0}\right)$ and confinement immediately before the push-off test $\left(\sigma_{0}\right)$ were established.

$$
\begin{array}{ll}
\text { Totally confined: } & W=0 ; \sigma_{0}=\sigma_{i n i}+\sigma_{p} \\
\text { Partially confined: } & W>0 ; \sigma_{0}=\sigma_{i n i}+\sigma_{p}-\sigma_{d} \\
\text { Totally released: } & W>0 ; \sigma_{0}=\sigma_{i n i}+\sigma_{p}-\sigma_{d}=0
\end{array}
$$

As $\sigma_{i n i}$ was set at $0.01 \mathrm{MPa}$ in all the specimens, when the desired $W$ was introduced, $\sigma_{d}$ was greater than the confinement achieved during the pre-cracking process. Thus $\sigma_{0}$ vanished at zero, as seen in Table 3-6. 
Chapter 3. PFRC in small specimens

After setting the initial conditions, load was applied with a servo-hydraulic jack (500 $\mathrm{kN}$ ) at a constant piston displacement rate of $0.015 \mathrm{~mm} / \mathrm{s}$. The applied load was measured by a load cell of $500 \mathrm{kN}$. In this stage, slip displacement $(s)$, crack opening $(w)$, strains of external steel bars, and relative displacements of plates A and B were recorded (see Section 3.2.2.1). The push-off test finished when $s$ reached a displacement of $10 \mathrm{~mm}$.

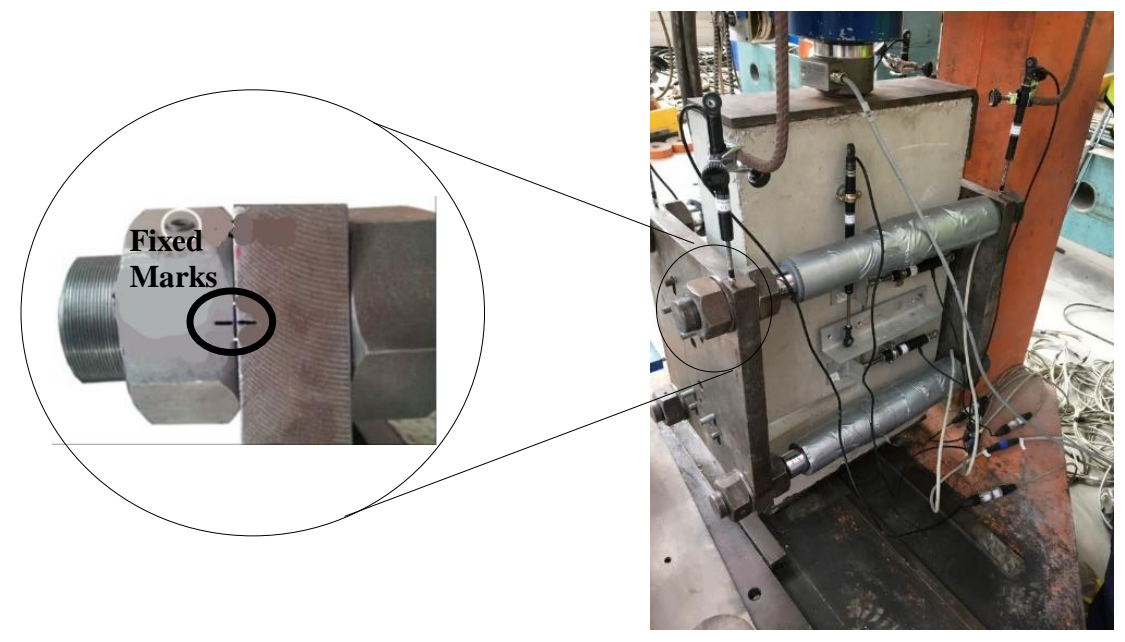

Figure 3-10: The nut setting

Table 3-6: Details of test specimens

\begin{tabular}{|c|c|c|c|c|c|c|c|}
\hline ID & Stirrup & $\begin{array}{c}\mathbf{\sigma}_{\text {ini }} \\
{[\mathbf{M P a}]}\end{array}$ & $\begin{array}{c}\mathbf{w}_{\mathbf{p}} \\
{[\mathbf{m m}]}\end{array}$ & $\begin{array}{c}\mathbf{\sigma}_{\mathbf{p}} \\
{[\mathbf{M P a}]}\end{array}$ & $\begin{array}{c}\mathbf{W} \\
{[\mathbf{m m}]}\end{array}$ & $\begin{array}{c}\mathbf{w}_{\mathbf{0}} \\
{[\mathbf{m m}]}\end{array}$ & $\begin{array}{c}\mathbf{\sigma}_{\mathbf{0}} \\
{[\mathbf{M P a}]}\end{array}$ \\
\hline Z1-PC & - & 0.01 & 0.116 & 0.411 & 1.00 & 1.116 & 0.000 \\
\hline Z2-PC & - & 0.01 & 0.160 & 0.301 & 0.25 & 0.410 & 0.000 \\
\hline Z3-PC & - & 0.01 & 0.227 & 0.234 & 0.50 & 0.727 & 0.000 \\
\hline Z4-PC & - & 0.01 & 0.053 & 0.497 & 0.75 & 0.803 & 0.000 \\
\hline Z6-PC & yes & 0.01 & 0.150 & 0.431 & 0.00 & 0.150 & 0.431 \\
\hline Z7-PC & - & 0.01 & 0.132 & 0.159 & 1.00 & 1.132 & 0.000 \\
\hline Z8-PC & - & 0.01 & 0.343 & 0.361 & 0.50 & 0.843 & 0.000 \\
\hline Z10-SFRC & - & 0.01 & 0.350 & 0.069 & 0.00 & 0.350 & 0.069 \\
\hline Z11-SFRC & - & 0.01 & 0.319 & 0.070 & 1.00 & 1.319 & 0.000 \\
\hline Z12-SFRC & yes & 0.01 & 0.080 & 0.336 & 0.00 & 0.080 & 0.336 \\
\hline Z13-PFRC & - & 0.01 & 0.083 & 0.126 & 0.50 & 0.583 & 0.000 \\
\hline Z14-PFRC & - & 0.01 & 0.117 & 0.195 & 0.75 & 0.867 & 0.000 \\
\hline Z15-PFRC & - & 0.01 & 0.098 & 0.284 & 0.25 & 0.348 & 0.000 \\
\hline
\end{tabular}


Effectiveness of polypropylene fibres as shear reinforcement in structural elements

\begin{tabular}{|l|c|c|c|c|c|c|c|}
\hline \hline \multicolumn{1}{|c|}{$\mathbf{I D}$} & Stirrup & $\begin{array}{c}\boldsymbol{\sigma}_{\text {ini }} \\
{[\mathbf{M P a}]}\end{array}$ & $\begin{array}{c}\mathbf{w}_{\mathbf{p}} \\
{[\mathbf{m m}]}\end{array}$ & $\begin{array}{c}\mathbf{\sigma}_{\mathbf{p}} \\
{[\mathbf{M P a}]}\end{array}$ & $\begin{array}{c}\mathbf{W} \\
{[\mathbf{m m}]}\end{array}$ & $\begin{array}{c}\mathbf{w}_{\mathbf{0}} \\
{[\mathbf{m m}]}\end{array}$ & $\begin{array}{c}\mathbf{\sigma}_{\mathbf{0}} \\
{[\mathbf{M P a}]}\end{array}$ \\
\hline Z16-PFRC & yes & 0.01 & 0.169 & 0.460 & 0.00 & 0.169 & 0.460 \\
\hline Z17-SFRC & - & 0.01 & 0.248 & 0.017 & 0.00 & 0.248 & 0.017 \\
\hline Z19-SFRC & - & 0.01 & 0.103 & 0.131 & 0.00 & 0.103 & 0.131 \\
\hline Z20-SFRC & yes & 0.01 & 0.090 & 0.231 & 0.00 & 0.090 & 0.231 \\
\hline Z21-PFRC & - & 0.01 & 0.181 & 0.325 & 0.00 & 0.181 & 0.325 \\
\hline Z22-PFRC & - & 0.01 & 0.123 & 0.040 & 1.00 & 1.123 & 0.000 \\
\hline Z23-PFRC & - & 0.01 & 0.181 & 0.125 & 0.00 & 0.181 & 0.125 \\
\hline Z24-PFRC & yes & 0.01 & 0.107 & 0.288 & 0.00 & 0.107 & 0.288 \\
\hline
\end{tabular}

\subsubsection{Experimental results and discussion}

The results obtained in the four previously described stages were processed to obtain the shear stress $(\tau)$, normal stress $(\sigma)$, crack opening $(w)$ and crack slip $(s)$ of each specimen.

Under ideal conditions, the external confinement frame should only confer specimens horizontal stiffness. However under real laboratory conditions, the relative vertical displacement $(\Delta)$ between steel plate A and steel plate B was detected. This vertical displacement meant that part of the shear transmitted to specimens was absorbed by the external steel bars. In this context, the $\tau$ that acted on the shear plane at instant ' $i$ ', was determined by dividing the applied load $(P)$ by the shear plane section $\left(h_{s p}=260 \mathrm{~mm}\right.$ and $\left.b_{s p}=100 \mathrm{~mm}\right)$ and subtracting the shear absorbed by the external steel bars $\left(\tau_{b}\right)$ as indicated in (Eq. 3-7). $\tau_{b}$ can be determined using (Eq.3-8), where $E, I$ and $L$ are the modulus of elasticity, the moment of inertia and the length of the four external steel bars, respectively.

The $\sigma$ at instant ' $i$ ' was determined as the sum of the forces on each external steel bar $\left(F_{b}\right)$ divided by the shear plane area as indicated in (Eq.3-9). In this equation, the three possible initial confinement scenarios prior to the push-off test should be taken into account: see (Eq. 3-4) to (Eq. 3-6).

Finally, the average crack opening and average crack slip were determined using their corresponding PTs as indicated in (Eq.3-10) and (Eq.3-11).

$$
\begin{gathered}
\tau_{i}=\frac{P_{i}}{h_{s p} b_{s p}}-\tau_{b, i} \\
\tau_{b, i}=\frac{12 E I}{h_{s p} b_{s p} L^{3}} \Delta
\end{gathered}
$$




$$
\begin{aligned}
\sigma_{i} & =\frac{\sum_{j=1}^{4} F_{b, j, i}}{h_{s p} b_{s p}} \\
w_{i} & =w_{0}+\frac{H 1+H 2+H 3+H 4}{4} \\
s_{i} & =\frac{V 1+V 2}{2}
\end{aligned}
$$

The shear behaviour of the three concrete types (PC, PFRC, SFRC) was analysed in the following subsections.

\subsubsection{Plain concrete results}

Table 3-7 summarises the test results of all the specimens arranged from the lowest initial crack opening to the widest. The presented results corresponded to those obtained when the crack of all the specimens reached $2.0 \mathrm{~mm}$ and $5.0 \mathrm{~mm}$ of slip. In addition, Figure 3-11 presents all the results of the PC specimens arranged in four figures, including crack kinematics (Figure 3-11a), crack opening vs. shear stress (Figure 3-11b), crack slip vs. shear stress (Figure 3-11c), and crack opening vs. normal stress (Figure 3-11d).

As seen in Table 3-7 and Figure 3-11, the highest values of shear and normal stresses were obtained when initial crack openings $w_{0}$ were lower. On the one hand, the specimen that reached the highest shear and normal stresses corresponded to that containing the 8$\mathrm{mm}$ stirrup crossing the shear plane (Z6-PC) with $\mathrm{w}_{0}=0.15 \mathrm{~mm}$. On the other hand, the specimen that had the lowest shear and normal stresses was Z1-PC with $\mathrm{w}_{0}=1.116 \mathrm{~mm}$.

As Figure 3-11b and Figure 3-11c show, the shear stress response in all the specimens was characterized by presenting more shear stiffness at the beginning of the test, especially in those elements with a lower $w_{0}$. However, after a 1-mm crack opening approximately, shear stiffness decreased, but the inclination among all the specimens remained constant, except for Z6-PC, which included the stirrup. In fact when comparing the shear transmitted by the specimens w/o stirrups, the lowest (Z2-PC) and the highest initial crack opening (Z1-PC), specimen Z2-PC could transmit a shear stress of $4.29 \mathrm{MPa}$, while specimen Z1-PC only transmitted $0.88 \mathrm{MPa}$. This represents a reduction of $80 \%$ in the total shear transferred in the crack due to the increment in $w_{0}$. This difference was reduced with increasing slip displacements. Thus for a slip displacement of $5 \mathrm{~mm}$, the shear transmitted by Z2-PC and Z1-PC was 5.68 and $2.91 \mathrm{MPa}$, which represents only a $50 \%$ reduction.

In PC, the shear transfer mechanisms that acted on the crack are the aggregate interlock and the effect of confinement combined with the macroroughness of the shear plane. Hence in the specimens with a low $w_{o}$, the aggregate interlock seemed to predominate upon small slips. When slip displacement increased, the shear transmitted by the aggregate interlock vanished, while the macroroughness influenced by confinement increased. This behaviour was clearly seen in shear stiffness (see in Figure 3-11b), where at an 
Effectiveness of polypropylene fibres as shear reinforcement in structural elements

approximately 1-mm crack opening, the stiffness of all the specimens w/o stirrups adopted a similar inclination, which meant that the main mechanism transferring shear stresses was macro-roughness.

When the crack kinematics of all the specimens w/o stirrups were compared to one another, all the specimens, except Z7-PC, followed a similar trend (see Figure 3-11a). Initially, crack seemed to allow a larger crack opening than slip displacement. However after the 4-mm slip displacement, the crack results stabilised and it continued to grow with a similar stiffness among specimens. This behaviour was probably due to the low initial confinement $\left(\sigma_{0}\right)$ introduced previously into the push-off test in experimental programme one.

Table 3-7: Plain concrete results

\begin{tabular}{|c|c|c|c|c|c|c|c|}
\hline \multirow[b]{2}{*}{ Specimen } & \multirow[b]{2}{*}{$\begin{array}{c}w_{0} \\
{[\mathbf{m m}]}\end{array}$} & \multicolumn{3}{|c|}{ Slip = 1 mm } & \multicolumn{3}{|c|}{ Slip $=5 \mathrm{~mm}$} \\
\hline & & $\begin{array}{c}\tau_{1 m m} \\
{[\mathrm{MPa}]}\end{array}$ & $\begin{array}{c}w_{1 m m} \\
{[\mathbf{m m}]}\end{array}$ & $\begin{array}{c}\sigma_{1 \mathrm{~mm}} \\
{[\mathrm{MPa}]}\end{array}$ & $\begin{array}{c}\tau_{5 \mathrm{~mm}} \\
{[\mathrm{MPa}]}\end{array}$ & $\begin{array}{c}w_{5 \mathrm{~mm}} \\
{[\mathrm{~mm}]}\end{array}$ & $\begin{array}{c}\sigma_{5 \mathrm{~mm}} \\
{[\mathrm{MPa}]}\end{array}$ \\
\hline Z6-PC & 0.15 & 5.98 & 0.47 & 0.89 & 6.13 & 1.24 & 2.91 \\
\hline $\mathrm{Z} 2-\mathrm{PC}$ & 0.41 & 4.29 & 0.77 & 0.74 & 5.68 & 2.15 & 5.13 \\
\hline Z3-PC & 0.73 & 2.36 & 1.22 & 0.66 & 4.57 & 2.65 & 3.09 \\
\hline Z4-PC & 0.80 & 1.70 & 1.71 & 0.72 & 3.94 & 3.07 & 3.81 \\
\hline Z8-PC & 0.84 & 1.43 & 1.38 & 0.71 & 3.50 & 2.82 & 3.33 \\
\hline Z1-PC & 1.12 & 0.88 & 1.68 & 0.37 & 2.91 & 2.95 & 1.73 \\
\hline Z7-PC & 1.13 & 1.90 & 1.83 & 1.06 & 5.36 & 3.69 & 4.63 \\
\hline
\end{tabular}

On the contrary, normal stress stiffness was low for low slip displacements. However as the crack opening grew, normal stiffness increased in all specimens (see Figure 3-11b and Table 3-7). When comparing the normal stresses during tests between specimens Z2-PC and Z1-PC (specimens with the highest and lowest $w_{0}$ ), their evolution results were quite different. In the first case, normal stresses resulted in a linear response, while a parabolic line was obtained in the second case. This difference in behaviour was due to confinement $\sigma_{0}$ introduced before the push-off test. In specimens Z2-PC, after the set up $W$ equalled $0.25 \mathrm{~mm}$, and specimens were still confined, which allowed the transmission of normal stresses from the beginning of the push-off test with constant stiffness. In the Z1-PC specimens, as $W$ was $1 \mathrm{~mm}$, the confinement immediately before the push-off test was insufficient to transmit normal stresses; i.e. the crack needed to accomplish a wider opening to be sufficiently confined to start transferring normal stresses. 


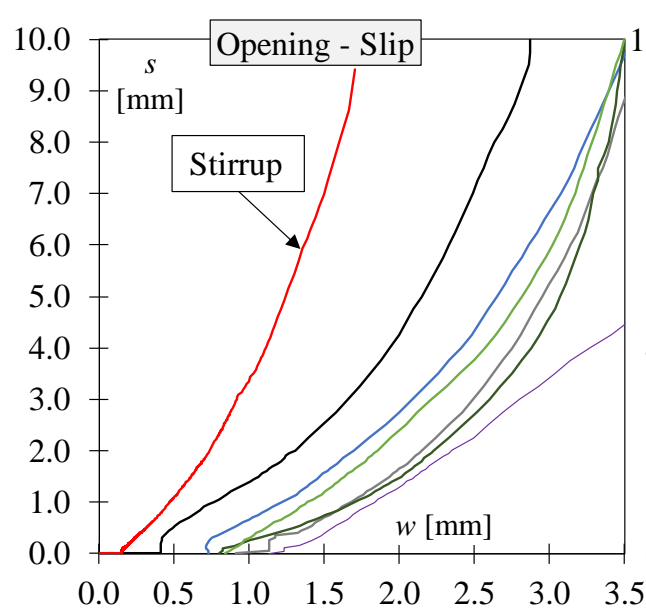

(a)

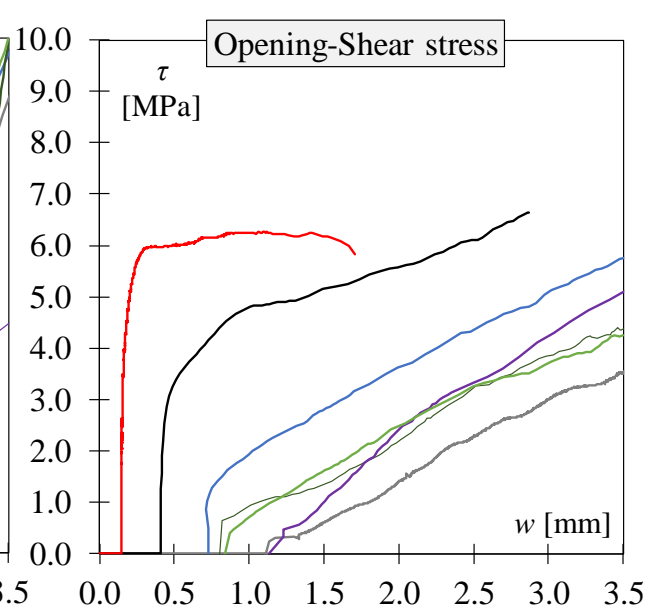

(b)

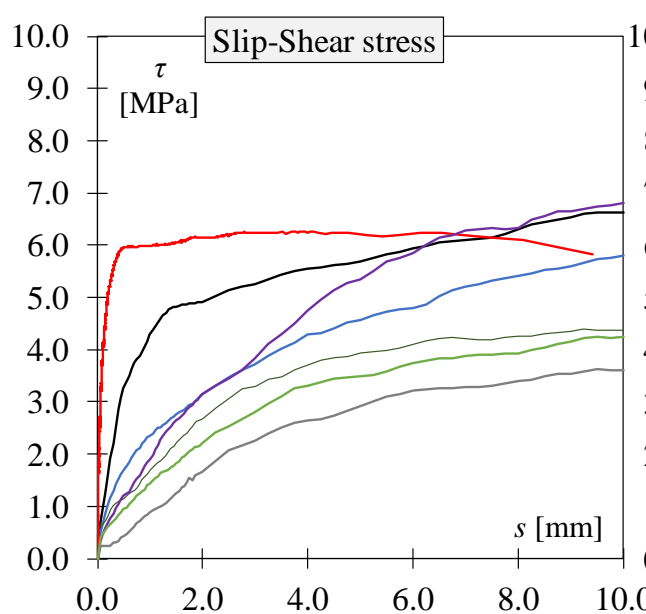

(c)

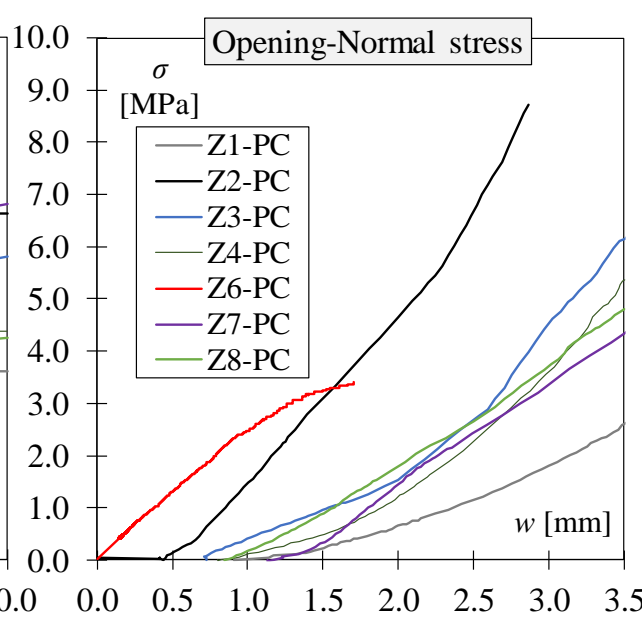

(d)

Figure 3-11: PC results: crack opening vs. crack slip curves (a), shear stress vs. crack opening curves (b), shear stress vs. crack slip curves (c) and normal stress vs. crack opening curves (d).

To better compare the $\tau, \sigma, w$ and $s$ obtained in all the tested specimens, the results are represented in Figure 3-12 by trend lines according to the constant crack opening values. To track trend lines, the points for given crack openings $(0.5,1.0,1.5,2.0$ and $2.5 \mathrm{~mm})$ were identified from all seven PC specimen test results. Having identified the point, their corresponding $\tau, \sigma$ and $s$ values were positioned on a coordinate plane, as Figure 3-12 indicates. When all the points were placed on the plane, a polynomial trend line was depicted and showed the average trend of the points according to constant crack opening 
Effectiveness of polypropylene fibres as shear reinforcement in structural elements

$w$. We outline that the graphs in Figure 3-12 are arranged similarly to the Walraven experimental tests on the aggregate interlock [92].

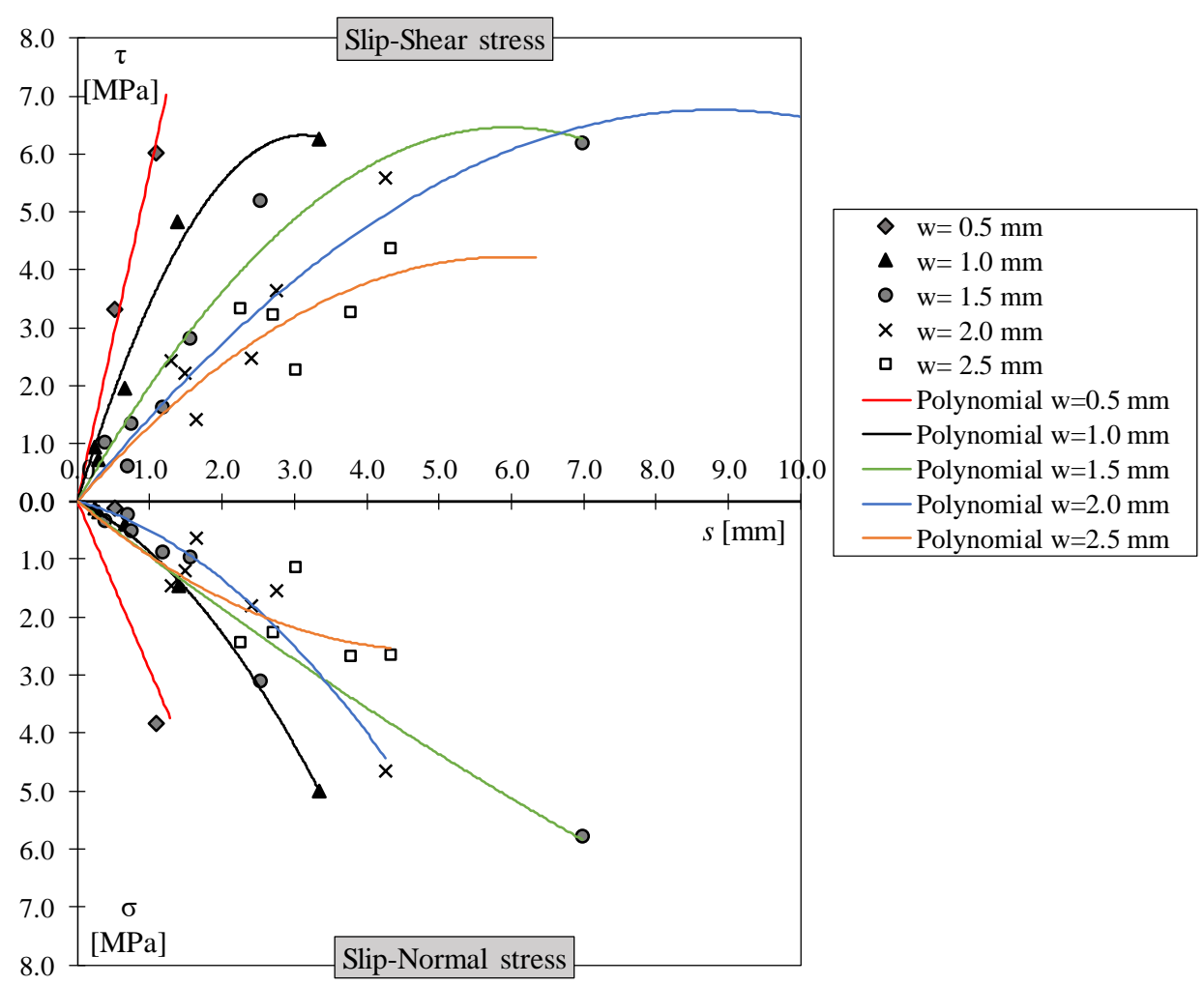

Figure 3-12: Shear interaction diagram of PC

As Figure 3-12 represents the $\tau$ and $\sigma$ stresses transferred by the aggregate interlock mechanism, the contribution to $\tau$ and $\sigma$ of the steel rebars crossing the shear plane in specimen Z6-PC was determined analytically to be subtracted from the experimental result. For this purpose, the model proposed by Millard and Johnson [198] was employed to quantify $\tau$ (from (Eq. 3-12) to (Eq. 3-15)).

$$
\begin{aligned}
& F_{d}=F_{d u}\left[1-\exp \left(\frac{-k_{i} \Delta}{F_{d u}}\right)\right] \\
& F_{d u}=1.30 D_{b}^{2} \sqrt{f^{\prime}{ }_{c} f_{y}\left(1-A^{2}\right)} \\
& k_{i}=0.166 k_{f}^{0.75} D_{b}^{1.75} E_{s}^{0.25}
\end{aligned}
$$


$k_{f}=127 \beta \sqrt{f^{\prime}}{ }_{c}\left(\frac{1}{D_{b}}\right)^{2 / 3}$

(Eq. 3-15)

where $\beta$ is a coefficient that ranges from 0.6 for the bar spacing of $25.4 \mathrm{~mm}$ to 1 for the bar spacing larger than 25.4. As in the present study the two bars of $\mathrm{D}_{\mathrm{b}}=8 \mathrm{~mm}$ (that constituted stirrups) were separated from one another by $80 \mathrm{~mm}$, the coefficient was taken as 1. $E_{s}$ is the Young modulus of steel (in this case, it was assumed to be 200000 $\mathrm{MPa}$ ), $f^{\prime}{ }_{c}$ is concrete compression strength (see Table 3-4) and $f_{y}$ is the yielding stress of the steel reinforcement (see Table 3-5). A is the ratio of the applied axial force to the yielding axial force of the bar. In the present case, as no axial forces were introduced into the 8-mm stirrup, $A$ is considered 0 (see Figure 3-13a). Finally, $\Delta$ represents the slip of crack faces, which were obtained in the push-off test stage.

Regarding the contribution of stirrup to $\sigma$, the use of the elasticity equation (see (Eq. 3-16)) was considered, where: $\varepsilon$ is the strain of the bar determined using the crack opening (by assuming that no debonding of the bar from the concrete matrix occurred), $A_{w}$ is the cross-section area of the stirrup (two bars of $8 \mathrm{~mm}$ ) and $h_{s p} b_{s p}$ is the shear plane area $(100 \times 260 \mathrm{~mm})$. Thus the stirrup normal stress can be obtained as follows:

$$
\sigma_{\text {stirrup }}=\frac{E_{s} * \varepsilon * A_{w}}{h_{s p} b_{s p}}
$$

Figure 3-13 represents the contribution of stirrups to shear $(\tau)$ and normal stress $(\sigma)$. As we can see, the contribution of stirrups to shear (based on the Millard and Johnson [198] model) was negligible compared to the aggregate interlock (see Figure 3-13a). This behaviour was also observed by Sagaseta and Vollum [199] after testing push-off specimens without confinement. In addition, the contribution of stirrup to normal stress was not negligible, as Figure 3-13b shows. 
Effectiveness of polypropylene fibres as shear reinforcement in structural elements

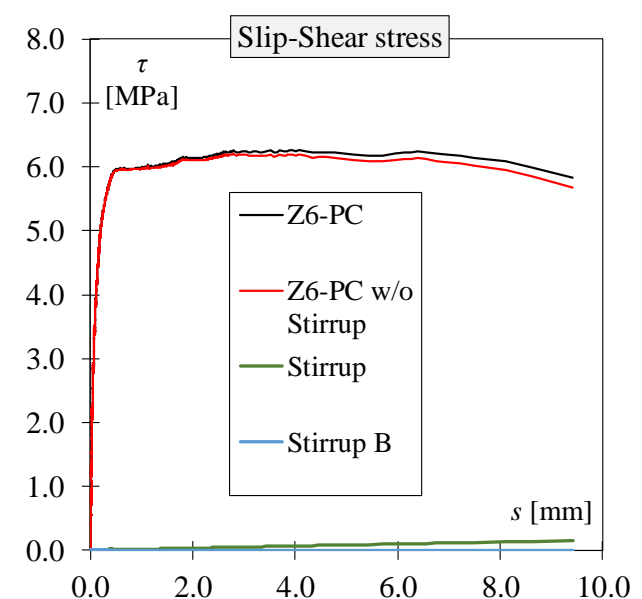

(a)

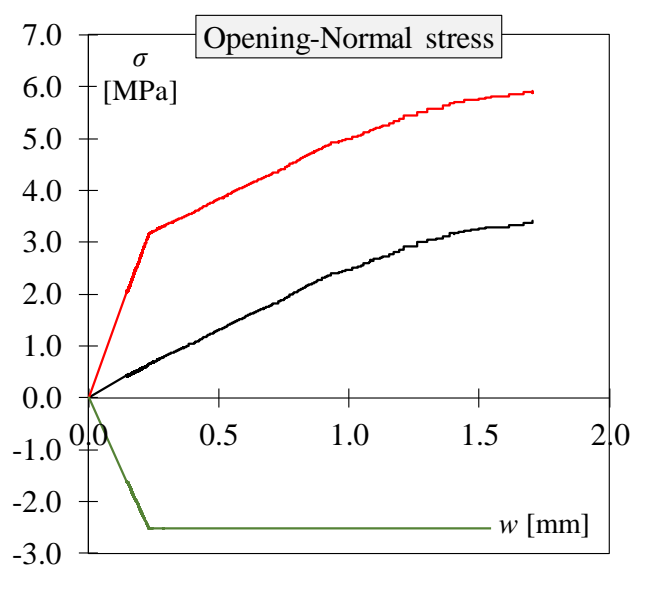

(b)

Figure 3-13: Estimation of stirrup contribution to shear (a) and normal stress (b)

Figure 3-12 clearly shows that shear and normal stresses were greater with less slip, as well as crack opening, were obtained. Although the crack achieved wide openings, considerable shear and normal stresses could be transferred due to the aggregate interlock. It is worth mentioning that trend lines represented an average behaviour of shear and normal stresses. Despite not all the dots accurately fitting trend lines, better fit occurred upon small crack openings. This behaviour was probably due to the fact that in specimens with large crack openings, the initial confinement immediately before the push-off test was not very effective as in the narrower ones. Moreover, we should remember that with large crack openings (over $1 \mathrm{~mm}$ ), the main mechanism that transmitted shear was the macroroughness influenced by confinement. Finally, it is highlighted that large crack openings and slip were analysed to compare the PC results with the SFRC and PFRC results.

In order to validate the results obtained for all the specimens, a comparison was made to the aggregate interlock models available in the literature, which is presented in Figure 3-14. The comparison was made using the shear interaction diagram (Figure 3-12) at a crack opening that equalled 0.5, 1.0, 1.5 and $2.5 \mathrm{~mm}$. The models we used were: Bazant and Gambarova [89] (Eq. 3-17) and (Eq. 3-18); Gambarova and Karakoç [90] (Eq. 3-19) and (Eq. 3-20), simplification of the two-phase model by Walraven [92] (Eq. 3-21) and (Eq. 3-22), and the Contact Density Model by Li and Maekawa [91] (Eq. 3-23) and (Eq. 3-24).

$$
\sigma=\frac{-0.000534}{w}(145|\tau|)^{1.3\left(1-\frac{0.231}{1+0.185 w+5.63 w^{2}}\right)}
$$


Chapter 3. PFRC in small specimens

$$
\begin{aligned}
& \tau=\frac{\left.0.195 f_{c} 0.01 D_{\max }^{2} \frac{2.45}{0.01 D_{\max }^{2}+w^{2}} \frac{0.195 f_{c}}{1+2.44\left(1-\frac{4}{0.195 f_{c}}\right) \frac{s^{4}}{w}}\right)\left.\frac{s}{w}\right|^{3}}{w} \\
& \sigma=-0.62 \sqrt{w} \frac{\frac{s}{w}}{\left(1+\left(\frac{s}{w}\right)^{2}\right)^{.25}} \tau_{a} \\
& \tau=.2 f_{c}\left(1-\sqrt{\frac{2 w}{D_{\max }}}\right) \frac{\frac{2.45}{2 f_{c}}+2.44\left(1-\frac{4}{.2 f_{c}}\right)\left|\frac{s}{w}\right|^{3}}{1+2.44\left(1-\frac{4}{.2 f_{c}}\right)\left(\frac{s}{w}\right)^{4}} \frac{s}{w} \\
& \tau=-\left(-\frac{f_{c, c}}{20}+1.35 w^{-.63}+\left(.191 w^{-.552}-.15\right) f_{c, c}\right. \\
& \tau=-\left(-\frac{f_{c, c}}{30}+1.8 w^{-.8}+\left(.234 w^{-.707}-.20\right) f_{c, c}\right. \\
& \tau=18 f_{c}^{1 / 3}\left[\frac{\pi}{2}-\tan ^{-1} \frac{w}{s}-\frac{w s}{w^{2}+s^{2}}\right] \\
&
\end{aligned}
$$

The followings parameters were considered to apply the models:

- $D_{\max }$ equalled $16 \mathrm{~mm}$

- $f_{c}$ according to Table 3-4

- $f_{c c}$ equalled to $f_{c} / 0.83$ in the Walraven model

- $\quad s$ and $w$ according to Figure 3-11a

The first conclusion is observed in Figure 3-14, with large differences in the predictions among all the aggregate interlock models. In addition, by analysing the increment in crack opening, the models' prediction differences were even larger to one another. In fact the prediction made by using the simplified Walraven model did not apparently work correctly with crack openings over $1 \mathrm{~mm}$. This was because these expressions were developed based on the Walraven test results using mathematical adjustment for certain slips and crack openings. Nevertheless, if the shear stress results (dots and trend lines) were compared to the models, the results came quite close to prediction, especially with the Gambarova and Karakoç model. Moreover, when comparing the normal stress results, better predictions were obtained for the $0.5 \mathrm{~mm}$ and $1.0 \mathrm{~mm}$ crack openings than for the $1.5 \mathrm{~mm}$ and 2.5 -mm crack opening. This test result provided slightly less confinement than the considered models. 
Effectiveness of polypropylene fibres as shear reinforcement in structural elements
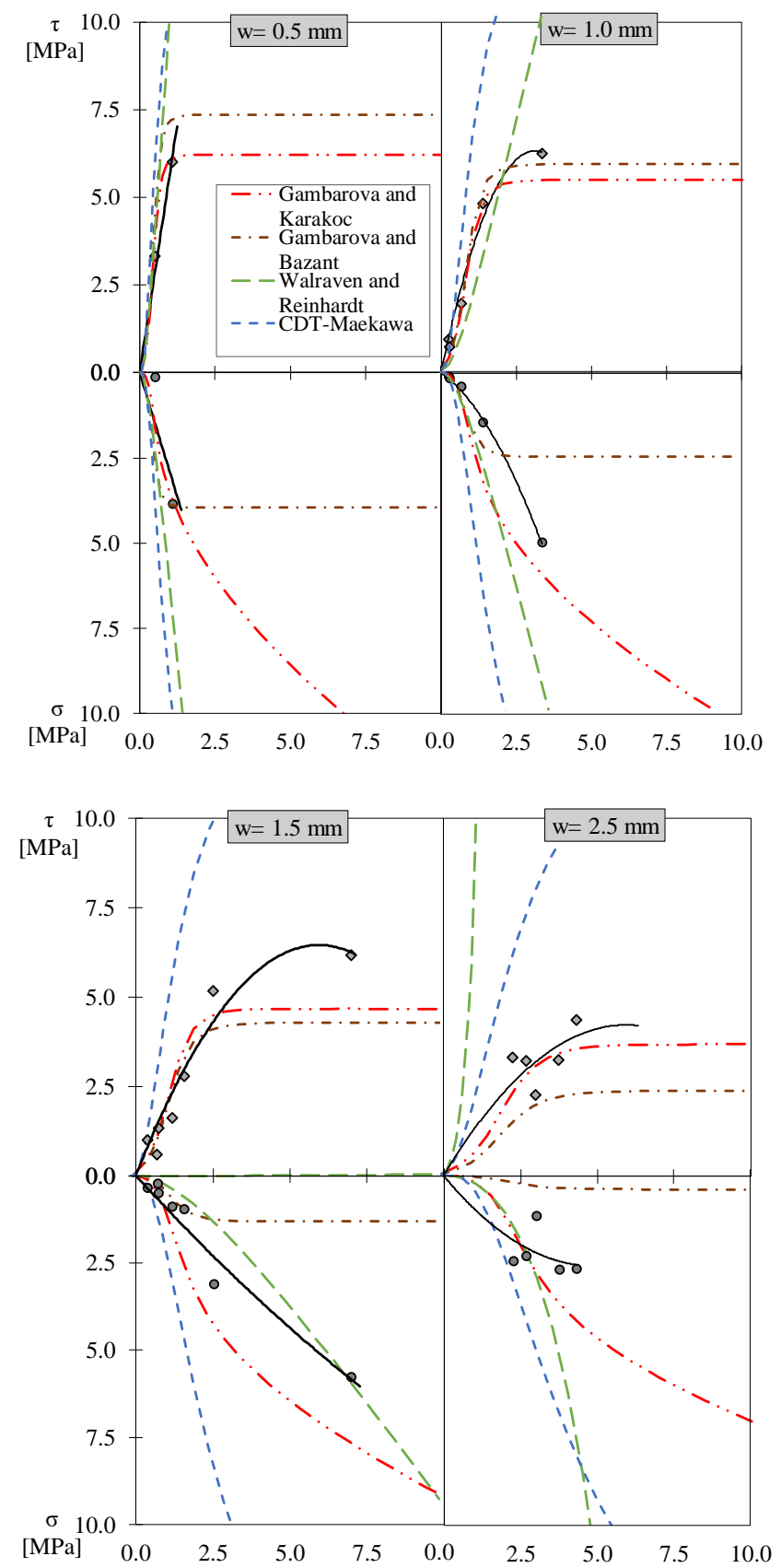

Figure 3-14: Comparison of the plain concrete results to the aggregate interlock models 


\subsubsection{PFRC and SFRC results}

Similarly to PC, Figure 3-15 and Figure 3-16 present the push-off results of the PFRC and SFRC specimens, respectively. Each figure contains crack path (Figure 3-15a and Figure 3-16a), crack opening vs. shear stress (Figure 3-15b and Figure 3-16b), crack slip vs. shear stress (Figure 3-15c and Figure 3-16c) and crack opening vs. normal stress (Figure 3-15d and Figure 3-16d).

As in $\mathrm{PC}$, the specimens with the highest shear and normal stresses corresponded to those containing a stirrup of $8 \mathrm{~mm}$ crossing the shear plane (Z16-PFRC, Z24-PFRC, Z12SFRC, Z20-SFRC). Moreover, the specimens with the lower shear and normal stresses corresponded to those with a higher initial crack opening, which in PFRC was Z22 and was Z11 in SFRC. With PFRC, despite the specimen (Z21-PFRC) not having a large initial crack opening, the specimen presented considerably less shear stresses than those with larger initial crack openings. This behaviour could be due probably to inadequate confinement before the push-off test. Nevertheless, the remaining PFRC and SFRC specimens displayed the expected behaviour. 
Effectiveness of polypropylene fibres as shear reinforcement in structural elements

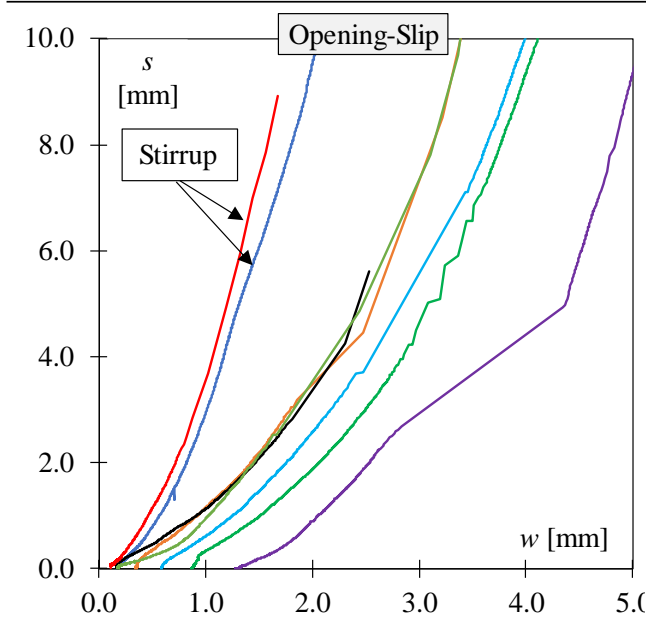

(a)

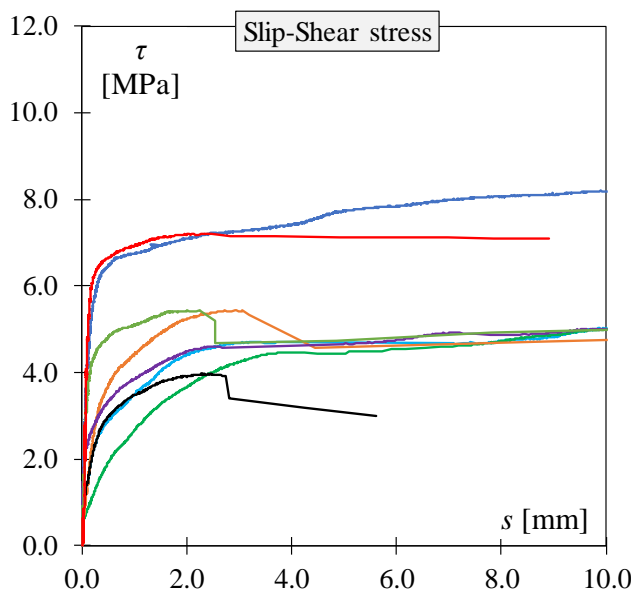

(c)

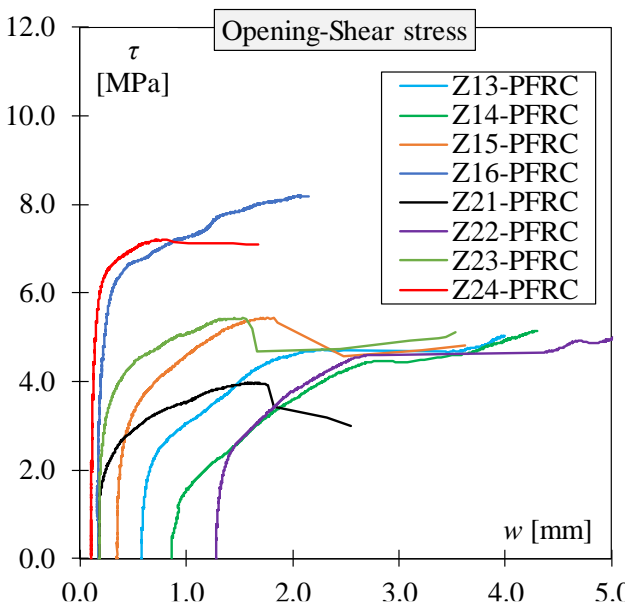

(b)

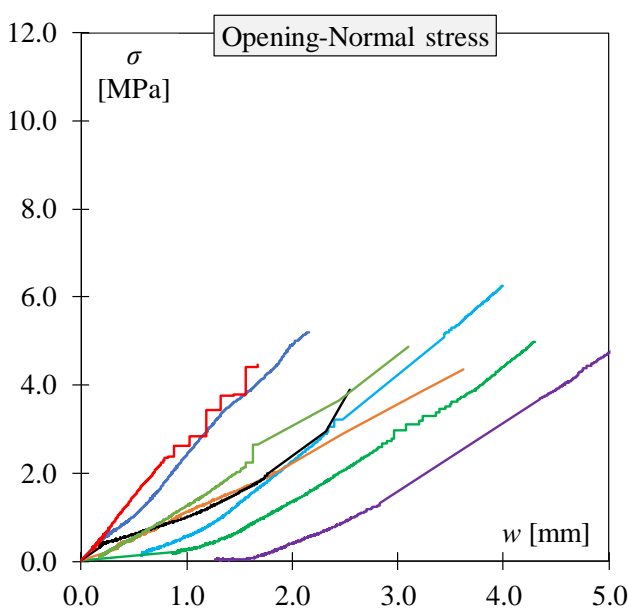

(d)

Figure 3-15: PFRC results: crack opening vs. crack slip curves (a), shear stress vs. crack opening curves (b), shear stress vs. crack slip curves (c) and normal stress vs. crack opening curves (d). 
Chapter 3. PFRC in small specimens
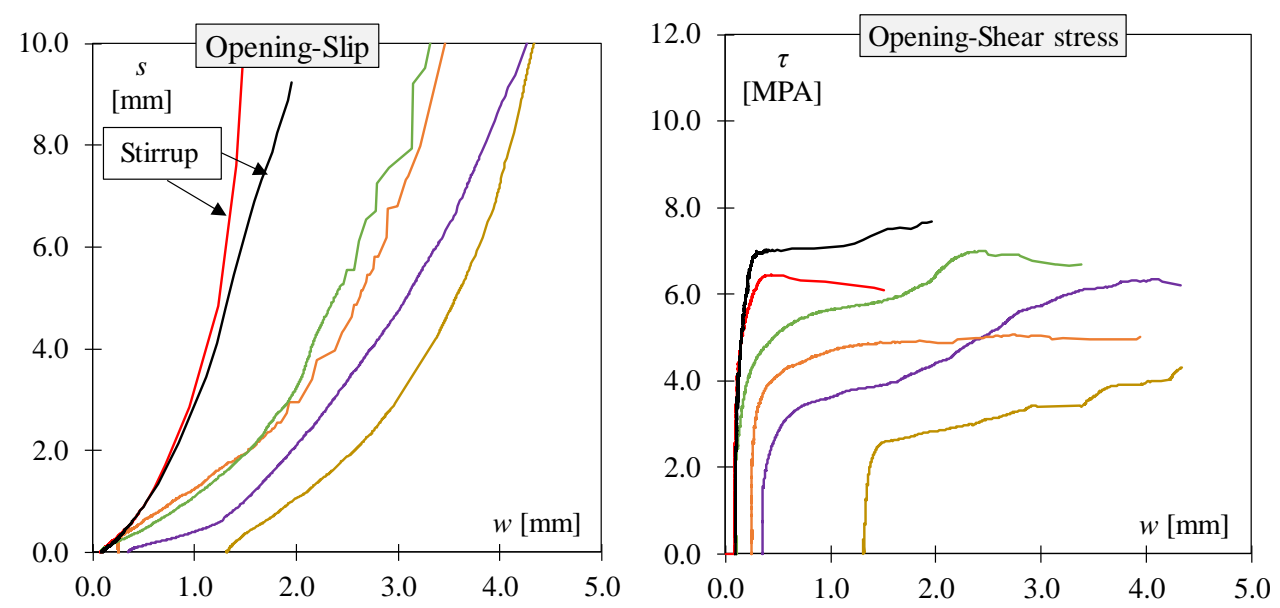

(a)

(b)

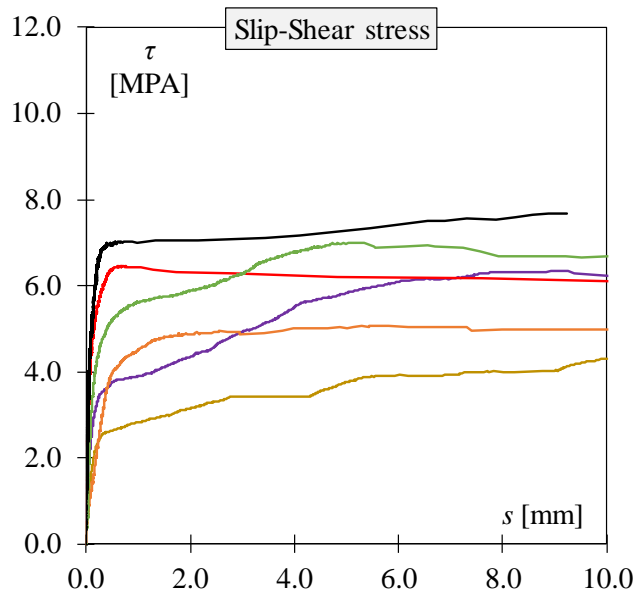

(c)

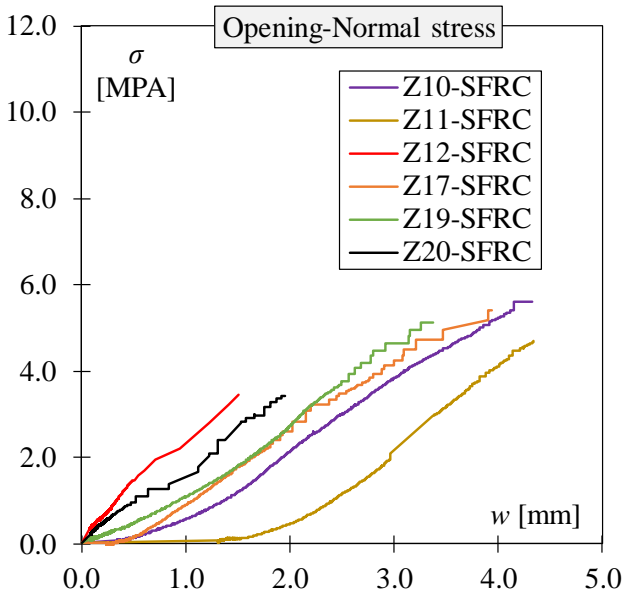

(d)

Figure 3-16: SFRC results: crack opening vs. crack slip curves (a), shear stress vs. crack opening curves (b), shear stress vs. crack slip curves (c) and normal stress vs. crack opening curves (d).

Table 3-8 and Table 3-9 present the shear stress, crack opening and normal stress of the PFRC and SFRC specimens. As we can see, with the increment in the initial crack opening, less shear and normal stresses were generally transferred in the crack. However, this trend was not observed for all the specimens. For example, specimens Z1- PFRC and Z22-PFRC had an initial crack opening, but similar stresses at $1.0 \mathrm{~mm}$ and $5.0 \mathrm{~mm}$ of slip displacement. The latter also occurred with specimens Z11-SFRC and Z10-SFRC. The explanation for this atypical trend might be related to the variability in the number 
Effectiveness of polypropylene fibres as shear reinforcement in structural elements

of fibres crossing the crack. In the fibre-reinforced cracks, the resistant mechanisms acting on the crack were the aggregate interlock, the effect of confinement combined with the macroroughness of the shear plane and fibres bridging crack faces. Hence the variability in the number of fibres directly influenced the shear transferred by fibres. It should be remembered that the coefficient of variation in the residual flexural strength of PFRC and SFRC went from $17 \%$ to $18 \%$ and from $21 \%$ to $30 \%$, respectively. This means that the contribution of fibres to transfer shear and normal stresses could have varied by approximately up to $18 \%$ in PFRC and $30 \%$ in SFRC.

Table 3-8: PFRC test results

\begin{tabular}{|l|c|c|c|c|c|c|c|}
\hline Specimen & $\begin{array}{c}\text { wo } \\
{[\mathbf{m m}]}\end{array}$ & $\begin{array}{c}\boldsymbol{\tau}_{\mathbf{1 m m}} \\
{[\mathbf{M P a}]}\end{array}$ & $\begin{array}{c}\mathbf{w}_{\mathbf{1 m m}} \\
{[\mathbf{m m}]}\end{array}$ & $\begin{array}{c}\boldsymbol{\sigma}_{\mathbf{1 m m}} \\
{[\mathbf{M P a}]}\end{array}$ & $\begin{array}{c}\boldsymbol{\tau}_{\mathbf{5 m m}} \\
{[\mathbf{M P a}]}\end{array}$ & $\begin{array}{c}\mathbf{w}_{\mathbf{5 m m}} \\
{[\mathbf{m m}]}\end{array}$ & $\begin{array}{c}\boldsymbol{\sigma}_{5 \mathbf{m m}} \\
{[\mathbf{M P a}]}\end{array}$ \\
\hline Z24-PFRC & 0.11 & 6.93 & 0.46 & 1.35 & 7.14 & 1.03 & 2.84 \\
\hline Z16-PFRC & 0.17 & 6.74 & 0.57 & 1.17 & 7.74 & 1.31 & 3.30 \\
\hline Z21-PFRC & 0.18 & 3.48 & 0.91 & 0.93 & 3.41 & 1.81 & 2.09 \\
\hline Z23-PFRC & 0.18 & 5.10 & 1.02 & 1.28 & 4.74 & 2.44 & 3.66 \\
\hline Z15-PFRC & 0.35 & 4.42 & 0.92 & 1.01 & 4.58 & 2.48 & 2.89 \\
\hline Z13-PFRC & 0.58 & 3.48 & 1.25 & 0.87 & 4.69 & 2.48 & 3.22 \\
\hline Z14-PFRC & 0.87 & 2.66 & 1.51 & 0.66 & 4.42 & 2.97 & 2.97 \\
\hline Z22-PFRC & 1.12 & 3.85 & 2.05 & 0.46 & 4.66 & 4.35 & 3.71 \\
\hline
\end{tabular}

Table 3-9: SFRC test results

\begin{tabular}{|l|c|c|c|c|c|c|c|}
\hline & & \multicolumn{3}{c}{ Slip = 1mm } & \multicolumn{3}{c|}{ Slip = 5mm } \\
\hline Specimen & $\begin{array}{c}\mathbf{w}_{\mathbf{0}} \\
{[\mathbf{m m}]}\end{array}$ & $\begin{array}{c}\boldsymbol{\tau}_{\mathbf{1 m m}} \\
{[\mathbf{M P a}]}\end{array}$ & $\begin{array}{c}\mathbf{w}_{\mathbf{1} m m} \\
{[\mathbf{m m}]}\end{array}$ & $\begin{array}{c}\boldsymbol{\sigma}_{\mathbf{1 m m}} \\
{[\mathbf{M P a}]}\end{array}$ & $\begin{array}{c}\boldsymbol{\tau}_{\mathbf{5 m m}} \\
{[\mathbf{M P a}]}\end{array}$ & $\begin{array}{c}\mathbf{w}_{\mathbf{5 m m}} \\
{[\mathbf{m m}]}\end{array}$ & $\begin{array}{c}\boldsymbol{\sigma}_{5 \mathbf{m m}} \\
{[\mathbf{M P a}]}\end{array}$ \\
\hline Z12-SFRC & 0.08 & 6.43 & 0.51 & 1.47 & 6.20 & 1.23 & 2.81 \\
\hline Z20-SFRC & 0.09 & 6.99 & 0.52 & 1.09 & 7.16 & 1.22 & 2.08 \\
\hline Z19-SFRC & 0.10 & 5.61 & 0.94 & 1.02 & 6.97 & 2.38 & 3.51 \\
\hline Z17-SFRC & 0.25 & 4.50 & 0.79 & 0.55 & 5.04 & 2.59 & 3.60 \\
\hline Z10-SFRC & 0.35 & 3.89 & 1.48 & 1.18 & 5.82 & 3.08 & 3.95 \\
\hline Z11-SFRC & 1.32 & 2.82 & 1.95 & 0.42 & 3.75 & 3.56 & 3.30 \\
\hline
\end{tabular}


Chapter 3. PFRC in small specimens

Moreover, Figure 3-15b and Figure 3-16b reveal that all the specimens presented similar shear trend responses, characterised by a major transmission of shear stiffness at the beginning of the test, even for those specimens with large initial crack openings ( $\left.w_{0}\right)(\mathrm{Z} 22-$ PFRC and Z11-SFRC). This behaviour differed considerably from the result of the PC specimens, where those with large $w_{0}$ presented less shear stiffness, even with an incremented crack opening. This difference was due to the ability of polypropylene and steel fibres to bridge the crack and to thus transmit shear and normal stresses.

Unlike shear stress, normal stress presented low slope at the start of the push-off test; however when crack opening grew, an increase in normal stiffness took place in all the specimens (see Figure 3-15d and Figure 3-16d). Similarly to the PC results, two types of evolution in the transmitted normal stresses occurred: a linear trend and a parabolic trend corresponding to Z14 and Z22 (lowest and highest $w_{0}$ ) in PFRC and Z11 and Z19 (lowest and highest $w_{0}$ ) in SFRC. These behaviours, as stated in the PC results, resulted from the $\mathrm{W}$ and $\sigma_{0}$ set up in the specimens.

To better compare $\tau, \sigma, w$ and $s$, the obtained results are represented in Figure 3-17 by the trend lines according to similar crack openings to those presented for the PC results. Figure 3-17a displays the polynomial trend lines of PFRC, while Figure 3-17b depicts SFRC. As seen, both fibre-reinforced concrete types clearly showed that shear and normal stresses were greater with less slip, and obtained a larger crack opening. In fact although cracks presented wider openings, cracks could transfer significant shear and normal stresses due to the combined effect of the aggregate interlock and fibre mechanisms. We underline that the polynomial trend lines represented average behaviour for shear and normal stresses. 
Effectiveness of polypropylene fibres as shear reinforcement in structural elements

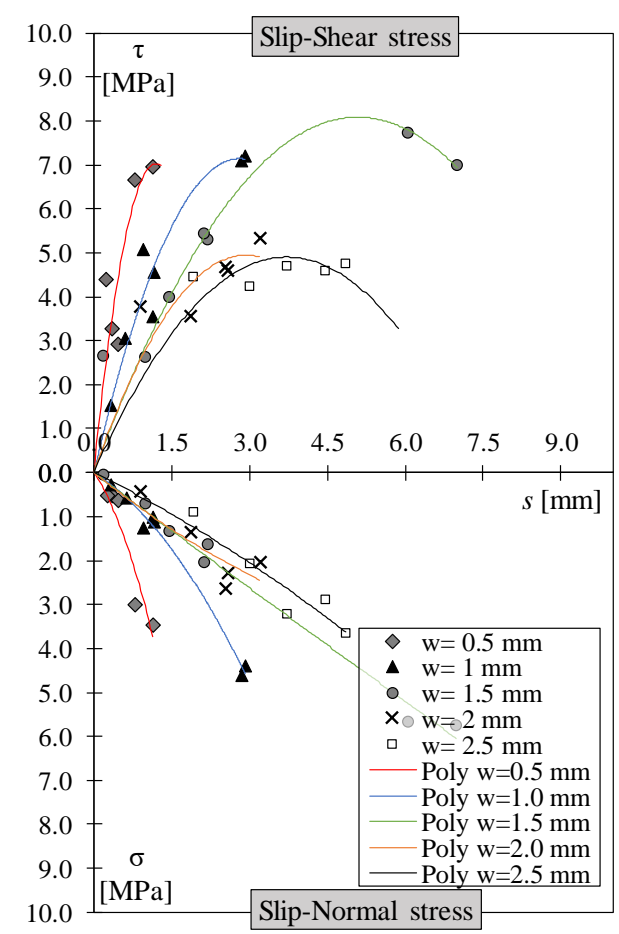

(a)

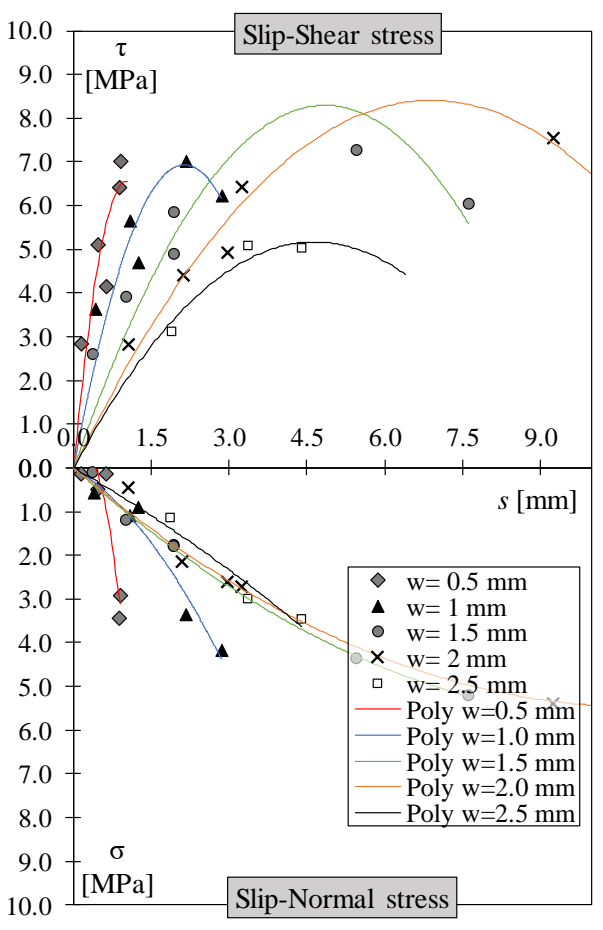

(b)

Figure 3-17: Shear interaction diagram of PFRC (a) and SFRC (b)

Moreover, when comparing both fibre-reinforced concrete types, they displayed similar behaviour in shear and normal stresses despite the number of specimens tested with each concrete type not being the same (eight for PFRC, six for SFRC). In addition, this similarity in behaviour was more evident for small slip displacement and crack openings than for larger ones. This behaviour is better observed in Figure 3-18, where the three used concrete types (PC, SFRC, SFRC) are compared with three different crack openings (0.5, $1.5,2.5 \mathrm{~mm}$ ). These crack openings were selected to explore the contribution of fibres to the serviceability limit state (SLS), which is related to crack openings up to $0.5 \mathrm{~mm}$ ), and also to the ultimate limit state (ULS) (crack openings of $2.5 \mathrm{~mm}$ ) of the structural elements. It is underlined that the polynomial trend line of $0.5 \mathrm{~mm}$ in PFRC and SFRC changed to a linear one to perform a better comparison to PC. 


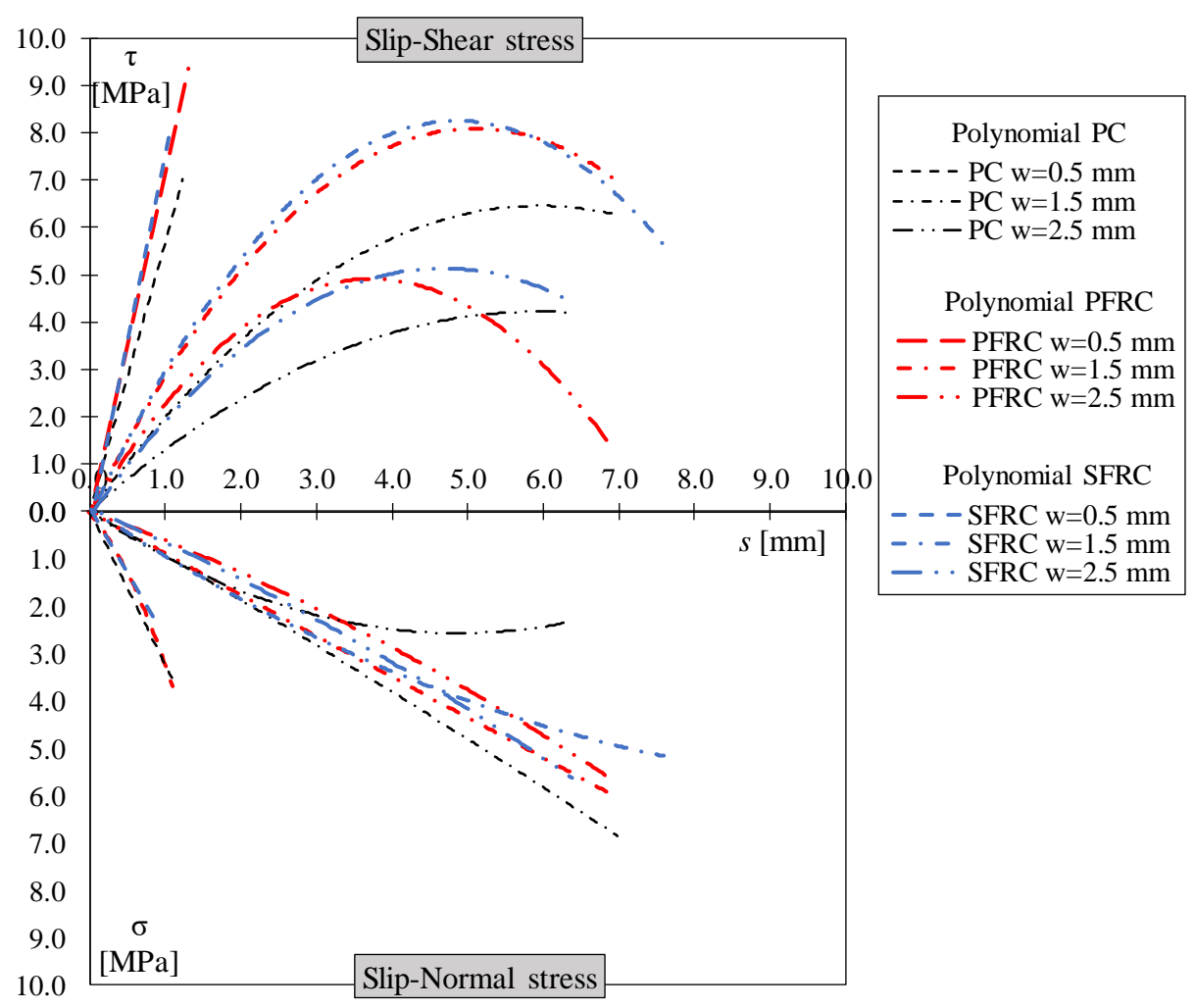

Figure 3-18: Comparison of the results of PC, PFRC and SFRC

As seen in Figure 3-18, both FRC types presented similar shear and normal behaviour. This clearly demonstrates that although polypropylene and steel fibres differed in material (polypropylene and steel), geometry (aspect ratio) and amount of fibres in the matrix $\left(10 \mathrm{~kg} / \mathrm{m}^{3}\right.$ in PFRC, $30 \mathrm{~kg} / \mathrm{m}^{3}$ in SFRC) as both fibre type provided similar residual flexural tensile strength, comparable shear behaviour was obtained. With these results, the authors confirmed that evaluating the shear performance of FRC elements in SLS and ULS according to residual flexural tensile strengths is convenient because fibres perform similarly in shear resistance mechanisms.

On the one hand, fibres significantly contributed to increase the shear and normal stresses transferred to the crack. This contribution was greater at large crack openings than small ones, and this behaviour was because in small cracks $(0.5 \mathrm{~mm})$, the aggregate interlock was one of the main transferring mechanisms, and the contribution of the fibres dosed at $10 \mathrm{~kg} / \mathrm{m}^{3}$ in PFRC and $30 \mathrm{~kg} / \mathrm{m}^{3}$ in SFRC was around $0.5 \mathrm{MPa}$ on average. On the other hand with the increment in slip displacement and crack opening, the contribution of fibres was more remarkable, and fibre contribution reached up to $1 \mathrm{MPa}$. Nevertheless, the 
Effectiveness of polypropylene fibres as shear reinforcement in structural elements

contribution of fibres with higher slip displacements was up to 2MPa. This contribution represents an approximation, especially for bigger crack slip displacements as trend lines represent the mean behaviour of the performed test. As Figure 3-17 depicts, the largest number of points used to prepare trend lines was concentrated at small slip displacements.

Moreover, the contribution of fibres was also observed in normal stresses, especially at the $0.5-\mathrm{mm}$ crack opening. However, no clear tendencies appeared among the three concrete types for the $1.5-\mathrm{mm}$ and $2.5-\mathrm{mm}$ crack openings. As stated before, these differences were influenced by the confinement provided by the previous push-off test.

In addition, in order to estimate the contribution of fibres to shear stress, the specimens in PC, PFRC and SFRC that contained a stirrup were compared to one another and are presented in Figure 3-19. These specimens were selected because the five specimens (1PC, 2PFRC and 2SFRC) presented similar boundary conditions ( $w_{0}$ and $\sigma_{0}$ ) and crack kinematics. The present test did not allow us to determine the contribution of fibres by subtracting each mechanism, unless the specimens presented equal or similar $w_{0}$ and $\sigma_{0}$, as both parameters determine the specimen's shear performance.

Figure 3-19a and Figure 3-19b present the comparison of shear stresses vs. crack opening and crack slip, respectively. In both figures, the average PFRC and SFRC performances were obtained by averaging Z16 and Z24 in PFRC and Z12 and Z20 in SFRC. In PC, only the only specimen (Z6) containing a stirrup was employed. The specimens with fibres presented more shear stress than the PC ones. Fibres contributed up to $1.7 \mathrm{MPa}$ in PFRC and $1.1 \mathrm{MPa}$ in SFRC when comparing the average values, and rose to $2.28 \mathrm{MPa}$ if specimens were separately compared. This contribution was similar to the contribution observed in Figure 3-18, with values up to $2 \mathrm{~mm}$. 
Chapter 3. PFRC in small specimens

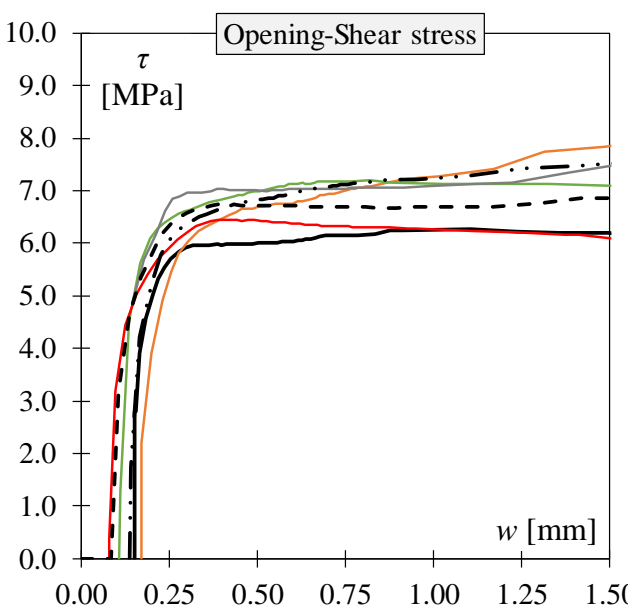

(a)

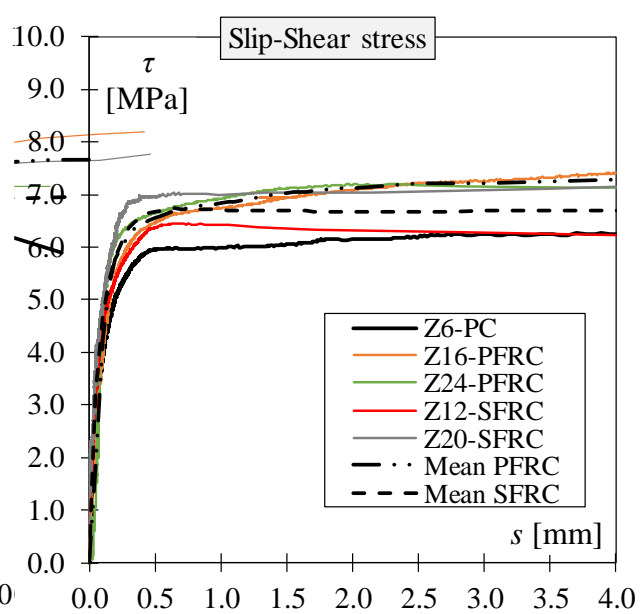

(b)

Figure 3-19: Comparison of specimens with stirrups

Finally, in order to determine the contribution of fibres to shear according to crack opening and slip, the diagonal displacement of the crack calculated with (Eq. 3-25) is presented in Figure 3-20a, where we can observe that both fibre types contributed to shear by approximately $1 \mathrm{MPa}$, and linearly increased stiffness up to approximately $0.5 \mathrm{~mm}$ in SFRC and $1.5 \mathrm{~mm}$ in PFRC. The contribution of both fibres was similar if we consider the variation in residual flexural tensile strength between both fibres. As seen in Figure 3-20b, when the experimental shear contribution of fibres was compared to the theoretical shear contribution of fibres, as obtained by the inverse analysis of the residual flexural tensile strength of FRC, similar results in SFRC were obtained with, however, reasonable differences in PFRC. This difference could be due to the dissimilar initial conditions (crack opening and confinement) that each specimen presented. It is worth mentioning that the theoretical shear contribution of fibres was determined from the tensile properties of FRC obtained by the inverse analysis. To do so, the tensile stress provided by fibres was decoupled as Figure 3-21 shows, and was discomposed into shear stresses using (Eq. 2-25).

$$
\begin{aligned}
& \delta=\sqrt{w^{2}+s^{2}} \\
& \tau_{f}=\sigma_{f} \cos \alpha_{w} \sin \alpha_{w} \\
& \alpha_{w}=\tan ^{-1} \frac{w}{s}
\end{aligned}
$$


Effectiveness of polypropylene fibres as shear reinforcement in structural elements

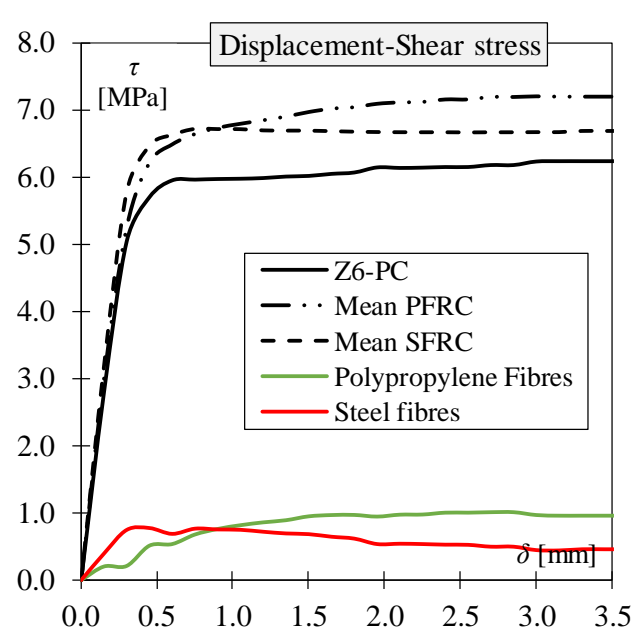

(a)

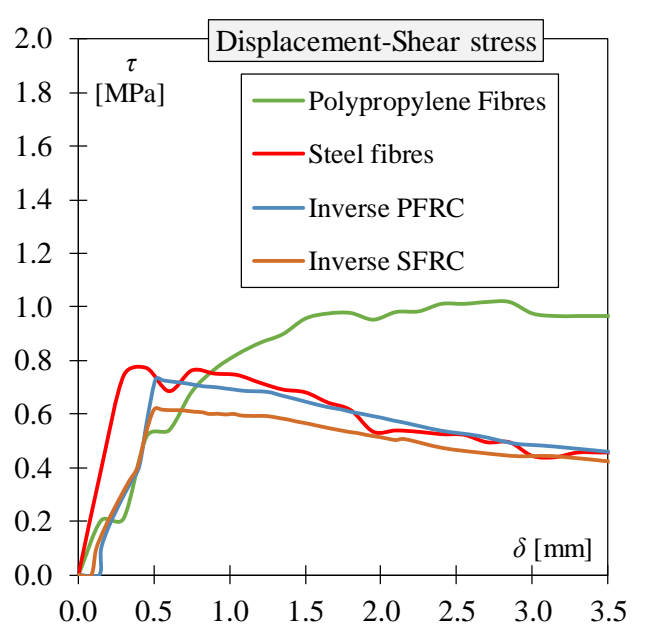

(b)

Figure 3-20: Experimental fibre contribution to shear (a), comparison of experimental fibre contribution vs. the contribution obtained by the inverse analysis (b).

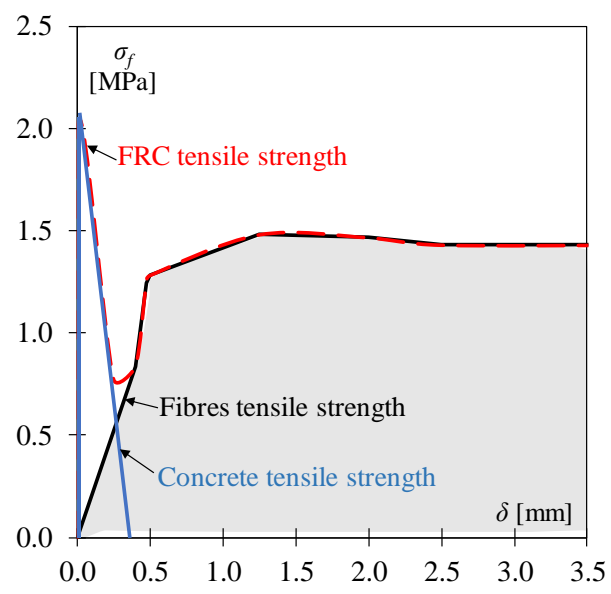

Figure 3-21: Theoretical tensile fibre contribution obtained with the inverse analysis.

\subsubsection{Concluding remarks}

The shear behaviour of 21 pre-cracked push-off specimens was experimentally analysed in this section by focusing on the effectiveness of polypropylene fibres to transmit stresses in a shear crack. To this end, the push-off specimens of PC, PFRC and SFRC were manufactured and tested. Polypropylene fibre and steel fibres were dosed in the matrix at a rate of $10 \mathrm{~kg} / \mathrm{m}^{3}$ and $30 \mathrm{~kg} / \mathrm{m}^{3}$, respectively. It is worth mentioning that both 
Chapter 3. PFRC in small specimens

fibre contents were selected to provide similar residual flexural tensile strengths to the concrete matrix.

The shear stresses results obtained with the PC specimens were validated using the aggregate interlock models available in the literature. In this way, the methodology proposed by Echegaray in 2014 to study the shear in pre-crack specimens was also validated. Furthermore, some recommendations to improve the methodology are presented in the next section of this chapter.

To study the effectiveness of polypropylene fibres, the PFRC specimen results were compared to the results obtained in specimens PC and SFRC. In this context, and based on the herein obtained experimental results, the following conclusion can be drawn:

a) In the PC specimens, the influence of the aggregate interlock and macroroughness was a confirmed mechanism to transfer shear and normal stresses in shear cracks. The influence of each mechanism depended on the initial crack opening introduced into specimens. Thus in those specimens with large initial crack openings, macroroughness was influenced by the confinement of specimens (the previous introduced push-off test) and played an important role to transmit stresses. The shear and normal stresses were larger for small slip displacements and crack openings, but reduced as slips and crack openings increased

b) When comparing the PC specimens results to the aggregate interlock, the shear experimental results at small crack openings $(\mathrm{w}=0.5 \mathrm{~mm})$ adjusted well to the results obtained with all the models. However at larger crack openings $(w=1.5$ and $2.5 \mathrm{~mm}$ ), the most accurate model was that proposed by Gambarova and Karakoç. In fact when comparing the predictions provided by all the models studied at crack openings of 1.5 and $2.5 \mathrm{~mm}$, considerably differences appeared among models. Similar conclusions were drawn in the normal stresses observations

c) The polypropylene fibres dosed at $10 \mathrm{kgm}^{3}$ incremented the shear and normal stresses transmitted in the crack from approximately 0.5 to $2.0 \mathrm{MPa}$. In fact this increment became more evident for large crack openings and slip displacements. This behaviour was due to loss of aggregate interlock efficiency in transmitting stresses when slip and crack openings increased, and fibres combined with macroroughness were the only mechanism able to transmit stresses. Nevertheless, this observation confirmed the effectiveness of the polypropylene fibres in bridging cracks and continuing to transmit stresses even at large crack openings

d) The shear behaviour of specimens PFRC and SFRC was similar. This was attributed to the fact that both fibre types provided similar residual flexural tensile strength. These results confirmed that regardless of fibre type (volume, material, shape, length, diameter), if fibres provided similar residual flexural tensile strengths, similar shear performance would be achieved. Thus the shear performance evaluation of the FRC element made according to the residual flexural tensile strengths is convenient 
Effectiveness of polypropylene fibres as shear reinforcement in structural elements

Finally, based on the experimental results, the methodology proposed by Echegaray proved effective for studying the stresses transmitted in a shear crack, especially shear stresses. However, it became evident that normal stresses, which were influenced by the initial confinement introduced into the specimens, was somewhat inconvenient, especially in those elements with initial large crack openings.

In order to improve the used methodology, setting up the average strains in each bar is recommended to achieve sufficient initial confinement, which allowed a desired initial gap $(W)$ to be introduced and the specimen to be totally or partially confined; see (Eq. 3-4) and (Eq. 3-5) before the push-off test. It is also mandatory to record the deconfinement effect due to the introduced $W$. In this way, the specimen's exact confinement is known before the push-off test.

\subsection{Experimental campaign two}

Twenty pre-cracked push-off specimens were tested by a direct shear loading scheme. For this purpose, four specimens were manufactured with PC and 16 with PFRC. The fibre content in the PFRC specimens was $8 \mathrm{~kg} / \mathrm{m}^{3}$ (eight specimens) and $12 \mathrm{~kg} / \mathrm{m}^{3}$ (eight specimens). The push-off specimens had the same geometry and reinforcement as in experimental campaign one (see Figure 3-1). In addition, specimens were tested following the methodology proposed by Echegaray et al. [127] with some modifications, which were incorporated to track the confinement of specimens and the crack kinematics in all the test stages (assembly, pre-cracking, handling, push-off test). To do so, all the specimens were totally confined before the push-off test (see (Eq.3-9)). The variables studied in the present campaign were concrete type (PC and PFRC), fibre content ( 8 and 12 $\left.\mathrm{kg} / \mathrm{m}^{3}\right)$ and the influence of confinement on shear behaviour. For this purpose, different initial crack gaps ( $W=0.0,0.2,0.4$ for the PC specimens, $W=0.0,0.2,0.4$ and 0.6 for the PFRC specimens) were introduced into specimens prior to the push-off test. In most cases, two specimens were tested for each W in PFRC. Finally, it is worth highlighting that the main objective of the present experimental campaign was to complement experimental campaign one, and to better understand the parameters that influenced the pushoff test and, hence, the shear transfer mechanism.

\subsubsection{Materials characterisation}

Table 3-10 shows the mix proportions used for each concrete. Both concrete and specimens were manufactured at the ICITECH laboratory. Portland cement type CEM I $42.5 \mathrm{~N}$, two gravels, two sand types and limestone filler were used as indicated in Table 3-10. The maximum aggregate size was $14 \mathrm{~mm}$. To evaluate the effect of the amount of fibres on concrete, the $8 \mathrm{~kg} / \mathrm{m}^{3}$ and $12 \mathrm{~kg} / \mathrm{m}^{3}$ polypropylene fibre doses were used (hereafter PFRC8 and PFRC12). All the main components were the same in both PC and PFRC8, but certain modifications were made in PFRC12 to improve concrete workabil- 
Chapter 3. PFRC in small specimens

ity. The mixed design for both PC and PFRC was done to achieve a characteristic compressive concrete strength of $40 \mathrm{MPa}$. Finally, all the specimens were cast indoors and cured in a room at $20^{\circ} \mathrm{C}$ and $100 \%$ humidity.

Macrosynthetic fibres (48 $\mathrm{mm}$ long) with a nominal aspect (length/diameter) ratio of 57, density of $0.91 \mathrm{~g} / \mathrm{cm}^{3}, 400 \mathrm{MPa}$ tensile strength and $4.7 \mathrm{GPa}$ of modulus of elasticity were used in this experimental campaign. It is worth mentioning that the fibres used herein were similar to the synthetic fibres employed in experimental campaign one.

Table 3-10: Mix doses of the employed concretes

\begin{tabular}{|c|c|c|c|}
\hline Material & PC & PFRC 8 & PFRC 12 \\
\hline Cement CEM I 42.5 N $\left[\mathbf{k g} / \mathbf{m}^{\mathbf{3}}\right]$ & 350 & 350 & 350 \\
\hline Crushed Sand $\left[\mathbf{k g} / \mathbf{m}^{\mathbf{3}}\right]$ & 950 & 950 & 1045 \\
\hline Limestone filler $\left[\mathbf{k g} / \mathbf{m}^{\mathbf{3}}\right]$ & 60 & 60 & 66 \\
\hline Coarse Gravel $\mathbf{7 / 1 4} \mathbf{m m}\left[\mathbf{k g} / \mathbf{m}^{\mathbf{3}}\right]$ & 600 & 600 & 540 \\
\hline Coarse Gravel 4/7 mm $\left[\mathbf{k g} / \mathbf{m}^{\mathbf{3}}\right]$ & 300 & 300 & 270 \\
\hline Water $\left[\mathbf{l t} / \mathbf{m}^{\mathbf{3}}\right]$ & 190 & 190 & 190 \\
\hline Fibres $\left[\mathbf{k g} / \mathbf{m}^{\mathbf{3}}\right]$ & 0 & $8\left(V_{f=}=0.88 \%\right)$ & $12\left(V_{f=1.31 \%}\right)$ \\
\hline Superplasticiser $\left[\mathbf{l t} / \mathbf{m}^{\mathbf{3}}\right]$ & 3.5 & 3.5 & 3.5 \\
\hline
\end{tabular}

To characterise the concrete compressive, flexure and shear strengths, and their postcracking behaviour, 28 cylindrical accompaniment specimens $(150 \times 300 \mathrm{~mm})$ and $28 \mathrm{ac}-$ companiment prismatic beams (150x150x600 $\mathrm{mm}$ ) were manufactured while producing the push-off specimens. Specimens were cured under the same environmental conditions as the push-off ones. To characterise shear strength, the prismatic specimen measuring $294 \times 150 \times 73.5 \mathrm{~mm}$ were sawed from the prismatic beams as Figure 3-22 shows. Twelve specimens (4 PC, 4 PFRC8, 4 PFRC12) were obtained. In addition, cubic samples were obtained from sawing the prismatic specimens, as indicated in Figure 3-22. 
Effectiveness of polypropylene fibres as shear reinforcement in structural elements

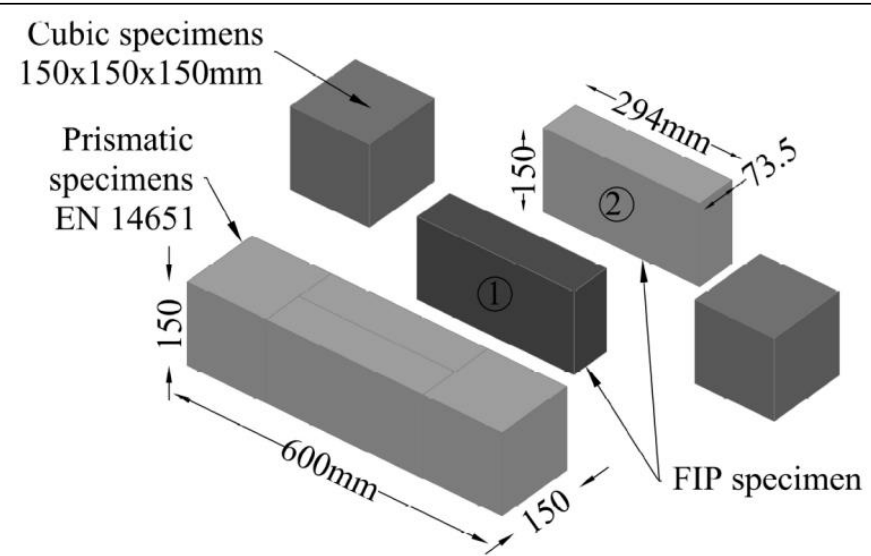

Figure 3-22: Obtaining specimens for shear characterisation.

The concrete compression strength obtained from the cylindrical $\left(f_{c}\right)$ and cubic samples $\left(f_{c, \text { cube }}\right)$ was determined according to EN 12390-3 [196]. Based on EN 14651 [15], the flexural strength $\left(f_{L}\right)$ and residual flexural tensile strength $\left(f_{R j}\right)$ at the CMOD (crack mouth opening displacement) values of $0.5,1.5,2.5$ and $3.5 \mathrm{~mm}$ were obtained for each concrete type (eight for PC, 15 for PFRC). The mean mechanical properties of each concrete are presented in Table 3-11 (coefficient of variation in brackets). The mechanical properties were obtained 28 days after casting specimens.

Table 3-11: Main mechanical properties of PC and PFRC

\begin{tabular}{|c|c|c|c|}
\hline Parameter & $\boldsymbol{R C}$ & PFRC8 & PFRC12 \\
\hline$f_{c}[\mathrm{MPa}]$ & $43.62(0.06)$ & $43.50(0.07)$ & $45.89(0.09)$ \\
\hline$f_{c, \text { cube }}[\mathrm{MPa}]$ & $48.47(0.01)$ & $48.22(0.01)$ & $53.01(0.01)$ \\
\hline$f_{L}[\mathrm{MPa}]$ & $4.0(0.04)$ & $4.39(0.05)$ & $4.49(0.08)$ \\
\hline$f_{R, 1}[\mathrm{MPa}]$ & - & $1.52(0.18)$ & $2.27(0.19)$ \\
\hline$f_{R, 2}[\mathrm{MPa}]$ & - & $1.91(0.21)$ & $3.01(0.20)$ \\
\hline$f_{R, 3}[\mathrm{MPa}]$ & - & $2.09(0.23)$ & $3.29(0.19)$ \\
\hline$f_{R, 4}[\mathrm{MPa}]$ & - & $2.13(0.24)$ & $3.34(0.18)$ \\
\hline Fibres $\left[\right.$ fibres $\left./ \mathrm{cm}^{2}\right]$ & - & $0.84(0.11)$ & $1.35(0.16)$ \\
\hline
\end{tabular}

Figure 3-23 displays the nominal shear stress vs. the CMOD response for the PFRC beam samples according to EN 14651. Note that by incrementing the fibre doge from 8 to 12 $\mathrm{kg} / \mathrm{m}^{3}$, the residual flexure tensile strength also rose. The flexural toughness measured 
in Figure 3-23 from CMOD $=0.5 \mathrm{~mm}$ to $3.5 \mathrm{~mm}$ for PFRC8 and PFRC12 (area under the curve) was in 5.88 and 9.22 MPA-mm, respectively.

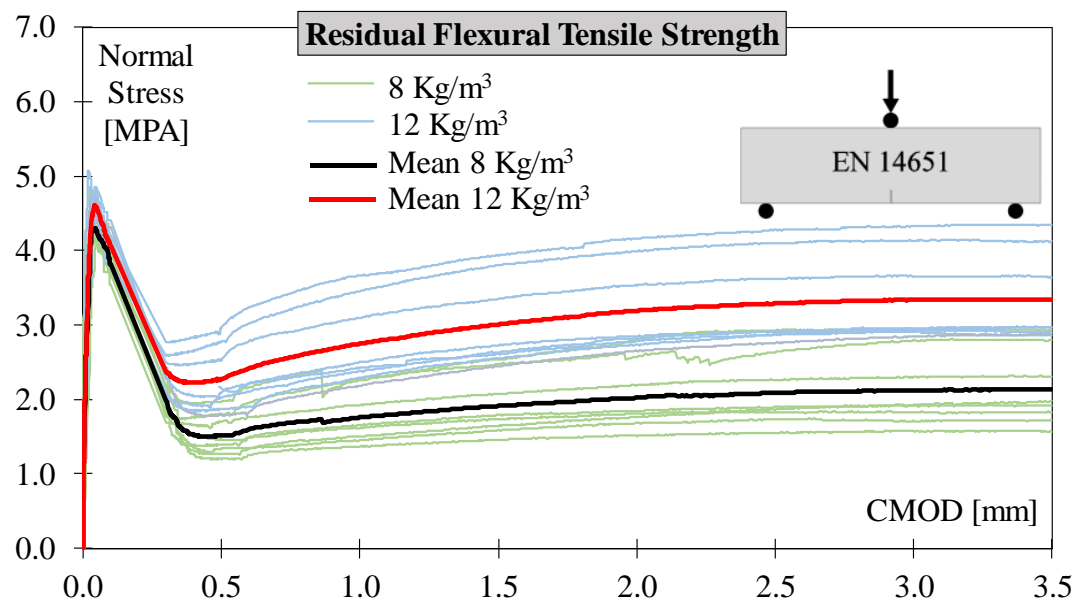

Figure 3-23: Nominal stress-CMOD responses according to EN 14651

In order to characterise the shear strength of PC, PFRC8 and PFR12, as well as the shear post-cracking behaviour of PFRC, the 12 prismatic specimens $(294 \times 150 \times 73.5)$ were tested based on the FIP shear test [139] with some modifications. It should be noted that as this specimen was obtained from the middle of the prismatic beams (see Figure 3-22), the shear failure plane coincided with the location of the notch and, subsequently, the location of the flexure crack of the prismatic beam tested according to EN 14651. Moreover, in order to avoid cracking outside the shear plane, a notch of $12.5 \mathrm{~mm}$ deep and a 
Effectiveness of polypropylene fibres as shear reinforcement in structural elements

3-mm notch was sawn around the specimen as Figure 3-24 shows. Hence the shear failure plane was $125 \times 48.5 \mathrm{~mm}$.

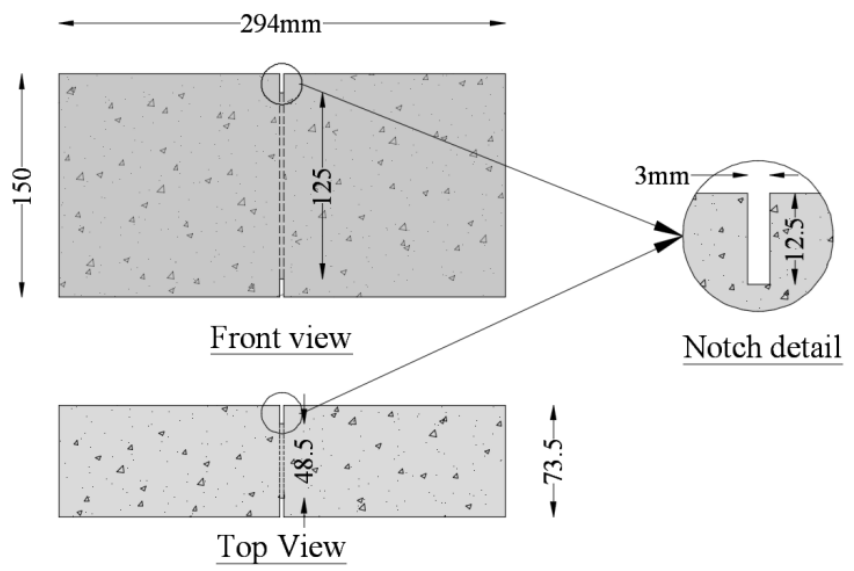

Figure 3-24: Geometry of the FIP specimens

Finally, it is worth mentioning that the geometry of the FIP specimens was selected to fulfil the load limitations of the testing machine $(100 \mathrm{kN})$ available at the ICITECH facilities, instead of the dimensions suggested by the FIP shear test [139] (250x250x540 $\mathrm{mm})$.

The scheme of the test setup is presented in Figure 3-25. Load was applied by running displacement control at a constant rate of $0.05 \mathrm{~mm} / \mathrm{min}$ up to a slip displacement of 1 $\mathrm{mm}$. Then the loading rate was incremented to $0.20 \mathrm{~mm} / \mathrm{min}$ until the end of the test. Tests were stopped at the 4-mm slip displacement. The supports of specimens were designed with one pin and rolling support at the top and bottom of specimens as Figure 3-25b shows. Supports had a separation $(115 \mathrm{~mm})$ between one another. Pin supports were also separated $12 \mathrm{~mm}$ from the shear plane axis. It is worth mentioning that the loading axis coincided with the shear plane axis.

To record the crack kinematics (opening and slip displacement), PTs of $25 \mathrm{~mm}$ with a precision of $0.01 \mathrm{~mm}$ were fixed on the front and rear sides of specimens. The results of the tested specimens are presented in Figure 3-26 and Figure 3-27. 
Chapter 3. PFRC in small specimens
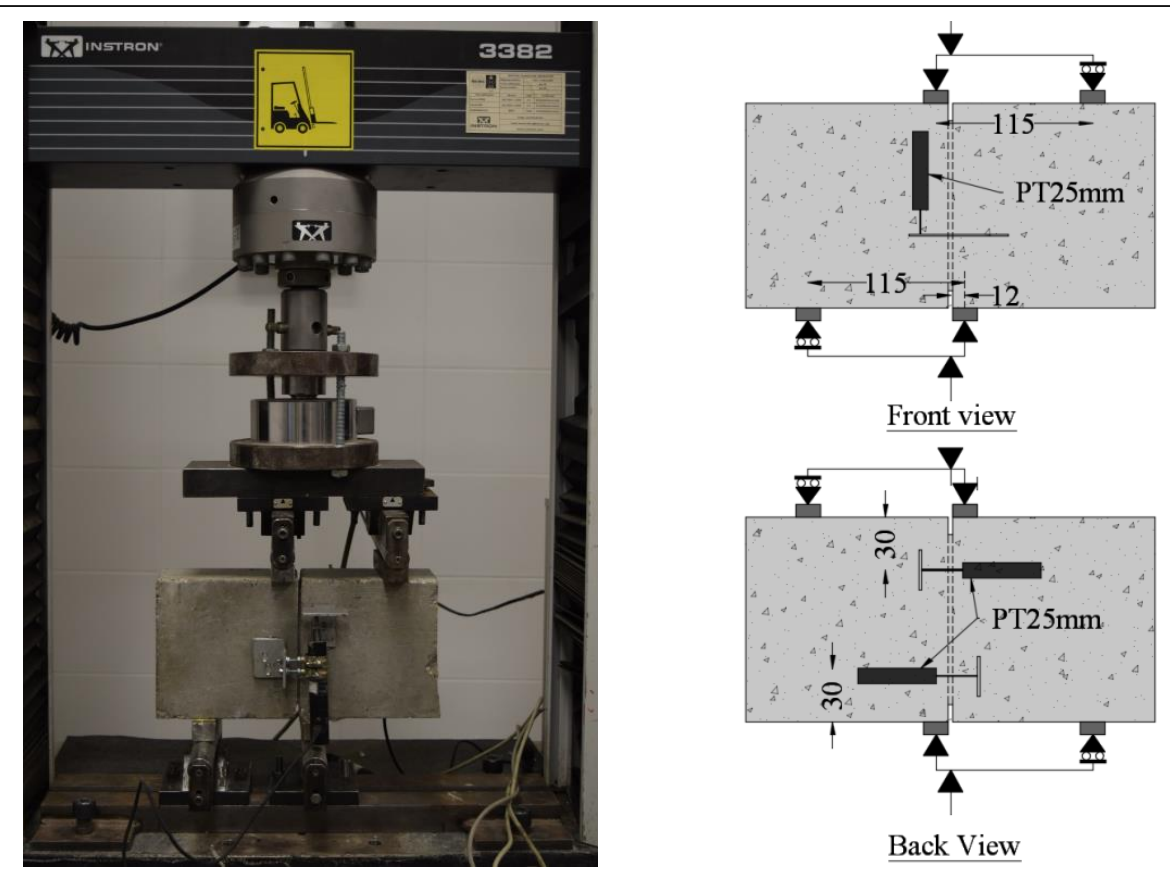

Back View

(a)

(b)

Figure 3-25: Specimens tested for shear characterisation 
Effectiveness of polypropylene fibres as shear reinforcement in structural elements

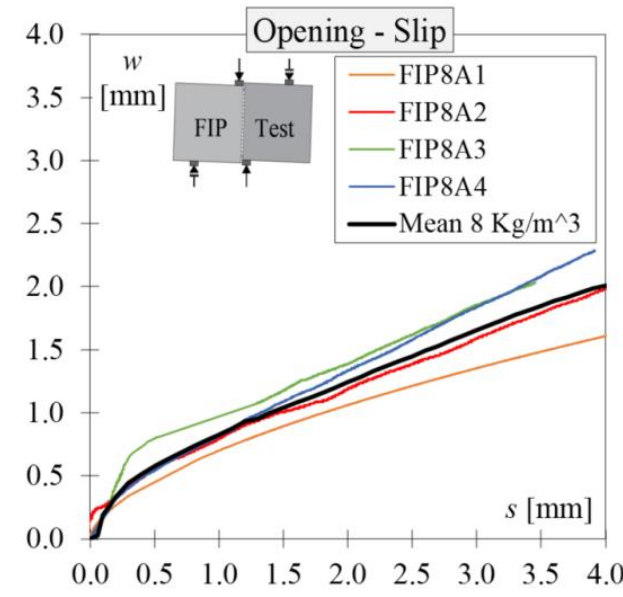

(a)

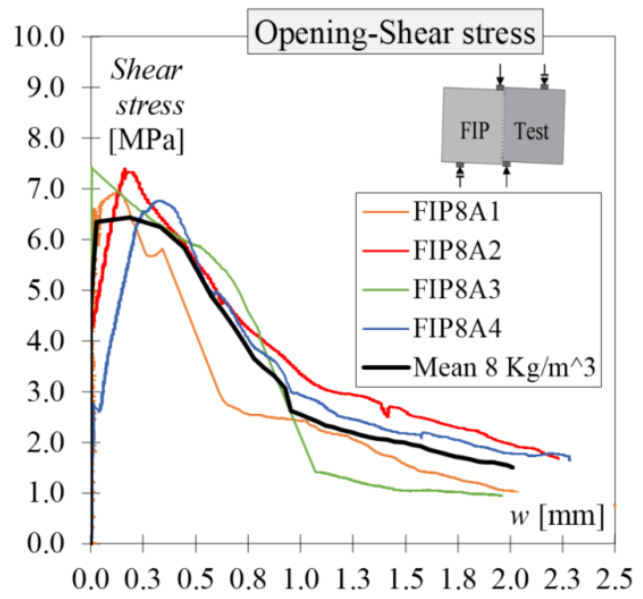

(b)

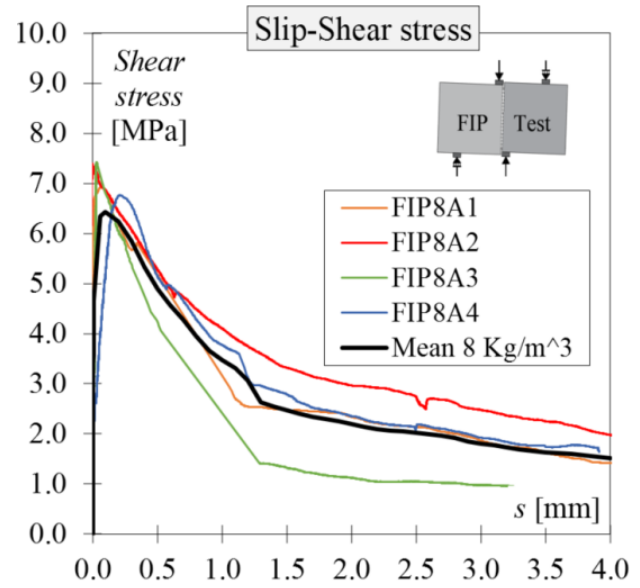

(c)

Figure 3-26: FIP direct shear test result for $8 \mathrm{~kg} / \mathrm{m}^{3}$ of polypropylene fibre: crack path (a) and shear stress vs. crack opening (b) and crack slip (c) 
Chapter 3. PFRC in small specimens

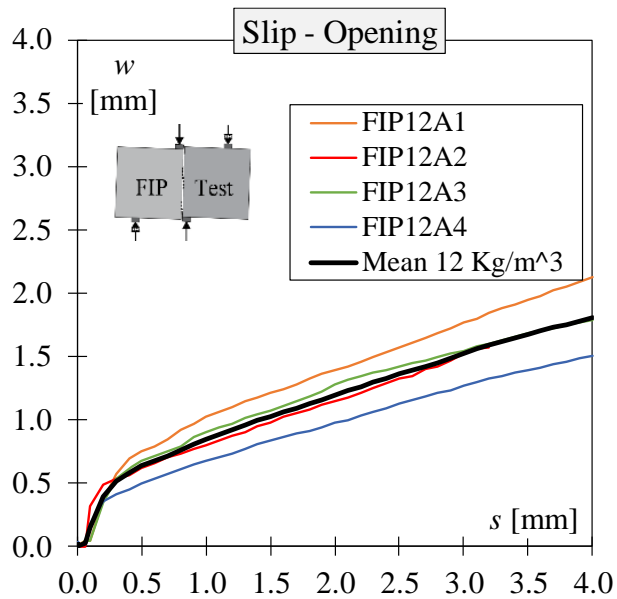

(a)

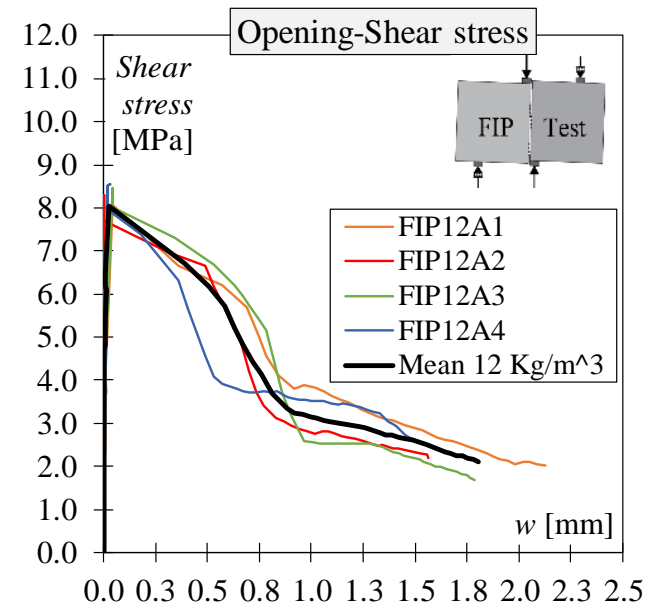

(b)

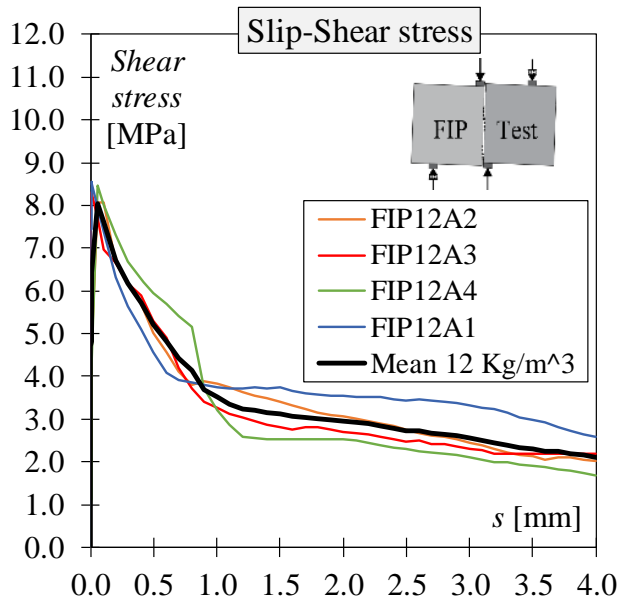

(c)

Figure 3-27: FIP direct shear test result for $12 \mathrm{~kg} / \mathrm{m}^{3}$ of polypropylene fibre: crack path (a) and shear stress vs. crack opening (b) and crack slip (c)

Each figure represents the crack path recorded during the test, shear stress vs. crack opening and shear stress vs. crack slip. In both PFRC types, the crack kinematics was characterised to present more crack opening than slip displacement up to $0.4 \mathrm{~mm}$, after which point crack opening and slip increased at a constant rate (see Figure 3-26a and Figure 3-27a). 
Effectiveness of polypropylene fibres as shear reinforcement in structural elements

In the PC specimens, the crack opening was abrupt and uncontrolled, and it was not possible to record shear behaviour after the peak stress. Conversely in the PFRC specimens, the crack was less abrupt and more controlled because fibres were included (see Figure 3-26c and Figure 3-27c).

In both PFRC ( 8 and $12 \mathrm{~kg} / \mathrm{m}^{3}$ ), shear behaviour was characterised by a drop in load after crack formation. It is worth mentioning that the crack opening recorded by the two PT occurred differently for each one In fact although specimens were developed to reduce the bending at the crack, the PT placed at the bottom of the specimen started before the PT placed at the top of specimens. In any case, Figure 3-26a and Figure 3-27a present an average measurement of both PTs.

Table 3-12 summarises the average shear results obtained during the test, including peak shear $\left(\tau_{\text {peak }}\right)$, and shear stresses at $0.5,1.5,2.5$ and $3.5 \mathrm{~mm}$ of slip displacement $\left(\tau_{0.5}, \tau_{1.5}\right.$, $\tau_{2.5}$ and $\tau_{3.5}$ ). With the inclusion of $8 \mathrm{~kg} / \mathrm{m}^{3}$ of fibres, peak stress did not change. However with $12 \mathrm{~kg} / \mathrm{m}^{3}$ of fibre, peak stress increased by $18 \%$ compared to the PC results. When comparing the shear stresses from 0.5 to $3.5 \mathrm{~mm}$ between both PFRC types, shear stress increased in PFRC with $12 \mathrm{~kg} / \mathrm{m}^{3}$ of fibres. The increments were $0.33 \mathrm{MPa}$ at $0.5 \mathrm{~mm}$, $0.65 \mathrm{MPa}$ at $1.0 \mathrm{~mm}, 0.72 \mathrm{MPa}$ at $2.5 \mathrm{~mm}$ and $0.67 \mathrm{MPa}$ at $2.5 \mathrm{~mm}$. The differences between PC and PFRCs are seen more clearly in Figure 3-28a. It should be noted that the stress variability obtained in Table 3-12 (CV in brackets) wassimilar to those obtained while performing the EN 14654 test, especially in the specimens with $12 \mathrm{~kg} / \mathrm{m}^{3}$ of fibre.

Table 3-12: Summary of the shear strength of PC and PFRC and post-cracking shear strength

\begin{tabular}{|c|c|c|c|}
\hline Parameter & PC & PFRC 8 & PFRC 12 \\
\hline$\tau_{\text {peak }}[\mathrm{MPa}]$ & $7.22(0.07)$ & $7.12(0.04)$ & $8.37(0.02)$ \\
\hline$\tau_{0.5}[\mathrm{MPa}]$ & - & $4.88(0.08)$ & $5.21(0.11)$ \\
\hline$\tau_{1.5}[\mathrm{MPa}]$ & - & $2.47(0.34)$ & $3.12(0.18)$ \\
\hline$\tau_{2.5}[\mathrm{MPa}]$ & - & $2.02(0.34)$ & $2.74(0.18)$ \\
\hline$\tau_{3.5}[\mathrm{MPa}]$ & - & $1.63(0.34)$ & $2.30(0.20)$ \\
\hline
\end{tabular}




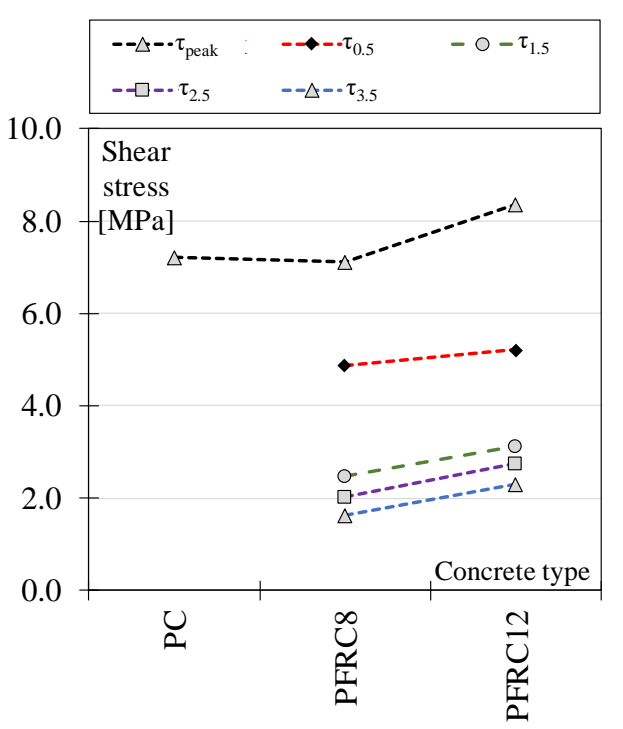

(a)

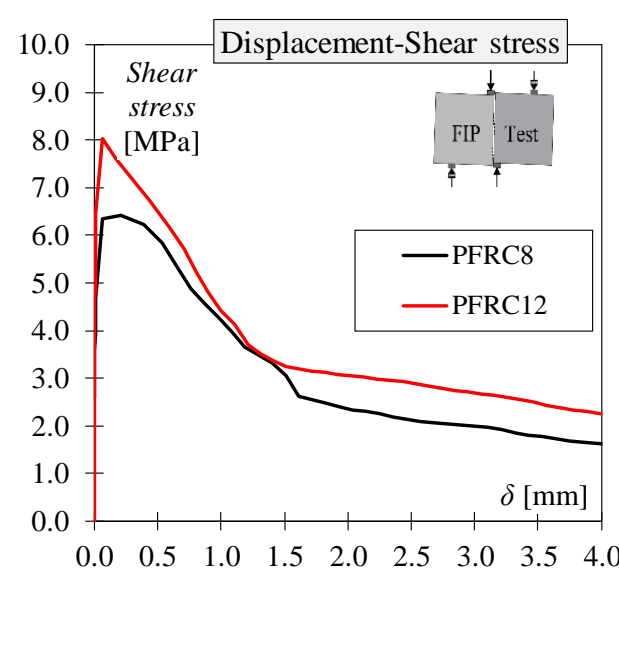

(b)

Figure 3-28: Comparison of shear and residual shear strength among concretes (a) and shear vs. total displacement of the crack (b).

Finally, the shear toughness of PFRC is measured in Figure 3-28b, which plots shear stress vs. crack displacement $(\delta)$. $\delta$ was determined as $\delta=\sqrt{w^{2}+s^{2}}$. Shear toughness was measured in both PFRCs from $\delta=0.36 \mathrm{~mm}$ to $2.71 \mathrm{~mm}$. These crack openings were selected to be analogous to the CMOD measured in the EN 14651 flexural test; i.e. CMOD $=0.5$ and $3.5 \mathrm{~mm}$ that equalled $\delta=0.36$ and $2.71 \mathrm{~mm}$, respectively. Therefore, shear toughness was7.97 and 11.50 MPa-mm for PFRC8 and PFRC12, respectively. When shear was compared to flexural toughness, the shear toughness were 1.36- and 1.25-fold the flexural toughness for PFRC8 and PFRC12, respectively.

\subsubsection{Instrumentation and test setup}

Similar to experimental campaign one, the total procedure to perform the test of the pushoff specimens consisted in the following four stages:

- Frame assembly

- Pre-cracking

- Handling

- Push-off test (direct shear test).

However, in order to improve the test procedure, the following differences from experimental campaign one were taken into account: 
Effectiveness of polypropylene fibres as shear reinforcement in structural elements

a) Frame assembly: in the last step in the frame assembly stage, where the 41-mm nuts were adjusted, the average strain of each bar was 26 microstrains to introduce an initial confinement $\left(\sigma_{i n i}\right)$ of approximately $0.7 \mathrm{MPa}$ into each specimen. This strain differs from Echegaray's methodology, and experimental campaign one, where an average strain of 0.015 microstrains was introduced into each bar; i.e. $\sigma_{i n i}$ varied from less than $0.01 \mathrm{MPa}$ to $0.7 \mathrm{MPa}$. With this change, confinement $\sigma_{0}$ prior to the push-off test was positive, which meant that the specimen would be completely confined regardless of the initial crack opening. The tested specimens' initial confinements are summarised in Table 3-13. The frame assembly finished by measuring the separation among the DEMEC targets prior to the pre-cracking stage

b) Pre-cracking process and handling: in these two stages, no differences to experimental campaign one were considered. See section 3.2.2.2

c) Push-off test: while the allowed initial crack gap (W) was introduced by adjusting the 41-mm nuts, the resulting confinement release $\left(\sigma_{d}\right)$ was recorded. Therefore, the total confinement provided by the external frame (see (Eq. 34 )) was known from the beginning of the push-off test. The remaining parameters and procedures in this test equalled those used in experimental campaign one.

The same arrangement of PT and DEMEC discs used in experimental campaign one were applied to measure crack opening, crack slip displacements and relative external confinement displacement in all four test stages. Normal stresses were also determined by the three strain gauges placed on each bar of the external frame.

Table 3-13 summarises initial confinement $\left(\sigma_{i n i}\right)$, crack opening $\left(w_{p}\right)$ and confinement $\left(\sigma_{p}\right)$ after the pre-cracking stage, confinement release $\left(\sigma_{d}\right)$, initial crack gap $(W)$ and crack opening $\left(w_{0}\right)$ as well as confinement immediately before the push-off test $\left(\sigma_{0}\right)$. As we can see in Table 3-13, four PC specimens were tested by varying $W(0.0,0.2,0.4 \mathrm{~mm})$. Two PC specimens were tested with $W=0.0 \mathrm{~mm}$ to study test repeatability. For specimens PFRC8 and PFRC12, $W$ were 0.0, 0.2, 0.4 and $0.6 \mathrm{~mm}$ when we considered two specimens for each $W$ Type.

It is noteworthy that the first number in the specimens' ID corresponded to fibre content $\left(0,8\right.$ or $\left.12 \mathrm{~kg} / \mathrm{m}^{3}\right)$, the second letter to specimens' repeatability (A to the first and B to the second), and the last two numbers corresponded to the $W$ introduced into the previous push-off test run with the specimens (example $02=0.2 \mathrm{~mm}$ ). When the results of two specimens with the same $W$ were averaged, the repeatability indicator was not considered in the specimens' ID and a hyphen was placed in its place. For example, ID Z0-00 was obtained when the results of specimens Z0A00 and Z0B00 were averaged. 
Chapter 3. PFRC in small specimens

Table 3-13: Initial state of the crack for each tested specimen.

\begin{tabular}{|c|c|c|c|c|c|c|c|c|}
\hline ID & $\boldsymbol{V}_{\boldsymbol{f}}$ & $\begin{array}{c}\boldsymbol{\sigma}_{\boldsymbol{i n i}} \\
{[\mathbf{M P a}]}\end{array}$ & $\begin{array}{c}\boldsymbol{w}_{\boldsymbol{p}} \\
{[\mathbf{m m}]}\end{array}$ & $\begin{array}{c}\boldsymbol{\sigma}_{\boldsymbol{p}} \\
{[\mathbf{M P a}]}\end{array}$ & $\begin{array}{c}\boldsymbol{\sigma}_{\boldsymbol{d}} \\
{[\mathbf{M P a}]}\end{array}$ & $\begin{array}{c}\boldsymbol{W} \\
{[\mathbf{m m}]}\end{array}$ & $\begin{array}{c}\boldsymbol{w}_{\boldsymbol{o}} \\
{[\mathbf{m m}]}\end{array}$ & $\begin{array}{c}\boldsymbol{\sigma}_{\boldsymbol{0}} \\
{[\mathbf{M P a}]}\end{array}$ \\
\hline Z0A00 & 0 & 0.77 & 0.22 & 1.06 & 0.00 & 0.00 & 0.22 & 1.83 \\
\hline Z0B00 & 0 & 0.85 & 0.26 & 0.99 & 0.00 & 0.00 & 0.26 & 1.84 \\
\hline Z0A02 & 0 & 0.78 & 0.27 & 0.95 & 0.64 & 0.20 & 0.28 & 1.09 \\
\hline Z0A04 & 0 & 0.79 & 0.31 & 1.00 & 1.16 & 0.40 & 0.33 & 0.64 \\
\hline Z8A00 & 8 & 0.73 & 0.18 & 0.66 & 0.00 & 0.00 & 0.18 & 1.39 \\
\hline Z8B00 & 8 & 0.81 & 0.23 & 0.99 & 0.00 & 0.00 & 0.23 & 1.80 \\
\hline Z8A02 & 8 & 0.77 & 0.28 & 0.75 & 0.59 & 0.20 & 0.28 & 0.93 \\
\hline Z8B02 & 8 & 0.72 & 0.20 & 0.70 & 0.61 & 0.20 & 0.21 & 0.81 \\
\hline Z8A04 & 8 & 0.74 & 0.22 & 0.61 & 1.05 & 0.40 & 0.24 & 0.31 \\
\hline Z8B04 & 8 & 0.92 & 0.21 & 0.51 & 1.05 & 0.40 & 0.21 & 0.38 \\
\hline Z8A06 & 8 & 0.76 & 0.19 & 0.98 & 1.35 & 0.60 & 0.19 & 0.39 \\
\hline Z8B06 & 8 & 0.79 & 0.33 & 1.11 & 0.93 & 0.60 & 0.35 & 0.97 \\
\hline Z12A00 & 12 & 0.78 & 0.25 & 0.80 & 0.00 & 0.00 & 0.25 & 1.58 \\
\hline Z12B00 & 12 & 0.78 & 0.28 & 0.78 & 0.00 & 0.00 & 0.28 & 1.56 \\
\hline Z12A02 & 12 & 0.78 & 0.27 & 0.90 & 0.55 & 0.20 & 0.28 & 1.13 \\
\hline Z12B02 & 12 & 0.79 & 0.26 & 0.81 & 0.66 & 0.20 & 0.27 & 0.93 \\
\hline Z12A04 & 12 & 0.77 & 0.21 & 0.89 & 0.96 & 0.40 & 0.24 & 0.70 \\
\hline Z12B04 & 12 & 0.78 & 0.16 & 0.64 & 1.04 & 0.40 & 0.18 & 0.37 \\
\hline Z12A06 & 12 & 0.77 & 0.17 & 0.59 & 0.92 & 0.60 & 0.19 & 0.44 \\
\hline Z12B06 & 12 & 0.79 & 0.31 & 1.43 & 1.41 & 0.60 & 0.31 & 0.81 \\
\hline
\end{tabular}

\subsubsection{Experimental results and discussion}

When the test ended, the results of the four previously described stages were processed to obtain the average shear stress $(\tau)$, average normal stress $(\sigma)$, crack opening $(w)$ and crack slip $(s)$ of each specimen using the equations from (Eq. 3-7) to (Eq.3-11).

The shear behaviour of the three concrete types PC, PFRC 8, PFRC 12 are depicted by means of crack opening and crack slip, vs. shear and normal stresses (see Figure 3-29, Figure 3-30 and Figure 3-31). All the figures include crack, crack path, shear stress vs. crack opening, shear stress vs. crack slip displacement and normal stress vs. crack opening. 
Effectiveness of polypropylene fibres as shear reinforcement in structural elements

\subsubsection{Plain concrete push-off results}

Figure 3-29a shows that all the PC specimens presented quite a similar crack kinematic behaviour, although $w_{0}$ was different among them. The shear transferred in the specimens (Figure 3-29a and Figure 3-29c) was characterised by presenting more stiffness at the beginning of the push-off tests. However, stiffness decreased from approximately $0.25 \mathrm{~mm}$ upwards of slip displacement. It should be noted that when shear stiffness reduced in all the specimens, shear stress continued to increase and similar slope remained among all the specimens. This behaviour was due to the influence of crack confinement. The two mechanisms of shear transfer acted at the crack at this point; the aggregate interlock and crack roughness were influenced by confinement. Finally regarding normal stress behaviour, Figure 3-29d shows that normal stresses remained at a similar slope rate among all the specimens, which represents the axial stiffness of the external steel frame.

As with the results obtained in experimental campaign one, with an incremented $w_{0}$, fewer shear stresses were transferred in the crack (see Figure 3-29a and Figure 3-29c). In addition, the specimens with the largest shear stresses were those (Z0A00 and Z0B00) into which no $W$ was introduced ( $W=0.0 \mathrm{~mm}$ ). In Figure 3-29d, the influence of confinement $\sigma_{0}$ on the shear transfer of the crack can be seen. Thus they were the elements with the largest $w_{0}$, the smallest $\sigma_{0}$ and, therefore, the smallest shear stress.

To better compare $\tau, \sigma, w$ and $s$, the obtained results are represented in Figure $3-29 \mathrm{e}$ by trend lines according to the constant crack opening values. To track trend lines, the points at the same crack opening $(0.3,0.5,0.75$ and $1.0 \mathrm{~mm})$ were identified from all the test results obtained for the four PC specimens and positioned on a coordinate plane.

As seen in Figure 3-29e, the shear and normal stresses transferred in a PC cracks increased with the crack opening and slip displacement. It was noted that normal and shear stresses were similar to one another with large crack openings ( $\mathrm{w}=0.75$ and $1 \mathrm{~mm}$ ), while shear stress doubled normal stress with small crack openings. 
Chapter 3. PFRC in small specimens
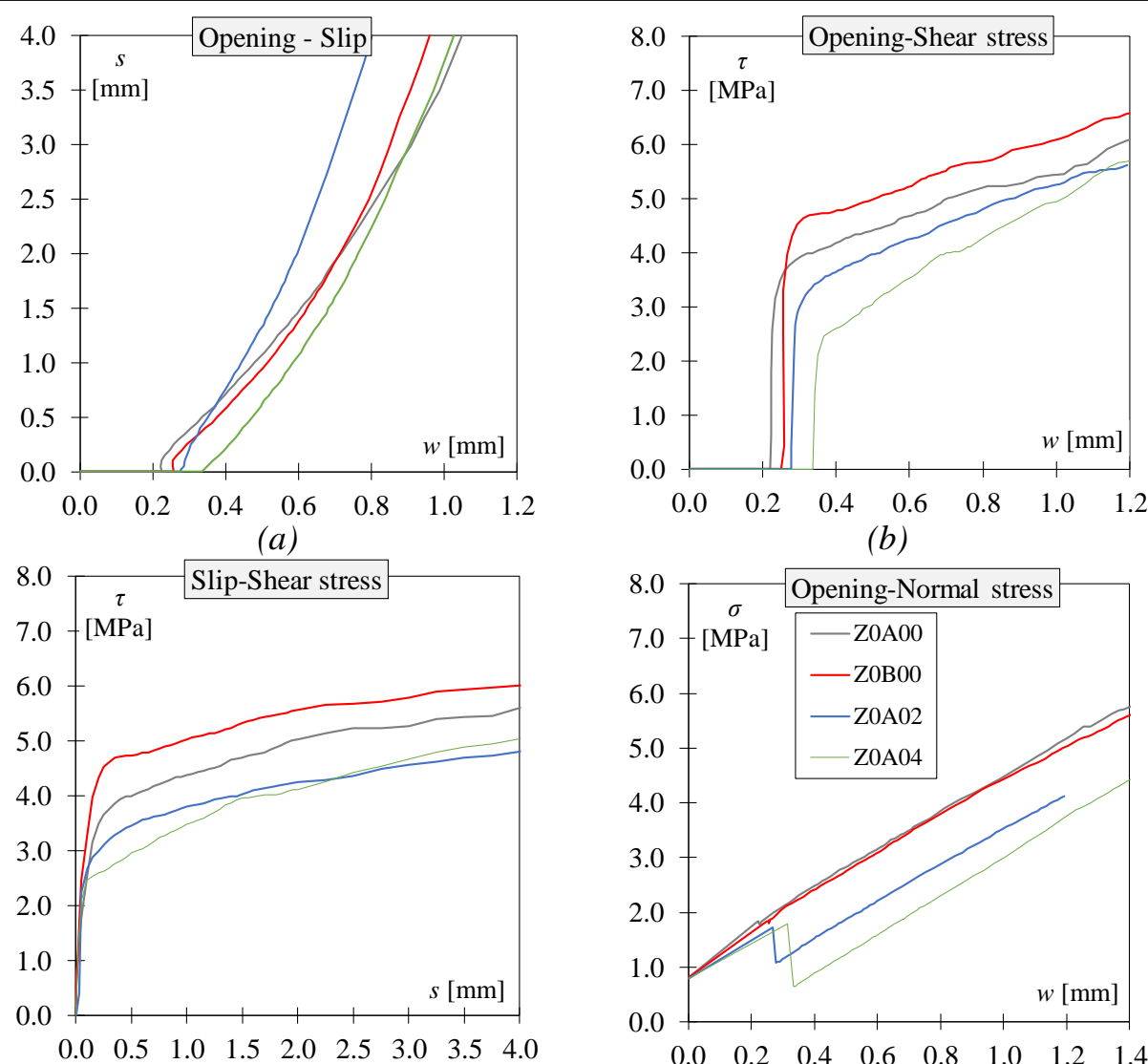

(c)

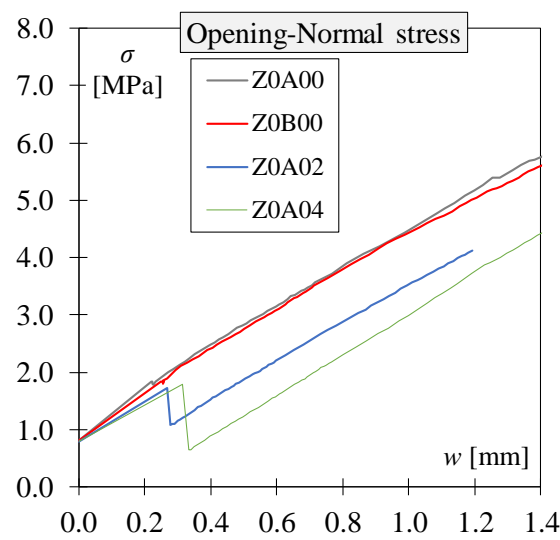

(d)

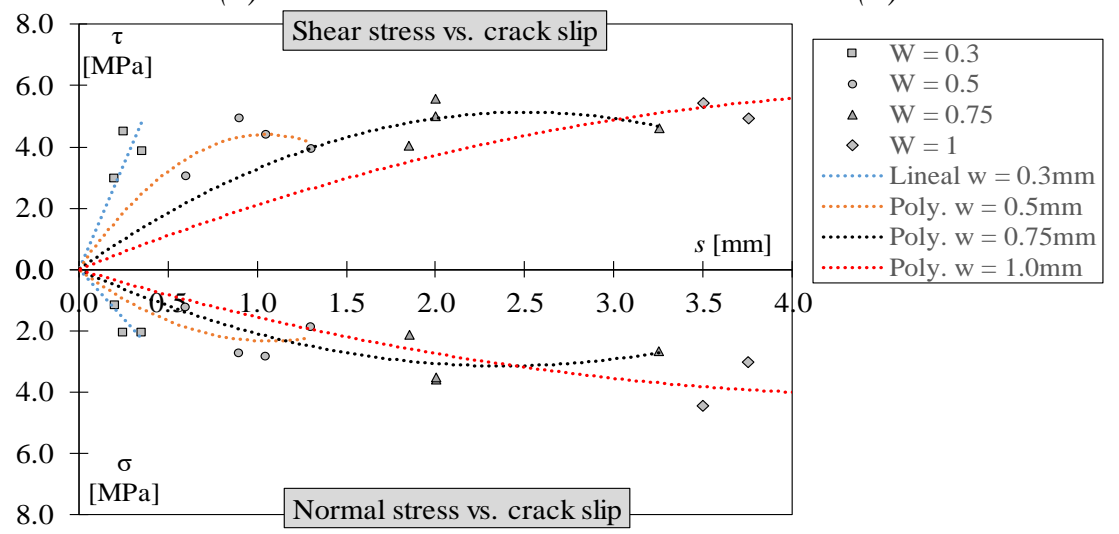

(e)

Figure 3-29: PC results: crack opening vs. crack slip (a), crack opening vs. shear stress (b), slip displacement vs. shear stress (c), crack opening vs. normal stress (d) and interaction diagram (d). 
Effectiveness of polypropylene fibres as shear reinforcement in structural elements

\subsubsection{PFRC push-off results}

The crack kinematic behaviour in the PFRC elements was analysed by using 16 precracked push-off specimens, For each concrete type (PFRC8 and PFRC12), two specimens were tested for each considered $W(0.0,0.2,0.4$ and $0.6 \mathrm{~mm})$. Therefore, the average results for two specimens with the same $W$ is presented in Figure 3-30 and Figure 3-31. Nevertheless, the test results of each specimen are found in Annexe B.

For PFRC8 and PFRC12, the shear stresses transferred (Figure 3-30c and Figure 3-31c) were characterised by presenting more stiffness at the beginning of the push-off test. As with the PC results, those PFRC elements with larger $w_{0}$ were those that transferred less shear stress; i.e. elements Z8-06 and Z12-06. In addition, the elements that transferred more shear stress were those for which $W$ equalled zero; i.e. those elements with lower $w_{0}$ (Z8-00 and Z12-00). After approximately $0.25 \mathrm{~mm}$ of slip displacement, shear stiffness decreased, but shear stress continued to increase and kept the same slope among all specimens due to the effect of the confinement provided by the external frame. In fact as Figure 3-30d and Figure 3-31d show, normal stresses were transferred in the crack with similar stiffness between all specimen types and PFRC types. This behaviour, similar to already observed with the PC specimens, was due to the effect of the confinement transmitted by the external frame during tests as this device was the same for all the specimens tested in this experimental campaign. Finally, the effect of the initial confinement on shear stresses is observed in Figure 3-30b and Figure 3-31b. Those specimens with larger $\sigma_{0}$ had larger transferred shear stress.

In order to observe the shear stress- normal stress-crack opening-slip displacements interaction among the tested specimens, the results are presented by trend lines in Figure 3-30e and Figure 3-31e for PFRC8 and PFRC12. Trend lines were fitted using the points at the same crack opening $(0.3,0.5,0.75$ and $1.0 \mathrm{~mm})$ from the corresponding concrete type. Trend lines were selected as linear or polynomial lines to obtain a better fit.

As seen in Figure 3-30e and Figure 3-31e, the transferred shear and normal stresses decreased with incremented crack opening and slip displacement. It was noted that points better fitted trend lines at small crack openings $(0.3$ and $0.5 \mathrm{~mm})$ than at larger ones. This effect could probably be due to the variability of fibres bridging the shear crack which, based on the FIP shear test, would be around $12 \%$. 
Chapter 3. PFRC in small specimens

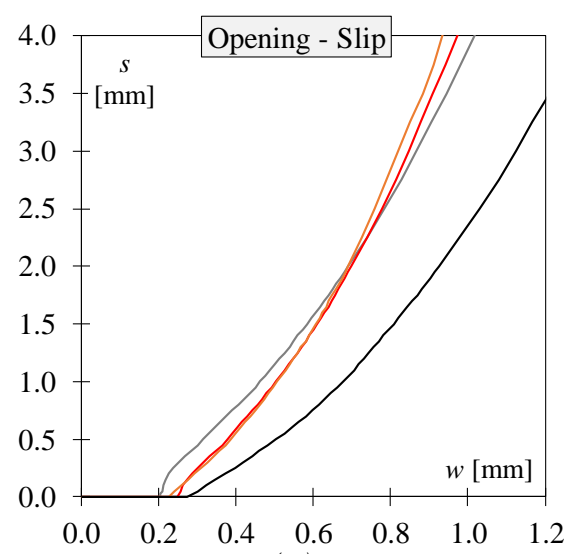

(a)

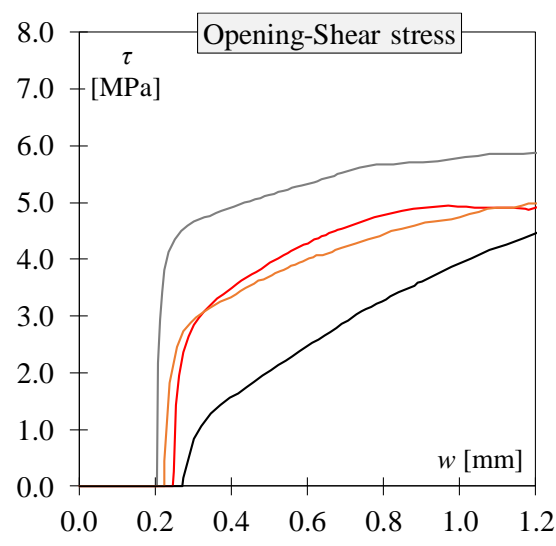

(b)

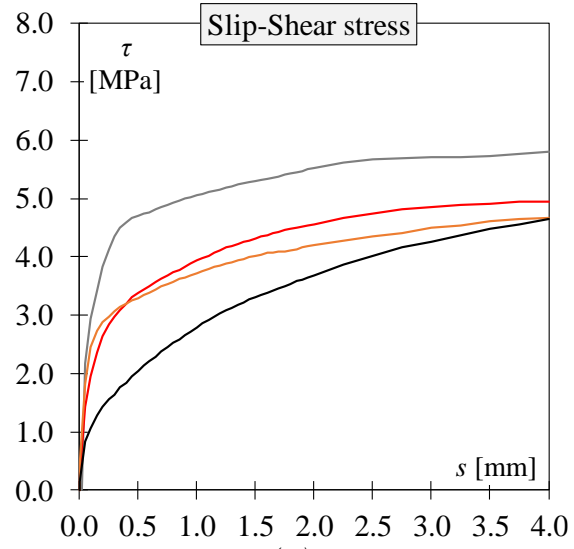

(c)

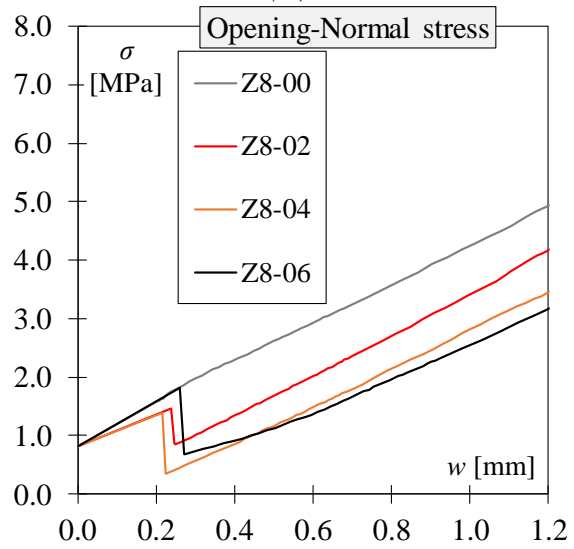

(d)

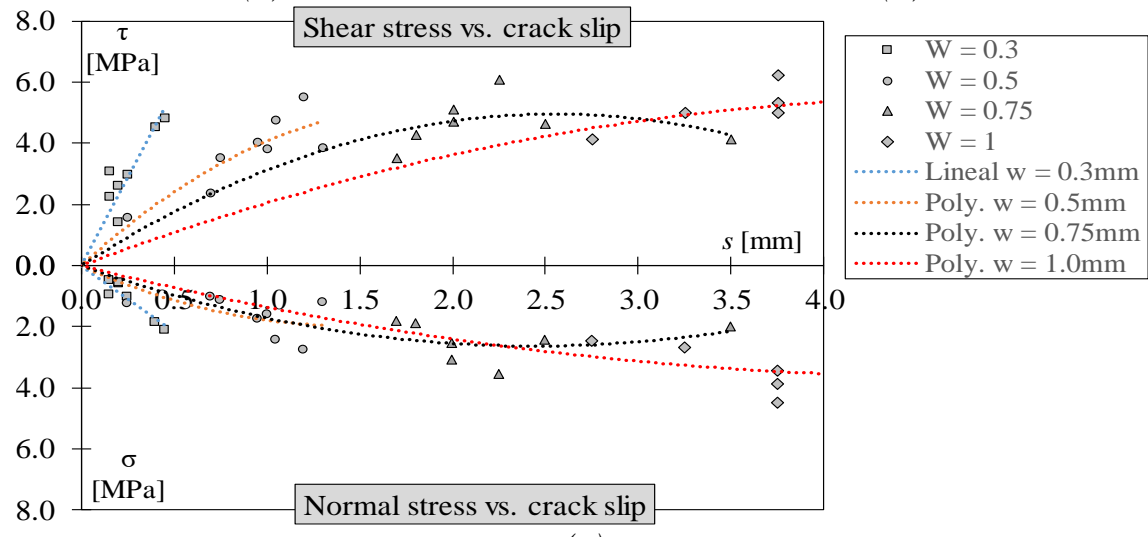

(e)

Figure 3-30: PFRC8 general results: crack opening vs. crack slip (a), crack opening vs. shear stress (b), slip displacement vs. shear stress (c), crack opening vs. normal stress (d) and interaction diagram $(d)$. 
Effectiveness of polypropylene fibres as shear reinforcement in structural elements

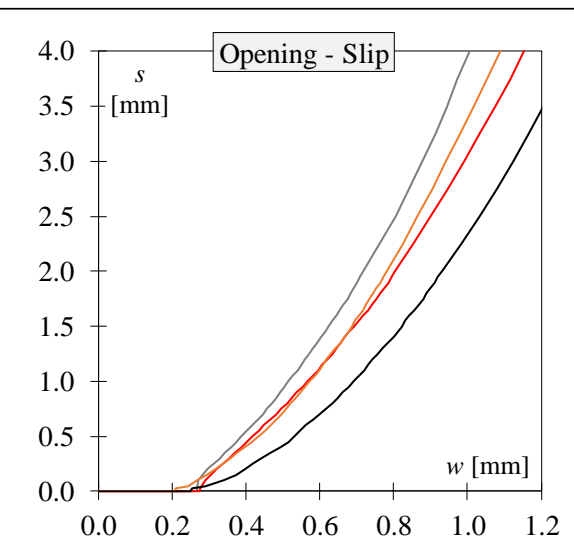

(a)

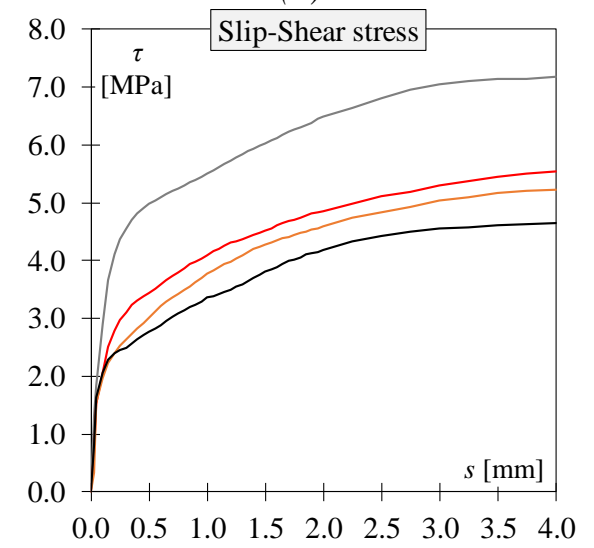

(c)

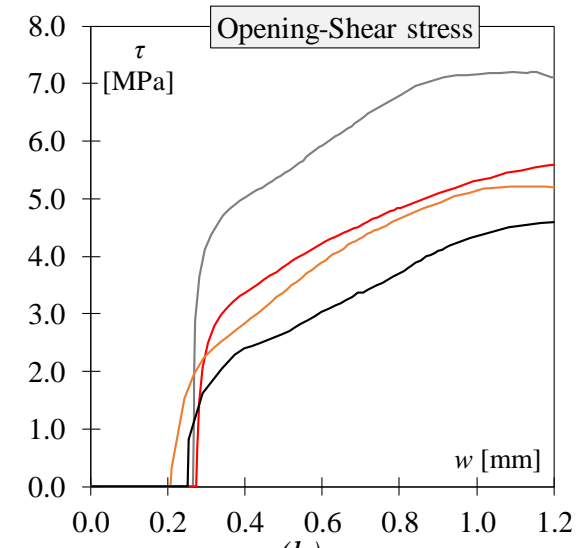

(b)

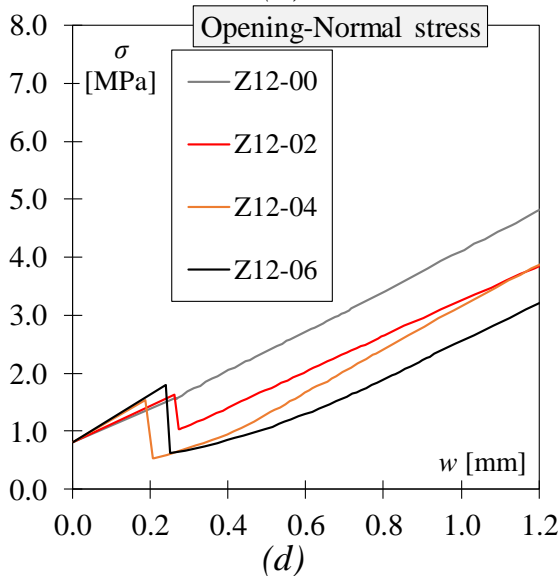

(d)

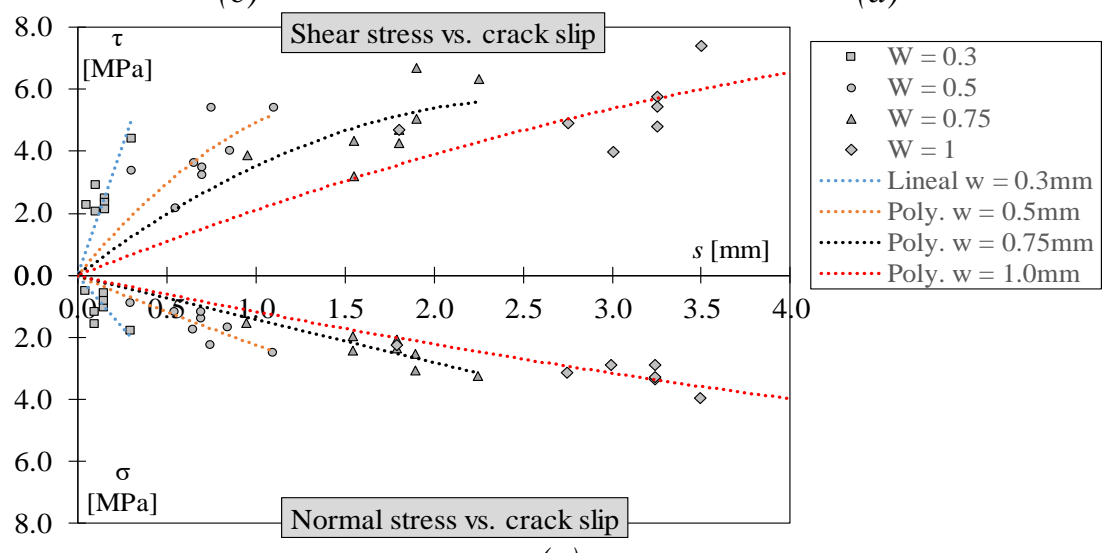

(e)

Figure 3-31: PFRC12 general results: crack opening vs. crack slip (a), crack opening vs. shear stress (b), slip displacement vs. shear stress (c), crack opening vs. normal stress (d) and interaction diagram (d). 
Chapter 3. PFRC in small specimens

\subsection{Effect of fibre content on shear behaviour}

Table 3-14 summarises the test results of specimens at $0.5,1.5,2.5$ and $3.5 \mathrm{~mm}$ of slip displacement to determine the effect of fibre content on shear. When comparing the PC shear stresses with PFRC8 and PFRC12, we observed an increment from 0.05 to 0.32 $\mathrm{MPa}$ in PFRC8, and from 0.61 to $1.46 \mathrm{MPa}$ in PFRC12. When comparing the shear stress increment between PFRC8 and PFRC12, the increment ranged from 0.08 to $1.41 \mathrm{MPa}$, depending on the crack slip and $W$. Nevertheless, we should remember that, as seen in Figure 3-29, Figure 3-30 and Figure 3-31, each specimen type had its particular initial conditions $\left(w_{0}\right.$ and $\sigma_{0}$ ) that affected its shear behaviour. As a result, the increments presented in Table 3-14 represent an estimation. Nevertheless, the increments between both types of PFRC results agree with those obtained in the FIP shear test.

The increment in shear due to fibres, as well as their differences owing to the initial conditions, is better visualised in Figure 3-32, where the specimens of each concrete type, with the same $W(0.0$ and $0.4 \mathrm{~mm})$, are compared. When comparing concretes at $W=0.0 \mathrm{~mm}$ (see Figure 3-32a and Figure 3-32b), different initial crack openings close to $0.2 \mathrm{~mm}$ were obtained. Shear stress incremented with 8 and $12 \mathrm{~kg} / \mathrm{m}^{3}$ of fibres. In addition, when comparing the tests results at $W=0.4 \mathrm{~mm}$ (Figure 3-32c and Figure 3-32c), a significant initial crack opening difference among the three appeared.

Table 3-14: The Sher tests results comparison (CV in brackets)

\begin{tabular}{|c|c|c|c|c|}
\hline ID & $\begin{array}{c}\boldsymbol{\tau}_{\mathbf{0 . 5}} \\
{[\mathbf{M P a}]}\end{array}$ & $\begin{array}{c}\boldsymbol{\tau}_{\mathbf{1 . 5}} \\
{[\mathbf{M P a}]}\end{array}$ & $\begin{array}{c}\boldsymbol{\tau} \text { 2.5 } \\
{[\mathbf{M P a}]}\end{array}$ & $\begin{array}{c}\boldsymbol{\tau}_{3.5} \\
{[\mathbf{M P a}]}\end{array}$ \\
\hline Z0-00 & $4.37(0.12)$ & $5.01(0.09)$ & $5.46(0.06)$ & $5.68(0.06)$ \\
\hline Z8-00 & $4.69(0.04)$ & $5.29(0.10)$ & $5.67(0.12)$ & $5.73(0.12)$ \\
\hline Z8-02 & $3.37(0.05)$ & $4.32(0.05)$ & $4.74(0.03)$ & $4.91(0.02)$ \\
\hline Z8-04 & $3.30(0.05)$ & $4.01(0.04)$ & $4.35(0.09)$ & $4.60(0.15)$ \\
\hline Z8-06 & $2.05(0.01)$ & $3.30(0.02)$ & $4.02(0.01)$ & $4.49(0.02)$ \\
\hline Z12-00 & $4.98(0.04)$ & $6.03(0.07)$ & $6.81(0.07)$ & $7.14(0.05)$ \\
\hline Z12-02 & $3.45(0.02)$ & $4.51(0.06)$ & $5.10(0.07)$ & $5.45(0.10)$ \\
\hline Z12-04 & $3.02(0.06)$ & $4.27(0.08)$ & $4.84(0.07)$ & $5.18(0.09)$ \\
\hline Z12-06 & $2.77(0.36)$ & $3.80(0.23)$ & $4.42(0.19)$ & $4.61(0.18)$ \\
\hline Inc. 0-8 in 00 & 0.32 & 0.28 & 0.21 & 0.05 \\
\hline Inc. 0-12 in 00 & 0.61 & 1.02 & 1.35 & 1.46 \\
\hline Inc. 8-12 in 00 & 0.29 & 0.74 & 1.14 & 1.41 \\
\hline Inc. 8-12 in 02 & 0.08 & 0.19 & 0.36 & 0.54 \\
\hline Inc. 8-12 in 04 & -0.28 & 0.26 & 0.49 & 0.58 \\
\hline Inc. 8-12 in 06 & 0.72 & 0.50 & 0.40 & 0.12 \\
\hline
\end{tabular}




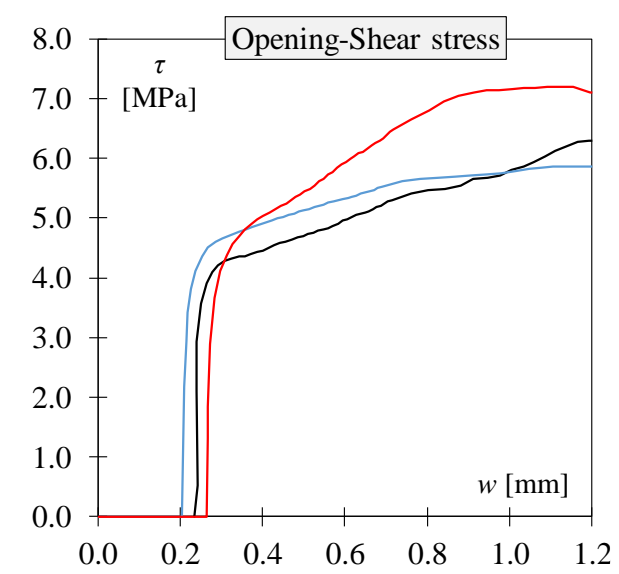

(a)
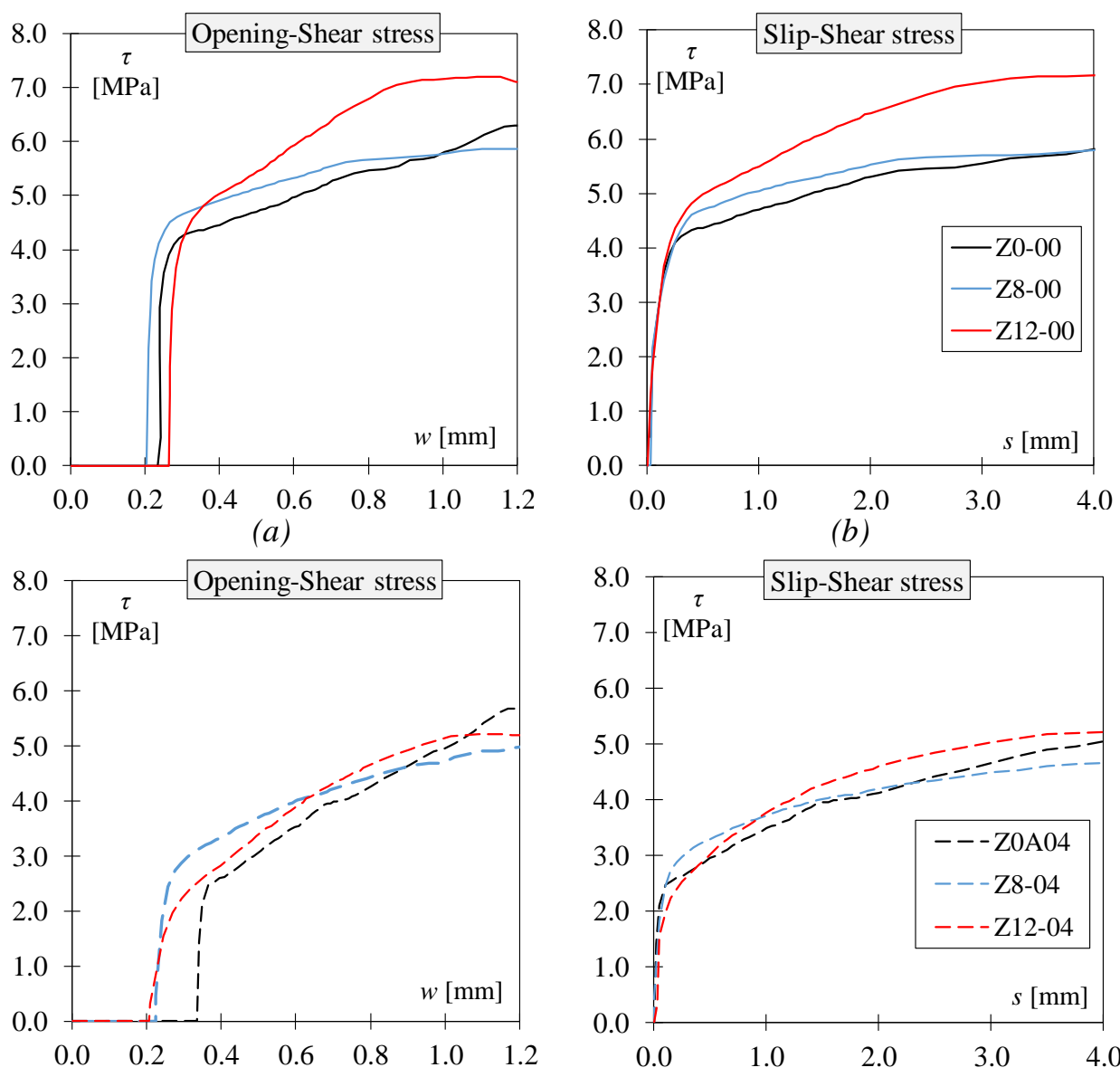

(c)

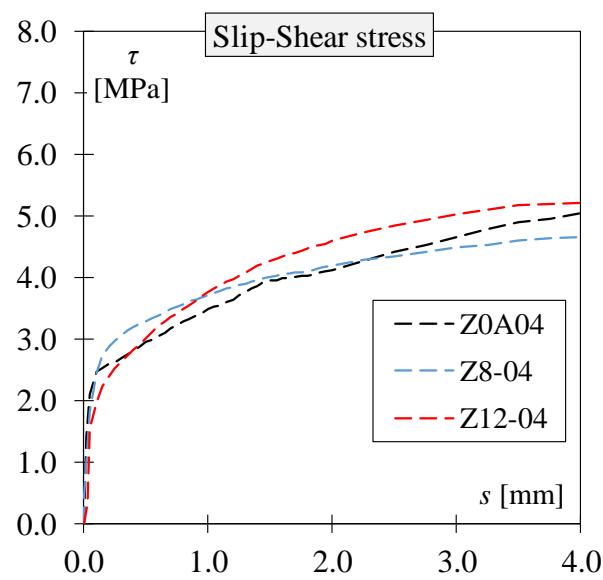

(d)

Figure 3-32: Comparison between the PC results and PFRC8 and PFRC12.

Finally, a comparison (Figure 3-33) of shear and normal stresses, according to slip and crack opening, between both the PFRC results was made using the previously obtained trend lines. Both shear and normal stresses increased with the increment in fibre content from 8 to $12 \mathrm{~kg} / \mathrm{m}^{3}$. In fact this increment was more evident for large slip displacement than for small ones. In Figure 3-33, we should note that the increase in normal stresses due to the increment in fibres was more evident at crack openings of 0.3 and $0.5 \mathrm{~mm}$ than at 0.75 and $1.0 \mathrm{~mm}$, where PFRC presented similar behaviour. 
Chapter 3. PFRC in small specimens

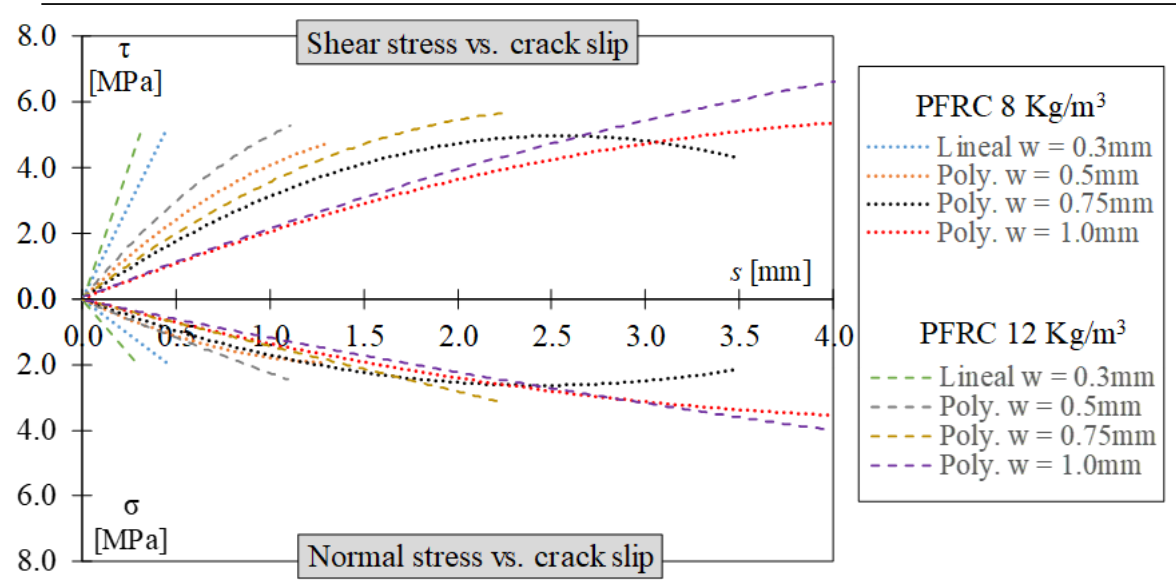

Figure 3-33: Comparison of the trend lines between PFRC8 and PFRC12

\subsection{Effect of initial confinement on specimens' shear behaviour}

Table 3-15 presents the shear results at a slip equalling 0.5 and $2.0 \mathrm{~mm}$ with their corresponding $\mathrm{W}, \sigma_{0}$ and $w_{0}$. To supplement Table 3-15, Figure 3-34 shows the influence of $W$ on crack opening and confinement prior to the push-off test of all the tests. On the one hand and as Figure 3-34a shows, $W$ significantly influenced the $\sigma_{0}$ of all the specimens, and the larger $W$ introduced into specimens, the less the confinement present in the specimens prior to the push-off test. No major variations in confinement were observed in W over $0.4 \mathrm{~mm}$. On the other hand (see in Figure 3-34b), apparently $W$ had no influence on the crack opening of specimens before the push-off test.

Table 3-15: Shear stress results with their corresponding confinement.

\begin{tabular}{|c|c|c|c|c|c|}
\hline $\mathbf{I D}$ & $\begin{array}{c}\boldsymbol{W} \\
{[\mathbf{m m}]}\end{array}$ & $\begin{array}{c}\boldsymbol{w o}_{\boldsymbol{0}} \\
{[\mathbf{m m}]}\end{array}$ & $\begin{array}{c}\boldsymbol{\sigma}_{\boldsymbol{0}} \\
{[\mathbf{M P a}]}\end{array}$ & $\begin{array}{c}\boldsymbol{\tau}_{0.5} \\
{[\mathbf{M P a}]}\end{array}$ & $\begin{array}{c}\boldsymbol{\tau}_{2.5} \\
{[\mathbf{M P a}]}\end{array}$ \\
\hline Z0-00 & 0.00 & 0.24 & 1.84 & 4.37 & 5.68 \\
\hline $\mathrm{Z} 0 \mathrm{~A} 02$ & 0.20 & 0.26 & 1.09 & 3.46 & 4.69 \\
\hline $\mathrm{Z} 0 \mathrm{~A} 04$ & 0.40 & 0.28 & 0.64 & 2.96 & 4.90 \\
\hline $\mathrm{Z} 8-00$ & 0.00 & 0.21 & 1.60 & 4.69 & 5.73 \\
\hline Z8-02 & 0.20 & 0.25 & 0.87 & 3.37 & 4.91 \\
\hline Z8-04 & 0.40 & 0.22 & 0.35 & 3.3 & 4.6 \\
\hline Z8-06 & 0.60 & 0.27 & 0.68 & 2.05 & 4.49 \\
\hline Z12-00 & 0.00 & 0.27 & 1.57 & 4.98 & 7.14 \\
\hline Z12-02 & 0.20 & 0.28 & 1.03 & 3.45 & 5.45 \\
\hline Z12-04 & 0.40 & 0.21 & 0.54 & 3.02 & 5.18 \\
\hline Z12-06 & 0.60 & 0.25 & 0.63 & 2.77 & 4.61 \\
\hline
\end{tabular}


Effectiveness of polypropylene fibres as shear reinforcement in structural elements

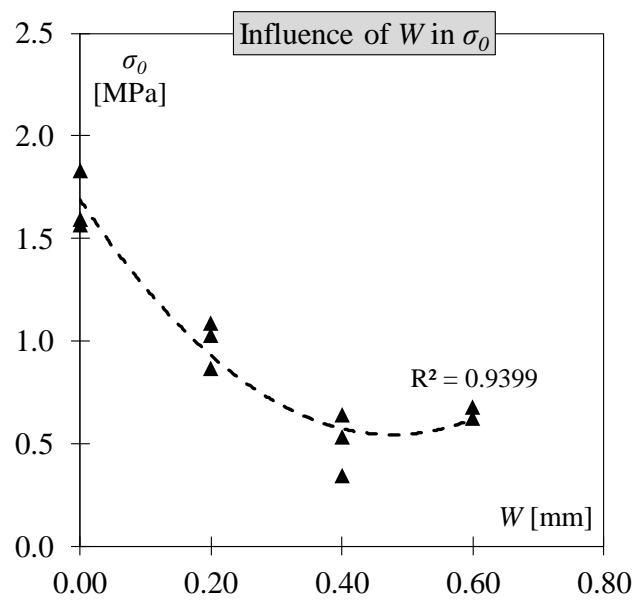

(a)

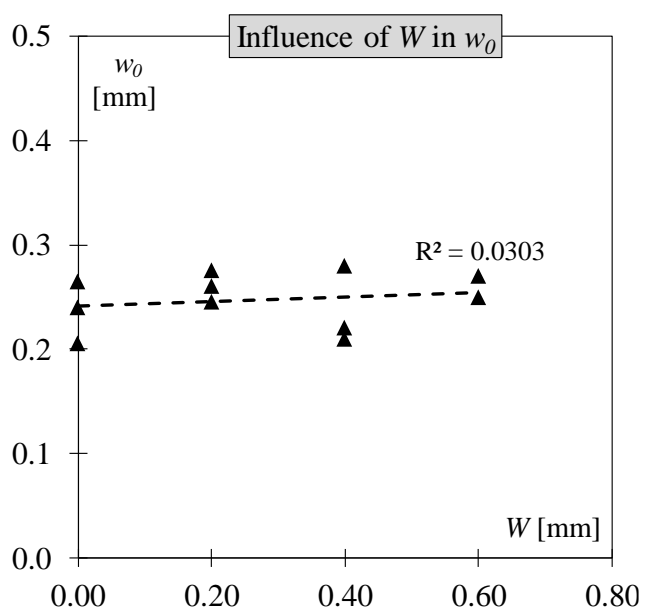

(b)

Figure 3-34: Relation between the initial crack gap with confinement (a) and crack opening (b).

Figure 3-35 slows the influence of the existing confinement $\left(\sigma_{0}\right)$ on the shear behaviour of specimens at different slip displacements $(s=0.5$ and $2.5 \mathrm{~mm})$. Confinement strongly influenced shear behaviour in the three employed concrete types. Therefore, when confinement was greater, the obtained shear stress was as Figure 3-35a shows. In fact this trend was observed in the three used concretes and when slip displacement equalled 2.5 (see Figure 3-35b).

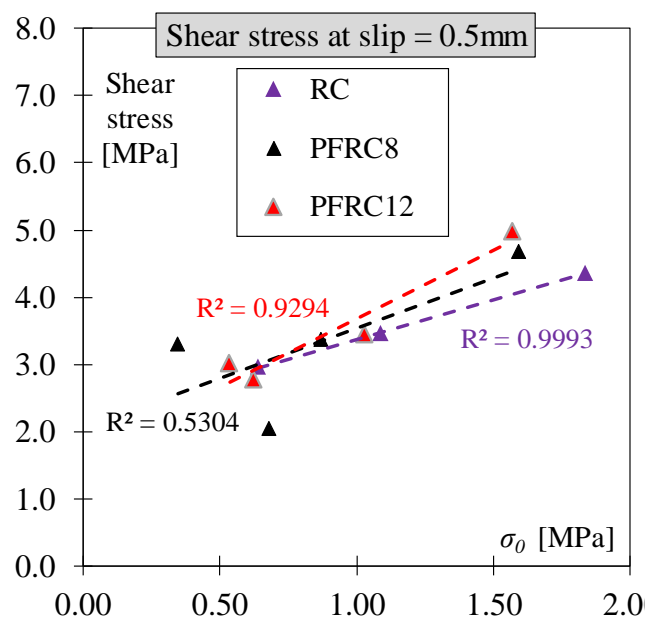

(a)

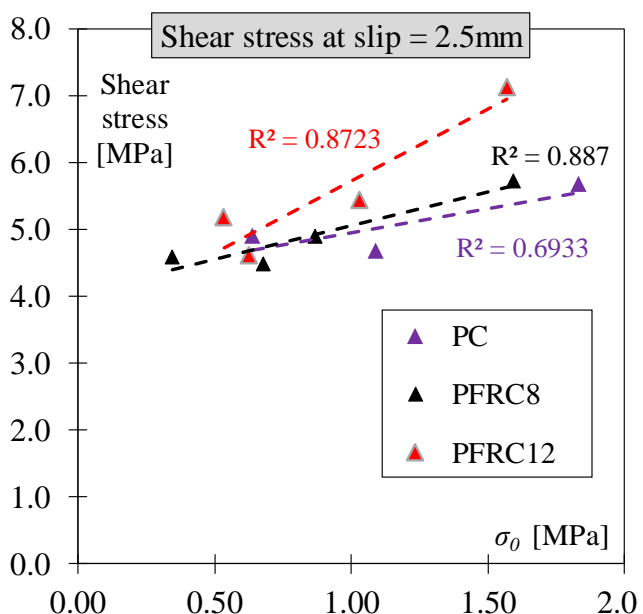

(b)

Figure 3-35: Relation between confinement and shear stress at $\operatorname{slip}=\mathbf{0 . 5} \mathrm{mm}(\mathrm{a})$ and $\mathrm{slip}=\mathbf{2 . 5}$ mm (b). 


\subsubsection{Concluding remarks}

Twenty pre-cracked push-off specimens were tested to experimentally explore the effect of fibre content, the confinement of specimens and initial crack opening prior to the pushoff test in the shear transfer of PFRC. To this end specimens, PC and PFRC were manufactured, pre-cracked and tested under direct shear. The studied fibre contents were 8 $\mathrm{kg} / \mathrm{m}^{3}$ and $12 \mathrm{~kg} / \mathrm{m}^{3}$.The initial conditions were introduced by the initial crack gap ( $\mathrm{W}=0.0,0.2,0.4$ and $0.6 \mathrm{~mm}$ ).

According to this framework, and based on the experimental results obtained in this study, the following conclusions can be drawn:

a) When fibre content increased from $8 \mathrm{~kg} / \mathrm{m}^{3}$ to $12 \mathrm{~kg} / \mathrm{m}^{3}$, post-cracking flexural and shear strengths also incremented. However, shear strength did not considerably increment when fibre content varied from 0 to $8 \mathrm{~kg} / \mathrm{m}^{3}$ as observed from 0 to $12 \mathrm{~kg} / \mathrm{m}^{3}$

b) The shear fracture energy measured from the crack displacements between 0.36 to $2.71 \mathrm{~mm}$ was 1.25 - to 1.36 -fold the flexural fracture energy measured at the same crack opening $(\mathrm{CMOD}=0.5$ to $3.5 \mathrm{~mm})$. Although more experimentation performed with different fibre contents is necessary, this result confirms a direct relation between PFRC shear behaviour and its post-cracking flexural tensile strength properties

c) Based on the PC and PFRC push-off results, the influence of the shear transfer mechanism depended on the initial conditions prior to the push-off test. In fact the specimens' confinement had a strong influence before test $\sigma_{0}$ on the shear strength in all the specimens

d) Similar to experimental campaign one, the present push-off results revealed that the crack opening introduced prior to the push-off test also played a key role in transmitting stresses. The shear and normal stresses were smaller upon greater crack opening

e) When fibre dose was increased from $8 \mathrm{~kg} / \mathrm{m}^{3}$ to $12 \mathrm{~kg} / \mathrm{m}^{3}$, normal and shear stresses rose up to 1.0 MPa. This increment mainly depended on crack opening and crack slip displacement. In fact with larger crack opening and slip displacements, the results better evidenced the contribution of fibres to transfer stresses than other shear transfer mechanisms.

Finally, it is underlined that the present experimental campaign was done to supplement experimental campaign one to obtain a better understanding of the the parameters and shear transfer mechanism that acted during the push-off test. Based on these results and conclusion, the specimens tested in the present campaign were studied analytically in the next section. 


\subsection{Analytical modelling of the shear transfer of PFRC cracks}

In the present section, an analytical model that evaluated the behaviour of shear crack was developed. For this purpose, the model incorporated the transfer mechanism that acted in shear crack, as well as the parameters observed in the previous experimental campaigns, which strongly influenced shear transfer. As the model also incorporated the shear transfer mechanism, the effects of the aggregate interlock and fibres could be quantified. Nevertheless, the experimental campaign two results were compare to the analytical results obtained by the present model.

Feenstra [200] stated that the formulation of a crack constitutive relation should consider three possible states that arise at discrete cracks: before cracking (state 1), at the initiation and development of discrete crack (state 2) and an open crack state (state 3). In this context, it is worth mentioning that the model's scope falls within an open crack state and, therefore, the states before cracking or initiation, and the development of a discrete crack, were not studied.

The state of a crack can be defined by its global displacements ( $\boldsymbol{\varepsilon})$, constituted by crack opening (w) and slip displacement (s), as well as its global stresses ( $\boldsymbol{\sigma})$, which includes normal stress $(\sigma)$ and shear stress $(\tau)$ (see Figure 3-36 and (Eq. 3-28)).

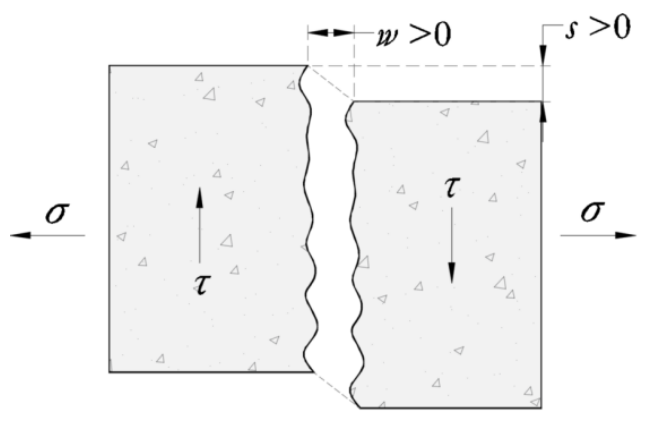

Figure 3-36: Crack opening state

$$
\varepsilon=\left[\begin{array}{l}
w \\
s
\end{array}\right] ; \sigma=\left[\begin{array}{l}
\sigma \\
\tau
\end{array}\right]
$$

The constitutive relation of an open crack has to establish a relation between the stresses and displacements acting on the crack. Thus following a total deformation theory, this relation could be expressed as (Eq. 3-29).

$$
\sigma=\sigma(\varepsilon)
$$

Based on (Eq. 3-28) and (Eq. 3-29), the formulation to study a shear crack in the present analysis was based on an additive model which took the following mechanisms into account (Figure 3-37): the initial confinement effect (pre-compression) $\left(\boldsymbol{\sigma}_{0}\right)$, the confinement effect by an active or passive mechanism $\left(\boldsymbol{\sigma}_{c}\right)$, the aggregate interlock $\left(\boldsymbol{\sigma}_{a}\right)$ and fibres $\left(\boldsymbol{\sigma}_{F}\right)$. Hence equations (Eq. 3-29) can be expressed as follows: 


$$
\sigma=\sigma_{0}+\sigma_{c}(\varepsilon)+\sigma_{a}(\varepsilon)+\sigma_{F}(\varepsilon)
$$

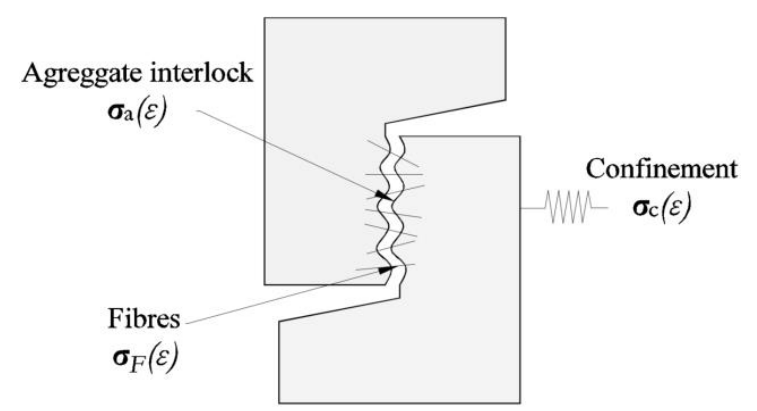

Figure 3-37: Transferring mechanism that acts on the pre-cracked push-off test

\subsubsection{Mechanisms of shear transfer in the pre-cracked push-off test}

\subsection{Initial confinement effect due to pre-compression}

The effect of pre-compression results in initial confinement $\left(\sigma_{\text {ini }}\right)$, pre-cracking stage $\left(\sigma_{p}\right)$ and confinement release $\left(\sigma_{d}\right)$, provided by the bars constituting the external rigid frame. This initial confinement causes normal stress in concrete at the start of the push-off test stage $\left(\sigma_{0}\right)$. Therefore, $\sigma_{0}$ could produce shear stresses due to friction when crack faces start sliding.

Based on the Coulomb friction law, the maximum shear stress transferred through an interface increases when normal stress also increases. Thus the effect of initial confinement was taken into account in the present analysis by the following expression (Eq. 3-31)

$$
\tau_{0}=\mu \sigma_{0}
$$

where $\mu$ is the characteristic friction coefficient of the crack interface; $\sigma_{0}$ is the confinement present in all specimens prior to the push-off test. As the experimental campaign results were analysed by an analytical model, $\sigma_{0}$ of each specimen is found in Table 3-13.

In order to determine the $\mu$ of the crack surfaces in experimental campaign two, a regression analysis using the PC experimental results (normal and shear stress vs. slip displacement) was performed to determine existing friction coefficient $\mu$ and cohesion based on the Coulomb equation $(\tau=c+\mu \sigma)$. As seen in Table 3-16, the average cohesion and friction coefficient of the crack surfaces in experimental campaign two resulted in 2.6 $\mathrm{MPa}$ and 0.75 , respectively, both with a coefficient of variation less than $13 \%$. In fact when taking into account that the concrete compression strength of the PC specimens was $43.62 \mathrm{MPa}$, an approximation of the cohesion according to compression strength resulted in $0.21\left(f_{c}\right)^{2 / 3}$ (see Table 3-17). 
Effectiveness of polypropylene fibres as shear reinforcement in structural elements

Finally, to validate the determined $\mu$ and $b$, they were compared in Table 3-17 with those $\mu$ and $b$ suggested by MC2010, Climaco and Regan[201], and Seung-Jun Kwon et al. [202] for rough surfaces. To supplement Table 3-17, Figure 3-38 displays the PC experimental results along with the analytical results proposed by MC2010, Climaco and Regan $(\mathrm{C} \& \mathrm{R})$ and Seung-Jun Kwon et al. (SJK), by applying the Coulomb equation. The present experimental results always provided slightly higher $\mu$ and $b$ coefficients than those recommended by MC2010, which were lower than the other expressions. Nevertheless, the results were expected. Therefore in the present analytical model, friction coefficient $\mu$ was considered to equal 0.75 , which is slightly higher than that recommended by $\operatorname{MC} 2010(\mu=0.7)$.

Table 3-16: Cohesion and friction coefficients of the PC specimens

\begin{tabular}{|c|c|c|c|}
\hline Specimen & $\begin{array}{c}\text { Cohesion }(\boldsymbol{c}) \\
{[\mathbf{M P a}]}\end{array}$ & $\begin{array}{c}\boldsymbol{\mu} \\
{[-]}\end{array}$ & $\begin{array}{c}\boldsymbol{f}_{\boldsymbol{c}} \\
{[\mathbf{M P a}]}\end{array}$ \\
\hline Z0A00 & 2.6 & 0.66 & 43.62 \\
\hline Z0B00 & 3 & 0.72 & 43.62 \\
\hline Z0A02 & 2.6 & 0.74 & 43.62 \\
\hline Z0A04 & 2.2 & 0.88 & 43.62 \\
\hline Average & $2.6(0.125)$ & $0.75(0.124)$ & \\
\hline
\end{tabular}

Table 3-17: Comparison of cohesion and friction coefficients with models

\begin{tabular}{|c|c|c|}
\hline Model & $\begin{array}{c}\boldsymbol{c} \\
{[\mathrm{MPa}]}\end{array}$ & $\begin{array}{c}\boldsymbol{\mu} \\
{[-]}\end{array}$ \\
\hline Model Code 2010 (MC2010) & $0.10\left(f_{c}\right)^{1 / 3}$ & 0.7 \\
\hline Climaco and Regan (C\&R) & $0.25\left(f_{c}\right)^{2 / 3}$ & 1.4 \\
\hline Seung-Jun Kwon et al. (SJK) & $0.27\left(f_{c}\right)^{0.65}$ & 0.95 \\
\hline This Study & $0.21\left(f_{c}\right)^{2 / 3}$ & 0.75 \\
\hline
\end{tabular}




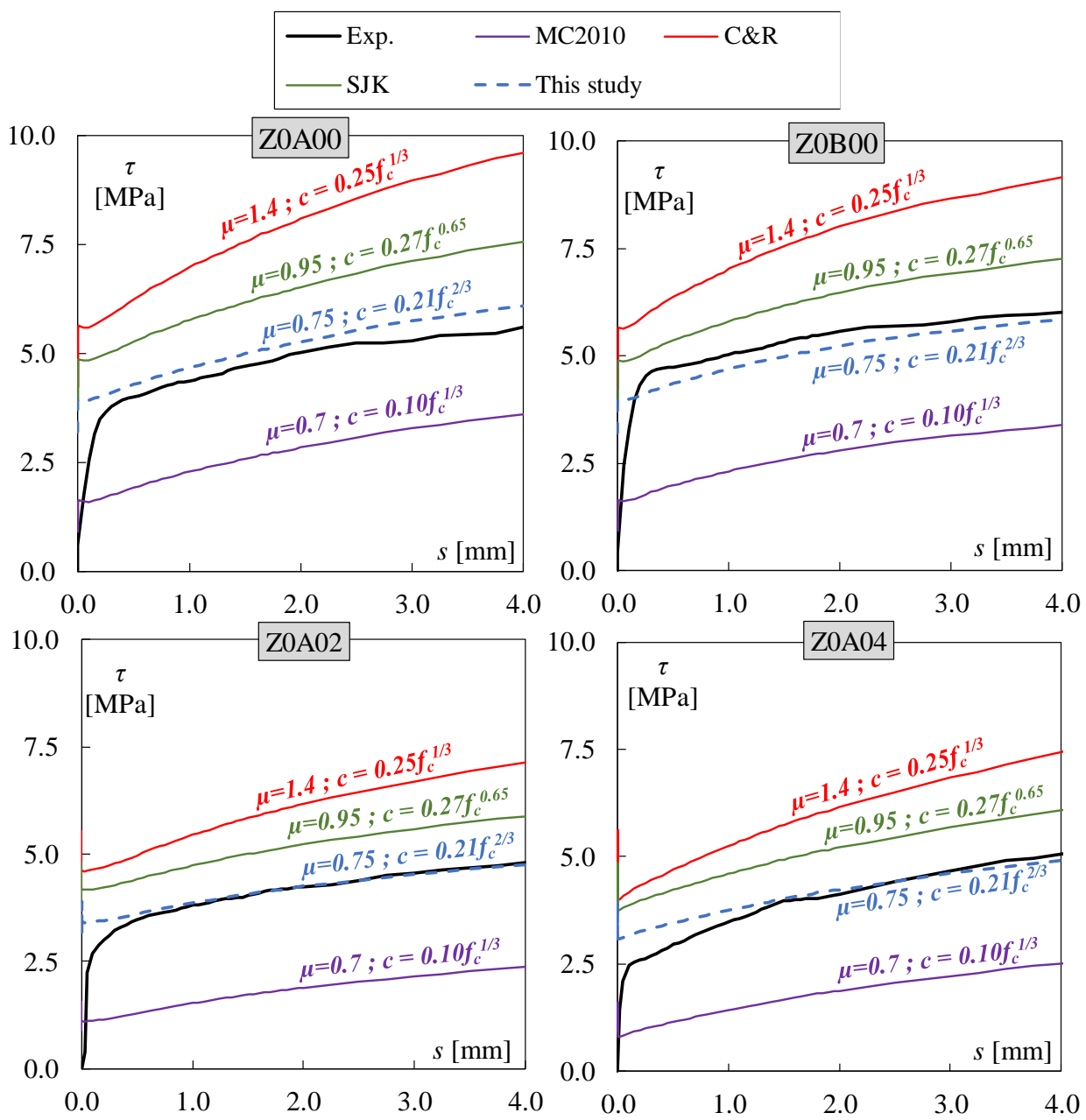

Figure 3-38: Comparison between friction and cohesion coefficients by applying the Coulomb equation.

\subsection{Confinement effect by an active or passive mechanism}

It is possible to control crack opening by means of an active (bar reinforcement) or passive mechanism (external mechanism) that acts normally to the shear plane. Several authors have done this to study the crack kinematics under crack control conditions using an active or passive mechanism $[82,92,127,135]$. This confinement effect can be formulated by normal stress, which depends only on crack opening. In this context, the confinement effect $\left(\boldsymbol{\sigma}_{c}\right)$ can be expressed as follows (Eq. 3-32). 
Effectiveness of polypropylene fibres as shear reinforcement in structural elements

$$
\sigma_{c}=\left[\begin{array}{c}
\sigma_{c}(w) \\
0
\end{array}\right]
$$

As the external steel frame (bars and plates) that provided the confinement effect was designed to work under linear deformation (elastic zone) without yielding steel, normal stresses highly depended on the external frame stiffness. Accordingly, the normal stress due to confinement $\left(\sigma_{c}(w)\right)$ can be expressed as a linear function as in (Eq. 3-33).

$$
\begin{aligned}
& \sigma_{c}(w)=k_{c}(w)+b \\
& \sigma_{c}\left(w_{0}\right)=k_{c}\left(w_{0}\right)+b=\sigma_{0}
\end{aligned}
$$

where $k_{c}$ is external frame stiffness and $b$ is an adjustment coefficient, both determined by a regression analysis of the experimental normal stresses obtained in the push-off tests. Thus if (Eq. 3-33) is evaluated at $w_{0}$, the normal stress confining the specimens $\left(\sigma_{0}\right)$ prior to the push-off test must be obtained (see Figure 3-39a) and (Eq. 3-34).

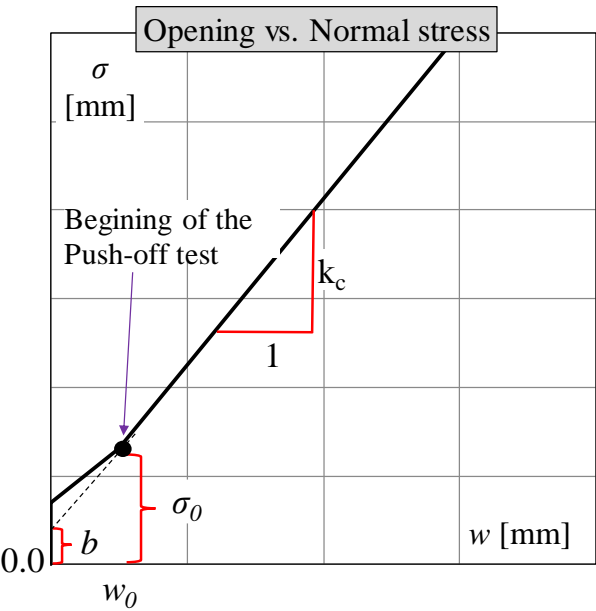

(a)

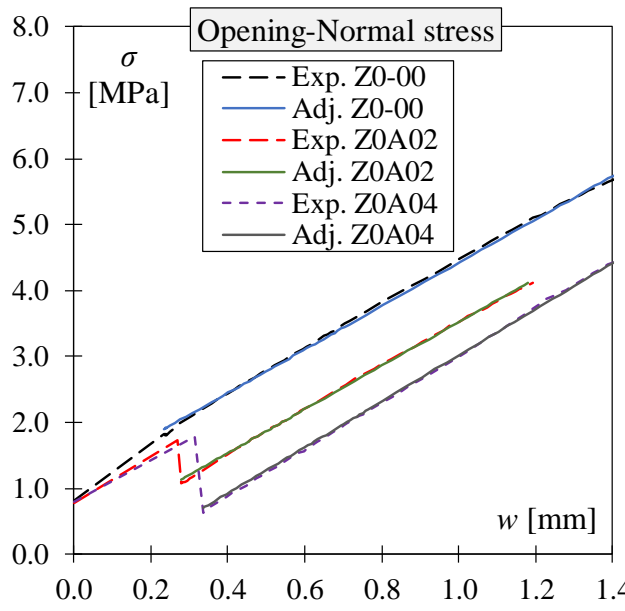

(b)

Figure 3-39: Function of confinement effect: scheme (a) and PC results adjustments

Table 3-18 summarises external frame $\left(k_{c}\right)$ stiffness by it acting on every experimental result, as well as its adjustment coefficient $(b) . k_{c}$ varied from 2.96 to $3.49\left[\mathrm{~N} / \mathrm{mm}^{3}\right]$, with an average value of 3.28 and a coefficient of variation of $6 \%$. Nevertheless, Figure 3-39b displays a comparison between the experimental and adjusted confinement of the PC specimens. 
Chapter 3. PFRC in small specimens

Table 3-18: Confinement Adjustment Parameters

\begin{tabular}{|c|c|c|}
\hline ID & $k_{c}$ & $\begin{array}{c}b \\
{[\mathrm{MPa}]}\end{array}$ \\
\hline Z0A00 & $\left.\mathbf{\mathbf { m }} \frac{\mathbf{m}}{\mathbf{m m}^{\mathbf{2}}}\right]$ & \\
\hline Z0B00 & 3.31 & 1.15 \\
\hline Z0A02 & 3.27 & 1.11 \\
\hline Z0A04 & 3.56 & 0.18 \\
\hline Z8A00 & 3.11 & -0.54 \\
\hline Z8B00 & 3.57 & 0.88 \\
\hline Z8A02 & 3.50 & 0.99 \\
\hline Z8B02 & 3.54 & -0.13 \\
\hline Z8A04 & 3.25 & -0.02 \\
\hline Z8B04 & 3.20 & -0.42 \\
\hline Z8A06 & 3.01 & -0.44 \\
\hline Z8B06 & 2.85 & -0.42 \\
\hline Z12A00 & 3.50 & -0.23 \\
\hline Z12B00 & 3.42 & 0.75 \\
\hline Z12A02 & 2.67 & 0.55 \\
\hline Z12B02 & 3.31 & 0.42 \\
\hline Z12A04 & 3.79 & 0.05 \\
\hline Z12B04 & 3.29 & -0.43 \\
\hline Z12A06 & 3.05 & -0.41 \\
\hline Z12B06 & 3.46 & -0.66 \\
\hline Average $k_{c}$ & $\mathbf{3 . 3 0}(\mathbf{0 . 0 7})$ & -0.52 \\
\hline & & \\
\hline
\end{tabular}

\subsection{Aggregate interlock}

In the present analysis, the following four constitutive models were taken into account to include the aggregate interlock mechanism:

- $\quad$ The empirical rough crack model proposed by Bazant and Karakoç in1983 [90] (Eq. 3-17) and (Eq. 3-18)

- $\quad$ The simplified model proposed by Walraven and Reinhardt in 1981 [92] (Eq. 3-21) and (Eq. 3-22)

- $\quad$ The empirical Contact Density Model proposed by Li and Maekawa in 1987 [91] (Eq. 3-23) and (Eq. 3-24) 
- The simplified method was developed by Vecchio and Collins (1986), is based on a regression analysis of the Walraven test results, and is only in accordance with crack opening ( $w$ ) and normal stress ( $\sigma$ ) (see (Eq. 3-35) and (Eq. 3-36)).

$$
\begin{gathered}
\tau=0.18 \tau_{\max }+\frac{1.64 \sigma^{2}}{\tau_{\max }} \\
\tau_{\max }=\frac{\sqrt{f_{c m}}}{0.21+\frac{24 \mathrm{w}}{D_{\max }+16}}
\end{gathered}
$$

\subsection{Fibre contribution}

Fibre contribution to shear in the present analysis was taken into account using three different models:

- Pfyl's model [144] (2003), previously presented in section 2.2.2.2. See (Eq. 2-35) and (Eq. 2-36)

$$
\begin{aligned}
& \sigma_{c f}=\sigma_{c f o}\left(2 \sqrt{\frac{u}{u_{0}}}-\frac{u}{u_{0}}\right), 0 \leq u \leq u_{0} \\
& \sigma_{c f}=\sigma_{c f o}\left(1-\frac{2 u}{l_{f}}\right)^{2}, u_{0}<u \leq \frac{l_{f}}{2}
\end{aligned}
$$

- Kaufmann et al. model (2019) [97], previously presented in section 2.2.2.2. See (Eq. 2-51) and (Eq. 2-52). The fibres-aggregate interlock interaction proposed in Kaufmann's model was taken into account during the present analytical modelling (see Figure 2-15 and (e.q. 2-31))

$$
\begin{aligned}
& \sigma_{c f \alpha}=\frac{1}{\sin \alpha_{r}} \sigma_{c f o}\left(2 \sqrt{\frac{\delta}{u_{0}}}-\frac{\delta}{u_{0}}\right), 0 \leq \delta \leq u_{0} \\
& \sigma_{c f \alpha}=\frac{1}{\sin \alpha_{r}} \sigma_{c f o}\left(1-\frac{2 u}{l_{f}}\right)^{2}, u_{0}<\delta \leq \frac{l_{f}}{2}
\end{aligned}
$$

- Tensile behaviour of fibres obtained by an inverse analysis (hereafter inverse model) of the small prismatic beams tested according to EN 14654, where the average residual flexural tensile strengths were determined for each PFRC type. The average tensile behaviour of each PFRC type used in the present analysis 
are presented in Figure 3-40. The tensile behaviour of each PFRC was obtained based on MC2010[7].

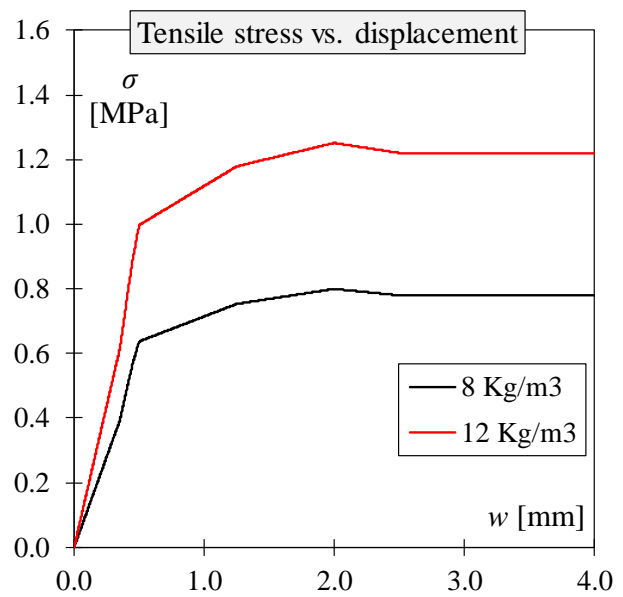

Figure 3-40: Tensile behaviour of PFRC obtained by an inverse model

Both Pfyl's and Kaufmann's models were developed to be used with hooked-end steel fibres. Thus a calibration of this model to be used with polypropylene fibres is required. This calibration is performed in the next section of this chapter.

Regarding the tensile behaviour of fibres, as Figure 3-41 shows it was assumed that all the fibres acted in Mode I (tension), although crack acted in Mode II (shear). This behaviour was considered because before the push-off test, a crack opening was induced during the pre-cracking process.

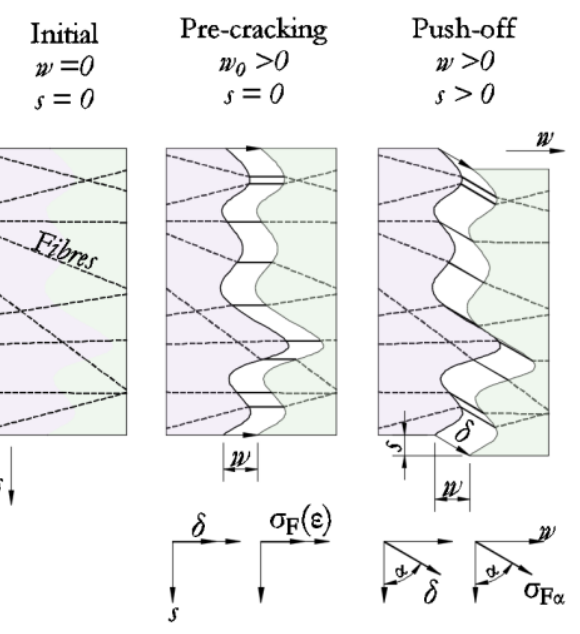

Figure 3-41: Fibre behaviour in concrete 
Effectiveness of polypropylene fibres as shear reinforcement in structural elements

As fibres acted in direction $(\delta)$ which, according to crack opening $(w)$ and crack slip $(s)$, developed an inclination $(\alpha)$ as Figure 3-41 shows, both direction and inclination were determined by (Eq. 3-37) and (Eq. 3-38).

$$
\begin{aligned}
& \delta=\sqrt{s^{2}+w^{2}} \\
& \alpha=\tan ^{-1} \frac{\delta_{w}}{\delta_{s}}
\end{aligned}
$$

With this framework, the uniaxial tensile behaviour of fibres was decomposed in both shear and normal stress contributions (see (Eq. 3-39)) using (Eq. 3-40) and (Eq. 3-41).

$$
\begin{aligned}
\sigma_{F} & =\left[\begin{array}{l}
\sigma_{f}(\varepsilon) \\
\tau_{f}(\varepsilon)
\end{array}\right] \\
\sigma_{f} & =\sigma_{F \alpha} \sin ^{2} \alpha \\
\tau_{f} & =\sigma_{F \alpha} \sin \alpha \cos \alpha
\end{aligned}
$$

\subsubsection{Calibration of the aggregate interlock and fibre models}

In the aggregate interlock, two of the three models (rough crack and contact density) considered in the present analysis took into account the effect of the maximum aggregate size $\left(D_{\max }\right)$. In both models, it was assumed that when a shear crack appeared in a concrete element, the crack would form through the concrete matrix and the borders of aggregates. This effect allowed the aggregate interlock when shear faces of the crack started slipping. Therefore, the roughness of crack faces increased with a bigger aggregate size. However during the FIP shear and push-off tests, the crack went through aggregates (see Figure 3-42) rather than around them. So less roughness of the interface crack really existed. In order to include this effect, the maximum aggregate size in the present analysis was replaced with half its value; i.e. from 14 to $7 \mathrm{~mm}$.

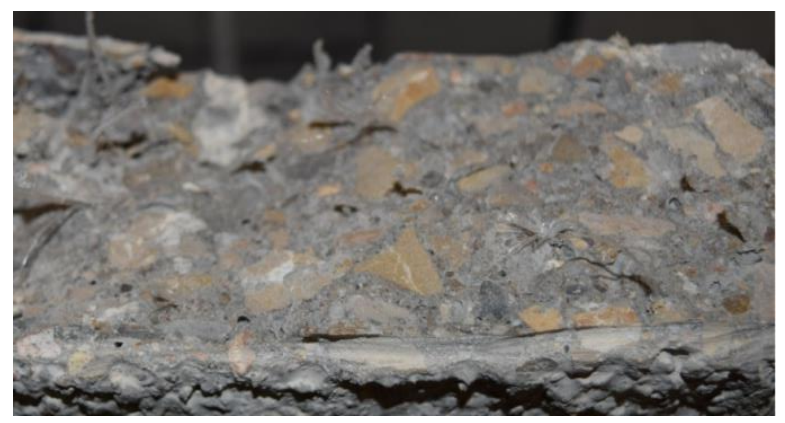

Figure 3-42: PC FIP specimen surface 
As two of the three fibre models used in the present analysis were developed using steel fibres, the models were calibrated to be used with macrosynthetic fibres. This calibration was based on the results of the pull-out test performed by Alberti et al. [45], where polyolefin fibres ( $60 \mathrm{~mm}$ long, $0.92 \mathrm{~mm}$ equivalent diameter) were pulled out from a selfcompacting concrete matrix at different embedded lengths and inclination angles. Table 3-19 summarises the debonding stresses obtained by Alberti et al. in those tests where the pull-out of fibre was reached. The average debonding stress resulted in 5.05 MPa for a fibre embedded in a matrix with a concrete compressive strength of 39MPa.

Table 3-19: Fibre pull-out results obtained by Alberti et al. [45]

\begin{tabular}{|c|c|c|c|}
\hline Case & $\begin{array}{c}\text { Embedded } \\
\text { length } \\
{[\mathbf{m m}]}\end{array}$ & $\begin{array}{c}\text { Inclined } \\
\text { angle } \\
{\left[{ }^{\circ}\right]}\end{array}$ & $\begin{array}{c}\text { Debonding } \\
\text { stress } \\
{[\mathbf{M P a}]}\end{array}$ \\
\hline 1 & 5 & 0 & 4.34 \\
\hline 2 & 5 & 15 & 5.70 \\
\hline 3 & 5 & 30 & 7.60 \\
\hline 4 & 5 & 45 & 3.98 \\
\hline 5 & 10 & 0 & 4.96 \\
\hline 6 & 10 & 15 & 5.12 \\
\hline 7 & 10 & 30 & 4.53 \\
\hline 8 & 10 & 45 & 5.81 \\
\hline 9 & 15 & 0 & 4.55 \\
\hline 10 & 15 & 15 & 4.69 \\
\hline 11 & 15 & 30 & 4.52 \\
\hline 12 & 15 & 45 & 4.76 \\
\hline & & Average $=$ & $\mathbf{5 . 0 5}(\mathbf{0 . 1 9})$ \\
\hline
\end{tabular}

Regarding fibre contributions, and based on the previous debonding stress, the fibre average bonding stress $\left(\tau_{b f}\right)$ (see (Eq. 2-38)) considered in both the Pfyl and Kaufmann models changed from $0.6 \sqrt[3]{f_{c}{ }^{2}}$ to $0.4 \sqrt[3]{f_{c}{ }^{2}}$.

Finally, in order to check the calibration of the aggregate and fibre models, the models and the experimental results of the FIP shear test were compared (see Figure 3-43). The models with modifications were able to simulate the shear-to slip behaviour of the experimental results obtained after performing a direct shear test based on the FIP standard. 
Effectiveness of polypropylene fibres as shear reinforcement in structural elements

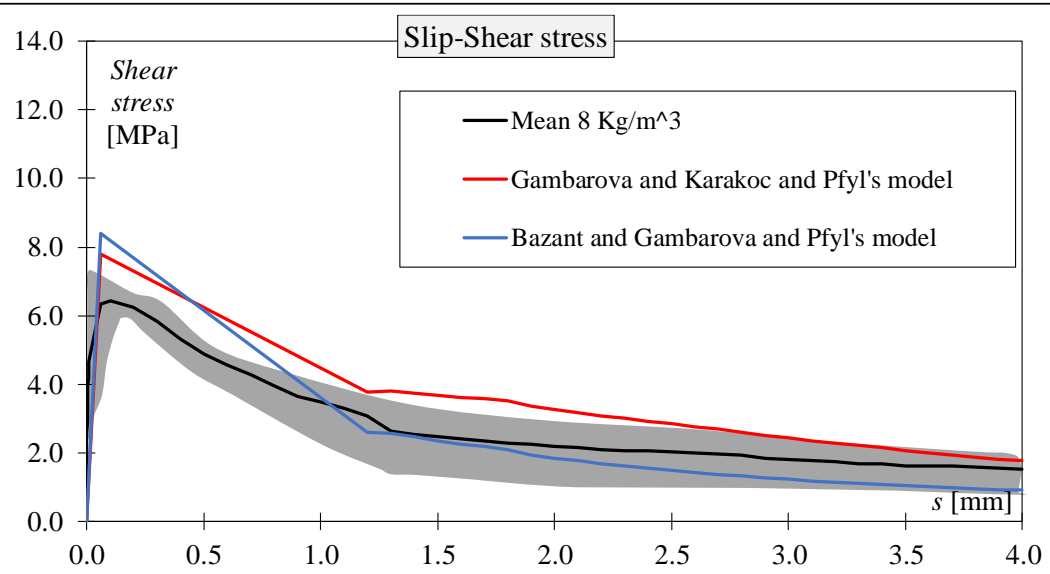

a)

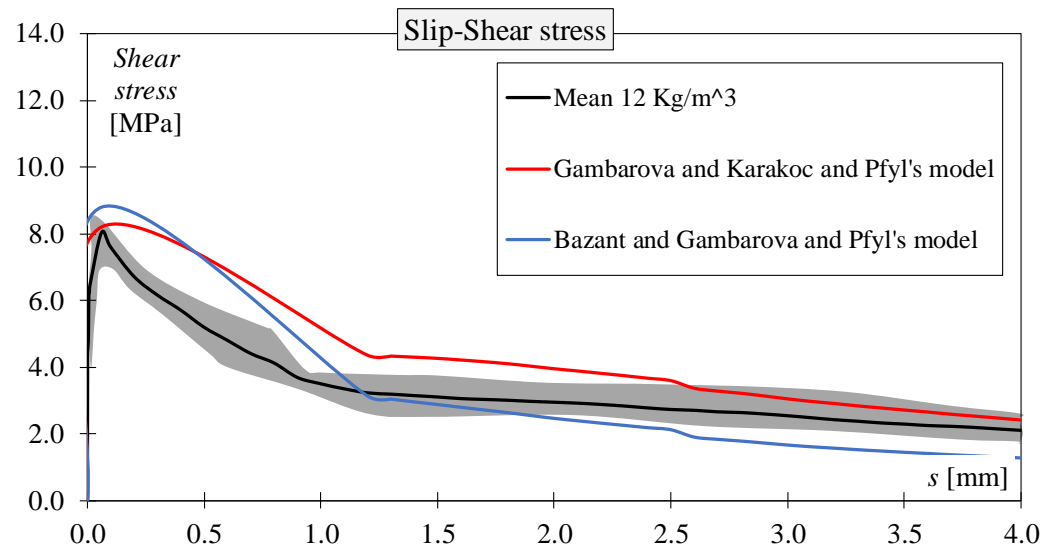

b)

Figure 3-43: Comparison between the FIP experimental results and models: $8 \mathrm{~kg} / \mathrm{m}^{3}$ (a) and 12 $\mathrm{kg} / \mathrm{m}^{3}(\mathbf{b})$

\subsubsection{Implementation and verification of the model}

\subsection{Implementation}

The numerical implementation of the model was done to reproduce the test under controlled crack opening conditions (see Figure 3-44). The test consisted of two main phases. The first one was constituted by the frame assembly, pre-cracking process and handling stage, while the second phase was the push-off test. In the first phase, specimens were subjected to a transverse load on the shear plane that generated displacements $(w>0$ and $s=0$ ) in the crack. 


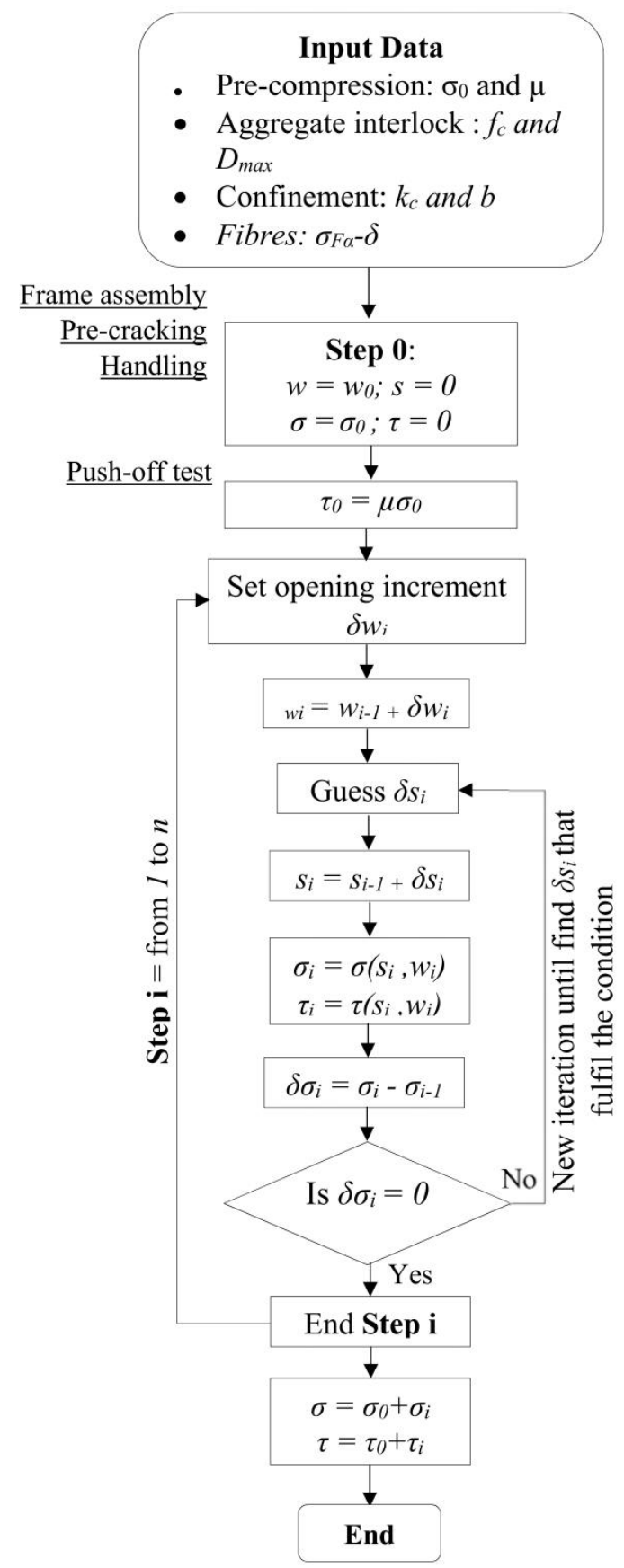

Figure 3-44: Numerical procedure, push-off test under crack opening control 
These displacements generated normal internal stress $\left(\sigma_{p}\right)$ that, once the allowed initial crack gap $(W)$ had been introduced, turned into $\left(\sigma_{0}\right)$, governed exclusively by confinement, pre-compression and fibres (in the PFRC specimens).

In the push-off test stage, the test was reproduced under controlled opening displacement conditions where, each increase in the slip displacement in the crack led to incremented shear stresses $(\Delta \tau)$. The increase in normal stresses $(\Delta \sigma)$ had to be zero because no external horizontal forces influenced the specimen, as seen in (Eq. 3-42) and (Eq. 3-43).

$$
\begin{aligned}
& \Delta \sigma=\Delta \sigma_{a}+\Delta \sigma_{c}+\Delta \sigma_{F}+\sigma_{0}=0 \\
& \Delta \sigma_{a}+\Delta \sigma_{F}+\sigma_{0}=-\Delta \sigma_{c}
\end{aligned}
$$

It was necessary to establish an iterative numerical procedure that solves all the steps considered in the crack opening control. This procedure was taken into account following a procedure based on crack tangent-stiffness. However, this was avoided in the present analysis methodology due to the fact stated by Bazant and Gambarova (1980): they stated that crack tangent-stiffness was never a positive definite, except for the shear displacements equalling zero. So crack showed an instability trend and it was necessary to stabilise the crack. A certain restrain can be obtained by means of the confinement system's effect. The adopted numerical procedure was based on a non-derivative procedure.

The numerical procedure was the push-off test under crack opening control according to Figure 3-44. To solve the model, the non-linear optimisation algorithms included in Visual Basic to solve a non-linear system of equations was used, where a convergence criterion of $0.0001 \mathrm{~mm}$ was employed. The step size was considered constant and equalled $0.05 \mathrm{~mm}$, which seemed a quasi-continuous numerical simulation.

\subsection{Validation}

The proposed method was first validated by the Walraven experimental tests with external restraint bars (Series B). In these specimens, the only activated mechanism was initial pre-compression, the aggregate interlock and the confinement effect.

By way of example, the complete numerical validation of specimens 1/0/7.8 and 3/0.4/0.6 is presented in Figure 3-45 and Figure 3-46, respectively. These two specimens were selected because in the first (1/0/7.8) specimen, three mechanisms of shear transfer acted: pre-compression, the aggregate interlock and confinement effect, while only acting the aggregate interlock and the confinement effect acted at large crack openings in the second specimens. Therefore, specimens $1 / 0 / 7.8$ were totally confined and specimens 3/0.4/0.6 were completely released.

The following material data were taken: $f_{c, \text { cube }}=38.5 \mathrm{MPa}$ for $1 / 0 / 7.8$ and $57.4 \mathrm{MPa}$ $3 / 0.4 / 0.6$. It is worth mentioning that the Walraven and Reinhardt simplified model (W\&R) used $f_{c, \text { cube }}$ instead of $f_{c}$. Hence we considered $f_{c}=0.83 f_{c, \text { cube }}$ for the models developed by Bazant and Karakoç (G\&K), Contact Density Model (CDM) and Vecchio 
Chapter 3. PFRC in small specimens

and Collins $(\mathrm{V} \& \mathrm{C})$. In all the models, the maximum aggregate size $\left(D_{\max }\right)$ was considered to equal $16 \mathrm{~mm}$, as Walraven reported [92]. Finally the initial crack opening ( $\left.w_{0}\right)$ and slip displacement $\left(s_{0}\right)$ introduced into the models were those reported by Walraven for each specimen.

Finally, as specimens 3/0.4/06 presented a non-linear crack opening - normal stress behaviour (see Figure 3-46d), the confinement effect was introduced into the model as a third grade function to improve model predictions.

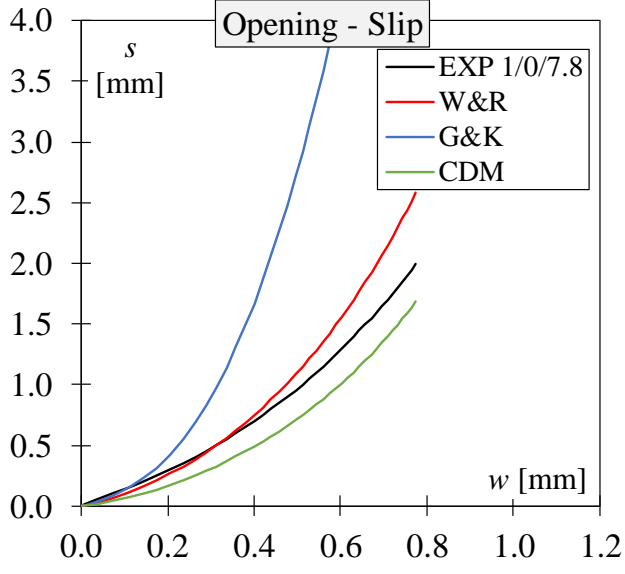

a)

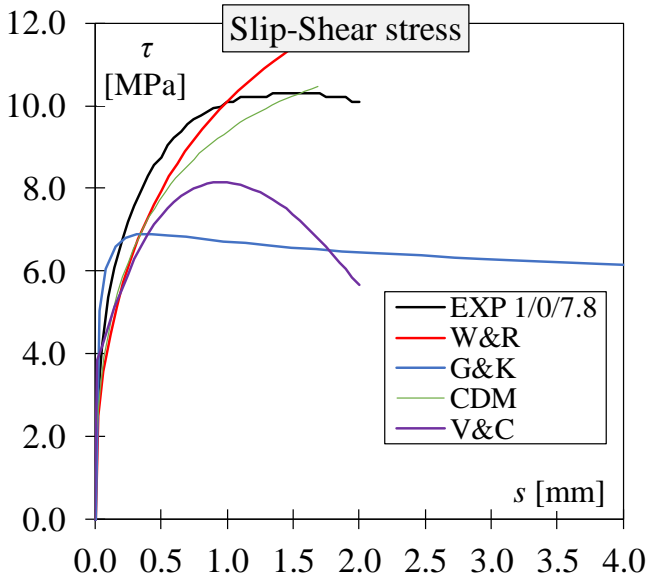

c)

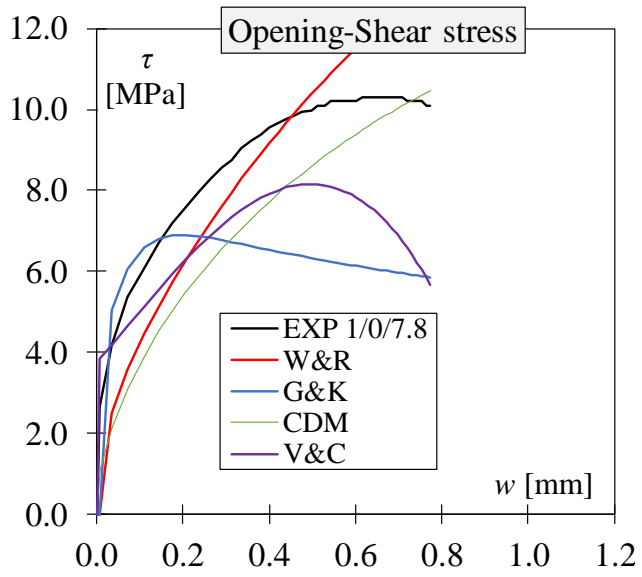

b)

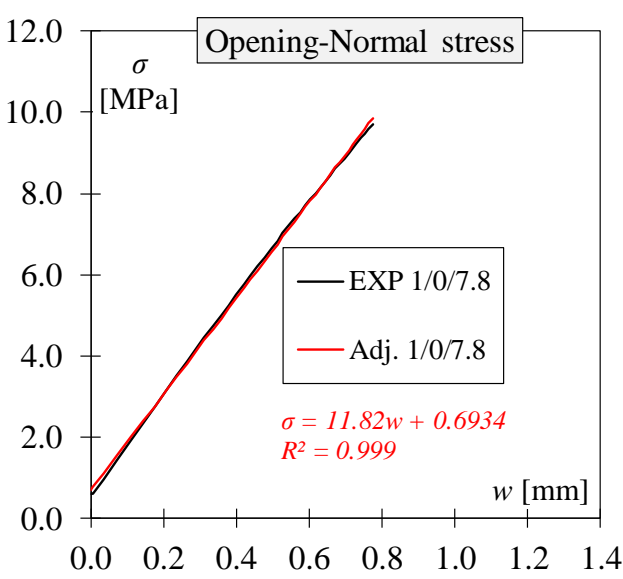

d)

Figure 3-45: Analytical validation of specimen 1/0/7.8 (totally confined specimen) tested by Walraven and Reinhardt 
Effectiveness of polypropylene fibres as shear reinforcement in structural elements

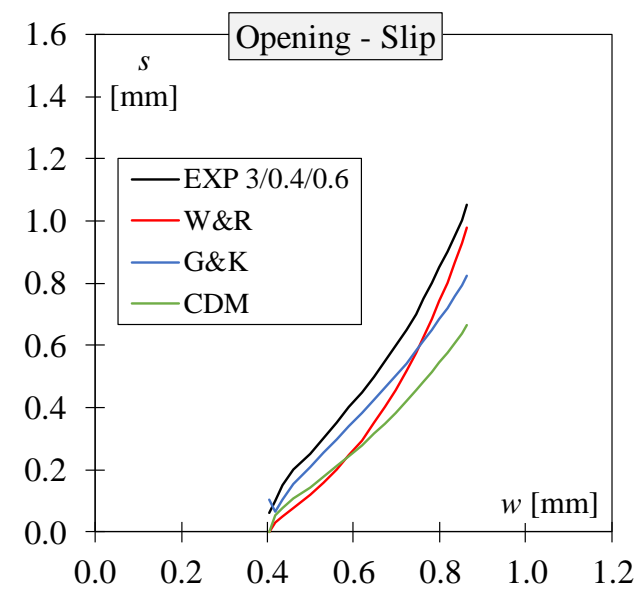

a)

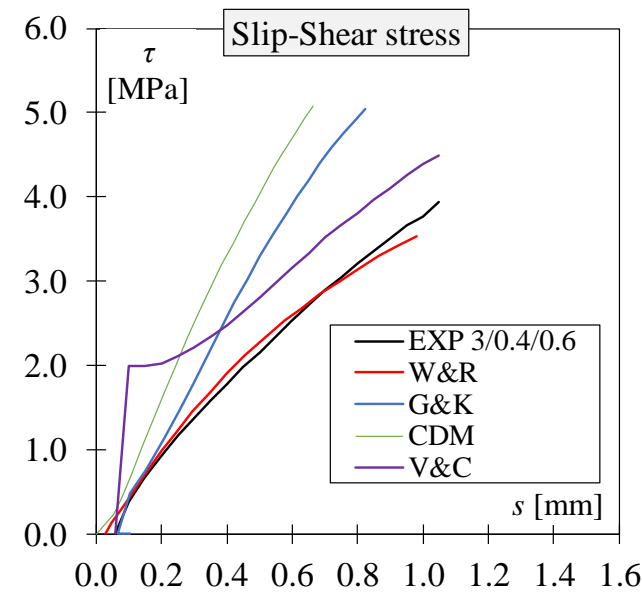

c)

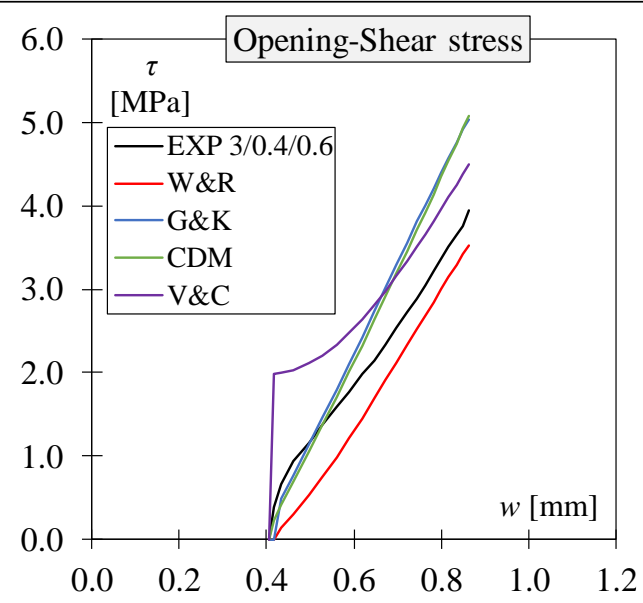

b)

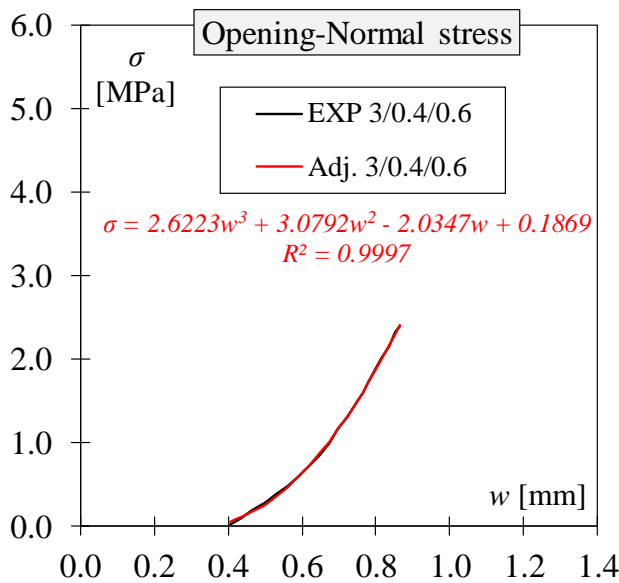

d)

Figure 3-46: Analytical validation of specimen 3/0.4/0.6 (totally released specimen) tested by Walraven and Reinhardt.

As seen in Figure 3-45d and Figure 3-46d, the employed adjustment function was quite accurate for capturing the confinement effect measured during the test, and presented an $\mathrm{R}^{2}$ over 0.99 in both specimens. The two specimens were selected as both presented different initial confinement conditions (totally confined, totally released) before the push-off test.

As seen in Figure 3-45c and Figure 3-46c, the analytical results are reasonably accurate despite the high sensitivity of shear crack. In fact the numerical procedure was capable of closely following all the behaviours noted in the experimental tests. The model that 
Chapter 3. PFRC in small specimens

better described the experiment shear behaviour of both specimens was that proposed by Walraven and Reinhardt. These results were expected because the experimental results of Walraven and Reinhardt were herein analysed to propose and validate their analytical model. Furthermore, differences to predict the shear behaviour among all the aggregate interlock models appeared despite most of them predicting the crack kinematics quite well with the experimental results. These results evidenced that the aggregate interlock needed to be studied in more depth to better understand the shear behaviour of concrete elements. Moreover, the present results also evidenced that to better determine the exact effect of fibres in shear, and the interaction of fibres with other mechanisms, firstly any doubts about the aggregate interlock should be solved before including a new unknown into the equation of the effect of fibres.

\subsubsection{Analytical push-off results}

\subsection{PC results}

The PC results of the numerical analysis are presented from Figure 3-47 to Figure 3-50. Each figure offers a comparison of the experimental results of push-off tests (tested in experimental campaign two) with the selected analytical models. Therefore, the comparison was made of the simplified models proposed by Walraven and Reinhardt (W\&R), Gambarova and Karakoç (G\&K), Contact Density Model (CDM) and the simplified formula set forward by Vecchio and Collins $(V \& C)$. For each specimen, the experimental response of crack slip vs. shear stress and crack opening vs. shear stress were compared with the aforementioned aggregate interlock models. In these comparisons, slip displacements up to $2.5 \mathrm{~mm}$ and crack openings up to $1.2 \mathrm{~mm}$ were taken into account.

As seen in Figure 3-47 to Figure 3-50, all the aggregate interlock models quite accurately described crack opening vs. shear behaviour of push-off tests. In fact the models that better fitted the experimental results were those developed by Vecchio and Shim based on a regression analysis of Walraven's tests. In addition, when comparing crack slip vs. shear stress to the aggregate interlock's models, that by Vecchio and Collins was able to well describe behaviour, followed by the prediction by the Walraven and Reinhardt model. However, the model that poorly described shear behaviour was CDM, as proposed by Li and Maekawa.

Figure 3-47 to Figure 3-50 revealed that the W\&R and G\&K aggregate interlock models started to considerably at decrease approximately $1.5 \mathrm{~mm}$ of slip displacement, while the $\mathrm{V} \& \mathrm{C}$ model continued growing. This behaviour could be due to W\&R and G\&K being developed based on push-off specimens that were tested up to $2 \mathrm{~mm}$ of displacement. TheV\&C model, which was developed based on the W\&R experimental result, also depended on normal stresses acting on specimens. 
Effectiveness of polypropylene fibres as shear reinforcement in structural elements

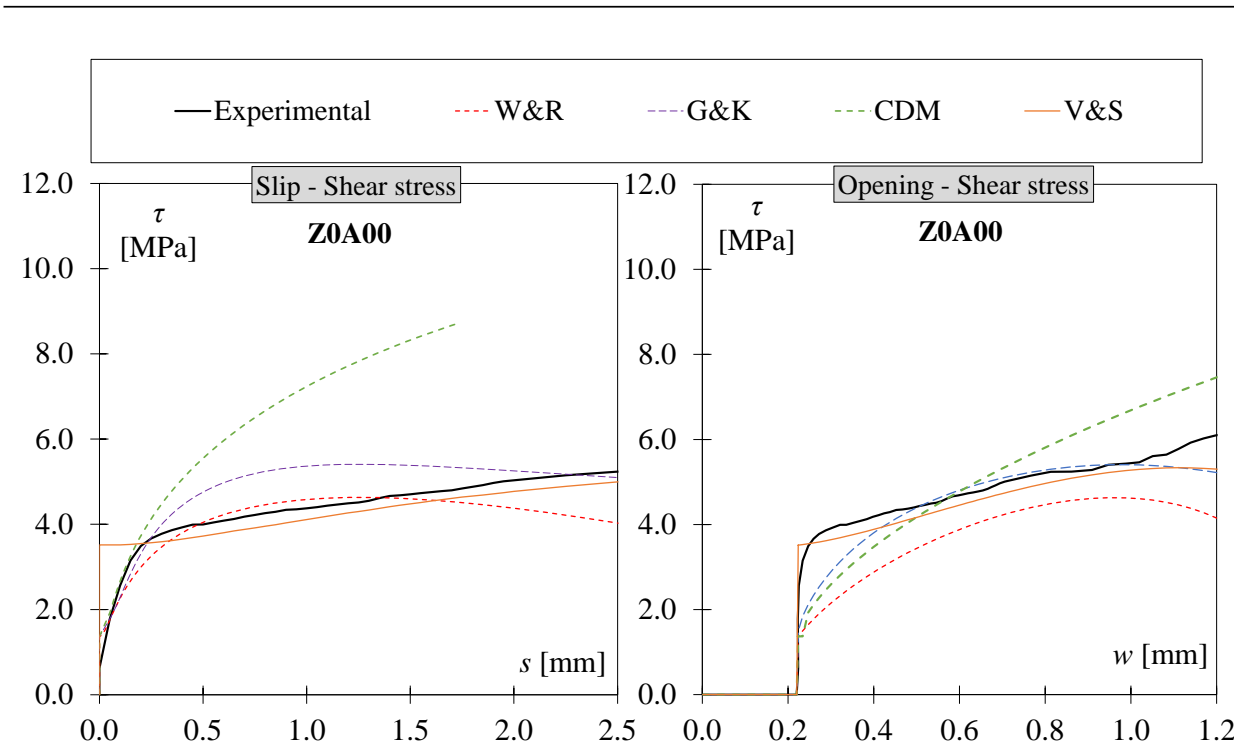

Figure 3-47: Analytical results of specimen Z0A00, $W=0.0 \mathrm{~mm}$ (totally confined).

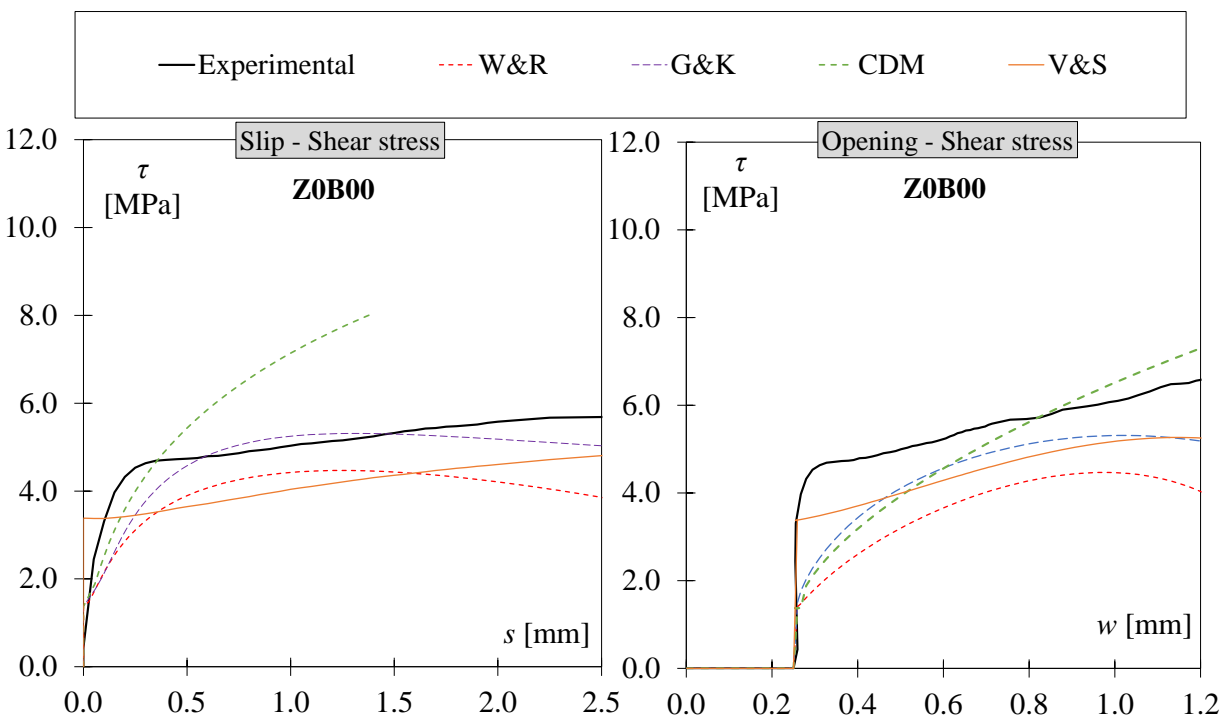

Figure 3-48: Analytical results of specimen $\mathrm{Z0B00}, W=\mathbf{0 . 0} \mathrm{mm}$ (totally confined). 


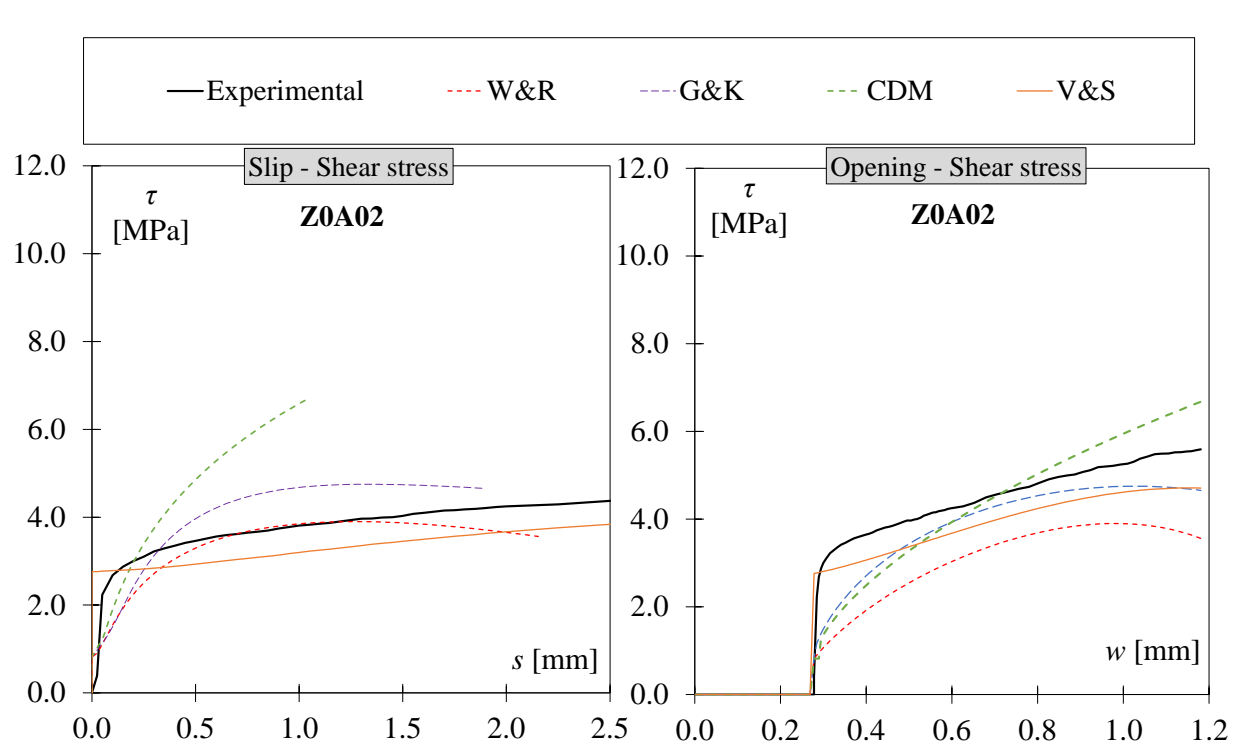

Figure 3-49: Analytical results of specimen Z0A02, $W=0.2 \mathrm{~mm}$ (partially confined).

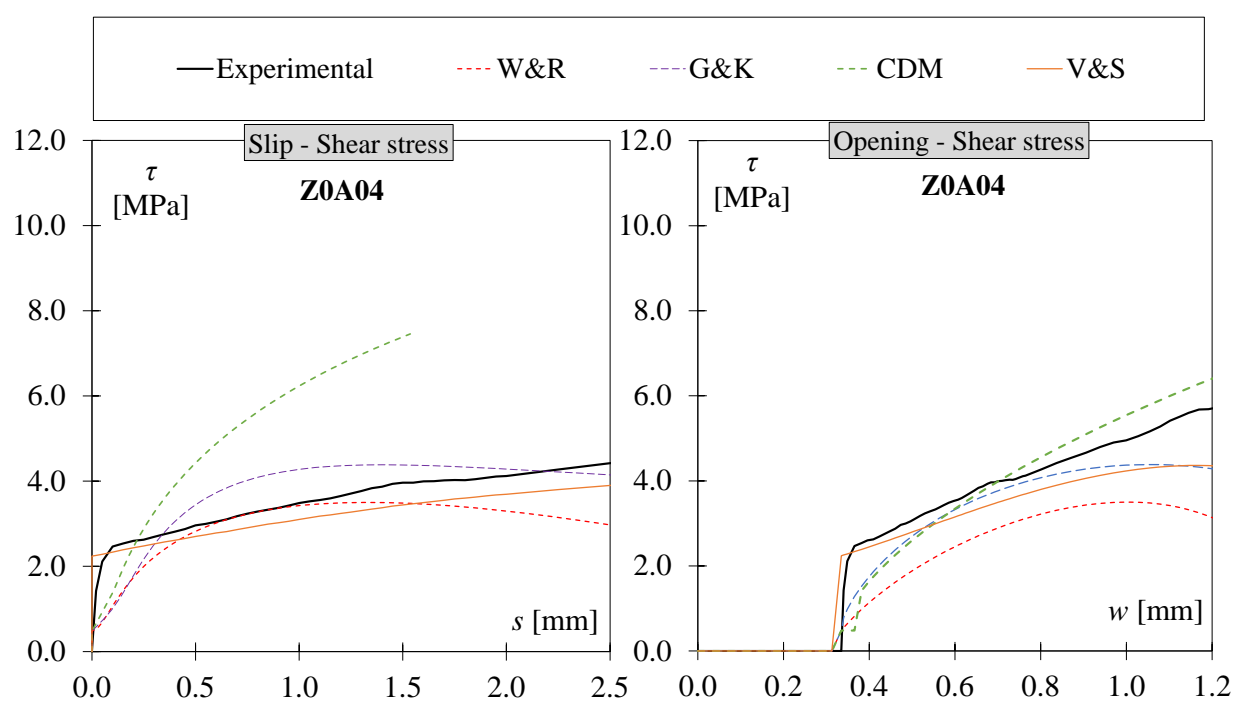

Figure 3-50: Analytical results of specimen Z0A04, $W=0.4 \mathrm{~mm}$ (partially confined). 
Effectiveness of polypropylene fibres as shear reinforcement in structural elements

The shear toughness provided by all the aggregate models employed and the experimental results were quantified and are presented in Table 3-20 and Table 3-21. Toughness was determined as the area below slip displacement and crack opening vs. the shear stress curves.

As seen in Table 3-20, the aggregate interlock model that better estimated shear behaviour according to the experimental crack slip was Gambarova and Karakoç's model with a ratio of 0.86 . The Contact Density Model (CDM) was the model that better estimated the shear behaviour of the PC specimens according to crack opening.

Despite the four aggregate models used in the present numerical validation providing good agreement compared to experimental results, further research is still required to better understand aggregate interlocks and the significant differences between them. 
Table 3-20: Shear toughness up to $\mathrm{s}=\mathbf{2 . 5} \mathrm{mm}$

\begin{tabular}{|c|c|c|c|c|c|c|c|c|c|}
\hline ID & $\begin{array}{c}\text { Exp. } \\
{[\mathrm{MPa}-\mathrm{mm}]}\end{array}$ & $\begin{array}{c}\text { W\&R } \\
{[\mathrm{MPa}-\mathrm{Rm}]}\end{array}$ & $\begin{array}{c}\text { G\&K } \\
{[\mathrm{MPa}-\mathrm{Mm}]}\end{array}$ & $\begin{array}{c}\mathrm{CDM} \\
{[\mathrm{MPa}-\mathrm{Mm}]}\end{array}$ & $\begin{array}{c}\text { V\&S } \\
{[\mathrm{MPa}-\mathrm{mm}]}\end{array}$ & $\begin{array}{c}\text { W\&R/Exp } \\
{[-]}\end{array}$ & $\begin{array}{c}\text { G\&K/Exp } \\
{[-]}\end{array}$ & $\begin{array}{c}\text { CDM/Exp } \\
{[-]}\end{array}$ & $\begin{array}{c}\text { V\&C/Exp } \\
{[-]}\end{array}$ \\
\hline Z0A00 & 12.31 & 9.65 & 11.79 & 10.96 & 10.66 & 0.78 & 0.96 & 0.89 & 0.87 \\
\hline Z0B00 & 14.00 & 9.98 & 11.62 & 7.99 & 10.36 & 0.71 & 0.83 & 0.57 & 0.74 \\
\hline Z0A02 & 10.55 & 7.37 & 7.75 & 4.71 & 8.27 & 0.70 & 0.74 & 0.45 & 0.78 \\
\hline Z0A04 & 10.00 & 7.38 & 9.21 & 7.75 & 8.01 & 0.74 & 0.92 & 0.77 & 0.80 \\
\hline
\end{tabular}

Table 3-21: Shear toughness up to $\mathrm{w}=1.5 \mathrm{~mm}$

\begin{tabular}{|c|c|c|c|c|c|c|c|c|c|}
\hline ID & Exp. & $\begin{array}{c}\text { W\&R } \\
{[\mathrm{MPa}-\mathrm{Rm}]}\end{array}$ & $\begin{array}{c}\text { G\&K } \\
{[\mathrm{MPa}-\mathrm{mm}]}\end{array}$ & $\begin{array}{c}\mathrm{CDM} \\
{[\mathrm{MPa}-\mathrm{mm}]}\end{array}$ & $\begin{array}{c}\mathrm{V} \& \mathrm{~S} \\
{[\mathrm{MPa}-\mathrm{mm}]}\end{array}$ & $\begin{array}{c}\text { W\&R/Exp. } \\
{[-]}\end{array}$ & $\begin{array}{c}\text { G\&K/Exp. } \\
{[-]}\end{array}$ & $\begin{array}{c}\text { CDM/Exp. } \\
{[-]}\end{array}$ & $\begin{array}{c}\text { V\&C/Exp. } \\
{[-]}\end{array}$ \\
\hline Z0A00 & 6.66 & 4.63 & 6.04 & 7.46 & 6.06 & 0.70 & 0.91 & 1.12 & 0.91 \\
\hline Z0B00 & 6.63 & 4.17 & 5.30 & 6.33 & 5.33 & 0.63 & 0.80 & 0.95 & 0.80 \\
\hline Z0A02 & 4.09 & 2.81 & 3.57 & 4.02 & 3.57 & 0.69 & 0.87 & 0.98 & 0.87 \\
\hline Z0A04 & 5.33 & 2.97 & 4.23 & 5.55 & 4.28 & 0.56 & 0.79 & 1.04 & 0.80 \\
\hline
\end{tabular}




\subsection{PFRC results}

Similarly to PC, the PFRC experimental results were compared to the agreggate interlock models: the simplified model by Walraven and Reinhardt (W\&R), the model of Gambarova and Karakoç (G\&K) and the Contact Density Model (CDM), by combining each one with three different fibre models. Hence the fibre models were the models of Pfyl and Kaufman et al. and the inverse model. The comparisons are presented from Figure 3-51 to Figure 3-66. In addition, for each specimen the experimental response of crack slip vs. shear stress and crack opening vs. shear stress were compared to the indicated model. In these comparisons, slip displacements up to $2.5 \mathrm{~mm}$ and crack openings up to $1.2 \mathrm{~mm}$ were taken into account.

As observed from Figure 3-51 to Figure 3-66, all the aggregate interlock models combined with the fibre model provided a good prediction of the shear stresses transmitted according to crack opening. However, if shear stresses were transmitted according to crack slip, then CDM combined with any of fibre model provide twice the experimental shear stresses. As with the PC specimens, the aggregate interlock model that better predicted the experimental results was that developed by Walraven and Reinhardt, followed by Gambarova and Karakoç's model.

For the fibre models used in the present analysis, the prediction of the shear stresses transmitted through the crack was similar between the model of Pfyl and the inverse model. In addition, the model proposed by Kaufmann et al., more overestimated the stresses transmitted by fibres, although the reduction deviation factor proposed by Kaufmann et al., that affects the aggregate interlock was incorporated into the employed threeaggregate model. In some cases, differences of almost 1.0 MPa were observed between Kaufmann's model and the other two considered fibre models.

Despite the combination of the different aggregate interlocks with the fibres model were pretty accurate in most cases compared to experimental results, Figure 3-67 shows the contribution of the different aggregate interlocks and fibres models to the total shear behaviour of specimens Z8B00. It is observed that the aggregate interlock was the main transfer mechanism in PFRC with fibre contents of $8 \mathrm{~kg} / \mathrm{m}^{3}$ and $12 \mathrm{~kg} / \mathrm{m}^{3}$, where fibres were only capable of transferring less than $1 \mathrm{MPa}$. This value is coincides with the contribution of fibres observed experimentally in campaign two.

Figure 3-67 illustrates the considerable differences between the different aggregate interlock models. When comparing these differences to those among the fibre models, the fibre differences were noticeably lesser than the aggregate interlock ones. These results evidence the need to firstly understand the shear transfer mechanism in PC to determine the fibre interaction with another mechanism. 
Chapter 3. PFRC in small specimens

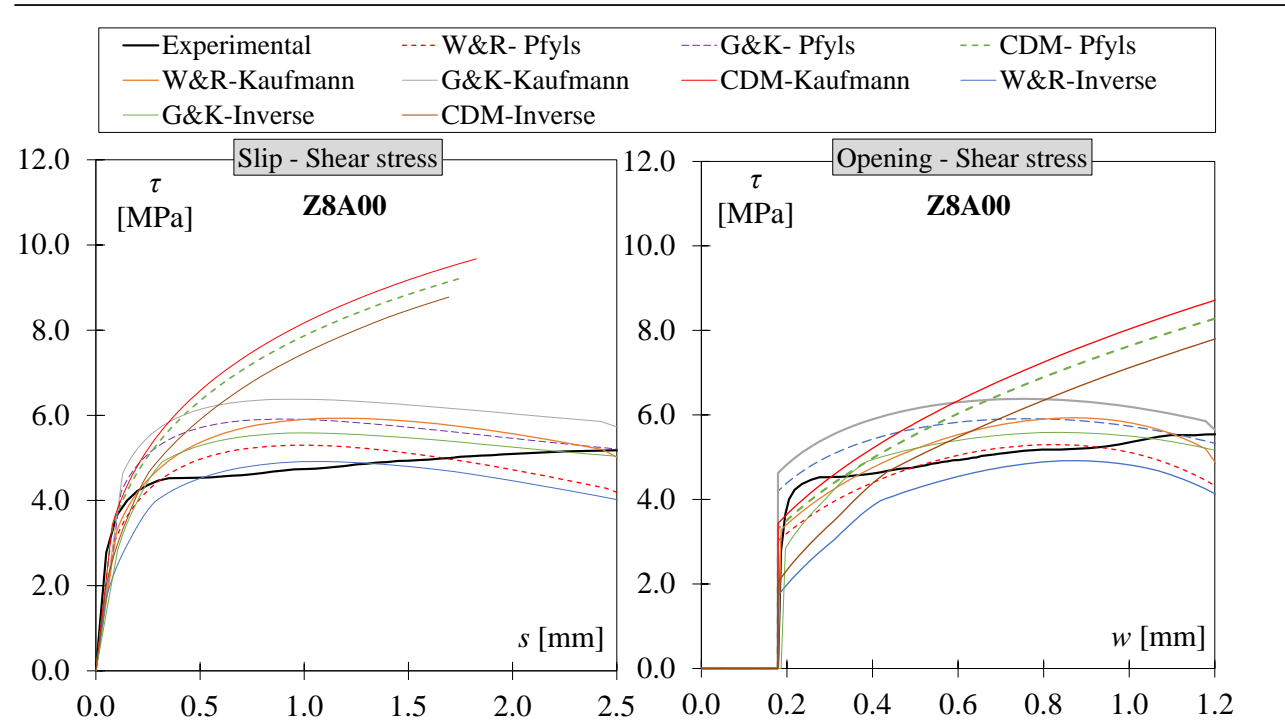

Figure 3-51: Analytical results of specimen $\mathrm{Z8A00}, W=0.0 \mathrm{~mm}, V_{f}=8 \mathrm{~kg} / \mathrm{m}^{3}$ (totally confined).

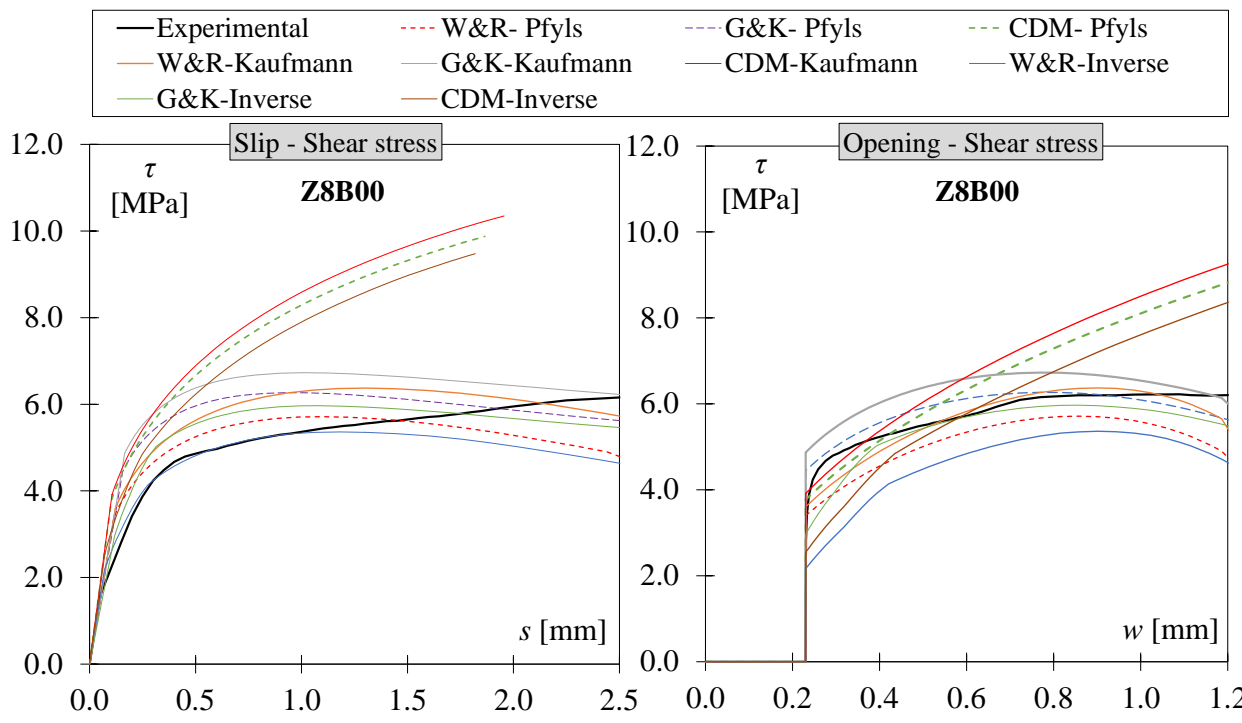

Figure 3-52: Analytical results of specimen $\mathrm{Z8B00}, W=0.0 \mathrm{~mm}, V_{f}=8 \mathrm{~kg} / \mathrm{m}^{3}$ (totally confined). 
Effectiveness of polypropylene fibres as shear reinforcement in structural elements

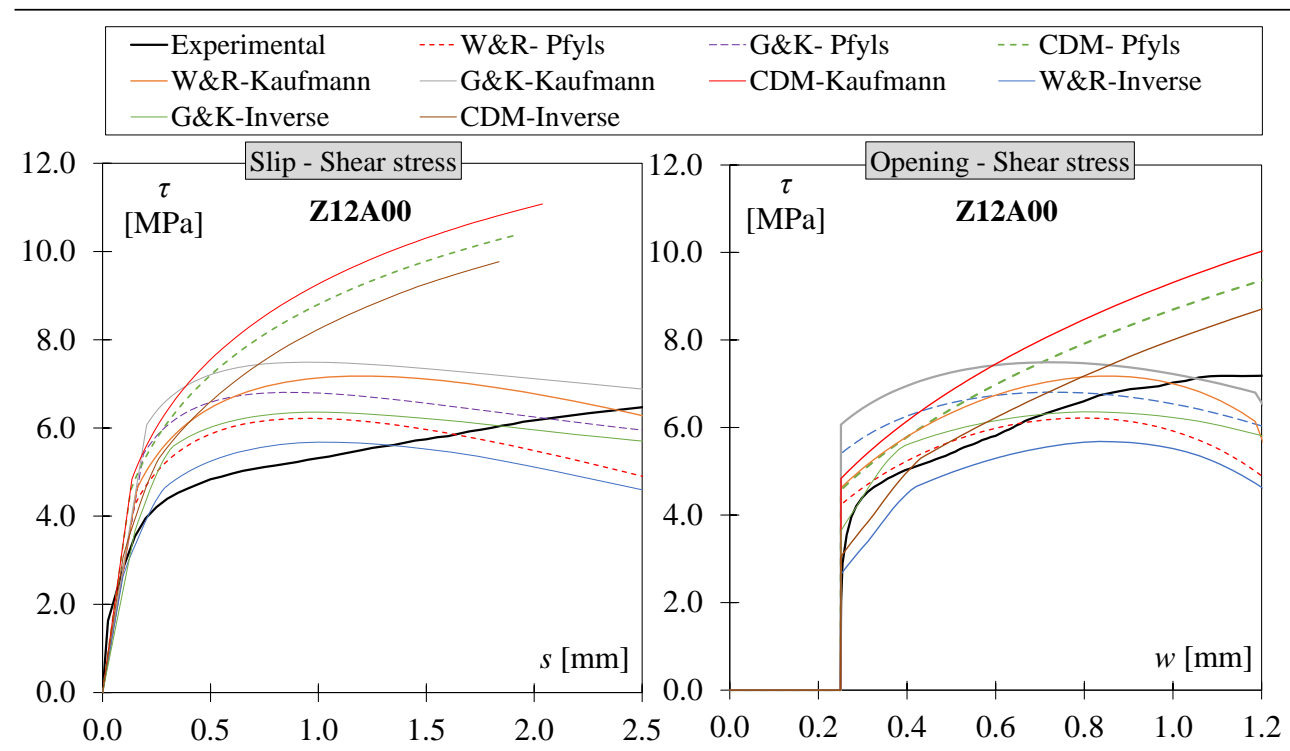

Figure 3-53: Analytical results of specimen $\mathrm{Z12A00}, W=0.0 \mathrm{~mm}, V_{f}=12 \mathrm{~kg} / \mathrm{m}^{3}$ (totally confined).

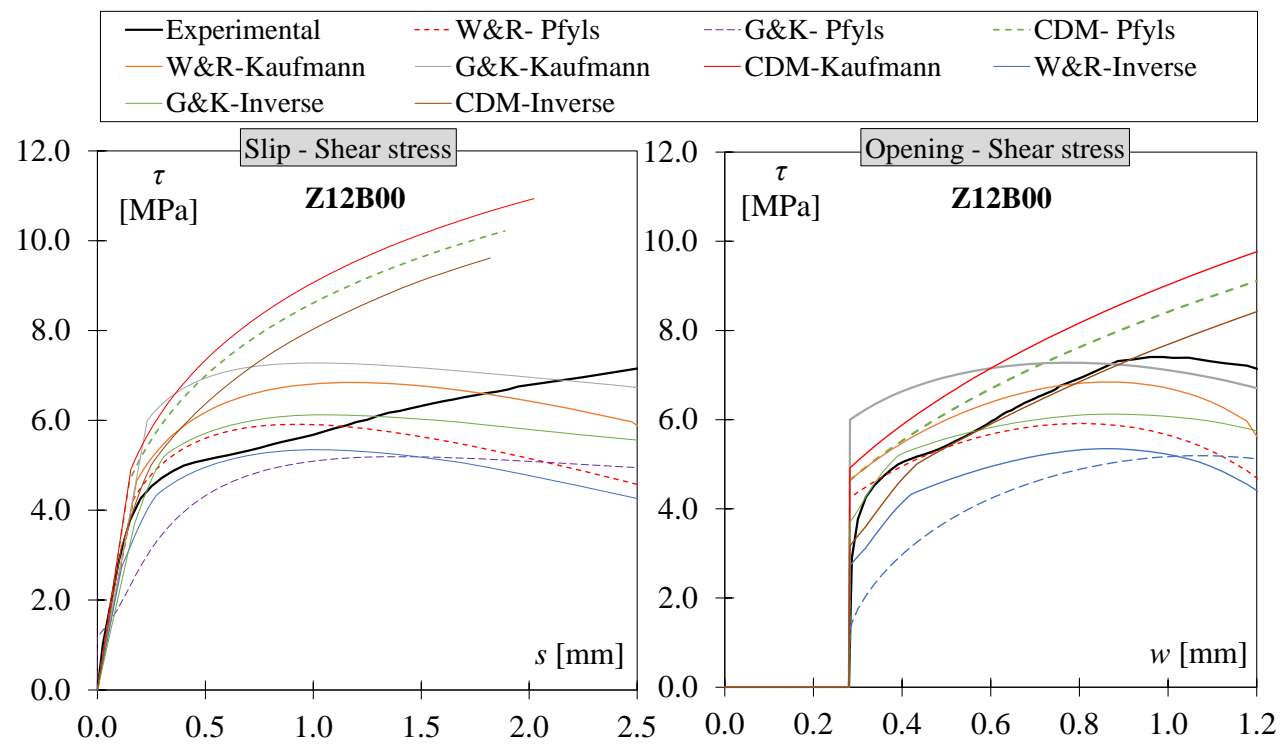

Figure 3-54: Analytical results of specimen $\mathrm{Z12B00}, W=0.0 \mathrm{~mm}, V_{f}=12 \mathrm{~kg} / \mathrm{m}^{3}$ (totally confined). 
Chapter 3. PFRC in small specimens

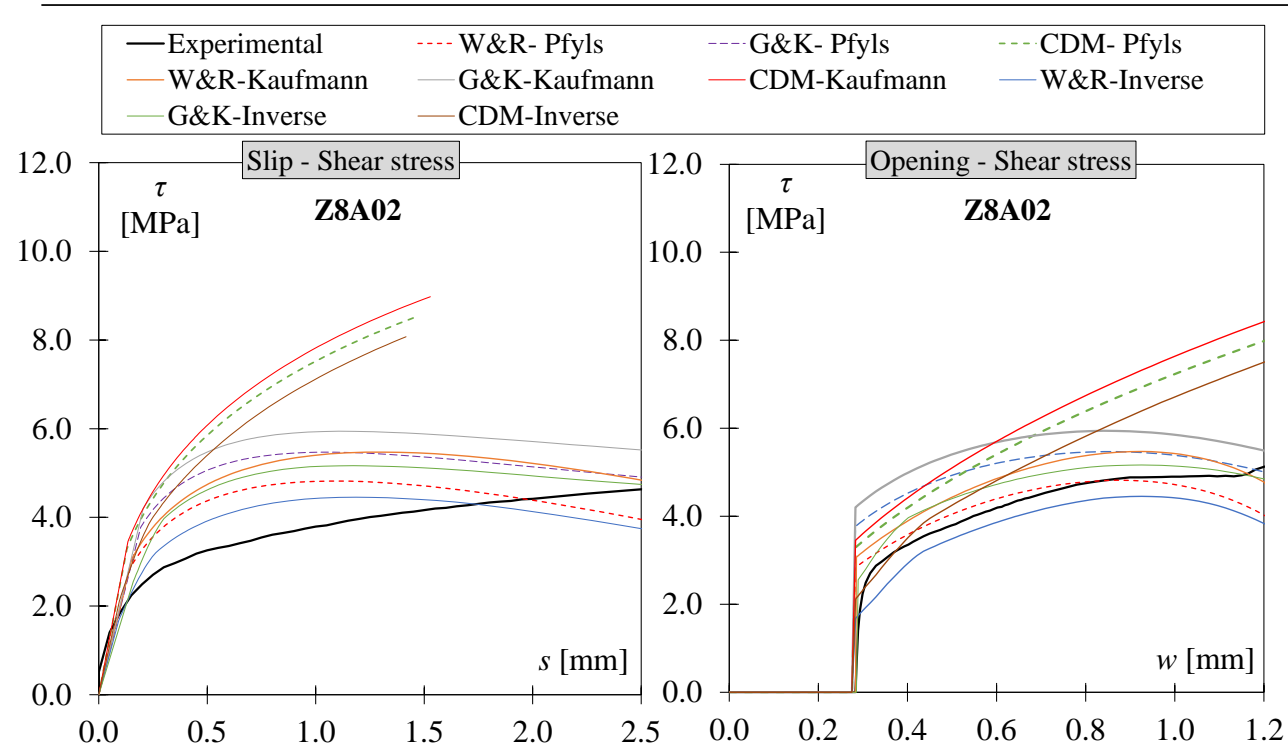

Figure 3-55: Analytical results of specimen $\mathrm{Z8A02}, W=0.2 \mathrm{~mm}, V_{f}=8 \mathrm{~kg} / \mathrm{m}^{3}$ (partially confined).

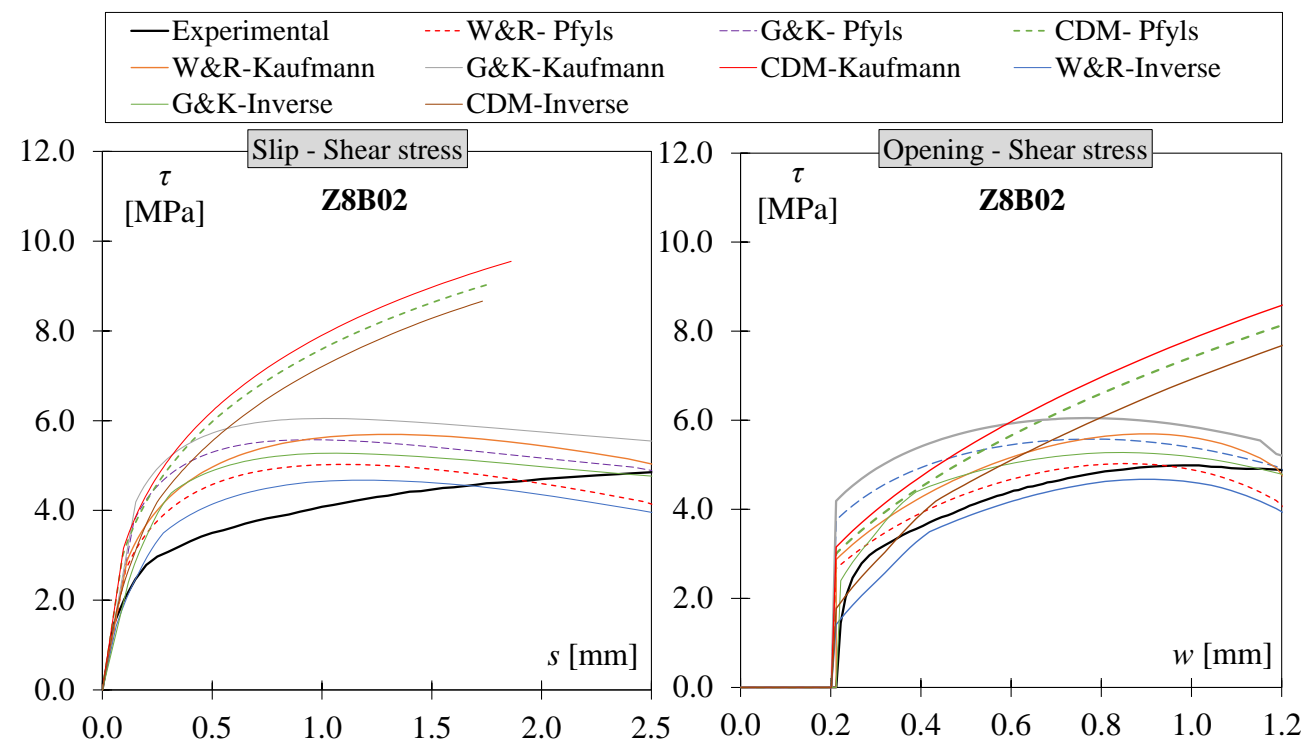

Figure 3-56: Analytical results of specimen $\mathrm{ZBB02}, W=0.2 \mathrm{~mm}, V_{f}=8 \mathrm{~kg} / \mathrm{m}^{3}$ (partially confined). 
Effectiveness of polypropylene fibres as shear reinforcement in structural elements

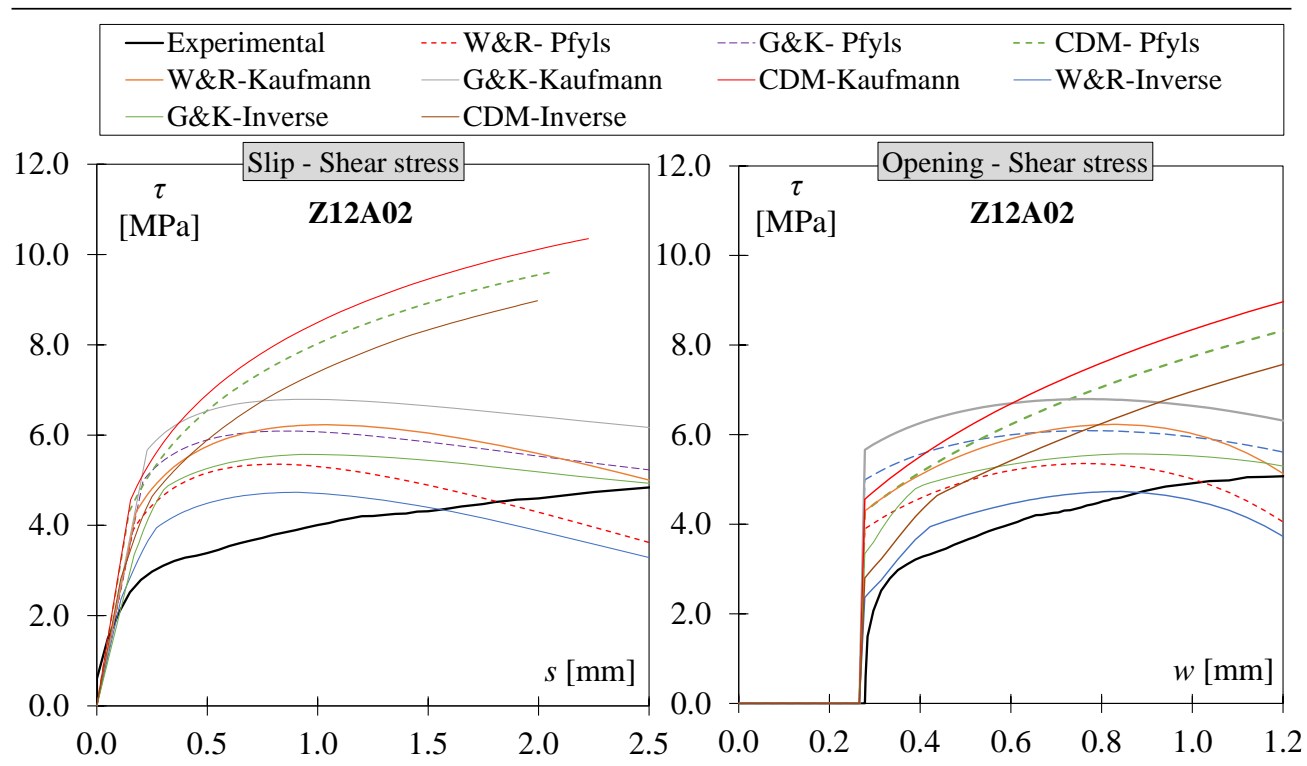

Figure 3-57: Analytical results of specimen $\mathrm{Z12A02}, W=0.2 \mathrm{~mm}, V_{f}=12 \mathrm{~kg} / \mathrm{m}^{3}$ (partially confined).

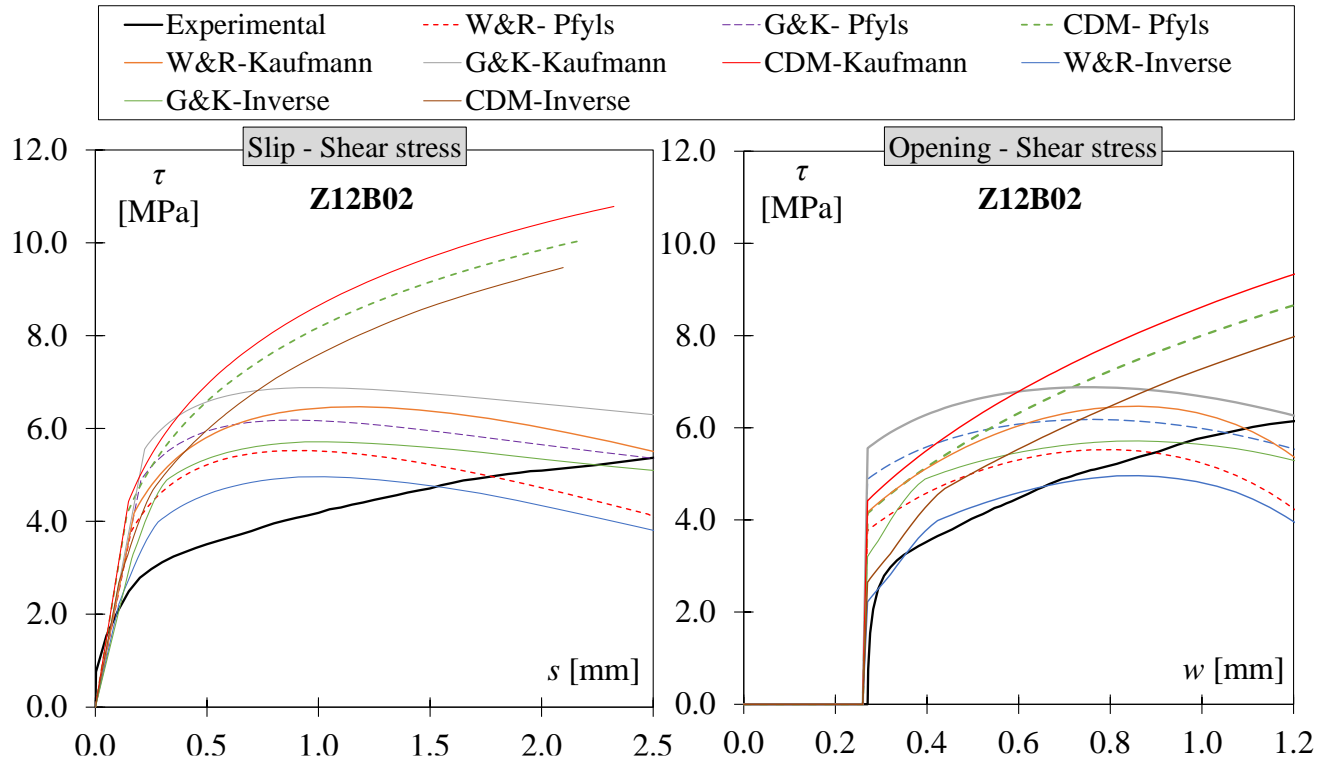

Figure 3-58: Analytical results of specimen $\mathrm{Z12B02}, W=0.2 \mathrm{~mm}, V_{f}=12 \mathrm{~kg} / \mathrm{m}^{3}$ (partially confined). 


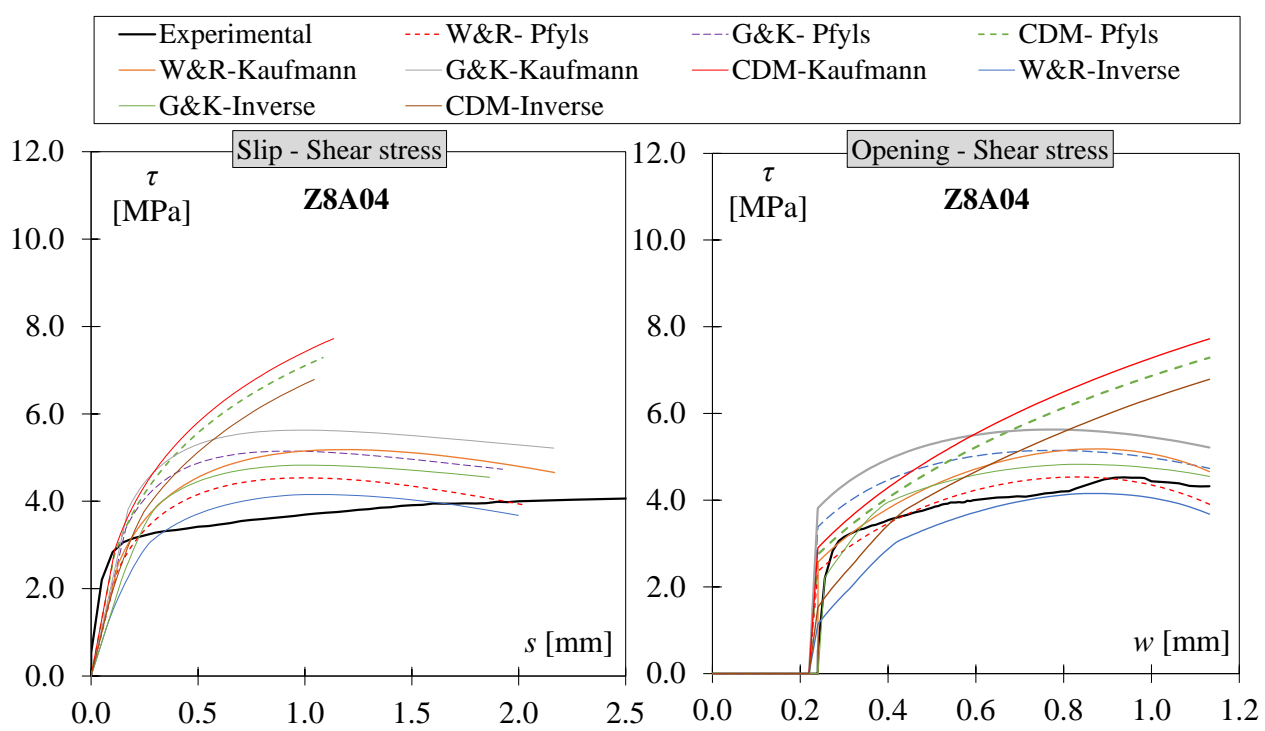

Figure 3-59: Analytical results of specimen $\mathrm{Z8A04}, W=0.4 \mathrm{~mm}, V_{f}=8 \mathrm{~kg} / \mathrm{m}^{3}$ (partially confined).

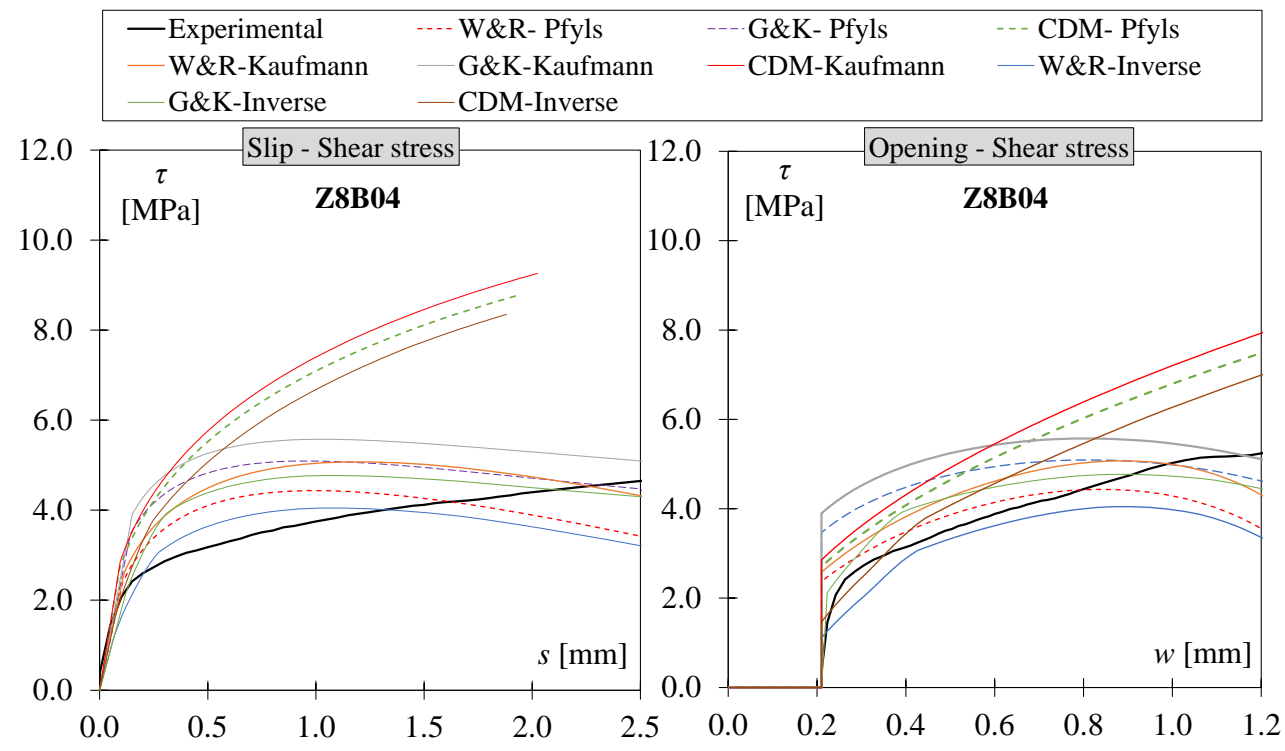

Figure 3-60: Analytical results of specimen $\mathrm{Z8B04}, W=0.4 \mathrm{~mm}, V_{f}=8 \mathrm{~kg} / \mathrm{m}^{3}$ (partially confined). 
Effectiveness of polypropylene fibres as shear reinforcement in structural elements

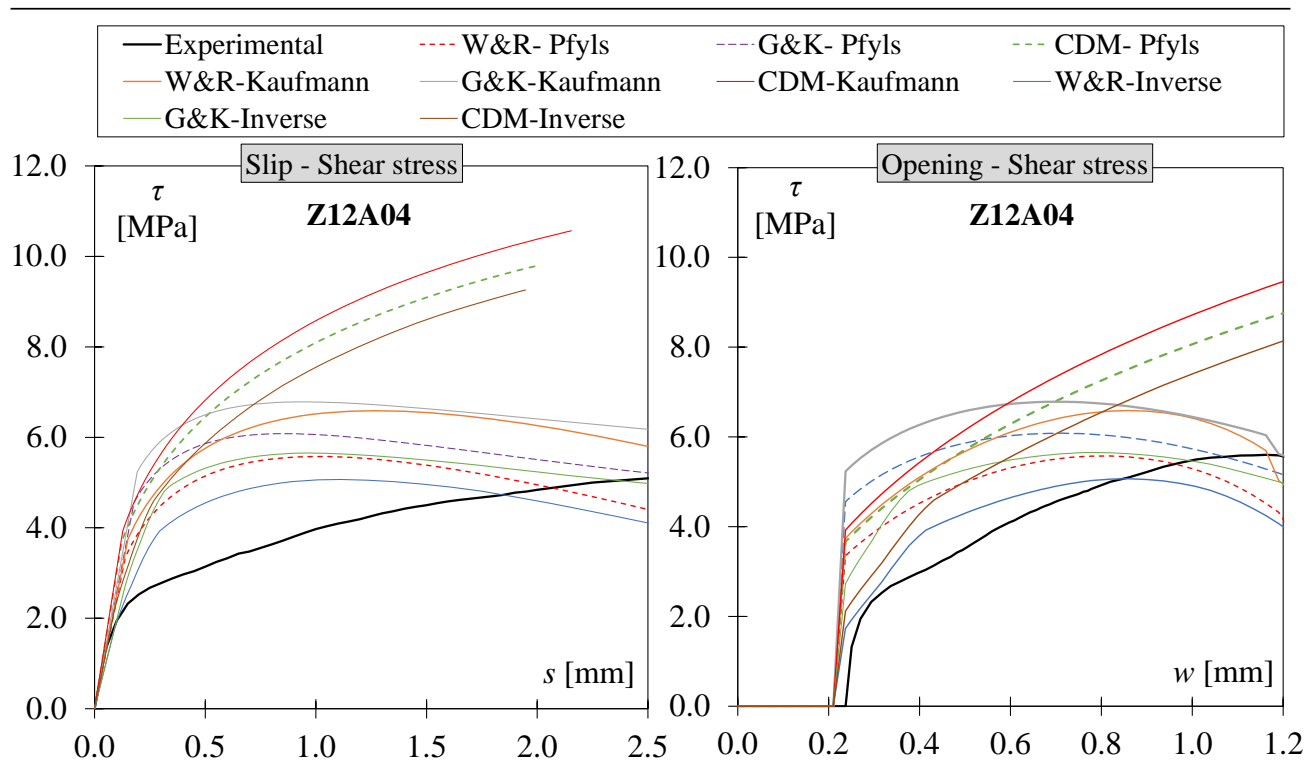

Figure 3-61: Analytical results of specimen $\mathrm{Z12A04}, W=0.4 \mathrm{~mm}, V_{f}=12 \mathrm{~kg} / \mathrm{m}^{3}$ (partially confined).

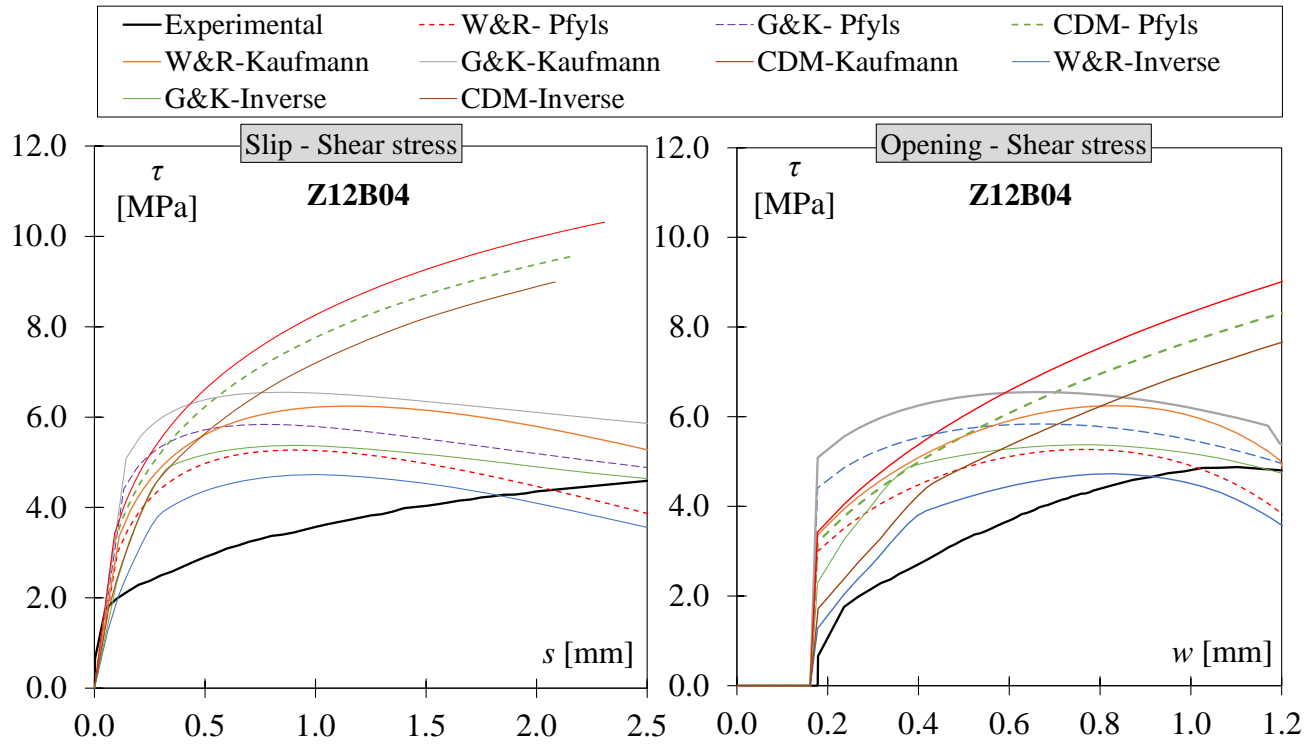

Figure 3-62: Analytical results of specimen $\mathrm{Z12B04}, W=0.4 \mathrm{~mm}, V_{f}=12 \mathrm{~kg} / \mathrm{m}^{3}$ (partially confined). 


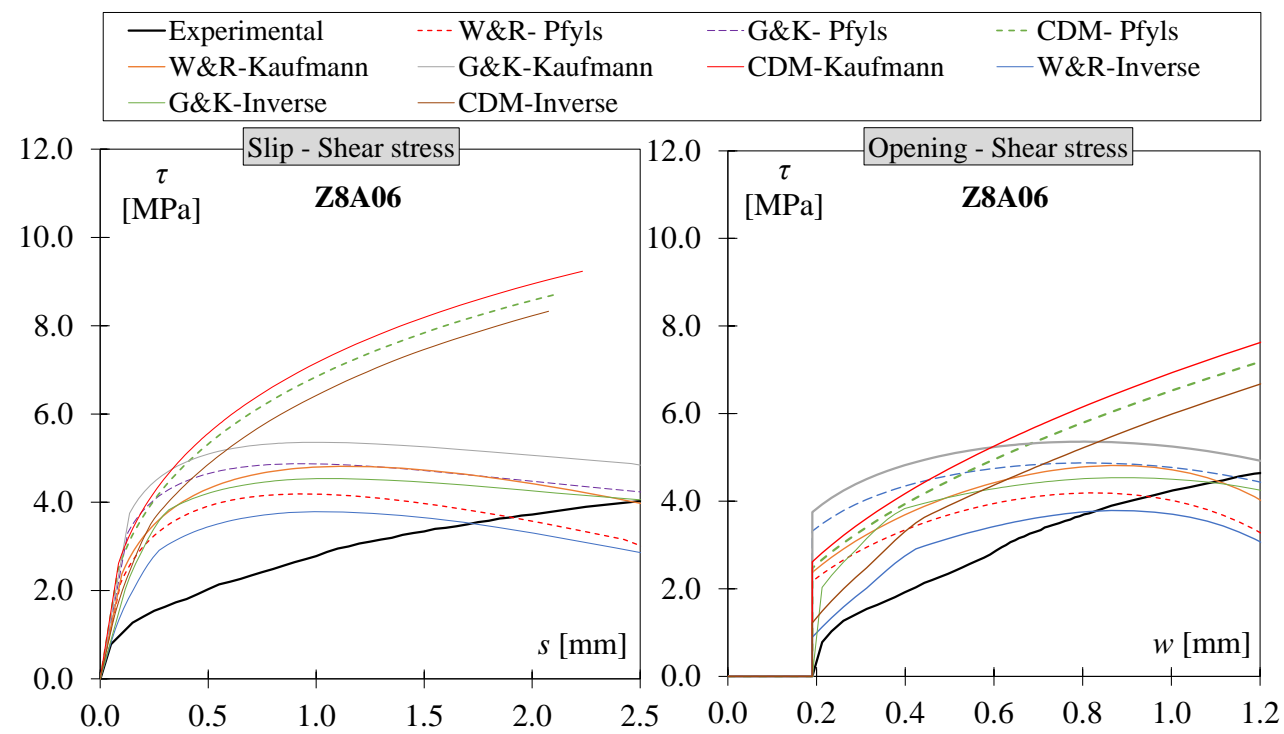

Figure 3-63: Analytical results of specimen $\mathrm{Z8A06}, W=0.6 \mathrm{~mm}, V_{f}=8 \mathrm{~kg} / \mathrm{m}^{3}$ (partially confined).

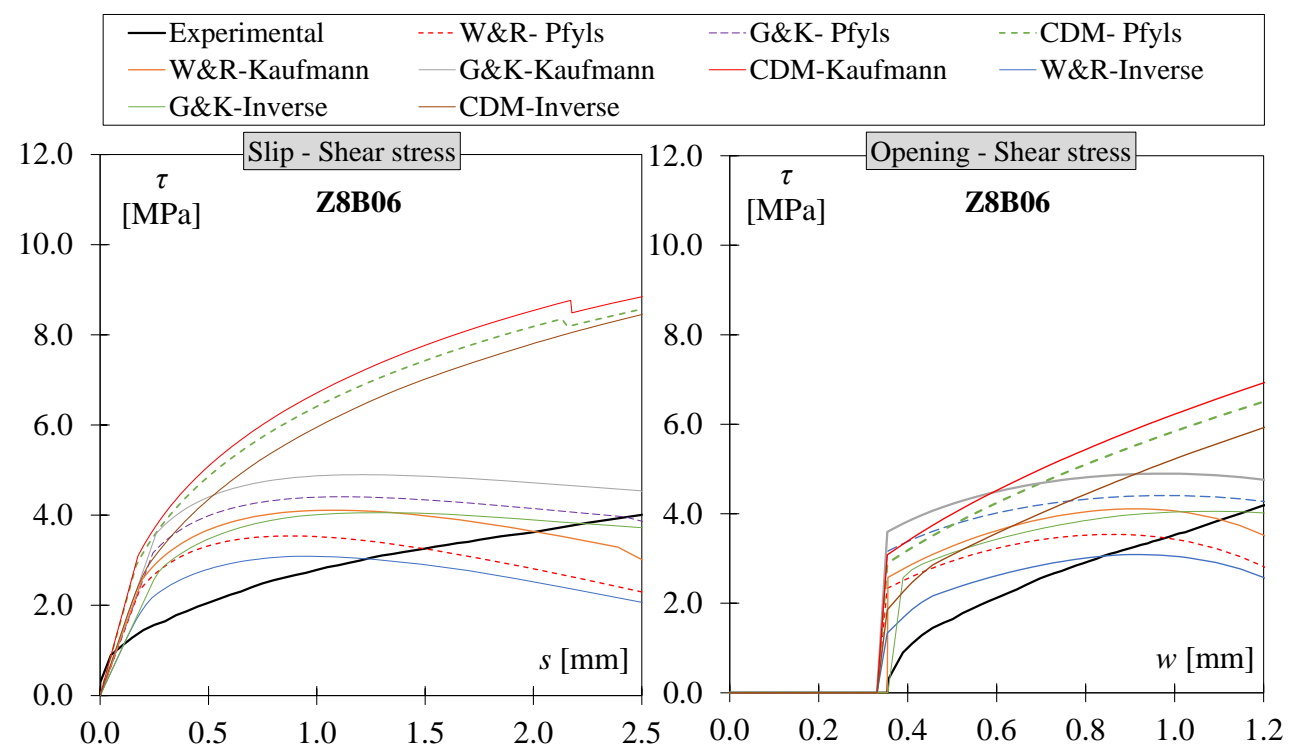

Figure 3-64: Analytical results of specimen $\mathrm{Z8B06}, W=0.6 \mathrm{~mm}, V_{f}=8 \mathrm{~kg} / \mathrm{m}^{3}$ (partially confined). 
Effectiveness of polypropylene fibres as shear reinforcement in structural elements

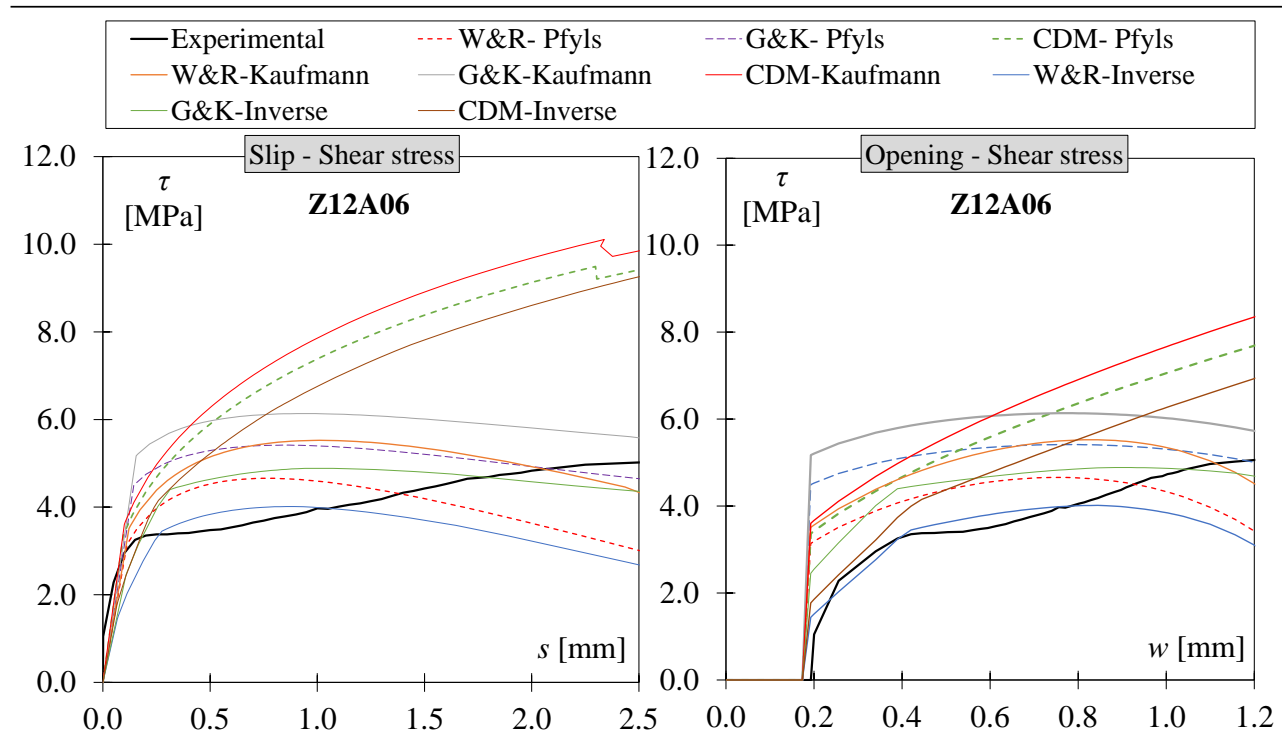

Figure 3-65: Analytical results of specimen $Z 12 \mathrm{A06}, W=0.6 \mathrm{~mm}, V_{f}=12 \mathrm{~kg} / \mathrm{m}^{3}$ (partially confined).

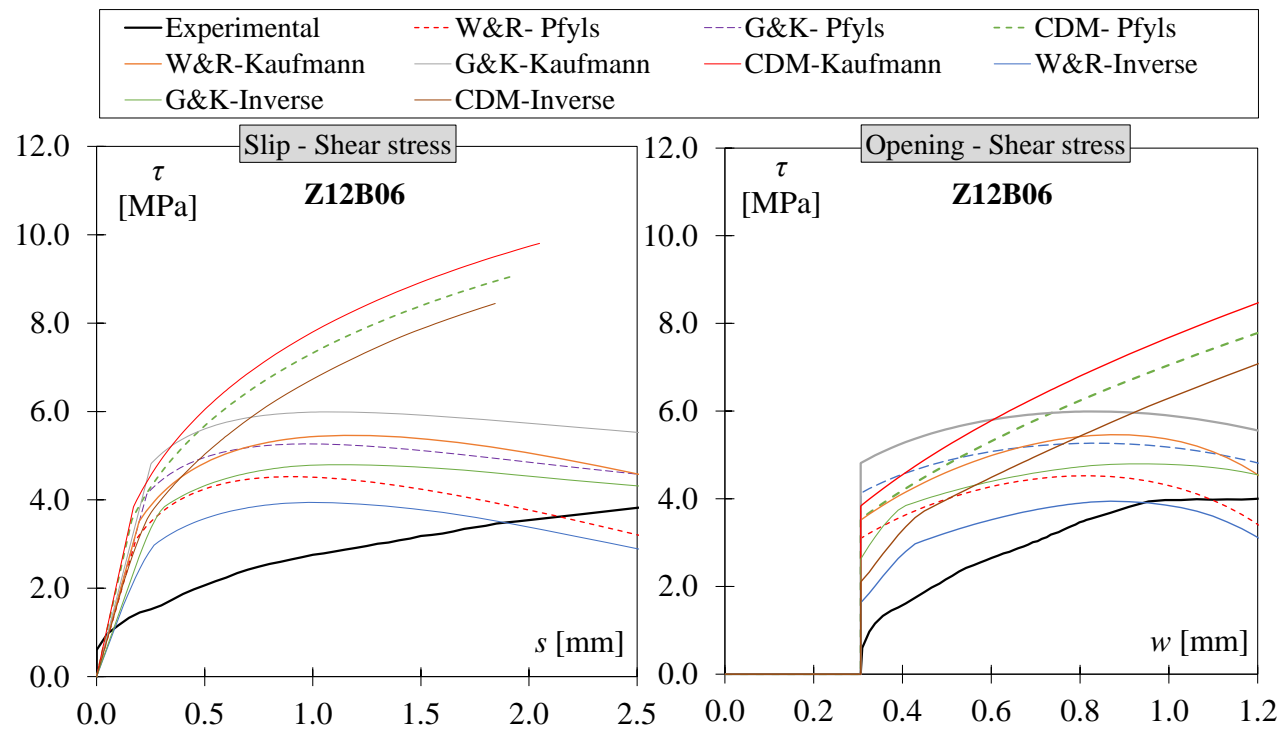

Figure 3-66: Analytical results of specimen $\mathrm{Z12A06}, W=0.6 \mathrm{~mm}, V_{f}=12 \mathrm{~kg} / \mathrm{m}^{3}$ (partially confined). 
Chapter 3. PFRC in small specimens

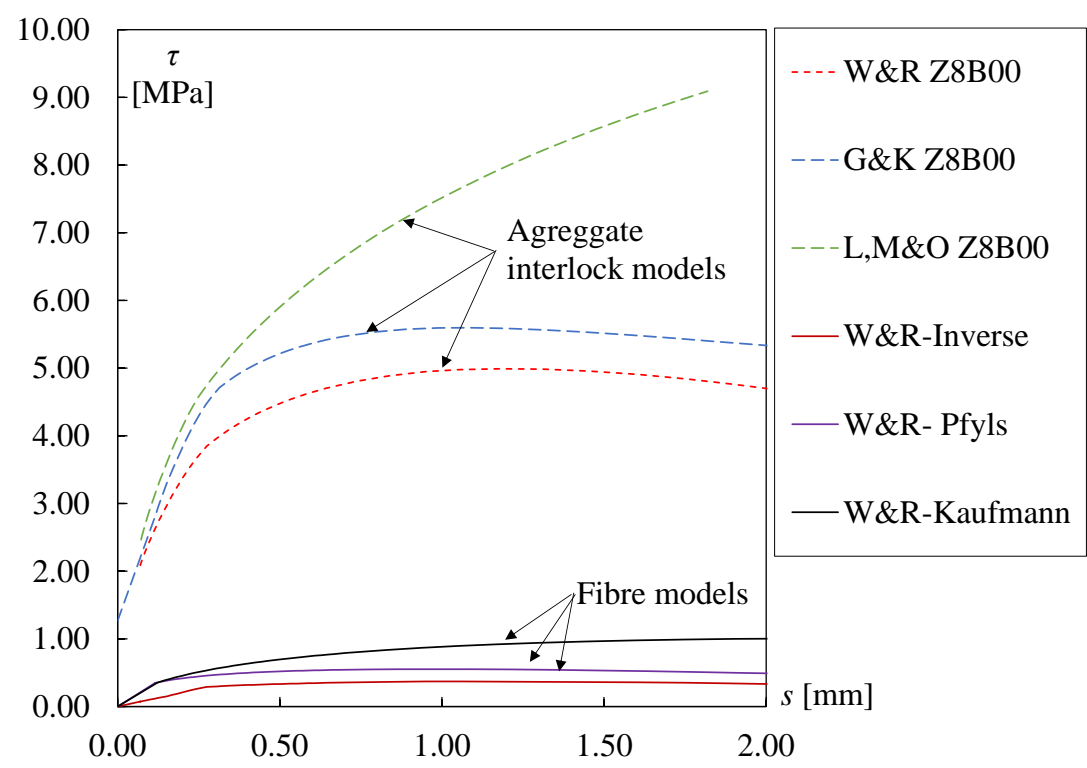

Figure 3-67: Aggregate interlock and fibre contribution

Similar to PC, the shear toughness of the PFRC results was determined and is presented from Table 3-22 to Table 3-25. Toughness was calculated up to a slip displacement of $2.5 \mathrm{~mm}$ and a crack opening of $1.2 \mathrm{~mm}$.

For the shear fracture toughness of the PFRC specimens, the combination of the Walraven and Reinhardt aggregate interlock model and Pfyl's model better estimated shear fracture. As previously stated, Kaufmann's model combined with any aggregate interlock model was that which most overestimated shear fracture toughness.

Finally, the stresses transferred by polypropylene fibres in a shear crack could be directly estimated from the tensile behaviour of PFRC; i.e. from the flexural residual tensile strength stress material properties which, in this case, were determined from the prismatic specimens tested according to EN 14651. So the work done by polypropylene fibres was probably similar in Mode I and Mode II. 
Effectiveness of polypropylene fibres as shear reinforcement in structural elements

Table 3-22: Shear toughnessup to $s=2.5 \mathrm{~mm}$ in PFRC specimens

\begin{tabular}{|c|c|c|c|c|c|c|c|c|c|c|}
\hline \multirow[b]{2}{*}{ ID } & \multirow[b]{2}{*}{$\underset{\text { [MPa-mm] }}{\text { Exp. }}$} & \multicolumn{3}{|c|}{ Pfyl } & \multicolumn{3}{|c|}{ Kaufman et al. } & \multicolumn{3}{|c|}{ Inverse A. } \\
\hline & & $\begin{array}{c}\mathbf{W} \& \mathbf{R} \\
{[\mathrm{MPa}-\mathbf{m m}]}\end{array}$ & $\begin{array}{c}\text { G\&K } \\
{[\mathrm{MPa}-\mathbf{m m}]}\end{array}$ & $\begin{array}{c}\text { CDM } \\
{[\mathrm{MPa}-\mathbf{m m}]}\end{array}$ & $\begin{array}{c}\text { W\&R } \\
{[\mathrm{MPa}-\mathbf{m m}]}\end{array}$ & $\begin{array}{c}\text { G\&K } \\
{[\mathbf{M P a - m m}]}\end{array}$ & $\begin{array}{c}\text { CDM } \\
{[\mathrm{MPa}-\mathbf{m m}]}\end{array}$ & $\begin{array}{c}\text { W\&R } \\
{[\mathrm{MPa}-\mathbf{m m}]}\end{array}$ & $\begin{array}{c}\text { G\&K } \\
{[\mathrm{MPa}-\mathbf{m m}][}\end{array}$ & $\begin{array}{c}\mathrm{CDM} \\
{[\mathrm{MPa}-\mathbf{m m}]}\end{array}$ \\
\hline Z8A00 & 11.78 & 11.61 & 13.02 & 12.27 & 12.84 & 14.02 & 13.40 & 10.58 & 12.45 & 11.07 \\
\hline Z8B00 & 12.99 & 12.56 & 13.65 & 14.07 & 13.68 & 13.58 & 15.29 & 11.54 & 12.43 & 12.83 \\
\hline Z8A02 & 9.41 & 10.37 & 11.80 & 9.06 & 11.69 & 12.78 & 9.79 & 9.35 & 11.17 & 8.02 \\
\hline Z8B02 & 10.05 & 11.04 & 12.25 & 12.02 & 12.02 & 12.52 & 13.16 & 10.05 & 11.07 & 10.88 \\
\hline Z8A04 & 9.16 & 8.13 & 8.87 & 5.70 & 9.74 & 10.68 & 6.16 & 7.21 & 7.76 & 4.90 \\
\hline Z8B04 & 9.36 & 9.35 & 11.47 & 12.55 & 10.60 & 12.41 & 13.81 & 8.35 & 10.24 & 11.29 \\
\hline Z8A06 & 7.18 & 8.88 & 10.41 & 13.83 & 10.05 & 11.85 & 15.29 & 7.86 & 9.87 & 12.47 \\
\hline Z8B06 & 7.12 & 6.72 & 9.48 & 15.75 & 8.27 & 10.46 & 16.35 & 6.33 & 8.00 & 14.47 \\
\hline Z12A00 & 13.34 & 13.35 & 14.81 & 15.32 & 15.39 & 15.87 & 17.27 & 11.88 & 13.91 & 13.50 \\
\hline Z12B00 & 14.44 & 11.91 & 10.72 & 14.81 & 14.73 & 15.54 & 16.65 & 10.42 & 12.15 & 12.95 \\
\hline $\mathrm{Z} 12 \mathrm{~A} 02$ & 9.90 & 10.77 & 13.24 & 15.60 & 12.68 & 13.75 & 17.67 & 9.23 & 12.13 & 13.46 \\
\hline Z12B02 & 10.60 & 11.93 & 13.44 & 16.79 & 12.95 & 14.93 & 19.09 & 10.44 & 12.50 & 14.78 \\
\hline Z12A04 & 9.94 & 11.81 & 12.97 & 15.04 & 13.98 & 14.69 & 17.20 & 10.44 & 12.25 & 13.30 \\
\hline Z12B04 & 9.03 & 11.46 & 13.07 & 15.86 & 13.03 & 14.46 & 18.29 & 10.05 & 11.47 & 14.00 \\
\hline Z12A06 & 10.28 & 8.99 & 11.46 & 18.15 & 11.78 & 13.62 & 19.39 & 8.37 & 10.62 & 16.90 \\
\hline Z12B06 & 6.98 & 9.39 & 11.28 & 12.72 & 11.54 & 12.27 & 14.52 & 7.93 & 10.28 & 10.93 \\
\hline
\end{tabular}

164 
Chapter 3. PFRC in small specimens

Table 3-23: Shear toughness up to $\mathrm{w}=1.2 \mathrm{~mm}$ in the PFRC specimens

\begin{tabular}{|c|c|c|c|c|c|c|c|c|c|c|}
\hline \multirow[b]{2}{*}{ ID } & \multirow[b]{2}{*}{ Exp. } & \multicolumn{3}{|c|}{ Pfyl } & \multicolumn{3}{|c|}{ Kaufman et al. } & \multicolumn{3}{|c|}{ Inverse A. } \\
\hline & & $\begin{array}{c}\text { W\&R } \\
{[\mathrm{MPa}-\mathrm{mm}]}\end{array}$ & $\begin{array}{c}\text { G\&K } \\
\text { [MPa-mm] }\end{array}$ & $\begin{array}{c}\text { CDM } \\
{[\mathrm{MPa}-\mathbf{m m}]}\end{array}$ & $\begin{array}{c}\text { W\&R } \\
\text { [MPa-mm] }\end{array}$ & $\begin{array}{c}\text { G\&K } \\
\text { [MPa-mm] }\end{array}$ & $\begin{array}{c}\text { CDM } \\
{[\mathrm{MPa}-\mathbf{m m}]}\end{array}$ & $\begin{array}{c}\text { W\&R } \\
\text { [MPa-mm] }\end{array}$ & $\begin{array}{c}\text { G\&K } \\
{[\mathrm{MPa}-\mathbf{m m}]}\end{array}$ & $\begin{array}{c}\text { CDM } \\
{[\text { MPa-mm] }}\end{array}$ \\
\hline Z8A00 & 5.10 & 4.87 & 5.71 & 6.43 & 5.38 & 6.19 & 6.76 & 4.34 & 5.19 & 5.80 \\
\hline Z8B00 & 5.69 & 5.06 & 5.79 & 6.66 & 5.59 & 6.24 & 6.97 & 4.59 & 5.38 & 6.07 \\
\hline Z8A02 & 3.95 & 3.97 & 4.70 & 5.50 & 4.45 & 5.11 & 5.79 & 3.52 & 4.27 & 4.93 \\
\hline Z8B02 & 4.41 & 4.53 & 5.31 & 6.21 & 5.07 & 5.76 & 6.54 & 4.03 & 4.83 & 5.59 \\
\hline Z8A04 & 3.53 & 3.60 & 4.31 & 4.89 & 4.05 & 4.70 & 5.15 & 3.13 & 3.84 & 4.32 \\
\hline Z8B04 & 4.02 & 3.89 & 4.72 & 5.45 & 4.41 & 5.20 & 5.77 & 3.38 & 4.23 & 4.82 \\
\hline Z8A06 & 3.20 & 3.79 & 4.69 & 5.41 & 4.33 & 5.19 & 5.75 & 3.25 & 4.15 & 4.76 \\
\hline Z8B06 & 2.47 & 2.86 & 3.71 & 4.48 & 3.28 & 4.10 & 4.74 & 2.39 & 3.16 & 3.86 \\
\hline $\mathrm{Z} 12 \mathrm{~A} 00$ & 5.87 & 5.44 & 6.20 & 7.11 & 6.24 & 6.86 & 7.60 & 4.83 & 5.68 & 6.35 \\
\hline Z12B00 & 6.05 & 5.16 & 4.15 & 6.94 & 5.94 & 6.64 & 7.42 & 4.55 & 5.45 & 6.17 \\
\hline $\mathrm{Z} 12 \mathrm{~A} 02$ & 4.00 & 4.67 & 5.58 & 6.41 & 5.41 & 6.21 & 6.86 & 4.01 & 4.97 & 5.58 \\
\hline Z12B02 & 4.53 & 4.75 & 5.56 & 6.44 & 5.53 & 6.20 & 6.90 & 4.13 & 5.01 & 5.66 \\
\hline Z12A04 & 4.22 & 4.91 & 5.62 & 6.60 & 5.70 & 6.24 & 7.07 & 4.26 & 5.05 & 5.80 \\
\hline Z12B04 & 3.89 & 4.88 & 5.75 & 6.60 & 5.74 & 6.44 & 7.11 & 4.16 & 5.10 & 5.74 \\
\hline Z12A06 & 3.85 & 4.31 & 5.33 & 5.99 & 5.07 & 6.01 & 6.46 & 3.53 & 4.58 & 5.05 \\
\hline Z12B06 & 2.76 & 3.72 & 4.54 & 5.41 & 4.48 & 5.20 & 5.88 & 3.13 & 4.01 & 4.66 \\
\hline
\end{tabular}


Effectiveness of polypropylene fibres as shear reinforcement in structural elements

Table 3-24: Shear toughness coefficient up to $s=2.5 \mathrm{~mm}$ in the PFRC specimens

\begin{tabular}{|c|c|c|c|c|c|c|c|c|c|c|}
\hline \multirow[b]{2}{*}{ ID } & \multirow[b]{2}{*}{ Exp. } & \multicolumn{3}{|c|}{ Pfyl } & \multicolumn{3}{|c|}{ Kaufman et al. } & \multicolumn{3}{|c|}{ Inverse A. } \\
\hline & & $\begin{array}{c}\mathbf{W} \& \mathbf{R} \\
{[-]}\end{array}$ & $\begin{array}{c}\mathbf{G} \& \mathbf{K} \\
{[-]}\end{array}$ & $\begin{array}{c}\text { CDM } \\
{[-]}\end{array}$ & $\begin{array}{c}\mathbf{W} \& \mathbf{R} \\
{[-]}\end{array}$ & $\begin{array}{c}\mathbf{G} \& \mathbf{K} \\
{[-]}\end{array}$ & $\begin{array}{c}\text { CDM } \\
{[-]}\end{array}$ & $\begin{array}{c}\mathbf{W} \& \mathbf{R} \\
{[-]}\end{array}$ & $\begin{array}{c}\mathbf{G} \& \mathbf{K} \\
{[-]}\end{array}$ & $\begin{array}{c}\text { CDM } \\
{[-]}\end{array}$ \\
\hline Z8A00 & 1.00 & 0.99 & 1.11 & 1.04 & 1.09 & 1.19 & 1.14 & 0.90 & 1.06 & 0.94 \\
\hline Z8B00 & 1.00 & 0.97 & 1.05 & 1.08 & 1.05 & 1.05 & 1.18 & 0.89 & 0.96 & 0.99 \\
\hline Z8A02 & 1.00 & 1.10 & 1.25 & 0.96 & 1.24 & 1.36 & 1.04 & 0.99 & 1.19 & 0.85 \\
\hline Z8B02 & 1.00 & 1.10 & 1.22 & 1.20 & 1.20 & 1.25 & 1.31 & 1.00 & 1.10 & 1.08 \\
\hline Z8A04 & 1.00 & 0.89 & 0.97 & 0.62 & 1.06 & 1.17 & 0.67 & 0.79 & 0.85 & 0.53 \\
\hline Z8B04 & 1.00 & 1.00 & 1.23 & 1.34 & 1.13 & 1.33 & 1.48 & 0.89 & 1.09 & 1.21 \\
\hline Z8A06 & 1.00 & 1.24 & 1.45 & 1.93 & 1.40 & 1.65 & 2.13 & 1.09 & 1.38 & 1.74 \\
\hline Z8B06 & 1.00 & 0.94 & 1.33 & 2.21 & 1.16 & 1.47 & 2.30 & 0.89 & 1.12 & 2.03 \\
\hline $\mathrm{Z} 12 \mathrm{~A} 00$ & 1.00 & 1.00 & 1.11 & 1.15 & 1.15 & 1.19 & 1.29 & 0.89 & 1.04 & 1.01 \\
\hline $\mathrm{Z} 12 \mathrm{~B} 00$ & 1.00 & 0.82 & 0.74 & 1.03 & 1.02 & 1.08 & 1.15 & 0.72 & 0.84 & 0.90 \\
\hline $\mathrm{Z} 12 \mathrm{~A} 02$ & 1.00 & 1.09 & 1.34 & 1.58 & 1.28 & 1.39 & 1.79 & 0.93 & 1.23 & 1.36 \\
\hline Z12B02 & 1.00 & 1.13 & 1.27 & 1.58 & 1.22 & 1.41 & 1.80 & 0.98 & 1.18 & 1.40 \\
\hline Z12A04 & 1.00 & 1.19 & 1.31 & 1.51 & 1.41 & 1.48 & 1.73 & 1.05 & 1.23 & 1.34 \\
\hline Z12B04 & 1.00 & 1.27 & 1.45 & 1.76 & 1.44 & 1.60 & 2.03 & 1.11 & 1.27 & 1.55 \\
\hline Z12A06 & 1.00 & 0.87 & 1.11 & 1.77 & 1.15 & 1.32 & 1.89 & 0.81 & 1.03 & 1.64 \\
\hline Z12B06 & 1.00 & 1.34 & 1.62 & 1.82 & 1.65 & 1.76 & 2.08 & 1.14 & 1.47 & 1.57 \\
\hline Avera & & 1.06 & 1.22 & 1.41 & 1.23 & 1.35 & 1.56 & 0.94 & 1.13 & 1.26 \\
\hline
\end{tabular}


Chapter 3. PFRC in small specimens

Table 3-25: Shear toughness coefficient up to $\mathrm{w}=1.2 \mathrm{~mm}$ in the PFRC specimens

\begin{tabular}{|c|c|c|c|c|c|c|c|c|c|c|}
\hline \multirow[b]{2}{*}{ ID } & \multirow[b]{2}{*}{ Exp. } & \multicolumn{3}{|c|}{ Pfyl } & \multicolumn{3}{|c|}{ Kaufman et al. } & \multicolumn{3}{|c|}{ Inverse A. } \\
\hline & & $\begin{array}{c}\mathbf{W} \& \mathbf{R} \\
{[-]}\end{array}$ & $\begin{array}{c}\text { G\&K } \\
{[-]}\end{array}$ & $\begin{array}{c}\text { CDM } \\
{[-]}\end{array}$ & $\begin{array}{c}\mathbf{W} \& \mathbf{R} \\
{[-]}\end{array}$ & $\begin{array}{c}\text { G\&K } \\
{[-]}\end{array}$ & $\begin{array}{c}\text { CDM } \\
{[-]}\end{array}$ & $\begin{array}{c}\mathbf{W} \& \mathbf{R} \\
{[-]}\end{array}$ & $\begin{array}{c}\mathbf{G} \& \mathbf{K} \\
{[-]}\end{array}$ & $\begin{array}{c}\text { CDM } \\
{[-]}\end{array}$ \\
\hline Z8A00 & 1.00 & 0.95 & 1.12 & 1.26 & 1.05 & 1.21 & 1.32 & 0.85 & 1.02 & 1.14 \\
\hline Z8B00 & 1.00 & 0.89 & 1.02 & 1.17 & 0.98 & 1.10 & 1.23 & 0.81 & 0.94 & 1.07 \\
\hline Z8A02 & 1.00 & 1.01 & 1.19 & 1.39 & 1.13 & 1.30 & 1.47 & 0.89 & 1.08 & 1.25 \\
\hline Z8B02 & 1.00 & 1.03 & 1.20 & 1.41 & 1.15 & 1.31 & 1.48 & 0.91 & 1.10 & 1.27 \\
\hline Z8A04 & 1.00 & 1.02 & 1.22 & 1.39 & 1.15 & 1.33 & 1.46 & 0.89 & 1.09 & 1.22 \\
\hline Z8B04 & 1.00 & 0.97 & 1.17 & 1.35 & 1.10 & 1.29 & 1.43 & 0.84 & 1.05 & 1.20 \\
\hline Z8A06 & 1.00 & 1.18 & 1.46 & 1.69 & 1.35 & 1.62 & 1.79 & 1.01 & 1.29 & 1.48 \\
\hline Z8B06 & 1.00 & 1.16 & 1.50 & 1.81 & 1.33 & 1.66 & 1.92 & 0.97 & 1.28 & 1.56 \\
\hline Z12A00 & 1.00 & 0.93 & 1.06 & 1.21 & 1.06 & 1.17 & 1.30 & 0.82 & 0.97 & 1.08 \\
\hline Z12B00 & 1.00 & 0.85 & 0.68 & 1.15 & 0.98 & 1.10 & 1.23 & 0.75 & 0.90 & 1.02 \\
\hline Z12A02 & 1.00 & 1.17 & 1.40 & 1.60 & 1.35 & 1.55 & 1.72 & 1.00 & 1.25 & 1.40 \\
\hline Z12B02 & 1.00 & 1.05 & 1.23 & 1.42 & 1.22 & 1.37 & 1.52 & 0.91 & 1.11 & 1.25 \\
\hline Z12A04 & 1.00 & 1.16 & 1.33 & 1.56 & 1.35 & 1.48 & 1.67 & 1.01 & 1.20 & 1.37 \\
\hline Z12B04 & 1.00 & 1.25 & 1.48 & 1.70 & 1.47 & 1.66 & 1.83 & 1.07 & 1.31 & 1.47 \\
\hline Z12A06 & 1.00 & 1.12 & 1.38 & 1.55 & 1.32 & 1.56 & 1.68 & 0.92 & 1.19 & 1.31 \\
\hline Z12B06 & 1.00 & 1.35 & 1.65 & 1.96 & 1.62 & 1.88 & 2.13 & 1.14 & 1.45 & 1.69 \\
\hline Avera & & 1.07 & 1.26 & 1.48 & 1.23 & 1.41 & 1.57 & 0.92 & 1.14 & 1.30 \\
\hline
\end{tabular}




\subsubsection{Concluding remarks}

Twenty experimental results of the push-off test obtained in experimental campaign two with specimens PC and PFRC were used to analytically analyse the shear stress transfer across an open crack in PC and PFRC. Four models were used and compared to one another. The stresses transferred by the following aggregate interlock models in PC were considered by the simplified method proposed by Walraven and Reinhardt (W\&R), the theoretical method proposed by Gambarova and Karakoç (G\&K), the Contact Density Model (CDM) developed by Li and Maekawa, and the theoretical model based on Walraven's experimental results proposed by Vecchio and Collins (V\&C). The aggregate interlock models were combined with three different fibre models: Thomas Pfyl's model, Kaufmann's et al. model and the tensile behaviour of PFRC obtained from the inverse analysis. As Pfyl's and Kaufmann's models were developed explicitly for SFRC, these models were calibrated using some experimental pull-out results of macrosynthetic fibres available in the literature. Moreover, the effects of specimens' pre-compression, as well as the confinement effect provided by the external frame, were also included in this analysis.

It is worth mentioning that the novelty of the present numerical analysis attempts to accurately reproduce the entire push-off test of the pre-cracked specimens where several transfer mechanisms acted together. For this purpose, the present analytical model determined the contribution of each transfer mechanism from the equilibrium of its normal and shear stresses, and not from the crack path. In this way, apart from studying the reliability of the proposed model in the literature for each transfer mechanism, the experimental campaign could also be validated.

Within this framework the following conclusions can be drawn:

a) The numerical procedure was capable of integrating the shear transfer mechanism by acting in a PC and PFRC crack of pre-cracked push-off specimen. In fact the numerical procedure could closely follow all the experimental test stages because the parameters existing in the crack before the test, such as initial crack and confinement, were taken into account in the models

b) Despite the four aggregate interlock models studied herein reasonably agreeing with the experimental results, major great differences among the models existed. In fact these differences could represent up to $100 \%$ shear stresses among the models for determining crack openings and slip displacement. This clearly shows that further research is needed to determine the real aggregate interlock that acts on a shear crack when the aggregate interlock is activated, and also on the crack opening and slip displacement where the aggregate interlock is ineffective to transfer cracks. Yet the aggregate interlock models that better describe the experimental results correspond to Vecchio and Collins and Walraven and Reinhardt, but when comparing the fracture shear toughness among the four aggregate interlocks up to a slip displacement of $2.5 \mathrm{~mm}$ and crack openings of $1.2 \mathrm{~mm}$, the G\&K model better captured this energy 
c) Regarding PFRC, the model developed by Walraven and Reinhardt combined with any of the three fibre models led to a good correlation with the experimental results. This good correlation was also observed when the shear toughness up to slip displacements of $2.5 \mathrm{~mm}$ and crack openings of $1.2 \mathrm{~mm}$ when compared to th experimental results. A theoretical over experimental ratio of 1.07 was obtained, which can be considered a reliable prediction

d) The stresses transferred by polypropylene fibres in a shear crack can be directly estimated from the tensile behaviour of PFRC; i.e. from flexural residual tensile stresses which, in this case, were determined from the prismatic specimens tested according to EN 14651. Indeed the work done by polypropylene fibres was probably the same in Mode I and Mode II. These results evidence that from an engineering point of view, the shear behaviour of PFRC could be directly determined from such well-known parameters like the residual flexural tensile strengths obtained from the bending tests, as MC2010 suggests.

To conclude, one suggestions is that to better understand the real effect of fibres transferring shear stresses, it is necessary to study the aggregate interlock that acts on a shear crack in more depth. It is also necessary to standardise a shear test method to study FRC shear behaviour as each method has its own particularities and are generally difficult to reproduce similarly in different laboratories.

Finally, the present analytical results allowed the methodology followed to test the pre-cracked push-off specimens to be validated. 



\section{Chapter 4. STUDY OF SHEAR IN PFRC SLENDER BEAMS}





\subsection{Introduction}

This chapter presents an experimental campaign program on slender beams in reinforced concrete (RC), polypropylene fibre-reinforced concrete (PFRC) and steel fibre-reinforced concrete (SFRC), both with and without (w/o) shear reinforcement.

Several research works about the shear performance of FRC have demonstrated the efficiency of fibres as shear reinforcement, especially steel fibres. In fact according to some studies, which have examined several fibre types as shear reinforcement $[137,164,168]$, steel fibres better performed than macrosynthetic ones in most cases. Nevertheless, no direct comparison between both fibre types (steel and macro-synthetic fibres) has yet been reported. In this context, the present study aims to firstly determine the benefits of macro-synthetic polypropylene fibres used as shear reinforcement in structural slender beams both with and w/o transversal reinforcement (stirrups). As a second objective, a direct shear performance comparison between PFRC and SFRC is made. Both fibre types are dosed in concrete to present similar residual flexure tensile strength properties. This comparison comprises the global element response, crack pattern evolution, effect of fibres on shear transfer mechanisms and shear deformation.

To fulfil the objectives, four series of six beams that cover two different cross-sections, two-shear span length, three concrete types and several transversal reinforcement levels were manufactured and tested by a four-point loading system. The series of beams were inspired in the RC beams tested by Bresler and Scordelis in 1963 [203].

\subsection{Presentation of the experimental programme}

The entire experimental campaign (herein ICITECH beams) consists of 24 slender beam constituted in four series of six beams. Each series contains six different shear reinforcement levels:

- RC w/o stirrups: 0A1, 0A2, 0B1, 0B2

- PFRC w/o stirrups: 0AP1, 0AP2, 0BP1, 0BP2

- SFRC w/o stirrups: 0AS1, 0AS2, 0BS1, 0BS2

- RC with stirrups: A1, A2, B1, B2

- PFRC with stirrups: AP1, AP2, BP1, BP2

- SFRC with stirrups: AS1, AS2, BS1, BS2

The geometry of beams is inspired in the classical beams series tested by Bresler-Scordelis in 1963 at the University of California Berkeley [203], most of which present shear failure. The research by Bresler-Scordelis consisted of 12 beams (four series of three beams) with a different cross-section geometry, longitudinal reinforcement ratio, transverse reinforcement, span length and concrete compressive strength. Most beams, except for those of maximum length, fail in shear, specifically due to diagonal tension (D-T) or 
Effectiveness of polypropylene fibres as shear reinforcement in structural elements

shear-compression (V-C). The ICITECH beams are somewhat inspired in these two classic series of reinforced concrete beams. In fact the reproduced beams are A1 $(305 \times 552 \times 3660 \mathrm{~mm})$, A2 $(305 \times 552 \times 4570 \mathrm{~mm})$, B1 $(229 \times 552 \times 3660 \mathrm{~mm})$, B2 (229x552x457 0mm), OA1 (A1 w/o stirrups) and OA2 (A2 w/o stirrups). Those beams with a span length of $6,400 \mathrm{~mm}$, "Series 3", and with a flexure-compression (F-C) MOF, were excluded from the experimental programme, as were the "C" series beams with a cross-section of $155 \times 552 \mathrm{~mm}$. Two new beams were added: OB1 (B1 w/o stirrups) and OB2 (B2 w/o stirrups). The section of RC beams with and w/o stirrups are shown in Figure 4-1. It is worth mentioning that beams series PFRC and SFRC present the same cross-section as the $\mathrm{RC}$ ones.

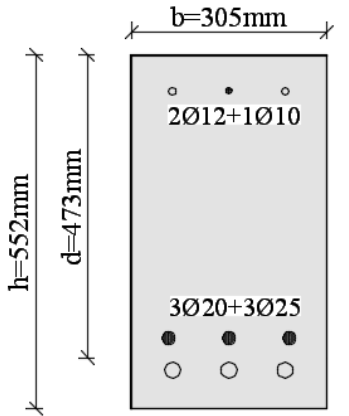

0A1

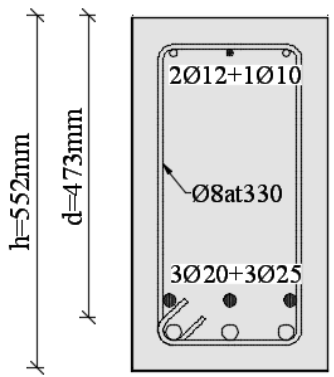

A1

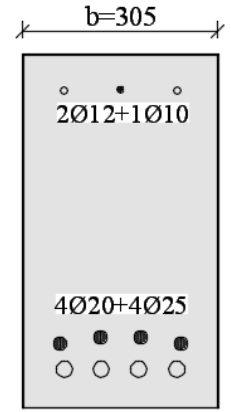

$0 \mathrm{A2}$

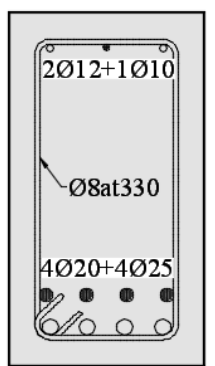

A2

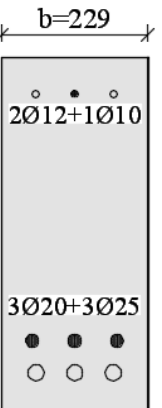

0B1

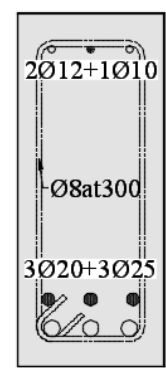

B1

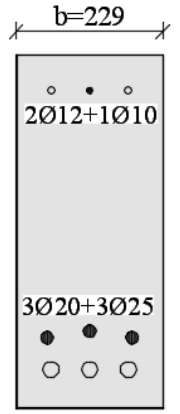

0B2

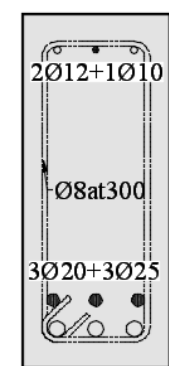

B2

Figure 4-1: Cross-section details (units in mm)

The geometry and reinforcement details are summarised in Table 4-1. The whole programme covers: (a) two different cross-sections ('section A' $305 \times 552 \mathrm{~mm}$ and 'section B' 229x552 mm); (b) two span lengths ('length 1' 3,360 mm and 'length 2' 4,570 mm) as Figure 4-2 shows; (c) three concrete types: RC, SFRC and PFRC; (d) repetitions with and w/o transverse reinforcement. It is worth mentioning that number ' 0 ' in the identification of the beam corresponding to those beams w/o stirrups, while letters ' $\mathrm{S}$ ' and ' $\mathrm{P}$ ' denote the beams with steel fibres and polypropylene fibre, respectively. For example, beam 0BP2 is a beam w/o stirrups of section B manufactured with PFRC and length 2. 
Chapter 4. PFRC in slender beams

Table 4-1: Geometry and reinforcement of slender beams

\begin{tabular}{|c|c|c|c|c|c|c|c|c|c|c|}
\hline Beam & $\begin{array}{c}b \\
{[\mathrm{~mm}]}\end{array}$ & $\begin{array}{c}h \\
{[\mathrm{~mm}]}\end{array}$ & $\begin{array}{c}d \\
{[\mathrm{~mm}]}\end{array}$ & $\begin{array}{c}L \\
{[\mathrm{~mm}]}\end{array}$ & $\begin{array}{l}\text { Span } \\
{[\mathrm{mm}]}\end{array}$ & $a / d$ & $\begin{array}{c}\text { Bottom } \\
\text { bars }\end{array}$ & $\begin{array}{c}\text { Top } \\
\text { bars }\end{array}$ & Stirrups & $\begin{array}{c}\text { Fibres } \\
{\left[\mathrm{kg} / \mathrm{m}^{3}\right]}\end{array}$ \\
\hline \multicolumn{11}{|c|}{ Series A1 } \\
\hline OA1 & \multirow{6}{*}{305} & \multirow{6}{*}{552} & \multirow{6}{*}{472.5} & \multirow{6}{*}{5060} & \multirow{6}{*}{3660} & \multirow{6}{*}{3.87} & \multirow{6}{*}{$\begin{array}{c}3 \Phi 20 \\
+ \\
3 \Phi 25\end{array}$} & \multirow{6}{*}{$\begin{array}{c}2 \Phi 12 \\
+ \\
1 \Phi 10\end{array}$} & - & - \\
\hline OAP1 & & & & & & & & & - & $P P 10$ \\
\hline OAS1 & & & & & & & & & - & $S T 30$ \\
\hline A1 & & & & & & & & & \multirow{3}{*}{ Ф8@330 } & - \\
\hline AP1 & & & & & & & & & & $P P 10$ \\
\hline AS1 & & & & & & & & & & ST 30 \\
\hline \multicolumn{11}{|c|}{ Series A2 } \\
\hline OA2 & \multirow{6}{*}{305} & \multirow{6}{*}{552} & \multirow{6}{*}{472.5} & \multirow{6}{*}{5970} & \multirow{6}{*}{4570} & \multirow{6}{*}{4.84} & \multirow{6}{*}{$\begin{array}{c}4 \Phi 20 \\
+ \\
4 \Phi 25\end{array}$} & \multirow{6}{*}{$\begin{array}{c}2 \Phi 12 \\
+ \\
1 \Phi 10\end{array}$} & - & - \\
\hline OAP2 & & & & & & & & & - & $P P 10$ \\
\hline OAS2 & & & & & & & & & - & ST 30 \\
\hline A2 & & & & & & & & & \multirow{3}{*}{ Ф8@330 } & - \\
\hline AP2 & & & & & & & & & & $P P 10$ \\
\hline AS2 & & & & & & & & & & ST 30 \\
\hline \multicolumn{11}{|c|}{ Series B1 } \\
\hline OB1 & \multirow{6}{*}{229} & \multirow{6}{*}{552} & \multirow{6}{*}{472.5} & \multirow{6}{*}{5060} & \multirow{6}{*}{3660} & \multirow{6}{*}{3.87} & \multirow{6}{*}{$\begin{array}{c}3 \Phi 20 \\
+ \\
3 \Phi 25\end{array}$} & \multirow{6}{*}{$\begin{array}{c}2 \Phi 12 \\
+ \\
1 \Phi 10\end{array}$} & - & - \\
\hline OBP1 & & & & & & & & & - & $P P 10$ \\
\hline OBS1 & & & & & & & & & - & ST 30 \\
\hline B1 & & & & & & & & & & - \\
\hline BP1 & & & & & & & & & Ф8@300 & $P P 10$ \\
\hline BS1 & & & & & & & & & & ST 30 \\
\hline & & & & & Serie & S B2 & & & & \\
\hline OB2 & & & & & & & & & - & - \\
\hline OBP2 & & & & & & & & & - & $P P 10$ \\
\hline OBS2 & 220 & 552 & 4725 & 5970 & 4570 & 484 & $\begin{array}{c}3 \Phi 20 \\
+\end{array}$ & $2 \Phi 12$ & - & ST 30 \\
\hline B2 & 229 & 352 & $4 / 2.5$ & טוני & $4 J 10$ & 4.04 & $3 \Phi 25$ & $1 \Phi 10$ & & - \\
\hline BP2 & & & & & & & & & Ф8@300 & $P P 10$ \\
\hline BS2 & & & & & & & & & & ST 30 \\
\hline
\end{tabular}

Moreover, the amounts of the longitudinal and transverse reinforcements in the ICITECH beams remained constant to the beams of Bresler-Scordelis. Hence a large 
Effectiveness of polypropylene fibres as shear reinforcement in structural elements

amount of longitudinal reinforcement was used to prevent flexure failure in bending. Therefore, the steel bars with diameters of $20 \mathrm{~mm}$ and $25 \mathrm{~mm}$ constituted the bottom longitudinal reinforcement by providing a reinforcement amount ratio of $1.43 \%$ to $1.91 \%$, depending on the beam series. In addition, the bars with diameters of $12 \mathrm{~mm}$ and $10 \mathrm{~mm}$ were chosen as the longitudinal top reinforcement, and the 8 -mm stirrups anchored with $135^{\circ}$ bends were used in the beams with transverse reinforcement.

Finally, in order to prevent the bond failure of longitudinal reinforcement, or the influence of bond failure on other failure mechanisms, the length of beams was extended 700 $\mathrm{mm}$ away from the supports to ensure sufficient anchorage, as shown in Figure 4-2. Thus no steel-end plates like those used by Bresler-Scordelis to ensure the anchorage of longitudinal reinforcement were used.

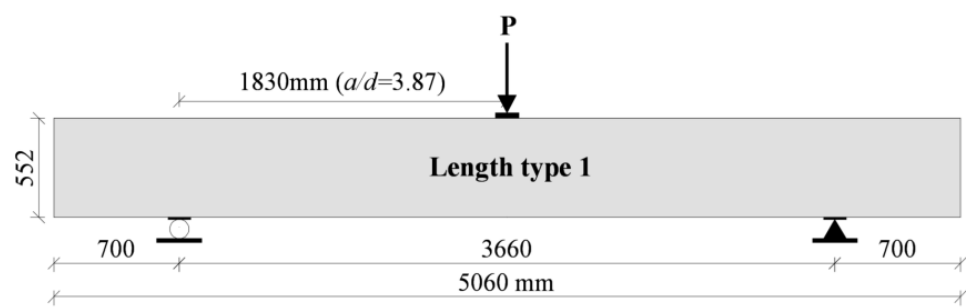

(a)

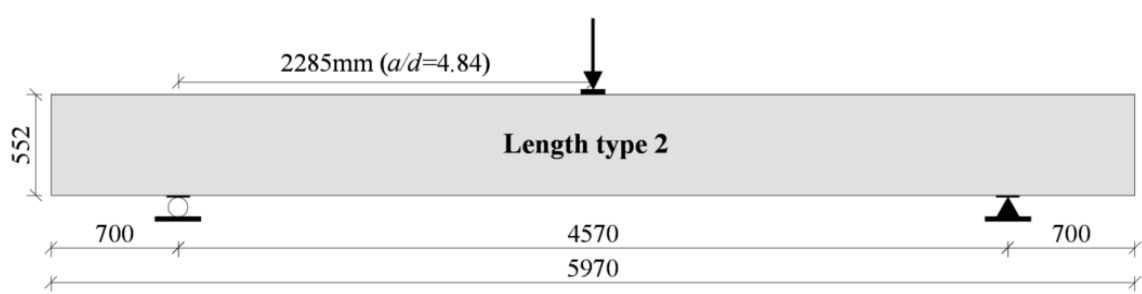

(b)

Figure 4-2: Three-point loading scenario: load scheme for $a / d=3.87$ (a) and $a / d=4.84$

Table 4-2 lists the mix designs of the three employed concrete types. Portland cement, two types of crushed limestone gravel, three kinds of fine aggregate, water and superplasticiser were used to prepare concrete. The employed cement was CEM I 42.5N with a water-to-cement ratio $(w / c)$ of 0.5 . The maximum aggregate size was $20 \mathrm{~mm}$. Superplasticiser was used to obtain the desired workability and well-distributed fibres in all the beams. The slump flow test of the three concrete types was $612 \mathrm{~mm}$ on average, evaluated according to EN 12350-8:2011 as Figure 4-3c shows. 
Chapter 4. PFRC in slender beams

Double hooked-end steel fibres were used at a dose of $30 \mathrm{~kg} / \mathrm{m}^{3}$ in the SFRC elements. Fibres were $0.9 \mathrm{~mm}$ in diameter and $60 \mathrm{~mm}$ long, with a nominal aspect (length/diameter) ratio equalling 65 . Tensile strength and modulus of elasticity were $2.300 \mathrm{MPa}$ and $210.0000 \mathrm{MPa}$, respectively. Macrosynthetic fibres, $48 \mathrm{~mm}$ long with a nominal aspect (length/diameter) ratio equalling 57 and a density of $0.91 \mathrm{~g} / \mathrm{cm}^{3}$, were used in the PFRC beams, which amounted to $10 \mathrm{~kg} / \mathrm{m}^{3}$. Tensile strength and modulus of elasticity were $400 \mathrm{MPa}$ and $4.7 \mathrm{GPa}$, respectively. Steel reinforcement bars were evaluated according to EN-ISO 6892-1[204]. The yielding stress $f_{y}$ and ultimate stress $f_{u}$ of the rebars were $518 \mathrm{MPa}$ and $660 \mathrm{MPa}$ for the $8 \mathrm{~mm}$ bar, 526 and 670 for the $10 \mathrm{~mm}$ bar, 529 and 640 for the $12 \mathrm{~mm}$ bar, 579 and 662 for the $20 \mathrm{~mm}$ bar, and 579 and 662 for the $25 \mathrm{~mm}$ bar.

Table 4-2: Mix design of reinforced concrete, SFRC and PFRC

\begin{tabular}{|c|c|}
\hline Cement CEM I 42.5N $\left[\mathrm{kg} / \mathrm{m}^{3}\right]$ & 350 \\
\hline Crushed sand type $1\left[\mathrm{~kg} / \mathrm{m}^{3}\right]$ & 482 \\
\hline Crushed sand type $2\left[\mathrm{~kg} / \mathrm{m}^{3}\right]$ & 168 \\
\hline Crushed sand type $3\left[\mathrm{~kg} / \mathrm{m}^{3}\right]$ & 482 \\
\hline Gravel 6/12 mm [kg/m³] & 591 \\
\hline Gravel $12 / 20 \mathrm{~mm}\left[\mathrm{~kg} / \mathrm{m}^{3}\right]$ & 118 \\
\hline \multirow{2}{*}{ Fibres $\left[\mathrm{kg} / \mathrm{m}^{3}\right]$} & 10 (PFRC) $V_{f}=1.1 \%$ \\
\hline & $30\left(\right.$ SFRC) $V_{f}=0.38 \%$ \\
\hline \multirow{3}{*}{ Superplasticiser $\left[\mathbf{l t} / \mathbf{m}^{3}\right]$} & $3.5(\mathrm{RC})$ \\
\hline & 3.8 (SFRC) \\
\hline & 4.7 (PFRC) \\
\hline
\end{tabular}

The mix design for RC, SFRC and PFRC was carried out to achieve a compressive concrete strength of $35 \mathrm{MPa}$. Beams were manufactured in a precast plant. Eighteen concrete batches of approximately $1.0 \mathrm{~m}^{3}$ were needed to manufacture the 24 beams. Reinforcement was placed inside steel formworks (see Figure 4-3a). Then formworks were filled with concrete using a concrete pocket to avoid aggregate segregation (see Figure 4-3b). Nevertheless, as concrete workability was high, there was no need to use mechanical vibration to disperse the concrete inside formworks. Steel formworks were removed from the beams the next day after casting. Beams were cured inside the plant, and were transported to the ICITECH facilities after 28 casting days. 
Effectiveness of polypropylene fibres as shear reinforcement in structural elements

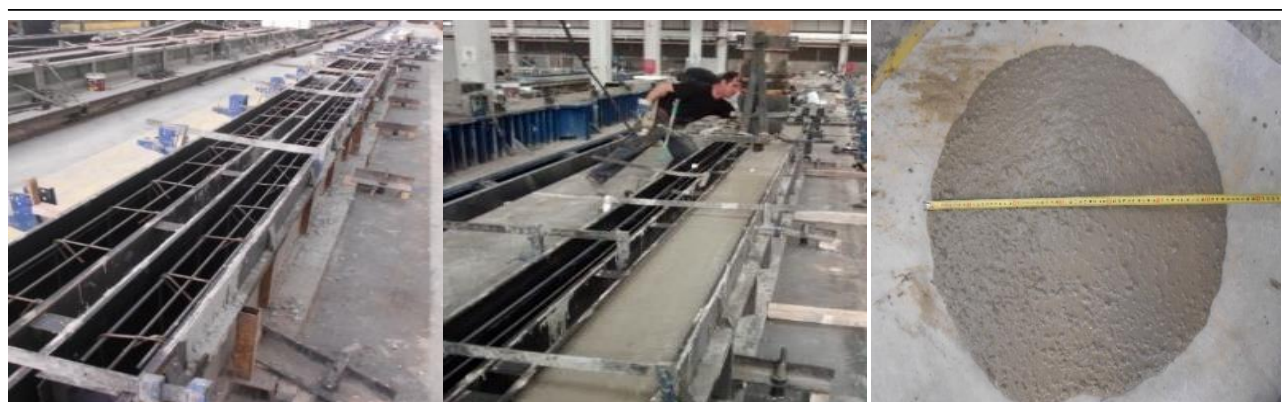

(a)

(b)

(c)

Figure 4-3: Manufacturing beams: formworks (a), full cast beam (b) and slump flow test (c)

In order to determine the mechanical properties of $\mathrm{RC}$ and PFRC, the samples of the concrete from each batch were used to obtain 48 cylindrical specimens of $150 \times 300 \mathrm{~mm}$ and 24 prismatic $(150 \times 150 \times 600 \mathrm{~mm})$ beam specimens. These specimens were cured under the same environmental conditions as beams.

Cylinder specimens were used to determine the concrete compressive strength $\left(f_{c}\right)$ and their modulus of elasticity $\left(E_{c}\right)$. Uniaxial compression tests were carried out according to EN 12390-3 [196]. Increased loading was applied at a rate of $0.6 \mathrm{MPa} / \mathrm{s}$. Four cylinder specimens were tested per cast batch. Modulus of elasticity was determined according to EN 12390-13 [197]. As shown in Table 4-3, the average compression strengths were 40.56 MPa for RC, 39.74MPa for SFRC and 43.6MPa for PFRC. The concrete characteristic compression strengths $\left(f_{c k}\right)$ were $37.18 \mathrm{MPa}, 36.54 \mathrm{MPa}$ and $40.56 \mathrm{MPa}$ for $\mathrm{RC}$, SFRC and PFRC calculated with a reliability factor value $(K)$ of $1.84,1.77$ and 1.96 , respectively.

The residual flexural tensile strengths of PFRC were tested according to EN 14651 [15]. Three-point bending test setups were chosen. Load was applied at a rate of $0.05 \mathrm{~mm} / \mathrm{min}$ until $\mathrm{CMOD}=0.1$. After $\mathrm{CMOD}=0.1$, the rate was gradually increased to $0.20 \mathrm{~mm} / \mathrm{min}$. Table 4-3 summarises the flexural strength $\left(f_{L}\right)$ and the residual flexural tensile strength $\left(f_{R, \mathrm{j}} ; \mathrm{j}=1\right.$ to 4$)$ for CMOD (crack mouth opening displacement) of $0.5,1.5,2.5$ and 3.5 $\mathrm{mm}$.

Figure 4-4 exhibits flexural tensile stress $v s$. the CMOD curves of each employed concrete. Both FRC types displayed typical postcracking behaviour, which consisted in a load drop after the peak load, followed by stable behaviour up to a CMOD of $3.5 \mathrm{~mm}$. It should be noted that both FRC types gave a similar response to one another, as seen in Figure 4-4a and b. Finally, the obtained residual results met the MC2010 requirements [7] for using fibres in structural elements because $f_{R, 1} / f_{L}>0.40$ and $f_{R, 3} / f_{R, 1}>0.50$, as far as the mean values were concerned. The material postcracking strength of SFRC and PFRC was classified as $3 \mathrm{~d}$ and $3 \mathrm{e}$ according to MC2010 [7]. The characteristic $f_{R, 1}$ and $f_{R, 3}$ values were 1.70 $\mathrm{MPa}$ and 2.28 MPa for SFRC $(\mathrm{k}=1.35$ and 1.49$)$, and $2.19 \mathrm{MPa}$ and 3.34MPa $(\mathrm{k}=1.53$ and 1.45$)$ for PFRC. 
Chapter 4. PFRC in slender beams

Fibre density was also evaluated using the prismatic specimens. Fibres were visually counted on the cracking plane after testing. As Table 4-3 shows, SFRC presented a wider variability in the number of fibres than PFRC. This phenomenon was because the number of steel fibres in the matrix was smaller than in PFRC. Thus the probability of fibre dispersion was greater in SFRC than in PFRC.

Table 4-3: Concrete mechanical properties.

\begin{tabular}{|c|c|c|c|}
\hline Property & RC & SFRC & PFRC \\
\hline $\boldsymbol{f}_{\boldsymbol{c}}[\mathrm{MPa}]$ & 40.59 & 39.74 & 43.6 \\
& $(0.05)$ & $(0.05)$ & $(0.04)$ \\
\hline $\boldsymbol{E}_{\boldsymbol{c}}[\mathrm{MPa}]$ & 29972 & 29282 & 29878 \\
& $(0.03)$ & $(0.05)$ & $(0.04)$ \\
\hline $\boldsymbol{f}_{\boldsymbol{L}}[\mathrm{MPa}]$ & 4.51 & 4.86 & 4.57 \\
& $(0.06)$ & $(0.08)$ & $(0.08)$ \\
\hline $\boldsymbol{f}_{\boldsymbol{R}, \boldsymbol{l}}[\mathrm{MPa}]$ & - & 3.16 & 2.94 \\
& - & $(0.33)$ & $(0.17)$ \\
\hline $\boldsymbol{f}_{\boldsymbol{R}, 2}[\mathrm{MPa}]$ & - & 3.95 & 4.28 \\
& - & $(0.31)$ & $(0.20)$ \\
\hline $\boldsymbol{f}_{\boldsymbol{R}, 3}[\mathrm{MPa}]$ & - & 4.01 & 4.71 \\
\hline & & $(0.30)$ & $(0.20)$ \\
\hline $\boldsymbol{f}_{\boldsymbol{R}, 4}[\mathrm{MPa}]$ & - & 3.88 & 4.77 \\
\hline Fibres $\left[\mathbf{f i b r e s} / \mathbf{c m}^{2}\right]$ & - & $(0.31)$ & $(0.20)$ \\
\hline & & 0.242 & 0.602 \\
& & & $(0.16)$ \\
\hline
\end{tabular}
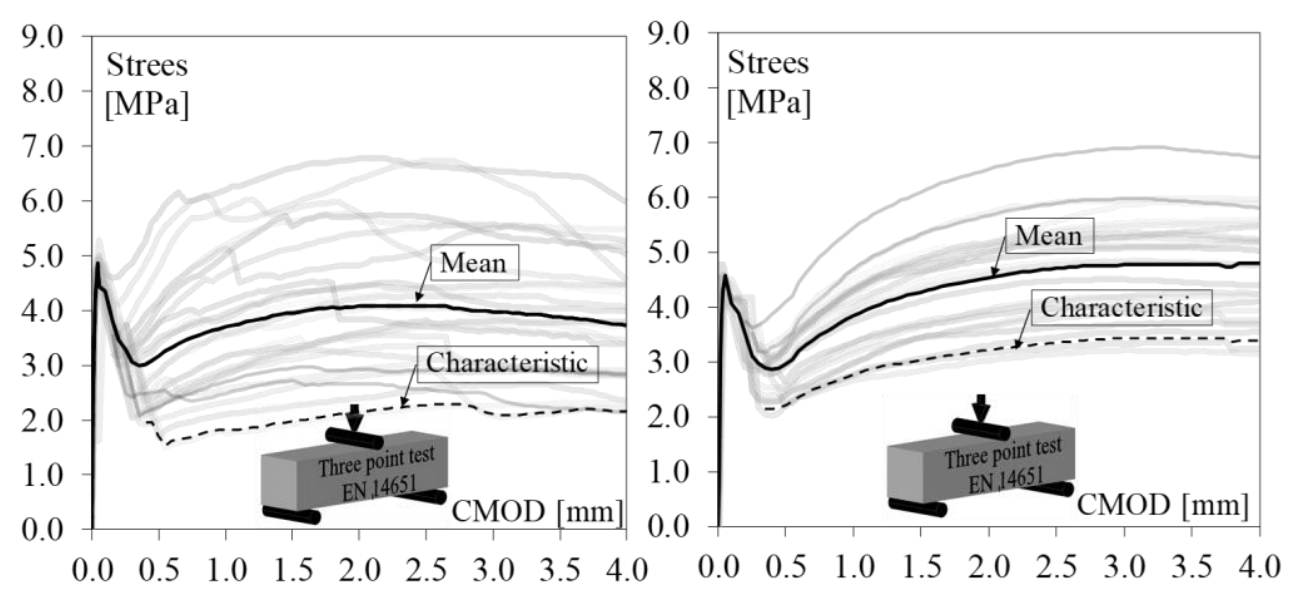

Figure 4-4: Nominal stress vs. CMOD response in line with EN14651[15] for SFRC (a) and $\operatorname{PFRC}(\mathbf{b})$ 
Effectiveness of polypropylene fibres as shear reinforcement in structural elements

\subsection{Test setup and instrumentation}

Beams were subjected to a three-point bending test, as indicated in Figure 4-5a. A servohydraulic jack of $1,000 \mathrm{kN}$ was used, which was connected to a universal testing machine. The test was carried out under the displacement control conditions of deflection at the mid-span. Load was applied to all the beams at an average constant deflection rate of $0.30 \pm 0.10 \mathrm{~mm} / \mathrm{min}$. Steel plate used to transfer the load to the beams was 140x100x300 mm.

In order to measure displacements, nine potentiometric displacement transducers (PTs) were used as shown in Figure 4-5a and Figure 4-5b. One was utilised for measuring deflection at the mid-span (PT50mm), and two as supports for capturing undesired vertical movements (PT125mm). Two horizontal devices (PT50mm) were located at the mid-span to measure the average strain in the compression and tension chords. Another set of two potentiometric (PT125mm) displacement transducers was placed with some inclination on the shear span to record the diagonal cracking induced by shear (see Figure 4-5b). Finally, two other devices (PT50mm) were placed at the top of the specimen, between the loading application point and supports.

Both supports (pinned and roller ones) were constituted by steel plates of 350x350x20mm.

In order to allow the horizontal displacements of the beam due to bending and shearing deformations, one of the used supports was a roller support and the other was a pinned support.

It is worth noting that the instruments were placed on only one of the two lateral beam faces (see Figure 4-5c). On the remaining lateral beam face, a 100x100 mm grid was painted to capture high-resolution images of the surface. For this purpose, four highperformance cameras (21 Mega pixels) were set up to take pictures every 10 seconds throughout the test (see Figure 4-5d).

These digital images were used to study the influence of fibres on the crack patterns, shear deformation and crack kinematics of the beams, as indicated in the following section. The methodology employed to process images was similar to that proposed by Diasda-Costa [205].

It is noteworthy that prior to the photogrammetry measurements, the intrinsic and extrinsic distortions in the images were corrected by an initial dot pattern. The measurements taken by photogrammetry were validated by those obtained with the potentiometric displacement transducers. 


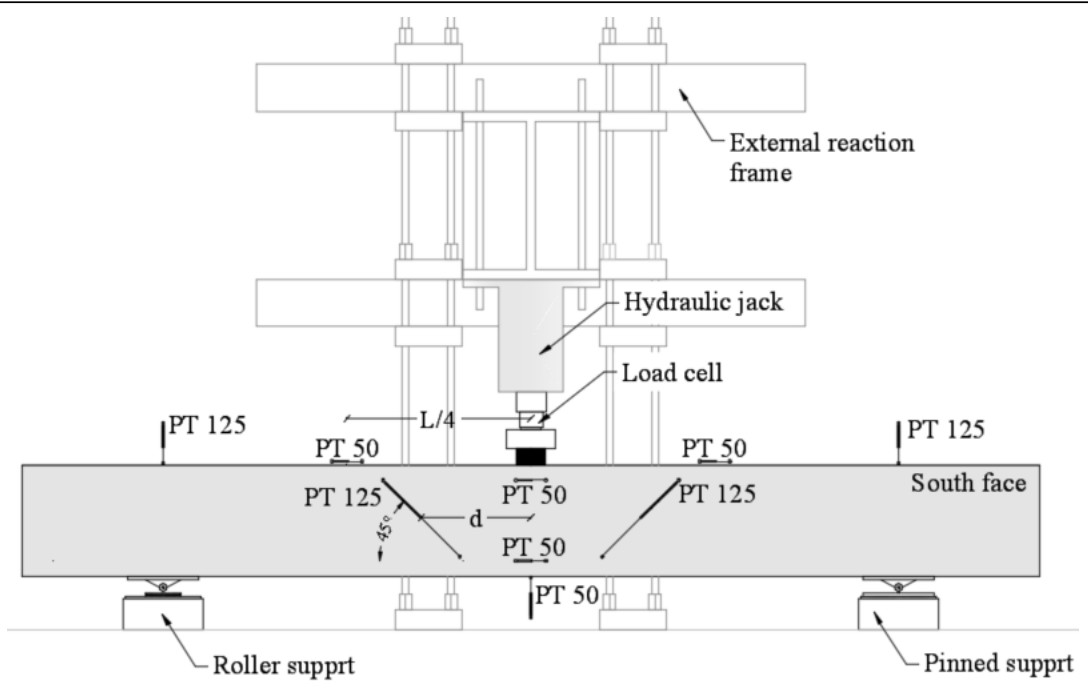

(a)

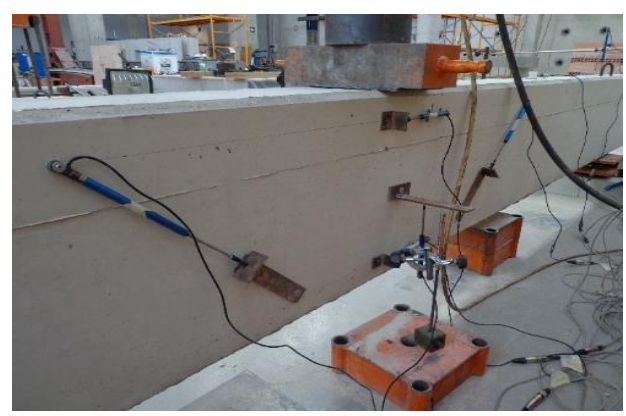

(b)

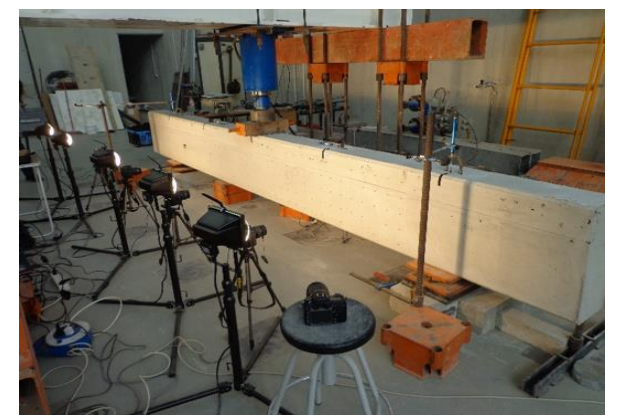

(c)

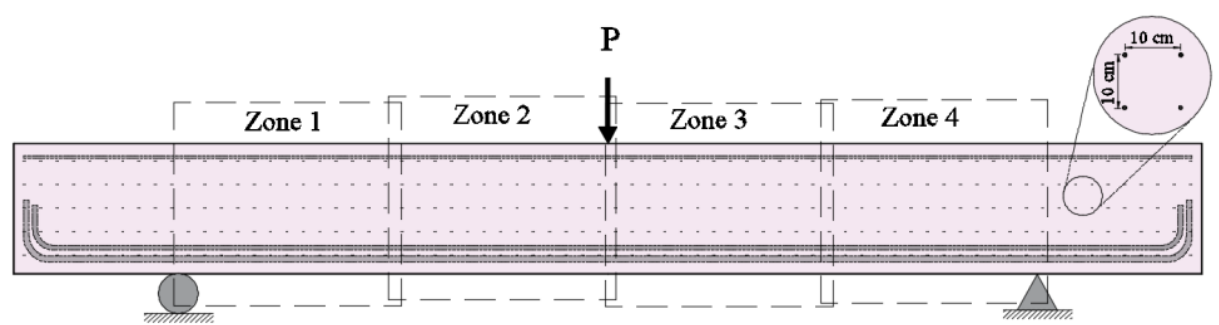

d)

Figure 4-5: Beams test setup (a), picture of instrumentation (b), picture of cameras setup (c) and target points (d) 
Effectiveness of polypropylene fibres as shear reinforcement in structural elements

\subsection{Experimental results and discussion}

The maximum applied load $\left(P_{u}\right)$, deflection at the mid-span $\left(\delta_{u}\right)$ at maximum load, shear strength $\left(V_{u}\right)$, including the element's self-weight, nominal shear strength $\left(v_{u}\right)$, normalised shear strength $\left(v_{u} /\left(f_{c}\right)^{0.5}\right)$, flexural moment $\left(M_{u}\right)$ and estimated flexural strength $\left(M_{u, c a l}\right)$, and the MOF of each beam, are presented in Table 4-4. The shear strength $\left(V_{u}\right)$ of each beam was determined as half the resisted maximum load $\left(P_{u}\right)$. The self-weight of each beam was calculated at a distance equal to the effective depth (d) from the bearing plate edge. Mid-span deflection $\left(\delta_{u}\right)$ was corrected using the vertical reading obtained with the LVDTs placed on the bearing plates (Figure 4-5a).

Three well-known and accepted MOFs in slender beams were addressed in:

- Diagonal - tension (DT), a brittle failure that takes place in slender beams with no or very little shear reinforcement

- The shear - compression (VC) MOF presents many inclined cracks, which grow and reduce the compression zone, with the beam failing at the end by splitting in the compression zone

- The flexure-compression (FC) MOF a ductile failure that occurs when flexural cracks progress until they reach the compression zone and concrete starts crushing after yielding the longitudinal reinforcement

Figure 4-6 shows the load-deflection responses of the 24 beams arranged in four graphs (Figure 4-6a to Figure 4-6d) corresponding to series A1, A2, B1 and B2, respectively. This makes it easier to study the effect of fibres and transverse reinforcement on shear behaviour in each case.

As shown in Figure 4-6 and Table 4-4, the beams that accomplished the lower load capacity corresponded to the RC beams $(0 \mathrm{~A} 1,0 \mathrm{~A} 2,0 \mathrm{~B} 1,0 \mathrm{~B} 2)$, which contained neither fibres nor stirrups. All those beams containing fibres (steel or polypropylene) achieved a higher load capacity compared to their RC w/o stirrups counterparts, and obtained a $38 \%$ average extra capacity in series A1 and A2, and one of $29 \%$ in series B1 and B2. Indeed for series $\mathrm{A} 1$ and $\mathrm{A} 2$, the peak load $\left(P_{u}\right)$ was comparable to that achieved by the RC beams with stirrups (A1 and A2). However in series B1 and B2, this behaviour was not observed in both FRC beams because fewer fibres crossed the diagonal cracks due to a narrower section width.

For the beams with stirrups and fibres, fibres provided extra load capacity with a $39 \%$ average in series $\mathrm{A} 1$ and $\mathrm{A} 2$, and one of $13 \%$ in series $\mathrm{B} 1$ and $\mathrm{B} 2$, compared to the $\mathrm{RC}$ beams with stirrups.

In all the beam series, as seen in Figure 4-6, the initial stiffness in the load-deflection response was similar in all the beam types. In fact the fibres in the PFRC and SFRC beams w/o stirrups allowed them to reach similar deflection levels to the RC beams with stirrups in series A1 and A2. For series B1 and B2, fibres did not confer elements PFRC and SFRC the similar characteristic to the RC beams with stirrups in load and deflection 
Chapter 4. PFRC in slender beams

terms. Nevertheless, the results evidence that the fibres (steel and polypropylene) in all the beam series improved both the peak load and deflection, which imply more ductility and strength.

Table 4-4: Summary of the tested beam results

\begin{tabular}{|c|c|c|c|c|c|c|c|c|}
\hline Beam & $\begin{array}{r}a / d \\
{[-]}\end{array}$ & $\begin{array}{c}P_{u} \\
{[\mathbf{k N}]}\end{array}$ & $\begin{array}{c}\delta_{u} \\
{[\mathbf{m m}]}\end{array}$ & $\begin{array}{c}V_{u} \\
{[\mathbf{k N}]}\end{array}$ & $\begin{array}{c}v_{u} \\
{[\mathrm{MPa}]}\end{array}$ & $\begin{array}{c}v_{u} /\left(f_{c}\right)^{\wedge} 0.5 \\
{[-]}\end{array}$ & $\begin{array}{c}M_{u} / M_{u, c a l} \\
{[-]}\end{array}$ & MOF \\
\hline \multicolumn{9}{|c|}{ Series A1 } \\
\hline OA1 & 3.87 & 312.11 & 5.74 & 160.96 & 1.12 & 0.18 & 0.51 & DT \\
\hline OAP1 & 3.87 & 446.68 & 15.81 & 228.24 & 1.58 & 0.24 & 0.64 & DT \\
\hline OAS1 & 3.87 & 466.47 & 15.62 & 238.14 & 1.65 & 0.26 & 0.69 & DT \\
\hline A1 & 3.87 & 472.71 & 16.31 & 241.25 & 1.67 & 0.26 & 0.76 & $\mathrm{VC}$ \\
\hline AP1 & 3.87 & 695.30 & 29.78 & 352.55 & 2.45 & 0.37 & 0.99 & $\mathrm{VC}$ \\
\hline AS1 & 3.87 & 682.20 & 24.62 & 346.00 & 2.40 & 0.38 & 1.00 & $\mathrm{FC}$ \\
\hline \multicolumn{9}{|c|}{ Series A2 } \\
\hline OA2 & 4.84 & 339.03 & 12.06 & 176.29 & 1.22 & 0.19 & 0.55 & DT \\
\hline OAP2 & 4.84 & 486.26 & 28.02 & 249.90 & 1.73 & 0.26 & 0.72 & DT \\
\hline OAS2 & 4.84 & 455.59 & 30.94 & 234.57 & 1.63 & 0.26 & 0.70 & $\mathrm{VC}$ \\
\hline $\mathbf{A 2}$ & 4.84 & 478.39 & 25.96 & 245.96 & 1.71 & 0.27 & 0.76 & $\mathrm{VC}$ \\
\hline AP2 & 4.84 & 678.60 & 35.49 & 346.07 & 2.40 & 0.36 & 1.00 & $\mathrm{VC}$ \\
\hline AS2 & 4.84 & 658.07 & 40.06 & 335.81 & 2.33 & 0.37 & 1.00 & $\mathrm{VC}$ \\
\hline \multicolumn{9}{|c|}{ Series B1 } \\
\hline OB1 & 3.87 & 274.97 & 7.48 & 141.17 & 1.30 & 0.20 & 0.47 & DT \\
\hline OBP1 & 3.87 & 361.73 & 15.30 & 184.55 & 1.71 & 0.26 & 0.56 & DT \\
\hline OBS1 & 3.87 & 309.86 & 10.92 & 158.57 & 1.47 & 0.23 & 0.50 & DT \\
\hline B1 & 3.87 & 468.01 & 17.69 & 237.66 & 2.20 & 0.34 & 0.78 & $\mathrm{VC}$ \\
\hline BP1 & 3.87 & 555.56 & 18.60 & 281.43 & 2.60 & 0.39 & 0.86 & $\mathrm{VC}$ \\
\hline BS1 & 3.87 & 546.22 & 20.57 & 276.75 & 2.56 & 0.41 & 0.87 & $\mathrm{VC}$ \\
\hline \multicolumn{9}{|c|}{ Series B2 } \\
\hline OB2 & 4.84 & 226.37 & 10.01 & 118.28 & 1.09 & 0.17 & 0.49 & DT \\
\hline OBP2 & 4.84 & 295.60 & 18.02 & 152.90 & 1.41 & 0.21 & 0.58 & DT \\
\hline OBS2 & 4.84 & 326.89 & 18.65 & 168.53 & 1.56 & 0.25 & 0.66 & DT \\
\hline B2 & 4.84 & 439.57 & 31.62 & 224.86 & 2.08 & 0.33 & 0.93 & $\mathrm{VC}$ \\
\hline BP2 & 4.84 & 487.37 & 32.37 & 248.77 & 2.30 & 0.35 & 0.95 & $\mathrm{FC}$ \\
\hline BS2 & 4.84 & 492.74 & 29.32 & 251.45 & 2.32 & 0.37 & 0.98 & $\mathrm{VC}$ \\
\hline
\end{tabular}




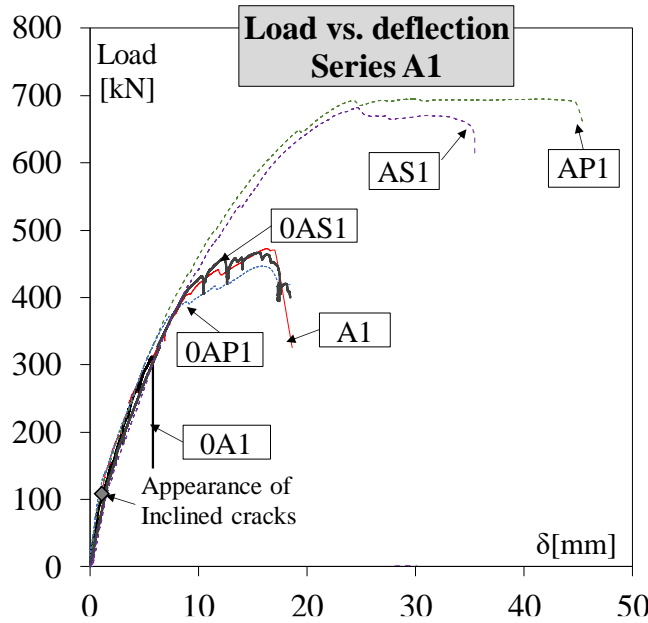

(a)

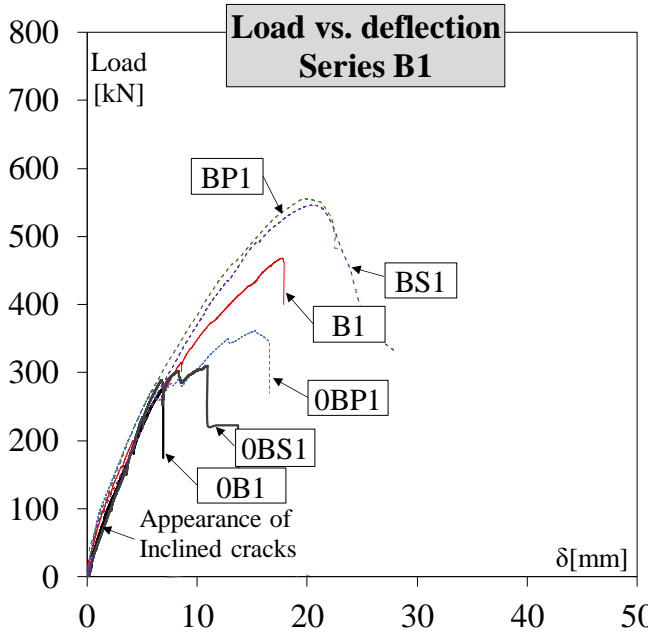

(c)

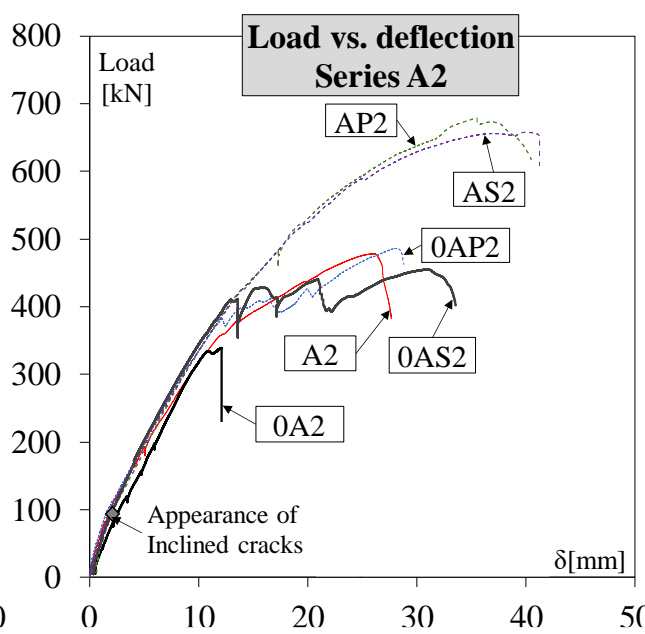

(b)

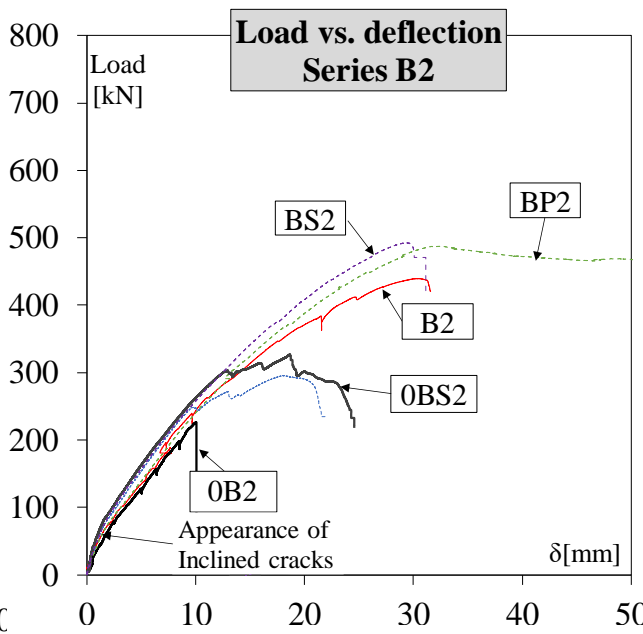

(d)

Figure 4-6: Load vs. deflection curves: series A1 (a), A2 (b), B1 (c), and B2 (d)

\subsubsection{Validation of the experimental results}

As some of the ICITECH beams (RC beams) equal those tested by Bresler and Scordelis, the present experimental results are compared against the experimental results obtained by Bresler and Scordelis (B\&S) in 1963. Moreover, the present experimental campaign is compared to the results obtained by Vecchio and Shim (V\&S) [206] in 2004. Figure 
4-7 presents the aforementioned comparison of beam series A1 (beams A1, 0A1), series A2 (beams A2 and 0A2), series B1 (beam B1) and series B2 (beams B2).
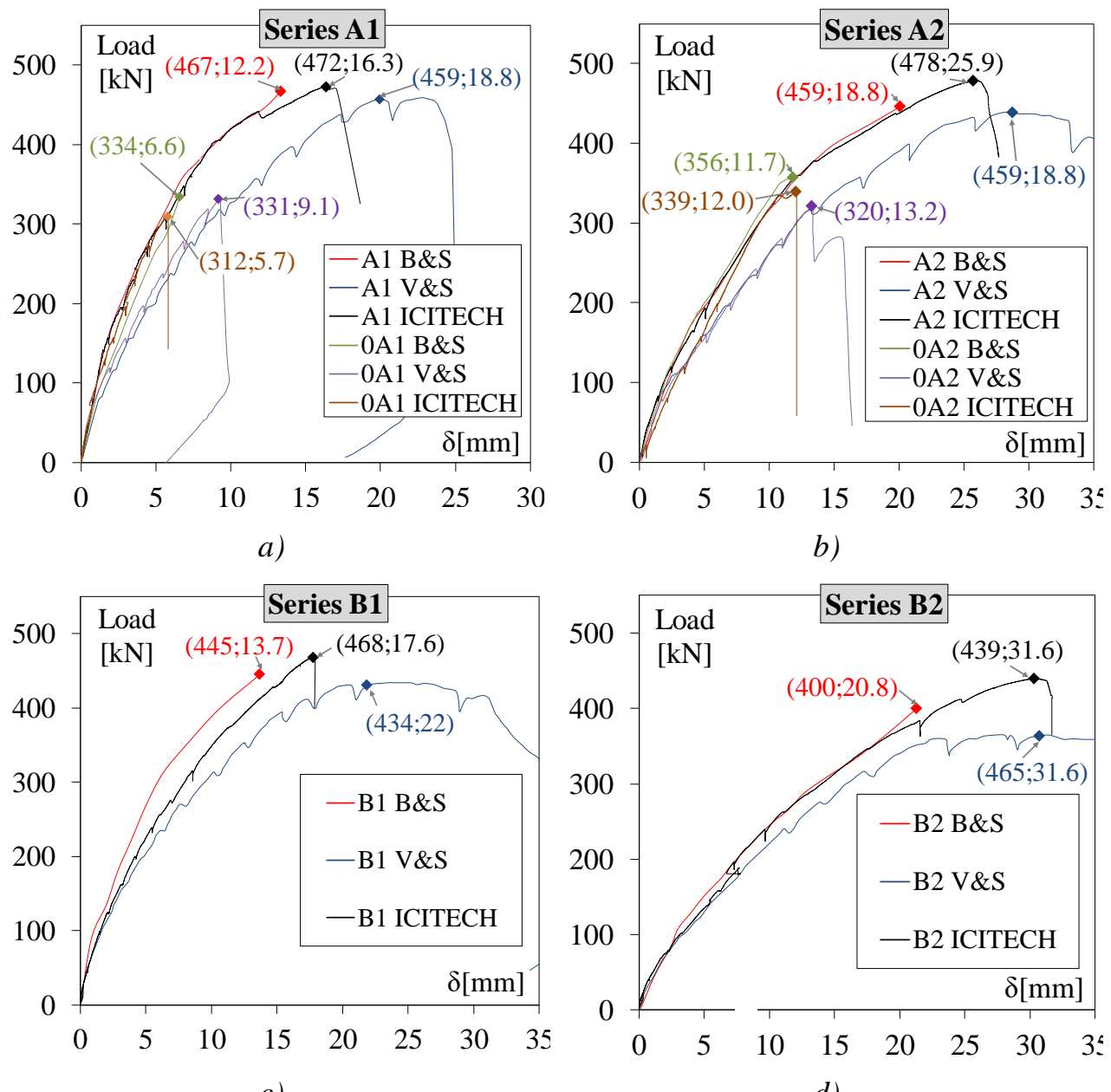

c)

Figure 4-7: Comparison of the Bresler-Scordelis, Vecchio-Shim and ICITECH beams

As seen in Figure 4-7a to d, a similar trend in the load-deflection responses was observed among the Bresler-Scordelis (B\&S), Vecchio-Shim (V\&S) and ICITECH beams despite certain differences in their material properties. Figure 4-7 also the peak load $\left(P_{u}\right)$ and deflection at the peak load $\left(\delta_{u}\right)$ of each experimental test in brackets. If the peak loads are compared of the three experimental tests, the ratio of the peak load between the ICITECH and $\mathrm{B} \& \mathrm{~S}$ beams $\left(\mathrm{P}_{\mathrm{u}, \mathrm{BS}} / \mathrm{P}_{\mathrm{u}}\right.$, ICITECH), ranges from 0.91 to 1.07 (an average of 0.99 with a $6 \%$ coefficient of variation. In addition, the ICITECH beams generally achieved greater deflection upon the peak load compared to their Bresler counterpart 
Effectiveness of polypropylene fibres as shear reinforcement in structural elements

beam, whereas the Vecchio-Shim beams achieved less load and more deflection than the ICITECH beams in most cases.

As regards the achieved MOF, we can see than the ICITECH beams presented an equal MOF to the Bresler and Scordelis ones, i.e. DT for those RC beams w/o stirrups and VC for the beams with stirrups. These results about MOF, as well as strength and deflection, validate the present experimental campaign, which ensures that the methodology and procedures used in the tests of all the beams are reliable.

\subsubsection{Mode of failure (MOF)}

Although it has been shown that fibres provide extra strength and less brittleness to the element, the effectiveness of fibres to change the MOF from a brittle to a ductile one is experimentally studied in this section. To do so, and in order to better visualize the MOF of all the beams, Figure 4-8 and Figure 4-9 present the crack pattern of the beams after their failure.

The RC beams w/o stirrups (0A1, A2, $0 \mathrm{~B} 1$ and $\mathrm{B} 2)$ were characterized to present a DT mode of failure. These beams showed a single main critical diagonal crack opening of around $0.4 \mathrm{~mm}$ before collapsing, which caused instantaneous brittle-like failure with no ductility when $P_{u}$ was reached. The same MOF was also observed in all the FRC beams without stirrups, except for beam 0AS2, which failed in shear-compression (VC). Nevertheless unlike the RC beams w/o stirrups, the PFRC w/o stirrups (0AP1, 0AP2, 0AS1, 0AS2, 0BP1, 0BP2, 0BS1 and 0BS2) presented more diagonal cracks. In fact prior to the peak load, several main diagonal cracks appeared on both beam sides, as seen in Figure 4-8 and Figure 4-9. Failure occurred when one of the main diagonal cracks reached the loading point. Nevertheless, it is worth mentioning that although the MOF of the PFRC non-stirrup beams remained unaltered compared to their corresponding RC beams, the main diagonal shear crack behaviour differed as it was less fragile and more predictable. So it can be classified as a controlled diagonal tension (C-D-T) MOF.

The RC and FRC beams with stirrups failed in shear-compression (VC) in most cases. However with AS1 and BP2, the MOF changed from shear-compression (VC) to flexural-compression (FC). This change was due to the high bending moment level achieved at the peak load. As seen in Table 4-4, coefficient $M_{u} / M_{u, \text { cal }}$ came close to 1 for those beams for which stirrups and fibres were combined, which means that shear failure or flexure failure can indistinctly occur.

As observed, although the inclusion of both polypropylene fibres in the $10 \mathrm{~kg} / \mathrm{m}^{3}$ and steel fibres in the $10 \mathrm{~kg} / \mathrm{m}^{3}$ ones led to similar shear strength and ductility as stirrups (especially in series A1 and A2), they were not capable of changing the MOF compared to the RC beams w/o stirrups. In other words, stirrups were more effective than fibres in redistributing internal stresses when a main diagonal crack appeared. However, the efficiency of fibres in controlling the main diagonal crack and in reducing the brittleness of failure should be highlighted. 
When fibres were combined with stirrups (beams AP1, AP2, AS1, AS2, BP1, BP2, BS1 and BS2), and as beams were doubly reinforced in shear, fibres were capable of delaying shear failure. This allowed flexural failure, as flexural-compression, to take place rather than shear failure, which occurred in beams AS1 and BP2.
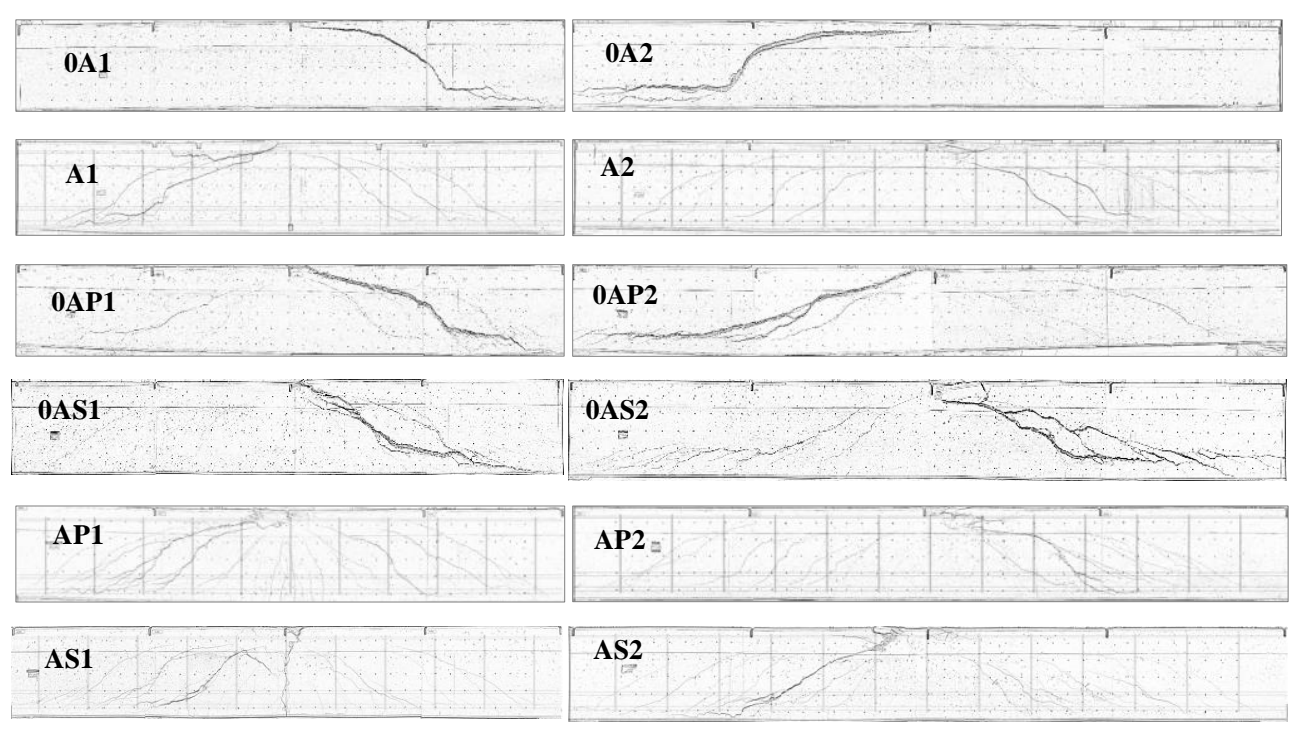

Figure 4-8: Crack pattern at failure of series A1 and series A2.
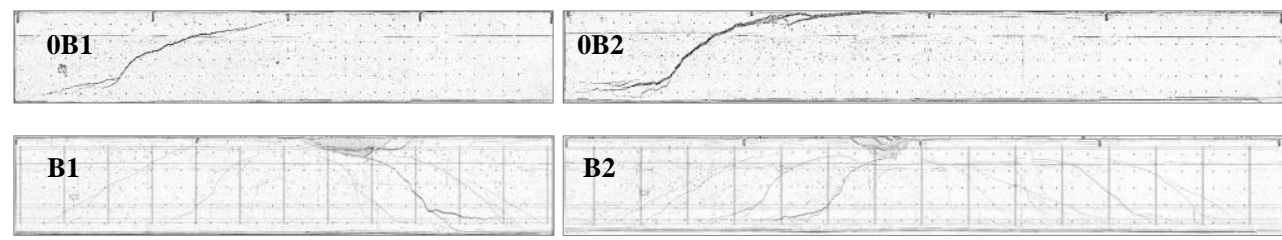

B2
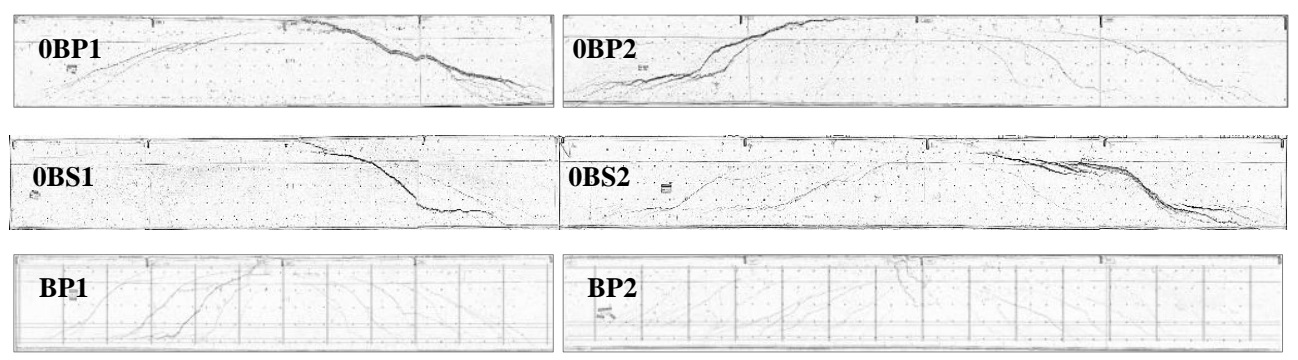

OBS2

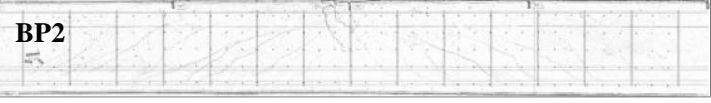

BS2 -

Figure 4-9: Crack pattern at failure of series B1 and series B2. 


\subsubsection{Synergy effect between fibres and stirrups}

Table 4-5: The obtained experimental synergy

\begin{tabular}{|c|c|c|c|c|c|c|c|}
\hline Beam & $\begin{array}{c}v_{u} \\
{[\mathrm{MPa}]}\end{array}$ & $\begin{array}{c}v_{u} /\left(f_{c}\right)^{0.5} \\
{[-]}\end{array}$ & $v_{c}$ & $v_{s}$ & $v_{f}$ & $\Sigma=v_{c}+v_{s}+v_{f}$ & Synergy \\
\hline \multicolumn{8}{|c|}{ Series A1 } \\
\hline OA1 & 1.12 & 0.18 & 0.18 & & & & \\
\hline A1 & 1.67 & 0.26 & & 0.08 & & & \\
\hline OAP1 & 1.58 & 0.24 & & & 0.06 & & \\
\hline OAS1 & 1.65 & 0.26 & & & 0.08 & & \\
\hline AP1 & 2.45 & 0.37 & & & & 0.32 & 0.05 \\
\hline AS1 & 2.4 & 0.38 & & & & 0.34 & 0.04 \\
\hline \multicolumn{8}{|c|}{ Series A2 } \\
\hline OA2 & 1.22 & 0.19 & 0.19 & & & & \\
\hline A2 & 1.71 & 0.27 & & 0.08 & & & \\
\hline OAP2 & 1.73 & 0.26 & & & 0.07 & & \\
\hline OAS2 & 1.63 & 0.26 & & & 0.07 & & \\
\hline AP2 & 2.4 & 0.36 & & & & 0.34 & 0.02 \\
\hline AS2 & 2.33 & 0.37 & & & & 0.34 & 0.03 \\
\hline \multicolumn{8}{|c|}{ Series B1 } \\
\hline OB1 & 1.3 & 0.2 & 0.20 & & & & \\
\hline B1 & 2.2 & 0.34 & & 0.14 & & & \\
\hline OBP1 & 1.71 & 0.26 & & & 0.06 & & \\
\hline OBS1 & 1.47 & 0.23 & & & 0.03 & & \\
\hline BP1 & 2.6 & 0.39 & & & & 0.40 & -0.01 \\
\hline BS1 & 2.56 & 0.41 & & & & 0.37 & 0.04 \\
\hline \multicolumn{8}{|c|}{ Series B2 } \\
\hline OB2 & 1.09 & 0.17 & 0.17 & & & & \\
\hline B2 & 2.08 & 0.33 & & 0.16 & & & \\
\hline OBP2 & 1.41 & 0.21 & & & 0.04 & & \\
\hline OBS2 & 1.56 & 0.25 & & & 0.08 & & \\
\hline BP2 & 2.3 & 0.35 & & & & 0.37 & -0.02 \\
\hline BS2 & 2.32 & 0.37 & & & & 0.41 & -0.04 \\
\hline
\end{tabular}


Chapter 4. PFRC in slender beams

A synergy effect among concrete, steel and fibre was also identified in beams PFRC and SFRC. Table 4-5 shows the experimental synergy of all the beam series, in which each resistance was decoupled in concrete $\left(v_{c}\right)$, stirrups $\left(v_{s}\right)$ and fibre $\left(v_{f}\right)$, and was finally normalised according to the corresponding square root of concrete compressive strength. The synergy effect occurred in series A1 and A2. The following results were obtained when evaluating synergy in both series: PFRC A1 beams $0.05 \mathrm{MPa} / \mathrm{MPa}$, SFRC A1 beams $0.04 \mathrm{MPa} / \mathrm{MPa}$, PFRC A2 beams $0.02 \mathrm{MPa} / \mathrm{MPa}$ and SFRC A2 beams 0.03 $\mathrm{MPa} / \mathrm{MPa}$. This scenario respectively represents greater fibre resistance efficiency from $5 \%$ to $15 \%$.

In addition, this synergy effect did not occur in series B1 and B2, where the synergy was negative in three of the four cases (see Table 4-5). This finding respectively represents decreasing fibre resistance from $3 \%$ to $10 \%$. This behaviour probably occurred because the width of section $\mathrm{B}$, compared to section $\mathrm{A}$, was narrower, and only a few fibres bridged cracks. It is worth noting that this synergy effect occurred when contributions of both fibres and stirrups were similar to one another, which was the case of series A, but not of series B, in which the contribution of fibres was less than half the contribution of steel (see Table 8). The results also indicated that synergy did not always occur. Further research should be conducted to increase knowledge about a synergy effect between fibres and stirrups.

\subsubsection{Comparison between beams SFRC and PFRC}

When comparing performance between the steel and polypropylene fibres, Table 4-4, Figure 4-6, Figure 4-8 and Figure 4-9 show that both FRC types presented similar behaviour in terms of strength, deflection, MOF, and even synergy. In fact the differences in shear strength between both FRC types were 5.5\% (average) in series A1 and A2, and $14 \%$ in series B1 and B2. Moreover, both fibre types performed similarly in narrower sections (0BP1, 0BP2, OBS1 and 0BS2), but did not achieve a similar load response to their RC counterparts with stirrups (B1 and B2). This performance indicates that the introduced amount of fibres (steel and macrosynthetic in residual-flexural strength terms) was not comparable to the reinforcement provided by the stirrups in series B1 and B2.

Moreover, despite SFRC presenting more scatter results in post-cracking behaviour terms (residual flexural tensile strengths $f_{L}$ and $f_{R, j}$ ) than PFRC, the structural performance of both FRC beam types was similar. This phenomenon may be due to a greater scatter of the amount of fibres that crossed the crack in the bending tests compared to the inclined cracks in the full-scale beams. In the former, it was more likely that fewer fibres crossed the section of the specimen in a good orientation $(150 \mathrm{~mm} \times 125 \mathrm{~mm}$ after making the notch). Moreover, this phenomenon evidenced the importance of in-depth knowledge about fibre orientation, especially when using low-fibre contents. 
Effectiveness of polypropylene fibres as shear reinforcement in structural elements

In order to observe if any difference appeared between beams SFRC and PFRC, the crack-pattern of the four series was studied at different load levels using the high-resolution images captured during the test. The load analysed levels ranged from $100 \mathrm{kN}$ to the failure of beams. At each load level, the crack evolution in the dowel zone, the uncracked compression zone, number of cracks, crack kinematics and the effect of fibres on stirrups were compared between SFRC and PFRC.

\subsubsection{Crack pattern analysis}

Figure 4-10 and Figure 4-11 display the crack pattern evolution of series A1 from 100 $\mathrm{kN}$ to the peak load of each beam. The shown range of crack openings corresponds to cracks from $0.5 \mathrm{~mm}$ onwards. It is worth noting that the crack pattern evolution of series A2, B1 and B2 is fully presented in Annexe C.

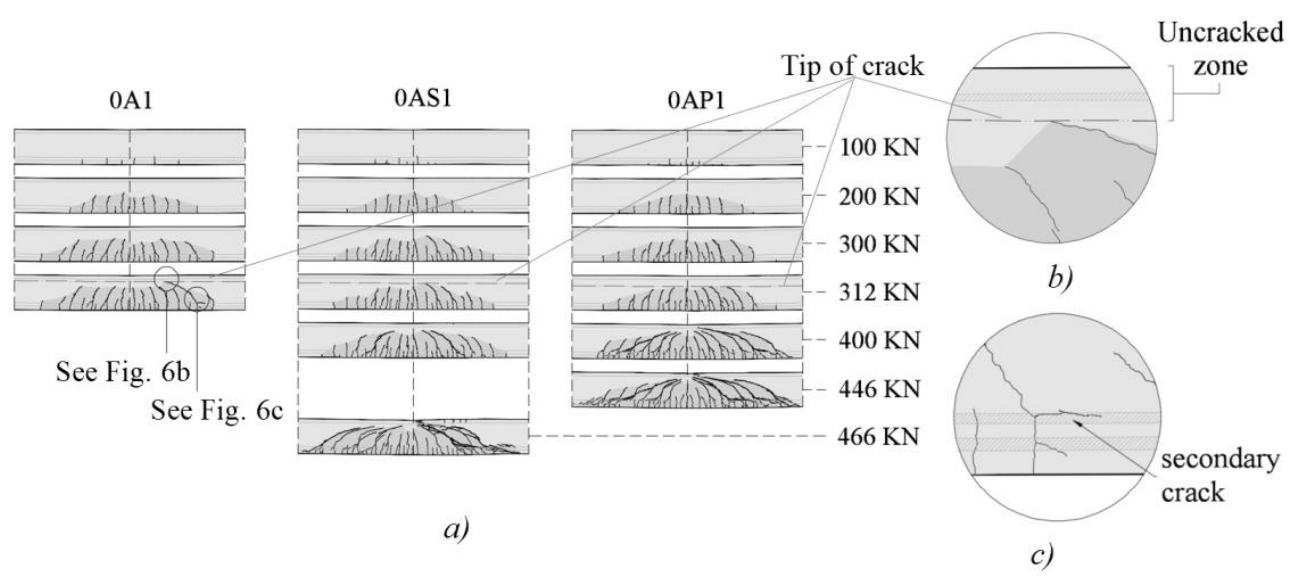

Figure 4-10: Crack pattern of series A1 w/o stirrups (a), compression zone (b), dowel action crack (c)

$\mathrm{A} 1$

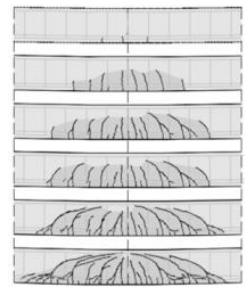

AS1

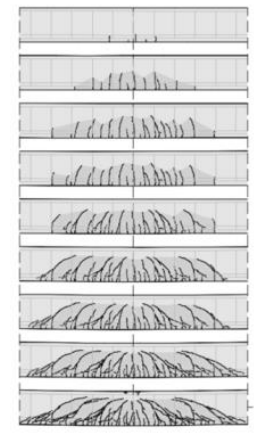

AP1

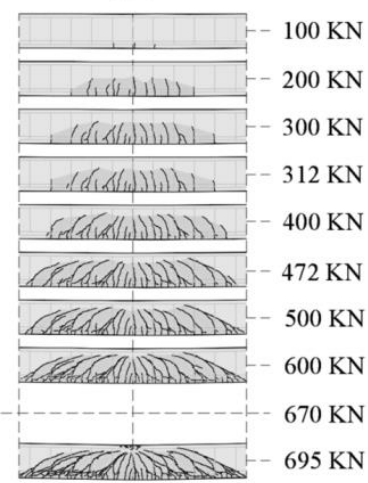

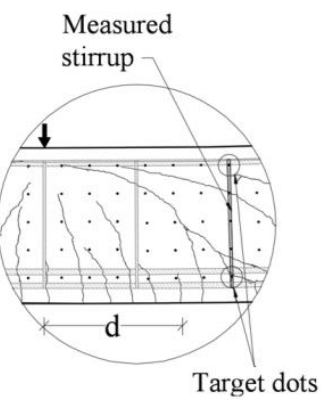

Figure 4-11: Crack pattern of series A1 with stirrups (a), analysed stirrups (b) 
Chapter 4. PFRC in slender beams

As seen in Figure 4-10a and Figure 4-11a, a limited number of flexural cracks was present in all the beam series at the $100 \mathrm{kN}$ load. The numbers of flexural cracks in the beams w/o stirrups were slightly higher and were closer to one another than their counterparts with stirrups. In fact for the beams with stirrups, flexural cracks were usually located in the same position as stirrups. No clear differences appeared between beams SFRC and PFRC. The first observed crack appeared at an average load of $73 \mathrm{kN}$ for series $\mathrm{A} 1,78 \mathrm{kN}$ for $\mathrm{A} 2,60 \mathrm{kN}$ for $\mathrm{B} 1$ and $55 \mathrm{kN}$ for $\mathrm{B} 2$.

At $200 \mathrm{kN}$, flexural cracks had propagated and some inclined towards the loading point, while new flexural cracks appeared. At this load level, inclined cracks started appearing at $115 \mathrm{kN}$ on average in series A1 and A2, but at $91 \mathrm{kN}$ in series B1 and B2, which is the equivalent to a web stress of $0.43 \mathrm{MPa}$ in the web. The appearance of inclined cracks led to a change in stiffness in the load-deflection response (see Figure 4-6).

The third analysed phase involved comparing the performance of all the beam types w/o stirrups at the maximum load immediately before the failure of the RC beams w/o stirrups $(312 \mathrm{kN}, 339 \mathrm{kN}, 274 \mathrm{kN}$ and $225 \mathrm{kN}$ for $0 \mathrm{~A} 1,0 \mathrm{~A} 2,0 \mathrm{~B} 1$ and $0 \mathrm{~B} 2$, respectively). At these load levels, the first observed difference was a critical diagonal crack occurring on the RC beams, which propagated very quickly towards the loading point. This did not happen in beams SFRC and PFRC. Failure occurred on the RC beams when a secondary crack, which ran in parallel to longitudinal reinforcement, grew from an inclined crack and propagated towards one of the supports (see Figure 4-10c).

\subsection{Number and separation of cracks}

In all the beams RC, SFRC and PFRC, flexural cracks were the first to be observed, followed by inclined cracks with increasing load. However, most flexural cracks did not become inclined cracks. At this point, it was necessary to examine why not all the flexural cracks turned into shear cracks. Bazant et al. [207] experimentally defined two crack types. the first being those that develop up to the neutral axis (also called secondary flexural cracks), and the second being those that pass the neutral axis (commonly known as major flexural cracks [208]). Only the second crack type is critical in slender beams because they turn into shear cracks.

In order to observe the effect of both fibre types on the crack pattern of beams within this framework, the separation of the major flexural cracks and the inclined cracks is determined and compared among the RC, SFRC and PFRC beams w/o stirrups. The separation was evaluated at the maximum load of the $\mathrm{RC}$ beams and is presented according to effective depth (d).

Figure. 4-12 presents the crack separation of the flexural cracks in the beams w/o stirrups. The major flexural cracks in the RC beams went from $0.44 \mathrm{~d}$ to $0.47 \mathrm{~d}$, from $0.37 \mathrm{~d}$ to $0.41 \mathrm{~d}$ in SFRC, and from $0.39 \mathrm{~d}$ to $0.43 \mathrm{~d}$ in PFRC. As we can see, both fibre types narrowed the major flexural crack spacing. The reductions in crack spacing reached values up to $20 \%$ in some beams series. 


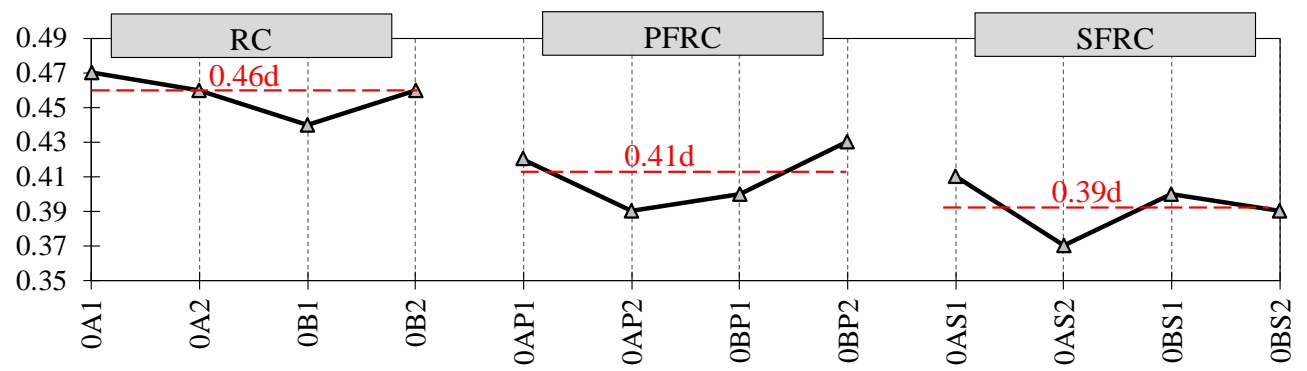

Figure. 4-12: Flexural crack spacing in the beams w/o stirrups

Regarding inclined cracks, the FRC beams presented less inclined and more separated cracks than their counterpart did in RC. In fact the average separation between cracks at the RC peak load was $0.47 \mathrm{~d}, 0.41 \mathrm{~d}$ and $0.42 \mathrm{~d}$ for beams RC, SFRC and PFRC beams w/o stirrups, and $0.50 \mathrm{~d}, 0.45 \mathrm{~d}$ and $0.39 \mathrm{~d}$ for beams RC, SFRC and PFRC with stirrups. We can see in Figure 4-10 a and Figure 4-11a that the number of inclined cracks in FRC increased with at a higher load level. Hence the average crack separation of inclined cracks at the peak load dropped to $0.38 \mathrm{~d}$ and $0.42 \mathrm{~d}$ in the SFRC and PFRC beams w/o stirrups, and to 0.36d for SFRC and PFRC with stirrups.

Based on the presented results, fibres influenced the formation of major flexural cracks and, hence, the inclined shear cracks. The separation between inclined cracks was around $12 \%$ in SFRC and $11 \%$ in PFRC (average values). We underline that the reduction in the spacing provided by both fibres was almost the same in the present experimental campaign However, this reduction differed from that reported in the literature (38\% reported by Kwak et al. [110] with SFRC specimens).

\subsection{Influence of fibres on the uncracked zone}

The uncracked zone is one of the shear transfer mechanisms in RC beams. Although no consensus has been reached about its exact contribution, some authors have estimated that is over $20 \%$ of a beam's total shear strength [82].

Within this framework, the uncracked compression depth was measured and compared (at the peak load of the RC beam) among the RC, PFRC and SFRC beams w/o stirrups in Figure 4-13. It can be seen that the beams with the lowest uncracked depth value correspond to $\mathrm{RC}(0 \mathrm{~A} 1,0 \mathrm{~A} 2,0 \mathrm{~B} 1$ and $0 \mathrm{~B} 2)$, with depths from 95 to $148 \mathrm{~mm}$. The depths for the FRC beams obtained significantly higher values (44\% more depth on average). This effect is seen in Figure 4-10a, where the tip of the larger diagonal crack is delimited by dashed lines. This effect was more notorious in series A1 and A2, whereas it was less significant in series B1 and B2. 


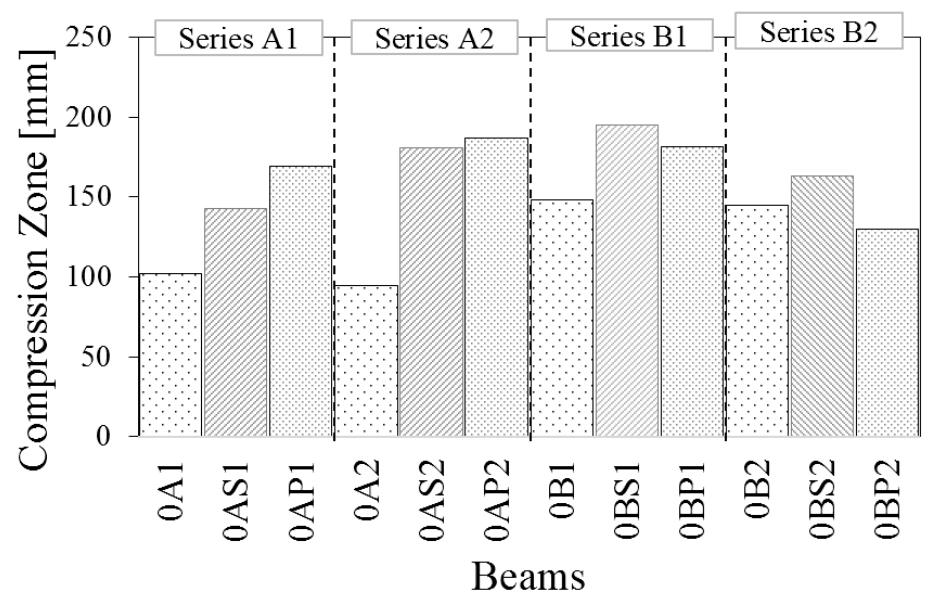

Figure 4-13: Comparison of compression zone depth

It is worth noting that, as shown in Figure 4-10a and Figure 4-13, both SFRC and PFRC presented very similar uncracked depths. This increment in the uncracked compression zone evidenced that both fibre types could control crack propagation similarly; i.e., bridging and transferring stresses through crack faces [151]. This effect allows the uncracked zone to continue resisting shear for longer times. In fact with the increment in load from 312 to $400 \mathrm{kN}$ in series A1 (see Figure 4-10a), the inclined cracks in the FRC beams continued propagating through the uncracked zone to almost reach the loading point. Nevertheless, although the depth of the uncracked zone was small from $400 \mathrm{kN}$, the FRC beams remained stable and continued resisting the increment in load up to failure. This effect was probably due to the great effectiveness of fibres (steel or polypropylene) in redistributing stresses inside beams.

\subsection{Influence of fibres on the dowel zone}

Similarly to the crack pattern presented in Figure 4-10c, a crack over longitudinal reinforcement was observed in all the RC beams w/o stirrups prior to their failure. The appearance of this crack is commonly related to the shear transfer provided by longitudinal reinforcement, also known as dowel action. During the test, this secondary crack also appeared one instant before beam failure, and propagated abruptly towards the support (see Figure 4-8 and Figure 4-9) and caused the failure of the RC elements. In fact the opening of this secondary crack reached $0.166 \mathrm{~mm}, 0.171 \mathrm{~mm}, 0.120 \mathrm{~mm}$ and $0.119 \mathrm{~mm}$ in beams $0 \mathrm{~A} 1,0 \mathrm{~A} 2,0 \mathrm{~B} 1$ and $0 \mathrm{~B} 2$, respectively. It is worth noting that this mechanism of failure is commonly presented in the diagonal tension (DT) MOF [209] where, due to abrupt dowel crack opening, a sudden reduction in shear, transferred by the aggregate interlock, occurs in diagonal cracks [208]. Some authors [210,211] have estimated that the mechanism of dowel action contributes approximately $15-50 \%$ of the element's total shear strength. 
Effectiveness of polypropylene fibres as shear reinforcement in structural elements

With the SFRC and PFRC beams w/o stirrups, this secondary crack did not appear at the peak load of their counterpart in RC $(312 \mathrm{kN}$ in series A1, 339 in series A2, 274 in series B1 and 226 in series B2). In fact the appearance of the dowel crack was significantly delayed and, as seen in Figure 4-10a, the crack was not detected up to $400 \mathrm{kN}$ in series A1. This behaviour also was observed in series A2, B1 and B2 (see Annexe C)

With incremented load, more secondary cracks continued to appear in both shear spans of the RC beams. Indeed at the peak load of the PFRC and SFRC beams w/o stirrups, the dowel zones (along longitudinal reinforcement) were badly damaged, and presented multiple cracks over a 2-mm crack opening (see Figure 4-10a).

These results evidence the positive influence of fibres on delaying and controlling this secondary dowel crack. In fact unlike what happened with the RC beams, this dowel crack control probably allowed interlock aggregation by acting for longer on diagonal cracks. When analysing the crack pattern of each beam with their corresponding loaddeflection response (see Figure 4-6), the extra ductility presented in the FRC beams was directly related to cracks developing all over the dowel zone.

Some of these effects of fibres in the dowel zone have been observed exclusively in the SFRC beams by other authors [212,213]. Some authors have also evidenced that the major contribution of fibres to shear corresponds to improvement in the mechanism of dowel action [84]. Nevertheless with the present experimental campaign results, in addition to confirming the efficiency of fibres in dowel action, these benefits were not exclusive to steel fibre because this also occurred with polypropylene fibres. In fact as shown in Figure 4-10, both types of FRC types (SFRC and PFRC) presented a similar crack pattern in the dowel zone, which clearly indicates that this shear mechanism acts similarly in both FRC cases.

\subsection{Influence of fibres on crack kinematics}

In order to study the crack kinematics of the RC, PFRC and SFRC beams w/o stirrups, it is necessary to firstly understand the exact behaviour of diagonal cracks. For this analysis, series A1 was selected, as was the series in which, despite the effectiveness of fibres, all the beams w/o stirrups (0A1, 0AP1, and 0AS1) presented a similar MOF.

Figure 4-14 depicts a comparison of the crack opening and crack slip of the main diagonal shear crack among beams 0A1, 0AP1 and 0AS1. In all cases, the crack was measured at the mid-section. It is worth mentioning that measures were evaluated by photogrammetry techniques. 


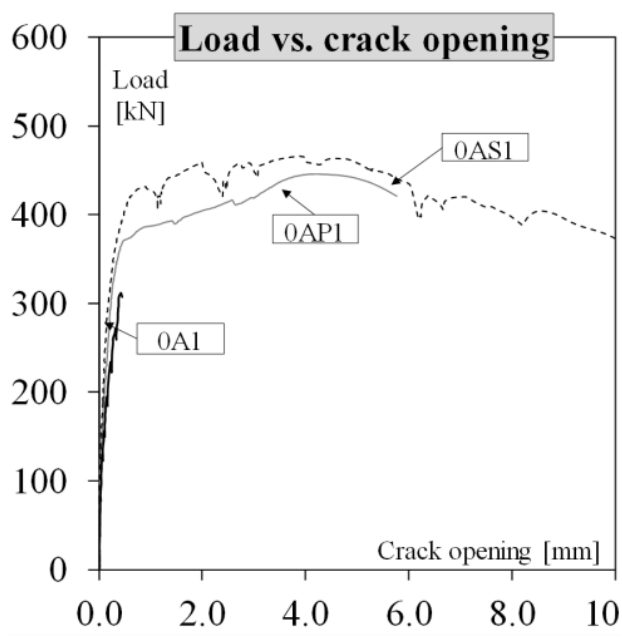

(a)

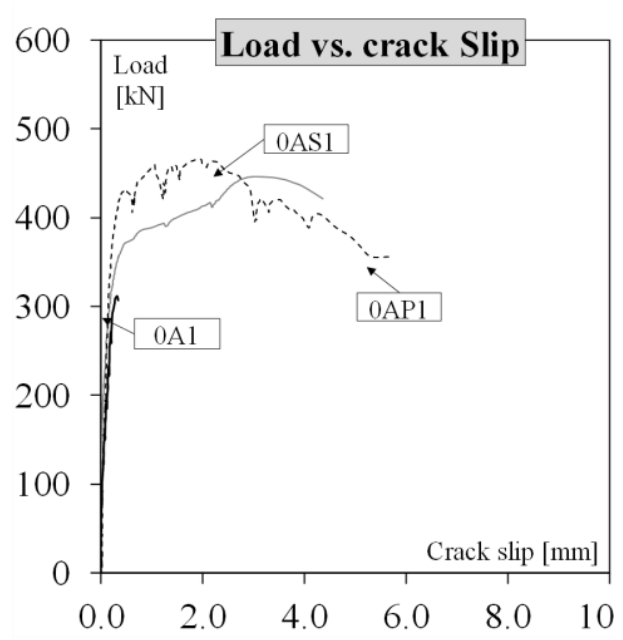

(b)

Figure 4-14: Crack kinematics of the beams w/o stirrups in series A1

As seen in Figure 4-14a, all the cracks behaved similarly up to approximately $200 \mathrm{kN}$. However after this load level, the crack openings of PFRC and SFRC remained closer compared to RC. The crack openings at the maximum load were $0.45,4.01$ and $4.43 \mathrm{~mm}$ for 0A1, 0AS1 and 0AP1, respectively. Similar trends were observed in the slip behaviour between both FRCs, while beam 0AP1 presented slightly more slip. It is important to mention that, although the difference in crack opening and crack slip at $312 \mathrm{kN}$ was relatively small, these measurements confirmed the effectiveness of both fibre types in bridging the crack, and also in delaying the crack propagation rate towards the loading point.

As observed in other mechanisms, both types (steel and polypropylene) seemed to similarly influence the crack shear transfer (aggregate interlock and fibres). In fact this result also confirms the experimental test results obtained after testing the pre-cracked pushoff specimens (see Section 3.2) used to study the shear transfer in the small elements of SFRC and PFRC.

\subsection{Effect of fibres on stirrup performance}

In order to see the effect of fibres on stirrup performance, a comparison of load upon stirrup yielding is presented in Table 4-6. The average stirrup strain was measured at a distance of an effective depth (d) from the loading point in the shear span, which presented the critical diagonal crack. The considered stirrup yielding strain was 0.0026 $\mathrm{mm} / \mathrm{mm}$ if we bear in mind the yield stress of the tested $8-\mathrm{mm}$ bars (see Section 4.2) and $\mathrm{E}_{\mathrm{s}}=200,000 \mathrm{MPa}$. It is worth noting that, although the measurements 
taken over concrete did not exactly represent the strains in stirrups, they would provide an average strain of stirrups and the effect of fibres on them.

As shown in Table 4-6, in the beams that contained fibres, stirrups started to yield at higher external loads than in the RC ones, i.e. fibres allowed stirrups to contribute less to shear and delayed their yielding. In fact the increment in load provided by fibres went from $15 \%$ to $40 \%$, depending on the studied beam series. Nevertheless, these increments were not observed in series B2, where the load upon stirrup yielding was the same among beams.

Finally, we underline that although, in this case, the contribution between steel and polypropylene fibres was not the same, as evidenced by the polypropylene fibres being effective steel fibres in delaying stirrup yielding.

Table 4-6: Measurements of stirrups upon yielding

\begin{tabular}{|c|c|c|}
\hline Beam & $\begin{array}{c}\text { Load upon } \\
\text { stirrup yield- } \\
\text { ing [kN] }\end{array}$ & $\begin{array}{c}\text { Increment of load } \\
\text { upon stirrup } \\
\text { yielding [\%] }\end{array}$ \\
\hline A1 & 410.63 & \\
\hline AS1 & 526.17 & $28 \%$ \\
\hline AP1 & 575.49 & $40 \%$ \\
\hline A2 & 378.97 & \\
\hline AS2 & 504.74 & $33 \%$ \\
\hline AP2 & 561.22 & $48 \%$ \\
\hline B1 & 375.66 & \\
\hline BS1 & 430.39 & $15 \%$ \\
\hline BP1 & 448.94 & $20 \%$ \\
\hline B2 & 302.27 & \\
\hline BS2 & 294.41 & $-3 \%$ \\
\hline BP2 & 300.15 & $-1 \%$ \\
\hline
\end{tabular}

\subsubsection{Shear deformation}

In order to understand the shear ductility provided by fibres, the experimental shearstrain $\left(\gamma_{x y}\right)$ was evaluated. To do so, the displacement of the corners targets was measured during the test by photogrammetry techniques. Then based on the theory of the finite element models, these displacements were transformed to strains using the kinematic equations of a 4-node quadrilateral element (see Figure 4-15). It should be mentioned that displacements were evaluated only in that shear span on which the main diagonal crack appeared. Thus in order to determine the total strain of the selected shear span, shear strains 1 and 2 were averaged as shown in Figure 4-15. 


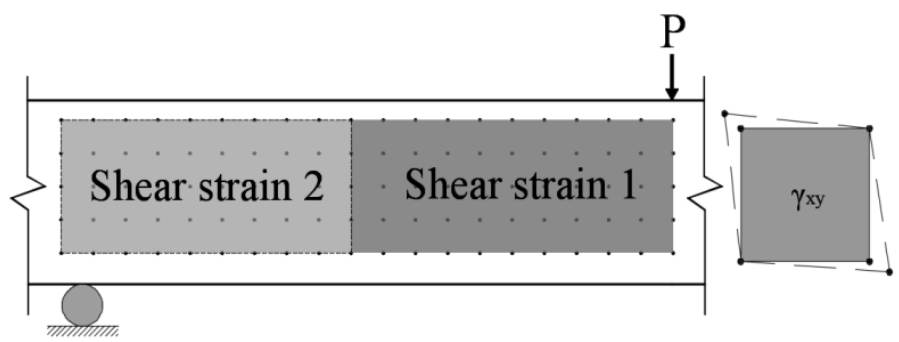

Figure 4-15: Scheme of the area used to measure shear strain

Table 4-7 summarises the shear-strain achieved at the peak load $\left(P_{u}\right)$ of the total experimental programme. The RC beams presented the lowest shear strain. The maximum shear-train among the RC beams w/o stirrups was approximately the same: 0.000632 $\mathrm{mm} / \mathrm{mm}$. Moreover, the SFRC and PFRC beams w/o stirrups presented a 10 -fold higher shear strain than their counterpart in RC. This strain was relatively similar to that corresponding to the RC beams with stirrups. As shown in Figure 4-16, which presents the load-shear strain response of series A1, similar strain stiffness values were observed for all the beams up to approximately $325 \mathrm{kN}(1.15 \mathrm{MPa})$, from which point stiffness decreased. This reduction in stiffness coincided with the occurrence of secondary cracks due to dowel action, as shown in Figure 4-10a. After this point, shear strain increased considerably until failure.

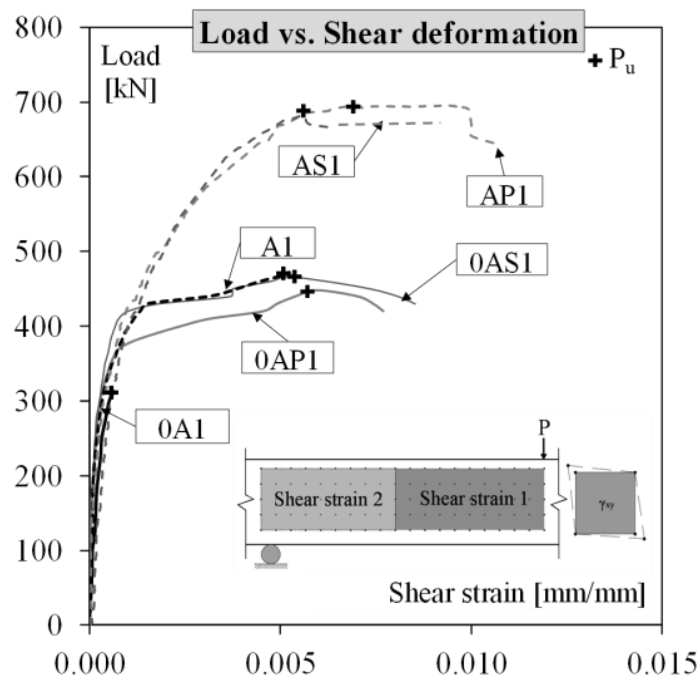

Figure 4-16: Load vs. Shear Deformation, series A1 
Effectiveness of polypropylene fibres as shear reinforcement in structural elements

Regarding the beams reinforced with stirrups, and as observed in Figure 4-16 and Table 4-7, similar shear strains were achieved in the three concrete types (RC, SFRC and PFRC). This similar strain behaviour was also observed when both fibres were compared in the elements with and w/o stirrups.

The contribution of fibres to deflection is observed in Figure 4-17 (for series A1), where the contribution of shear deformation to vertical deflection is represented and compared with flexural and total deflection. Shear deflection was calculated by multiplying shear span length $(a)$ by the previously determined average shear strain. Total deflection was experimentally measured during the test at the mid-span.

Table 4-7: Shear strain and deflection of beams

\begin{tabular}{|c|c|c|c|c|c|}
\hline Beam & $\begin{array}{c}\boldsymbol{P}_{\boldsymbol{u}} \\
{[\mathbf{k N}]}\end{array}$ & $\begin{array}{c}\boldsymbol{\delta}_{\boldsymbol{u}} \\
{[\mathbf{m m}]}\end{array}$ & $\begin{array}{c}\boldsymbol{V}_{\mathbf{x y}, \mathbf{P u}} \\
{[-]}\end{array}$ & $\begin{array}{c}\boldsymbol{\delta}_{\boldsymbol{u}, \text { shear }} \\
{[\mathbf{m m}]}\end{array}$ & $\begin{array}{c}\boldsymbol{\delta}_{\boldsymbol{u} \text {, bending }} \\
{[\mathbf{m m}]}\end{array}$ \\
\hline OA1 & 312.11 & 5.74 & 0.000636 & 1.16 & 4.58 \\
\hline OAP1 & 446.68 & 15.81 & 0.005941 & 10.87 & 4.94 \\
\hline OAS1 & 466.47 & 15.62 & 0.005186 & 9.49 & 6.13 \\
\hline A1 & 472.71 & 16.31 & 0.005233 & 9.58 & 6.73 \\
\hline AP1 & 695.30 & 29.78 & 0.006324 & 11.57 & 18.21 \\
\hline AS1 & 682.20 & 24.62 & 0.005587 & 10.22 & 14.40 \\
\hline & & & Series A2 & & \\
\hline OA2 & 339.03 & 12.06 & 0.000659 & 1.50 & 10.56 \\
\hline OAP2 & 486.26 & 28.02 & 0.007214 & 16.48 & 11.54 \\
\hline OAS2 & 455.59 & 30.94 & 0.007839 & 17.91 & 13.03 \\
\hline A2 & 478.39 & 25.96 & 0.005954 & 13.60 & 12.36 \\
\hline AP2 & 678.60 & 35.49 & 0.005528 & 12.63 & 22.86 \\
\hline AS2 & 658.07 & 40.06 & 0.005191 & 11.86 & 28.20 \\
\hline & & & Series B1 & & \\
\hline OB1 & 274.97 & 7.48 & 0.000606 & 1.11 & 6.37 \\
\hline OBP1 & 361.73 & 15.30 & 0.005416 & 9.91 & 5.39 \\
\hline OBS1 & 309.86 & 10.92 & 0.004318 & 7.90 & 3.02 \\
\hline B1 & 468.01 & 17.69 & 0.006621 & 12.12 & 5.57 \\
\hline BP1 & 555.56 & 18.60 & 0.006093 & 11.15 & 7.45 \\
\hline BS1 & 546.22 & 20.57 & 0.005915 & 10.82 & 9.75 \\
\hline & & & Series B2 & & \\
\hline OB2 & 226.37 & 10.01 & 0.000626 & 1.43 & 8.58 \\
\hline OBP2 & 295.60 & 18.02 & 0.004360 & 9.96 & 8.06 \\
\hline OBS2 & 326.89 & 18.65 & 0.004020 & 9.19 & 9.46 \\
\hline B2 & 439.57 & 31.62 & 0.005198 & 11.88 & 19.74 \\
\hline BP2 & 487.37 & 32.37 & 0.004222 & 9.65 & 22.73 \\
\hline BS2 & 492.74 & 29.32 & 0.004141 & 9.46 & 19.86 \\
\hline & & & & & \\
\hline & & & \\
\hline
\end{tabular}


The presented load-deflection response showed that the main contribution to total deflection was due to flexure up to $400 \mathrm{kN}$. After this point, the dominant deflection was due to shear. In the beams with stirrups and fibres (AP1 and AS1), both types of deflections (shear and flexure) significantly contributed to total deflection. This indicates that failure by flexure and shear may indistinctly occur.

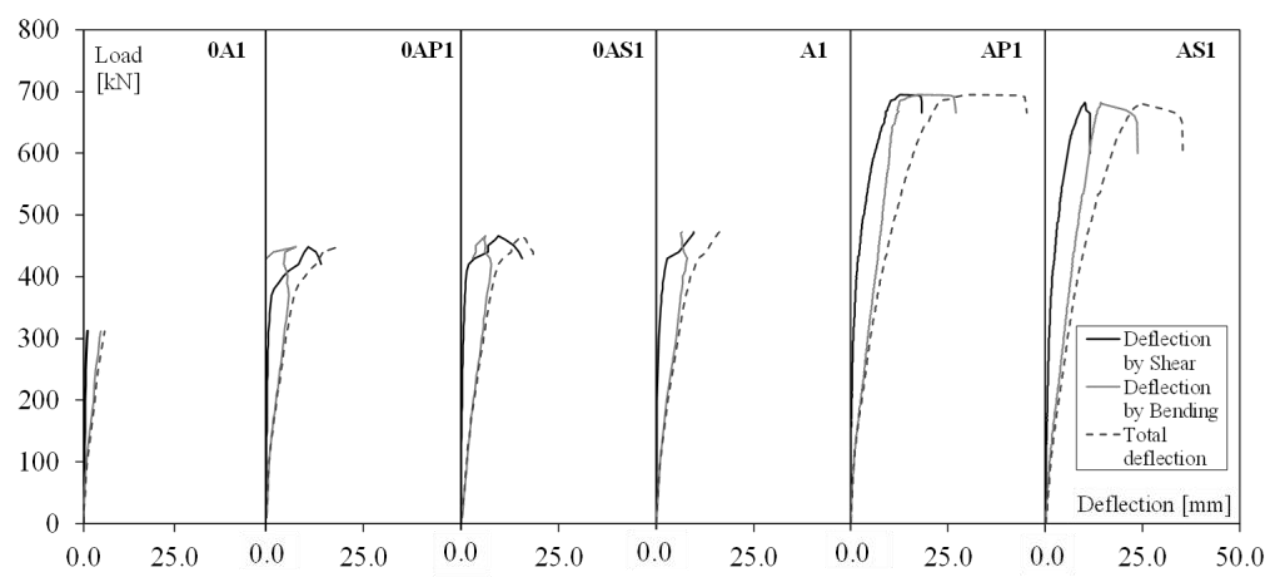

Figure 4-17: Contribution of shear to deflection in series A1

\subsection{Comparison to code predictions}

This section compares between the experimental shear strength $\left(V_{u}\right)$ of the FRC beams and the shear strength predicted by MC2010 [7], Australian concrete code AS 3600-2018 [73] and RILEM TC 162-TDF [74]. The equations of the aforementioned codes are summarized in Table 2-3.The two equations proposed by MC2010 (Model 1 (Eq. 2-16) and Model 2 (Eq. 2-17)) were considered in the analysis. Moreover, the $V_{u}$ of the RC beams with and w/o stirrups were compared only against the shear strength predicted by MC2010. For this purpose level II was used to determine the web shear strength in the beams with no transverse reinforcement, while level III was employed for the beams with stirrups. Table 7 summarises the equations of MC2010 used to predict the shear strength of the RC beams.

In order to make these comparisons, the predicted shear strength of all the codes was determine by assuming that a safety factor $\left(\gamma_{c}\right)$ equalled 1 , along with the mean values of the material mechanical properties summarized in Table 4-3. The mean tensile strength $f_{c t}$ values were determined according to Eq. 5.1-3a of MC2010 $\left(f_{c t}=0.3\left(f_{c k}\right)^{2 / 3}\right)$. For the predictions of RC and FRC with MC2010 and AS 3600-2018, the angle of the compressive stress field $(\theta)$ was taken as the minimum indicated by each code: (e.q. 4-8) for RC, (Eq. 2-9) for FRC with As 3600-2018 and (Eq. 2-18) for FRC with MC2010. In the 
Effectiveness of polypropylene fibres as shear reinforcement in structural elements

FRC predictions, the ultimate crack opening $\left(w_{u}\right)$ was considered to be $1.5 \mathrm{~mm}$ in MC2010 Model I, while $w_{u}$ was determined according to the strain at the middle depth $\left(\varepsilon_{x}\right)$ in MC2010 Model II and AS 3600-2018 (see Table 2-3).

Table 4-8: Shear strength formulations for RC according to MC2010

\begin{tabular}{|c|c|c|}
\hline \multirow{3}{*}{$\begin{array}{l}\text { Beams with no } \\
\text { transverse rein- } \\
\text { forcement }\end{array}$} & $V_{u}=V_{u, c}$ & (e.q. 4-1) \\
\hline & $V_{u, c}=k_{v} \cdot \sqrt{f_{c}} \cdot z \cdot b_{w}$ & (e.q. 4-2) \\
\hline & $k_{v}=0.4 /\left(1+1500 \varepsilon_{x}\right) * 1300 /\left(1000+k_{d g} z\right)$ & (e.q. 4-3) \\
\hline \multirow{5}{*}{$\begin{array}{l}\text { Beams with trans- } \\
\text { verse reinforce- } \\
\text { ment } \\
\text { (Level III) }\end{array}$} & $V_{u}=V_{u, c}+V_{u, s}$ & (e.q. 4-4) \\
\hline & $V_{u, c}=k_{v} \cdot \sqrt{f_{c}} \cdot z \cdot b_{w}$ & (e.q. 4-5) \\
\hline & $k_{v}=0.4 /\left(1+1500 \varepsilon_{x}\right) *\left(1-V_{E} / V_{R, \max }\right)$ & (e.q. 4-6) \\
\hline & $V_{u, s}=A_{s w} / s \cdot z \cdot f_{y} \cdot \cot \theta$ & (e.q. 4-7) \\
\hline & $\theta=20^{\circ}+10000 \cdot \varepsilon_{x}$ & (e.q. 4-8) \\
\hline
\end{tabular}

Table 4-9 and Table 4-10 summarize the predicted shear strength of the RC and FRC beams, respectively. Complementing Table 4-9 and Table 4-10, Figure 4-18 graphically shows the coefficient $\left(V_{u} / V_{u, \text { code }}\right)$ of each beam.

As seen in Table 4-9, the predicted results were overestimated by MC2010 in those RC beams w/o stirrups. However, the predictions made for the RC beams with stirrups were quite accurate and obtained a conservative $V_{u} / V_{u \text {,code }}$ ratio of 1.02, as seen in Figure 4-18.

The predicted results for the FRC beams with and w/o stirrups were unconservative according to both expressions of MC2010 and AS 3600-2018, and were conservative according to RILEM (see Figure 4-18). The most accurate results between both MC2010 FRC models were for Model 1, which obtained a $V_{u} / V_{u, \text { code }}$ ratio of 0.82 vs. 0.69 obtained by Model II. In fact this trend was observed in the FRC beams with and w/o stirrups. Similar unconservative results were obtained by Australian Code $\left(V_{u} / V_{u, \text { code }}\right.$ ratio of 0.75). Nevertheless in both MC-2010 and AS 3600-2018, more accurate results were obtained for the FRC beams with stirrups than those w/o them.

In the FRC beams with and w/o stirrups, RILEM provided conservative predictions compared to MC2010 and AS 3600-2018. These results were expected as the contribution of concrete in shear is approximately $30 \%$ less than that provided by MC2010 and AS 36002018. In addition, as the angle of the web compression $(\theta)$ is considered $45^{\circ}$ in RILEM, the contribution of stirrups to the shear results is less in RILEM than in the other codes, 
where $\theta$ is determined according to $\varepsilon_{x}$. In fact if angle $\theta$ is considered to be $45^{\circ}$ instead of the minimum one in MC2010 and AS 3600-2018, more accurate results were obtained in all the FRC members.

Table 4-9: Prediction for the RC beams

\begin{tabular}{|c|c|c|c|}
\hline Beam & $\begin{array}{c}V_{u, e x p} \\
{[\mathbf{k N}]}\end{array}$ & $\begin{array}{c}V_{u, M C} \\
{[\mathbf{k N}]}\end{array}$ & $\begin{array}{c}V_{u, \text { exp }} / \boldsymbol{V}_{u, M C} \\
{[-]}\end{array}$ \\
\hline OA1 & 160.96 & 196.06 & 0.82 \\
\hline OA2 & 176.29 & 201.89 & 0.87 \\
\hline OB1 & 141.17 & 158.03 & 0.89 \\
\hline OB2 & 118.28 & 147.70 & 0.80 \\
\hline A1 & 241.25 & 244.81 & 0.99 \\
\hline A2 & 245.97 & 246.13 & 1.00 \\
\hline B1 & 237.67 & 229.34 & 1.04 \\
\hline B2 & 224.86 & 214.16 & 1.05 \\
\hline & Average $=$ & $0.93(0.11)$ \\
\hline
\end{tabular}

We can see Figure 4-18 that the models provided quite similar predictions between SFRC and PFRC with and w/o stirrups. In fact they were unconservative regardless of fibre type. When the $V_{u} / V_{u \text {, code }}$ ratio of each code was compared between both FRC types, the ratios varied by less than $4 \%$. Despite predictions being generally unconservative, codes provide the same efficiency indistinctly of fibre type material and volume fraction. These results evidence that the FRC expression in the analysed model can be used with polypropylene fibres. It should be remembered that FRC expressions were developed based on experimentation by using only steel fibres. Furthermore, these experimental results suggest that evaluating the shear strength of FRC members according to their residual flexural tensile strength, instead of parameters such as fibre type or volume fraction, is worthwhile.

Finally, the obtained results still evidence the need to improve formulations in codes and standards to predict the shear capacity of slender beams, especially now as the new application of FRC to structural elements in the construction industry is available. 
Effectiveness of polypropylene fibres as shear reinforcement in structural elements

Table 4-10: Prediction of the SFRC and PFRC beams

\begin{tabular}{|c|c|c|c|c|c|c|c|c|c|}
\hline Beam & $\begin{array}{l}V_{u, e x p} \\
{[\mathbf{k N}]}\end{array}$ & $\begin{array}{l}V_{u, M C-I} \\
{[\mathbf{k N}]}\end{array}$ & $\begin{array}{l}V_{u, M C I} \\
{[\mathbf{k N}]}\end{array}$ & $\begin{array}{l}V_{u, R I L} \\
{[\mathbf{k N}]}\end{array}$ & $\begin{array}{l}V_{u, A S} \\
{[\mathbf{k N}]}\end{array}$ & $\begin{array}{c}V_{u, \exp } \\
/ V_{u, M C-I}\end{array}$ & $\begin{array}{c}V_{u, \exp } \\
/ V_{u, M C-I I}\end{array}$ & $\begin{array}{c}V_{u, \text { exp }} \\
V_{u, R I L}\end{array}$ & $\begin{array}{c}V_{u, \exp } \\
/ V_{u, A S}\end{array}$ \\
\hline OAP1 & 228.2 & 289.0 & 374.6 & 214.6 & 345.5 & 0.79 & 0.61 & 1.06 & 0.66 \\
\hline OAP2 & 249.9 & 306.5 & 374.5 & 221.9 & 345.4 & 0.82 & 0.67 & 1.13 & 0.72 \\
\hline OBP1 & 184.5 & 230.1 & 303.2 & 166.6 & 278.5 & 0.80 & 0.61 & 1.11 & 0.66 \\
\hline OBP2 & 152.9 & 230.1 & 281.1 & 166.6 & 259.2 & 0.66 & 0.54 & 0.92 & 0.59 \\
\hline AP1 & 352.5 & 377.0 & 437.2 & 281.8 & 411.0 & 0.94 & 0.81 & 1.25 & 0.86 \\
\hline AP2 & 346.1 & 393.4 & 437.1 & 289.0 & 410.9 & 0.88 & 0.79 & 1.20 & 0.84 \\
\hline BP1 & 281.4 & 330.7 & 377.4 & 240.4 & 355.3 & 0.85 & 0.75 & 1.17 & 0.79 \\
\hline BP2 & 248.8 & 322.9 & 348.9 & 240.4 & 330.4 & 0.77 & 0.71 & 1.03 & 0.75 \\
\hline OAS1 & 238.1 & 277.6 & 374.3 & 193.2 & 323.3 & 0.86 & 0.64 & 1.23 & 0.74 \\
\hline OAS2 & 234.6 & 294.5 & 370.5 & 200.3 & 323.2 & 0.80 & 0.63 & 1.17 & 0.73 \\
\hline OBS1 & 158.6 & 221.1 & 304.4 & 150.4 & 258.3 & 0.72 & 0.52 & 1.05 & 0.61 \\
\hline OBS2 & 168.5 & 221.1 & 278.1 & 150.4 & 242.6 & 0.76 & 0.61 & 1.12 & 0.69 \\
\hline AS1 & 346.0 & 366.5 & 417.6 & 260.3 & 393.4 & 0.94 & 0.83 & 1.33 & 0.88 \\
\hline AS2 & 335.8 & 382.2 & 417.5 & 267.4 & 393.2 & 0.88 & 0.80 & 1.26 & 0.85 \\
\hline BS1 & 276.8 & 322.3 & 364.5 & 224.2 & 339.4 & 0.86 & 0.76 & 1.23 & 0.82 \\
\hline BS2 & 251.5 & 314.7 & 333.4 & 224.2 & 318.6 & 0.80 & 0.75 & 1.12 & 0.79 \\
\hline \multicolumn{6}{|c|}{ Average $=$} & $\begin{array}{c}0.82 \\
(\mathbf{0 . 0 9})\end{array}$ & $\begin{array}{c}0.69 \\
(0.14)\end{array}$ & $\begin{array}{c}1.15 \\
(0.09)\end{array}$ & $\begin{array}{c}0.75 \\
(\mathbf{0 . 1 2})\end{array}$ \\
\hline
\end{tabular}




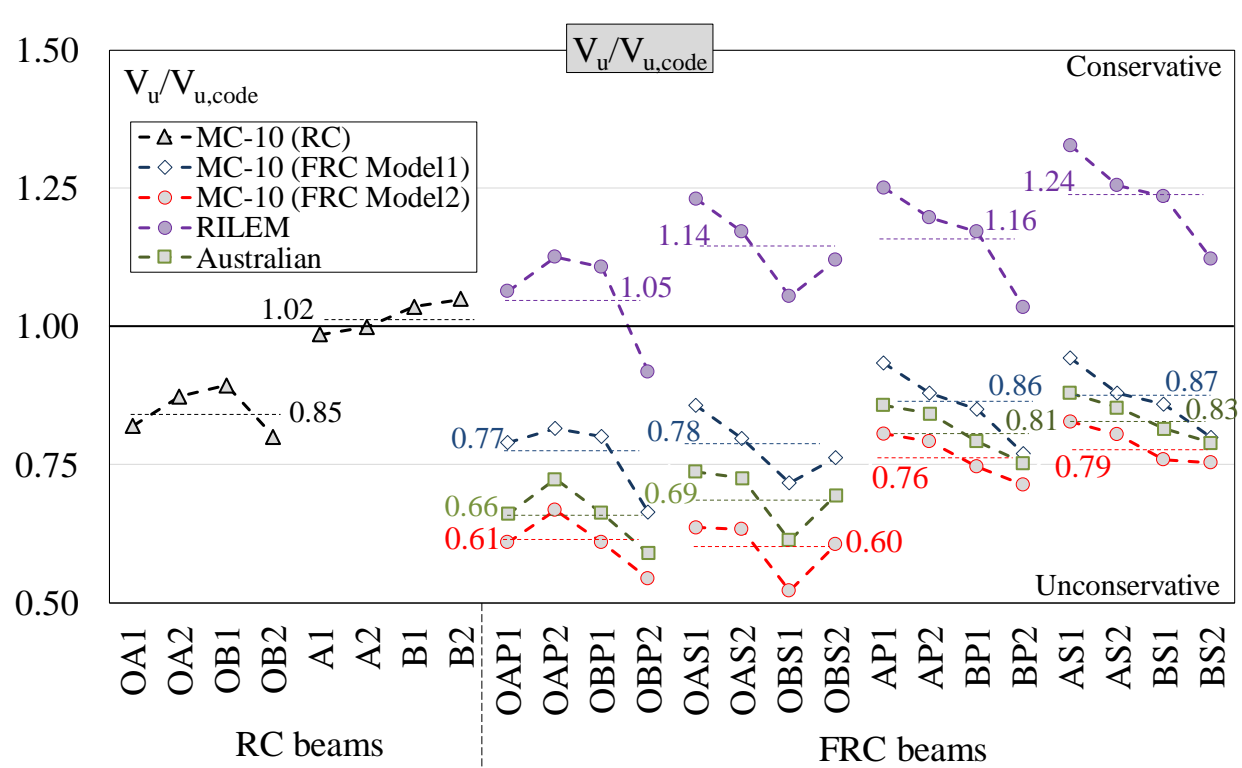

Figure 4-18: Comparison of the test results to international codes.

\subsection{Concluding remarks}

The shear behaviour of 24 full-scale beams was studied in this chapter to evaluate the shear effectiveness of polypropylene fibres compared to steel fibres. To do so, eight RC beams, eight SFRC beams and eight PFRC beams were manufactured and tested by a three-point bending scheme. Beams covered different levels of transverse reinforcement: with and w/o stirrups, with polypropylene fibres $\left(10 \mathrm{~kg} / \mathrm{m}^{3}\right)$ or steel fibres $\left(30 \mathrm{~kg} / \mathrm{m}^{3}\right)$, and combining stirrups and fibres. Both fibre contents were selected to provide similar residual flexural tensile strengths to concrete. Finally, photogrammetry techniques were used to compare the effect of both fibre types on the crack pattern evolution of beams.

Based on the experimental results and photogrammetry measurements, the following main conclusions can be drawn:

a) Steel and macrosynthetic fibres significantly improved beam shear performance by increasing ultimate load and improving ductility. In fact polypropylene or steel fibres added to beams w/o transverse reinforcement obtained a similar response in some cases to those observed in the RC beams with transverse reinforcement.

b) The inclusion of steel or polypropylene fibres was unable to change the MOF of the beams w/o stirrups. However, as fibres improved the post-cracking behaviour of the main diagonal cracks, the MOF in beams SFRC and PFRC was 
considerably more controlled and less abrupt than in the RC beams w/o stirrups. In fact unlike the $\mathrm{RC}$ beams in which failure occurred quickly after the main diagonal crack formed and immediately after the dowel crack formed, the FRC beams presented several inclined dowel cracks prior to failure.

c) A synergy effect between the steel or polypropylene fibres and stirrups was identified in four of the eight beams that combined fibres and stirrups. This behaviour was related to the effect of fibres on incrementing the number of inclined cracks crossing stirrups, and on reducing crack spacing. However, the synergy effect was observed only in those beams in which fibres and stirrups provided similar amounts of transversal reinforcement.

d) Despite it not being possible to directly evaluate the shear transfer mechanism on beams RC and FRC, photogrammetry revealed that both fibre types reduced the crack propagation of the main diagonal crack, incremented the uncracked compression zone, delayed and controlled dowel crack formation, and changed the kinematics of inclined cracks.

e) Fibres provided 10-fold more shear deformation in the FRC beams than in the $\mathrm{RC}$ ones w/o stirrups, as well as a similar shear deformation to the $\mathrm{RC}$ beams with stirrups. Major ductility and, hence deflection, was provided by fibres in the beams with and w/o stirrups thanks to their ability to control dowel cracks.

f) As beams PFRC and SFRC presented similar experimental results (shear strength, deflection and MOF), and similar measured parameters (crack pattern, shear crack evolution, influence of fibres on stirrups and shear deformation), we confirm that, regardless of fibre type (volume, material, shape, length, diameter), if fibres provide similar residual flexural tensile strengths, similar shear performance takes place. As a result, residual flexural tensile strengths can act as good parameters to characterise the behaviour of FRC shear-critical beams.

g) Model Code 2010 and Australian AS 3600-2018 code proved unconservative. However, they provide the same efficiency indistinctly of fibre type (steel or polypropylene fibre). Furthermore, thee experimental results suggested that the methodology used in the code studies in which the shear strength of FRC members is evaluated according to residual flexural tensile strength, instead of parameters such as fibre type or volume fraction, is convenient. 


\section{Chapter 5. STUDY OF SHEAR IN HOLLOW-CORE SLABS}





\subsection{Introduction}

This chapter explores a real application of macrosynthetic fibres. For this purpose, the possibility of using polypropylene fibre as shear reinforcement in hollow-core slabs (HCS) is experimentally evaluated. As previously stated, HCS are frequently used in elements residential, parking and industrial buildings for their high quality control, easy installation and short construction time. HCS can be critical elements in shear due to their manufacturing process and, in most cases, it is not possible to use traditional shear reinforcement. Moreover, HCS are also critical in their end zones as they constitute disturbed regions where the beneficial effects of prestressing in shear are still not completely active. Finally, as HCS are precast elements w/o stirrups, their handling and lifting (especially those with large dimensions) can be extremely dangerous operations as their shear failure can be fragile and abrupt.

Within this framework, the present chapter aims to determine the benefits of macrosynthetic polypropylene fibres used as shear reinforcement. For this purpose, an experimental programme was conducted with five full-scale HCS (420 mm high, 1,200 $\mathrm{mm}$ wide, 6,000 mm long), one in RC and four in PFRC. A three-point-loading scheme was used in each test. Two tests were run on each slab by varying the $a / d$, i.e. 10 shear tests were run in all. Thus one of the end zones of HCS was tested with $a / d=3.5$, and the remaining end zone was tested with $a / d=2.8$ according to Annexe J of EN1168 [193].

\subsection{Specimen geometry and material}

One RC HCS and four PFRC HCS were manufactured indoors in a precast plant GRUPPO CENTRO NORD S.p.A (Italy) by an extrusion process and dry concrete. High tensile prestressed strands were placed and stressed up to the desired tension before manufacturing slabs, as Figure 5-1a shows. Using an extruding machine (see Figure 5-1b), HCS were casted on a production bed without having to use formworks. Some gaps in slabs (see Figure 5-1c) were left every $6 \mathrm{~m}$ to delimit total slab length. After a few hours, slabs were covered with a concrete curing blanket to control loss of moisture and to ensure correct cement hydration. Three days after casting, tendons were released from the anchored supports to transfer prestressing to concrete. Afterwards, slabs were cut to the length of $6,000 \mathrm{~mm}$ and stored until they were transported to the laboratory. 


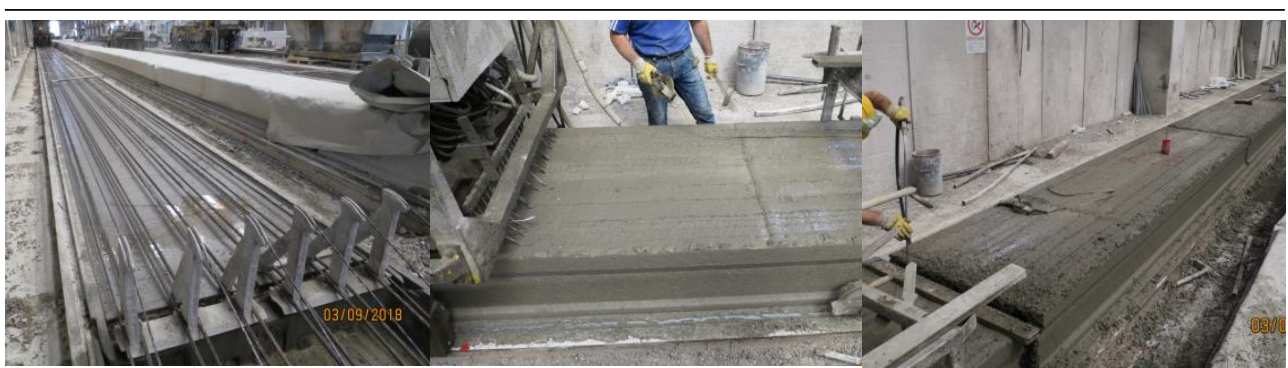

a)

b)

c)

Figure 5-1: Manufacturing HCS: picture of tendons prior to casting (a), picture of extruder machine (b) and picture of one manufactured HCS (c).

Figure 5-2 and Table 5-1 show the cross-section and reinforcement detail of all the HCS (RC and PFRC). The section of HCS was characterised by being rectangular- shaped with five non-circular voids and six webs $\left(b_{w}\right.$ of 50-60 mm). The total depth $(h)$ and width (b) were $420 \mathrm{~mm}$ and 1,200 $\mathrm{mm}$, respectively.

Moreover, the longitudinal reinforcement was constituted by three types of high tensile strength prestressed wire strands distributed on two layers. The bottom longitudinal reinforcement consisted in ten 6/10" and two 3/8" wire prestressing strands (leading to an effective depth (d) of $382 \mathrm{~mm}$ and a longitudinal reinforcement radio $(\rho)$ of $1.05 \%$ ), while the top reinforcement was made by six $3 \Phi 3 \mathrm{~mm}$ wire strands. No plastic sheathing was used. In order to analyse the tendon slip, each tendon was identified with a number (1 to 12), as seen in Figure 5-2. Tendons were prestressed up to 1,200 MPa to provide a mean compressive stress on the concrete cross-section of $7.96 \mathrm{MPa}$. The cross-section and reinforcement details are a typical commercial solution used in building floors for storage and industrial activities. This type of HCS is characterised by a span of $12.1 \mathrm{~m}$, a dead load of $18.8 \mathrm{kN} / \mathrm{m}^{2}$ (including the weight of the member itself) and a live load of $6.0 \mathrm{kN} / \mathrm{m}^{2}$.

1165

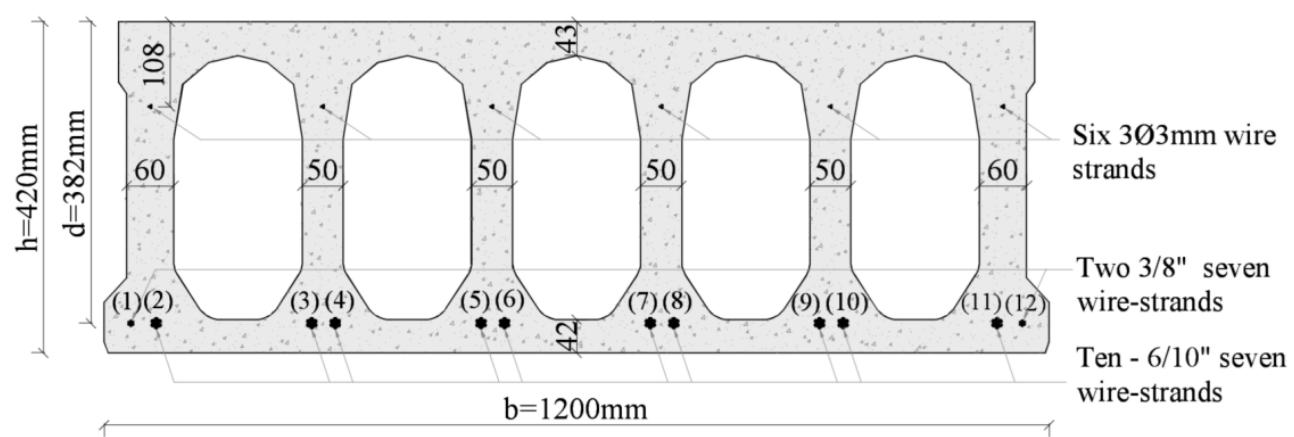

Figure 5-2: Cross-section details 
Table 5-1: Characteristics of HCS

\begin{tabular}{|c|c|}
\hline Total depth $(h)[\mathrm{mm}]$ & 420 \\
\hline Length $(L)[\mathrm{mm}]$ & 6000 \\
\hline Width $(b)[\mathrm{mm}]$ & 1200 \\
\hline Web width $\left(b_{w}\right)[\mathrm{mm}]$ & $2 \times 60 \mathrm{~mm}+5 \times 50 \mathrm{~mm}$ \\
\hline Effective depth $(d)[\mathrm{mm}]$ & 382 \\
\hline Nominal Cross section Area $\left[\mathrm{mm}^{2}\right]$ & 242568 \\
\hline Total weight $[\mathrm{kN}]$ & 34 \\
\hline Top Reinforcement & $6-3 \Phi 3 \mathrm{~mm}$ wire strands \\
\hline Bottom Reinforcement & $10-6 / 10 "+2-3 / 8$ " wire strands \\
\hline Top reinforcement Area $\left[\mathrm{mm}^{2}\right]$ & 127 \\
\hline Bottom reinforcement Area $\left[\mathrm{mm}^{2}\right]$ & 1494 \\
\hline Longitudinal reinforcement ratio & $1.05 \%$ \\
\hline Initial Prestress [MPa] & 1200 \\
\hline
\end{tabular}

a)

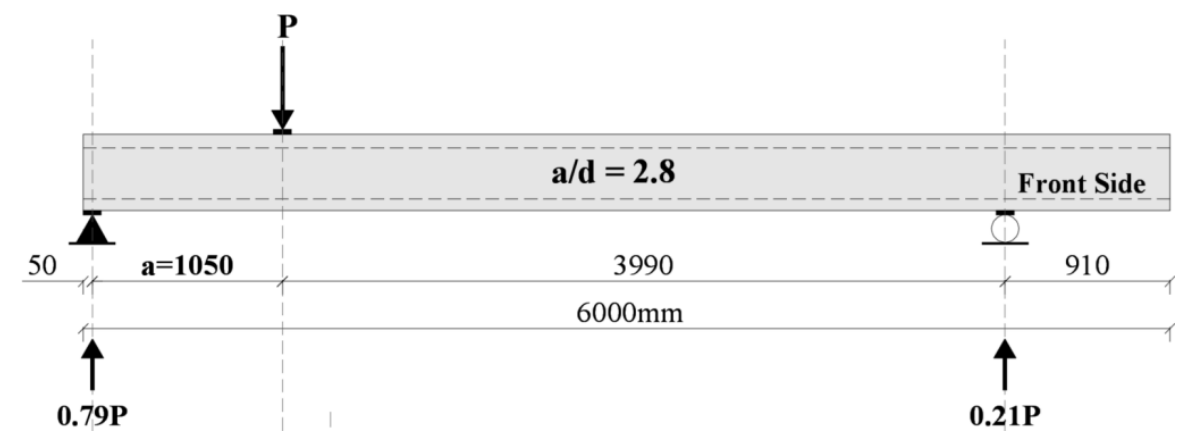

b)

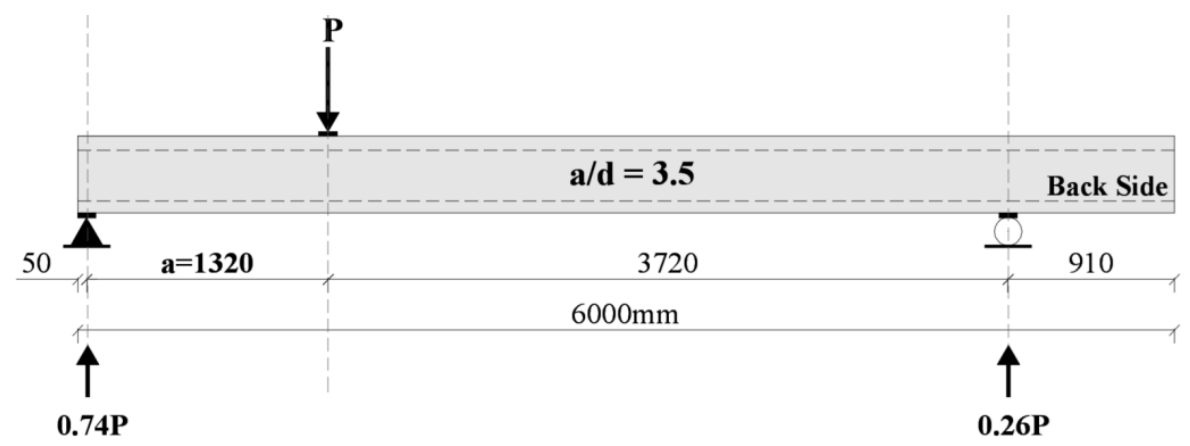

Figure 5-3: Three-point-loading scheme for the end zone: Load scheme for $a / d=2.8(a)$ and $a / d=$ 3.5

As the main objective is to analyse the shear performance of the end zones, two loading scenarios were selected to test both the end zones of each specimen (see Figure 5-3). The 
Effectiveness of polypropylene fibres as shear reinforcement in structural elements

first test was conducted in one of the end zones of HCS by adopting an equal a/d to 2.8. This scheme was selected to fulfil the requirements suggested in Annexe J of European standard EN 1168 [193], which provides guidelines for the full-scale testing of precast concrete products of HCS. In fact EN 1168 indicates that the load must be applied at $2.5 \mathrm{~h}(1,050 \mathrm{~mm})$ and no less than $600 \mathrm{~mm}$. This configuration is the equivalent to $\mathrm{a} / \mathrm{d}=2.8$. In the other end zone, the test was conducted by adopting $a / d$ of 3.5 to avoid the arch effect as much as possible on shear behaviour, which is characteristic in shot beams. It is worth mentioning that the distance of $5,040 \mathrm{~mm}$ between supports in both schemes $(\mathrm{a} / \mathrm{d}=2.8$ and 3.5$)$ was selected to also fulfil the requirements of EN 1168 , where requires a bigger span between $4 \mathrm{~m}$ and $12 \mathrm{~h}$.

Table 5-2 lists the mix designs of the two employed concrete types. Two cement types, and two types of crushed gravel, plus river sand, water and superplasticiser, were used to prepare concrete. The employed cements were Cement II/A-LL 42.5R and Cement I $52.5 \mathrm{R}$ with a water-to-cement ratio $(\mathrm{w} / \mathrm{c})$ of 0.43 . The maximum aggregate size was $15 \mathrm{~mm}$. Superplasticiser MasterCast 750 was used in PFRC to improve the distribution of fibres and the consistency of dry concrete.

Table 5-2: Mix design of reinforced concrete, SFRC and PFRC

\begin{tabular}{|c|c|}
\hline Cement II/A-LL 42.5R $\left[\mathrm{kg} / \mathrm{m}^{3}\right]$ & 240 \\
\hline Cement I 52.5R $\left[\mathrm{kg} / \mathrm{m}^{3}\right]$ & 120 \\
\hline Crushed sand $\left[\mathrm{kg} / \mathrm{m}^{3}\right]$ & 410 \\
\hline Gravel 2/7 mm [kg/m $]$ & 551 \\
\hline Gravel 8/15mm [kg/m³] & 650 \\
\hline River sand $\left[\mathrm{kg} / \mathrm{mm}^{3}\right]$ & 330 \\
\hline Polypropylene fibres $\left[\mathrm{kg} / \mathrm{m}^{3}\right]$ & $\begin{array}{c}0 \text { (RC) } \\
10.5 \text { (PFRC) }\end{array}$ \\
\hline Superplasticiser $\left[1 / \mathbf{m}^{3}\right]$ & $\begin{array}{c}0 \text { (RC) } \\
0.7 \text { (PFRC) }\end{array}$ \\
\hline
\end{tabular}

Figure 5-4 shows the crimped macrosynthetic polypropylene fibres ( $40 \mathrm{~mm}$ long) with a nominal aspect ratio (length/diameter) of 53, a density of $0.91 \mathrm{~g} / \mathrm{cm}^{3}$, used in the PFRC slabs dosed at $10.5 \mathrm{~kg} / \mathrm{m}^{3}$. The tensile strength and modulus of elasticity of fibres were $400 \mathrm{MPa}$ and $3.63 \mathrm{GPa}$, respectively. This fibre type differed from the fibres used in Chapters 3 and 4, where fibres were $48 \mathrm{~mm}$ long with a 56 aspect ratio. However, the remaining properties were the same, such as modulus of elasticity or tensile strength.

Steel wire strands were evaluated according to EN15630-1 [214]. The yielding stress $f_{y m}$ and ultimate stress $f_{u m}$ of longitudinal reinforcement were $1,819 \mathrm{MPa}(\mathrm{CV}=0.01)$ and $1,986 \mathrm{MPa}(\mathrm{CV}=0.01)$ for the $6 / 10$ " wire strands, $1,734 \mathrm{MPa}(\mathrm{CV}=0.01)$ and $1,933 \mathrm{MPa}$ 
Chapter 5. PFRC in Hollow Core Slabs

$(\mathrm{CV}=0.01)$ for the $3 / 8$ " wire strands, and 1,854 MPa $(\mathrm{CV}=0.01)$ and 2,021 $\mathrm{MPa}$ $(\mathrm{CV}=0.01)$ for the $3 \Phi 3 \mathrm{~mm}$ braids.

In order to determine the mechanical properties of RC and PFRC, concrete samples were obtained while manufacturing slabs. Six cubic specimens (150x150x150 mm) and nine prismatic beams $(150 \times 150 \times 600 \mathrm{~mm})$ were used to determine concrete compression strength $\left(f_{c, \text { cube }}\right)$ and post-cracking residual strength. Both cubes and prismatic beams were produced by an external vibrator and hand compaction. These sample specimens were cured under similar conditions to HCS.

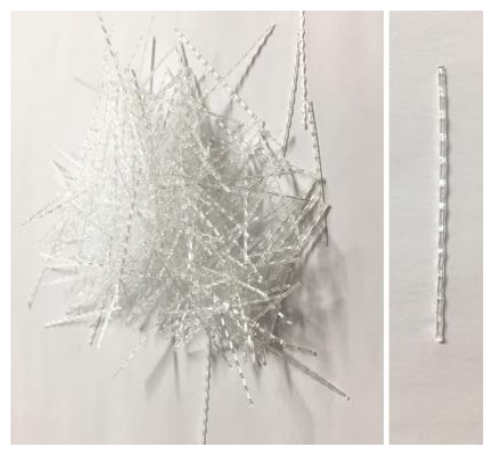

Figure 5-4: The employed crimped polypropylene fibres

Table 5-3 lists the mechanical properties of concretes (coefficient of variation (CV) in brackets) 28 days after casting. Concrete compression tests were carried out according to EN 12390-3. Equivalence factor $f_{c}=0.83 f_{c, \text { cube }}$ was employed to determine cylindrical concrete compression strength $\left(f_{c}\right)$. The limit of proportionality $f_{L}$ and residual flexural tensile strengths $f_{R, j}$ for CMOD equalled $0.5,1.5,2.5$ and $3.5 \mathrm{~mm}$, determined according to EN14651.

Table 5-3: Mechanical properties of concrete.

\begin{tabular}{|c|c|c|}
\hline Property & RC & PFRC \\
\hline$f_{c, \text { cube }}[\mathrm{MPa}]$ & $54.3(0.04)$ & $48.9(0.05)$ \\
\hline$f_{c}[\mathrm{MPa}]$ & 45.1 & 40.6 \\
\hline$f_{L}[\mathrm{MPa}]$ & $5.67(0.02)$ & $5.92(0.03)$ \\
\hline$f_{R, 1}[\mathrm{MPa}]$ & - & $2.66(0.17)$ \\
\hline$f_{R, 2}[\mathrm{MPa}]$ & - & $3.00(0.19)$ \\
\hline$f_{R, 3}[\mathrm{MPa}]$ & - & $3.43(0.19)$ \\
\hline$f_{R, 4}[\mathrm{MPa}]$ & - & $3.39(0.17)$ \\
\hline Density $\left[\right.$ fibres $\left./ \mathrm{cm}^{2}\right]$ & - & $1.21(0.18)$ \\
\hline
\end{tabular}


Figure 5-5 shows the total residual flexural tensile response vs. CMOD of seven PFRC and two RC prismatic specimens. It should be noted that two of the seven PFRC specimens were tested after 3 days of casting HCS to determine the structural performance of PFRC upon tendon cutting. The residual tensile strengths of PFRC at the tendon cutting age (3 days) were $4.34 \mathrm{MPa}(\mathrm{CV}=0.05), 2.12 \mathrm{MPa}(\mathrm{CV}=0.16)$ and $2.71 \mathrm{MPa}(\mathrm{CV}=0.21)$ for $f_{L}, f_{R, I}$ and $f_{R, 3}$, respectively. The polypropylene fibres showed the typical post-cracking behaviour, characterised by a load drop after the peak load, followed by stable constant behaviour up to a CMOD of around $3.5 \mathrm{~mm}$. Moreover, significant post-cracking performances were provided by fibres only after 3 days. Finally, the obtained results met the MC2010requirements [7] for using fibres in structural elements as $f_{R, I} / f_{L}>0.40$ and $f_{R, 3} / f_{R, I}>0.50$ in terms of mean values.

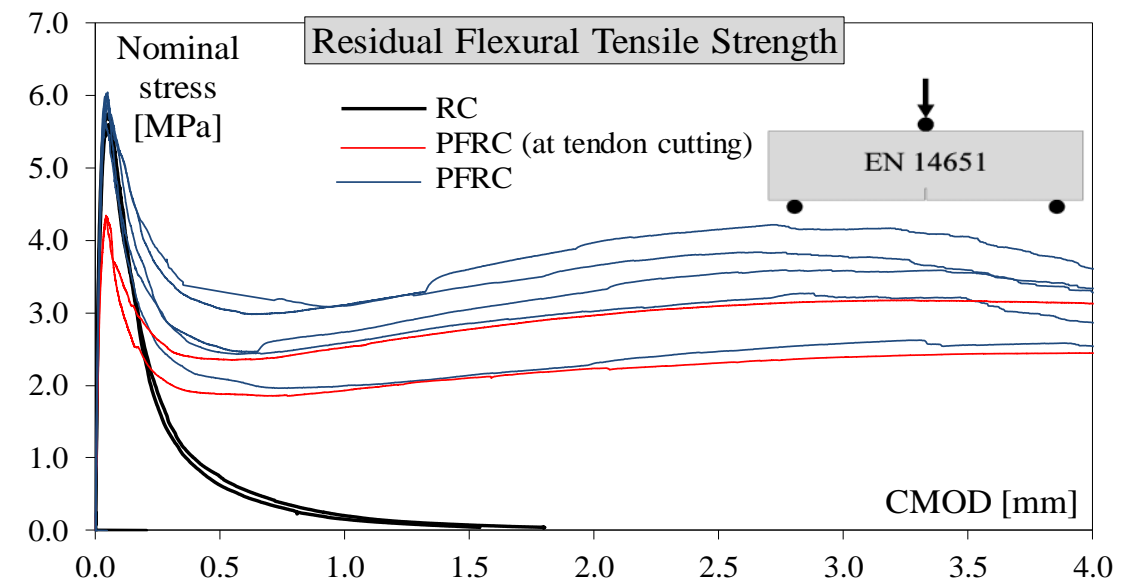

Figure 5-5: Nominal stress vs. CMOD curves according to EN14651[193] for RC and PFRC.

Finally, in order to study the fibre distribution in PFRC, the numbers of fibres in the prismatic specimens $(150 \times 150 \times 600 \mathrm{~mm})$ were counted in a section parallel to cracking (the result of being tested according to EN14651). To do so, the analysed section was treated with sodium hydroxide $(\mathrm{NaOH})$ and phenolphthalein $\left(\mathrm{C}_{20} \mathrm{H}_{14} \mathrm{O}_{4}\right)$ to increase the contrast between fibres and the concrete matrix. The results are presented in Table 5-3.

\subsection{Test setup and instrumentation}

The front and lateral views of the entire system are seen in Figure 5-6. HCS were tested by a three-point-loading scheme, as shown in Figure 5-6a, based on EN1168 recommendations. Thus the net span equalled 12-fold the total depth (h) and continuous supports (100 mm wide) on the entire sample width (see Figure 5-6b). 


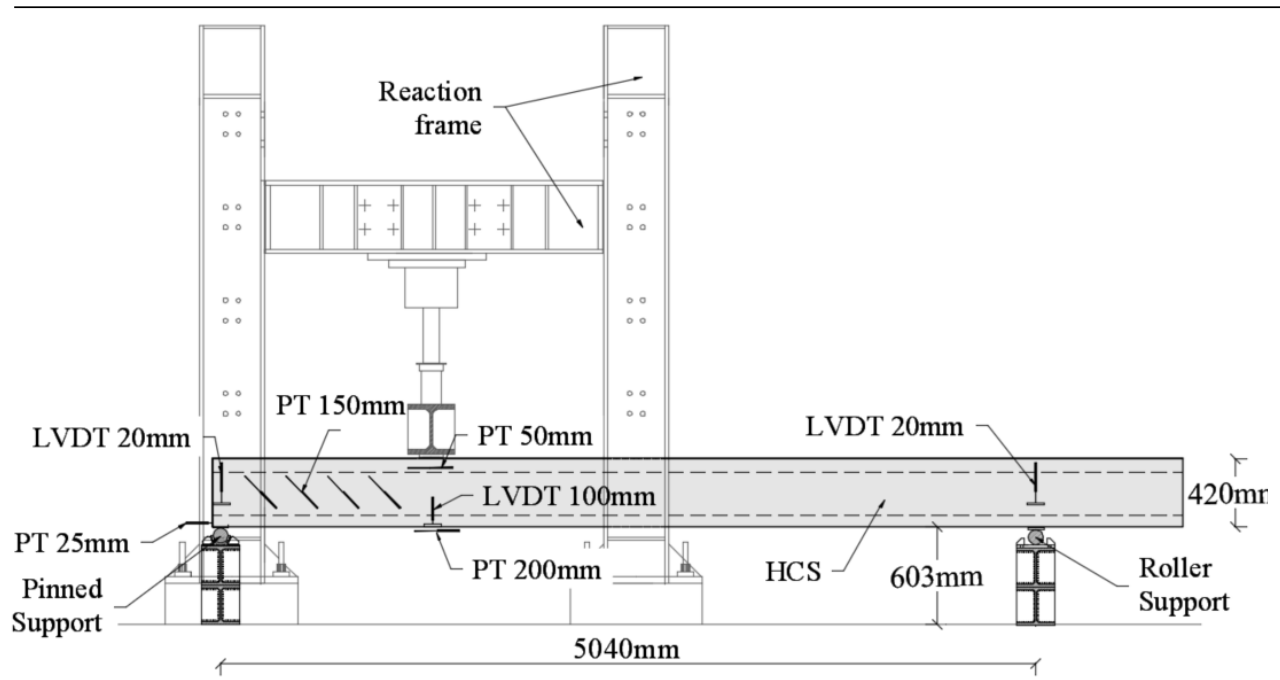

The same instrumentation was placed on back side

a)

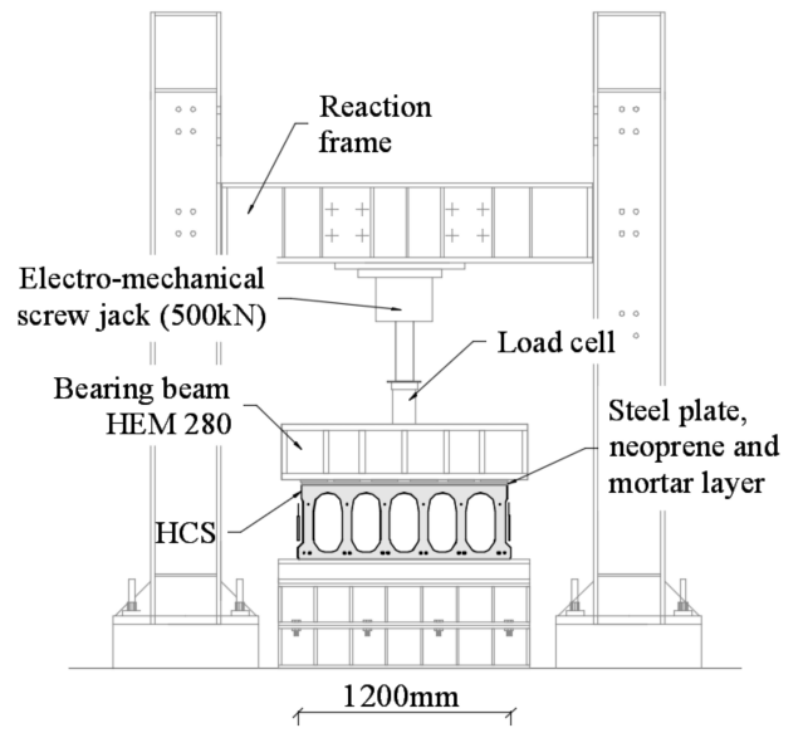

b)

Figure 5-6: Test setup of hollow-core slabs, lateral view (a) and front view (b).

An electromechanical screw jack $(500 \mathrm{kN})$ supported by a rigid reaction frame was used to apply load with displacement control on HCS. As seen in Figure 5-7, load was trans- 
mitted by a rigid steel beam (HEM280), which was placed on a bearing system constituted by neoprene ( $25 \mathrm{~mm}$ thick), a steel plate and a high-strength mortar layer. Tests were conducted at a quasi-static loading rate of $0.15 \mathrm{~mm} / \mathrm{min}$. However, three preliminary elastic cycles up to $20 \mathrm{kN}$ were conducted prior to tests to verify the entire test setup on each HCS.

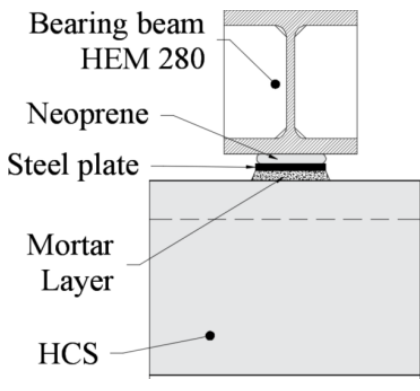

a)

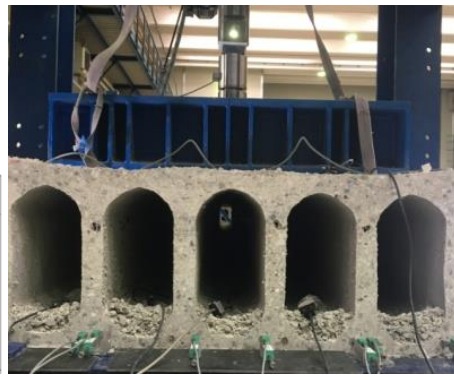

b)

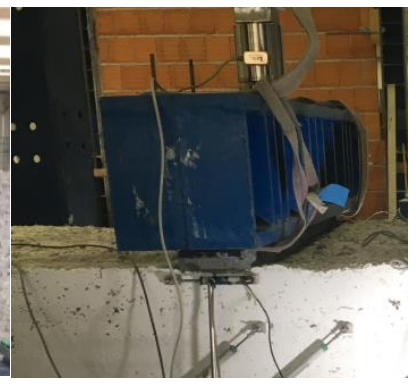

c)

Figure 5-7: Bearing beam details (a), pictures of front and perspective bearing beam (b and c).

Figure 5-8 presents details of the support system employed during tests. In order to guarantee a uniform distributed support along HCS width, steel plates (100 mm wide), along with a $20 \mathrm{~mm}$-thick high-strength mortar layer, were used in the pinned and roller supports. The employed support system met the EN1168 requirements, where the nearest support to the loading point had to be a roller bearing to eliminate the axial forces due to the slab rotating. In addition, EN 1168 requires a 10-mm layer of material, such as neoprene or a bed of mortar, between the supports and slab to better distribute loads and to compensate the unevenness and transversal curvature of slabs. The support's configuration nearest to the loading point was analogous to a support commonly used in practice for HCS. Finally, it is highlighted that the EN 1168 requirements were used for both test schemes $(\mathrm{a} / \mathrm{d}=2.8$ and 3.5$)$.

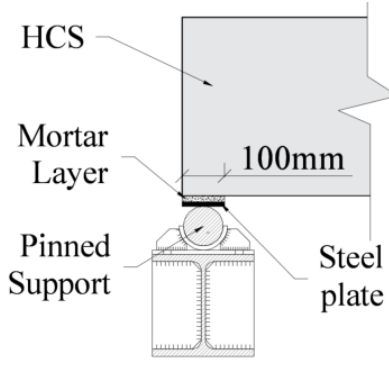

a)

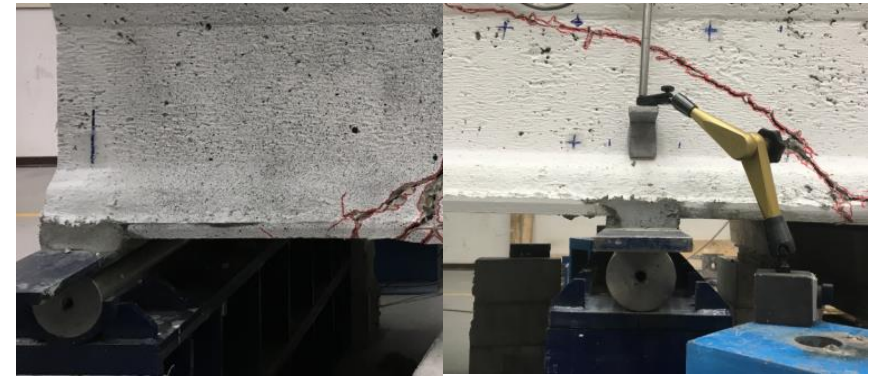

b)

c)

Figure 5-8: Supports detail (a), picture of pinned support (b) and picture of roller support (c). 
Chapter 5. PFRC in Hollow Core Slabs

Figure 5-6 also shows the employed instrumentation, whereas Figure 5-9 presents some pictures of it. Six linear variable differential transducers (LVDT) were employed to measure the deflection and support displacements, while eight potentiometric displacement transducers (PT) were adopted to measure the inclined shear crack opening at both the external webs of specimens. Flexural crack opening and compression chord shortening were also evaluated by the point load using 3 and 2 PT, respectively. Finally, to determine tendon sliding (as the difference between tendon and concrete displacement), eight PT were placed to measure the displacement of both concrete (at two points) and tendons on any HCS webs.

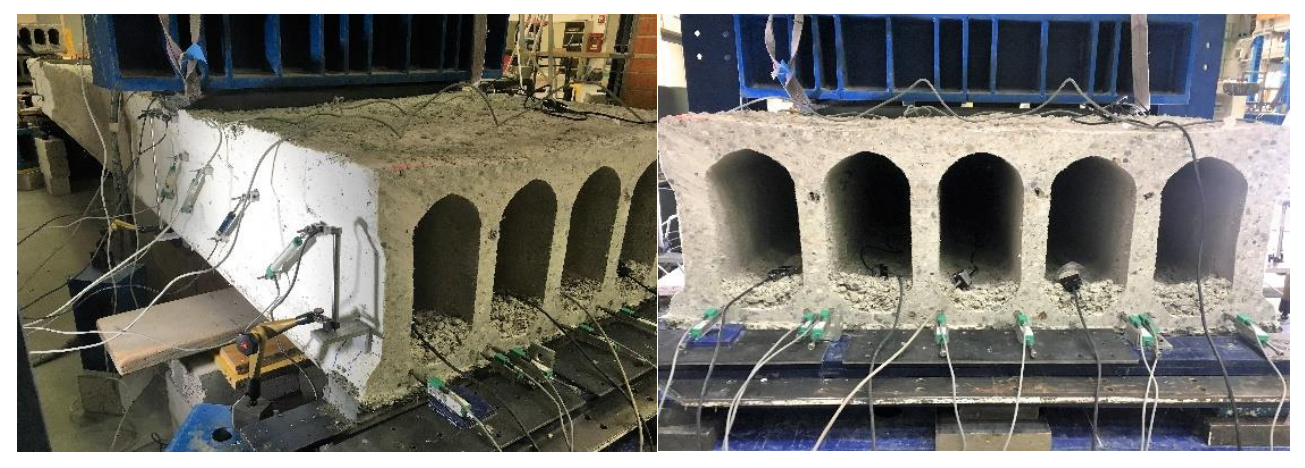

a)

b)

Figure 5-9: Instrumentation details: Picture of PT for the diagonal shear crack opening measurement (a) and picture of PT at the tendon layer (c).

\subsection{Experimental results and discussion}

All the HCS ( $a / d=2.8$ and $a / d=3.5$ ) presented a web-shear failure with loss of bond, as Figure 5-10a shows. This MOF is characterised by presenting a main shear crack due to the diagonal tension before the flexural crack appeared. Failure was abrupt and noisy, especially in the RC slabs. In fact in a previous failure, the failure zone was completely uncracked. Due to loss of bond between tendons and concrete, some cracks around tendons and below slabs appeared after failure (see Figure 5-10 b and Figure 5-10c). Flexural cracks were neither detected by instrumentation while testing, nor visually after tests.

Although both schemes were similar in MOF terms, some differences during tests between schemes, especially in post-cracking behaviour, appeared. The results of each used scheme are presented in the next sections. 


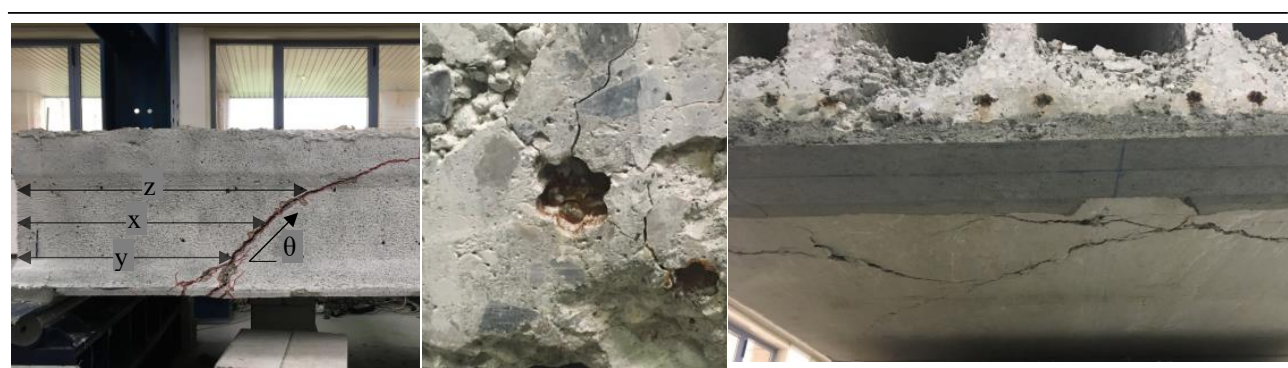

a)

b)

c)

Figure 5-10: Tested Slab: picture of web-shear failure (a), picture of slip of tendon due to loss of bond (b) and picture of bottom cracks due to loss of bond (c)

\subsubsection{HCS tested with a/d $=3.5$}

Table 5-4 summarises the maximum load $\left(P_{\max }\right)$, deflection $\left(\delta_{\max }\right)$ at $P_{\max }$, shear strength $\left(V_{u}\right)$, nominal shear strength $\left(\mathrm{v}_{\mathrm{u}}\right)$, normalised shear strength, and the ratio between flexural moment $\left(M_{u}\right)$ and estimated flexural strength $\left(M_{u, f l}\right)$. $V_{u}$ was evaluated by considering the applied load based on the corresponding static scheme (see Figure 5-3) and the self-weight of slabs, including the bearing system (steel beam, steel plates, mortar layer). $v_{u}$ was determined as $\left.V_{u} /\left(b_{w} \cdot d\right)\right)$, while normalised shear strength was established as $\left(v_{u}\right.$ $\left./\left(f_{c}\right)^{0.5}\right) . \delta_{\max }$ was corrected with the vertical displacements of supports, recorded during tests by LVDT. Finally to supplement Table 5-4, Figure 5-11a shows the load vs. deflection of the tested samples using $a / d=3.5$.

As seen in Table 5-4 and Figure 5-11a, HCS, including polypropylene fibres, presented a higher load capacity, from $12 \%$ to $39 \%$, than the control RC slab. In fact web shear failure occurred at $0.28 \sqrt{f_{c}}$ in the reinforced concrete HCS, while web shear failure was $0.37 \sqrt{f_{c}}$ on average in the PFRC slabs (see Table 5-4); i.e. polypropylene fibres incremented web strength by around $32 \%$ on average.

Table 5-4: Main experimental results of tests using $a / d=3.5$

\begin{tabular}{|c|c|c|c|c|c|c|c|}
\hline HCS & Specimen & $\begin{array}{l}\boldsymbol{P}_{\max } \\
{[\mathbf{k N}]}\end{array}$ & $\begin{array}{c}\delta_{\max } \\
{[\mathrm{mm}]}\end{array}$ & $\begin{array}{c}V_{u} \\
{[\mathbf{k N}]}\end{array}$ & $\begin{array}{c}v_{u} \\
{[\mathrm{MPa}]}\end{array}$ & $\begin{array}{c}v_{u} /\left(f_{c}\right)^{0.5} \\
{[-]}\end{array}$ & $\begin{array}{c}M_{u} / M_{u, f l} \\
{[-]}\end{array}$ \\
\hline $\mathrm{RC}$ & 42-RC-3.5 & 346.6 & 4.31 & 273.4 & 1.89 & 0.28 & 0.39 \\
\hline \multirow{5}{*}{ PFRC } & 42-PFRC-3.5-I & 489.0 & 6.75 & 378.7 & 2.60 & 0.41 & 0.52 \\
\hline & 42-PFRC-3.5-II & 413.9 & 4.94 & 323.4 & 2.11 & 0.33 & 0.45 \\
\hline & 42-PFRC-3.5-III & 465.8 & 5.38 & 361.3 & 2.44 & 0.38 & 0.50 \\
\hline & 42-PFRC-3.5-IV & 392.8 & 5.55 & 307.9 & 2.14 & 0.34 & 0.43 \\
\hline & Mean & $\begin{array}{l}440.4 \\
(0.10)\end{array}$ & $\begin{array}{l}5.65 \\
(0.14)\end{array}$ & 342.8 & 2.32 & 0.37 & 0.47 \\
\hline
\end{tabular}


Chapter 5. PFRC in Hollow Core Slabs

As seen in Figure 5-11a, all the slabs (RC and PFRC) initially presented quite similar linear behaviour to one another in load and deflection terms. However after $200 \mathrm{kN}$, certain differences in load vs. deflection stiffness associated with tendon slip were observed in those HCS with polypropylene fibres. Accordingly, shear behaviour was summarises in four main consecutive phases.

The first phase, which corresponded up to $200 \mathrm{kN}$, resulted in an uncracked stage where no differences between the PFRC and RC slabs were found. In this stage, as seen in Figure 5-11b, no significant differences in tendons slips were observed.

The second phase was between $200 \mathrm{kN}$ and $\mathrm{P}_{\max }$ when an incremented tendon slip was observed in all the slabs, which was significantly higher on external webs due to the smaller amount of concrete confining tendons (see Figure 5-11c). This general increment in tendon slip resulted in the progressive reduction of the effectiveness of the prestressing action on shear strength. In fact in this stage, a change in stiffness could be observed in the load vs. deflection response of slabs at approximately $300 \mathrm{kN}$. 
Effectiveness of polypropylene fibres as shear reinforcement in structural elements
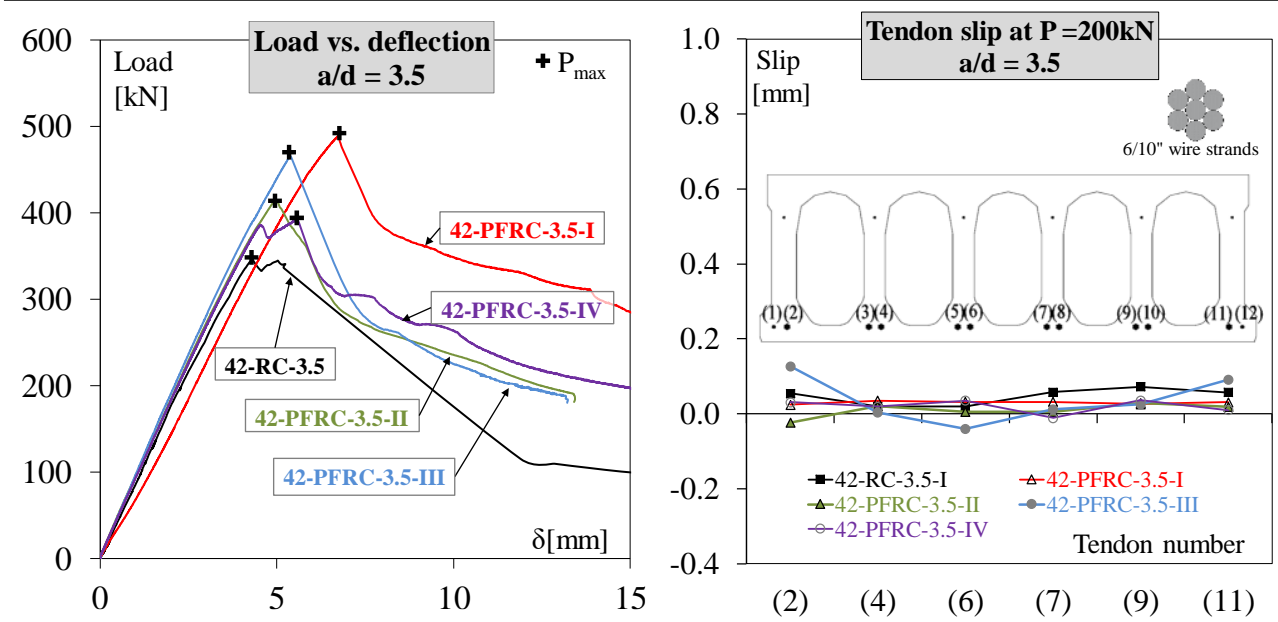

a)

b)

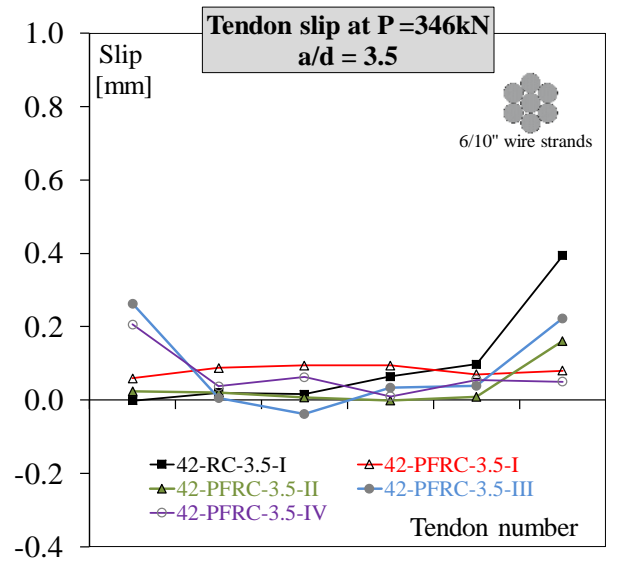

$\begin{array}{lllll}(2) & \text { (4) (6) (7) (9) (11) }\end{array}$

c)

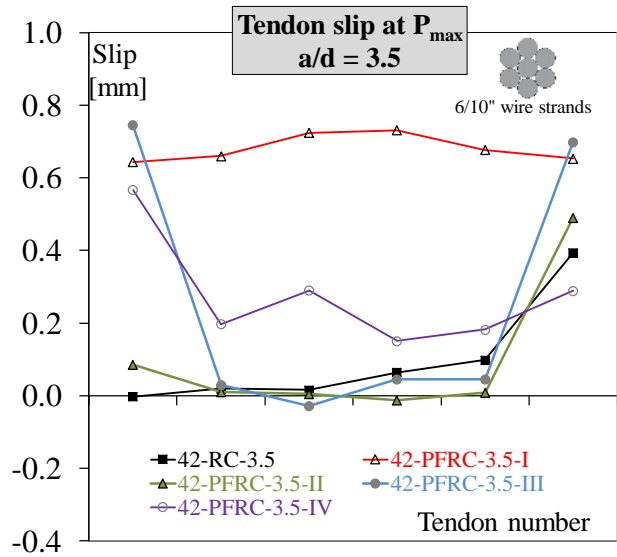

(4)

(6) (7)

(9)

(11)

d)

Figure 5-11: Test results using $a / d=3.5$ : load vs. deflection curves (a), tendons slip at $200 \mathrm{kN}(\mathrm{b})$, tendons slip at $346 \mathrm{kN}(\mathrm{c})$ and tendons slip at $\mathrm{P}_{\max }(\mathrm{d})$

The third phase corresponded exactly to $P_{\max }$. In this phase, one of the external webs suddenly failed in shear, which led to quite an abrupt failure of all the other webs. This was expected because; even external webs are thicker than internal ones, so they are less prestressed at end zones insomuch as tendons are less confined by surrounding concrete. These results are confirmed in Figure 5-11d, where a more marked tendon slips were captured at $P_{\max }$ in the external webs of all the slabs, except for sample 42-PFRC-3.5-I, where slips were similar in all the webs. 
Chapter 5. PFRC in Hollow Core Slabs

The last phase corresponded to the behaviour of slabs after $P_{\max }$. In this stage, the RC slab suddenly presented brittle failure with an abrupt drop in loading capacity and an increase in tendon slip. as seen in Figure 5-11a, even though a sudden drop in load occurred, all the samples showed post-cracking resistance with stable softening. The failure in all the HCS took place at a significantly lower load level than their flexural bearing capacity, as seen in Table 5-4; i.e. the $M_{u} / M_{u, f}$ ratio in the RC slab was 0.39 , while it was 0.47 on average in the PFRC slabs.

It was evident that the incremented shear strength in PFRC was due mainly to the ability of polypropylene fibres to better control tendon slip in comparison to the RC slab. As Figure 5-12 shows, polypropylene fibres reduced tendon slip from $200 \mathrm{kN}$ in the critical web shear, by providing more load vs. tendon slip stiffness, to a load of about the maximum load reached by the RC sample $(346 \mathrm{kN})$, which allowed a greater tendon slip with the PFRC slabs at $P_{\max }$. In fact this reduction in tendon slip went from $200 \mathrm{kN}$, and also led to a slightly greater stiffness of load vs. deflection in the PFRC slabs up to $P_{\max }$. Thus polypropylene fibres were able to enhance the bond between wire strands and the surrounding concrete, which allowed a better control of the developing splitting cracks. This improvement also guaranteed prestressing action on shear behaviour by allowing PFRC slabs to achieve greater shear strength than RC slabs.

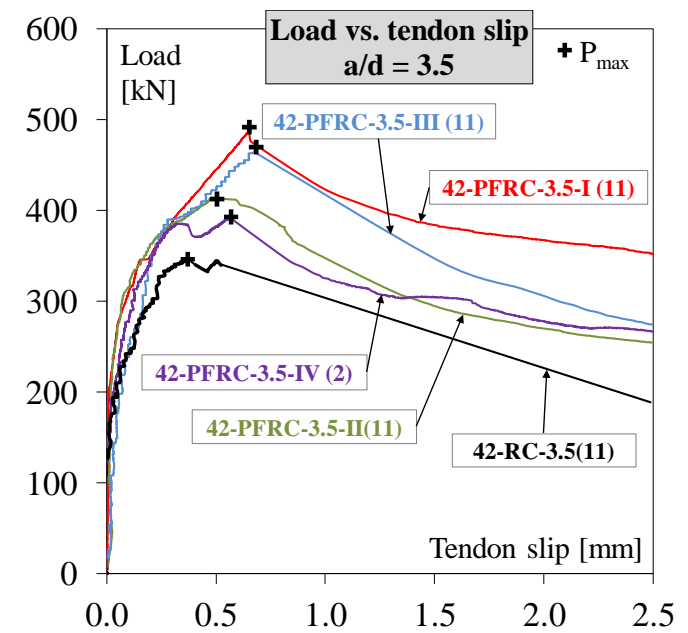

Figure 5-12: Test results using $a / d=3.5$ : load vs. tendon slip of critical web

Concerning web-shear cracking, Figure 5-13 presents the final crack patterns of HCS, where the first crack (critical crack), and the crack that caused failure and the abrupt load drop (crack B) are presented. The critical crack appeared in one of the external webs when the principal tensile stress of the web reached the tensile strength of concrete. Figure 5-14 shows the load vs. crack opening of the critical crack. As seen in Figure 5-14, crack B in slabs 42-RC-3.5 and 42-PFRC-3.5-III occurred instantly after the critical crack formed. In slabs 42-PFRC-3.5-I, 42-PFRC-3.5-II and 42-PFRC-3.5-IV, crack B 
Effectiveness of polypropylene fibres as shear reinforcement in structural elements

did not occur instantly after the critical crack formed: i.e. the critical crack continued to open until a new inclined crack suddenly appeared, which caused load to drop. In fact in slab 42-PFRC-3.5-IV, load incremented after the critical crack had formed, but failure and load drop happened when crack B appeared.

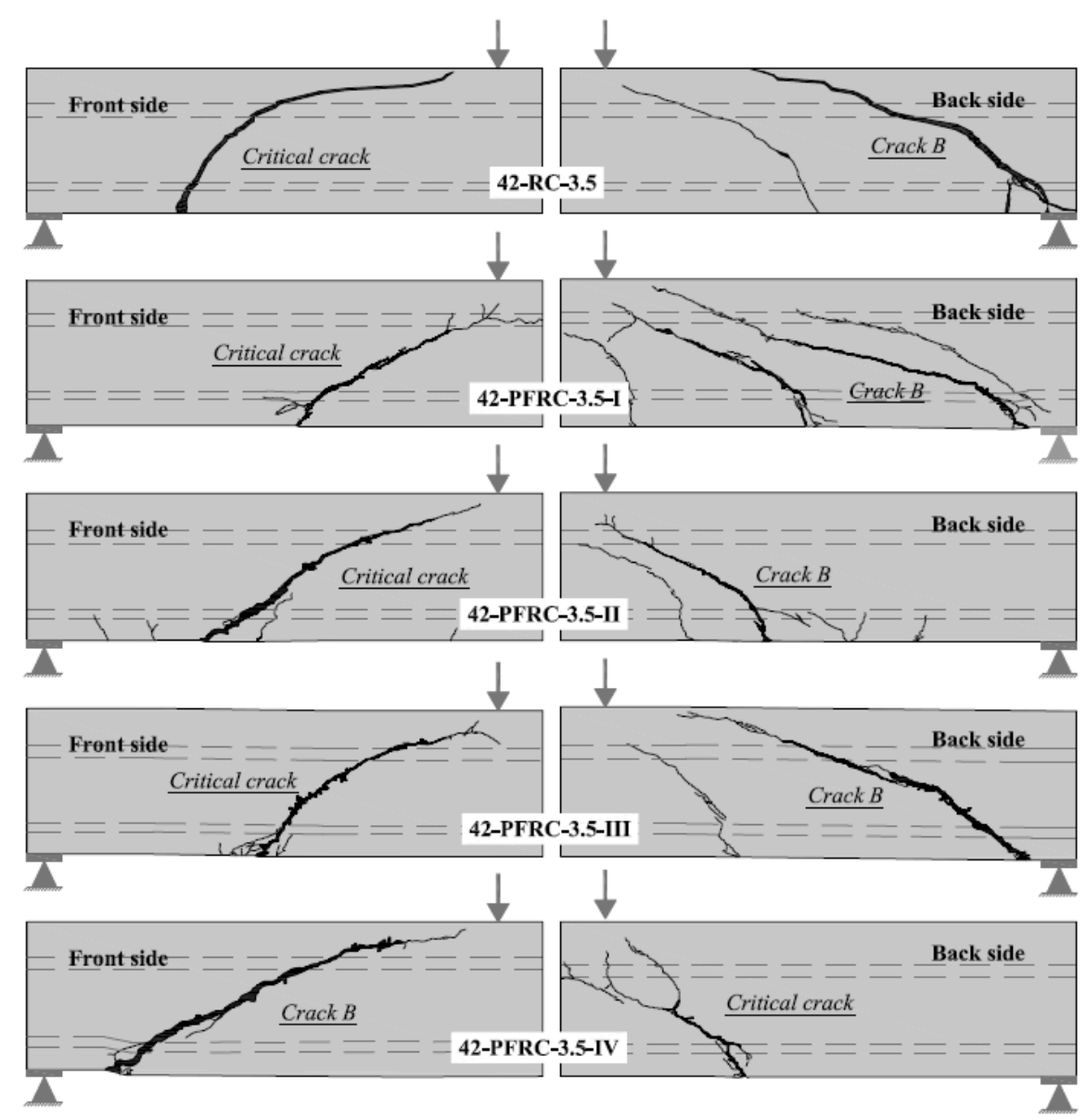

Figure 5-13: Final crack pattern of the slabs tested with $a / d=3.5$.

Figure 5-14 depicts how polypropylene fibres guaranteed controlled softening behaviour in post-cracking resistance in three of the four HCS, and a provided a slightly increased shear strength in slab 42-PFRC-3.5-IV. This softening behaviour was a combined effect of progressive tendon slip and web-shear crack opening. Thus the fibres dosed in 10.5 $\mathrm{kg} / \mathrm{m}^{3}$ were unable to either redistribute load to different webs or provide extra postcracking shear strength to slabs. 
Chapter 5. PFRC in Hollow Core Slabs

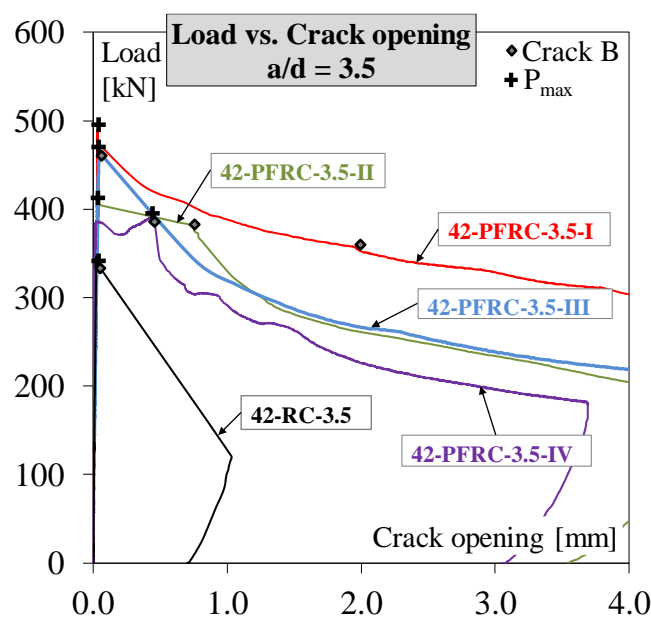

Figure 5-14: Test results using $a / d=3.5$ : load vs. shear crack opening of the most critical external web and load vs. tendon slip of critical web (b)

Table 5-5 summarises the crack average distance (x) measured from the end of the slab at the mid-web depth and its slope $(\theta)$. For this purpose, all the inclined cracks presented in the external and internal webs were measured at the end of the test at three points (z, $\mathrm{x}$ and $\mathrm{y}$ ) as Figure 5-10a shows. As seen in Table 5-5, the PFRC slabs presented cracks closer to the point load that were less inclined at around $+44 \%$ and $-25 \%$, respectively, compared to the RC slabs; i.e. the critical section in the PFRC slabs was further away from the slab end (see Figure 5-15). These results confirmed the positive influence of polypropylene fibres on tendon slip to improve prestressing actions in PFRC slabs.

Table 5-5: Average position and average slope of shear cracks.

\begin{tabular}{|c|l|c|c|}
\hline HCS & Specimen & $x[\mathrm{~mm}]$ & $\theta\left[^{\circ}\right]$ \\
\hline \multirow{3}{*}{ RC } & $42-R C-3.5$ & 395 & 34.0 \\
& & $(0.50)$ & $(0.26)$ \\
\hline & $42-P F R C-3.5-I$ & 707 & 24.3 \\
& & $(0.35)$ & $(0.23)$ \\
\cline { 2 - 5 } & \multirow{4}{*}{ 42-PFRC-3.5-II } & 643 & 25.2 \\
& & $(0.44)$ & $(0.27)$ \\
\cline { 2 - 5 } & $42-$ PFRC-3.5-III & 544 & 27.8 \\
& & $(0.32)$ & $(0.22)$ \\
\cline { 2 - 4 } & \multirow{3}{*}{$42-$ PFRC-3.5-IV } & 674 & 26.6 \\
& & $(0.38)$ & $(0.22)$ \\
\cline { 2 - 4 } & \multirow{4}{*}{ Mean } & 642 & 26.0 \\
& & $(0.11)$ & $(0.06)$ \\
\hline
\end{tabular}




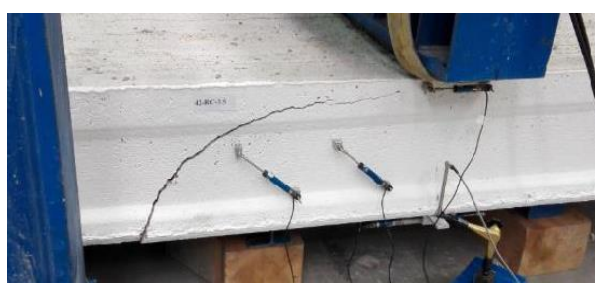

a)

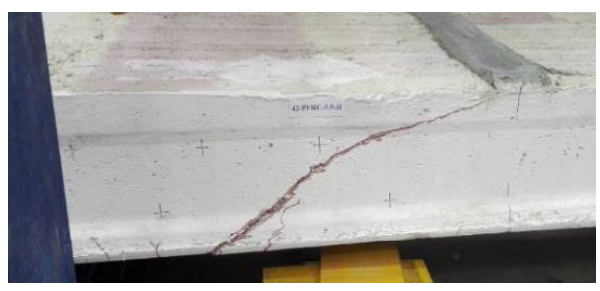

b)

Figure 5-15: Pictures of examples of slabs after failure: 42-RC-3.5 (a) and 42-PFRC-3.5-II (b).

\subsubsection{HCS tested with $\mathrm{a} / \mathrm{d}=2.8$}

Table 5-6 summarises the main experimental results of the HCS tested with $a / d=2.8$. Peak load (load at first shear crack, $\left.P_{\text {peak }}\right)$ and its corresponding deflection $\left(\delta_{\text {peak }}\right)$ are included in Table 5-6, along with those included in Table 5-4 ( $a / d=3.5)$. To supplement Table 5-6, Figure 5-16a plots the load vs. deflection curve of the RC and PFRC slabs tested with $a / d=2.8$. Figure 5-16b and Figure 5-16d show the tendon slip at $70 \mathrm{kN}$ and $P_{p e a k}$, while Figure 5-16c displays the load vs. tendon slip of the critical web. Concerning to crack behaviour, Figure 5-17 shows the load vs. crack opening of the first diagonal crack and Figure 5-19 presents the final crack pattern of all the slabs.

Table 5-6: Main experimental results of the tests using $a / d=2.8$

\begin{tabular}{|c|c|c|c|c|c|c|c|c|}
\hline HCS & Specimen & $\begin{array}{l}P_{\text {peak }} \\
{[\mathbf{k N}]}\end{array}$ & $\begin{array}{c}\delta_{\text {peak }} \\
{[\mathrm{mm}]}\end{array}$ & $\begin{array}{l}P_{\max } \\
{[\mathbf{k N}]}\end{array}$ & $\begin{array}{c}V_{u} \\
{[\mathbf{k N}]}\end{array}$ & $\begin{array}{c}v_{u} \\
{[\mathrm{MPa}]}\end{array}$ & $\begin{array}{c}v_{u} /\left(f_{c}\right)^{0.5} \\
{[-]}\end{array}$ & $\begin{array}{c}M_{u} / M_{u, f l} \\
{[-]}\end{array}$ \\
\hline $\mathrm{RC}$ & 42-RC-2.8 & 316.9 & 3.40 & 316.9 & 268.5 & 1.88 & 0.28 & 0.31 \\
\hline \multirow{5}{*}{ PFRC } & 42-PFRC-2.8-I & 370.7 & 4.69 & 381.2 & 319.3 & 2.17 & 0.34 & 0.35 \\
\hline & 42-PFRC-2.8-II & 384.6 & 3.39 & 391.1 & 322.2 & 2.15 & 0.34 & 0.35 \\
\hline & 42-PFRC-2.8-III & 340.7 & 3.22 & 340.7 & 287.4 & 1.93 & 0.30 & 0.32 \\
\hline & 42-PFRC-2.8-IV & 366.7 & 4.44 & 366.7 & 307.8 & 2.24 & 0.35 & 0.34 \\
\hline & Mean & $\begin{array}{l}365.7 \\
(0.05)\end{array}$ & $\begin{array}{c}3.93 \\
(0.19)\end{array}$ & $\begin{array}{l}369.9 \\
(0.06)\end{array}$ & 309.2 & 2.12 & 0.33 & 0.34 \\
\hline
\end{tabular}

Once again, all the HCS showed web-shear cracking with tendon slip failure (see Figure 5 -19). The HCS that included polypropylene fibres presented a $17 \%$ average extra shear strength than the control RC slab (see Table 5-6 and Figure 5-16a). In fact the web shear failure in the RC slab occurred at $0.28 \sqrt{f_{c}}$ (equalling the RC slab tested with $a / d=3.5$ ). In the PFRC slabs, web shear failure occurred at $0.33 \sqrt{f_{c}}$ on average (Table 5-6); i.e, 
Chapter 5. PFRC in Hollow Core Slabs

polypropylene fibres incremented the web strength in the PFRC slabs by around $20 \%$ on average. This increment was $12 \%$ lower than that obtained in the HCS with $a / d=3.5$.

As Figure 5-16a shows, all the slabs (RC and PFRC) presented a similar stiffness up to $P_{\text {peak }}$. However, post-cracking behaviour differed from the samples tested with $a / d=3.5$ due to the stronger arch action influence. Three main phases were observed in the shear behaviour of slabs.

The first phase, which went up to $P_{\text {peak }}$, resulted in an uncracked stage where no shear or flexural cracks were observed. No differences in tendon slip among slabs were recorded up to $170 \mathrm{kN}$, as Figure 5-16b shows, but tendon slip significantly increased in some strands of the RC slabs by about $170 \mathrm{kN}$ (see Figure 5-16c) .

In the second phase (at $P_{\text {peak }}$ ), a shear crack appeared closer to the applied load (see Figure 5-19) because part of the shear stresses were directly transferred to a pinned support by arch action. The appearance of this crack, which occurred first in the external webs, incremented the tendon slip of the external webs as Figure 5-16d shows, and led to a drop in load as a result of loss of prestressing action (see Figure 5-17a). 
Effectiveness of polypropylene fibres as shear reinforcement in structural elements

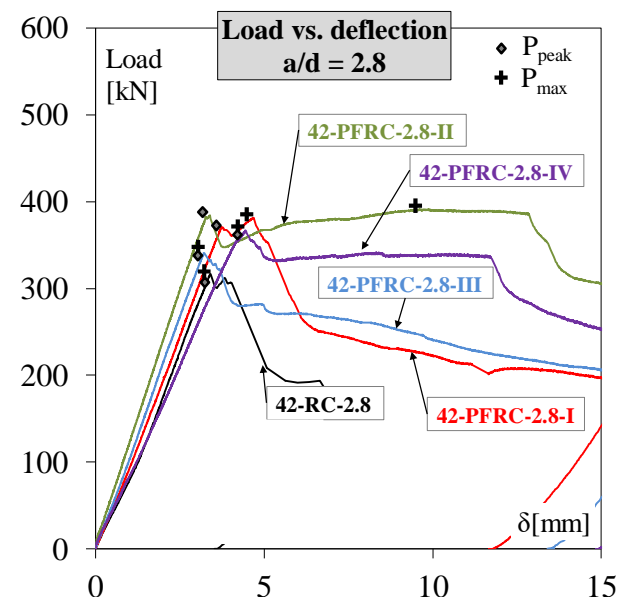

a)

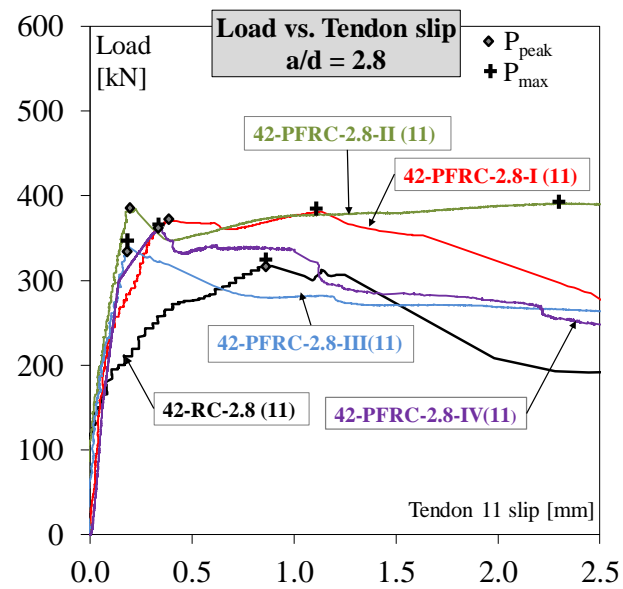

c)

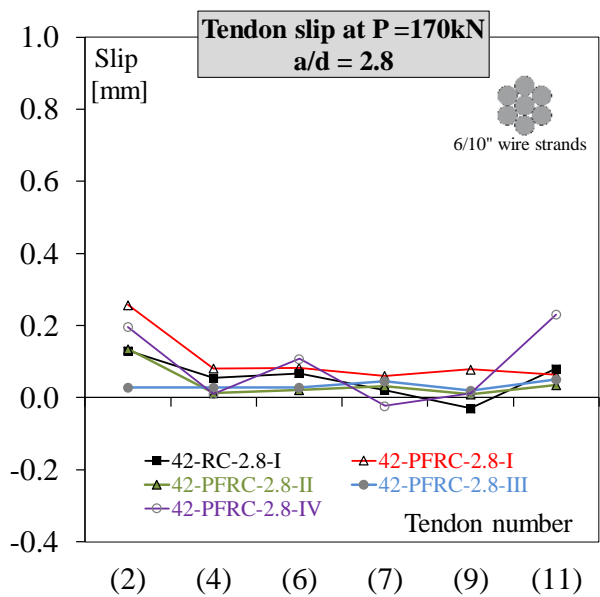

b)

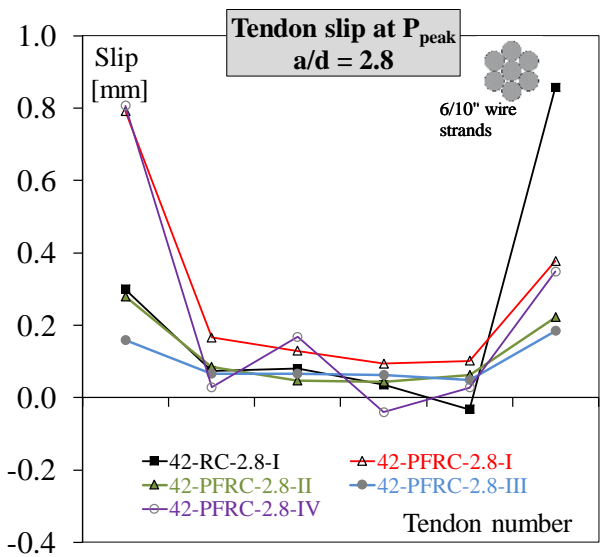

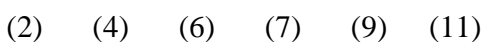

d)

Figure 5-16: Test results using $a / d=2.8$ : load vs. deflection curves (a), tendons slip at $170 \mathrm{kN}$ (b) and load vs. tendon slip of critical web (c), and tendons slip at $\boldsymbol{P}_{\text {peak }}(\mathrm{d})$

After $P_{\text {peak }}$, the initial inclined crack continued to open until a new inclined crack suddenly appeared (see crack $B$ in Figure 5-17, as well as $\theta$ and $\mathrm{x}$ in Table 5-7), which disrupted the transfer of stress flow from the load to the support. This led to an uncontrolled load drop in the RC slab, while the load drop was characterised by being a softening behaviour in the PFRC samples. Given the ability of polypropylene fibres to control both tendon slip and shear crack, four different post-cracking scenarios were observed: 
- $\quad$ Fibres provided a load increment after $P_{\text {peak }}$ in 42-PFRC-2.8-I. The extra provided strength $\left(P_{\max }\right)$ was around 1.03 -fold greater than $P_{\text {peak }}$

- Fibres provided stable post-cracking behaviour up to $13 \mathrm{~mm}$ on average of deflection in 42-PFRC-2.8-II and 42-PFRC-2.8-IV, despite a load increment being observed in the latter $\left(P_{\max } / P_{\text {peak }}=1.02\right)$

- Fibres provided controlled post-cracking behaviour in 42-PFRC-2.8-III, where $P_{\text {max }} / P_{\text {peak }}=1.0$.

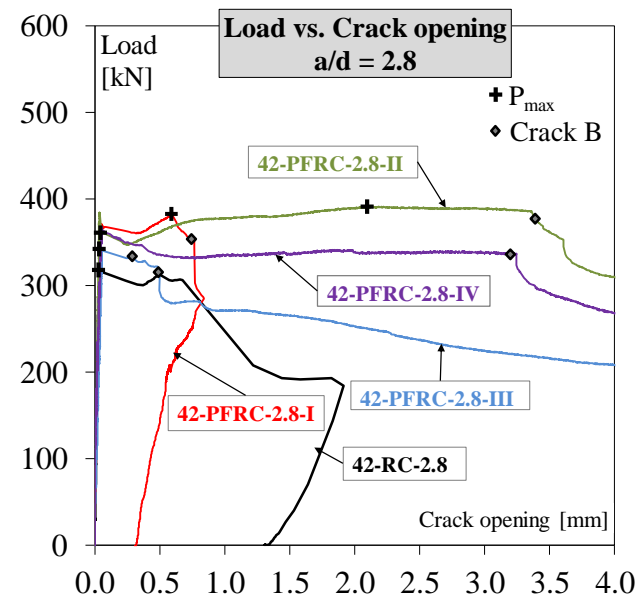

Figure 5-17: Test results using $a / d=2.8$ : load vs. shear crack opening

Table 5-7: Average position and average slope of shear cracks.

\begin{tabular}{|c|c|c|c|}
\hline \multirow{2}{*}{ HCS } & Specimen & $\boldsymbol{\theta}\left[{ }^{\circ}\right]$ & $\boldsymbol{x}[\mathbf{m m}]$ \\
\hline \multirow{2}{*}{ RC } & 42-RC-2.8 & $24.9(0.25)$ & $598(0.26)$ \\
\hline \multirow{3}{*}{ PFRC } & $42-$ PFRC-2.8-I & $27.9(0.29)$ & $543(0.19)$ \\
\cline { 2 - 4 } & 42-PFRC-2.8-II & $32.9(0.16)$ & $687(0.34)$ \\
\hline & $42-$ PFRC-2.8-III & $31.5(0.33)$ & $546(0.29)$ \\
\cline { 2 - 4 } & $42-$ PFRC-2.8-IV & $31.2(0.29)$ & $590(0.44)$ \\
\hline & Mean & $30.9(0.07)$ & $591(0.11)$ \\
\hline
\end{tabular}


Effectiveness of polypropylene fibres as shear reinforcement in structural elements

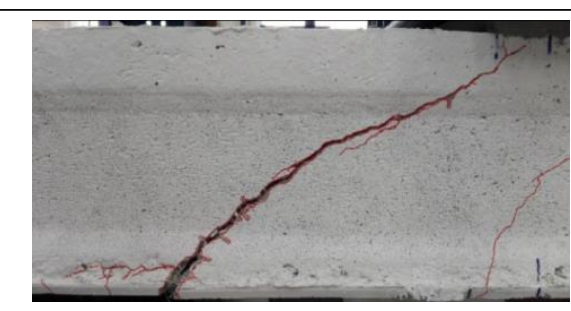

a)

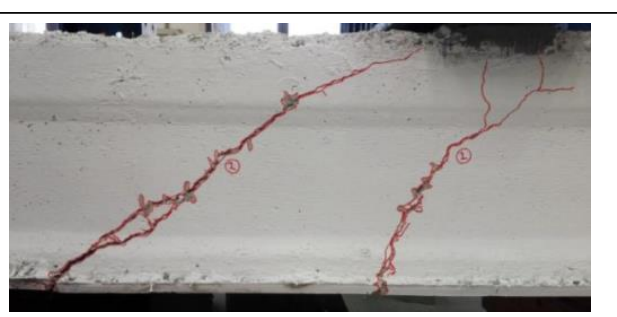

b)

Figure 5-18: Example pictures of slabs after failure: 42-RC-2.8 (a) and 42-PFRC-2.8-I (b).

By comparing the two tested RC slabs (42-RC-2.8 and 42-RC-3.5), both presented an equal bearing capacity and, hence similar, shear strength, although slab 42-RC-2.8 was influenced by the arch effect. This behaviour was probably because of the minor effectiveness of tendon anchorage in both slab types; hence slab 42-RC-2.8 did not offer any benefits from the arch effect. We should remember that, by having a good arch action effect, good anchorage of longitudinal reinforcement is required to balance the force transfers by the strut.

When comparing the PFRC average slab results between both schemes, the PFRC slab tested with $a / d=2.8$ presented a less marked increment (around 12\%) of nominal shear strength than the slab tested with $a / d=3.5$, even if the crack pattern showed that the arch effect had a significant influence. Nevertheless, the polypropylene fibres in HCS with $a / d=2.8$ could lead to significantly better post-cracking performance than the samples tested by using $a / d=3.5$, and even to an incremented load in some cases. 


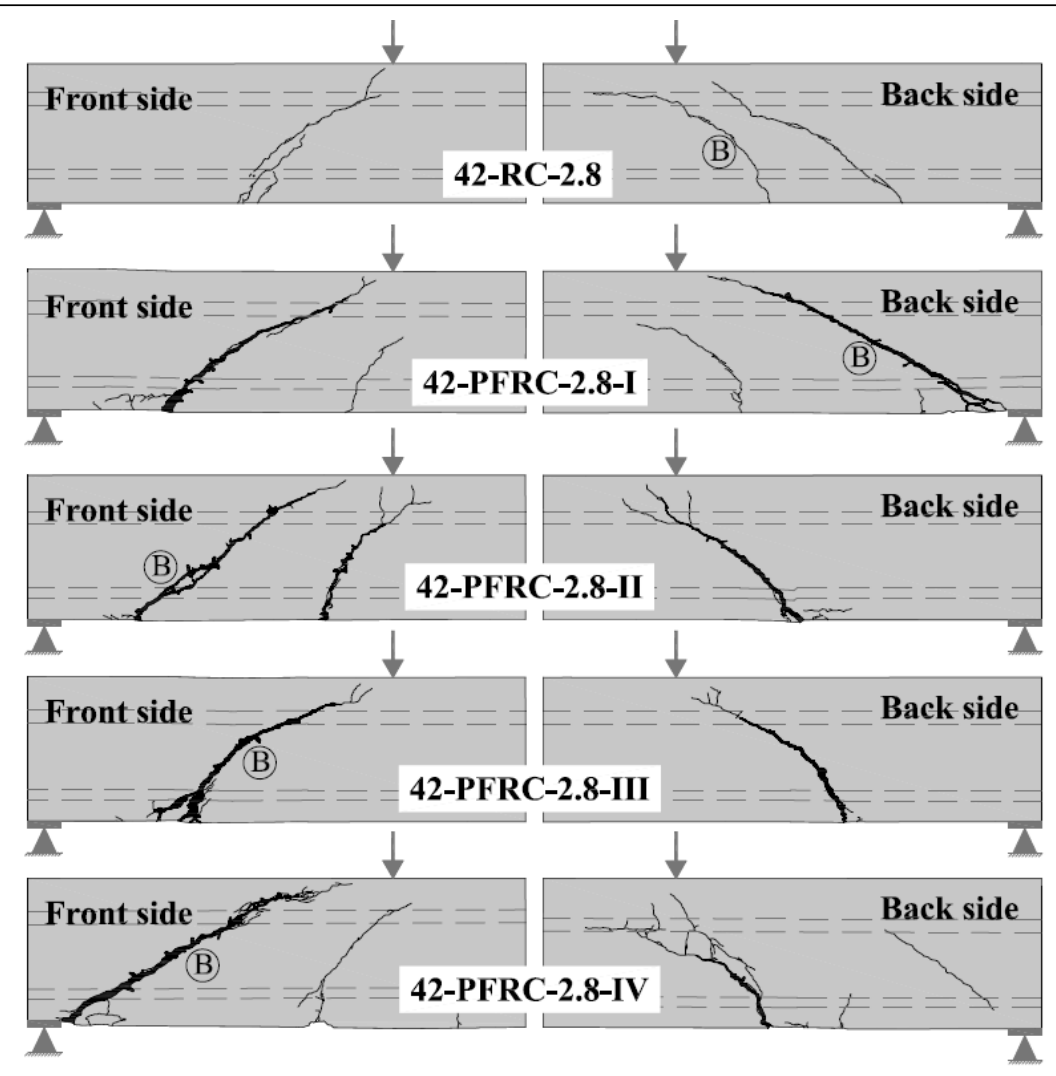

Figure 5-19: Final crack pattern of the slabs tested with $a / d=2.8$

\subsubsection{Distribution of polypropylene fibres in HCS webs}

In order to evaluate the density of fibres on each web of the ending cross-section, the number of fibres was counted as Figure 5-20 shows. For this purpose, a sodium hydroxide $(\mathrm{NaOH})$ and phenolphthalein $\left(\mathrm{C}_{20} \mathrm{H}_{14} \mathrm{O}_{4}\right)$ (see Figure 5-20b) treatment was applied to the natural concrete surface (see Figure 5-20a) to enhance the contrast between fibres and concrete. Finally, fibres were visually counted as indicated in Figure 5-20c.

Fibre density was 1.23 fibres $/ \mathrm{cm}^{2}$ with a $16 \%$ coefficient of variation. When we compared this distribution to the distribution obtained in the prismatic specimens (see Table 5-3) during concrete mechanical characterisation, slabs had a good and similar fibre distribution to the sample specimens. This result confirms that the mechanical properties of sample specimens correspond to real ones in slabs. 
Effectiveness of polypropylene fibres as shear reinforcement in structural elements

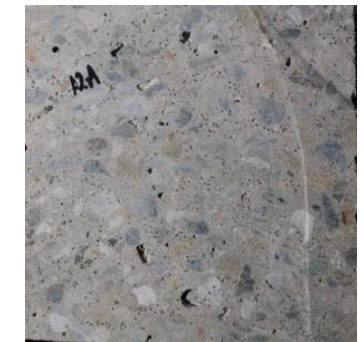

a)

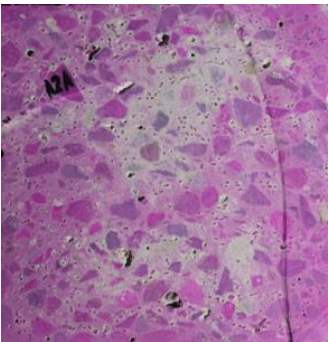

b)

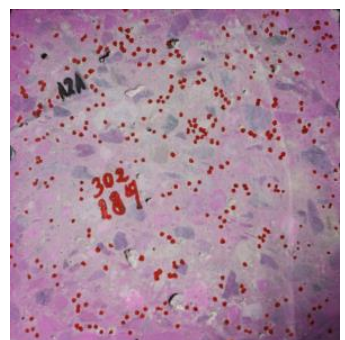

c)

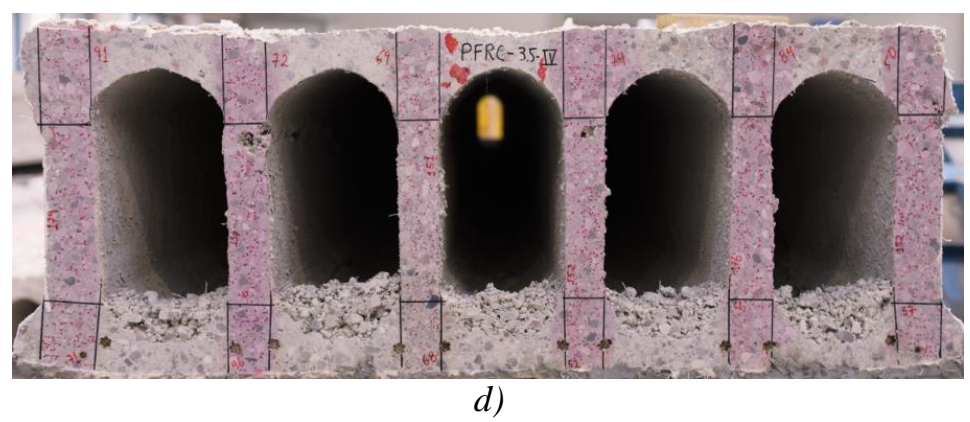

Figure 5-20: Surface treatment: pictures of surface previous treatment (a), after treatment (b) and after counting fibres (c)

In order to explore fibre orientation on slabs' webs, fibre density was evaluated on different inclined planes $\left(0^{\circ}, 45^{\circ}, 90^{\circ}\right)$. To this end, two cylinder cores (100-mm diameter) were drilled from all the external webs because they were the critical ones, as stated in Section 5.4.1. Having obtained the cores, they were cut at an angle of $0^{\circ}$ (parallel plane to that of splitting cracks), $45^{\circ}$ (plane with a similar inclination to that of shear cracks) and $90^{\circ}$ (vertical plane) (see Figure 5-21 for more details).

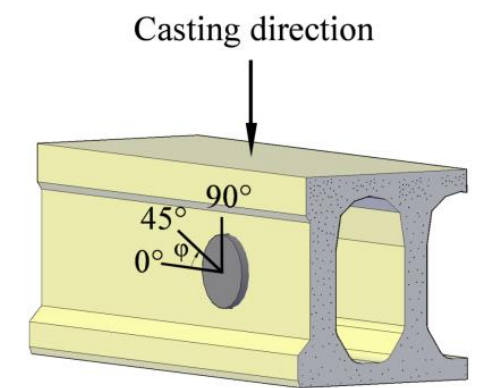

Figure 5-21: Cylinder core and inclination of the studied planes. 
Chapter 5. PFRC in Hollow Core Slabs

Figure 5-22 shows the fibre density (mean value for each sample) of each studied plane. The incremented plane inclination resulted in a higher fibre density. This evidenced that the distribution of fibres in HCS webs was good, even on the plane parallel to both shear $\left(45^{\circ}\right)$ and splitting $\left(0^{\circ}\right)$ cracks. In fact the obtained results justified the effectiveness of fibres in controlling tendon slip, as well as controlling post-cracking behaviour in PFRC slabs.

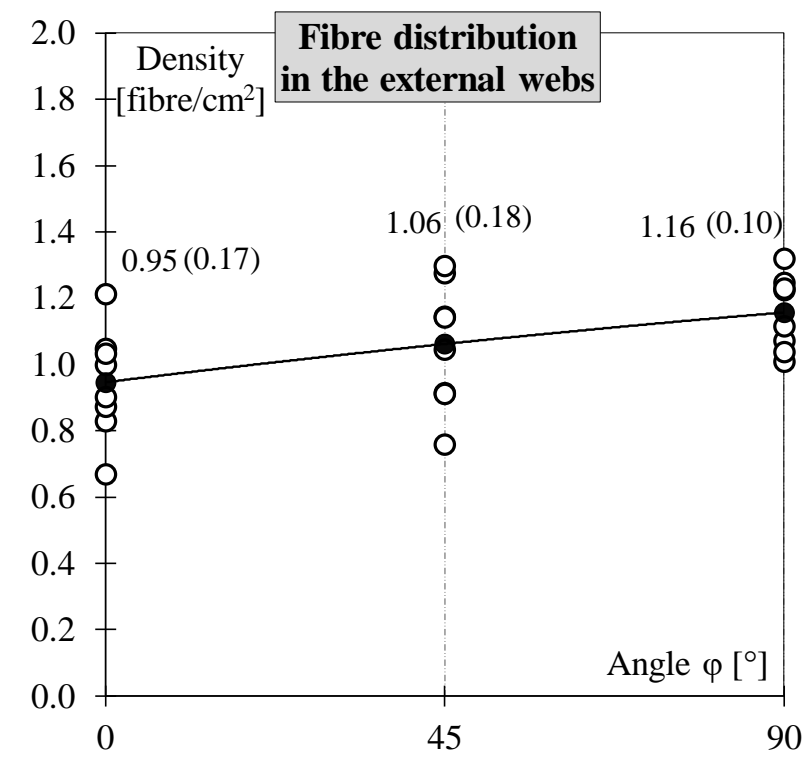

Figure 5-22: Fibre distribution in the external webs

\subsection{Comparison to code predictions}

In this section, the experimental results obtained after performing the 10 tests (five with $a / d=2.8$, five with $a / d=3.5$ ) were compared to the analytical expression provided by four international codes: ACI 318-14 [13], Eurocode 2 (EC2) [76], MC2010 [7] and EN1168 [193]. In all the formulations, the strength reduction factor $\left(\gamma_{c}\right.$ for EC2, MC2010 and EN1168, $\phi$ for ACI 318-14) was considered to equal one, while the mean values of the mechanical properties listed in Table 5-3 were used. The mean tensile concrete strength $f_{c t}$ values were evaluated as $\left(f_{c t}=0.3\left(f_{c k}\right)^{2 / 3}\right)$ (see Eq. 5.1-3a of MC2010). The selfweight and loading system, the real section geometry and the real tendon position were considered in each slab while performing prediction calculations. In addition, based on the suggested lump estimates of the time-dependent prestress losses suggested by Naaman [186], which can range from 242 to $276 \mathrm{MPa}$, i.e. losses ranging from $21 \%$ to 
Effectiveness of polypropylene fibres as shear reinforcement in structural elements

$17.5 \%$, the shear strength predictions were calculated by considering prestress tendon losses of $20 \%$.

Regarding the RC slabs, Table 5-8 summarises the code expressions in terms of SI units. For ACI 318-14, the shear calculation was taken as the lowest value given by expressions (e.q. 5-1) and (e.q. 5-2). As expected, the lowest value equalled the expression (e.q. 5-1). Expressions (e.q. 5-3), (e.q. 5-4) and (e.q. 5-11) for EC2, MC2010 level I, and EN1168 level II respectively, were to one another. However, MC2010 level I and EN1168 level II included a calibration factor of 0.8. MC2010 and EN1168 included more refined expressions (from (e.q. 5-5) to (e.q. 5-10)), with shear stressed $\tau_{c p}$ ((e.q. 5-7) and (e.q. 5-10)) due to the prestressing force transfer. The evaluated control sections were:

- Distance $\mathrm{h} / 2$ from the support's internal face according to ACI 318-14;

- Distance $l_{x}$ measured from the slab edge to the intersection of the fibre that passed through the centre of gravity of the gross section and an inclined line ( $45^{\circ}$ for $\mathrm{EC} 2$ and $\mathrm{MC} 2010$ and $35^{\circ}$ for EN1168) from the support's internal face

- In the expressions (e.q. 5-5) and (e.q. 5-8) the critical point was the point on the previously mentioned inclined line where the lowest shear strength was found

Regarding the PFRC slabs, even though no formulation was specifically developed for the contribution in shear of the fibres in regions w/o flexural cracks, the second model (Eq. 2-17), which indicated in MC2010 and previously in Section 2.1, was evaluated by considering $\varepsilon_{x}=0$. Thus the angle of compressive stress field $\theta$ was $29^{\circ}$, while $k_{v}=$ $0.4 \frac{1300}{\left(1000+k_{d g} z\right)}$.

Table 5-8: Shear resistance formulations for elements RC and FRC.

\begin{tabular}{|c|c|c|}
\hline Code & \multicolumn{1}{|c|}{ Expression } & Equation \\
\hline ACI 318-14 & $V_{u, c o d e}=\left(0.29 \lambda \sqrt{f_{c}}+0.3 f_{p c}\right) b_{w} d_{p}+V_{p}$ & (e.q. 5-1) \\
\hline EC2 & $V_{u, c o d e . i}=0.05 \lambda \sqrt{f_{c}} b_{w} d_{p}+V_{d}+\frac{V_{i} M_{c r e}}{M_{\max }}$ & (e.q. 5-2) \\
\hline MC2010-I & $V_{u, c o d e}=\frac{I b_{w}}{S} \sqrt{\left(f_{c t}\right)^{2}+\alpha_{1} \sigma_{c p} f_{c t}}$ & (e.q. 5-3) \\
\hline MC2010-II & $V_{u, c o d e}=0.8 \frac{I b_{w}}{S_{c}} \sqrt{\left(f_{c t}\right)^{2}+\alpha_{1} \sigma_{c p} f_{c t}}$ & (e.q. 5-4) \\
\hline$V_{u, c o d e}=\frac{I b_{w}(y)}{S_{c}(y)} \sqrt{\left(f_{c t}\right)^{2}+\alpha_{1} \sigma_{c p}(y) f_{c t}}-\tau_{c p}(y)$ & (e.q. 5-5) \\
\hline
\end{tabular}


Chapter 5. PFRC in Hollow Core Slabs

\begin{tabular}{|c|c|c|}
\hline Code & Expression & Equation \\
\hline & $\sigma_{c p}(y)=\left[\frac{1}{A_{c}}+\frac{y_{c}-y}{I}\right] F_{p}\left(l_{x}\right)$ & (e.q. 5-6) \\
\hline & $\tau_{c p}(y)=\frac{1}{b_{w}(y)}\left[\frac{A_{c}(y)}{A_{c}}-\frac{S_{c}(y)\left(y_{c}-y_{p t}\right)}{I}\right] \frac{d F_{p}\left(l_{x}\right)}{d_{x}}$ & (e.q. 5-7) \\
\hline \multirow{3}{*}{ EN1168-I } & $V_{u, \text { code }}=\frac{I b_{w}(y)}{S_{c}(y)} \sqrt{\left(f_{c t}\right)^{2}+\sigma_{c p}(y) f_{c t}}-\tau_{c p}(y)$ & (e.q. 5-8) \\
\hline & $\sigma_{c p}(y)=\sum_{i=1}^{n}\left\{\left[\frac{1}{A}+\frac{\left(Y_{c}-y\right)\left(Y_{p}-Y_{p t}\right)}{I}\right] P_{t}\left(l_{x}\right)\right\}-\frac{M_{E d}}{I}\left(Y_{c}-y\right)$ & (e.q. 5-9) \\
\hline & $\tau_{c p}(y)=\frac{1}{b_{w}(y)} \sum_{i=1}^{n}\left\{\left[\frac{A_{c}(y)}{A}-\frac{S_{c}(y)\left(Y_{c}-Y_{p t}\right)}{I}+C p_{t}(y)\right] \frac{d P_{t}\left(l_{x}\right)}{d_{x}}\right\}$ & (e.q. 5-10) \\
\hline EN1168-II & $V_{u, \text { code }}=0.8 \frac{I b_{w}}{S} \sqrt{\left(f_{c}\right)^{2}+0.9 \alpha_{1} \sigma_{c p} f_{c t}}$ & (e.q. 5-11) \\
\hline
\end{tabular}

Table 5-9 summarises the ultimate shear strength predicted by the models, while Table 5-10 presents the experimental vs. predicted ratios $\left(V_{u} / V_{u, c o d e}\right)$ of the RC slabs. In addition, Table 5-11 presents the predicted shear strength and ratios of slabs, including polypropylene fibres. Finally, to supplement the tables, Figure 5-23 shows the comparison made between the experimental and ultimate shear strength predicted by the models arranged in the tests with $a / d=3.5$ and $a / d=2.8$.

With the RC slabs, all the code's predictions were somewhat non-conservative. Nevertheless, level II of EN1 168 was the most accurate estimation with a ratio $\left(V_{u} / V_{u, c o d e}\right)$ of 0.96 and one of 0.97 for $a / d=2.8$ and $a / d=3.5 \mathrm{r}$ (EN-II), respectively. Similar results were obtained with the predictions using MC2010 level II (MC-I). Both formulations included a reduction factor that equalled 0.8 , which calibrated the element's bearing capacity by $-20 \%$. The Eurocode 2 (EC2) formulation, which does not include any calibration factor, predicted an overestimated shear capacity and obtained a factor of 0.75 in both cases for the $a / d$ slabs. Finally, the prediction using ACI 318-14 (ACI) was also non-conservative, and obtained a coefficient ratio $\left(V_{u} / V_{u, c o d e}\right)$ of 0.78 in both loading schemes.

Table 5-9: Shear strength prediction of the RC slabs.

\begin{tabular}{|c|c|c|c|c|c|c|c|}
\hline HCS & $\begin{array}{c}\boldsymbol{V}_{\boldsymbol{u}} \\
{[\mathbf{k N}]}\end{array}$ & $\begin{array}{c}\boldsymbol{V}_{\boldsymbol{u}, \boldsymbol{A C I}} \\
{[\mathbf{k N}]}\end{array}$ & $\begin{array}{c}\boldsymbol{V}_{\boldsymbol{u}, \boldsymbol{E C}-2} \\
{[\mathbf{k N}]}\end{array}$ & $\begin{array}{c}\boldsymbol{V}_{\boldsymbol{u}, M C-I} \\
{[\mathbf{k N}]}\end{array}$ & $\begin{array}{c}\boldsymbol{V}_{\boldsymbol{u}, M C-I I} \\
{[\mathbf{k N}]}\end{array}$ & $\begin{array}{c}\boldsymbol{V}_{\boldsymbol{u}, E N-I} \\
{[\mathbf{k N}]}\end{array}$ & $\begin{array}{c}\boldsymbol{V}_{\boldsymbol{u}, E N-I I} \\
{[\mathbf{k N}]}\end{array}$ \\
\hline $42-\mathrm{RC}-3.5$ & 273.4 & 351.4 & 366.7 & 294.8 & 316.6 & 401.6 & 284.9 \\
\hline $42-\mathrm{RC}-2.8$ & 268.5 & 344.4 & 357.5 & 287.5 & 308.9 & 391.2 & 278.0 \\
\hline
\end{tabular}


Effectiveness of polypropylene fibres as shear reinforcement in structural elements

Table 5-10: Comparison between the experiments and predictions of the RC slabs.

\begin{tabular}{|c|c|c|c|c|c|c|}
\hline HCS & $V_{u} / V_{u, A C I}$ & $V_{u} / V_{u, E C-2}$ & $V_{u} / V_{u, M C-I}$ & $V_{u} / V_{u, M C-I I}$ & $V_{u} / V_{u, E N-I}$ & $V_{u} / V_{u, E N-I I}$ \\
\hline 4- & {$[-]$} & {$[-]$} & {$[-]$} & {$[-]$} & {$[-]$} & {$[-]$} \\
\hline 42-RC-3.5 & 0.78 & 0.75 & 0.93 & 0.86 & 0.68 & 0.96 \\
\hline
\end{tabular}

As seen in Table 5-11 and Figure 5-23, the prediction of the shear strength of the PFRC slabs employing the second fibres model proposed by MC2010 overestimated the capacity of HCS and gave a low ratio $V_{u} / V_{u, c o d e}=0.73$ on average as $a / d=3.5$ and as 0.65 on average in $a / d=2.5$. The obtained results were expected because the formulation was not specifically developed for uncracked bending regions. In fact these results evidenced the need to improve the formulations present in codes and standards to predict the shear capacity of HCS, especially nowadays when industry performs HCS with larger dimensions, which makes shear behaviour even more critical. Moreover, developing new expressions for FRC elements when critical shear strength occurs in regions w/o flexural cracks is clearly needed.

Table 5-11: Shear strength prediction of PFRC slabs.

\begin{tabular}{|c|c|c|c|}
\hline HCS & $\begin{array}{c}V_{u} \\
{[\mathrm{kN}]}\end{array}$ & $\begin{array}{c}V_{u, M C-F R C} \\
{[\mathrm{kN}]}\end{array}$ & $\begin{array}{c}V_{u} / V_{u, M C-F R C} \\
{[-]}\end{array}$ \\
\hline 42-PFRC-3.5-I & 378.7 & 495.8 & 0.76 \\
\hline 42-PFRC-3.5-II & 323.4 & 527.5 & 0.61 \\
\hline 42-PFRC-3.5-III & 361.3 & 501.0 & 0.72 \\
\hline 42-PFRC-3.5-IV & 307.9 & 521.6 & 0.59 \\
\hline 42-PFRC-2.8-I & 319.3 & 503.5 & 0.63 \\
\hline 42-PFRC-2.8-II & 322.2 & 513.6 & 0.63 \\
\hline 42-PFRC-2.8-III & 287.4 & 502.9 & 0.57 \\
\hline 42-PFRC-2.8-IV & 307.9 & 493.7 & 0.62 \\
\hline
\end{tabular}


Chapter 5. PFRC in Hollow Core Slabs

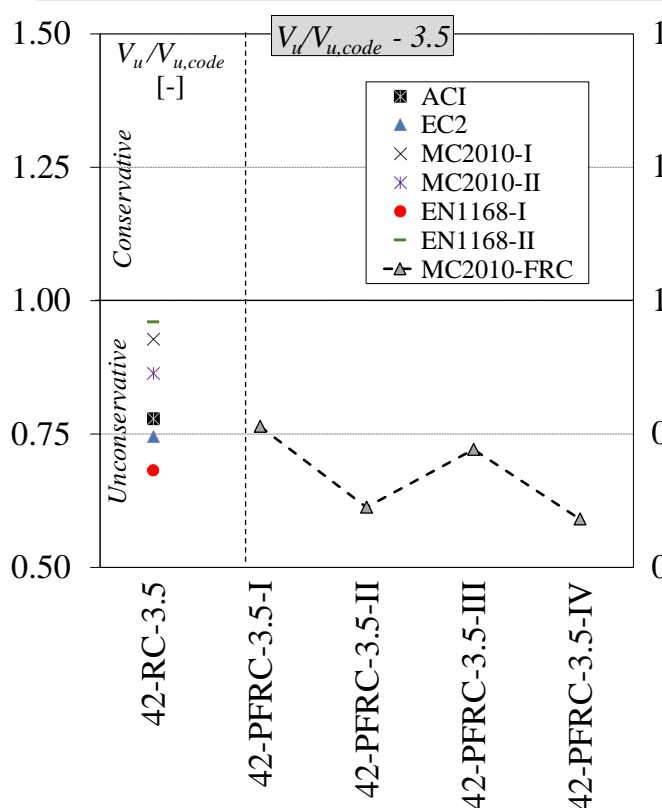

a)

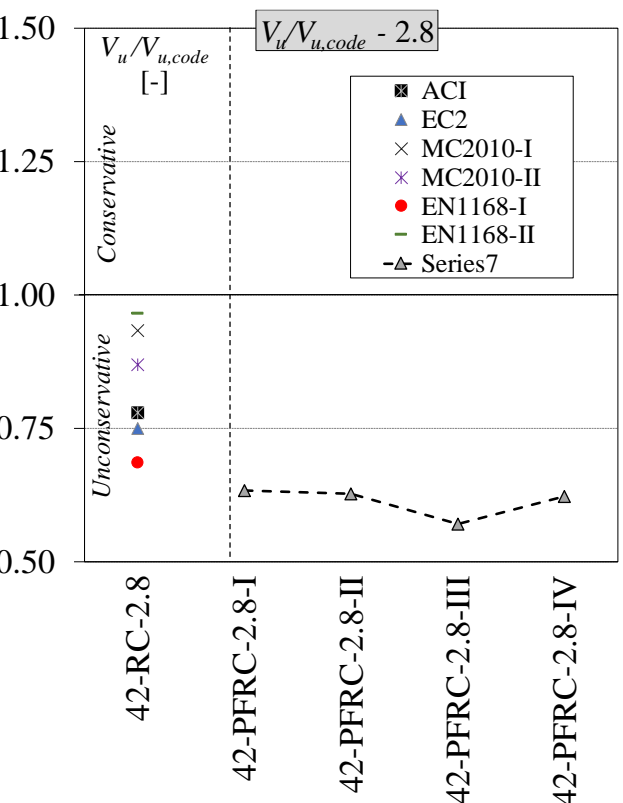

b)

Figure 5-23: Comparison to the shear strength predictions of different standards for: $a / d=3.5$ (a) and $a / d=2.8$ (b).

\subsection{Concluding remarks}

In this chapter, the effectiveness of polypropylene fibres used to enhance the shear strength of HCS end critical zones was experimentally explored. For this purpose, five real-scale HCS were manufactured and tested in both end zones by loading schemes of $a / d=3.5$ and $a / d=2.8$. The latter followed EN1168 recommendations. Based on the experimental results, the following results can be indicated:

a) Polypropylene fibres were effective in enhancing the bearing capacity of the HCS end zones by providing extra shear strength capacity of $25 \%$ on average, as well as post-cracking resistance when fibres were dosed at $10.5 \mathrm{~kg} / \mathrm{m}^{3}$. In fact the improved shear strength provided by polypropylene fibres resulted mainly by improving the bond between tendon and concrete, and by delaying and controlling the development of splitting cracks and, hence, reducing tendon slip

b) The samples tested according to EN1168 ( $a / d=2.8)$ showed a considerable arch action influence compared to those tested using $a / d=3.5$. Therefore, the test setup suggested by EN1168 should be revised; a good compromise between the need to carry out end zone tests and to avoid the arch effect would apparently involve adopting $a / d=3.5$ 
Effectiveness of polypropylene fibres as shear reinforcement in structural elements

c) There was evidence that the formulation proposed to predict the shear strength of HCS was somewhat non-conservative, especially when more sophisticated formulations like those proposed by EN1168 level I and MC2010 level II are used.

d) Finally, there was also evidence for the need to develop a new analytical fibrereinforced model that can be used in those zones w/o bending cracks, such as the end zones of HCS. In fact the prediction made using the second FRC expression of MC2010 proved even more non-conservative than for the RC slab. 


\section{Chapter 6. CONCLUSIONS AND FUTURE RESEARCH LINES}





\subsection{Main conclusions}

This $\mathrm{PhD}$ thesis presents several experimental and analytical programmes developed to study the shear behaviour of polypropylene fibre-reinforced concrete (PFRC) elements. The main purpose of this research is to evaluate the effectiveness of polypropylene macrosynthetic fibres to be used as shear reinforcement in certain elements like beams or hollow-core slabs.

Firstly, a thorough review of the literature survey is reported. The report started with a material review of PFRC, where some characteristics of polypropylene fibres and their differences to other fibre types were studied. Then a bibliographical review about shear transfer mechanisms in fibre reinforced-concrete (FRC) and about the elements studied in the present thesis by emphasising those of PFRC was done. This information was used to prepare the first shear database of beams manufactured with PFRC.

Two experimental campaigns, conducted on pre-cracked push-off specimens, were tested to investigate the shear transfer mechanisms in plain concrete and PFRC. To do so, 11 plain concrete, six steel fibre-reinforced concrete and 24 PFRC push-off specimens were manufactured during both experimental campaigns. The push-off specimens were tested under direct shear following a specific methodology proposed in the literature. The studied variables were different concrete types, fibre contents, initial confinement and crack openings, and fibre content with similar residual flexural tensile strengths. Finally, a robust model that involved the transfer mechanism and the parameters affecting them was developed to analytically study the shear transfer in a PFRC crack. The analytical results were compared with the experimental ones.

Based on the experimental studies and analytical modelling, the following main conclusions were drawn.

a) The aggregate interlock and macro-roughness influenced by external confinement were the main shear transfer mechanism to transmit stresses in a plain concrete shear crack. Shear and normal stresses were larger for small slip displacements and crack openings, and reduced as the slip and opening of cracks increased. The influence of the aggregate interlock or macro-roughness depended on the initially introduced crack opening, and also on the confinement existing before the test done with each specimen. Therefore with the wider initially introduced crack openings, the influence of macro-roughness was stronger.

b) When the plain concrete experimental results were compared to the different aggregate interlock models, all the models accurately predicted the experimental results when cracks were less than $1 \mathrm{~mm}$. However with wider crack openings, the models were less accurate. In fact large differences among the models' pre- 
dictions were observed. This result evidenced the need to calibrate existing aggregate interlock models to wide crack openings to better understand the fibreaggregate interlock interaction.

c) The polypropylene fibres dosed at $8 \mathrm{~kg} / \mathrm{m}^{3}$ of fibres were unable to increase shear strength as $12 \mathrm{~kg} / \mathrm{m}^{3}$ did. However, 8,10 and $12 \mathrm{~kg} / \mathrm{m}^{3}$ incremented the post-cracking shear and normal stresses transmitted in cracks. In fact this increment was more evident with large crack openings and slip displacements. This observation confirms the effectiveness of polypropylene fibres in bridging the crack and continuing the transmission of stresses, even with large crack openings.

d) When the shear behaviour of SFRC and PFRC with similar residual flexure tensile strengths were compared to one another, both FRC presented similar behaviour. These results confirmed that regardless of fibre type, fibre content, material, shape, length and diameter, if fibres provide similar residual flexural tensile strengths, similar shear performance will be achieved.

e) The numerical procedure was capable of integrating the shear transfer mechanism acting in a PC and PFRC crack. In fact the numerical procedure could closely follow all the experimental test stages since parameters like initial crack and confinement existing in cracks before the direct shear tests were taken into account in models.

f) When the experimental results were compared to the analytical shear transfer results, the Walraven and Reinhardt aggregate interlock model combined with any of the three fibre models (Pfyl, Kaufmann and inverse models) presented good shear transfer predictions. In fact differences appeared among the shear transfer fibre models were negligible in comparison to those differences presented among the aggregate interlock models.

g) The stresses transferred by polypropylene fibres in a shear crack can be directly estimated from the tensile behaviour of PFRC; i.e. from the flexural residual tensile stresses that, in this case, were determined from prismatic specimens tested according to EN 14651. Thus the toughness provided by polypropylene fibres would be the same in Mode I and Mode II. These results evidence that from an engineer point of view, shear PFRC behaviour could be directly determined from some well-known parameters, such as residual flexural tensile strengths obtained from bending tests, as MC2010 suggests.

Having evidenced the effectiveness of polypropylene to transmit shear and normal stresses in a PFRC crack, the study of PFRC was projected to full-scale elements. For this purpose, 24 slender beams with and w/o stirrups made of reinforced concrete ( 8 beams), steel fibre-reinforced concrete ( 8 beams) and PFRC ( 8 beams) were tested according to a three-point-loading scheme. The studied fibre content was $30 \mathrm{~kg} / \mathrm{m}^{3}$ and 10 $\mathrm{kg} / \mathrm{m}^{3}$ for steel and polypropylene fibre-reinforced concrete, respectively. Fibre contents were selected to provide both fibre-reinforced concretes similar residual flexure tensile strengths. Therefore, the effects of both fibres on shear behaviour were compared. This comparison comprised the global element response, crack pattern evolution, effect of 
Chapter 6. Conclusions and future research lines

fibres on shear transfer mechanisms and shear deformation. Finally, a comparison of the results to code predictions was made. Within this framework, and based on the experimental results, the following main conclusions were drawn:

a) Steel and polypropylene fibres significantly improved beam shear performance by increasing shear strength and improving ductility. Polypropylene or steel fibres added to beams w/o transverse reinforcement obtained a similar response in some cases to those observed in the RC beams with transverse reinforcement. The fibre contents of $30 \mathrm{~kg} / \mathrm{m}^{3}$ and $10 \mathrm{~kg} / \mathrm{m}^{3}$ were unable to change the mode of failure (MOF) of the beams w/o stirrups, but in some cases, the MOF changed in the beams with stirrups from shear to flexure failure.

b) Despite it not being possible to directly evaluate the shear transfer mechanism on beams RC and FRC, photogrammetry revealed that both fibre types reduced the crack propagation of the main diagonal crack, incremented the uncracked compression zone, delayed and controlled dowel crack formation, and changed the kinematics of the inclined cracks. In fact based on the crack pattern analysis in several load stages, it was observed how both fibre types reduced crack spacing and increased the number of flexural and inclined cracks.

c) As steel and PFRC beams presented similar experimental results (shear strength, deflection, MOF), and similar measured parameters (crack pattern, shear crack evolution, influence of fibres on stirrups, shear deformation), we confirm that, regardless of fibre type (volume, material, shape, length, diameter), if fibres provide similar residual flexural tensile strengths, similar shear performance takes place.

d) Residual flexural tensile strengths can act as excellent parameters to characterise the shear behaviour of FRC elements. Therefore, the methodology used by Model Code 2010 or Australian AS 3600-2018 or RILEM TC 162-TDF, where the contribution of fibres to shear is included from the tensile behaviour of FRC, is convenient because it can be obtained from residual flexural tensile strengths. These parameters provide the same efficiency regardless of fibre type, steel or polypropylene fibre in this case.

The study of the effectiveness of polypropylene fibre as shear reinforcement was explored in a real application. For this purpose, the possibility of using polypropylene fibres to enhance the shear behaviour of hollow core slabs was experimentally evaluated. To do so, five full-scale hollow-core slabs were tested in both end zones by a three-pointloading scheme. One of the end zones of the slab was tested with $a / d=3.5$, and the remaining end zone was tested with $a / d=2.8$, according to Annexe J of EN1168 [193]. The following main conclusions were drawn:

a) Polypropylene fibres enhance shear strength by an average of $25 \%$ compared to plain concrete slabs. In fact this improvement was related to the effect of fibres 
on improving the bond between tendon and concrete by delaying and controlling the developed splitting cracks and, hence, reducing the tendon slip.

b) Despite dry-concrete being used to manufacture hollow-core slabs, polypropylene fibres were capable of providing significant residual flexure tensile strength. In fact the density and distribution of fibres in HCS webs was good, even on planes parallel to both shear $\left(45^{\circ}\right)$ and splitting $\left(0^{\circ}\right)$ cracks. The obtained results justified the effectiveness of fibres in controlling tendons slip, and in controlling post-cracking behaviour in PFRC slabs

c) In those slabs tested with $a / d=2.8$, as the European standard EN1 168 suggests, a considerable arch action influenced the shear behaviour of slabs. This influence was not observed in the slabs tested with $a / d=3.5$. Therefore, a good compromise between the need to carry out end zone tests and avoiding the arch effect seems to be the adoption of $a / d=3.5$ scheme.

d) The expression formulated by different codes to predict shear strength in uncracked zones was non-conservative when compared to the plain concrete hollow-cores slabs results. The need to develop new analytical fibre-reinforced expression to be used in zones where no bending cracks occurs as end zones of this slab type was evidenced.

Based on the literature survey studied in this thesis, a shear database of macrosynthetic FRC failed in shear was built. Several parameters were collected from each experimental campaign and were consulted to first analyse their distribution in the shear database and then to study their influence on the shear behaviour of beams. Within this framework, the following conclusions were drawn:

a) The database results evidenced that characterizing the shear behaviour of macrosynthetic FRC beams according to the fibre content (volume fraction) results was not convenient because there no trend of increasing normalized shear stress with incremented fibre content was observed. This was probably due to the fact that the performance of macrosynthetic fibres does not depend only on the material type or geometry, but also on material surface treatment.

b) The residual flexural tensile strengths were probably the most effective method to characterise the shear performance of macrosynthetic FRC. In fact the results showed a positive trend of increasing the normalised shear strength of beams with incremented residual flexural tensile strength, specially that related to $\mathrm{CMOD}=0.5 \mathrm{~mm}$. 
Chapter 6. Conclusions and future research lines

\subsection{Future lines of research}

The results of the thesis open up many lines for future research and development. Therefore, future research lines may include:

a) Concerning pre-cracked push-off tests, further tests should be carried out on plain concrete specimens with varying aggregate sizes and distributions. At the same time, it would be necessary to scan the surface topography at different crack slip displacements to correlate the aggregate interlock mechanism with the shear transferred in cracks. A study could also be done as to how this mechanism varies with the aggregate degradation. The results could be used to develop or calibrate models to explain the aggregate interlock transfer at large crack openings and slip displacements.

b) FRC push-off tests could be extended to include new fibre materials, shapes and fibre contents to obtain different residual flexural tensile strengths. Therefore, new physical models based on post-cracking properties of concrete could be developed to predict shear transfer at different crack openings and slip displacements.

c) Further research to characterise different shear transfer mechanisms acting on a beam with shear failure according to residual flexural tensile strength. Therefore, physical models, such as the critical shear displacement model developed by Yuguang Yang for RC beams, could be extended to FRC beams.

d) Further research to develop expressions that determine the shear strength of FRC elements in those zones where no flexural cracks occur (uncracked zones). 



\section{References}

[1] P. Serna, S. Arango, T. Ribeiro, A.M. Núñez, E. Garcia-Taengua, Structural cast-inplace SFRC: technology, control criteria and recent applications in spain, Mater. Struct. 42 (2009) 1233. doi:DOI 10.1617/s11527-009-9540-9.

[2] A. Pacios, P. Tanner, J. Márquez, Prototipo de la fabricación de una bóveda con hormigón autocompactante, in: $3^{\circ}$ Congr. Iberoam. Sobre Hormigón Autocompactante. Av. y Oportunidades, Madrid, España, 2012: pp. 447-456. http://oa.upm.es/20849/.

[3] S. Goldfein, Plastic fibrous reinforcement for portland cement, 1963.

[4] B.J.P. Romualdi, G.B. Batson, Behavior of Reinforced Concrete Beams with Closely Spaced Reinforcement, ACI J. Proc. 60 (1963) 775-790. doi:10.14359/7878.

[5] J.P. Romualdi, J.A. Mandel, Tensile Strength of concrete Affected by UnigormlyDistributed and Closely Spaced Short Lengths of wire Reinforcement, ACI J. Proc. 61 (1964) 657-672. doi:10.14359/7801.

[6] A.J. Majumdar, J.F. Ryder, Glass Fiber Reinforcement of Cement Products, J. Glas. Technol. 9 (1968) 78-84.

[7] International Federation for Structural Concrete (fib), Model Code 2010, final drafts, Wilhelm Ernst \& Sohn, 2013.

[8] ACI, ACI 544.1R-96 State-of-the-Art Report on Fiber Reinforced Concrete, Farmington Hills, 1996.

[9] S. Grunewald, Performance-based design of self-compacting fibre reinforced concrete, Delft University of Technology, 2004. http://repository.tudelft.nl/view/ir/uuid:07a817aa-cba1-4c93-bbed-40a5645cf0f1/.

[10] E. Cuenca, P. Serna, Shear behavior of Self-Compacting concrete and FiberReinforced concrete Push-Off specimens, in: RILEM Bookseries, 2010: pp. 429438. doi:10.1007/978-90-481-9664-7_36.

[11] N. Mohamed, A.M. Soliman, M.L. Nehdi, Full-scale pipes using dry-cast steel fibrereinforced concrete, Constr. Build. Mater. 72 (2014) 411-422. doi:10.1016/j.conbuildmat.2014.09.025.

[12] E. Cuenca, P. Serna, Failure modes and shear design of prestressed hollow core slabs made of fiber-reinforced concrete, Compos. Part B Eng. 45 (2013) 952-964. doi:10.1016/j.compositesb.2012.06.005.

[13] ACI, Building Code Requirements for Structural Concrete (ACI 318-14) and Commentary (ACI 318R-14), 2014. doi:10.1016/0262-5075(85)90032-6.

[14] ASTM, A820 Standard Specification for Steel Fibers for Fiber-Reinforced Concrete, (2011) 1-4. doi:10.1520/A0820.

[15] European Committee for Standardization, EN 14651: Test method for metallic fibres concrete. Measuring the flexural tensile strength, 2005.

[16] AmericanStandard ASTM International, ASTM C1609: Standard Test Method for Flexural Performance of Fiber-Reinforced Concrete (Using Beam With Third-Point Loading), (2012). doi:10.1520/C1609.

[17] Japan Society for Civil Engineers (JSCE), JSCE-SF4-Method-of-Test-For-Flexural- 
Effectiveness of polypropylene fibres as shear reinforcement in structural elements

Strength-and-Flexural-Toughness, (1994).

[18] A. Conforti, F. Minelli, G.A. Plizzari, G. Tiberti, Comparing test methods for the mechanical characterization of fiber reinforced concrete, Struct. Concr. 19 (2017) 114. doi:10.1002/suco.201700057.

[19] Z. Zheng, D. Feldman, Synthetic fibre-reinforced concrete, Prog. Polym. Sci. 20 (1995) 185-210. doi:10.1016/0079-6700(94)00030-6.

[20] L. Sarvaranta, E. Mikkola, Fibre mortar composites under fire conditions: effects of ageing and moisture content of specimens, Mater. Struct. 27 (1994) 532-538. doi:10.1007/BF02473214.

[21] L. Sarvaranta, M. Elomaa, E. Järvelä, A study of spalling behaviour of PAN fibrereinforced concrete by thermal analysis, Fire Mater. 17 (1993) 225-230. doi:10.1002/fam.810170505.

[22] A.M. López-Buendía, M.D. Romero-Sánchez, V. Climent, C. Guillem, Surface treated polypropylene (PP) fibres for reinforced concrete, Cem. Concr. Res. 54 (2013) 29-35. doi:10.1016/j.cemconres.2013.08.004.

[23] C. Zhang, V.S. Gopalaratnam, H.K. Yasuda, Plasma Treatment of Polymeric Fibers for Improved Performance in Cement Matrices, J. Appl. Polym. Sci. 76 (2000) 1985 1996. doi:10.1002/(SICI)1097-4628(20000628)76:14<1985::AID-APP1>3.0.CO;2G.

[24] S. Singh, A. Shukla, R. Brown, Pullout behavior of polypropylene fibers from cementitious matrix, Cem. Concr. Res. 34 (2004) 1919-1925. doi:10.1016/j.cemconres.2004.02.014.

[25] L. Yan, R.L. Pendleton, C.H.M. Jenkins, Interface morphologies in polyolefin fiber reinforced concrete composites, Compos. Part A Appl. Sci. Manuf. 29 (1998) 643 650. doi:10.1016/S1359-835X(97)00114-0.

[26] V. Ramakrishnan, Structural Application of Polyolefin Fiber Reinforced Concrete, ACI Symp. Publ. 182 (n.d.). doi:10.14359/5530.

[27] J.R. Roesler, S.A. Altoubat, D.A. Lange, K.A. Rieder, G.R. Ulreich, Effect of synthetic fibers on structural behavior of concrete slabs-on-ground, ACI Mater. J. 103 (2006) 3-10. doi:10.14359/15121.

[28] M.M. Jean-Francois Trottier and Dean Forgeron, Can Synthetic Fibers Replace Welded-Wire Mesh in Slabs-on-Ground?, Concr. Int. 24 (2002).

[29] P. Pujadas, A. Blanco, S.H.P. Cavalaro, A. Aguado, S. Grünewald, K. Blom, J.C. Walraven, Plastic fibres as the only reinforcement for flat suspended slabs: Parametric study and design considerations, Constr. Build. Mater. 70 (2014) 88-96. doi:10.1016/j.conbuildmat.2014.07.091.

[30] G. Tiberti, A. Conforti, G.A. Plizzari, Precast segments under TBM hydraulic jacks: Experimental investigation on the local splitting behavior, Tunn. Undergr. Sp. Technol. 50 (2015) 438-450. doi:10.1016/j.tust.2015.08.013.

[31] M. Di Prisco, S. Tomba, P. Bonalumi, A. Meda, On the use of macro synthetic fibres in precast tunnel segments, in: Proc. Int. Conf. FIBRE Concr., 2015.

[32] A. Conforti, G. Tiberti, G.A. Plizzari, A. Caratelli, A. Meda, Precast tunnel segments reinforced by macro-synthetic fibers, Tunn. Undergr. Sp. Technol. 63 (2017) 1-11. doi:10.1016/j.tust.2016.12.005.

[33] M. Mostafazadeh, A. Abolmaali, M. Ghahremannejad, Shear Strength of Synthetic 
References

Fiber-Reinforced Concrete Box Culverts, J. Bridg. Eng. 24 (2019) 1-13. doi:10.1061/(ASCE)BE.1943-5592.0001402.

[34] A. Pacios-Álvarez, P. Carballosa-de-Miguel, J. Gutiérrez-Jiménez, P. Tanner, Polypropylene fiber-reinforced self-compacting concrete for the reconstruction of the cathedral of La Laguna, Canary Island, Spain, in: 9th Symp. High Perform. Concr. Des. Verif. Util., Rotorua, New Zealand, 2011: pp. 1-8.

[35] E. Bernard, Durability of cracked fibre reinforced shotcrete, Shotcrete More Eng. Dev. (2004) 59-66. doi:10.1201/9780203023389.ch6.

[36] B.H. AbdelAleem, M.K. Ismail, A.A.A. Hassan, Effect of synthetic fibers on shear capacity of reinforced rubberized concrete beams, ACI Mater. J. 115 (2018) 279288. doi:10.14359/51701123.

[37] A. Conforti, F. Minelli, G.A. Plizzari, Shear behaviour of prestressed double tees in self-compacting polypropylene fibre reinforced concrete, Eng. Struct. 146 (2017) 93-104. doi:10.1016/j.engstruct.2017.05.014.

[38] M.G. Alberti, A. Enfedaque, J.C. Gálvez, A review on the assessment and prediction of the orientation and distribution of fibres for concrete, Compos. Part B Eng. 151 (2018) 274-290. doi:10.1016/j.compositesb.2018.05.040.

[39] M.G. Alberti, A. Enfedaque, J.C. Gálvez, Comparison between polyolefin fibre reinforced vibrated conventional concrete and self-compacting concrete, Constr. Build. Mater. 85 (2015) 182-194. doi:10.1016/j.conbuildmat.2015.03.007.

[40] A. Conforti, A. Tinini, F. Minelli, G. Plizzari, S. Moro, Structural applicability of polypropylene fibres : deep and wide-shallow beams subjected to shear Experimental program, FRC 2014 Jt. ACI-Fib Int. Work. - Fibre Reinf. Concr. from Des. to Struct. Appl. (2014) 341-356.

[41] M. Ozturk, R. Secer, O. Keskin, G. Arslan, THE BEHAVIOR OF PFRC BEAMS WITH AND WITHOUT WEB, 1 (2017) 347-352.

[42] S.K.S. Pachalla, S.S. Prakash, Behaviour of Synthetic Fibre Reinforced Prestressed Hollowcore Slabs under Flexure-Shear, 2nd R.N. Raikar Int. Conf. Banthia- Basheer Int. Symp. Adv. Sci. Technol. Concr. (2015).

[43] J.P. Won, D.H. Lim, C.G. Park, Bond behaviour and flexural performance of structural synthetic fibre-reinforced concrete, Mag. Concr. Res. 58 (2006) 401-410. doi:10.1680/macr.2006.58.6.401.

[44] R. Breitenbücher, G. Meschke, F. Song, Y. Zhan, Experimental, analytical and numerical analysis of the pullout behaviour of steel fibres considering different fibre types, inclinations and concrete strengths, Struct. Concr. 15 (2014) 126-135. doi: $10.1002 /$ suco. 201300058 .

[45] M.G. Alberti, A. Enfedaque, J.C. Gálvez, A. Ferreras, Pull-out behaviour and interface critical parameters of polyolefin fibres embedded in mortar and selfcompacting concrete matrixes, Constr. Build. Mater. 112 (2016) 607-622. doi:10.1016/j.conbuildmat.2016.02.128.

[46] P. Di Maida, E. Radi, C. Sciancalepore, F. Bondioli, Pullout behavior of polypropylene macro-synthetic fibers treated with nano-silica, Constr. Build. Mater. 82 (2015) 39-44. doi:10.1016/j.conbuildmat.2015.02.047.

[47] A.J. Babafemi, W.P. Boshoff, Pull-out response of macro synthetic fibre from concrete matrix: Effect of loading rate and embedment length, Constr. Build. Mater. 
Effectiveness of polypropylene fibres as shear reinforcement in structural elements

135 (2017) 590-599. doi:10.1016/j.conbuildmat.2016.12.160.

[48] A.J. Babafemi, A. du Plessis, W.P. Boshoff, Pull-out creep mechanism of synthetic macro fibres under a sustained load, Constr. Build. Mater. 174 (2018) 466-473. doi:10.1016/j.conbuildmat.2018.04.148.

[49] C. Del Prete, N. Buratti, S. Manzi, C. Mazzotti, Macro synthetic fibre reinforced concrete: Influence of the matrix mix design on interfacial bond behavior, IOP Conf. Ser. Mater. Sci. Eng. 596 (2019). doi:10.1088/1757-899X/596/1/012025.

[50] K. Behfarnia, A. Behravan, Application of high performance polypropylene fibers in concrete lining of water tunnels, Mater. Des. 55 (2014) 274-279. doi:10.1016/j.matdes.2013.09.075.

[51] M.G. Alberti, A. Enfedaque, J.C. Gálvez, On the prediction of the orientation factor and fibre distribution of steel and macro-synthetic fibres for fibre-reinforced concrete, Cem. Concr. Compos. 77 (2017) 29-48. doi:10.1016/j.cemconcomp.2016.11.008.

[52] M.G. Alberti, A. Enfedaque, J.C. Gálvez, V. Agrawal, Reliability of polyolefin fibre reinforced concrete beyond laboratory sizes and construction procedures, Compos. Struct. 140 (2016) 506-524. doi:10.1016/j.compstruct.2015.12.068.

[53] S. Altoubat, A. Yazdanbakhsh, K.A. Rieder, Shear behavior of macro-synthetic fiber-reinforced concrete beams without stirrups, ACI Mater. J. 106 (2009) 381-389.

[54] A. Conforti, F. Minelli, A. Tinini, G.A. Plizzari, Influence of polypropylene fibre reinforcement and width-to-effective depth ratio in wide-shallow beams, Eng. Struct. 88 (2015) 12-21. doi:10.1016/j.engstruct.2015.01.037.

[55] E. Nawy, Concrete construction engineering handbook, 2nd ed., Florida, 2008.

[56] V.M.C.F. Cunha, J.A.O. Barros, J.M. Sena-Cruz, Pullout behavior of steel fibers in self-compacting concrete, J. Mater. Civ. Eng. 22 (2010) 1-9. doi:10.1061/(ASCE)MT.1943-5533.0000001.

[57] P. Robins, S. Austin, P. Jones, Pull-out behaviour of hooked steel fibres, Mater. Struct. Constr. 35 (2002) 434-442. doi:10.1007/bf02483148.

[58] P. Pujadas, A. Blanco, S. Cavalaro, A. de la Fuente, A. Aguado, The need to consider flexural post-cracking creep behavior of macro-synthetic fiber reinforced concrete, Constr. Build. Mater. 149 (2017) 790-800. doi:10.1016/j.conbuildmat.2017.05.166.

[59] A.M. Alani, D. Beckett, Mechanical properties of a large scale synthetic fibre reinforced concrete ground slab, Constr. Build. Mater. 41 (2013) 335-344. doi:10.1016/j.conbuildmat.2012.11.043.

[60] P. Pujadas, A. Blanco, S. Cavalaro, A. Aguado, Plastic fibres as the only reinforcement for flat suspended slabs: Experimental investigation and numerical simulation, Constr. Build. Mater. 57 (2014) 92-104. doi:10.1016/j.conbuildmat.2014.01.082.

[61] M. Di Prisco, G. Plizzari, L. Vandewalle, "MC2010: Overview on the shear provisions for FRC ", in: Work. SALO, 2010: pp. 61-76.

[62] J. Susetyo, P. Gauvreau, F.J. Vecchio, Effectiveness of steel fiber as minimum shear reinforcement, ACI Struct. J. 108 (2011) 488. doi:10.14359/51682990.

[63] K.S. Kim, D.H. Lee, J.H. Hwang, D.A. Kuchma, Shear behavior model for steel fiber-reinforced concrete members without transverse reinforcements, Compos. Part B Eng. 43 (2012) 2324-2334. doi:10.1016/j.compositesb.2011.11.064. 
[64] F. Bencardino, L. Rizzuti, G. Spadea, R.N. Swamy, Experimental evaluation of fiber reinforced concrete fracture properties, Compos. Part B Eng. 41 (2010) 17-24. doi:10.1016/j.compositesb.2009.09.002.

[65] Y. Ding, Z. You, S. Jalali, The composite effect of steel fibres and stirrups on the shear behaviour of beams using self-consolidating concrete, Eng. Struct. 33 (2011) 107-117. doi:10.1016/j.engstruct.2010.09.023.

[66] S.A. Ashour, G.S. Hasanain, F.F. Wafa, Shear behavior of high-strength fiber reinforced concrete beams, Struct. J. 89 (1992) 176-184.

[67] K. Marar, Ö. Eren, H. Roughani, The influence of amount and aspect ratio of fibers on shear behaviour of steel fiber reinforced concrete, KSCE J. Civ. Eng. 00 (2016) 1-7. doi:10.1007/s12205-016-0787-2.

[68] D.R. Sahoo, S. Bhagat, T.C.V. Reddy, Experimental study on shear-span to effectivedepth ratio of steel fiber reinforced concrete T-beams, Mater. Struct. 49 (2016) 38153830. doi:10.1617/s11527-015-0756-6.

[69] T. Greenough, M. Nehdi, Shear behavior of fiber-reinforced self-consolidating concrete slender beams, ACI Mater. J. 105 (2008) 468-477.

[70] R.D. Lequesne, G.J. Parra-Montesinos, J.K. Wight, Seismic Behavior and Detailing of High-Performance Fiber-Reinforced Concrete Coupling Beams and Coupled Wall Systems, J. Struct. Eng. 139 (2013) 1362-1370. doi:10.1061/(ASCE)ST.1943541X.0000687.

[71] P. Casanova, P. Rossi, I. Schaller, Can steel fibers replace transverse reinforcements in reinforced concrete beams?, ACI Mater. J. 94 (1997) 341-354. doi:10.14359/9874.

[72] B. Singh, K. Jain, Appraisal of steel fibers as minimum shear reinforcement in concrete beams, ACI Struct. J. 111 (2014) 1191-1202. doi:10.14359/51686969.

[73] Standards Australia, AS 3600 Concrete Structures, (2018).

[74] F. Recommendation, RILEM TC 162-TDF: "Test and design methods for steel fibre reinforced concrete" $\sigma$ - $\varepsilon$-design method, Mater. Struct. Constr. 36 (2003) 560-567. doi: $10.1617 / 14007$.

[75] F. Minelli, G. Plizzari, Steel fibers as shear reinforcement for beams, in: Proc. Second Fib Congr., Naples, Italy, 2006.

[76] European Committee for Standardization, Eurocode 2: Design of concrete structures, Brussels, Belgium, 2004.

[77] S.J. Foster, Design of FRC beams for shear using the VEM and the draft model code approach, in: Shear Punching Shear RC FRC Elem., Fib Bulletin 57, Saló Lake Garda, Italy, 2010: pp. 195-201.

[78] F.J. Vecchio, M.P. Collins, The Modified Compression-Field Theory for Reinforced Concrete Elements Subjected to Shear, ACI J. Proc. 83 (1986) 219-231. doi:10.14359/10416.

[79] Association Française de Genie Civil, Ultra high performance fibrereinforced concretes-Recommandations, 2013.

[80] ACI ASCE Committee 426, The Shear Strength of Reinforced Concrete Members, J. Proc. 70 (n.d.). doi:10.14359/11224.

[81] American Concrete Institute - American Society of Civil Engineers (ACI-ASCE) Joint Committee 445, Recent Approaches to Shear Design of Strucutral Concrete (ACI-ASCE 445R-99), 1999. 
Effectiveness of polypropylene fibres as shear reinforcement in structural elements

[82] R.. Fenwick, T. Pauley, Mechanism of Shear resistance of Concrete Beams, J. Struct. Div. 94 (1968) 25.

[83] M. Kani, W. Huggings, R. Wittkopp, G. Kani, Kani on shear in reinforced concrete, Department of Civil Engineering, 1979.

[84] M.R. Zarrinpour, S.-H. Chao, Shear Strength Enhancement Mechanisms of Steel Fiber-Reinforced Concrete Slender Beams, ACI Struct. J. 114 (2017) 729-742. doi: $10.14359 / 51689449$.

[85] A.F. Pruijssers, Shear resistance of beams based on the effective shear depth, Rep. Stevin Lab. Concr. Struct. 5-86-1. (1986). https://repository.tudelft.nl/islandora/object/uuid\%3A55850a4d-40d6-41e9-b233a8b802f9717e.

[86] R. Narayanan, I.Y.S. Darwish, Use of Steel Fibers As Shear Reinforcement., ACI Struct. J. 84 (1987) 216-227. doi:10.14359/2654.

[87] M.A. Mansur, M. ASCE, K.C.G.G. Ong, P. Paramasivam, Shear strength of fibrous concrete beams without stirrups, J. Struct. Eng. 112 (1986) 2066-2079. doi:https://doi.org/10.1061/(ASCE)0733-9445(1986)112:9(2066).

[88] H. Aoude, M. Belghiti, W.D. Cook, D. Mitchell, Response of steel fiber-reinforced concrete beams with and without stirrups, ACI Struct. J. 109 (2012) 359-367. doi: $10.14359 / 51683749$.

[89] Z.P. Bazant, P. Gambarova, Rough Cracks in Reinforced Concrete, J. Struct. Div. $106 \quad$ (1980) 819-842. https://cedb.asce.org/CEDBsearch/record.jsp?dockey=0009420.

[90] P.G. Gambarova, C. Karakoc, A new approach to the analysis of the confinement role in regularly cracked concrete elements, North-Holland, Netherlands, 1983. http://inis.iaea.org/search/search.aspx?orig_q=RN:15048850.

[91] B. Li, K. Maekawa, Contact density model for cracks in concrete, in: Comput. Mech. Concr. Struct. - Adv. Appl., 1987.

[92] J.C. Walraven, Aggregate interlock: A theoretical and experimental analysis, Delft University, 1980.

[93] Y. Yang, J. Walraven, J. Den Uijl, Shear Behavior of Reinforced Concrete Beams without Transverse Reinforcement Based on Critical Shear Displacement, 143 (2017) 1-13. doi:10.1061/(ASCE)ST.1943-541X.0001608.

[94] J. Echegaray-Oviedo, J. Navarro-Gregori, E. Cuenca, P. Serna, Modified push-off test for analysing the shear behaviour of concrete cracks, Strain. 53 (2017) 1-17. doi:10.1111/str.12239.

[95] A. Khanlou, G.A. Macrae, A.N. Scott, S.J. Hicks, G.C. Clifton, Shear Performance of Steel Fibre-Reinforced Concrete, Australas. Struct. Eng. Conf. 1 (2012) 8. https://core.ac.uk/download/pdf/35472430.pdf.

[96] G. Lee, S. Foster, Modelling of shear-fracture of fibre-reinforced concrete for the future, in: E. In: Walraven JC, Stoelhorst D (Ed.), Proc Int FIB Symp Taylor Made Concr Struct - New Solut Our Soc Amst Neth 19-22 May, 2008: p. 493 to 499.

[97] W. Kaufmann, A. Amin, A. Beck, M. Lee, Shear transfer across cracks in steel fibre reinforced concrete, Eng. Struct. $186 \quad$ (2019) 508-524. doi:10.1016/j.engstruct.2019.02.027.

[98] E.N. Vintzēleou, T.P. Tassios, Mathematical models for dowel action under 
References

monotonic and cyclic conditions, Mag. Concr. Res. 38 (1986) 13-22. doi:10.1680/macr.1986.38.134.13.

[99] E. Vintzileoe, Shear transfer by Dowel Action and Friction as related to Size Effect, in: Concr. Tens. Size Eff., 1997: pp. 53-77. https://www.fibinternational.org/publications/ceb-bulletins/concrete-tension-and-size-effectsdetail.html.

[100] R.N.S. and H.M. Bahia, Influence of Fiber Reinforcement on the Dowel Resistance to Shear, ACI J. 76 (1979). doi:10.14359/6950.

[101] V.C. Li, R. Ward, A.M. Hamza, Steel and synthetic fibers as shear reinforcement, ACI Mater. J. 89 (1992) 499-508. doi:10.14359/1822.

[102] R. Manju, S. Sathya, B. Sylviya, Shear strength of high - Strength steel fibre reinforced concrete rectangular beams, Int. J. Civ. Eng. Technol. 8 (2017) 17161729.

[103] R. Narayanan, I.Y.S. Darwish, Fiber Concrete Deep Beams in Shear., ACI Struct. J. 85 (1988) 141-149. doi:10.14359/2698.

[104] J. Zhao, J. Liang, L. Chu, F. Shen, Experimental study on shear behavior of steel fiber reinforced concrete beams with high-strength reinforcement, Materials (Basel). 11 (2018). doi:10.3390/ma11091682.

[105] M.A. Qissab, M.M. Salman, Shear strength of non-prismatic steel fiber reinforced concrete beams without stirrups, Struct. Eng. Mech. 67 (2018) 347-358. doi:10.12989/sem.2018.67.4.347.

[106] K. Chiranjeevi Reddy, K.V.L. Subramaniam, Experimental investigation of crack propagation and post-cracking behaviour in macrosynthetic fibre reinforced concrete, Mag. Concr. Res. 69 (2017) 467-478. doi:10.1680/jmacr.16.00396.

[107] S. Gali, K.V.L. Subramaniam, Investigation of the dilatant behavior of cracks in the shear response of steel fiber reinforced concrete beams, Eng. Struct. 152 (2017) 832842. doi:10.1016/j.engstruct.2017.09.050.

[108] S.C. Khuntia, M., Stojadinovic, B., and Goel, Shear strenght of normal and highstreng fiber reinforced concrete beams without stirrups, ACI Struct. J. 99 (1999) 530538.

[109] H.E. Yakoub, Shear Stress Prediction: Steel Fiber-Reinforced Concrete Beams without Stirrups, (2012) 2012.

[110] and J.K. Yoon-Keun Kwak, Woo-Suk Kim, Marc O Eberhard, Shear Strength of Steel Fiber-Reinforced Concrete Beams without Stirrups, ACI Struct. J. 99 (2002). doi: $10.14359 / 12122$.

[111] S. Gali, K.V.L. Subramaniam, Shear behavior of steel fiber reinforced concrete using full-field displacements from digital image correlation, MATEC Web Conf. 120 (2017) 1-13. doi:10.1051/matecconf/201712004003.

[112] A. Amin, S.J. Foster, Shear strength of steel fibre reinforced concrete beams with stirrups, Eng. Struct. 111 (2016) 323-332. doi:10.1016/j.engstruct.2015.12.026.

[113] C. Cucchiara, L. La Mendola, M. Papia, Effectiveness of stirrups and steel fibres as shear reinforcement, Cem. Concr. Compos. 26 (2004) 777-786. doi:10.1016/j.cemconcomp.2003.07.001.

[114] A. Meda, F. Minelli, G.A. Plizzari, P. Riva, Shear behaviour of steel fibre reinforced concrete beams, Mater. Struct. Constr. 38 (2005) 343-351. doi:10.1617/14112. 
Effectiveness of polypropylene fibres as shear reinforcement in structural elements

[115] S.R. SARHAT, R.B. ABDUL-AHAD, The Combined Use of Steel Fibers and Stirrups as Shear Reinforcement in Reinforced Concrete Beams, ACI Spec. Publ. 235 (2017). doi:10.14359/15915.

[116] S.F. Júnior, J.B. De Hanai, Prestressed fiber reinforced concrete beams with reduced ratios of shear reinforcement, Cem. Concr. Compos. 21 (1999) 213-221. doi:10.1016/S0958-9465(98)00054-7.

[117] K. Watanabe, T. Kimura, J. Niwa, Synergetic effect of steel fibers and shearreinforcing bars on the shear-resistance mechanisms of RC linear members, Constr. Build. Mater. 24 (2010) 2369-2375. doi:10.1016/j.conbuildmat.2010.05.009.

[118] Japanese society of civil engineers, JSCE-SF6 Method of test for shear strength of steel fiber reinforced concrete, (1990).

[119] Japan Society of Civil Engineers (JSCE), JSCE-G553-1999. Test method for shear strength of steel fiber reinforced concrete, 2005.

[120] K. Liu, B.I.G. Barr, J. Watkins, Mode II fracture of fibre reinforced concrete materials, Int. J. Cem. Compos. Light. Concr. 7 (1985) 93-101. doi:10.1016/02625075(85)90064-8.

[121] B.I.G. Barr, E.B.D. Hasso, K. Liu, Shear strength of FRC materials, Composites. 16 (1985) 326-334. doi:10.1016/0010-4361(85)90285-X.

[122] Van de Lock, Influence of steel fibres on the shear transfer in cracks, in: Proc. Int. Symp. Fibre Reinf. Concr., Madras, 1987: p. . 1101-1112.

[123] P.B. and M.G. Dipsia, Properties of Fiber Reinforced High-Strength SemiLightweight Concrete, ACI Mater. J. 90 (n.d.). doi:10.14359/3865.

[124] M.V. and O. Buyukozturk, Behavior of Fiber Reinforced High-Strength Concrete Under Direct Shear, ACI Mater. J. 90 (n.d.). doi:10.14359/4006.

[125] B. Barragán, R. Gettu, L. Agulló, R. Zerbino, Shear failure of steel fiber-reinforced concrete based on push-off tests, ACI Mater. J. 103 (2006) 251-257.

[126] G. Lee, Direct shear behaviour of steel fibres in a cementitious matrix, The University of New South Wales, 2007.

[127] J. Echegaray-Oviedo, Upgrading the push off test to analyze the contribution of steel fiber on shear transfer mechanisms, 2014. doi:10.4995/Thesis/10251/43723.

[128] A. Picazo, J.C. Gálvez, M.G. Alberti, A. Enfedaque, Assessment of the shear behaviour of polyolefin fibre reinforced concrete and verification by means of digital image correlation, Constr. Build. Mater. 181 (2018) 565-578. doi:10.1016/j.conbuildmat.2018.05.235.

[129] M. Alberti, A. Picazo, A. Enfedaque, J.C. Gálvez, Shear behaviour of polyolefin and steel fibre-reinforced concrete, 10th Int. Conf. Fract. Mech. Concr. Concr. Struct. (2019). doi:10.21012/fc10.235614.

[130] A.R. Khaloo, N. Kim, Influence of concrete and fiber characteristics on behavior of steel fiber reinforced concrete under direct shear, ACI Mater. J. 94 (1997) 592-601.

[131] A.A. Mirsayah, N. Banthia, Shear Strength of Steel Fiber-Reinforced Concrete, ACI Mater. J. (2003).

[132] AmericanStandard ASTM International, C 1018: Standard Test Method for Flexural Toughness and First-Crack Strength of Fiber-Reinforced Concrete (Using Beam With Third-Point Loading), (1997).

[133] G. Appa Rao, A. Sreenivasa Rao, Toughness indices of steel fiber reinforced concrete 
under mode II loading, Mater. Struct. 42 (2009) 1173. doi:10.1617/s11527-0099543-6.

[134] B. Boulekbache, M. Hamrat, M. Chemrouk, S. Amziane, Influence of yield stress and compressive strength on direct shear behaviour of steel fibre-reinforced concrete, Constr. Build. Mater. 27 (2012) 6-14. doi:10.1016/j.conbuildmat.2011.07.015.

[135] T. Soetens, S. Matthys, Shear-stress transfer across a crack in steel fibre-reinforced concrete, Cem. Concr. Compos. 82 (2017) 1-13. doi:10.1016/j.cemconcomp.2017.05.010.

[136] E. Cuenca, A. Conforti, L. Monfardini, F. Minelli, Shear transfer across a crack in ordinary and alkali activated concrete reinforced by different fibre types, Mater. Struct. 5 (2020). doi:10.1617/s11527-020-1455-5.

[137] F. Majdzadeh, S.M. Soleimani, N. Banthia, Shear strength of reinforced concrete beams with a fiber concrete matrix, Can. J. Civ. Eng. 33 (2006) 726-734. doi:10.1139/105-118.

[138] M. Mostafazadeh, A. Abolmaali, Shear Behavior of Synthetic Fiber Reinforced Concrete, Adv. Civ. Eng. Mater. 5 (2016) 371-386. doi:10.1520/ACEM20160005.

[139] Federation Internationale de La Precontrainte (FIP), Shear at the interface of precast and in situ concrete: FIP technical report, 1978. https://www.fibinternational.org/publications/fip-reports/shear-at-the-interface-of-precast-and-insitu-concrete-pdf-detail.html.

[140] F. Vecchio, M.P. Collins, Stress-Strain Characteristics of Reinforced Concrete in Pure Shear., Reports Work. Comm. (International Assoc. Bridg. Struct. Eng. 34 (1981) 211-225.

[141] J. Susetyo, P. Gauvreau, F.J. Vecchio, Steel Fiber-Reinforced Concrete Panels in Shear: Analysis and Modeling, ACI Struct. J. 110 (2013) 285-296.

[142] D. Carnovale, F.J. Vecchio, Effect of Fiber Material and Loading History on Shear Behavior of Fiber-Reinforced Concrete, ACI Struct. J. 111 (2014) 1235-1244. doi: $10.14359 / 51686809$.

[143] J. Susetyo, Fibre reinforcement for shrinkage crack control in prestressed, precast segmental bridges, University of Toronto, 2009.

[144] T. Pfyl, Tragverhalten von Stahlfaserbeton (Structural Behavior of Steel Fiber Concrete), Swiss Federal Institute of Technology Zurich, 2003. doi:https://doi.org/10.3929/ethz-a-004501155.

[145] T.S. Ng, T. Htut, S.J. Foster, Fracture of steel fibre reinforced concrete - The Unified Variable Engagement Model, Sydney, 2012.

[146] J. Voo, S. Foster, Variable Engagement Model for fibre reinforced concrete in tension, Sydney, 2003.

[147] G. Lee, S.J. Foster, Behaviour of steel bre reinforced concrete in shear III: Variable Engagement Model II, (2007).

[148] G.N.J. Kani, Basic Facts Concerning Shear Failure, ACI J. Proc. 63 (1966) 675-692. doi: $10.14359 / 7644$.

[149] S. Gali, K.V.L. Subramaniam, Shear Behavior of Slender and Non-Slender Steel Fiber- Reinforced Concrete Beams, ACI Struct. J. 116 (2019) 149-158. doi:10.14359/51713307.

[150] M. Imam, L. Vandewalle, F. Mortelmans, D. Van Gemert, Shear domain of fibre- 
Effectiveness of polypropylene fibres as shear reinforcement in structural elements

reinforced high-strength concrete beams, Eng. Struct. 19 (1997) 738-747. doi:10.1016/S0141-0296(96)00150-2.

[151] and J.K.W. Dinh, H.H., G.J. Parra-Montesinos, Shear Behavior of Steel FiberReinforced Concrete Beams without Stirrup Reinforcement, ACI Struct. J. 107 (2010). doi:10.14359/51663913.

[152] E. Cuenca, On Shear Behavior of Structural Elements Made of Steel Fiber Reinforced Concrete, universidad Politécnica de Valencia, 2012. doi:10.4995/Thesis/10251/18326.

[153] E. Cuenca, J. Echegaray-Oviedo, P. Serna, Influence of concrete matrix and type of fiber on the shear behavior of self-compacting fiber reinforced concrete beams, Compos. Part B Eng. 75 (2015) 135-147. doi:10.1016/j.compositesb.2015.01.037.

[154] A. Amin, S.J. Foster, Shear strength of steel fibre reinforced concrete beams with stirrups, Eng. Struct. 111 (2016) 323-332. doi:10.1016/j.engstruct.2015.12.026.

[155] Y. Ding, F. Zhang, F. Torgal, Y. Zhang, Shear behaviour of steel fibre reinforced self-consolidating concrete beams based on the modified compression field theory, Compos. Struct. 94 (2012) 2440-2449. doi:10.1016/j.compstruct.2012.02.025.

[156] D. Sahoo, A. Sharma, Effect of Steel Fiber Content on Behavior of Concrete Beams with and without Stirrups, ACI Struct. J. 111 (2014). doi:10.14359/51686821.

[157] E.I. El-Niema, Reinforced Concrete Beams With Steel Fibers Under Shear, ACI Struct. J. 88 (1992).

[158] C.D. Johnston, Å. Skarendahl, Comparative flexural performance evaluation of steel fibre-reinforced concretes acoording to ASTM C1018 shows importance of fibre parameters, Mater. Struct. 25 (1992) 191-200. doi:10.1007/BF02473063.

[159] D.Y. Yoo, J.M. Yang, Effects of stirrup, steel fiber, and beam size on shear behavior of high-strength concrete beams, Cem. Concr. Compos. 87 (2018) 137-148. doi:10.1016/j.cemconcomp.2017.12.010.

[160] F. Minelli, G.A. Plizzari, F.J. Vecchio, Influence of steel fibers on full-scale RC beams under shear loading, in: Proc. Int. Conf. Fram. - High Perform. Concr. BrickMansory Environnmental Asp., Catania, Italy, 2007.

[161] F. Minelli, G. Plizzari, On the Effectiveness of Steel Fibers as Shear Reinforcement, ACI Struct. J. 110 (2014). doi:10.14359/51685596.

[162] G.J. Parra-Montesinos, Shear strength of beams with deformed steel fibers, Concr. Int. 28 (2006) 57-66.

[163] S. Furlan, J.B. De Hanai, Shear behaviour of fiber reinforced concrete beams, Cem. Concr. Compos. 19 (1997) 359-366. doi:10.1016/S0958-9465(97)00031-0.

[164] G. Campione, L. La Mendola, G. Zingone, Shear Resistant Mechanisms Of High Strength Fibre Reinforced Concrete Beams, Trans. Built Environ. 41 (1999) 23-32. doi:10.2495/ERES990031.

[165] S. Altoubat, Y. Ardavan, K. Rieder, Shear Strength of Beams Reinforced With Synthetic Macro-Fibers and Stirrups, in: BEFIB2012 - Fibre Reinf. Concr., 2012.

[166] B. Barragan, A. Conforti, F. Minelli, S. Moro, A. Giovanni, L. Toffoli, Shear Behaviour of Shallow Beams in Polypropylene, (2012).

[167] B. Parmentier, N. Cauberg, L. Vandewalle, Shear Resistance of Macro-Synthetic and Steel Fibre Reinforced Concrete Beams Without Stirrups, Befib 2012. (2012) 1-12.

[168] D.R. Sahoo, K. Maran, A. Kumar, Effect of steel and synthetic fibers on shear 
strength of RC beams without shear stirrups, Constr. Build. Mater. 83 (2015) 150158. doi:10.1016/j.conbuildmat.2015.03.010.

[169] E. Navadeh, Shear investigation of polypropylene fiber-reinforced concrete beams, The University of Texas at Arlington, 2016.

[170] G. Arslan, R.S.O. Keskin, M. Ozturk, Shear behaviour of polypropylene fibrereinforced-concrete beams without stirrups, Proc. Inst. Civ. Eng. - Struct. Build. 170 (2017) 190-198. doi:10.1680/jstbu.16.00202.

[171] G. Arslan, R.S.O. Keskin, Influence of polypropylene fibres on the shear strength of RC beams with web reinforcement, Eur. J. Environ. Civ. Eng. 23 (2019) 1222-1234. doi:10.1080/19648189.2017.1344151.

[172] E.O.L. Lantsoght, Database of shear experiments on steel fiber reinforced concrete beams without stirrups, Materials (Basel). $16 \quad$ (2019) 1-36. doi: $10.3390 / \mathrm{ma1} 2060917$.

[173] E. Cuenca, A. Conforti, F. Minelli, G.A. Plizzari, J. Navarro Gregori, P. Serna, A material-performance-based database for FRC and RC elements under shear loading, Mater. Struct. Constr. 51 (2018). doi:10.1617/s11527-017-1130-7.

[174] K.M.A. Hossain, L.R. Gladson, M.S. Anwar, Modeling shear strength of mediumto ultra-high-strength steel fiber-reinforced concrete beams using artificial neural network, Neural Comput. Appl. 28 (2017) 1119-1130. doi:10.1007/s00521-0162417-2.

[175] J.A.O. Barros, S.J. Foster, An integrated approach for predicting the shear capacity of fi bre reinforced concrete beams, Eng. Struct. 174 (2018) 346-357. doi:10.1016/j.engstruct.2018.07.071.

[176] M. Abambres, ANN-Based Shear Capacity of Steel Fiber-Reinforced Concrete Beams without Stirrups, (2019) 1-24.

[177] M. Sarveghadi, A.H. Gandomi, H. Bolandi, Development of prediction models for shear strength of SFRCB using a machine learning approach, Neural Comput. Appl. (2015). doi:10.1007/s00521-015-1997-6.

[178] A.K. Sharma, Shear Strength of Steel Fiber Reinforced Concrete Beams, ACI J. Proc. 83 (1987) 624-628. doi:10.14359/10559.

[179] T. Zsutty, Shear Strength Prediction for Separate Catagories of Simple Beam Tests, ACI J. Proc. 68 (1971) 138-143. doi:10.14359/11300.

[180] H.H. Dinh, G.J. Parra-montesinos, J.K. Wight, Shear Strength Model for Steel Fiber Reinforced Concrete Beams without Stirrup Reinforcement, J. Struct. Eng. 137 (2011) 1039-1051. doi:10.1061/(ASCE)ST.1943-541X.0000362.

[181] S. Matthys, T. Soetens, Engineering Model for SFRC Shear Strength Based on MC2010 MCFT Approach Engineering Model for SFRC Shear Strength Based on MC2010 MCFT Approach, in: D.A. Hordijk (Ed.), High Tech Concr. Where Technol. Eng. Meet 2017 Fib Symp., Springer, Maastricht, The Netherlands, 2018. doi:10.1007/978-3-319-59471-2.

[182] F. Zhang, Y. Ding, J. Xu, Y. Zhang, W. Zhu, Y. Shi, Shear strength prediction for steel fiber reinforced concrete beams without stirrups, Eng. Struct. 127 (2016) 101116. doi:10.1016/j.engstruct.2016.08.012.

[183] S. Lee, J. Cho, F.J. Vecchio, Analysis of Steel Fiber-Reinforced Concrete Elements Subjected to Shear, ACI Struct. J. 113 (2016) 275-286. doi:10.14359/51688474. 
Effectiveness of polypropylene fibres as shear reinforcement in structural elements

[184] S. Lee, J. Cho, F.J. Vecchio, Diverse Embedment Model for Steel Fiber-Reinforced Concrete in Tension : Model Development, ACI Mater. J. (2012).

[185] E. Cuenca, P. Serna, Failure modes and shear desing of prestressed hollow core slabs made of fiber-reinforced concrete, Compos. Part B Eng. (2013) 952-964.

[186] A.E. Naaman, Prestressed concrete analysis and design: Fundamentals, Third Edit, Michigan, 2012.

[187] K. Bernander, Tests with Fibre Reinforced Extruded Hollow Core Slab, Nacka, 1986.

[188] K.A. Paine, Steel fibre reinforced concrete for prestressed hollow core slabs, University of Nottingham, 1998. http://eprints.nottingham.ac.uk/11095/.

[189] C.H. Peaston, K.S. Elliott, K.A. Paine, Steel fiber reinforcement for extruded prestressed hollow core slabs, ACI Spec. Publ. 182 (1999) 87-107. doi: $10.14359 / 5523$.

[190] S. Simasathien, S.-H. Chao, Shear strength of steel-fiber-reinforced deep hollow-core slabs, PCI J. 60 (2015) 85-101. doi:10.15554/pcij.07012015.85.101.

[191] K.D. Palmer, A.E. Schultz, Experimental investigation of the web-shear strength of deep hollow-core units, PCI J. $56 \quad$ (2011) 83-104. doi:10.15554/pcij.09012011.83.104.

[192] P. Kankeri, S. Pachalla, , Thammishetti, S. Prakash, Behavior of structural macrosynthetic fiber-reinforced precast, prestressed hollow-core slabs at different flexure-to-shear ratios, PCI J. (2019) 76-91.

[193] European Committee for Standardization, EN 1168:2005+A3 Precast concrete products. Hollow core slabs., (2012) 82.

[194] L. Yang, Design of Prestressed Hollow Core Slabs with Reference to Web Shear Failure, J. Struct. Eng. 120 (1994) 2675-2696. doi:10.1061/(ASCE)07339445(1994)120:9(2675).

[195] R. Narayanan, I.Y.S. Darwish, Shear in prestressed concrete beams containing steel fibres, Int. J. Cem. Compos. Light. Concr. 9 (1987) 81-90. doi:10.1016/02625075(87)90023-6.

[196] European Committee for Standardization, EN 12390-3: Testing hardened concrete. Part 3: Compressive strenght of test specimens, 2009.

[197] European Committee for Standardization, EN 12390-13: Testing hardened concrete. Part 13: Determination of secant modulus of elasticity in compression, 2014.

[198] S.G. Millard, R.P. Johnson, Shear transfer across cracks in reinforced concrete due to aggregate interlock and to dowel action, Mag. Concr. Res. 36 (1984) 9-21. doi:https://www.icevirtuallibrary.com/doi/abs/10.1680/macr.1984.36.126.9.

[199] J. Sagaseta, R.L. Vollum, Influence of aggregate fracture on shear transfer through cracks in reinforced concrete, Mag. Concr. Res. 63 (2011) 119-137. doi:10.1680/macr.9.00191.

[200] P.H. Feenstra, Computational Aspects of Biaxial Stress in Plain and Reinforced Concrete, Delf university, 1993. http://resolver.tudelft.nl/uuid:faf2fd16-1c43-4711b783-9e8e00d10c21.

[201] J.C.T.S. Clímaco, P.E. Regan, Evaluation of bond strength between old and new concrete in structural repairs, Mag. Concr. Res. 53 (2001) 377-390. doi:10.1680/macr.2001.53.6.377.

[202] S.J. Kwon, K.H. Yang, J.H. Mun, Mechanical Model for Shear Friction Capacity of 
References

Concrete at Construction Joints, Adv. Mater. Sci. Eng. 2018 (2018). doi:10.1155/2018/9264503.

[203] B. Bresler, A.C. Scordelis, Shear strength of reinforced concrete beams, J. Am. Concr. Inst. 60 (1963) 51-72.

[204] European Committee for Standardization-International Organization for Standardization, EN-ISO 6892-1-2009: Metallic materials - Tensile testing Part 1: Method of test at room temperature, 2009.

[205] D. Dias-da-Costa, J. Valença, E. Júlio, H. Araújo, Crack propagation monitoring using an image deformation approach, Struct. Control Heal. Monit. 24 (2017) 1-14. doi:10.1002/stc. 1973.

[206] F.J. Vecchio, W. Shim, Experimental and Analytical Reexamination of Classic Concrete Beam Tests, J. Struct. Eng. $130 \quad$ (2004) 460-469. doi:10.1061/(ASCE)0733-9445(2004)130:3(460).

[207] Z.P. Bažant, H. Ohtsubo, Stability conditions for propagation of a system of cracks in a brittle solid, Mech. Res. Commun. 4 (1977) 353-366. doi:10.1016/00936413(77)90015-5.

[208] Y. Yang, Shear Behaviour of Reinforced Concrete Members without Shear Reinforcement A New Look at an Old Problem. PhD Thesis. Delft (Netherlands): Delft University of Technology, None (EN). ISBN 9789461695161, 2014.

[209] P.S. Chana, Investigation of the mechanism of shear failure of reinforced concrete beams, Mag. Concr. Res. 39 (2009) 196-204. doi:10.1680/macr.1987.39.141.196.

[210] S.S. Panda, A.R. Gangolu, Study of dowel action in reinforced concrete beam by factorial design of experiment, ACI Struct. J. 114 (2017) 1495-1505. doi:10.14359/51700831.

[211] P.E. Regan, Research on shear: a benefit to humanity or a waste of time?, Struct. Eng. 71 (1993) 337-347.

[212] R.N. Swamy, H.M. Bahia, INFLUENCE OF FIBER REINFORCEMENT ON THE DOWEL RESISTANCE TO SHEAR., J Am Concr Inst. 76 (1978).

[213] R.N. Swamy, H.M. Bahia, The Effectiveness of Steel Fibers as Shear Reinforcement, Concr. Int. 7 (1985).

[214] European Committee for Standardization, EN ISO 15630-1 Steel for the reinforcement and prestressing of concrete. Test methods. Part 1: Reinforcing bars, wire rod and wire (ISO 15630-1:2010)., (2010) 28. 



\section{Annexes}





\section{Annexe A \\ Shear database of macrosynthetic fibre-reinforced concrete beams.}

Similar to other authors of SFRC beams, the first shear database of macrosynthetic fibrereinforced concrete beams failed in shear is built and analysed in the present annexe of the thesis. The sources of beams are the experimental campaigns reviewed in Chapter 2 of this thesis, and summarised in Table A.1 for PFRC beams and in Table A.2 for their counterpart beam in RC. Nevertheless during data collection, the following parameters were included in both tables:

- Source (reference);

- Number of beam (\#);

- Beam ID (identified as the original authors did);

- Web width $\left(b_{w}\right)$ in mm;

- Effective depth $(d)$ in mm;

- Shear span to effective depth ratio $a / d$;

- Longitudinal reinforcement ratio $\left(\rho_{l}\right)$ as a percentage;

- Transversal reinforcement ratio $\left(\rho_{w}\right)$ as a percentage;

- Cylinder concrete compressive strength $\left(f_{c}\right)$ in $\mathrm{MPa}$;

- Maximum aggregate size $\left(d_{g}\right)$ in $\mathrm{mm}$;

- Compressive stress in the section due to the active prestress reinforcement $\left(\sigma_{p}\right)$ in $\mathrm{MPa}$

- Fibre type classified as:
$\circ$ Multifilament polypropylene (MPP)
- Straight polyolefin (SP)
- Self-fibrilant polypropylene (SFP)
- Crimped polypropylene (CPP)
- Straight polypropylene (SPP)

- Fibres volume ratio $\left(V_{f}\right)$ as a percentage;

- Flexural strength $\left(\mathrm{f}_{L}\right)$ in $\mathrm{MPa}$;

- Residual flexural tensile strength $\left(f_{R, I}\right)$ and $\left(f_{R, 3}\right)$ according to EN 14651 in MPa;

- Failure Mode (MOF) classified as:
- Diagonal tension (DT)
- Shear compression (VC)
- Shear flexure (FS)

- Experimental shear strength $\left(V_{u, e x p}\right)$ in $\mathrm{kN}$;

- Experimental ultimate shear stress $\left(v_{u}\right)$ in MPa determined as $v_{u}=$ $V_{u, \exp } /\left(b_{w} d\right)$

- $\quad$ Normalized shear stress $\left(v_{u} /\left(f_{c m}\right)^{0.5}\right)$; 
It is worth mentioning that when some authors did not specify the exact type of shear or flexure failure (DT, VS or FS), shear failure as (S) and flexure as (F) are specified in Table A.1.

All the samples were rectangular section, and failed in shear with PFRC, while in the control RC beams (see Table A.2) some elements with transversal reinforcement failed in flexure. However, not all the authors specified what shear failure type occurred (diagonal tension, shear compression or shear flexure), and classified only their specimens' failures as shear or flexure.

In all, 64 PFRC and 49 RC control beams are included in Table A.1 and Table A.2. A distribution of the main parameters, such as $a / d$, effective depth $(d)$, concrete compression strength $\left(f_{c m}\right)$, longitudinal reinforcement $\left(\rho_{l}\right)$, volume of fibres $\left(V_{f}\right)$ and residual flexural tension strength at CMOD equalling 0.5 and 2.5, are presented from Figure A.1a to Figure A.1f.

(a)

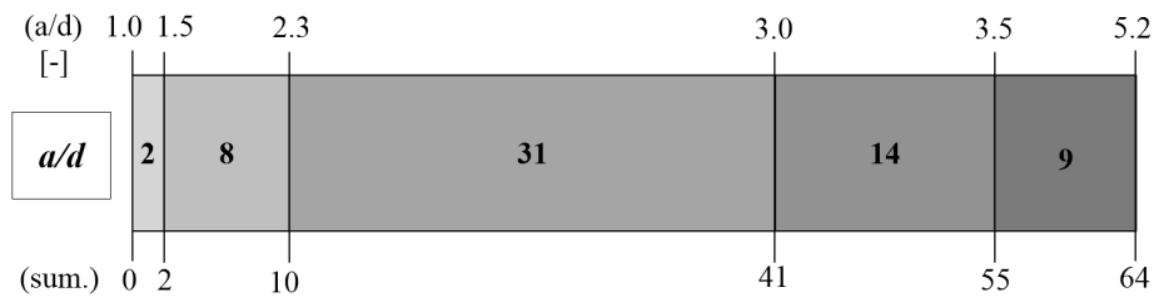

(b)

(d) 0.0100 200

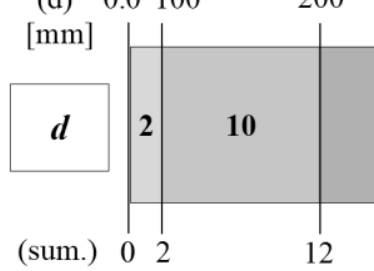

300

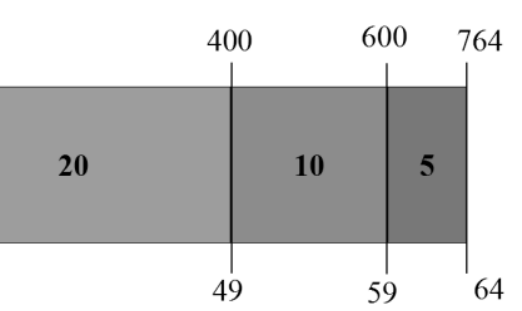

( $\left.\rho_{1}\right) \quad 1.0$

12

17

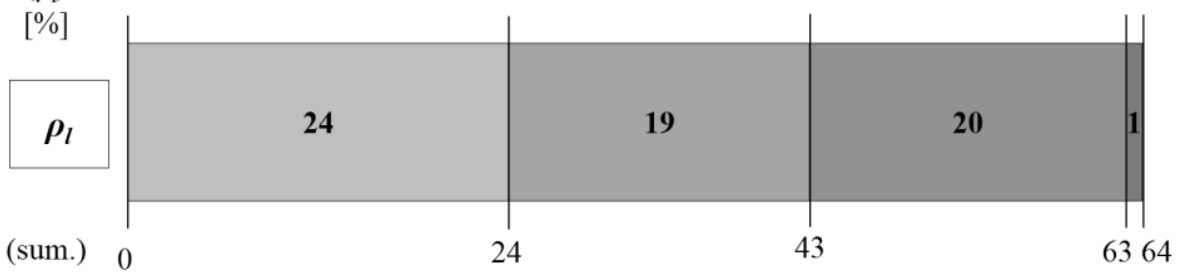


(d)

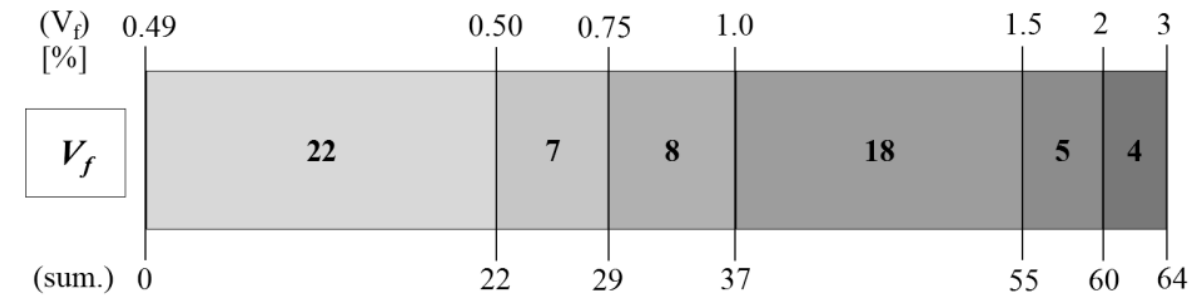

(e)

$\begin{array}{lllll}\left(f_{c}\right) & 0.0 & 14 & 27 & 39\end{array}$
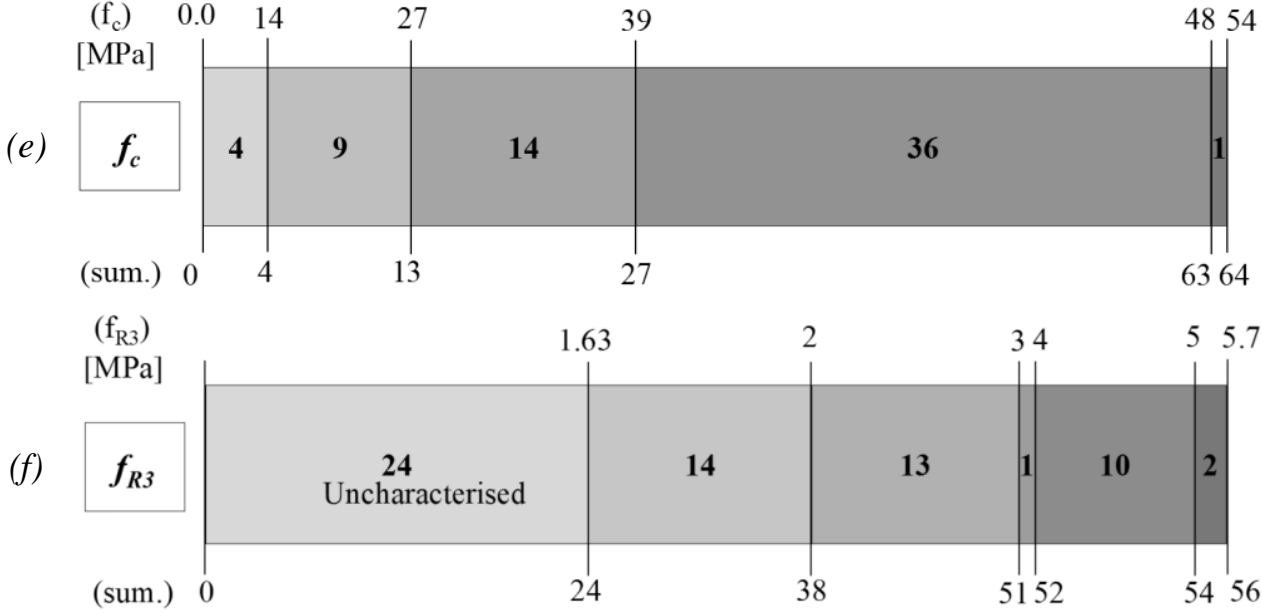

Figure A.1: Distribution of parameters in the shear database for PFRC beams

As Figure A.1a shows, most elements were tested by considering $a / d$ ranging from 2.3 to 3.0 , which represents $48 \%$ of all the specimens. In fact 23 specimens were tested with a/d from 2.4 to 2.5 , which are considered boundary to classify beams as short $(a / d<2.4)$ or slender beams $(a / d>2.4)$ in accordance with Kani's valley [185]. In addition, 10 beams are considered short beams and 54 slender beams. Moreover, the beams with the smallest effective depth $(d)$ correspond to $100 \mathrm{~mm}$ [163], while those with the most depth correspond to $764 \mathrm{~mm}$, as performed by Conforti et al. [40] to study the size effect of PFRC beams. Nevertheless, the commonest tested beams correspond to those with an effective depth from 300 to $400 \mathrm{~mm}$ (see Figure A.1b). The typical $\rho_{l}$ adopted ranges from $1 \%$ to $1.3 \%$ which represent $37 \%$ of the all the tested beams. Consequently for $\rho_{l}$, up to $3.94 \%$ was employed.

Concerning the volume fraction $\left(V_{f}\right)$ (see Figure A.1d), the minimum $V_{f}$ was $0.49 \%$, while the maximum went up to $3 \%$. The commonest beams were those with $V_{f}$ ranging from 0.5 to $1.5 \%$. Different concrete compression strengths $\left(f_{c}\right)$ were studied within the range of $13.9 \mathrm{MPa}$ to $54 \mathrm{MPa}$ (see Figure A.1e). 
Finally, it is highlighted that residual flexural tensile strengths were characterised only in 40 of the 64 beams, which represents $63 \%$ of the PFRC database. It is worth mentioning that the PFRC used in the beams tested by Ensan Navadeh [169] was characterised by ASTM C1609[16] by the author and is included in Table A.1, and a transformation to EN 6451 [15] was done using the correlations in Conforti et al.[18].

Figure A.2 presents an analysis of the 64 PFRC and 49 RC control beams included in Table A.1 and Table A.2. The first analysis corresponded to the maximum normalised shear stress versus the fibre volume fraction of the PFRC and $\mathrm{RC}\left(V_{f}=0 \%\right)$ beams w/o stirrups. First of all, in Figure A.2a we can see the mean maximum normalised shear stress reached in the RC beams, which corresponded to 0.24 and was over 0.17 , as estimated by ACI 318-14 in the contribution of concrete in shear $\left(0.17 \sqrt{f^{\prime}{ }_{c}}\right)$. When the FRC results in Figure A.2a were analysed, no strong trend of the increase in normalised shear strength with incremented fibre content appeared. In fact the result showed that the $0.5 \%$ fibre content provided more normalised shear stress than fibre content over $1 \%$ in some cases. This was due to the wide variability in the post-cracking behaviour provided by synthetic fibres. In fact indicated in Section 2.1.2.2 the performance of macrosynthetic fibres depends on the bond between fibre and matrix and, in turn, on the bond of the surface treatment of fibres. Therefore, the performance of macrosynthetic fibres not only depends on material type or geometry, but also on the material surface treatment. Nevertheless, we can see in Figure A.2a that most of them were able to provide a normalised shear stress over 0.29 .

Figure A.2b presents the fibre contribution ratio $\left(v_{u F R C} / v_{u R C}\right)$ vs. fibre content in beams with and w/o stirrups. As shown, a slight trend $\left(\mathrm{R}^{2}=0.34\right)$ of increasing fibre contribution when fibre content increased was found. In addition, the contribution of fibres was positive in $98 \%$ of cases. It is worth mentioning that in this analysis, Arslan et al.'s [170,171] results with fibre contents of $2 \%$ and $3 \%$ were not considered due to the concrete workability and compression strength problems reported by them (concrete ranged from 13 to $27 \mathrm{MPa}$ ). Nevertheless, Figure A.2b presents wide variability in the results similarly to Figure A.2a.

Moreover, when the fibre contribution ratio was compared to the control RC beams with stirrups in Figure A.2c, we observed that in most cases (79\%), fibres could not provide similar shear stresses to stirrups, and only $21 \%$ provided equal or better stresses than stirrups. It is worth mentioning that the RC beams with stirrups contained transverse reinforcement ratios ranging from $0.1 \%$ to $0.45 \%$, and some of them contained the minimum reinforcement ratio $[40,165,169]$. In any case, the transverse reinforcement ratio was higher than that required by international codes $[7,13]$.

Figure A.2d presents the fibre normalised shear strength $v s$. residual flexure tensile strengths $f_{R, 1}$ and $f_{R, 3}$. A slight positive direct relation was noted when increasing $f_{R, I}$ and $f_{R, 3}$. This trend was stronger for $f_{R, I}$ where an $\mathrm{R}^{2}$ of 0.30 was obtained instead of 0.13 , 
which was obtained for $f_{R, 3}$. In addition, we can see that $f_{R, I}$ and $f_{R, 2}$ over 1.7 were capable of providing shear stress that equalled or exceeded $0.29 \sqrt{f^{\prime}}{ }_{c}$ with elements.

Finally, the experimental shear strength of those beams, for which the postcracking behaviour was characterised according to EN 14651 [15], was compared to the expressions available in MC2010 [7] to calculate the shear strength of FRC elements. The employed expressions were (Eq. 2-16) and (Eq. 2-17) included in Table 2-3 of this thesis. The mean tensile strength $\left(f_{\mathrm{ct}}\right)$ value was evaluated according to that evaluated according to Eq. 5.1-3a of MC2010 $\left(f_{c t}=0.3\left(f_{c k}\right)^{2 / 3}\right)$ as all the specimens obtained $f_{c k} \leq 50 \mathrm{MPa}$, calculated as $f_{c k}=f_{c m}-8$ according to Eq. 5.1-1 of MC2010. Moreover for expression (Eq. 2-16), $w_{u}$ was considered to equal $1.5 \mathrm{~mm}$. In addition, the control section considered for both MC2010 expressions was the effective depth of the section from the supports. The element's self-weight of the element was not considered in any case. Moreover, as both expressions were created to determine the contribution to shear of fibres in regions with bending cracks, the second expression (Eq. 2-17) was evaluated in those beams with $a / d=1.5$ by taking $\varepsilon_{x}=0$. This expression allowed us to choose the angle of the compressive stress field $\theta$ from $29^{\circ}$ (if $\varepsilon_{x}$ equalled to 0 ) to $45^{\circ}$. In the present evaluation, $\theta$ was taken as $29^{\circ}$. Finally, as expression (Eq. 2-16) could not be used in regions without bending cracks, the contribution of fibres in those beams with $a / d=1.5$ was not evaluated.

Figure A.2e shows the comparison between the experimental and theoretical shear strength predicted by MC2010. In this figure, beams are ordered by increasing effective depth. The mean values of the prediction using MC2010-I (Eq. 2-16) were 1.23 with a coefficient of variation (CV) of 0.23, and 1.04 with a CV of 0.21 for MC2010-II (Eq. 2-17). In this context, (Eq. 2-16) provided more conservative values than (Eq. 2-17). These values were in the same order as those obtained by Barros and Foster [175] when evaluating SFRC database beams using (Eq. 2-16) and (Eq. 2-17) proposed by MC2010. 
Effectiveness of polypropylene fibres as shear reinforcement in structural elements

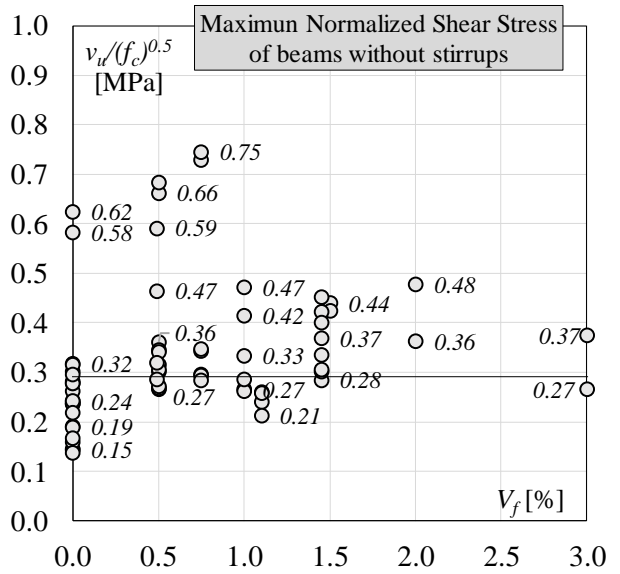

(a)

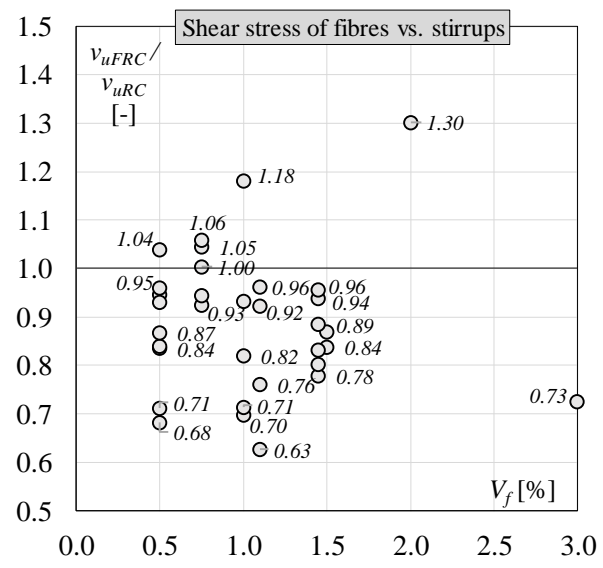

(c)

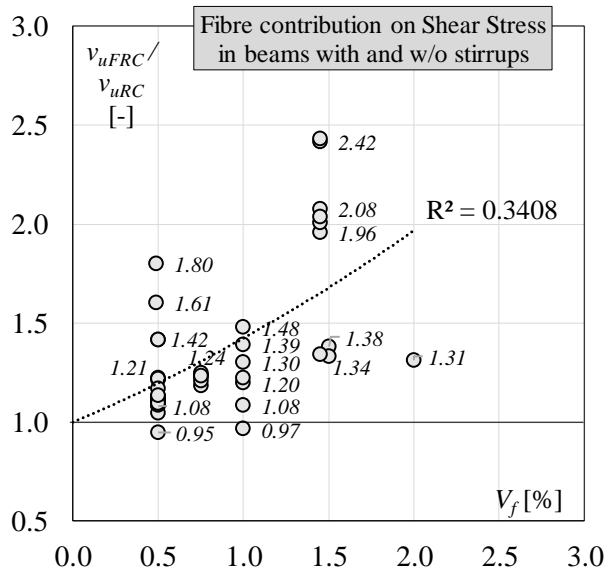

(b)

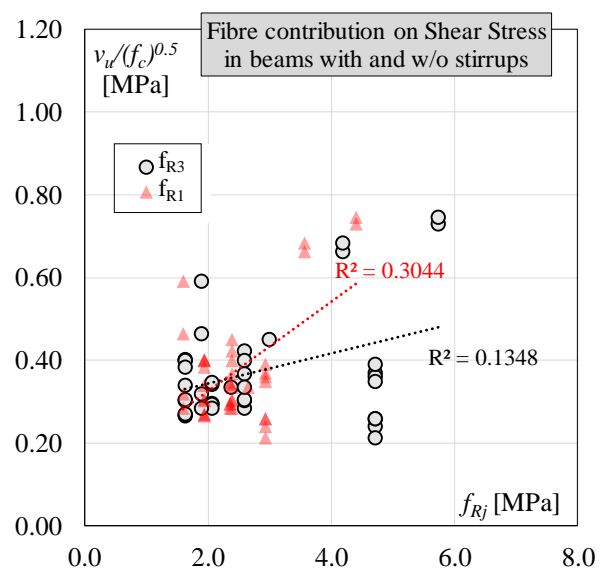

(d)

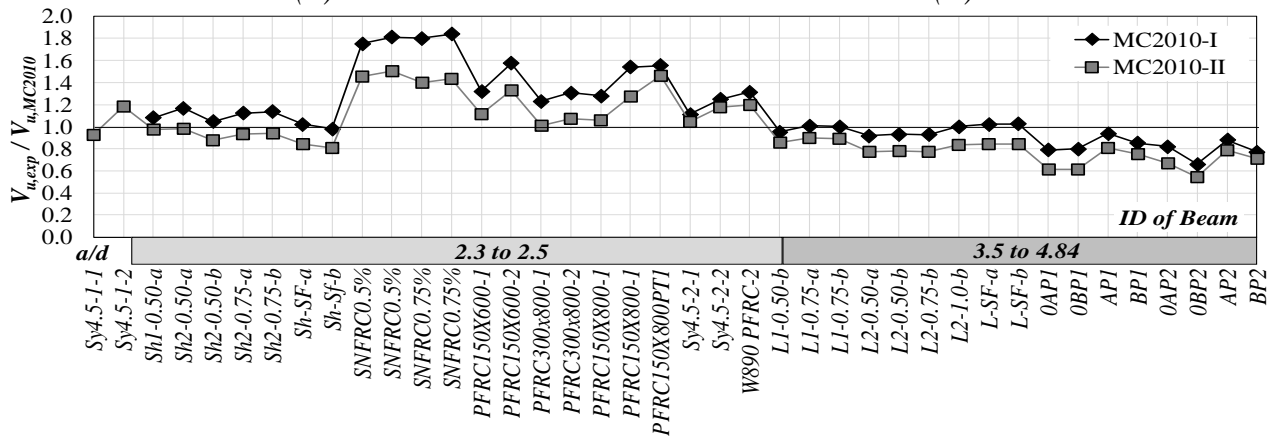

(e)

Figure A.2: Analysis of fibre contribution (a to d) and comparison to MC2010 (e) 
After the previous analysis of the PFRC beams database, some conclusions can be drawn on the shear behaviour of PFRC beams:

- The use of macrosynthetic fibres needs to be further investigated because of the limited numbers of the 64 tested beams reported in the literature.

- Can synthetic fibres be used as minimum shear reinforcement according to ACI318-14[13] as with steel fibres? To answer this question, it is necessary to study the criteria stated to allow the use of steel fibres as minimum shear reinforcement. The steel fibres used as minimum shear reinforcement were based on the study of Parra-Montesinos [162], where the shear stress provided by a steel fibre content over $0.75 \%$ was greater than $\left(0.29 \sqrt{f^{\prime}{ }_{c}}\right)$. This stress value $\left(0.29 \sqrt{f_{c}^{\prime}}\right)$, based on the stress provided by minimum stirrups according to ACI-318, corresponded approximately to $0.255 \sqrt{f^{\prime}}{ }_{c}$ as determined from $\left(v_{c}+\right.$ $v_{s, \min }\left(0.5 v_{c}\right)$, where $v_{c}$ is the shear stress of concrete $\left(0.17 \sqrt{f^{\prime}}\right)$ and $v_{s, \min }$ is the shear stress provided by the minimum stirrups equalling $0.5 v_{c}$ to fulfil $\left(0.5 \phi v_{c}<v_{u} \leq v \phi_{c}\right.$, where $v_{u}$ is the ultimate shear stress of beams and $\phi$, is the reduction coefficient factor).

In this context, and as Figure A.2a illustrates, $76 \%$ of the beams with synthetic fibres surpassed $\left(0.29 \sqrt{f_{c}^{\prime}}\right)$, but there was no clear trend of fibre content (volume fractions) to guarantee this stress. In fact some results containing $0.5 \%$ fibre contents exceeded this stress, whereas some beams with $0.75 \%$ or $1 \%$ did not.

- The results evidenced that characterising the shear performance of macrosynthetic fibre reinforced concrete according to fibre content would probably not be convenient. In fact as observed in Figure A.2a, there was no clear trend of increasing normalised shear stress when fibre content also increased, as with steel fibres [172]. This was probably due to the fact that all types of commercial macrosynthetic fibre have specific properties despite their similar geometry and materials.

- Similar to SFRC, the residual flexural tensile strengths probably turned out to be the most effective method to characterise the shear performance of macrosynthetic fibre-reinforced concrete. In fact the results showed a positive trend of increasing the normalised shear strength of beams with an increment of residual flexural tensile strength, especially that related to $\mathrm{CMOD}=0.5 \mathrm{~mm}$. Moreover, macrosynthetic fibres were able to confer beams shear stresses over $0.29 \sqrt{f^{\prime}}{ }_{c}$ when macrosynthetic fibre-reinforced concretes presented $f_{R, 1}$ and $f_{R, 3}$ over 1.7.

The shear strength of macrosynthetic fibre-reinforced concrete did not seem to be well predicted by MC2010 when the effective-to-depth ratio went over 3.5. In addition, the FRC shear strength expression of MC2010 based on Eurocode 2 (MC2010-I in Figure A.2e) (Eq. 2-16) was more conservative than that developed based on the Modified Compression Field Theory (Eq. 2-17) (MC2010-II in Figure A.2e). 
Effectiveness of polypropylene fibres as shear reinforcement in structural elements 
Annexes

Table A.1: Shear database of PFRC beams.

\begin{tabular}{|c|c|c|c|c|c|c|c|c|c|c|c|c|c|c|c|c|c|c|c|}
\hline Reference & $\#$ & Beams ID. & $\begin{array}{c}b_{w} \\
{[\mathrm{~mm}]}\end{array}$ & $\begin{array}{c}d \\
{[\mathrm{~mm}]}\end{array}$ & $\begin{array}{c}a / d \\
{[-]}\end{array}$ & $\begin{array}{c}\rho_{l} \\
{[\%]}\end{array}$ & $\begin{array}{c}\rho_{\mathrm{w}} \\
{[\%]}\end{array}$ & $\begin{array}{c}f_{c m} \\
{[\mathrm{MPa}]}\end{array}$ & $\begin{array}{c}d_{g} \\
{[\mathrm{~mm}]}\end{array}$ & $\begin{array}{c}\sigma_{p} \\
{[\mathrm{MPa}]}\end{array}$ & $\begin{array}{l}\text { Fibre } \\
\text { Type }\end{array}$ & $\begin{array}{c}V_{f} \\
{[\%]}\end{array}$ & $\begin{array}{c}f_{L} \\
{[\mathrm{MPa}]}\end{array}$ & $\begin{array}{c}f_{R, 1} \\
{[\mathrm{MPa}]}\end{array}$ & $\begin{array}{c}f_{R, 3} \\
{[\mathrm{MPa}]}\end{array}$ & MOF & $\begin{array}{l}V_{u, e x p} \\
{[\mathrm{kN}]}\end{array}$ & $\left.\begin{array}{c}v_{u} \\
{[\mathrm{MPa}]}\end{array}\right]$ & $\begin{array}{c}v_{u} /\left(f_{c m}\right)^{0.5} \\
{[\mathrm{MPa}]}\end{array}$ \\
\hline \multirow{2}{*}{$\begin{array}{c}\text { Furlan and Hana } \\
\text { [162] }\end{array}$} & 1 & $\mathrm{P} 2 \mathrm{~A}$ & 100 & 80 & 3.50 & 1.67 & 0.18 & 48.0 & $\mathrm{~N} / \mathrm{S}$ & - & MPP & 0.50 & - & - & - & DT & 22.60 & 2.83 & 0.41 \\
\hline & 2 & P2B & 100 & 80 & 3.50 & 1.67 & - & 48.0 & $\mathrm{~N} / \mathrm{S}$ & - & MPP & 0.50 & - & - & - & DT & 17.50 & 2.19 & 0.32 \\
\hline $\begin{array}{c}\text { Campione et al } \\
{[163]}\end{array}$ & 3 & $\mathrm{~N} / \mathrm{S}$ & 100 & 102 & 2.20 & 3.94 & 0.35 & 53.0 & $\mathrm{~N} / \mathrm{S}$ & - & SP & 2.00 & - & - & - & $\mathrm{VC}$ & 48.65 & 4.77 & 0.66 \\
\hline \multirow{8}{*}{$\begin{array}{c}\text { Majdzadeh et al } \\
{[136]}\end{array}$} & 4 & B3 & 150 & 120 & 3.02 & 2.62 & 0.28 & 37.8 & 10 & - & SPP & 0.50 & - & - & - & $\mathrm{VC}$ & 68.00 & 3.78 & 0.61 \\
\hline & 5 & B4 & 150 & 120 & 3.02 & 2.62 & 0.28 & 44.1 & 10 & - & SFP & 0.50 & - & - & - & VC & 57.50 & 3.19 & 0.48 \\
\hline & 6 & B6 & 150 & 120 & 3.02 & 2.62 & - & 43.9 & 10 & - & SPP & 0.50 & - & - & - & $\mathrm{VC}$ & 43.00 & 2.39 & 0.36 \\
\hline & 7 & B7 & 150 & 120 & 3.02 & 2.62 & - & 44.2 & 10 & - & SPP & 1.00 & - & - & - & $\mathrm{VC}$ & 56.50 & 3.14 & 0.47 \\
\hline & 8 & B8 & 150 & 120 & 3.02 & 2.62 & - & 43.1 & 10 & - & SPP & 1.50 & - & - & - & VC & 52.00 & 2.89 & 0.44 \\
\hline & 9 & B9 & 150 & 120 & 3.02 & 2.62 & - & 43.4 & 10 & - & SFP & 0.50 & - & - & - & $\mathrm{VC}$ & 41.00 & 2.28 & 0.35 \\
\hline & 10 & B10 & 150 & 120 & 3.02 & 2.62 & - & 44.8 & 10 & - & SFP & 1.00 & - & - & - & VC & 50.00 & 2.78 & 0.42 \\
\hline & 11 & B11 & 150 & 120 & 3.02 & 2.62 & - & 42.0 & 10 & - & SFP & 1.50 & - & - & - & VC & 49.50 & 2.75 & 0.42 \\
\hline \multirow{3}{*}{$\begin{array}{l}\text { Altoubat et al } \\
{[52]}\end{array}$} & 12 & L1-0.50-b & 280 & 400 & 3.50 & 2.15 & - & 41.9 & 20 & - & SPP & 0.50 & 5.7 & 1.94 & 1.63 & DT & 193.00 & 1.72 & 0.27 \\
\hline & 13 & L1-0.75-a & 280 & 400 & 3.50 & 2.15 & - & 41.9 & 20 & - & SPP & 0.75 & 5.7 & 2.36 & 2.06 & DT & 214.50 & 1.92 & 0.30 \\
\hline & 14 & L1-0.75-b & 280 & 400 & 3.50 & 2.15 & - & 41.9 & 20 & - & SPP & 0.75 & 5.7 & 2.36 & 2.06 & DT & 213.00 & 1.90 & 0.29 \\
\hline
\end{tabular}


Effectiveness of polypropylene fibres as shear reinforcement in structural elements

\begin{tabular}{|c|c|c|c|c|c|c|c|c|c|c|c|c|c|c|c|c|c|c|c|}
\hline Reference & $\#$ & Beams ID. & $\begin{array}{c}b_{w} \\
{[\mathrm{~mm}]}\end{array}$ & $\begin{array}{c}d \\
{[\mathrm{~mm}]}\end{array}$ & $\begin{array}{l}\text { a/d } \\
{[-]}\end{array}$ & $\begin{array}{c}\rho_{l} \\
{[\%]}\end{array}$ & $\begin{array}{c}\rho_{\mathrm{w}} \\
{[\%]}\end{array}$ & $\left.\begin{array}{c}f_{c m} \\
{[\mathrm{MPa}]}\end{array}\right]$ & $\begin{array}{c}d_{g} \\
{[\mathrm{~mm}]}\end{array}$ & $\left.\begin{array}{c}\sigma_{p} \\
{[\mathrm{MPa}]}\end{array}\right]$ & $\begin{array}{l}\text { Fibre } \\
\text { Type }\end{array}$ & $\begin{array}{c}V_{f} \\
{[\%]}\end{array}$ & $\begin{array}{c}f_{L} \\
\text { [MPa] }\end{array}$ & $\begin{array}{c}f_{R, I} \\
{[\mathrm{MPa}]}\end{array}$ & $\begin{array}{c}f_{R, 3} \\
{[\mathrm{MPa}]}\end{array}$ & MOF & $\begin{array}{c}V_{u, e x p} \\
{[\mathrm{kN}]}\end{array}$ & $\left.\begin{array}{c}v_{u} \\
{[\mathrm{MPa}]}\end{array}\right]$ & $\begin{array}{c}v_{u} /\left(f_{c m}\right)^{0.5} \\
{[\mathrm{MPa}]}\end{array}$ \\
\hline & 15 & Sh1-0.50-a & 280 & 400 & 2.30 & 2.15 & - & 41.9 & 20 & - & SPP & 0.50 & 5.7 & 1.94 & 1.63 & $\mathrm{~S}$ & 219.50 & 1.96 & 0.30 \\
\hline & 16 & L2-0.50-a & 230 & 330 & 3.50 & 3.18 & - & 41.9 & 20 & - & SPP & 0.50 & 5.7 & 1.94 & 1.63 & DT & 131.50 & 1.73 & 0.27 \\
\hline & 17 & L2-0.50-b & 230 & 330 & 3.50 & 3.18 & - & 41.9 & 20 & - & SPP & 0.50 & 5.7 & 1.94 & 1.63 & DT & 133.50 & 1.76 & 0.27 \\
\hline & 18 & L2-0.75-b & 230 & 330 & 3.50 & 3.18 & - & 41.9 & 20 & - & SPP & 0.75 & 5.7 & 2.36 & 2.06 & DT & 139.50 & 1.84 & 0.28 \\
\hline & 19 & L2-1.0-b & 230 & 330 & 3.50 & 3.18 & - & 35.6 & 20 & - & SPP & 1.00 & 4.8 & 2.66 & 2.37 & $\mathrm{~S}$ & 151.50 & 2.00 & 0.33 \\
\hline & 20 & Sh2-0.50-a & 230 & 330 & 2.30 & 3.18 & - & 41.9 & 20 & - & SPP & 0.50 & 5.7 & 1.94 & 1.63 & S & 167.50 & 2.21 & 0.34 \\
\hline & 21 & Sh2-0.50-b & 230 & 330 & 2.30 & 3.18 & - & 41.9 & 20 & - & SPP & 0.50 & 5.7 & 1.94 & 1.63 & $\mathrm{~S}$ & 150.00 & 1.98 & 0.31 \\
\hline & 22 & Sh2-0.75-a & 230 & 330 & 2.30 & 3.18 & - & 41.9 & 20 & - & SPP & 0.75 & 5.7 & 2.36 & 2.06 & $S$ & 168.50 & 2.22 & 0.34 \\
\hline & 23 & Sh2-0.75-b & 230 & 330 & 2.30 & 3.18 & - & 41.9 & 20 & - & SPP & 0.75 & 5.7 & 2.36 & 2.06 & $\mathrm{~S}$ & 170.50 & 2.25 & 0.35 \\
\hline \multirow{4}{*}{$\begin{array}{c}\text { Altoubat et al } \\
{[164]}\end{array}$} & 24 & L-SF-a & 230 & 330 & 3.50 & 3.18 & 0.10 & 42.0 & 20 & - & SPP & 0.50 & 5.7 & 1.94 & 1.63 & S & 197.00 & 2.60 & 0.40 \\
\hline & 25 & L-SF-b & 230 & 330 & 3.50 & 3.18 & 0.10 & 42.0 & 20 & - & SPP & 0.50 & 5.7 & 1.94 & 1.63 & S & 197.50 & 2.60 & 0.40 \\
\hline & 26 & Sh-SF-a & 230 & 330 & 2.30 & 3.18 & 0.10 & 42.0 & 20 & - & SPP & 0.50 & 5.7 & 1.94 & 1.63 & SF & 196.55 & 2.59 & 0.40 \\
\hline & 27 & Sh-Sf-b & 230 & 330 & 2.30 & 3.18 & 0.10 & 42.0 & 20 & - & SPP & 0.50 & 5.7 & 1.94 & 1.63 & $\mathrm{SF}$ & 188.60 & 2.48 & 0.38 \\
\hline \multirow{3}{*}{$\begin{array}{l}\text { Conforti et al } \\
{[39,53,165]}\end{array}$} & 28 & W890 PFRC-2 & 890 & 295 & 2.50 & 1.22 & - & 26.0 & 16 & - & CPP & 1.45 & 3.87 & 2.4 & 3 & $\mathrm{~S}$ & 605.00 & 2.30 & 0.45 \\
\hline & 29 & PFRC300x800-1 & 300 & 761 & 2.50 & 1.00 & - & 34.3 & 16 & - & СРP & 1.45 & 3.87 & 2.4 & 2.6 & S & 381.00 & 1.67 & 0.28 \\
\hline & 30 & PFRC300x800-2 & 300 & 761 & 2.50 & 1.00 & - & 34.3 & 16 & - & CPP & 1.45 & 3.87 & 2.4 & 2.6 & $\mathrm{~S}$ & 405.00 & 1.77 & 0.30 \\
\hline
\end{tabular}


Annexes

\begin{tabular}{|c|c|c|c|c|c|c|c|c|c|c|c|c|c|c|c|c|c|c|c|}
\hline Reference & \# & Beams ID. & $\begin{array}{c}b_{w} \\
{[\mathrm{~mm}]}\end{array}$ & $\begin{array}{c}d \\
{[\mathrm{~mm}]}\end{array}$ & $\begin{array}{l}a / d \\
{[-]}\end{array}$ & $\begin{array}{c}\rho_{l} \\
{[\%]}\end{array}$ & $\begin{array}{c}\rho_{\mathrm{w}} \\
{[\%]}\end{array}$ & $\begin{array}{c}f_{c m} \\
\text { [MPa] }\end{array}$ & $\begin{array}{c}d_{g} \\
{[\mathrm{~mm}]}\end{array}$ & $\begin{array}{c}\sigma_{p} \\
{[\mathrm{MPa}]}\end{array}$ & $\begin{array}{l}\text { Fibre } \\
\text { Type }\end{array}$ & $\begin{array}{c}V_{f} \\
{[\%]}\end{array}$ & $\begin{array}{c}f_{L} \\
{[\mathrm{MPa}]}\end{array}$ & $\begin{array}{c}f_{R, 1} \\
{[\mathrm{MPa}]}\end{array}$ & $\begin{array}{c}f_{R, 3} \\
{[\mathrm{MPa}]}\end{array}$ & MOF & $\begin{array}{l}V_{u, e x p} \\
{[\mathrm{kN}]}\end{array}$ & $\begin{array}{c}v_{u} \\
\text { [MPa] }\end{array}$ & $\begin{array}{c}v_{u} /\left(f_{c m}\right)^{0.5} \\
{[\mathrm{MPa}]}\end{array}$ \\
\hline & 31 & PFRC150X800-1 & 150 & 763 & 2.50 & 1.10 & - & 34.3 & 16 & - & СРP & 1.45 & 3.87 & 2.4 & 2.6 & $\mathrm{~S}$ & 205.00 & 1.79 & 0.31 \\
\hline & 32 & PFRC150X800-1 & 150 & 763 & 2.50 & 1.10 & - & 34.3 & 16 & - & CPP & 1.45 & 3.87 & 2.4 & 2.6 & $\mathrm{~S}$ & 247.00 & 2.16 & 0.37 \\
\hline & 33 & PFRC150X800PT1 & 150 & 764 & 2.50 & 1.10 & - & 34.3 & 16 & 1.3 & $\mathrm{CPP}$ & 1.45 & 3.87 & 2.4 & 2.6 & $\mathrm{~S}$ & 284.00 & 2.48 & 0.42 \\
\hline & 34 & PFRC150X600-1 & 150 & 563 & 2.50 & 1.12 & - & 34.3 & 16 & - & CPP & 1.45 & 3.87 & 2.4 & 2.6 & $\mathrm{~S}$ & 166.00 & 1.97 & 0.34 \\
\hline & 35 & PFRC150X600-2 & 150 & 563 & 2.50 & 1.12 & - & 34.3 & 16 & - & CPP & 1.45 & 3.87 & 2.4 & 2.6 & $\mathrm{~S}$ & 198.00 & 2.34 & 0.40 \\
\hline \multirow{4}{*}{$\begin{array}{c}\text { Parmentier et al } \\
{[166]}\end{array}$} & 36 & Sy $4.5-1-1$ & 200 & 270 & 1.50 & 1.21 & - & 45.2 & 14 & - & SFP & 0.49 & 4.3 & 1.6 & 1.9 & $\mathrm{~S}$ & 168.90 & 3.13 & 0.47 \\
\hline & 37 & Sy4.5-1-2 & 200 & 270 & 1.50 & 1.21 & - & 45.2 & 14 & - & SFP & 0.49 & 4.3 & 1.6 & 1.9 & $\mathrm{~S}$ & 214.90 & 3.98 & 0.59 \\
\hline & 38 & Sy4.5-2-1 & 200 & 270 & 2.50 & 1.21 & - & 45.2 & 14 & - & SFP & 0.49 & 4.3 & 1.6 & 1.9 & $\mathrm{~S}$ & 103.60 & 1.92 & 0.29 \\
\hline & 39 & Sy4.5-2-2 & 200 & 270 & 2.50 & 1.21 & - & 45.2 & 14 & - & SFP & 0.49 & 4.3 & 1.6 & 1.9 & $\mathrm{~S}$ & 116.10 & 2.15 & 0.32 \\
\hline $\begin{array}{c}\text { Sahoo et al } \\
\text { [167] }\end{array}$ & 40 & PFRC & 150 & 172 & 5.23 & 2.45 & - & 31.2 & 10 & - & SPP & 1.00 & 10.1 & - & - & $\mathrm{S}$ & 38.40 & 1.49 & 0.27 \\
\hline \multirow{4}{*}{$\begin{array}{c}\text { Ensan Navadeh } \\
{[168]}\end{array}$} & 41 & SNFRC0.5\% & 254 & 319 & 2.40 & 2.40 & - & 37.1 & N/S & - & SPP & 0.50 & 5.6 & 3.57 & 4.20 & $\mathrm{~S}$ & 327.08 & $\begin{array}{l}3.04 \\
\end{array}$ & 0.66 \\
\hline & 42 & SNFRC $0.5 \%$ & 254 & 319 & 2.40 & 2.40 & - & 37.1 & N/S & - & SPP & 0.50 & 5.6 & 3.57 & 4.20 & $\mathrm{~S}$ & 337.91 & 4.17 & 0.68 \\
\hline & 43 & SNFRC0.75\% & 254 & 319 & 2.40 & 2.40 & - & 38.1 & N/S & - & SPP & 0.75 & 6.49 & 4.41 & 5.74 & $\mathrm{~S}$ & 365.31 & 4.51 & 0.73 \\
\hline & 44 & SNFRC $0.75 \%$ & 254 & 319 & 2.40 & 2.40 & - & 38.1 & N/S & - & SPP & 0.75 & 6.49 & 4.41 & 5.74 & $\mathrm{~S}$ & 373.20 & 4.61 & 0.75 \\
\hline \multirow{2}{*}{$\begin{array}{c}\text { Arslan et al } \\
{[169.170]}\end{array}$} & 45 & $\mathrm{~B} 2.5 \mathrm{~F} 1.0$ & 150 & 210 & 2.50 & 1.28 & - & 27.0 & 12 & - & CPP & 1.00 & - & - & - & $\mathrm{S}$ & 42.94 & 1.36 & 0.26 \\
\hline & 46 & B2.5F 2.0 & 150 & 210 & 2.50 & 1.28 & - & 13.9 & 12 & - & CPP & 2.00 & - & - & - & $\mathrm{S}$ & 56.06 & 1.78 & 0.48 \\
\hline
\end{tabular}


Effectiveness of polypropylene fibres as shear reinforcement in structural elements

\begin{tabular}{|c|c|c|c|c|c|c|c|c|c|c|c|c|c|c|c|c|c|c|c|}
\hline Reference & \# & Beams ID. & $\begin{array}{c}b_{w} \\
{[\mathrm{~mm}]}\end{array}$ & $\begin{array}{c}d \\
{[\mathrm{~mm}]}\end{array}$ & $\begin{array}{c}a / d \\
{[-]}\end{array}$ & $\begin{array}{c}\rho_{l} \\
{[\%]}\end{array}$ & $\begin{array}{c}\rho_{\mathrm{w}} \\
{[\%]}\end{array}$ & $\begin{array}{c}f_{c m} \\
{[\mathrm{MPa}]}\end{array}$ & {$\left[\begin{array}{c}d_{g} \\
{[\mathrm{~mm}]}\end{array}\right.$} & $\begin{array}{c}\sigma_{p} \\
{[\mathrm{MPa}]}\end{array}$ & $\begin{array}{l}\text { Fibre } \\
\text { Type }\end{array}$ & $\begin{array}{c}V_{f} \\
{[\%]}\end{array}$ & $\begin{array}{c}f_{L} \\
{[\mathrm{MPa}]}\end{array}$ & $\begin{array}{c}f_{R, I} \\
\text { [MPa] }\end{array}$ & $\begin{array}{c}f_{R, 3} \\
\text { [MPa] }\end{array}$ & MOF & $\begin{array}{l}V_{u, e x p} \\
{[\mathrm{kN}]}\end{array}$ & $\left.\begin{array}{c}v_{u} \\
{[\mathrm{MPa}]}\end{array}\right]$ & $\begin{array}{c}v_{u} /\left(f_{c m}\right)^{0.5} \\
{[\mathrm{MPa}]}\end{array}$ \\
\hline & 47 & B2.5F3.0 & 150 & 210 & 2.50 & 1.28 & - & 18.5 & 12 & - & CPP & 3.00 & - & - & - & $\mathrm{S}$ & 36.03 & 1.14 & 0.27 \\
\hline & 48 & B3.5F1.0 & 150 & 210 & 3.50 & 1.28 & - & 27.0 & 12 & - & CPP & 1.00 & - & - & - & $\mathrm{S}$ & 46.75 & 1.48 & 0.29 \\
\hline & 49 & B $3.5 F 2.0$ & 150 & 210 & 3.50 & 1.28 & - & 13.9 & 12 & - & CPP & 2.00 & - & - & - & $\mathrm{S}$ & 42.50 & 1.35 & 0.36 \\
\hline & 50 & B $3.5 F 3.0$ & 150 & 210 & 3.50 & 1.28 & - & 18.5 & 12 & - & CPP & 3.00 & - & - & - & $\mathrm{S}$ & 50.72 & 1.61 & 0.37 \\
\hline & 51 & B $2.5 \mathrm{~S} 15 \mathrm{P} 1.0$ & 150 & 210 & 2.50 & 1.28 & 0.45 & 27.0 & 12 & - & CPP & 1.00 & - & - & - & $\mathrm{VC}$ & 73.63 & 2.34 & 0.45 \\
\hline & 52 & B $2.5 \mathrm{~S} 15 \mathrm{P} 2.0$ & 150 & 210 & 2.50 & 1.28 & 0.45 & 13.9 & 12 & - & CPP & 2.00 & - & - & - & $\mathrm{VC}$ & 53.84 & 1.71 & 0.46 \\
\hline & 53 & В $2.5 \mathrm{~S} 15 \mathrm{P} 3.1$ & 150 & 210 & 2.50 & 1.28 & 0.45 & 18.5 & 12 & - & CPP & 3.00 & - & - & - & $\mathrm{VC}$ & 66.72 & 2.12 & 0.49 \\
\hline & 54 & B $2.5 \mathrm{~S} 20 \mathrm{P} 1.0$ & 150 & 210 & 2.50 & 1.28 & 0.34 & 27.0 & 12 & - & CPP & 1.00 & - & - & - & $\mathrm{VC}$ & 66.47 & 2.11 & 0.41 \\
\hline & 55 & B $2.5 \mathrm{~S} 20 \mathrm{P} 2.0$ & 150 & 210 & 2.50 & 1.28 & 0.34 & 13.9 & 12 & - & CPP & 2.00 & - & - & - & $\mathrm{VC}$ & 54.73 & 1.74 & 0.47 \\
\hline & 56 & B2.5S20P3.0 & 150 & 210 & 2.50 & 1.28 & 0.34 & 18.5 & 12 & - & CPP & 3.00 & - & - & - & VC & 63.61 & 2.02 & 0.47 \\
\hline \multirow{8}{*}{ This Thesis } & 57 & 0AP1 & 350 & 473 & 3.87 & 1.67 & - & 43.6 & 20 & - & CPP & 1.10 & 4.57 & 2.94 & 4.71 & DT & 228 & 1.58 & 0.24 \\
\hline & 58 & 0AP2 & 350 & 473 & 4.84 & 2.23 & - & 43.6 & 20 & - & CPP & 1.10 & 4.57 & 2.94 & 4.71 & DT & 249 & 1.73 & 0.26 \\
\hline & 59 & 0BP1 & 229 & 473 & 3.87 & 2.24 & - & 43.6 & 20 & - & CPP & 1.10 & 4.57 & 2.94 & 4.71 & DT & 184.6 & 1.71 & 0.26 \\
\hline & 60 & 0BP2 & 229 & 473 & 4.84 & 2.25 & - & 43.6 & 20 & - & CPP & 1.10 & 4.57 & 2.94 & 4.71 & DT & 152.9 & 1.41 & 0.21 \\
\hline & 61 & AP1 & 350 & 473 & 3.87 & 1.67 & 0.21 & 43.6 & 20 & - & CPP & 1.10 & 4.57 & 2.94 & 4.71 & VC & 352.6 & 2.45 & 0.37 \\
\hline & 62 & AP2 & 350 & 473 & 4.84 & 2.23 & 0.21 & 43.6 & 20 & - & CPP & 1.10 & 4.57 & 2.94 & 4.71 & VC & 346.1 & 2.40 & 0.36 \\
\hline & 63 & BP1 & 229 & 473 & 3.87 & 2.24 & 0.28 & 43.6 & 20 & - & CPP & 1.10 & 4.57 & 2.94 & 4.71 & VC & 281.4 & 2.60 & 0.39 \\
\hline & 64 & BP2 & 229 & 473 & 4.84 & 2.25 & 0.28 & 43.6 & 20 & - & CPP & 1.10 & 4.57 & 2.94 & 4.71 & $\mathrm{VC}$ & 248.8 & 2.30 & 0.35 \\
\hline
\end{tabular}


Annexes

Table A.2: Shear database of RC beams.

\begin{tabular}{|c|c|c|c|c|c|c|c|c|c|c|c|c|c|c|}
\hline Reference & $\#$ & Beams ID. & $\begin{array}{c}b_{w} \\
{[\mathrm{~mm}]}\end{array}$ & $\begin{array}{c}d \\
{[\mathrm{~mm}]}\end{array}$ & $\begin{array}{c}a / d \\
{[-]}\end{array}$ & $\begin{array}{c}\rho_{l} \\
{[\%]}\end{array}$ & $\begin{array}{c}\rho_{\mathrm{w}} \\
{[\%]}\end{array}$ & $\begin{array}{c}f_{c m} \\
{[\mathrm{MPa}]}\end{array}$ & $\begin{array}{c}d_{g} \\
{[\mathrm{~mm}]}\end{array}$ & $\begin{array}{c}\sigma_{p} \\
{[\mathrm{MPa}]}\end{array}$ & MOF & $\begin{array}{l}V_{u, \exp } \\
{[\mathrm{kN}]}\end{array}$ & $\begin{array}{c}v_{u} \\
{[\mathrm{MPa}]}\end{array}$ & $\begin{array}{c}v_{u} /\left(f_{c m}\right)^{0.5} \\
{[\mathrm{MPa}]}\end{array}$ \\
\hline \multirow{2}{*}{$\begin{array}{c}\text { Furlan and Hanai } \\
\text { [162] }\end{array}$} & 1 & P1A & 100 & 80 & 3.50 & 1.67 & 0.18 & 43.8 & $\mathrm{~N} / \mathrm{S}$ & - & DT & 20.00 & 2.50 & 0.38 \\
\hline & 2 & P1B & 100 & 80 & 3.50 & 1.67 & - & 43.8 & $\mathrm{~N} / \mathrm{S}$ & - & DT & 16.00 & 2.00 & 0.30 \\
\hline $\begin{array}{c}\text { Campione et al } \\
{[163]}\end{array}$ & 3 & $\mathrm{~N} / \mathrm{S}$ & 100 & 102 & 2.20 & 3.94 & 0.35 & 70.2 & $\mathrm{~N} / \mathrm{S}$ & - & VC & 42.64 & 4.18 & 0.50 \\
\hline \multirow{2}{*}{$\begin{array}{l}\text { Majdzadeh et al } \\
{[136]}\end{array}$} & 4 & B1 & 150 & 120 & 3.02 & 2.62 & 0.28 & 37.8 & 10 & - & $\mathrm{VC}$ & 56.00 & 3.11 & 0.51 \\
\hline & 5 & B2 & 150 & 120 & 3.02 & 2.62 & - & 43.9 & 10 & - & $\mathrm{VC}$ & 38.00 & 2.11 & 0.32 \\
\hline \multirow{9}{*}{$\begin{array}{c}\text { Altoubat et al } \\
\text { [52] }\end{array}$} & 6 & L1-0.0-a & 280 & 400 & 3.50 & 2.15 & - & 40.9 & 20 & - & DT & 173.50 & 1.55 & 0.24 \\
\hline & 7 & L1-0.0-b & 280 & 400 & 3.50 & 2.15 & - & 40.9 & 20 & - & DT & 169.50 & 1.51 & 0.24 \\
\hline & 8 & L1-0.0-c & 280 & 400 & 3.50 & 2.15 & - & 40.9 & 20 & - & DT & 170.50 & 1.52 & 0.24 \\
\hline & 9 & Sh1-0.0-a & 280 & 400 & 2.30 & 2.15 & - & 40.9 & 20 & - & DT & 202.50 & 1.81 & 0.28 \\
\hline & 10 & Sh1-0.0-b & 280 & 400 & 2.30 & 2.15 & - & 40.9 & 20 & - & DT & 188.00 & 1.68 & 0.26 \\
\hline & 11 & L2-0.0-a & 230 & 330 & 3.50 & 3.18 & - & 40.9 & 20 & - & DT & 115.00 & 1.52 & 0.24 \\
\hline & 12 & L2-0.0-b & 230 & 330 & 3.50 & 3.18 & - & 40.9 & 20 & - & DT & 118.00 & 1.55 & 0.24 \\
\hline & 13 & Sh2-0.0-a & 230 & 330 & 2.30 & 3.18 & - & 40.9 & 20 & - & DT & 135.00 & 1.78 & 0.28 \\
\hline & 14 & Sh2-0.0-b & 230 & 330 & 2.30 & 3.18 & - & 40.9 & 20 & - & DT & 135.00 & 1.78 & 0.28 \\
\hline \multirow{5}{*}{$\begin{array}{c}\text { Altoubat et al } \\
\text { [164] }\end{array}$} & 15 & L-S-a & 230 & 330 & 3.50 & 3.18 & 0.10 & 42.0 & 20 & - & $\mathrm{S}$ & 138.85 & 1.83 & 0.28 \\
\hline & 16 & L-S-b & 230 & 330 & 3.50 & 3.18 & 0.10 & 42.0 & 20 & - & $\mathrm{S}$ & 139.50 & 1.84 & 0.28 \\
\hline & 17 & Sh-S-a & 230 & 330 & 2.30 & 3.18 & 0.10 & 42.0 & 20 & - & $S$ & 151.65 & 2.00 & 0.31 \\
\hline & 18 & Sh-S-b & 230 & 330 & 2.30 & 3.18 & 0.10 & 42.0 & 20 & - & $S$ & 170.90 & 2.25 & 0.35 \\
\hline & 19 & PC $300 \times 800-1$ & 300 & 761 & 2.50 & 1.00 & - & 30.3 & 16 & - & $\mathrm{S}$ & 183.00 & 0.80 & 0.15 \\
\hline
\end{tabular}


Effectiveness of polypropylene fibres as shear reinforcement in structural elements

\begin{tabular}{|c|c|c|c|c|c|c|c|c|c|c|c|c|c|c|}
\hline Reference & $\#$ & Beams ID. & $\begin{array}{c}b_{w} \\
{[\mathrm{~mm}]}\end{array}$ & $\begin{array}{c}d \\
{[\mathrm{~mm}]}\end{array}$ & $\begin{array}{l}a / d \\
{[-]}\end{array}$ & $\begin{array}{c}\rho_{l} \\
{[\%]}\end{array}$ & $\begin{array}{c}\rho_{\mathrm{w}} \\
{[\%]}\end{array}$ & $\begin{array}{c}f_{c m} \\
{[\mathrm{MPa}]}\end{array}$ & $\begin{array}{c}d_{g} \\
{[\mathrm{~mm}]}\end{array}$ & $\begin{array}{c}\sigma_{p} \\
{[\mathrm{MPa}]}\end{array}$ & MOF & $\begin{array}{l}V_{u, \exp } \\
{[\mathrm{kN}]}\end{array}$ & $\begin{array}{c}v_{u} \\
{[\mathrm{MPa}]}\end{array}$ & $\begin{array}{c}v_{u} /\left(f_{c m}\right)^{0.5} \\
{[\mathrm{MPa}]}\end{array}$ \\
\hline \multirow{11}{*}{$\begin{array}{l}\text { Conforti et al } \\
{[39,53,165]}\end{array}$} & 20 & MSR300x800-1 & 300 & 761 & 2.50 & 1.00 & 0.16 & 30.3 & 16 & - & $\mathrm{F}$ & 424.00 & 1.86 & 0.34 \\
\hline & 21 & MSR300x800-1 & 300 & 761 & 2.50 & 1.00 & 0.16 & 30.3 & 16 & - & $\mathrm{F}$ & 436.00 & 1.91 & 0.35 \\
\hline & 22 & PC150X800-1 & 150 & 763 & 2.50 & 1.10 & - & 30.3 & 16 & - & $\mathrm{S}$ & 91.00 & 0.80 & 0.14 \\
\hline & 23 & PC150X800-2 & 150 & 763 & 2.50 & 1.10 & - & 30.3 & 16 & - & $S$ & 101.00 & 0.88 & 0.16 \\
\hline & 24 & MSR150X800-1 & 150 & 763 & 2.50 & 1.10 & 0.32 & 30.3 & 16 & - & $\mathrm{F}$ & 244.00 & 2.13 & 0.39 \\
\hline & 25 & MSR150X800-2 & 150 & 763 & 2.50 & 1.10 & 0.32 & 30.3 & 16 & - & $\mathrm{F}$ & 250.00 & 2.18 & 0.40 \\
\hline & 26 & PC150X800PT1 & 150 & 764 & 2.50 & 1.10 & - & 30.3 & 16 & 1.3 & $S$ & 199.00 & 1.74 & 0.32 \\
\hline & 27 & PC150X600-1 & 150 & 563 & 2.50 & 1.12 & - & 30.3 & 16 & - & $S$ & 89.00 & 1.05 & 0.19 \\
\hline & 28 & PC150X600-2 & 150 & 563 & 2.50 & 1.12 & - & 30.3 & 16 & - & $S$ & 64.00 & 0.76 & 0.14 \\
\hline & 29 & MSR150X600-1 & 150 & 563 & 2.50 & 1.12 & 0.32 & 30.3 & 16 & - & $\mathrm{F}$ & 185.00 & 2.19 & 0.40 \\
\hline & 30 & MSR150X600-2 & 150 & 563 & 2.50 & 1.12 & 0.32 & 30.3 & 16 & - & $\mathrm{F}$ & 204.00 & 2.42 & 0.44 \\
\hline \multirow{2}{*}{$\begin{array}{c}\text { Parmentier et al } \\
{[166]}\end{array}$} & 31 & B-2-1 & 200 & 270 & 2.50 & 1.21 & - & 42.4 & 14 & - & $S$ & 66.30 & 1.23 & 0.19 \\
\hline & 32 & B-2-2 & 200 & 270 & 2.50 & 1.21 & - & 42.4 & 14 & - & $\mathrm{S}$ & 58.60 & 1.09 & 0.17 \\
\hline $\begin{array}{c}\text { Sahoo et al } \\
{[167]}\end{array}$ & 33 & Plain & 150 & 172 & 5.23 & 2.45 & 0.22 & 30.0 & 10 & - & S & 53.90 & 2.09 & 0.38 \\
\hline \multirow{5}{*}{$\begin{array}{c}\text { Ensan Navadeh } \\
{[168]}\end{array}$} & 34 & $\mathrm{RC}$ & 254 & 319.05 & 2.40 & 2.40 & - & 34.1 & $\mathrm{~N} / \mathrm{S}$ & - & S & 275.34 & 3.40 & 0.58 \\
\hline & 35 & $\mathrm{RC}$ & 254 & 319.05 & 2.40 & 2.40 & - & 34.1 & $\mathrm{~N} / \mathrm{S}$ & - & $\mathrm{S}$ & 295.29 & 3.64 & 0.62 \\
\hline & 36 & RCS & 254 & 319.05 & 2.40 & 2.40 & 0.37 & 34.1 & $\mathrm{~N} / \mathrm{S}$ & - & $S$ & 371.09 & 4.58 & 0.78 \\
\hline & 37 & RCS & 254 & 319.05 & 2.40 & 2.40 & 0.37 & 34.1 & $\mathrm{~N} / \mathrm{S}$ & - & $S$ & 374.83 & 4.63 & 0.79 \\
\hline & 38 & $\mathrm{~B} 2.5 \mathrm{R}$ & 150 & 210 & 2.50 & 1.28 & - & 26.5 & 12 & - & $S$ & 35.46 & 1.13 & 0.22 \\
\hline
\end{tabular}


Annexes

\begin{tabular}{|c|c|c|c|c|c|c|c|c|c|c|c|c|c|c|}
\hline Reference & $\#$ & Beams ID. & $\begin{array}{c}b_{w} \\
{[\mathrm{~mm}]}\end{array}$ & $\begin{array}{c}d \\
{[\mathrm{~mm}]}\end{array}$ & $\begin{array}{c}a / d \\
{[-]}\end{array}$ & $\begin{array}{c}\rho_{l} \\
{[\%]}\end{array}$ & $\begin{array}{c}\rho_{\mathrm{w}} \\
{[\%]}\end{array}$ & $\begin{array}{c}f_{c m} \\
{[\mathrm{MPa}]}\end{array}$ & $\begin{array}{c}d_{g} \\
{[\mathrm{~mm}]}\end{array}$ & $\begin{array}{c}\sigma_{p} \\
{[\mathrm{MPa}]}\end{array}$ & MOF & $\begin{array}{l}V_{u, \exp } \\
{[\mathrm{kN}]}\end{array}$ & $\begin{array}{c}v_{u} \\
{[\mathrm{MPa}]}\end{array}$ & $\begin{array}{c}v_{u} /\left(f_{c m}\right)^{0.5} \\
{[\mathrm{MPa}]}\end{array}$ \\
\hline \multirow{3}{*}{$\begin{array}{c}\text { Arslan et al } \\
{[169.170]}\end{array}$} & 39 & B3.5R & 150 & 210 & 3.50 & 1.28 & - & 26.5 & 12 & - & $S$ & 47.92 & 1.52 & 0.30 \\
\hline & 40 & $\mathrm{~B} 2.5 \mathrm{~S} 15 \mathrm{R}$ & 150 & 210 & 2.50 & 1.28 & 0.45 & 26.5 & 12 & - & $\mathrm{VC}$ & 59.52 & 1.89 & 0.37 \\
\hline & 41 & B2.5S20R & 150 & 210 & 2.50 & 1.28 & 0.34 & 26.5 & 12 & - & $\mathrm{VC}$ & 60.71 & 1.93 & 0.37 \\
\hline \multirow{8}{*}{ This Thesis } & 42 & 0A1 & 350 & 473 & 3.87 & 1.67 & - & 40.59 & 20 & - & DT & 160.96 & 1.12 & 0.18 \\
\hline & 43 & $0 \mathrm{~A} 2$ & 350 & 473 & 4.84 & 2.23 & - & 40.59 & 20 & - & DT & 176.29 & 1.22 & 0.19 \\
\hline & 44 & 0B1 & 229 & 473 & 3.87 & 2.24 & - & 40.59 & 20 & - & DT & 141.17 & 1.3 & 0.2 \\
\hline & 45 & 0B2 & 229 & 473 & 4.84 & 2.25 & - & 40.59 & 20 & - & DT & 118.28 & 1.09 & 0.17 \\
\hline & 46 & A1 & 350 & 473 & 3.87 & 1.67 & 0.21 & 40.59 & 20 & - & $\mathrm{VC}$ & 241.25 & 1.67 & 0.26 \\
\hline & 47 & $\mathrm{~A} 2$ & 350 & 473 & 4.84 & 2.23 & 0.21 & 40.59 & 20 & - & $\mathrm{VC}$ & 245.96 & 1.71 & 0.27 \\
\hline & 48 & B1 & 229 & 473 & 3.87 & 2.24 & 0.28 & 40.59 & 20 & - & $\mathrm{VC}$ & 237.66 & 2.2 & 0.34 \\
\hline & 49 & B2 & 229 & 473 & 4.84 & 2.25 & 0.28 & 40.59 & 20 & - & $\mathrm{VC}$ & 224.86 & 2.08 & 0.33 \\
\hline
\end{tabular}



Annexe B

Push-off experimental results

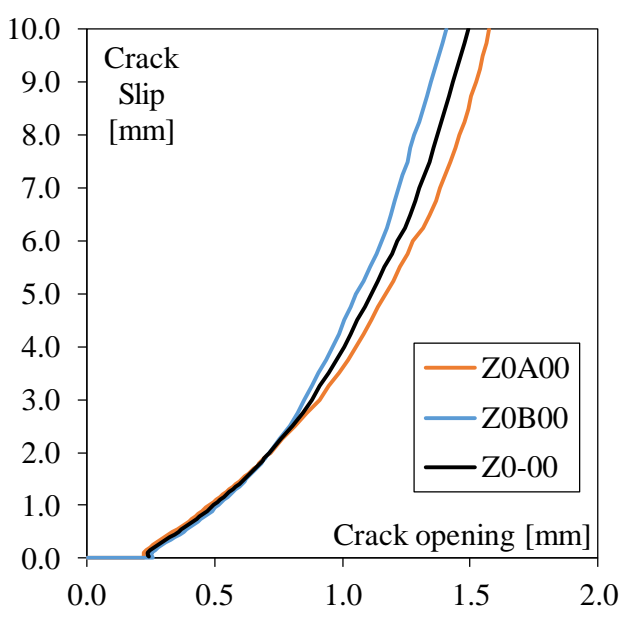

Crack opening vs. slip displacement

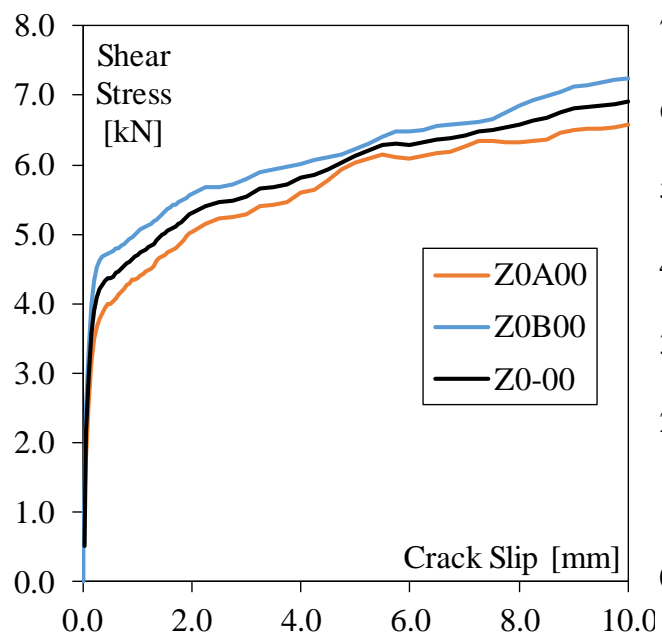

Slip displacement vs. shear stress

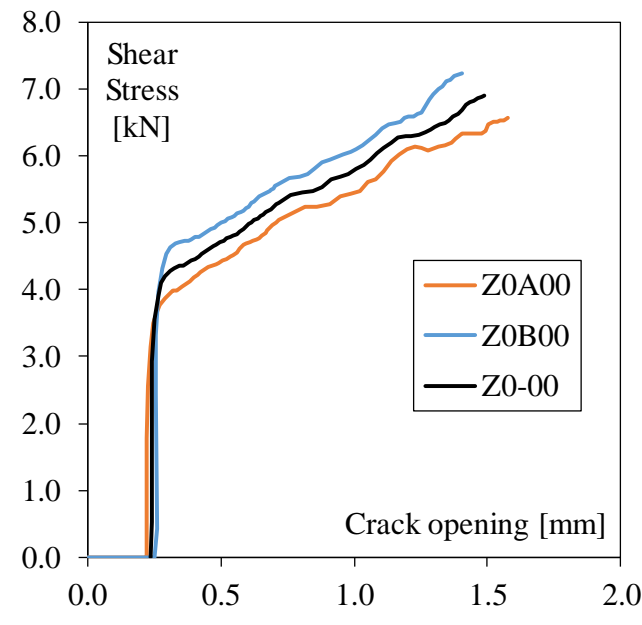

Crack opening vs. shear stress

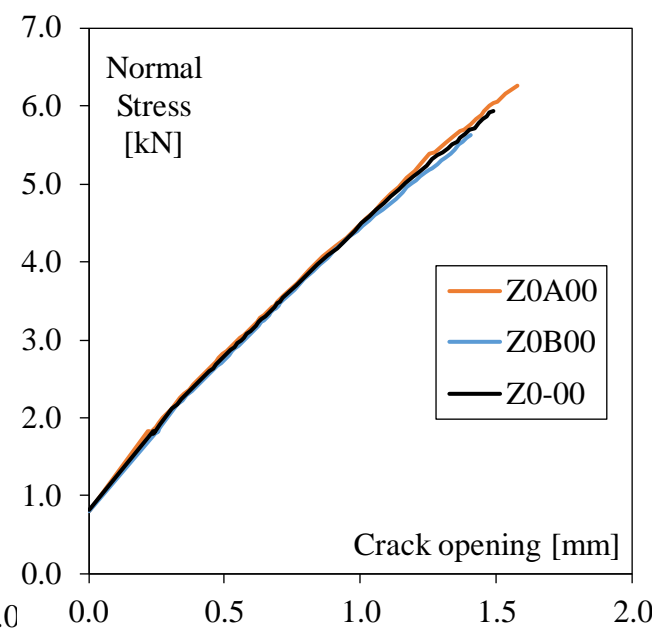

Crack opening vs. normal stress

Figure B.1: Plain concrete push-off results $\left(W=0.0 \mathrm{~mm}, V_{\mathrm{f}}=0.0 \%\right.$ and $\left.f_{c}=43.62 \mathrm{MPa}\right)$ 
Effectiveness of polypropylene fibres as shear reinforcement in structural elements
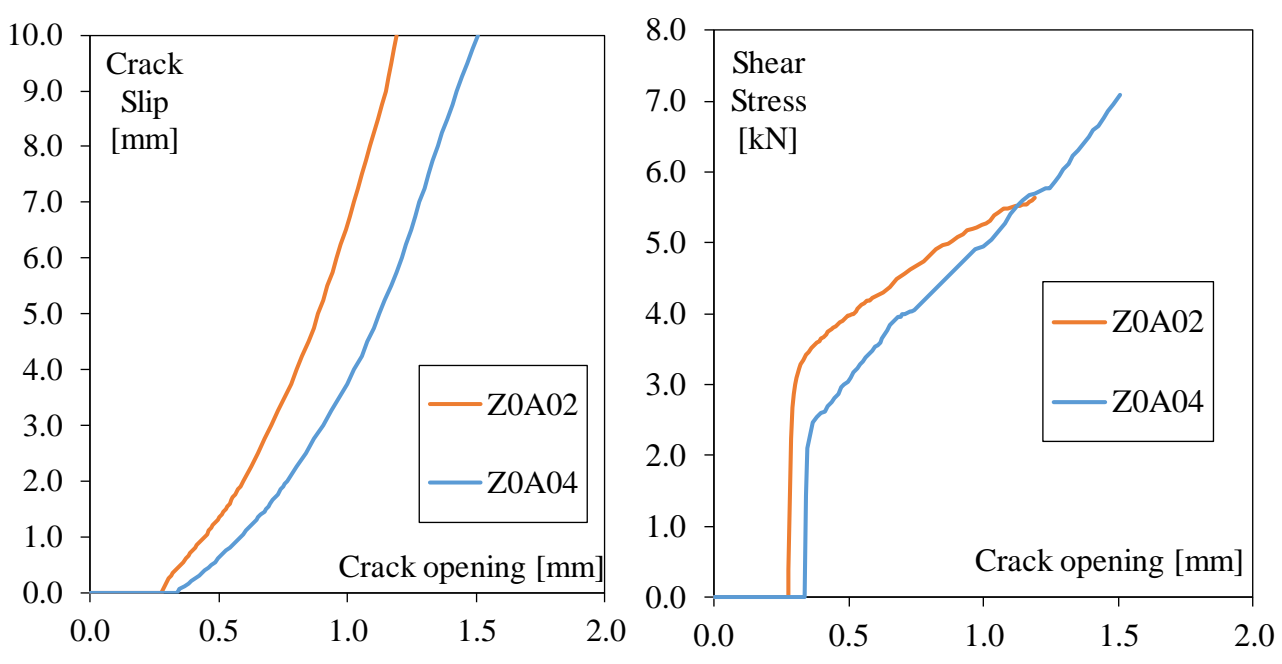

Crack opening vs. slip displacement

Crack opening vs. shear stress

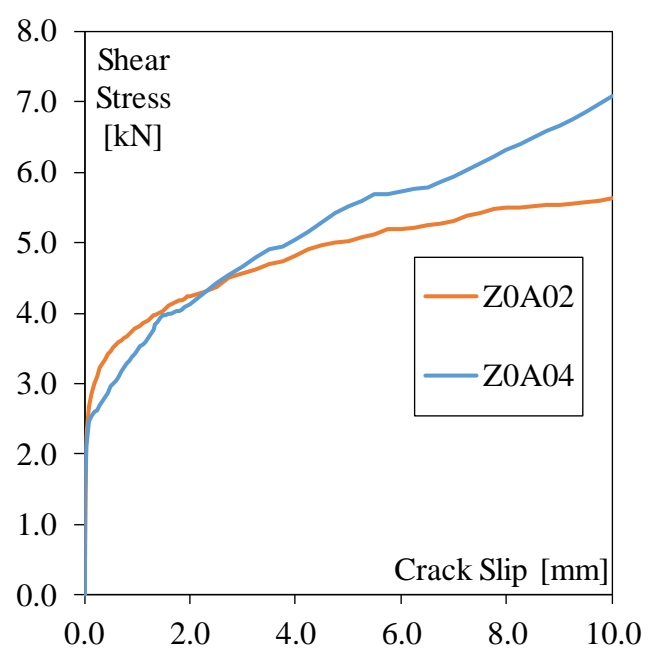

Slip displacement vs. shear stress

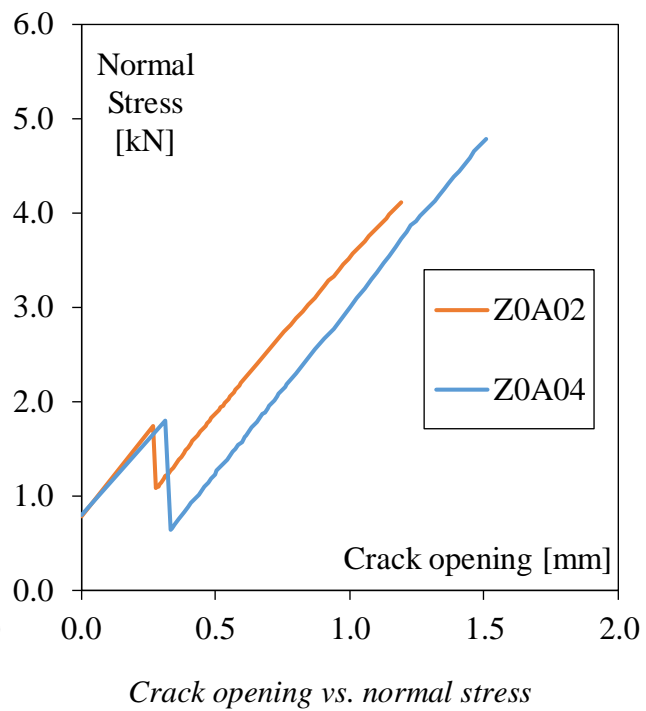

Crack opening vs. normal stress

Figure B.2: Plain concrete push-off results $\left(W=0.2\right.$ and $0.4 \mathrm{~mm}, \mathrm{~V}_{\mathrm{f}}=0.0 \%$ and $\left.f_{c}=43.62 \mathrm{MPa}\right)$ 


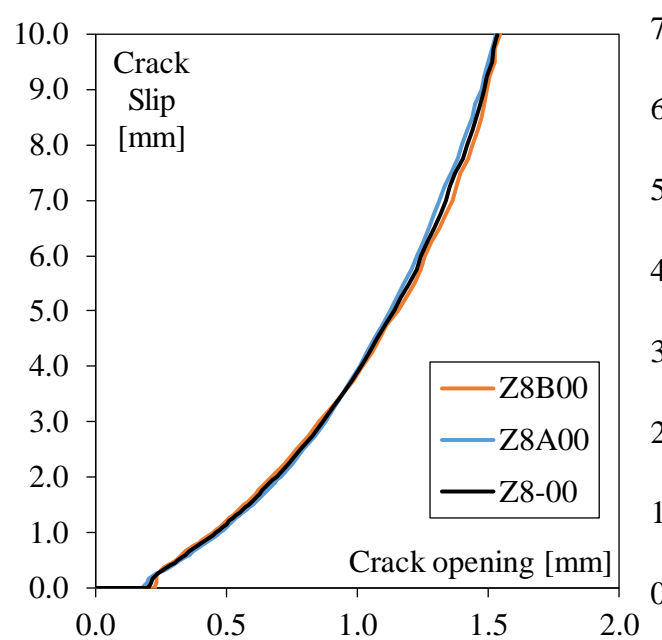

Crack opening vs. slip displacement

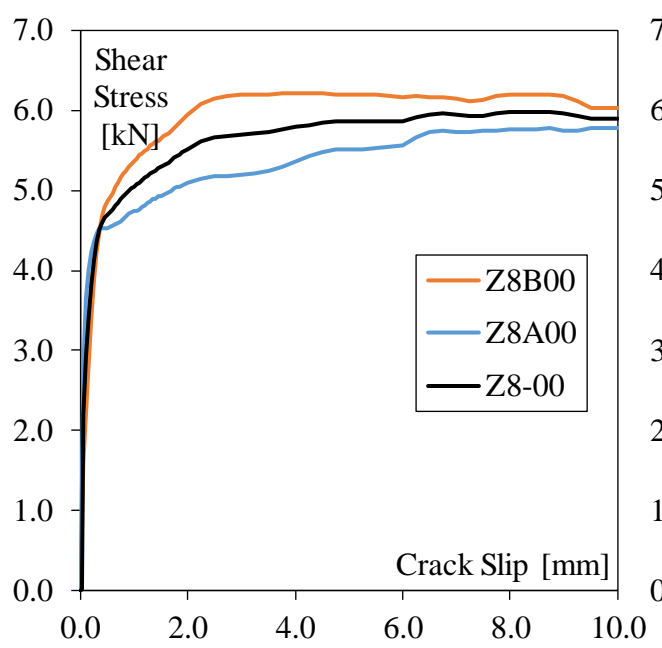

Slip displacement vs. shear stress

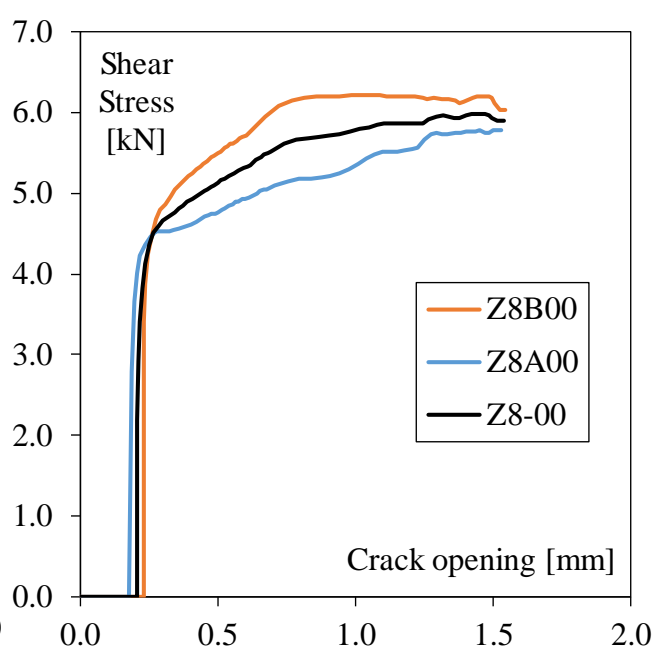

Crack opening vs. shear stress

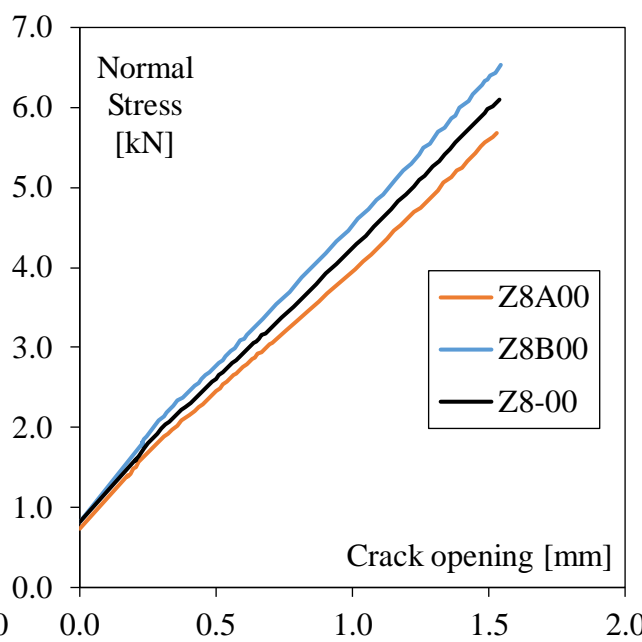

Crack opening vs. normal stress

Figure B.3: PFRC push-off results $\left(W=0.0 \mathrm{~mm}, V_{\mathrm{f}}=8.0 \%\right.$ and $\left.f_{c}=43.50 \mathrm{MPa}\right)$ 
Effectiveness of polypropylene fibres as shear reinforcement in structural elements

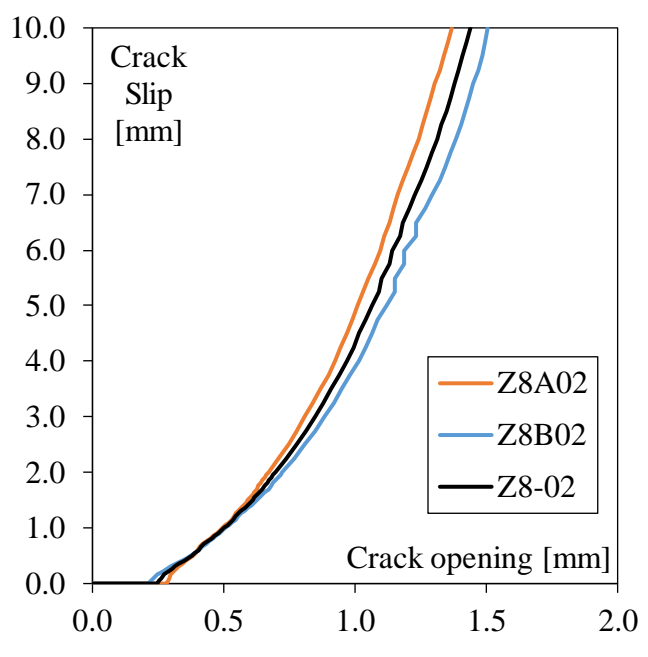

Crack opening vs. slip displacement

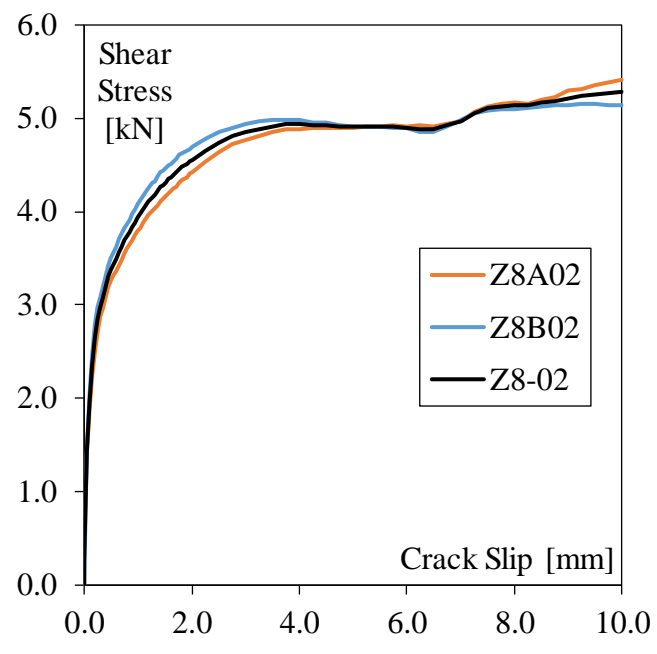

Slip displacement $v$ s. shear stress

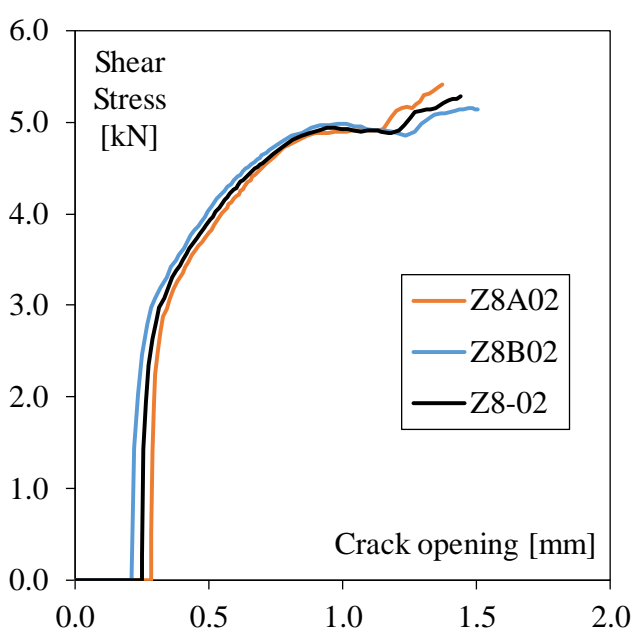

Crack opening vs. shear stress

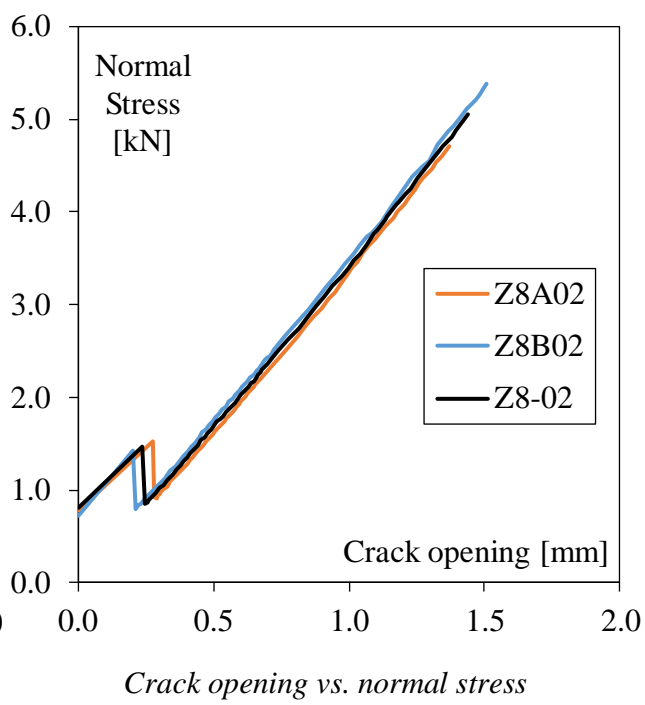

Figure B.4: PFRC push-off results $\left(W=0.2 \mathrm{~mm}, V_{\mathrm{f}}=8.0 \%\right.$ and $\left.f_{c}=43.50 \mathrm{MPa}\right)$ 


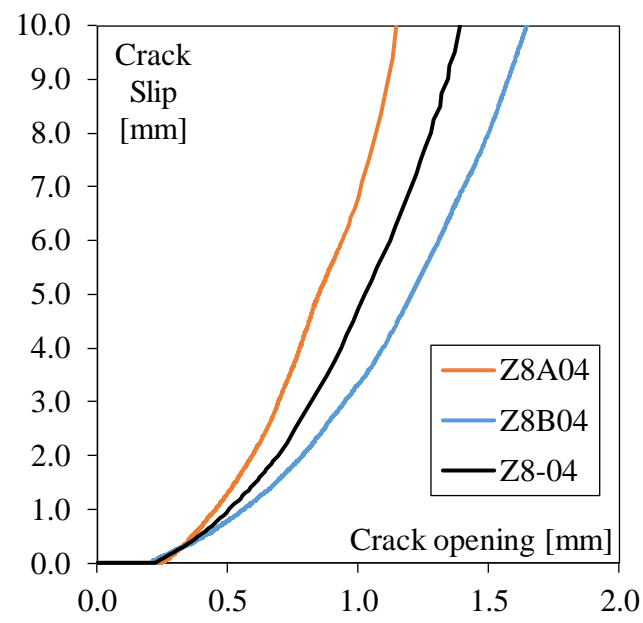

Crack opening vs. slip displacement

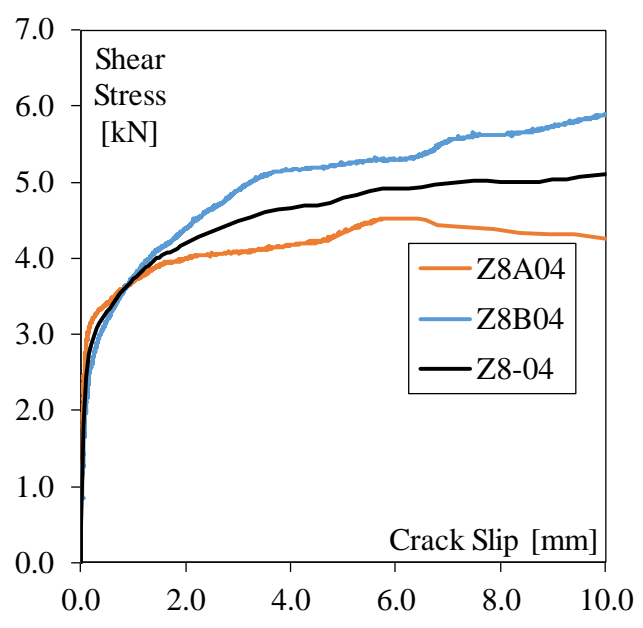

Slip displacement vs. shear stress

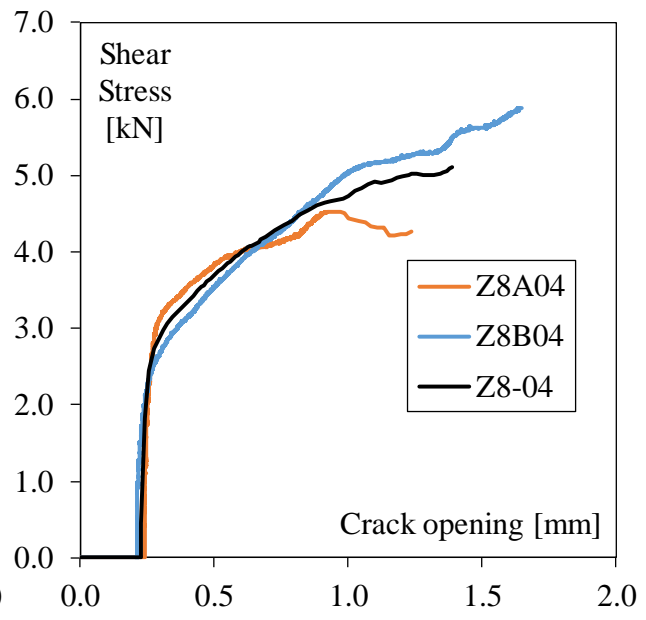

Crack opening vs. shear stress

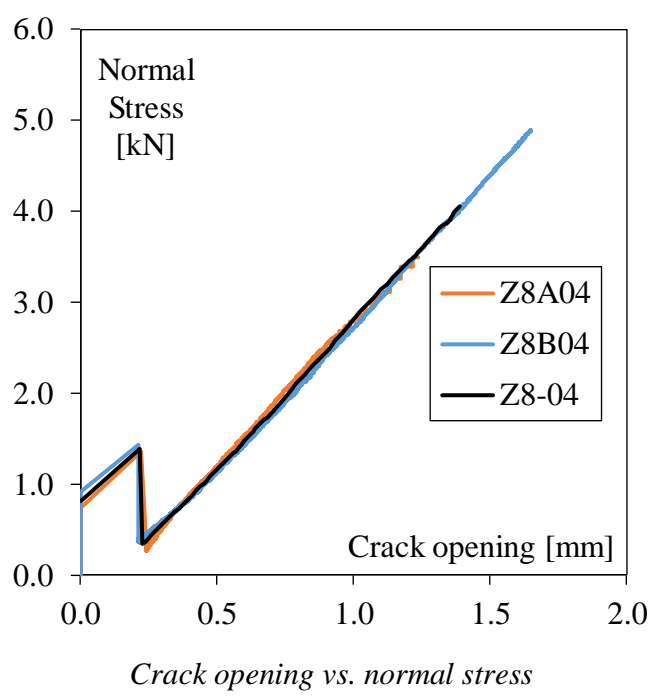

Crack opening vs. normal stress

Figure B.5: PFRC push-off results $\left(W=0.4 \mathrm{~mm}, \mathrm{~V}_{\mathrm{f}}=8.0 \%\right.$ and $\left.f_{c}=43.50 \mathrm{MPa}\right)$ 
Effectiveness of polypropylene fibres as shear reinforcement in structural elements

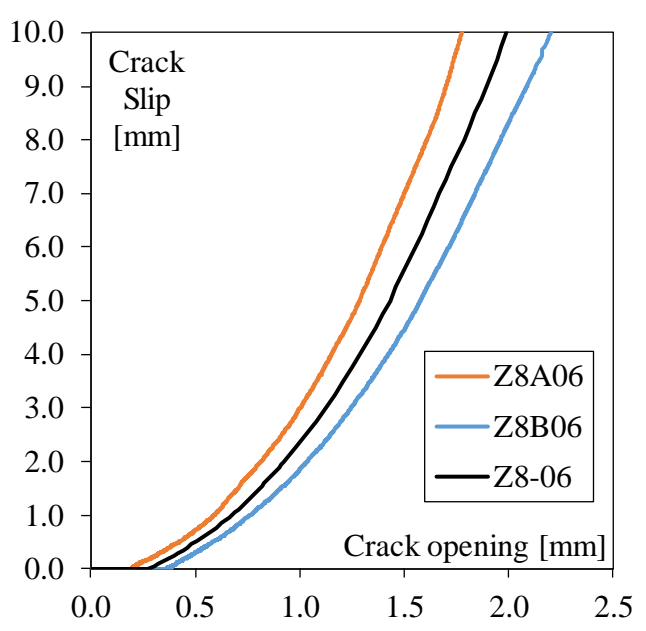

Crack opening vs. slip displacement

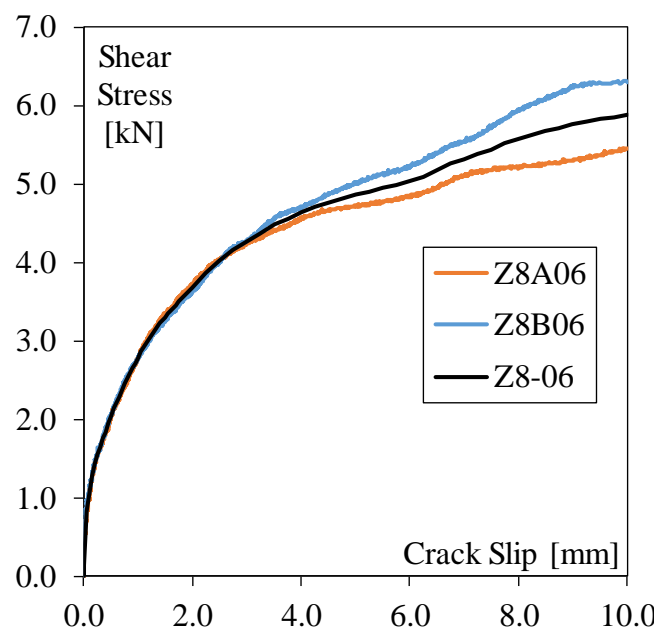

Slip displacement vs. shear stress

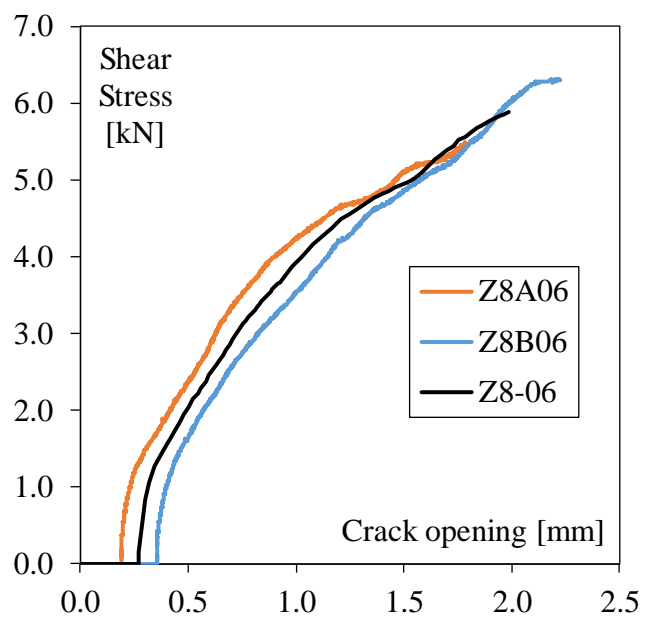

Crack opening vs. shear stress

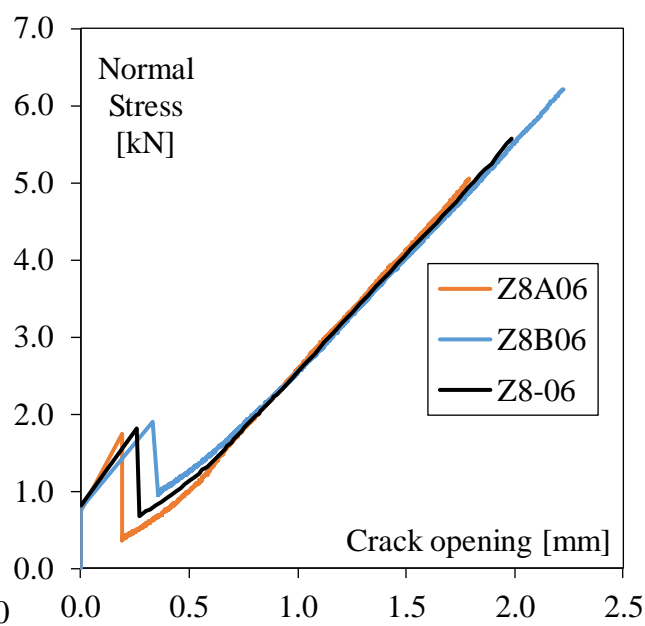

Crack opening vs. normal stress

Figure B.6: PFRC push-off results $\left(W=0.6 \mathrm{~mm}, V_{\mathrm{f}}=8.0 \%\right.$ and $\left.f_{c}=43.50 \mathrm{MPa}\right)$ 
Annexes
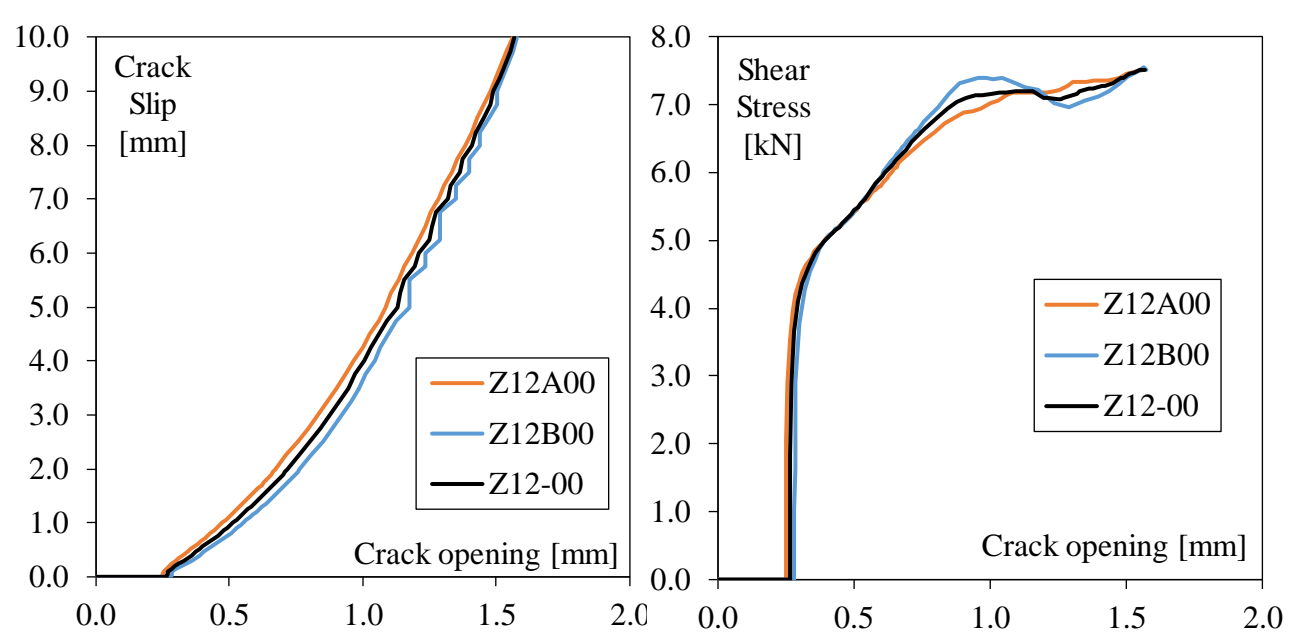

Crack opening vs. slip displacement

Crack opening vs. shear stress
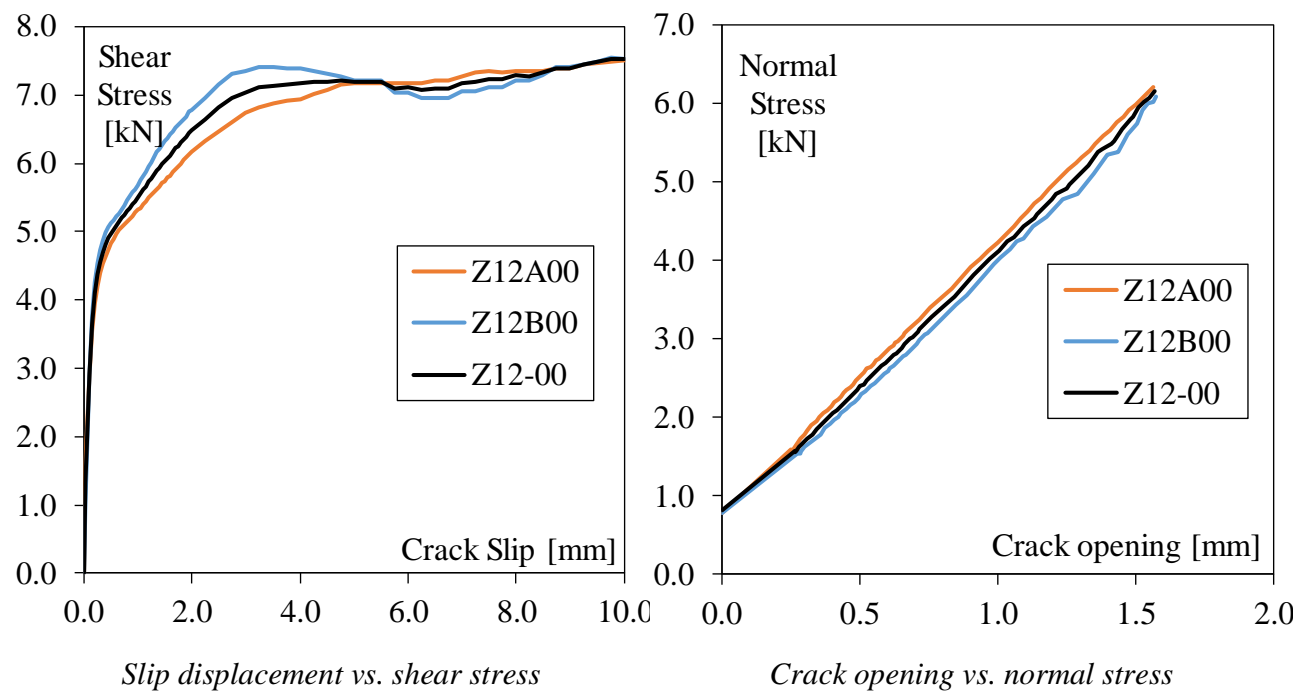

Figure B.7: PFRC push-off results $\left(W=0.0 \mathrm{~mm}, \mathrm{~V}_{\mathrm{f}}=12.0 \%\right.$ and $\left.f_{c}=45.89 \mathrm{MPa}\right)$ 
Effectiveness of polypropylene fibres as shear reinforcement in structural elements
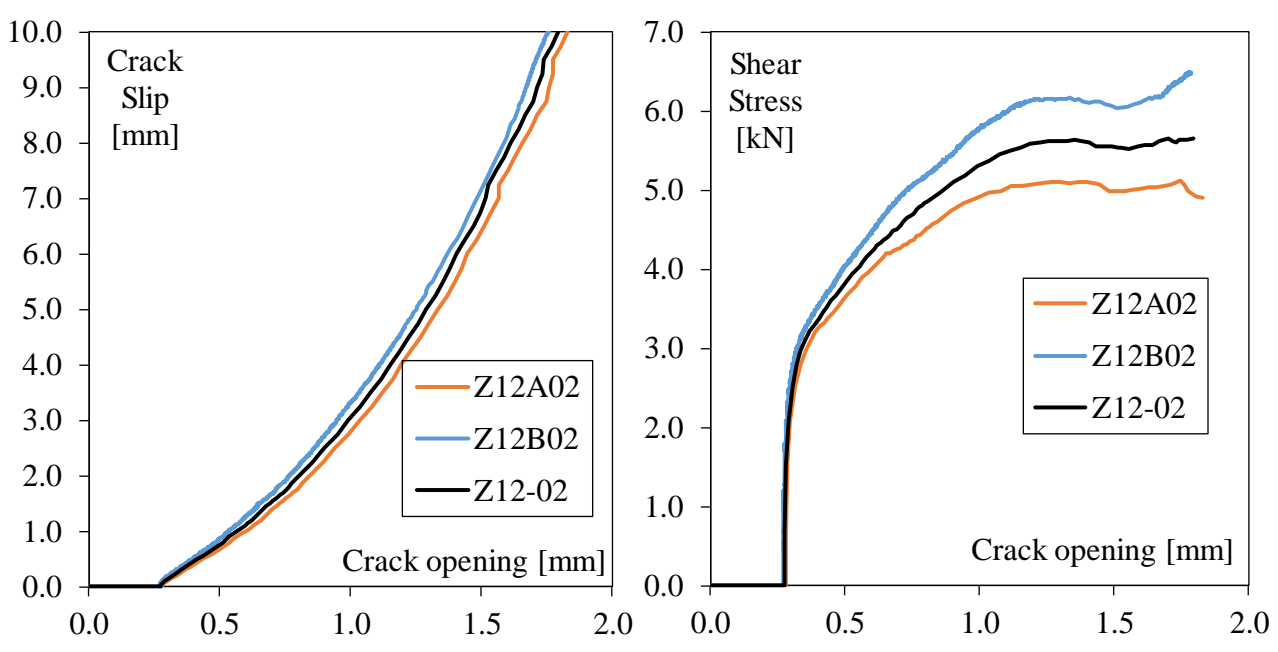

Crack opening vs. slip displacement

Crack opening vs. shear stress
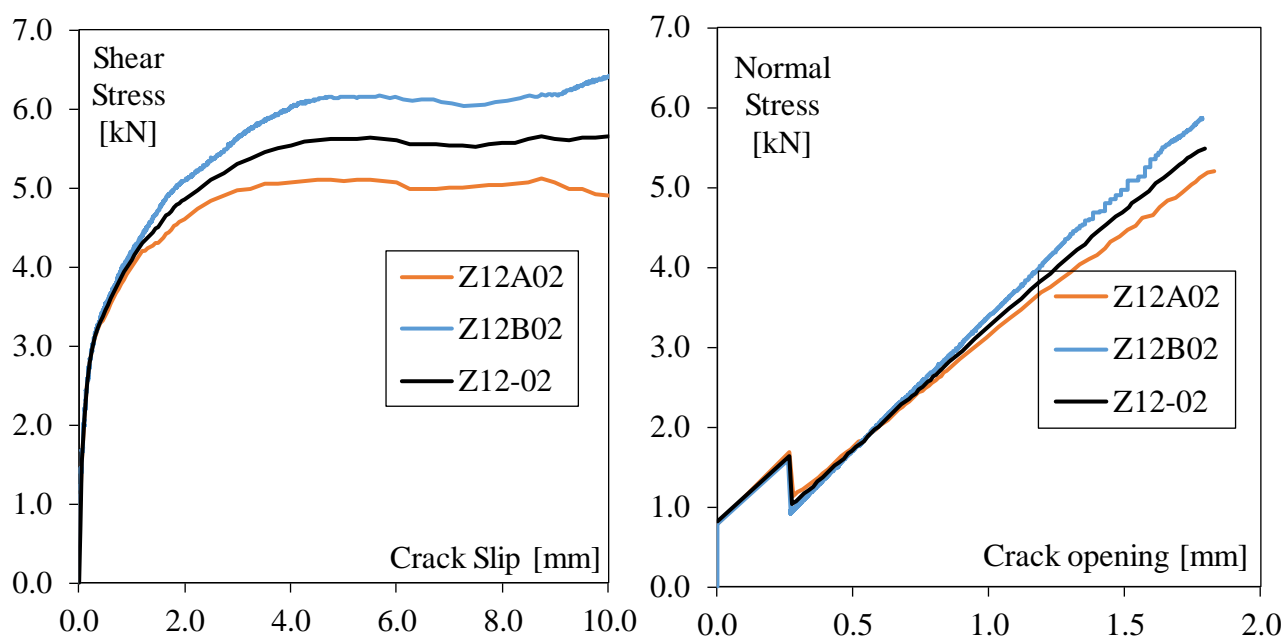

Slip displacement $v$ s. shear stress

Crack opening vs. normal stress

Figure B.8: PFRC push-off results $\left(W=0.2 \mathrm{~mm}, \mathrm{~V}_{\mathrm{f}}=12.0 \%\right.$ and $\left.f_{c}=45.89 \mathrm{MPa}\right)$ 


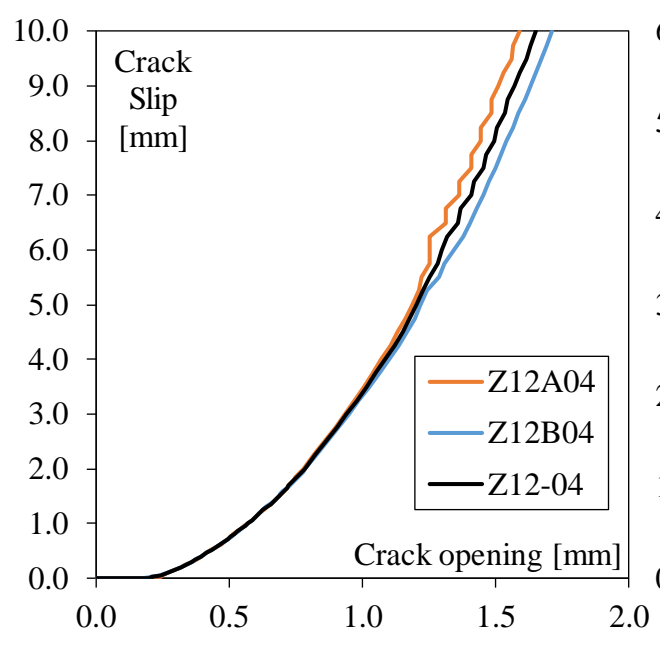

Crack opening vs. slip displacement

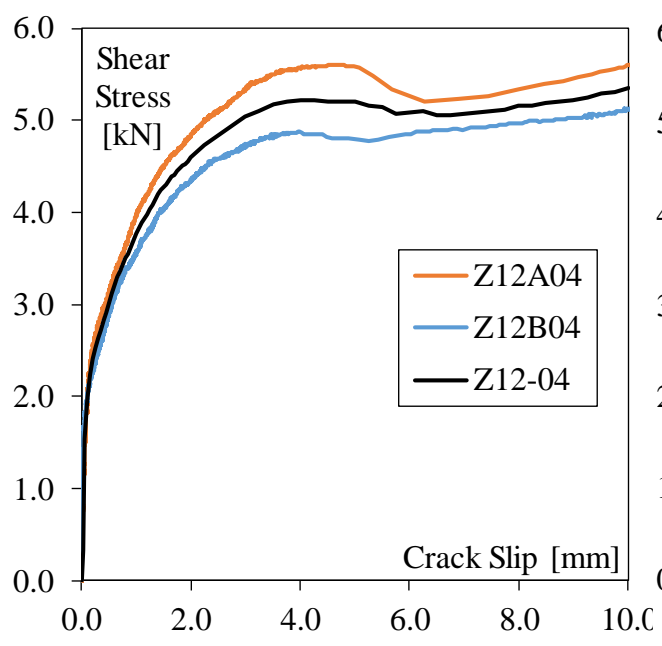

Slip displacement vs. shear stress

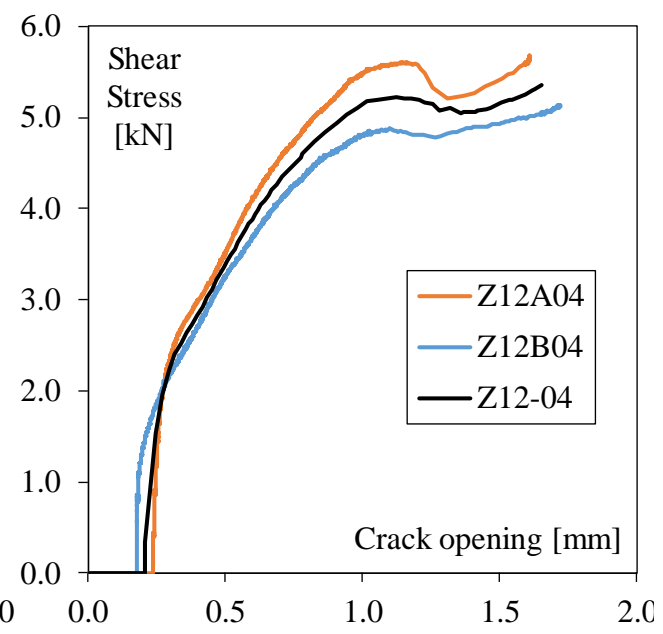

Crack opening vs. shear stress

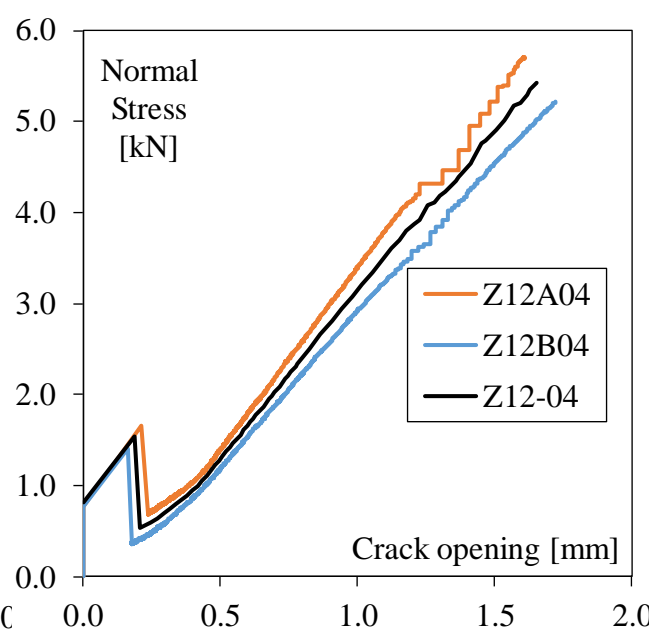

Crack opening vs. normal stress

Figure B.9: PFRC push-off results $\left(W=0.4 \mathrm{~mm}, V_{\mathrm{f}}=12.0 \%\right.$ and $\left.f_{c}=45.89 \mathrm{MPa}\right)$ 
Effectiveness of polypropylene fibres as shear reinforcement in structural elements
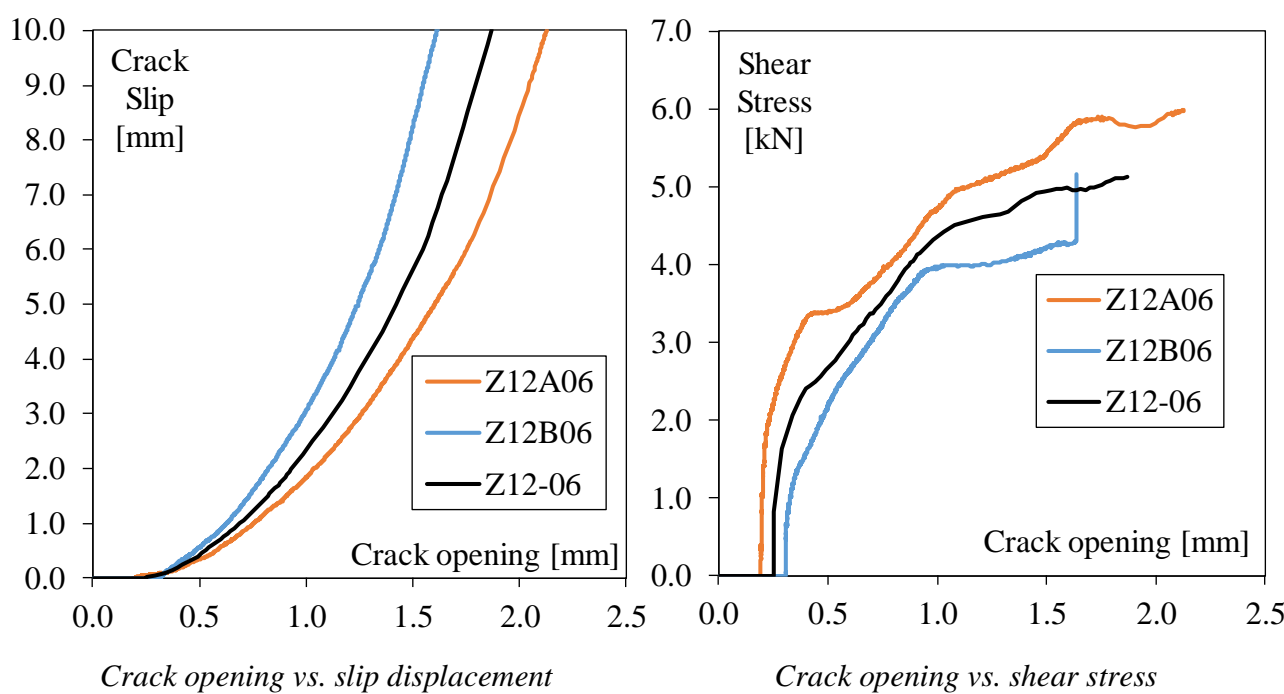

Crack opening vs. slip displacement

Crack opening vs. shear stress

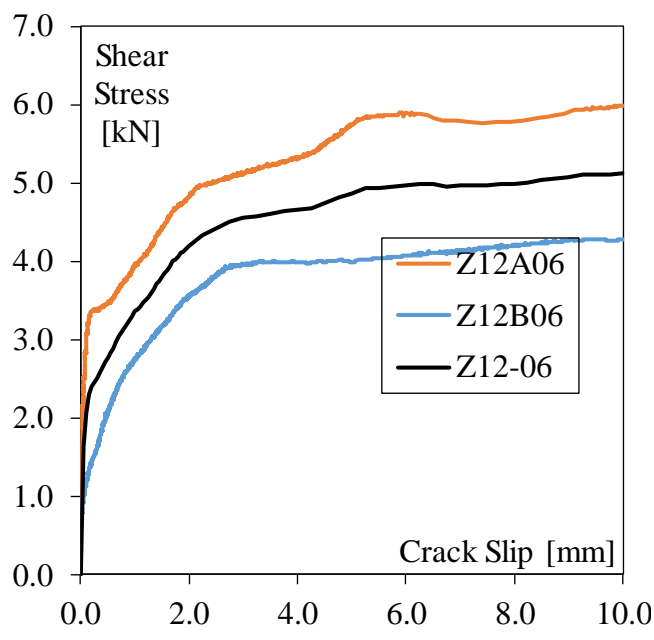

Slip displacement vs. shear stress

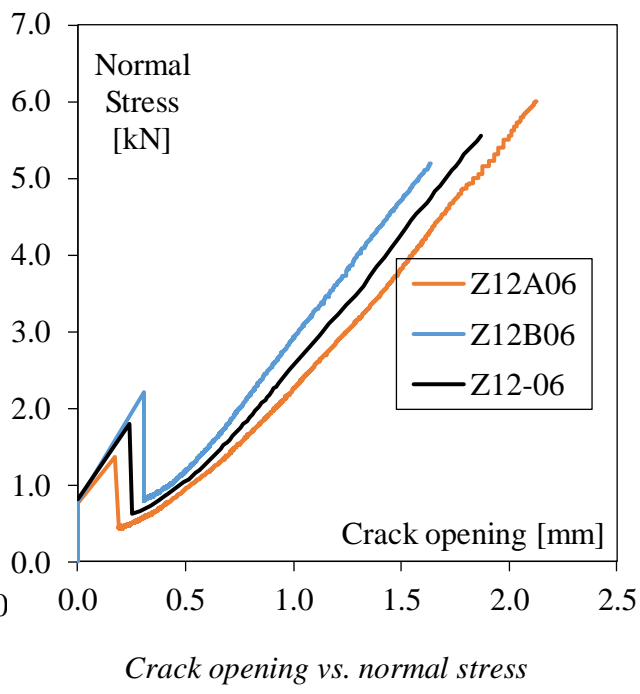

Crack opening vs. normal stress

Figure B.10: PFRC push-off results $\left(W=0.6 \mathrm{~mm}, \mathrm{~V}_{\mathrm{f}}=12.0 \%\right.$ and $\left.f_{c}=45.89 \mathrm{MPa}\right)$ 
Annexe C

Crack pattern of ICITECH beams

$0 \mathrm{~A} 2$

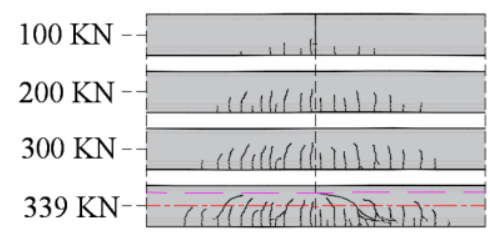

$400 \mathrm{KN}$

$455 \mathrm{KN}$

$478 \mathrm{KN}$

$486 \mathrm{KN}$

(a)

A2

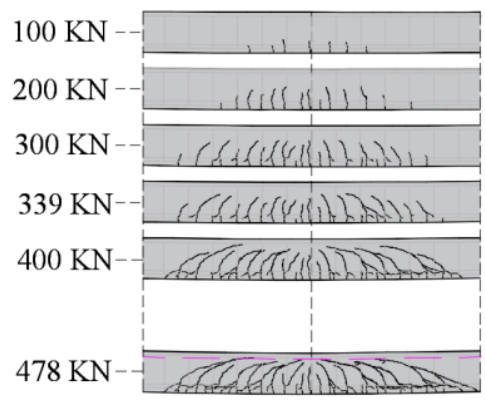

$500 \mathrm{KN}$

$600 \mathrm{KN}$

$658 \mathrm{KN}$

$678 \mathrm{KN}$

0AP2
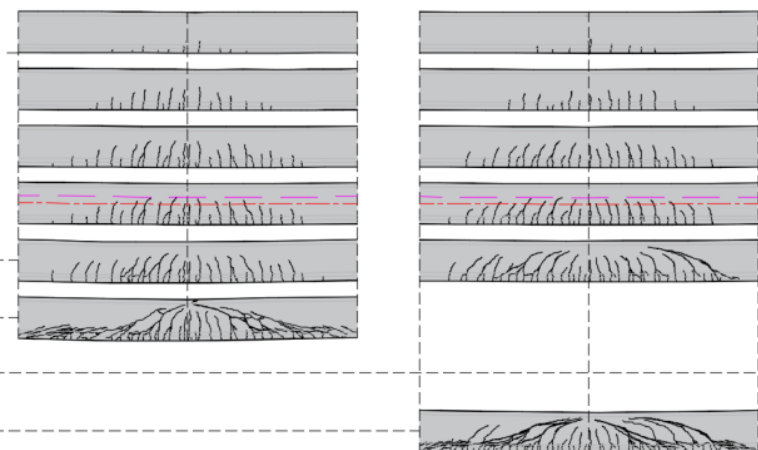

AS2

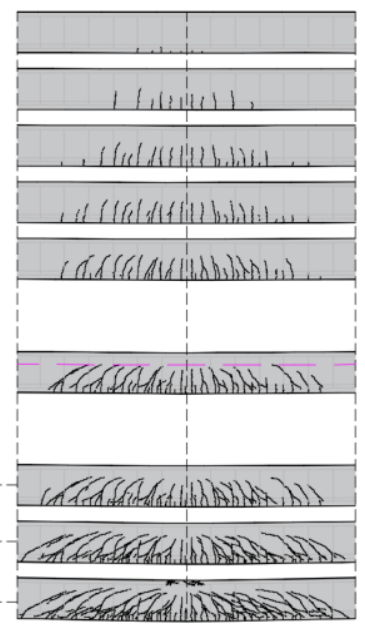

AP2

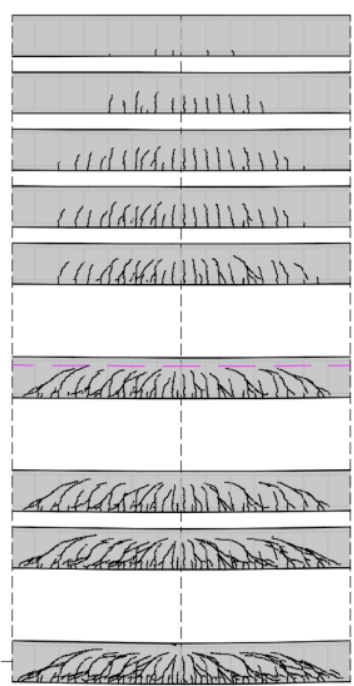

(b)

Figure C.1: Crack pattern evolution of beams series A2: Beams without stirrups (a) and with stirrups (b). 
0B1

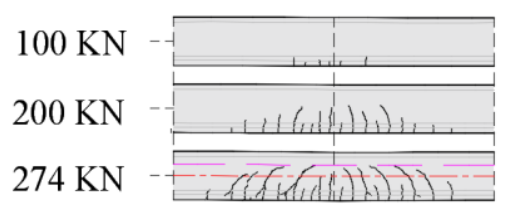

$300 \mathrm{KN}$

$310 \mathrm{KN}$

$361 \mathrm{KN}$

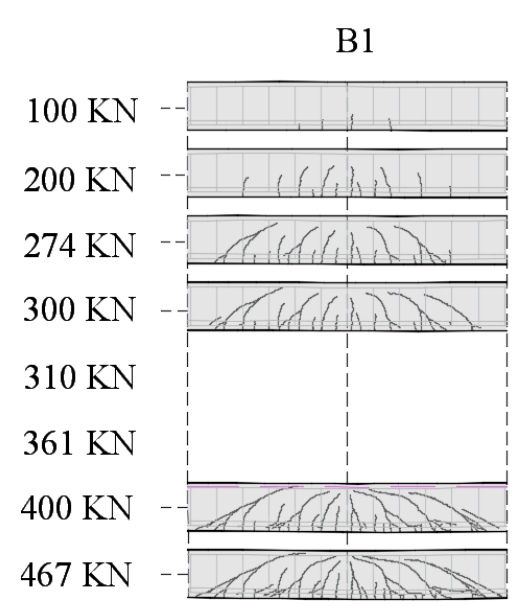

$500 \mathrm{KN}$

$546 \mathrm{KN}$

$555 \mathrm{KN}$

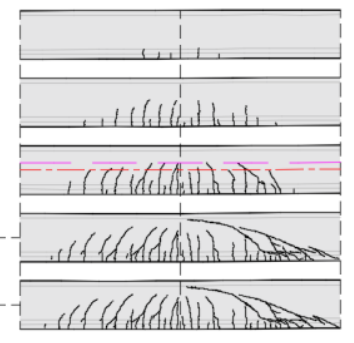

(a)
BS1

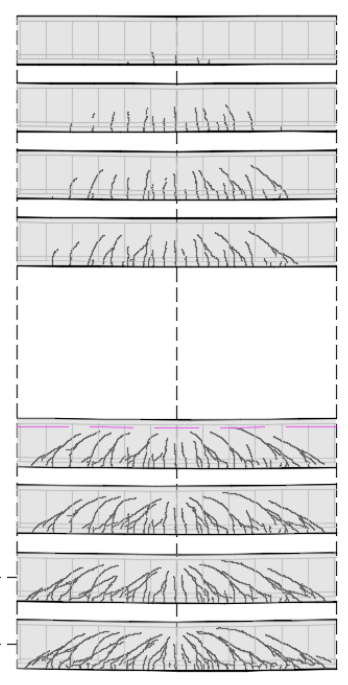

(b)
0BS 1

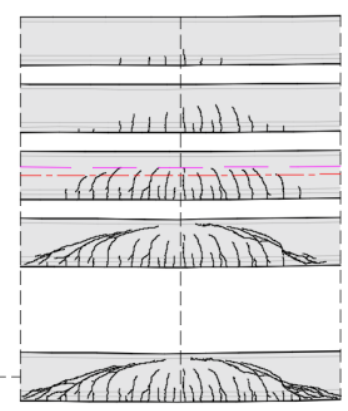

0BP1

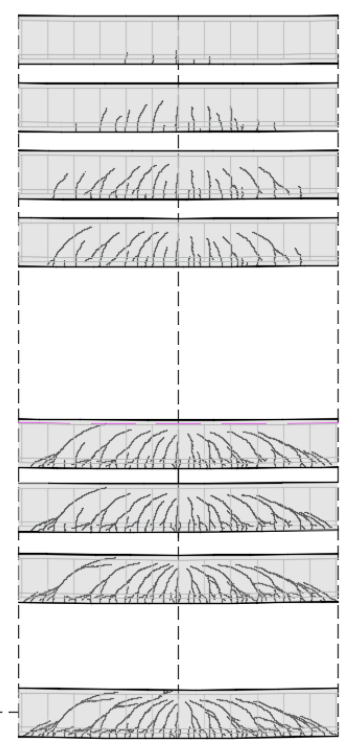

Figure C.2: Crack pattern evolution of beams series B1: Beams without stirrups (a) and with stirrups (b). 
0B2

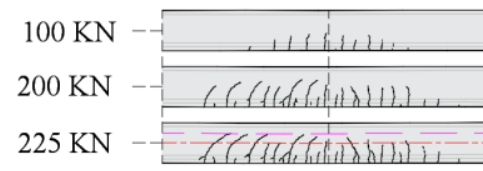

$295 \mathrm{KN}$

$300 \mathrm{KN}$

$327 \mathrm{KN}$

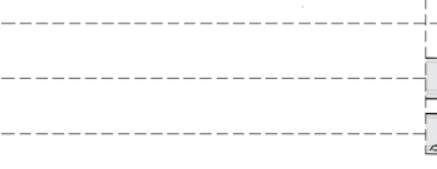

B2

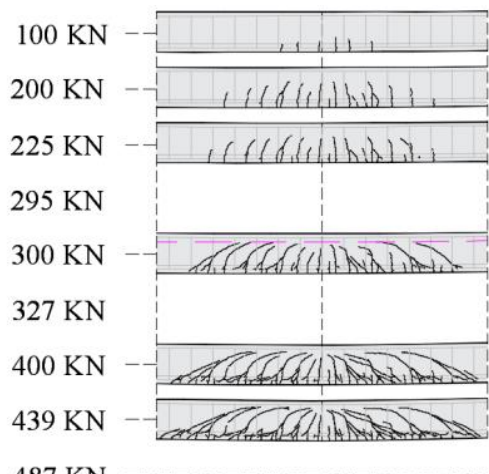

$487 \mathrm{KN}$

$492 \mathrm{KN}$
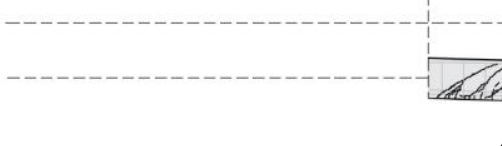

Figure C.3: Crack pattern evolution of beams series B2: Beams without stirrups (a) and with

Figure C.3: Crack pattern evolution of (b).
stirups (b)ams (b)

OBS2

0BP2

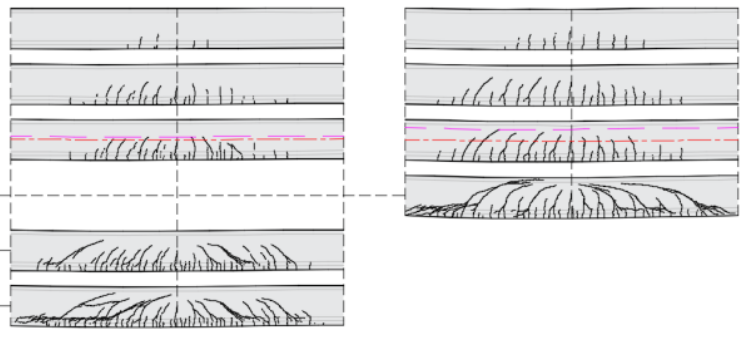

(a)

BS2

$\mathrm{BP} 2$

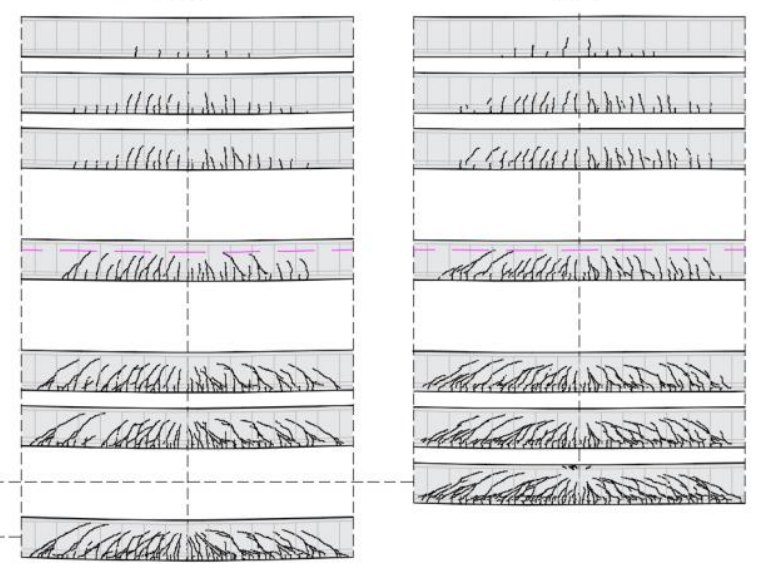

b) 